\title{
DISKURS UND NACHHALTIGKEIT
}

\section{ZUR DEMATERIALISIERUNG IN DEN INDUSTRIALISIERTEN DEMOKRATIEN}

\section{DISSERTATION}

ZUR ERLANGUNG DES SOZIALWISSENSCHAFTLICHEN DOKTORGRADES DER SOZIALWISSENSCHAFTLICHEN FAKULTÄT

DER GEORG-AUGUST-UNIVERSITÄT GÖTTINGEN

VORGELEGT VON FRANK SCHILLER

AUS NORTHEIM 
1. GUTACHTER: PROF. (EM.) DR. WALTER EUCHNER

2. GUTACHTER: PD (HABIL.) DR. FRANK HAMPEL

3. GUTACHTER: PROF. DR. WALTER GIRSCHNER

TAG DER MÜNDLICHEN PRÜFUNG: 8. DEZEMBER 2003 
1.1 Umweltprobleme und Nachhaltigkeit 5

$\begin{array}{lll}1.2 & \text { Übersicht über die Arbeit } & 7\end{array}$

2 DIE DISKURSTHEORIE $\quad 12$

2.1 Der Universalismus der Universalpragmatik 12

2.1.1 Lebenswelt und Systemwelt 13

2.1.2 Dualität von Lebenswelt und System? 19

2.2 Die Krise der Moderne 25

2.2.1 Soziologische Gegenwartsdiagnostik: Risikogesellschaft und Reflexivität 25

2.2.2 Reflexive, ökologische Modernisierung 33

2.2.3 Unsicherheit und Nichtwissen $\quad 40$

2.3 Die Lebenswelt als Quelle von Rationalität und Relevanz?

2.3.1 Kommunikatives Handeln und Rationalität $\quad 48$

2.3.2 Wissenschaft, epistemische Rationalität und Argumentationstheorie 51

2.3.3 Rationalität und Reflexivität

2.4 Diskurstheorie und praktische Vernunft 60

2.4.1 Begründung der universalpragmatischen Diskursethik 63

2.4.2 Praktische Philosophie und ökologische Krise 67

2.4.3 Universale Verantwortung für Nachhaltigkeit 69

3 DER METABOLISMUS MIT DER NATUR: DAS WIRTSCHAFTSSYSTEM 77

$\begin{array}{lll}3.1 & \text { Die Wirtschaft als System der Gesellschaft } & 77\end{array}$

3.2 Umwelt- und Ressourcenökonomie und nachhaltige Entwicklung 80

3.3 Thermodynamik und die Grenzen der Ökonomie 92

3.3.1 Naturkapital und schwache Nachhaltigkeit 95

3.3.2 Der nachhaltige Umfang des Wirtschaftssystems: Scale 99

3.3.3 Der historische Stoffstrom des ökonomischen Systems 102

3.4 Die Emergenz des ökonomischen Stoffstroms 106

3.4.1 Rationalität angesichts von Irreversibilität und emergenter Unsicherheit 107

3.4.2 Die Rationalität nicht-ökonomischer Indikatoren der Nachhaltigkeit 110

$\begin{array}{lll}3.5 & \text { Stoffstrommanagement und Ordnungspolitik } & 114\end{array}$

3.6 Eine inputorientierte Ordnungspolitik der Nachhaltigkeit 122 
4.1 Legitimität und Begründung von Demokratie und Rechtssystem 129

4.1.1 Die Konstruktion der Diskurstheorie des Rechts 132

4.2 Die Entwicklung des Umweltrechts aus der Gefahrenabwehr 142

4.2.1 Staatliche Sicherheitsgewähr und 'freisetzendes' Technikrecht 146

4.2.2 Unsicherheit im Recht 153

4.2.3 Theoretische Steuerungsgrenzen des Rechts ? 157

$\begin{array}{lll}4.3 & \text { Recht als Steuerungsmedium } & 160\end{array}$

4.3.1 Regulatives Recht und Umweltpolitik 161

4.3.2 Das Konzept reflexiven Rechts 163

4.3.3 Prozedurales Recht 166

4.4 Das Paradigma des Umweltstaats 172

4.4.1 Das Präventionsparadigma als Umweltstaat 175

4.4.2 Der Umweltstaat als prozedurales Programm 179

4.4.3 Vorsorgender Umweltstaat und Stoffstrommanagement 182

5 SOLIDARITÄT UND POLITISCHE ÖFFENTLICHKEIT 191

5.1 Nachhaltigkeit für eine wohlgeordnete, zivile Gesellschaft 191

5.1.1 Gerechtigkeit und Verhandlungssysteme 199

5.1.2 Eine Theorie der Zivilgesellschaft 211

5.1.3 Solidarische Integration als reflexive Demokratie 221

$5.2 \quad$ Politische Öffentlichkeit 226

5.2.1 Öffentlichkeit als funktional stabiliserte Integration 232

5.2.2 Die Öffentlichkeit politischer Institutionen 237

5.2.3 Symbolische Politik und argumentative Kritik 245

5.3 Massenmediale Vermittlungen des politischen Systems 248

5.3.1 Massenmediale Kommunikation als (umwelt)politische Sozialisation? 248

5.3.2 Die Thematisierung von Umweltpolitik 252

5.3.3 Innovationsorientierte Vermittlung von Umweltpolitik 258 
6.1 Ökologische Kommunikation 263

6.1.1 Die Diskursanalyse von Umweltpolitik 263

6.1.2 Die Analyse des Mülldiskurses 266

6.1.3 Das abfallpolitische Verhandlungssystem in Deutschland 270

6.2 Die politikwissenschaftliche Herausforderung der Dematerialisierung 275

6.2.1 Netzwerke und politische Wohlfahrtsoptimierung 275

6.2.2 Ideen und sozio-politische Netzwerke 278

6.2.3 Ökologische Kommunikation und Nachhaltigkeitsdiskurs 287

6.3 Zur Institutionalisierung diskursiv vermittelter Ideen 295

$\begin{array}{lll}\text { 6.3.1 Verteilungsarenen und Agenturen } & 295\end{array}$

6.3.2 Diskursive Entzerrung der Agenda einer UZB 301

6.3.3 Direktdemokratisch bestimmter Steuerpfad 305

$\begin{array}{lll}7 & \text { SCHLUß } & 309\end{array}$

8 ANHANG $\quad 312$

8.1 Typen des Sprachgebrauchs nach Habermas (1999) 312

8.2 Handlungstypen nach Habermas (1999) 312

$\begin{array}{lll}8.3 & \text { Spieltheorie } & 313\end{array}$

8.3.1 Mixed-motive games 313

$\begin{array}{lll}8.4 & \text { Nash-Verhandlungslösung } & 316\end{array}$

$\begin{array}{lll}9 & \text { REGISTER } & 317\end{array}$

10 LITERATURVERZEICHNIS 322 


\section{Abkürzungsverzeichnis}

AbfG: Abfallgesetz

BImSchG: Bundesimmissionsschutzgesetz

BIP: Bruttoinlandsprodukt

BS: Battles of the Sexes

BSP: Bruttosozialprodukt

CG: Chicken Game

ChemG: Chemikaliengesetz

DMI: direktes Materialinput

DSD: Duales System Deutschland AG

EMAS: Environmental Monitoring and Audit Scheme

FCKW: Flohrkohlenwasserstoffe

GenTG: Gentechnikgesetz

GD: Gefangenendilemma

GMA: globaler Materialaufwand

GMO: genetisch modifizierte Organismen

GTS: große technische Systeme

KNA: Kosten-Nutzen-Analyse

KrW-/AbfG: Kreislaufwirtschafts- und Abfallgesetz

MAIA: Materialintensitätsanalyse

MIPS: Materialintensität pro Serviceeinheit

MISZ: Materialinputsteuern/-zertifikate

ÖKK: ökologische Kuznets-Kurve

NPÖ: Neue Politische Ökonomie

PD: Prisoners Dilemma

PflSchG: Planzenschutzgesetz

PSR-Ansatz: Pressure-State-Response-Ansatz

PSIR-Ansatz: Pressure-State-Impact-Response-Ansatz

TA: Technische Anleitung

VGR: volkswirtschaftliche Gesamtrechnung

UGR: umweltökonomische Gesamtrechnung

UVPG: Umweltverträglichkeitsprüfungsgesetz

VerpackV: Verpackungsverordnung

WHG: Wasserhaushaltsgesetz

WRMG: Wasch- und Reinigungsmittelgesetz 


\section{Einführung}

\subsection{Umweltprobleme und Nachhaltigkeit}

Das Umweltproblem in den modernen industrialisierten Demokratien läßt sich sehr umfassend anhand der Symptome Ressourcenverbrauch, Dissipation und Veränderung ökologischer Kreisläufe beschreiben. Der Abbau von nachwachsenden und nicht-nachwachsenden Ressourcen ist dabei der Ausgangspunkt eines Dissipationsprozesses, in welchem die im ökonomischem Prozeß veränderten Ressourcen auf die natürliche Umwelt einwirken. Dissipation bezeichnet dabei die zumeist irreversible Verteilung von Stoffen und Energie in den Umweltmedien (Luft, Wasser, Boden). Während stoffliche Dissipation zumindest teilweise technisch und durch Einsatz von Energie reduziert werden kann, ist dies bei Energie selbst nicht möglich. Stoffe zerstreuen als Abrieb, als Verbrennungsprodukte, als Düngemittel, als Abfall etc. Dabei verändern die verteilten Stoffe die quantitative Zusammensetzung der Umweltmedien und damit deren Beschaffenheit. Die Stoffe wirken zum Teil direkt als Gifte auf Organismen in Ökosystemen und zum Teil als Katalysatoren, welche mit anderen Stoffen reagieren und so wiederum Ökosysteme verändern.

Damit ist allerdings das Umweltproblem keinesfalls vollständig beschrieben. Vielmehr muß noch auf die Zerstörung der Biodiversität verwiesen werden, welches wohl das älteste ökologische Problem des Menschen ist und spätestens seit der Neuzeit zu einem zentralen Problem geworden ist. Es ist damit älter als die bereits genannten Probleme, die mit der Nutzung von nichterneuerbaren Stoffen erst im Zuge der Industrialisierung dringend wurden. Die Zerstörung von Biodiversität resultiert zumeist direkt aus der Naturnutzung des Menschen und hängt insofern mit dem Problem der Nutzung nachwachsender Ressourcen zusammen.

Die intensive Nutzung nachwachsender Ressourcen durch die moderne Agrarwirtschaft hat auch zu dem wichtigen Problem der Bodenzerstörung beigetragen, welches negativ auf die Ernährungsgrundlagen des Menschen zurückwirkt. Teilweise geht die Bodenzerstörung auf Windoder Wassererosion zurück, teilweise auf Versalzung oder Versiegelung von Flächen. Und obwohl Böden die Fähigkeit zur Regeneration haben, ist die Nutzung vielfach nicht nachhaltig. Es kann, wie etwa die Versalzung durch das Austrocknen des Aralsee (in Folge des intensiven Bewässerungsfeldbaus an den einfließenden Flüssen) zeigt, gravierende, generationenübergreifende Folgen haben.

Als vierter und jüngster Aspekt eines Umweltproblems muß die technische Fähigkeit des Menschen zur Manipulation von Organismen angesehen werden. Zwar ist diese Fähigkeit nicht generell neu, doch hat sie durch die Genetik eine völlig neue Tiefe der Eingriffsmöglichkeit erhalten. Der Mensch beansprucht mit der Anwendung von Gentechnik, Natur kontrolliert zu seinem Nutzen verändern zu können. Dabei wird dieser Anspruch erhoben, ohne daß die Auswirkung von freigesetzten Organismen für die Evolution vorhersagbar wäre. Daß freigesetzte 
Organismen aber evolutionäre Folgen zeitigen werden, scheint angesichts der Fähigkeit von Organismen zu Selbstreproduktion unvermeidlich.

Die genannten Aspekte unterscheiden sich hinsichtlich ihres (potentiellen) Schadensausmaßes. So wurde der stoffliche Dissipationsprozeß lange Zeit als relativ harmlos angesehen, da er als Smog in Städten lokal begrenzt schien. Später würde er als weiträumige Luftverschmutzung zu einem regionalen Problem und mit dem Ozonloch schließlich zu einem globalen Problem von existentiellem Ausmaß für die Menschheit. Die Zerstörung der Biodiversität ist erst mit der Entdeckung und der Wertschätzung derselben als globales Problem wahrgenommen worden. Allerdings gibt es seit einigen Jahrzehnten lokale, regionale und globale Bemühungen zum Schutz bedrohter Arten. Auch die Zerstörung von Böden beruht nicht nur auf lokaler Unwissenheit über geeignete Anbaumethoden, sondern geht auch auf falsche globale ökonomische Imperative zurück. Die Freisetzung manipulierter Organismen ist aufgrund der irreversiblen, d.h. zeitlich unbegrenzten Selbstreproduktionsfähigkeit als mögliches Problem auch räumlich kaum einzugrenzen. Die Gesellschaft der Gegenwart nimmt so mögliche Gefahren in Kauf, die zu globalen werden und bis ans Ende der Evolution andauern könnten.

Wichtig ist die zeitliche Dimension des Umweltproblems: So steht etwa die veränderte räumliche Wahrnehmung des stofflichen Dissipationsprozesses auch in Zusammenhang mit der Dauer seiner zeitlichen Ausbreitung. Stoffe haben unterschiedliche Geschwindigkeiten sowohl in bezug auf ihre Dissipation als auch in bezug auf ihre Reaktionseigenschaften in verschiedenen Umweltmedien. Dagegen liegt die Vernichtung von Arten zeitlich relativ nahe bei der zugrundeliegenden Hauptursache, der Zerstörung des Lebensraums.

Trotz der Unterschiede in Hinsicht auf Zeit und Schadenspotential vereint eines die genannten Umweltprobleme: Sie beinhalten bereits heute irreversible Veränderungen und Schäden der uns umgebenden Natur, die zukünftigen Generationen vielleicht von ihnen nicht nur negativ bewertete Einschränkungen aufzwingen, die aber doch unzweifelhaft Einschränkungen sein werden. Und dabei entscheidet letztendlich das Ausmaß irreversibler Schäden ultimativ über das Wohl und Wehe zukünftiger Generationen oder eventuell gar über die Möglichkeit nachfolgender Generationen überhaupt. Dabei spielt auch unser wachsendes Wissen über die globalen Zusammenhänge in der Natur eine wichtige Rolle. Oft werden ökologische Probleme erst nach langer Latenzzeit praktisch akut oder wissenschaftlich entdeckt wie etwa beim Treibhauseffekt und Ozonloch. Lange Latenzzeiten erschweren nicht nur das Erkennen von ökologischen Problemen, sondern auch ihre ökosoziale Reintegration in eine ausdifferenzierte Gesellschaft. Dies scheint sehr grundsätzlich gegen die (bewußte) Inkaufnahme von irreversiblen Gefährdungen zu sprechen. So wie Pascal den Atheisten für irrational hielt, weil dieser durch die Negierung Gottes gegen die Unendlichkeit nach dem Tod wette, so scheinen irreversible Schäden und Gefährdungen eine Wette des modernen Menschen gegen die Natur als Grundlage seiner Existenz zu beinhalten und somit auf die Irrationalität der Moderne zu verweisen. 


\section{2 Übersicht über die Arbeit}

Es ist, wie ein Politologe kürzlich bemerkte, bemerkenswert, "in wie geringem Maße in der jüngeren politischen Theorie und Ideengeschichte das Verhältnis zwischen kognitivem und soziopolitischem Wandel thematisiert worden ist." (Münkler, 1999, 291) Die vorliegende Arbeit will diesem Zustand themenspezifisch abhelfen und Nachhaltigkeit als kognitiven Wandel unseres Mensch-Naturbildes darstellen, der erste soziopolitische Reformprozesse eingeleitet hat. Ausgangspunkt dieser Arbeit ist dabei die Diskurstheorie von Jürgen Habermas. Diese hat in ihren Ansätzen zu einer politischen Theorie besonders die kognitive Dimension des Politischen und des Sozialen hervorgehoben (Habermas, 1996, 95 ff, 277 ff). Gleichwohl sind in Habermas' äußerst komplexem Theorieprojekt Spannungen hinsichtlich des theoretischen Verhältnisses von Subjekt und Natur aufgetaucht, die Habermas beflissentlich übergeht, - sehr zum möglichen Schaden seines Projektes.

Um zur Lösung dieser Spannungen beizutragen (Kapitel 2), wird die Arbeit zwischen Realismus und Konstruktivismus entfaltet: Natur erscheint einerseits als sprachlich immer existenter lebensweltlicher Kontext der Gesellschaft und andererseits als wissenschaftlich objektiviertes Konstrukt, das in der Moderne durch den naturwissenschaftlichen Diskurs geschaffen wird. Die Arbeit schließt an die Argumentationstheorie v. Schombergs an, die im wissenschaftlichen Diskurs zwischen sicherem und unsicherem Wissen zu unterscheiden erlaubt. Sie teilt damit die Sicht der Wissenssoziologie und der Diskursanalyse, von der Problemwahrnehmung sozialer Akteure auszugehen. Doch Wissenssoziologie und Diskursanalyse enthalten sich weitestgehend einer Bewertung von sozialem Wissen. Dies läuft Gefahr, so die Annahme dieser Arbeit, in einen sozialwissenschaftlichen Konstruktivismus einzumünden, der die objektive Welt unterhalb des naturwissenschaftlichen Niveaus erfaßt. Die argumentationstheoretische Unterscheidung zwischen sicherem und unsicherem Wissen erlaubt es dagegen, bestehende moralische Forderungen nach einer Nichtintervention in die Natur bei Unsicherheit zu präzisieren. Doch wie können moralische Normen wertbesetzte, unnachhaltige Praxis verändern?

Die Diskurstheorie tritt in den zwei bestehenden Spielarten als universale Philosophie auf. Während Karl-Otto Apels transzendentalpragmatische Variante ganz Philosophie bleibt, hat Habermas aus seiner universalpragmatischen Variante sozial- und rechtswissenschaftliche Theorien entwickelt, die politikwissenschaftlich fruchtbar gemacht werden können. Habermas' Theorie eröffnet insbesondere über ihren kritischen sozialphilosophischen Gehalt die Möglichkeit einer materialen, politikwissenschaftlichen Nachhaltigkeitsforschung. Dafür läßt sich der kognitive Gehalt der (soziologischen) Theorie des kommunikativen Handelns nutzen und die kritische Untersuchung an den systemisch verselbständigten Bereichen der Gesellschaft ansetzen: dem politisch-administrativen und dem ökonomischen System.

Während das Wirtschaftsystem den Metabolismus von Gesellschaft und Natur geradezu naturalistisch determiniert - ohne daß dies von philosophischer Seite mit dem Vorwurf belegt werden würde, Praxis als naturalistischen Fehlschluß zu betreiben -, ermöglicht das Medium des 
Rechts prinzipiell die Selbstregierung einer solidarischen, pluralistischen Zivilgesellschaft. Damit sind die drei zentralen Bereiche der Gesellschaft genannt: das monetär gesteuerte ökonomische System, das rechtlich dirigierte politisch-administrative System und die sich solidarisch reproduzierende Zivilgesellschaft.

Größte Handlungsmacht dieser drei gesellschaftlichen Bereiche besitzt das ökonomische System. In seiner internen Beschreibung durch die Wirtschaftswissenschaften definiert sich das ökonomische System fast ausschließlich über Handlungen. Die materielle, d. h. stofflichenergetische Dimension des zweckrationalen Handelns wird dabei aber zumeist übersehen oder ignoriert. Angesichts der stofflich-energetischen Dimension der ökologischen Krise muß der kritische Gehalt normativer Nachhaltigkeitsforschung deshalb beim ökonomischen System ansetzen, zumal die Rationalität bzw. Systemfunktionalität des ökonomischen Subsystems in der kapitalistischen Moderne immer auch die emanzipatorischen Möglichkeiten des politischadministrativen Systems bestimmt hat. So hat bereits die Umweltpolitikforschung in den 80er Jahren einer rein politischen Modernisierungsstrategie die 'ökologische Modernisierung' des Wirtschaftssystems zur Seite gestellt.

Mittlerweile hat die Ökonomik selbst zu einer Kritik ihrer Wachstumstheorie gefunden. Die Ökologische Ökonomie geht von einer stofflich-energetisch hierarchischen Struktur des Wirtschaftssystems aus und hat erste Ansätze zur makroökonomischen Steuerung der Wirtschaft entwickelt. Diese überspannt durch die zugrunde gelegten stofflich-energetischen Indikatoren verschiedenste Politikfelder und verbindet diese miteinander (Kapitel 3).

Im Mittelpunkt von Habermas' Theorie steht mittlerweile die Rechtstheorie. Diese rekonstruiert den ideellen und den materiellen Gehalt der Aufklärung. Allerdings scheint sich die empirische Demokratietheorie von den Hoffnungen der Aufklärung - zumindest für den historischen Augenblick - verabschiedet zu haben. Habermas schränkt den demokratischen Impuls durch die Institution des Rechts ebenfalls ein, bestätigt ihn aber gleichzeitig als Ergebnis eines historischen Lernprozesses. Normativ wird die Spannung zwischen Selbstgesetzgebung und Konstitutionalismus von Habermas dem Rechtssystem selbst eingeschrieben. Der kritische Gehalt der Theorie des kommunikativen Handelns soll als Rechtsparadigma lebendig gehalten werden. Doch ist das Rechtssystem ein unvollkommenes Handlungssystem, so daß allenfalls mittels Recht, aber nicht durch Recht, Nachhaltigkeit erzielt werden kann. Das Rechtssystem sieht sich vor das Problem gestellt, nur ökologisch relevante Handlungen effektiv normieren zu können, Natur oder Naturzustände jedoch weitgehend unbestimmt lassen zu müssen. Externe Beobachter und interne Teilnehmer des Rechtssystems haben stark divergierende Perspektiven. Wie also kann die ökologische Krise durch Recht bewältigt werden und die Ökologisierung des Rechtssystems demokratisch weiterentwickelt werden? Die schwache Handlungsorientierung des Rechtssystems steht in deutlichem Gegensatz zum modernen Wirtschaftssystem und scheint sich dessen Instrumente bedienen zu müssen, um eine notwendige Handlungstiefe zu erzielen. Das Rechtssystem besitzt dazu Geltungsmaßstäbe, die es von der Rationalität des ökonomischen Systems distanzieren. Dies ist Gegenstand von Kapitel 4. 
In Kapitel 5 wird der zivilgesellschaftliche Zusammenhang entfaltet. Er ist Kern dessen, worum sich der Prozeduralismus von sowohl normativer als auch empirischer politischer Theorie bemüht: die solidarische Reform der Gesellschaft. Verfolgt man diese Aufgabenstellung zunächst unter dem Gesichtspunkt strategischer Rationalität, öffnen sich der sozialwissenschaftlichen Forschung institutionelle Arrangements der Nachhaltigkeit, und Nachhaltigkeit wird als regulative Idee interpretiert, die in allen Formen und auf allen Ebenen der Politik institutionell verfolgt werden soll. Politik bleibt dabei auf solidarische Interaktion verwiesen. Angelehnt an das funktionalistische Konzept des Mediums hat Habermas der Zivilgesellschaft generalisierend Solidarität unterstellt. Diese Annahme wird jedoch nur noch begrenzt von Habermas' wissenschaftstheoretischen Annahme einer Lebenswelt getragen. In Hinblick auf das Ziel einer genügsamen Lebensweise (Suffizienz) scheinen Zivilgesellschaft und kritische Öffentlichkeit jedoch keineswegs umstandslos zusammenzufallen. Öffentlichkeit kann als lebensweltlich eingebettet verstanden werden, da Diskurse von ökologischer Sozialisation und Kulturation durchdrungen sind und diese selbst reproduzieren. Als funktional stabilisiert kann Öffentlichkeit beobachtet werden, insofern in ihr ablaufende Diskurse wechselseitig mit prozedural strukturierten und rechtlich verfaßten, soziopolitischen Verhandlungssystemen interagieren. Doch erst wenn die Gesellschaft ein Bewußtsein ihrer selbst besitzt, kann sie in der politischen Öffentlichkeit demokratisch und reflexiv die systemischen Pathologien der Moderne bekämpfen. In diesem Sinne rahmen Diskurse Policyprozesse. Diskurse ermöglichen dabei argumentative Kritik an ökologisch ineffektiver, symbolischer Politik und symbolischem Recht. In der Ökonomik werden Ideen entwickelt, die ebenfalls Verhandlungssysteme und Policies diskursiv beeinflussen. Zugleich kann seitens des politisch-administrativen Systems eine innovationsorientierte Vermittlung von Umweltpolitik einsetzen, die sich wiederum an Zivilgesellschaft und ökonomisches System richtet. Denn erst wenn die Rückbindung an die lebensweltlichen Strukturen gelingt, können ökologische Krise sowie Nachhaltigkeitsagenda dauerhaft im politischen Prozess thematisiert werden.

Reformen zur Nachhaltigkeit entwickeln sich zwar primär innerhalb des Umweltpolitikfeldes, aber doch mit einem Regelungsanspruch, der tendenziell darüber hinaus auszuweiten ist (Kapitel 6). Ohne begleitende Forschung wären policy-übergreifende, institutionelle Regelungen kaum durchführbar. Die politikwissenschaftliche Umweltforschung stützt diese Regelungen punktuell. Die Policy-Analyse hat die Herausbildung und Institutionalisierung der Umweltpolitik seit ihren systematischen Anfängen in den 70er Jahren gefördert und begleitet. Sie hat in diesem Prozeß politikwissenschaftliche Erkenntnisse erbracht, die auch auf andere Politikfelder übertragen werden konnten. Sie arbeitet empirisch und muß sich mit wichtigen methodologischen Problemen auseinandersetzen, die erst seit dem kurzen Bestehen umweltpolitisch-administrativer Institutionen von diesen erhoben werden (vgl. Jörgens, 1996). Die Umweltpolitikforschung hat in diesem Prozeß immer wieder situativ genutzte und potentiell verfügbare umweltpolitische Handlungskapazitäten aufzeigen können und einen praktisch-theoretischen Entwicklungsprozeß zwischen Gesellschaft und Sozialwissenschaft initiiert. 
Es ist jedoch These dieser Arbeit, daß sich der normative Anspruch von 'Nachhaltigkeit' nicht allein durch das empirische Aufzeigen umweltpolitischer Handlungskapazitäten absichern läßt. Vielmehr bedürfen die umweltpolitologischen Befunde einer theoriesystematischen Einbettung, um "vorteilhafte Rahmenbedingungen für die Erweiterung geeigneter umweltpolitischer Handlungsund Steuerungskapazitäten im Verlauf diesbezüglicher sozialer Lernprozesse der relevanten Akteure" zu identifizieren und "innerhalb angemessener Zeiträume" zu gestalten (Conrad, 1997, 360). Die Verbindung der umweltpolitologischen Befunde mit der Diskurstheorie könnte insofern fruchtbar sein, als daß diese moralisch-kognitiv begründet ist, und deshalb für die Konzeption von Nachhaltigkeit, wie zu zeigen ist, die geeignete Makrotheorie abgibt. Während die Diskursethik die Unsicherheit über die Zukunft in der Interaktion von Gesellschaft und Natur moralisch zugänglich macht, läßt sich mit der Diskurstheorie ökologische Ökonomie und prozeduralen Umweltstaat als systemische Reaktionen (von Ökonomik und Jurisprudenz) auf diese Unsicherheit verstehen. Derart eröffnet eine nachhaltige Stoffpolitik Reformen der Gesellschaft.

So schließt sich der Kreis zwischen dem Diskurs über Nachhaltigkeit und der gegenwärtigen umweltpolitologischen Forschung. Aus Sicht der Umweltpolitikforschung sind Nachhaltigkeitsziele nur unklar zu identifizieren. Nachhaltigkeit wird deshalb gar nicht näher bestimmt, sondern soll in bestehenden und zu reformierenden Institutionen erst materiell generiert werden (vgl. Tscheulin et al., 1998). In bezug auf die stofflich-energetischen Aspekte der ökologischen Krise eröffnet jedoch bereits die bisherige philosophische, ökonomische, sozial- und rechtswissenschaftliche Forschung die Möglichkeit eines diskurstheoretischen Ansatzes zur Nachhaltigkeit. Dieser konzentriert sich auf den sozialen Metabolismus mit der Natur, d.h. auf gesellschaftlich initiierte Stoff- und Energieströme. Prospektiv lassen sich durch die makrotheoretische Bezugnahme Stoffbilanzen von Policyarenen und nationale Materialbilanzen gegenüberstellen. Dadurch rückt eine integrative Politik der Nachhaltigkeit näher, die Handeln zwischen verschiedenen Politikfeldern und Sektoren systematisch abwägen und institutionell effektivieren kann.

Am Beispiel der Abfallpolitik wird gezeigt werden, wie sich im öffentlichen Diskurs Koalitionen bilden, die im Fallbeispiel systemische Grenzen hinter sich ließen und zivile wie auch politischadministrative Akteure umfaßten. Im einsetzenden, policybezogenen Diskurs konnten dann ressourcenschwache, nicht-kooperative Diskurskoalitionen durch die Öffentlichkeit - und dennoch nichtstrategisch - Politiken initiieren, die der Umwelt (als öffentlich konstruiertes Gut) dienlicher waren, als kooperative Verhandlungslösungen zwischen etablierten Netzwerkakteuren es gewesen wären. Obgleich die Fortentwicklung der Abfallpolitik unter den im Policyprozeß geschaffenen rechtlichen und ökonomischen Restriktionen bisher durch eine weitgehend unabhängige Agentur (DSD AG) öko-effektiv betrieben werden konnte, erweist sich die ausgehandelte Netzwerksteuerung als überaus kompliziert und wenig beteiligungsoffen. So gesehen dürfte die Delegation von Umweltpolitik an unabhängige Institutionen, die hochspeziellen Politikfeldern vorsitzen, langfristig der öffentlichen Reproduktion einer Nachhaltigkeitsagenda eher schaden, weil öffentliche Diskurse ersatzlos in rein policy- und rechtsbezogene Expertendiskurse überführt werden. Deliberation wird dabei nicht nur kulturell, sondern auch politikwissenschaftlich verkürzt. 
In der Politicsdimension stoßen öffentliche Diskurse in eine institutionelle Leere. Generell sind, um umweltpolitische Agenturen effizienter zu machen, von ökonomischer Seite unabhängige Parafiski in die Diskussion eingebracht worden, die jenseits von aktuellen Haushaltserwägungen kontinuierlich Umweltabgaben/-zertifikate erheben bzw. erlassen sollen. Doch diese könnten das Ziel von Nachhaltigkeit bereits systemintern aufgrund mangelnder Effektivität oder Steuerungstiefe - vor allem in schwierigen Bereichen, wie dem Konsum - verfehlen. Als potentielle Lösung einer unzureichenden Steuerungstiefe trotz prozedural ausgestalteter Policydiskurse und parallel arbeitenden Verhandlungssystemen könnten solche unabhängigen Agenturen zentralisiert und allein auf Stoffströme bezogen werden und schließlich direktdemokratisch ausgestaltet werden. 


\section{Die Diskurstheorie}

\subsection{Der Universalismus der Universalpragmatik}

Theorien mit universalem Geltungsanspruch wie die Diskurstheorien Habermas' und Apels sowie die Systemtheorie Luhmanns werden nicht all zu häufig direkt mit der globalen Dimension der ökologischen Krise konfrontiert. Und eine direkte Zurückweisung des universalen Geltungsanspruchs einer Theorie allein aufgrund der fehlenden Berücksichtigung der ökologischen Krise würde seitens der entsprechenden Fachwissenschaften auf Unverständnis stoßen. Universale Begründung und Anwendungsfall sind zu trennen. Zwar scheint die Globalität der ökologischen Krise (wie die Globalisierung allgemein) zwingend universale Theorien aufzugeben - partikularen Theorien könnte, je nach Begründung, schon die Grundvoraussetzungen globaler ökologischer Bezugnahme fehlen -, doch die globale ökologische Krise zum Kriterium eines universalen Geltungsanspruchs zu machen, würde normative Begründung und praktische Anwendung miteinander vermengen. Dagegen ist eine relative Autonomie universaler Geltungsansprüche gegenüber partikularen Kontexten zu wahren. Doch wie wären universale Geltungsansprüche zu bewerten, wenn sie keine Anwendungsmöglichkeiten in partikularen Kontexten ermöglichen könnten?

In seinem Hauptwerk, der Theorie des kommunikativen Handelns, begründet Habermas eine Sozialphilosophie kommunikativer Rationalität am Leitbild sprachlicher Verständigung. Die Theorie fordert die beiden großen sozialwissenschaftlichen Paradigmen des zweckrationalen Handelns und der Systemtheorie heraus und expliziert einen sozialintegrativen Kognitivismus, der beide Theoriensträngen aufnimmt und sich gleichzeitig von ihnen abgrenzt. Mit dieser Abgrenzung strebt Habermas nichts weniger als einen Paradigmenwechsel in der Soziologie an.

Der Paradigmenwechsel setzt auf drei Ebenen an. Er hat metatheoretische, methodologische und empirisch-theoretische Implikationen für die Sozialwissenschaften. Auf der metatheoretischen Ebene beschäftigen Habermas die Rationalitätsimplikationen der forschungsleitenden Begriffe, auf der methodologischen Ebene erklärt er die Rationalitätsimplikationen einer sinnverstehenden Sozialwissenschaft und auf der empirisch-theoretischen Ebene geht er der Frage nach, inwieweit die Modernisierung der Gesellschaft (oder ihrer Teilbereichen) als Rationalisierung beschrieben werden kann. ${ }^{1}$ Die metatheoretische Ebene klärt die Zusammenhänge zwischen Philosophie und den Sozialwissenschaften, die zweite Ebene expliziert die Methodik sozialwissenschaftlicher Forschung und die dritte Ebene enthält eine kritische Theorie der Moderne.

Kommunikatives Handeln läßt sich vom teleologischen Handeln unterscheiden, das auf die Verwirklichung eines Zwecks gerichtet ist und als strategisches Handeln entscheidungs- und spieltheoretischen Ansätzen in der Ökonomie und den Sozialwissenschaften zugrunde liegt und als

1 Vgl. Habermas, 1981, I, 8, 23 ; Dietz, 1993, 70 f; Hoester, 1999, 67 ff; Krüger, 1990, 372 f 
instrumentelles Handeln die nichtmenschliche Umwelt wissenschaftlich und ökonomisch objektiviert. Vom kommunikativen Handeln läßt sich weiter normatives Handeln unterscheiden, das sich auf Gruppen bezieht, die ihr Handeln durch gemeinsame Werte koordinieren. Dieses Modell ist aus der Rollentheorie bekannt (Durkheim, Parsons). Schließlich ist dramaturgisches Handeln vom kommunikativen Handeln zu differenzieren; es bezieht sich auf die expressive Selbstrepräsentation vor einem Publikum (Goffman). Kommunikatives Handeln greift als verständigungsorientiertes Handeln alle drei Aspekte des Handelns auf. Die genannten Handlungsformen sind als Grenzfälle kommunikativen Handelns zu verstehen (vgl. Habermas, 1988, 68 ff). Das Konzept kommunikativen Handelns wird im symbolischen Interaktionismus sozialwissenschaftlich angewandt.

\subsubsection{Lebenswelt und Systemwelt}

Der Theorie des kommunikativen Handelns liegt ein zweistufiges Gesellschaftskonzept zugrunde, dessen Grundbegriffe Lebenswelt und System sind. Während funktional integrierte Bereiche der Gesellschaft von Habermas als Systeme bezeichnet werden, führt er die Lebenswelt als Komplementärbegriff zum kommunikativen Handeln ein. Eine zweistufige Betrachtung der Gesellschaft - als Verhältnis von Theorie/Technik und Praxis - hat Habermas schon früh in seinem Werk verfolgt (1963). Dabei war zu Beginn eine eher aristotelisch geprägte Position Ausgangspunkt seiner Untersuchungen. Dieses Schema hat Habermas als einen Gegensatz zwischen technischer und praktischer Rationalität zur Ideologiekritik benutzt (Habermas, 1968). Marcuses These einer repressiven Technik, die, angewandt auf das Soziale, ideologisch sei, hielt er jedoch die Eigenständigkeit wissenschaftlich-technischer Erkenntnis entgegen und sah diese grundsätzlich als gattungsgeschichtliche Errungenschaft an, die nur demokratisch kontrolliert werden müsse. Das Verhältnis zwischen Theorie und Praxis hat Habermas aber nicht nur in der Technikentwicklung sowohl antagonistisch als auch ergänzend gedeutet - wobei sich hier sogar die theoretischen Bezugspunkte wandelten ${ }^{2}$-, sondern auch in der Ideengeschichte, bis das Verhältnis dann in der Theorie des kommunikativen Handelns zugunsten sozialer und sozialwissenschaftlicher, kommunikativer Praxis bestimmt wurde (vgl. Schnädelbach, 1986). Durch die Fundierung der universalpragmatischen Theorie auf einem zweistufigen Gesellschaftskonzept, beabsichtigt Habermas, die Spannungen zwischen normativer Geltung und empirisch-sozialer Faktizität der Gesellschaft abzufedern. Die Theorie geht dabei mit ihrem zentralen Lebensweltkonzept in praktisch-kritischer Absicht über die bewußtseinsphilosophische Phänomenologie Husserls hinaus. Sie folgt der sprachphänomenologischen Soziologie A. Schütz'.

Die Theorie des kommunikativen Handelns wird auch als Diskurstheorie bezeichnet. Diesen Namen trägt sie aufgrund der Auszeichnung der Sprache als Medium der argumentativen Verständigung. Beide Versionen der Diskurstheorie, sowohl die Transzendentalpragmatik von Karl-

2 Dies hat, wie S. Dietz $(1993,85)$ feststellt, auch zur Folge, daß nicht immer deutlich ist, "in welchem Verhältnis die dabei entwickelten Begriffspaare [Technik und Praxis] zueinander stehen." 
Otto Apel als auch die universalpragmatische Theorie von Jürgen Habermas fundieren ihr Programm der Intersubjektivität in der menschlichen Sprache, da dieser das Telos der Verständigung inne ist. Im Gebrauch der Sprache lassen sich den Sprechern unabdingbare, über Sprechakte vollzogene Präsuppositionen formalpragmatisch nachweisen. Die lebensweltlichen Verständigungsprozesse erfolgen über Sprechhandlungen, mit denen sich Akteure auf eine Situation beziehen. Sie erheben in diesen Sprechhandlungen verschiedene Geltungsansprüche über die Gültigkeit des von ihnen Gesagten. Habermas folgt K. Bühlers Modell der Zeichenverwendung und arbeitet formalpragmatisch drei Bestandteile in den lebensweltlichen, situativen Bezugnahmen auf die Welt heraus, eine objektive Welt existierender Gegenstände, eine soziale Welt interpersonal geregelter Beziehungen und eine subjektive Welt innerer Erlebnisse. In lebensweltlichen Situationen nehmen handelnde Akteure somit immer eine objektivierende, eine normenkonforme und eine expressive Einstellung ein. Auf diesen Einstellungen aufbauend, lassen sich der Lebenswelt so formale Weltbegriffe zuschreiben, welche die drei Geltungsansprüche Wahrheit, Richtigkeit und Wahrhaftigkeit enthalten. Jeder Akt der Verständigung verweist auf die Geltungsansprüche der jeweiligen Welt. Zugleich wird nach Habermas mit sprachlicher Kommunikation immer auch die Verständlichkeit derselben vorausgesetzt.

Verständlichkeit angenommen, werden diese Weltbegriffe im kommunikativen Handeln reflexiv so zusammengeführt, daß der Andere rational zu einer Anschlußhandlung motiviert wird. Über Sprechakte wird eine interpersonale Beziehung zwischen Aktoren hergestellt, die ein rational motiviertes Einverständnis zwischen ihnen ermöglicht. Handlungen können dabei durch Sprechakte auf einer abstrakteren Ebene als der unmittelbar intendierten interpersonalen Beziehungsebene koordiniert werden. Im Gegensatz dazu beziehen sich Akteure mit strategischen Handlungen ausschließlich objektivierend auf andere Akteure und ihre Umgebung. Da sich mit strategischen Handlungen keine kritisierbaren Geltungsansprüche verbinden lassen, zielen damit einhergehende Sprechakte nicht auf Verständigung, sondern benutzen Sprache nur parasitär. Im einverständnisorientierten Sprachgebrauch kommt dagegen auch Intentionalität zum Ausdruck, die nicht erfolgsorientiert ist. Kommunikative Rationalität schließt die kognitive, die normative und die expressive Dimension sowie Intentionalität ein. "Das kommunikative Handeln unterscheidet sich also vom strategischen in der Hinsicht, daß sich eine erfolgreiche Handlungskoordination nicht auf die Zweckrationalität der jeweils individuellen Handlungspläne stützt, sondern auf die rational motivierende Kraft von Verständigungsleistungen, auf eine Rationalität also, die sich in den Bedingungen für kommunikativ erzieltes Einverständnis manifestiert." (Habermas, 1988, 70)

Die gegenüber dem lebensweltlichen Alltag mit seinem impliziten lebensweltlichen Hintergrundwissen außeralltägliche Kommunikationsform ist der Diskurs. Diskurse knüpfen in der Universalpragmatik an Erfahrungen und Probleme der Lebenswelt an. Probleme werden nicht durch philosophische Reflexion konstituiert, sondern durch kontingente Erfahrungen aufgeworfen. Strittige Fragen, die in der Lebenswelt auftreten, werden in Diskursen thematisiert und argumentativ behandelt. Im theoretischen Diskurs werden Wahrheitsansprüche thematisiert. Wahrheitsgeltung kann sowohl aufgrund negativer Erfahrungen im teleologischen (strategisches 
und instrumentelles) Handeln als auch bei der Verständigung über Tatsachen (empirischtheoretisches Wissen) angezweifelt werden. Probleme des normenregulierten Handelns können im praktischen Diskurs argumentativ gelöst werden und dramaturgisches Handeln ist der therapeutischen sowie der ästhetischen Kritik zugänglich. Zwar hat der verständigungsorientierte Sprachgebrauch, da er immer auf kritisierten oder bestätigten Geltungsgründen beruht, insgesamt einen argumentativen Charakter, doch verweist Habermas erst im Kontext des Diskurses auf die Argumentationstheorie. Den im Diskurs vorgebrachten Argumenten ist eine zwanglose Kraft zur Überzeugung inne, so daß der Widerstreit der Argumente schließlich durch einen Konsens beendet werden kann. Die Lebenswelt wird dann wieder zum unproblematischen Hintergrund der Akteure. Der formalpragmatisch explizierte Begriff der Lebenswelt verweist wieder zurück auf etwas NichtObjektiviertes, dem wir alle angehören. Auch die Wissenschaften können die Lebenswelt nur auszugsweise thematisieren.

Im Unterschied zum subjektphilosophischen Lebensweltkonzept Husserls basiert Habermas' Konzept der Lebenswelt auf der rationalen Intersubjektivität sprechender Akteure. In Habermas' Begriff der Lebenswelt sind Rationalität und Kommunikation vereint. Mit sprachlicher Kommunikation verwenden sprach- und handlungsfähige Subjekte Wissen. In der Teilnehmerperspektive sprechender Subjekte erscheint die Lebenswelt als horizontbildender Kontext einer Handlungssituation. Die Lebenswelt hält für die Kommunikationsteilnehmer immer ein unthematisches, präreflexives Hintergrundwissen parat. Dieses ist resistent gegen den Problematisierungsdruck kontingenzerzeugender Erfahrungen und kann nur methodisch und nur auszugsweise zugänglich gemacht werden.

Der lebensweltliche Hintergrund ist, da er totalisierende Kraft besitzt, nicht beliebig verfügbar. Er läßt sich auch nicht durch abstrakten, cartesischen Zweifel in seiner Totalität erschüttern. Die Stabilität der Lebenswelt resultiert aus ihrem Holismus, den selbst die formalpragmatische Analyse nur rudimentär explizieren kann. Zweifel erwachsen dann auch nur aus pragmatischen Problemen, die "mit der objektiven Macht geschichtlicher Kontingenzen auf uns zukommen." (Habermas, 1988, 91) Dem lebensweltlichen Hintergrund ist eine unvermittelte Gewißheit zueigen. Diese Gewißheit ist insofern paradox, als daß sie zwar die intensivere aber gleichwohl defizitäre Form des Wissens darstellt, denn sie ist ohne internen Bezug zu einer Problematisierung. Erst "im Augenblick des Aussprechens kommt [das lebensweltliche Wissen] mit kritisierbaren Geltungsansprüchen in Berührung [...] und [wird] damit in fehlbares Wissen transformiert" (Habermas, 1988, 92).

Die Plausibilisierung von Geltungsansprüchen beruht prima facie auf einem unthematisch mitlaufenden, vordergründigen Wissen. Auf dieses stützen sich die Beteiligten in der Form von pragmatischen und semantischen Voraussetzungen. Dieses vordergründige Wissen kann unterschieden werden in ein situationsbezügliches Horizontwissen, das Sprechsituation immer implizit in konzentrisch angeordnete, raumzeitliche Horizonte einbettet, und ein themenabhängiges Kontextwissen, welches einen Erlebnishorizont aufbaut aus dem heraus nach Bedarf Informationen und Gründe mobilisiert werden können. Beide Varianten vordergründigen Wissens nehmen eine geltungsstabilisierende Rolle ein. Die Lebenswelt bildet also zu einer Situation hin den Kontext, 
wohingegen sie für den Bereich des Thematisierbaren überhaupt den unerreichbaren Horizont darstellt. Die Lebenswelt erscheint hier als kommunikationstheoretisch begründeter Wissensbegriff, so daß das Konzept der Lebenswelt auch insgesamt als "Komplementärbegriff zum kommunikativen Handeln" verstanden werden kann (Habermas, 1981, I, 377). Im Vergleich zu Husserls Lebensweltbegriff vollzieht sich bei Habermas der lebensweltliche Widerstreit "zwischen dem auf Idealisierung angewiesenen expliziten Wissen einerseits, dem risikoabsorbierenden Hintergrundwissen anderseits innerhalb des Bereichs des unthematisierten Wissens" und nicht erst "in der Konkurrenz zwischen erfahrungswissenschaftlichem Expertenwissen und vortheoretischen Überzeugungen des Alltags." (Habermas, 1988, 89)

Neben der kommunikationstheoretischen Bestimmung der Lebenswelt findet sich in der Theorie des kommunikativen Handelns noch eine andere Erläuterung der Lebenswelt. Diese ist methodologischer Art und bezeichnet die Gesamtheit symbolisch bedeutsamer, sinnhaft konstituierter Handlungen und Gegenstände für den Sozialwissenschaftler. Aus dessen Perspektive wird die Abgrenzung zwischen Situation und Lebenswelt eingezogen und die Lebenswelt erscheint insgesamt als symbolisch vorstrukturierte Wirklichkeit (Habermas, 1981, I, 159). Habermas begründet dies damit, daß der aus der Teilnehmerperspektive entwickelte kommunikationstheoretische Begriff der Lebenswelt nicht unmittelbar für theoretische Zwecke brauchbar sei; "er eignet sich nicht zur Abgrenzung eines sozialwissenschaftlichen Objektbereichs" (1981, II, 206). Habermas will diese Reinterpretation durch den Übergang von der Teilnehmerperspektive auf die Erzählerperspektive plausibel machen. In der Erzählperspektive werde nämlich das "vorausgesetzte Alltagskonzept der Lebenswelt immer schon zu kognitiven Zwecken verwendet" (Habermas, 1981, II, 208). Die Lebenswelt sei ein kognitives Bezugssystem (ebd., 207), das Habermas nunmehr als Ganzes darstellt. Sprache diene in Anlehnung an Mead als Medium der Verständigung, der Handlungskoordination und der Vergesellschaftung. Aus der verstehenden Perspektive des sozialwissenschaftlichen Erzählers erbringe die Lebenswelt unter dem funktionalen Aspekt der Verständigung drei grundlegende Leistungen hinsichtlich der strukturellen Komponenten Kultur, Gesellschaft und Persönlichkeit: 1. Die kulturelle Reproduktion der Lebenswelt sichere die Kontinuität der Überlieferung und eine für die Alltagspraxis jeweils hinreichende Kohärenz des Wissens. Kontinuität und Kohärenz bemäßen sich an der Rationalität des als gültig akzeptierten Wissens. 2. Die soziale Integration der Lebenswelt stelle sicher, daß neu auftretende Situationen an bestehende Weltzustände angeschlossen würden: Sie sorge für die Koordinierung von Handlungen über legitim geregelte interpersonale Beziehungen und verstetige die Identität von Gruppen durch Solidarität. 3. Die Sozialisation der Angehörigen einer Lebenswelt schließe neu auftretende Situationen in der historischen Zeit an bestehende Weltzustände an: Sie sichere für nachwachsende Generationen den Erwerb generalisierter Handlungsfähigkeiten und sorge für die Abstimmung von individuellen Lebensgeschichten und kollektiven Lebensformen (vgl. Habermas, 1981, II, 212 f) Im Gegensatz zu dieser symbolischen Reproduktion der Lebenswelt vollziehe sich die materielle im Medium der Zwecktätigkeit (ebd., 209 f). 
Habermas erschließt jedoch auch die strukturellen Komponenten der Lebenswelt nicht nur aus der Erzählperspektive des Sozialwissenschaftlers, sondern leitet diese ebenfalls aus dem kommunikativen Handeln ab. Die legitimen Institutionen der Lebenswelt beruhen auf sprachlicher Kommunikation bzw. auf dem normativen Einverständnis der Akteure. Die Lebenswelt und ihre Strukturen werden durch kommunikatives Handeln reproduziert und sozial integriert. Von diesem Modus der sozialen Integration unterscheidet Habermas die funktionale oder systemische Integration der Gesellschaft, die er methodologisch über die Perspektive eines sozialwissenschaftlichen Beobachters einführt. Die systemische Integration stützt sich nicht auf die generelle Verständigungsorientierung der Akteure, sondern setzt unabhängig von den jeweiligen Handlungsorientierungen der Akteure bei der funktionalen Aggregation von Handlungsfolgen an. Hierbei falle die Zweckmäßigkeit einzelner Handlungen für einen Gesamteffekt nicht notwendig mit der Handlungsintention der einzelnen Akteure zusammen. Die Funktionalität der Handlungen bliebe für die Akteure latent.

Habermas hat in der Theorie des kommunikativen Handelns versucht, den Gegensatz zwischen System- und Handlungstheorie evolutionstheoretisch aufzulösen. Soziale Evolution versteht Habermas "als einen Differenzierungsvorgang zweiter Ordnung: System und Lebenswelt differenzieren sich, indem die Komplexität des einen und die Rationalität der anderen wächst, nicht nur jeweils als System und als Lebenswelt - beide differenzieren sich gleichzeitig auch voneinander." (1981, II, 230) Die systemische Integration durch Medien setze nicht bei der kommunikativen Reproduktion der Strukturen der Lebenswelt an, sondern führe zu einer Entkoppelung von Lebenswelt und System im Zuge der sozialen Evolution. In der Entwicklungslogik sozialen Wandels komme den Steuerungsproblemen der materiellen Reproduktion eine Auslösefunktion zu, wohingegen der symbolischen Reproduktion eine Schrittmacherfunktion hinsichtlich der Einrichtung neuer Institutionen zukomme (vgl. Habermas, 1981, II, 232 f). Die mediengestützten Systeme ermöglichten eine enorme Komplexitätssteigerung der Gesellschaft. Dem folge die Rationalisierung der Lebenswelt durch kommunikatives Handeln. Die soziale Dynamik lasse in der symbolisch strukturierten Lebenswelt die Bereiche Kultur, Gesellschaft und Persönlichkeit auseinander treten und bringe generalisierte Normen hervor. Die symbolische Reproduktion fußt Habermas zufolge auf der Entwicklung des moralischen Bewußtseins, das nach L. Kohlberg präkonventionelle, konventionelle und postkonventionelle Stufen der gesellschaftlichen Konfliktregelung kennt. Die mit der moralischen Entwicklung einhergehende Motiv- und Wertgeneralisierung eröffne dann Räume für die Subsysteme zweckrationalen Handelns. Erst mit der Ausdifferenzierung von Zusammenhängen strategischen Handelns könne die Handlungskoordination auf entsprachlichte Kommunikationsmedien umgestellt werden, so daß eine systemische Dynamik ermöglicht werde. Die systemische Differenzierung sei nur mittelbar an die generalisierten Normen zurückgebunden: Nur formales Recht ermöglicht nach Habermas die Handlungskoordinierung durch entsprachlichte Steuerungsmedien (1981, II, 269). Im Ausdifferenzierungsprozeß trete formales Recht der Moral zur Seite und erlaube zugleich den Geltungsaufschub unmittelbarer, moralischer Imperative. Die funktionalen Handlungssysteme seien sittlich neutralisiert (vgl. Habermas, 1981, II, 265 ff). Sie beruhten auf formalisierten, 
sanktionierten Codes. Die systemintegrativen Prozesse hätten gegenüber der Lebenswelt eine bestandserhaltende Funktion und steigerten die Steuerungskapazitäten der Gesellschaft (ebd. 228).

Die Medien der Systeme treten demnach neben die verständigungsorientierte Sprache. Habermas versteht sie als zusätzliche Koordinationsmechanismen zur Effektivierung der Sprache. Sie könnten diese aber auch ersetzen. Habermas erklärt so die Parallelität von sprachlicher und mediatisierter Kommunikation im Rahmen einer Rationalisierungstheorie. Während die Rationalisierungsprozesse der Lebenswelt das Dissensrisiko erhöhten, erlaube der Übergang auf Kommunikationsmedien, Sprache in ihrer Koordinationsfunktion vollständig oder teilweise zu ersetzen und damit den erhöhten Kommunikationsbedarf auszugleichen. Habermas unterscheidet zwischen rational und empirisch wirksamen Steuerungsmedien. Während Geld und Macht empirisch motivierte Bindungen herstellten, könnten Einfluß und Wertbindung durch rational motiviertes Vertrauen den Kommunikationsbedarf reduzieren, - wenngleich auch niemals vollständig ersetzen (vgl. Habermas, 1981, II, 270 ff). In bezug auf die Medien Einfluß und Wertbindung verweist Habermas auf fachliche Reputation und moralische Autorität, die auf einem rational motivierten Vertrauen durch begründetes Einverständnis beruhen würden. Die entsprachlichten Medien Geld und Macht stellten dagegen die soziale Koordination auf der Ebene empirischer Beeinflussung her. Sie gehen, so Habermas, nicht auf rationale Gründe zurück, sondern auf empirische Bedingungen. Geld und Macht spezialisierten nicht die Funktionsweise kommunikativer Sprache, sondern ersetzten sie durch ihre eigenen konditionierenden Mechanismen. Habermas bezeichnet nur Geld und Macht als Medien im Sinne direkter Steuerungsmittel (1981, II, 396 ff). Sie wiesen Parallelitäten hinsichtlich der Meßbarkeit, der Zirkulations- und der Speicherungsfähigkeit auf und wichen nur in der institutionellen Verankerung der symbolisierten Wertmengen voneinander ab. Macht erfordere zusätzliche Legitimationsleistungen, um als Medium erhalten werden zu können.

Für den Bereich der materiellen und der administrativen Reproduktion macht Habermas schließlich sogar eine nicht auf Handlungsrationalität zurückführbare Systemrationalität geltend. Damit wechselt er die theoretische Orientierung. Es dürfe keine "lineare Abhängigkeit der Organisationsrationalität von der Handlungsrationalität der Mitglieder" angenommen werden (Habermas, 1981, II, 453). Habermas wechselt hierbei von der Systemtheorie Parsons, zu jener Luhmanns. "Die mediengesteuerten Interaktionen können sich in Raum und Zeit zu immer komplexeren Netzen verknüpfen, ohne daß diese kommunikativen Vernetzungen überschaut und verantwortet werden müßten, und sei es auch nur in der Art eines kollektiv geteilten kulturellen Wissens." (Ebd., 394; ähnlich: 275) Habermas konstatiert somit eine vollständige Abkoppelung der systemischen Interaktion von lebensweltlichen Kontexten überhaupt. Mit Luhmann spricht er von einem "evolutionären Eigenwert mediengesteuerter Subsysteme" (1981, II, 499). Die Systemrationalität lasse sich nicht mehr auf die Handlungsrationalität der Akteure zurückführen (ebd., 453 ff). Allerdings setze Systemrationalität den lebensweltlichen Aspekt der Zwecktätigkeit noch voraus. Die zweckrationalen Handlungszusammenhänge würden "funktional, d.h. über die Rückmeldung der funktionalen Nebenfolgen stabilisiert", soweit "die aggregierten Wirkungen kooperativer Handlungen Imperative der Erhaltung des materiellen Substrats erfüllen" (ebd., 348). 
Dies scheint zu implizieren, daß die intendierten und nicht-intendierten Nebenfolgen funktionaler Integration an die Lebenswelt zurückgebunden sind. Dafür spricht, daß im Hinblick auf die Stoffwechselprozesse zwischen Gesellschaft und Natur, die Lebenswelt als ein grenzerhaltendes System zu vergegenständlichen sei, "weil dafür funktionale Zusammenhänge relevant sind, die sich über das intuitive Wissen von lebensweltlichen Kontexten nicht zureichend erschließen lassen. Die Überlebensimperative verlangen eine funktionale Integration der Lebenswelt, die durch die symbolischen Strukturen der Lebenswelt hindurchgreift und deshalb nicht ohne weiteres aus der Perspektive von Teilnehmern erfaßt werden kann." (Habermas, 1981, II, 348 f) Die Lebenswelt wird durch den methodologisch begründeten Standpunkt eines objektivierenden Beobachters in ihrer systemischen Dimension kontraintuitiv zugänglich gemacht. Dies schließe, so Habermas, Kritik an der methodologisch objektivierten Lebenswelt nicht aus: Wenn ein Kompromiß zwischen kommunikativem Handeln und externen Überlebensimperativen "allein um den Preis der Institutionalisierung/Internalisierung von Wertorientierungen erreicht werden kann, die mit den tatsächlichen Funktionen der entsprechenden Handlungsorientierungen nicht in Einklang stehen, hält der Kompromiß nur solange, wie diese Funktionen latent bleiben." (1981, II, 350) Das Medienkonzept wird nur durch eine strukturelle Unvereinbarkeit mit den Funktionen symbolischer Reproduktion der Kritik zugänglich, da "sich das Medienkonzept nicht auf Bereiche der kulturellen Tradition, Sozialintegration und Sozialisation übertragen lässt" und "sich diese drei Funktionen nur übers Medium verständigungsorientierten Handelns, nicht über die Steuerungsmedien Geld und Macht erfüllen lassen: Sinn läßt sich weder kaufen noch erzwingen." (Habermas, 1986, 390) Interne Geltungsgründe des Handelns können gleichwohl diese Systemrationalität weder kritisieren noch zurückweisen!

\subsubsection{Dualität von Lebenswelt und System?}

Die dargestellte Dualität von Lebenswelt und System ist einer der zentralen Kritikpunkte an Habermas Theorie geworden. Die Kritik setzt an der metatheoretischen und methodologischen Ebene an und hat schließlich aufgrund dessen auch Auswirkungen auf Habermas' empirischtheoretische Analyse der Moderne.

Auf der metatheoretischen Ebene hat H. Schnädelbach aufgrund des Dualismus zwischen Lebenswelt und System Zweifel am kritischen Gehalt der Theorie des kommunikativen Handelns geäußert. Die Beobachterperspektive unterbreche das teilnehmende, kommunikative Handeln. Dann stellt sich aber die Frage, "wie ein rekonstruierendes Philosophieren mit lediglich hypothetischen Geltungsansprüchen [...] dazu taugen soll, jenes Moment von Unbedingtheit bereitzustellen, ohne daß normative Grundlagen nun einmal nicht zu haben sind. Die Alternative ist Hermeneutik als praktische Philosophie ohne Unbedingtheitsansprüche mit allen relativistischen Konsequenzen" (Schnädelbach, 1986, 34). Ähnlich hat auch K.-O. Apel die relativierende Preisgabe des moralischen Diskurses bei Habermas bemängelt (Apel, 1989, 17 f). 
Als 'nur' methodologisch begründeter Wechsel zwischen Teilnehmer- und Beobachterperspektive wirft der Dualismus für die Sozialwissenschaften das epistemologische Problem der 'Wertfreiheit' auf. Die Beobachterperspektive soll die Lebenswelt in ihrer Totalität erfassen, während die Teilnehmerperspektive mit einer verstehenden Sozialwissenschaft identifiziert wird. Aus der Sprecherperspektive von Kommunikationsteilnehmer heraus macht Habermas die objektiv erfaßbaren Sprachstrukturen zum Gegenstand der verstehenden Sozialwissenschaften. Kommunikative Alltagspraxis und sinnverstehende Wissenschaft werden durch die Konzeption einer integrierenden 'performativen Einstellung' gleichermaßen als kommunikatives Handeln interpretiert. Eine Differenz zwischen beiden Arten kommunikativen Handelns ergibt sich erst in der praktischen Handlungskoordination, an welcher der Wissenschaftler als virtueller Teilnehmer keinen Anteil hat.

Die (sozialwissenschaftliche) Beobachterperspektive ignoriert die Handlungsorientierung der Teilnehmerperspektive und nimmt nur Aggregationseffekte in den Fokus, die sich unabhängig von rationalen Motiven und Gründen einstellen. Mit der Unabhängigkeit von Motiven entfallen zugleich theoretische Aussagen über intendierte oder nicht-intendierte Handlungseffekte (vgl. Habermas, 1981, II, 179). Erst ein Abgleich zwischen der objektivierenden Beschreibung der systemischen Eigendynamik mit den symbolischen Strukturen der Lebenswelt eröffnet die Möglichkeit der Kritik. S. Dietz hat es als auffällig bezeichnet, "daß Habermas sich zur Begründung dieses Vorrangs der Beobachterperspektive bei der Analyse systemisch geregelter Prozesse nicht auf die Begrenztheit rekonstruktiv erschlossener rationaler Handlungsorientierungen bezieht, sondern auf die Beschränktheit des 'intuitiven Wissens' der Beteiligten." (Dietz, 1993, 186) Den Sozialwissenschaften wird damit ein privilegierter Zugang zur Gesellschaft im Vergleich zu sozialen Akteuren zugestanden.

McCarthy hat Habermas ganz ähnlich kritisiert und auf die mißlichen Konsequenzen für die Demokratietheorie und die theoriestrategische Abgrenzung zur Systemtheorie in der Politikwissenschaft hingewiesen. "Im Falle der sozialen Evolution muß das Wachstum der Systemkomplexität, entsprechend Habermas' eigenen Prinzipien, der kommunikativen Rationalisierung des Lebens als Maßstab des Fortschritts untergeordnet werden." (McCarthy, 1986, 200) Daraus würden Kompromisse und Verhandlungen zwischen demokratischen Forderungen und Systemen folgen, die keineswegs kolonialisierte Lebenswelt wieder kommunikativ verflüssigen müßten, sondern - ganz im Gegenteil - die Kolonialisierung der Lebenswelt bestärken könnten. Die durch die Sozialwissenschaften vermittelte soziale und funktionale Integration der Gesellschaft könne gelingen oder scheitern. Nur sei damit der von Habermas erhobene Anspruch, eine kritische Theorie der Gesellschaft verfaßt zu haben, nicht vollständig eingelöst. "Die an sich zugestandene Notwendigkeit einer nicht nur in anerkannten Institutionen verankerten, sondern in sprachlichen Konsensbildungsprozessen auch immer wieder neu zu leistenden Rückkoppelungen des Machtmediums an sozialintegrative Strukturen wird in der These der 'Entkoppelung von Sozialund Systemintegration' unterschlagen" (Dietz, 1993, 136). Andererseits darf, worauf U. Bermbach hingewiesen hat, die gesellschaftliche Evolution von politischen Institutionen, auch wenn sie als 
Praxis kollektiven Argumentierens verstanden wird, nicht mit dieser Praxis zusammenfallen. Es sei vielmehr ein systematischer Vermittlungsprozeß notwendig. Die Ausbildung struktureller Rationalität in den gesellschaftlichen Teilsystemen und deren Verbindung zu gesamtgesellschaftlichen Rationalisierungsprozessen müsse genau unterschieden werden (Bermbach, 1991, 210 f).

Die Beispiele verdeutlichen, daß Habermas' Theorie das Problem mit sich bringt, auf der Ebene empirischer Sozialwissenschaften klar zwischen Lebenswelt und Systemen zu differenzieren. Dieses Problem praktischer sozialwissenschaftlicher Forschung wird hinsichtlich von Nachhaltigkeit noch dadurch verstärkt, daß Habermas zwar eine System-Umwelt-Differenz für die materielle Reproduktion der Lebenswelt konstatiert, welche allein vom ökonomischen System übernommen werde, die symbolische Reproduktion der Lebenswelt aber zunächst formalpragmatisch durch den Theoretiker erfolgt. Die von Habermas aufgezeigten Strukturen der Lebenswelt, und die Rationalitätsformen gewinnen damit größte Relevanz für die Möglichkeit, Nachhaltigkeit überhaupt im Rahmen der Diskurstheorie zu entwickeln.

Habermas hat den methodologischen Wechsel von der Teilnehmerperspektive zur Beobachterperspektive später ein weiteres Mal zu klären versucht und dabei verdeutlicht, daß jede Wissenschaft sich mit den methodologischen Folgen des teilnehmenden Interpreten befassen muß, sobald sie Bedeutungsobjektivationen innerhalb eines Objektbereichs vornimmt. Denn die Teilnehmerrolle eines Interpreten impliziere, so Habermas, daß der Interpret den beobachteten Dingen nicht Bedeutung 'gebe', sondern er die 'gegebene' Bedeutung von Objektivationen des immer sprachlich verfaßten Hintergrunds nur aufnehme und ausführe (vgl. Habermas, 1983, 37). Im zweckrationalen Handeln liege dagegen jedem Handlungsplan eine Situationsauslegung zugrunde, in welcher das Handlungsziel (a) unabhängig von den intervenierenden Mitteln (b) als ein kausal zu bewirkender Zustand (c) in der objektiven Welt bestimmt werde. Sprechhandlungen lassen sich nach Habermas jedoch nicht unter dieses Modell der Zwecktätigkeit subsumieren, da ein Sprecher seine illokutionären Ziele nicht gemäß dieser Beschreibung intendieren könne (vgl. ders., 1988, 66). Natürlich müßte diese kommunikationstheoretische Akteursperspektive, nimmt man Habermas beim Wort, auch für kommunikatives Handeln im Prozeß naturwissenschaftlicher Forschung gelten. $^{3}$ Doch Habermas befürchtet, daß eine solche Perspektive "gerade jene Kontexttunabhängigkeit und Wertneutralität [bedrohen könnte], die für die Objektivität des theoretischen Wissens notwendig zu sein scheint." (Habermas, 1983, 37, vgl. auch Habermas, 1984, 159 ff) Wie noch auszuführen ist, hat diese Intuition Habermas mittlerweile dazu veranlaßt, nichtinstrumentelle Sprechhandlungen an naturwissenschaftliche Handlungen (instrumentelle Experimente) zu assimilieren, wodurch symbolische Sprechhandlungen und materielle

3 Habermas stellt zwar explizit fest, daß er mit der Unterscheidung zwischen hermeneutischer und nicht-hermeneutischer Wissenschaft keinen ontologischen Dualismus zwischen bestimmten Realitätsbereichen (z.B. Natur vs. Kultur) befürworten möchte. Nur gibt er zu bedenken, daß hermeneutische Wissenschaften ohne vorherige Interpretation Daten nicht einmal generieren könnten. Diese Möglichkeit besäßen lediglich die nichthermeneutischen Naturwissenschaften. Doch auch diese müßten sich auf der metatheoretischen Ebene wieder mit dem Problem der Interpretation auseinandersetzen (Habermas, 1983, 51 f, Fn 8). 
Interventionshandlungen unzulässig miteinander vermengt werden und als praktische Konsequenz potentiell Entdifferenzierung droht.

Mit dem Perspektivwechsel von der sozialen auf die objektivierte Welt (und Natur) verändert sich die Bedeutung der Systeme in der Theorie des kommunikativen Handelns. In bezug auf die soziale Umwelt sollen Systeme in der symbolischen Dimension an die Lebenswelt zurückgebunden sein, hinsichtlich der objektiven, natürlichen (Um)welt werden Systeme von den stofflichen, materiellen Folgen her auf die Lebenswelt bezogen, ohne daß daraus unmittelbar Konsequenzen für den Theorieaufbau ersichtlich werden würden. Die Theorie des kommunikativen Handelns wird von Habermas als Gegenmodell zur Systemtheorie entworfen. Sie soll innerhalb dieses Gegensatzes evolutionstheoretisch übergreifende Geltung beanspruchen können. Das Geltungsprimat kommt dem kommunikativen Handeln gegenüber der zweckrationalen Eigenlogik von Systemen deshalb zu, weil es kommunikative Lernprozesse ermöglicht, welche ihrerseits Systeme erst ermöglichen. Die Eigendynamik der Systeme droht aber wiederum die Lebenswelt zu fragmentieren. Evolutionstheoretisch besehen entsteht daraus das Paradox, daß die kommunikative Rationalität eine Systemdynamik in Gang setzt, die sie selbst zu zerstören droht. Habermas erkennt dieses Paradox (1981, II, 486 u. vgl. a. 277, 470, 491, 522, 593) und behandelt das spannungsreiche Verhältnis zwischen Handlungen und kontingenten Folgen teilweise als zeitliche Differenz zwischen Wissen und Erfahrung innerhalb der Lebenswelt ab. Das von kommunikativ Handelnden thematisierte Wissen schließt lebensweltliche Erfahrungen ein. Erfahrungen treten historisch kontingent auf und können Habermas zufolge die Lebenswelt zwar sogar insgesamt erschüttern jedoch nicht zerstören. Die Lebenswelt ermöglicht eine "erfahrungsnahe Kontingenzeindämmung" (Habermas, 1988, 93). Diese beruhe auf dem immer gegenwärtigen, präreflexiven, lebensweltlichen Hintergrundwissen kommunikativ Handelnder und dem vordergründigen Wissen über die symbolischen Strukturen der Lebenswelt und dem darin sedimentierten Sinn, der einer systemtheoretischen Beobachterperspektive nicht zugänglich sein kann.

Habermas führt an, daß die Stabilität und Funktionalität der Systeme und der sie tragenden Institutionen zweiter Ordnung nur noch empirisch zu beobachten und nicht mehr normativ-rational zugänglich sei. In systemtheoretischer Hinsicht verweist dies deutlich nicht mehr auf Parsons' Systemtheorie, sondern auf Luhmanns Theorie autopoietischer Systeme. Würde man dies als das letzte philosophische Wort der Theorie des kommunikativen Handelns erachten, wäre ihr Status als kritische Theorie kaum zu halten, obgleich Habermas' Intentionen zweifellos gegenteilig gewesen sind. Wie aber könnte die empirische Beobachtung des ökonomischen und des politischadministrativen Systems überhaupt aussehen? Luhmann gibt auf diese Frage keine Antwort und Habermas hat sich in den Jahren nach seinem "großen sozialwissenschaftlichen Theorieentwurf" (Reese-Schäfer, 2001, 65) im wesentlichen auf die Ausarbeitung der Diskursethik konzentriert und zuletzt auf die rationalitätstheoretische Basis der Theorie des kommunikativen Handelns, die er 1981 noch an die Philosophie abtreten wollte. Fragen nach der Verknüpfung von empirischen Sozialwissenschaften und der Theorie des kommunikativen Handelns standen demgegenüber eher im Hintergrund. 
Habermas hat kommunikatives Handeln über die drei formalen Weltbezüge (objektiver, subjektiver und sozialer Weltbezug) in der Lebenswelt verankert. Aus der Lebenswelt geht die Systemwelt hervor. Auch die objektivierenden Naturwissenschaften entspringen der Lebenswelt. Das naturwissenschaftliche Erkenntnisprimat ist in Habermas' Konzeption der Lebenswelt zwar durch deren Intersubjektivität korrigiert worden (1981, II, 1981, 196 ff) - womit er nicht zuletzt den phänomenologischen Begriff der Lebenswelt entscheidend modifizieren kann -, doch formuliert Habermas in der Theorie des kommunikativen Handelns keine Relevanzkriterien für forschungsleitende lebensweltlichen Annahmen. Die Lebenswelt ist in dieser Hinsicht lediglich der Komplementärbegriff zum kommunikativen Handeln, womit, über die zugrunde gelegte Rationalitätstheorie (Habermas 1999, 102 ff), wiederum auf den kognitiven Gehalt der formalpragmatisch hergeleiteten Weltbezüge zurückverwiesen wird. Identifiziert man Naturwissenschaften nun allein mit instrumenteller Rationalität, bleiben trotz Habermas' phänomenologisch-pragmatischer Modifikationen des naturwissenschaftlichen Erkenntnisprogramms mindestens noch zwei Grundprobleme der Naturwissenschaften auch für die Diskurstheorie noch bestehen: Sie kann zum einen keine Antworten auf die Frage geben, was Leben ist. Die wissenschaftliche Methodologie vermeidet diese Frage und damit auch die moralische Bewertung von Leben, - das menschliche Leben ausgenommen. Während dessen Bewahrung der Diskursethik aber prinzipiell zugänglich ist, bleibt vor allem das zweite Problem auch eines für die Diskurstheorie: Die Naturwissenschaften können die Frage, was Natur ist, nicht qua Einzelwissenschaft beantworten. Natur ist aufgrund des hohen Abstraktionsgrades ein Begriff, der für das praktische Handeln in den naturwissenschaftlichen Einzeldisziplinen keinen (wissenschaftlichen) Sinn hat. Somit erscheinen die Probleme der Naturwissenschaften, Fragmentierung und moralischer Geltungsverlust, auch für die Theorie des kommunikativen Handelns relevant.

Zwar hat Habermas im praktischen Diskurs die wissenschaftlichen Erkenntnisinteressen oft kritisiert, doch zugleich blieb sein theoretisches Bestreben an einheitlichen physikalisch dominierten Naturwissenschaftlichen orientiert. Schon in Erkenntnis und Interesse subsumierte Habermas alle Naturwissenschaften unter ein 'technisches Erkenntnisinteresse', und identifizierte dieses scheinbar vollständig mit der Physik. Der naturwissenschaftliche Begriff der Natur bezieht sich in den 'harten Naturwissenschaften' methodisch auf die Anwendung von Experimenten und der daraus folgenden Formulierung mathematischer Gesetze. Derart werden Zustandsveränderungen der Natur in Naturgesetzen beschrieben; diese wiederum erlauben teilweise Vorhersagen über zukünftige Zustandsveränderungen. Die Diskurstheorie orientiert sich in ihrem zentralen Rationalitätsbegriff epistemischer Rationalität an diesen experimentellen Naturwissenschaften. Damit aber übergeht sie etwa die Differenz zwischen offenen und geschlossenen Systemen oder Labor und Natur. So verwischt sie wichtige Unterschiede zwischen 'harten' und 'weichen' Naturwissenschaften. Nach Meinung von Gunnar Skirbekks hat Habermas dann auch "kaum etwas zur Ökologie zu sagen." (Skirbekk, 1986, 230; ähnlich auch Fjelland, 1986) 
Es scheint also so, als wenn sich ein unverfälschter Zugang zur soziologischen Zeitdiagnose nur finden läßt, wenn man die Unterschiede zwischen Handlungs- und Systemtheorie nicht als erkenntnistheoretisch-philosophisches, sondern als methodologisch-soziologisches Problem behandelt. ${ }^{4}$ Dafür spricht, so Habermas, daß die "relative Gewichtung zwischen Sozial- und Systemintegration [...] eine schwierige, und allein empirisch zu beschreibende Frage [ist]." (1981, II, 462) In gewissen Bereichen sind dabei Annäherungen zwischen System- und Handlungstheorie zu verzeichnen (vgl. Schimank, 1985, 1988, 2000; Nolte, 1999).

Habermas' Diagnose der Gegenwart mündet in der These einer Kolonialisierung der Lebenswelt durch Systeme. Er unterscheidet die einseitige Rationalisierung und Verdinglichung der kommunikativen Alltagspraxis in der Moderne von der Zerstörung traditioneller Lebensformen (Habermas, 1981, II, 489 ff). Die moderne Rationalisierung der Lebenswelt folge ungleichgewichtig zweckrationalen Motiven; kommunikative Handlungsrationalität sei demgegenüber unterentwickelt. Habermas folgt der Frage, inwieweit die Modernisierung der Gesellschaft (oder ihrer Teilbereiche) handlungstheoretisch als Rationalisierung beschrieben werden kann und geht ihr auf der empirisch-theoretischen Ebene nach. Die Modernisierung sei eindimensional auf das ökonomische und das politisch-administrative System konzentriert und werde auf Kosten der lebensweltlichen Strukturen von Kultur, Gesellschaft und Persönlichkeit vollzogen.

Mit Marx - aber gegen dessen Werttheorie - kritisiert die Theorie des kommunikativen Handelns die kapitalistische Modernisierung der Gesellschaft als einsinnige Rationalisierung und nimmt damit das Thema von Legitimationsprobleme im Spätkapitalismus (Habermas, 1973) wieder auf. Die kapitalistisch organisierte Wirtschaft, stehe in einem legitimationsgefährdenden Spannungsverhältnis zur Demokratie (Habermas, 1981, II, 507 ff). Der ökonomische Imperialismus der Lebenswelt zeitigt darüber hinaus als ökologische Krise auch Folgen für die natürliche Umwelt. Die Kolonialisierung der Lebenswelt zeige sich auch deutlich in der zunehmenden Verrechtlichung der Lebensverhältnisse (ebd., 522 ff). Generell trennten die medial gesteuerten systemischen Handlungszusammenhänge die sozialen Beziehungen von der Identität der Aktoren ab. So komme es zu sozialen Pathologien in der Moderne. Insbesondere die Massenkultur weise solche pathologischen Züge auf.

Für die Soziologie ist die ökologische Krise eine Herausforderung und die Idee nachhaltiger Entwicklung eine Provokation, da ihr einflußreichstes historisches Modell die Modernisierungstheorie ist (vgl. Wehling, 1997). Von dieser wird der Gegensatz von Statik und Dynamik aber nur als innergesellschaftliches Verhältnis beschrieben, das die gesellschaftlichen Naturverhältnisse nicht berücksichtigt (vgl. Görg, 1999). Die die Soziologie prägenden Grundbegriffe - und dies gilt sowohl für System- als auch Handlungstheorie - arbeiten dichotomisch entlang von 'Modernisierung' (z.B. Differenzierung vs. Integration, Systemstabilität vs. Evolution etc.). Dies trifft auch auf Habermas' Begriffe von 'Lebenswelt' und 'System' zu. Zwar wendet er sich gegen den

4 Diese theoriestrategische Option, hat Habermas (1986) schließlich angesichts der nachdrücklichen Kritik am Dualismus von Lebenswelt und Systemen auch gewählt und dabei am Primat der Lebenswelt festgehalten. 
universalen Erklärungsanspruch der Modernisierungstheorie (Habermas, 198510 f), und führt dagegen kommunikatives Handeln ein, welches das gesellschaftliche Naturverhältnis im wesentlichen über die 'objektive Welt' konstruiert und ihre materielle Dimension dem ökonomischen System zuschreibt. Schließlich wirft Habermas rudimentäre Bemerkungen zu den ökologischen Folgen der Entwicklung moderner Gesellschaften ein und schreibt diese mehr oder weniger vollständig dem ökonomischen System zu. Aber mit dieser allein auf das verselbständigte ökonomische System gerichteten Kritik verkennt Habermas zugleich das Verhältnis von Statik gesellschaftlicher Naturverhältnisse und Dynamik der Wissenschaft. Denn unbeschadet der Kritik an der soziologischen Modernisierungstheorie werden von Habermas im theoretischphilosophischen Diskurs Aussagen getroffen, welche die nichtmenschlichen Umwelt in der Theorie des kommunikativen Handelns ganz entscheidend konstruieren.

$\mathrm{Zu}$ einer soziologischen Theorie der Moderne - mit ihrem notwendigen, modernisierungstheoretischen Gehalt - liegt nachhaltige Entwicklung als normatives Leitbild aber insofern quer, als daß der stofflich-energetische Aspekt von Gesellschaft in der Geschichte der Soziologie gänzlich vernachlässigt wurde. Erst in jüngster Zeit wurden neben den bestehenden Theorien der Moderne Ansätze einer ökologisch-reflexiven Moderne (Offe, Beck u.a.) entwickelt, die sich speziell mit der Theorie einer selbstreferentiellen, systemisch-ausdifferenzierten Moderne (Luhmann, Willke) auseinandergesetzt und an der ökologischen Krise der Gegenwart abgearbeitet haben (vgl. zur ökologischen Modernisierung der Modernisierungstheorie Conrad, 1997b). An die Auseinandersetzungen um diese Theorien kann ein kommunikationstheoretisches Modell der Moderne anknüpfen, ohne daß damit der empirischen Diagnose und Rekonstruktion der modernen Gesellschaft sogleich ein normatives, diskursethisches Leitbild von nachhaltiger Entwicklung gegenüber gestellt werden würde.

\subsection{Die Krise der Moderne}

\subsubsection{Soziologische Gegenwartsdiagnostik: Risikogesellschaft und Reflexivität}

Mit seiner Diagnose einer Risikogesellschaft hat Ulrich Beck die moderne Gesellschaft 1986 auf einen ihrer zentralen Begriff gebracht. Die Subjekte der Moderne produzieren nicht nur soziale, sondern auch ökologische Folgen. Mit der gesellschaftlichen Produktion von Wohlstand gehe eine systematische gesellschaftliche Produktion von Risiken einher, die, so Beck, nicht mehr dem klassischen Gegensatz von Arbeit und Kapital folge, wie er der einfachen Modernisierung der Tradition zugrunde lag. Die moderne Emanzipation von Tradition und Natur droht von ihren Nebenfolgen eingeholt zu werden. Die Produktion von Wohlfahrt ist mit ökologischen Risiken verbunden, die ubiquitär verteilt werden und sich der kapitalistischen Entwicklungslogik entziehen. Diese Produktion von nichtvorhersagbaren und unbegrenzten Risiken bricht nicht nur die ökonomische Rationalität, sondern auch das moderne Rationalitätsmonopol der Wissenschaften auf 
und führt zu einer eigenen sozialen Risikodefinition (vgl. Beck, 1986, 38 ff, 76 ff, 254 ff). Gleichwohl wird in der Gesellschaft versucht, das Fortschrittsparadigma aufrecht zu erhalten, indem Nebenfolgen in der Gesellschaft latent gehalten werden. Dies gelingt jedoch nur unvollständig, Schäden treten weiterhin auf und soziale Konflikte über die Zuschreibung von Verantwortung und systematische Ursachen der Schäden entbrennen.

Becks Theorie der Risikogesellschaft ist trotz ihres überwältigenden publizistischen Erfolges von soziologischer Seite eingehend kritisiert worden. ${ }^{5}$ Trotz der Berechtigung, nicht der generellen, sondern der spezifischen Kritik, war Becks Theorie doch Anstoß für die vehemente Entwicklung der Risikosoziologie. Beck hat sich am umgangssprachlichen Verständnis von Risiko orientiert. In der bestehenden Risikoforschung wurde Risiko jedoch als Produkt aus Eintrittswahrscheinlichkeit und Schadenspotential definiert. Beck hat dieses utilitaristische Verständnis zurecht kritisiert, denn im Kontext der Techniksoziologie beinhaltet dieses allgemein herangezogene Entscheidungskriterium, das Bayes-Kriterium, eine Indifferenz gegenüber dem potentiellen Schadensmaß. Die Bayes'sche Theorie rationaler Wahl ermöglichte zudem die Kommensurabilität von sozialen und individuellen Risiken. Eine derartige normative Indifferenz konnte die sozialpsychologische Forschung jedoch nicht bestätigen. Katastrophale Schäden werden in der Risikowahl vermieden; ebenso werden individuell eingegangene Risiken anders bewertet als kollektiv eingegangene Risiken. Die Bayes'sche Entscheidungsrationalität, auf deren Basis Wirtschaftssystem und politischadministratives System exklusive Entscheidungen fällen konnten (vgl. dazu auch Kap. 3.4.1), hatte dagegen die Irrationalität lebensweltverankerter Laienurteilen nahegelegt. Durch Aufklärung über die Irrationalität individueller und kultureller Maßstäbe wollte die Risikokommunikation die Kluft zwischen rationalen Experten und irrationalen Laien überbrücken. Die begleitende Akzeptanzforschung zu technischen Systemen wurde jedoch mit der Normalität von Unfällen in komplexen technischen Anlagen konfrontiert (Perrow, 1987) und mußte schließlich den paradoxen Charakter ihres Ansatzes eingestehen (Otway, Wynne, 1993).

Dennoch erscheint Risiko der Risikosoziologie als Schlüsselkategorie der Gesellschaft, die drei Perspektiven bietet: Sie kann die Gefahren moderner Technologien thematisieren, zur Naturbeherrschung beitragen und Sicherheiten schaffen (Bechmann, 1993). Risiko setzt dabei immer bestimmte Dekontextualisierungs-, Individualisierungs- und Abstraktionsleistungen voraus, die der individualistischen Entscheidungstheorie oftmals entgehen. Risikostrategien werden nicht aus einem vorgegebenen Universum von (objektiven) Ungewißheiten ausgewählt, sondern intersubjektiv konstituiert (vgl. Bonß, 1996, 180 ff). Die soziale Konstitution von Risiken zielt als Modernisierungsstrategie auf die Beherrschung von Natur und/oder die Schaffung von Erwartungssicherheit. Zu Risiken transformierte Ungewißheit haben die Entmythologisierung und Säkularisierung vormoderner Praktiken erlaubt, die als 'ungewisser Kosmos' weder in sozialer noch in sachlicher Hinsicht bewältigt werden konnten. Nach allgemeiner risikosoziologischer Auffassung kennzeichnen zwei Risikodiskurse die Moderne: die Auseinandersetzung über die sozialen Risiken

5 Vgl. dazu die Beiträge in Beck, 1991. 
der Modernisierung und die Debatte über technische Risiken. Bechmann hat die These vertreten, daß auch moderne Gesellschaften noch ihre Zukunft als Risiko vergegenwärtigten (Bechmann, 1993, 239). Dabei trifft jedoch die entscheidungstheoretisch, am Ideal strategischer Rationalität orientierte Risikoforschung auf Probleme.

Wenn man Ungewißheiten eher auf erkenntnistheoretische Sachverhalte und Unsicherheit eher auf entscheidungstheoretische und soziale Sachverhalte bezieht, kann in bezug auf einen geschlossenen Ereignisraum von eindeutigen Unsicherheiten gesprochen werden, die mittels entsprechender Wahrscheinlichkeiten zu Risiken transformiert werden können. Demgegenüber verweist ein offener Ereignisraum auf uneindeutige Unsicherheiten, welche die additive Sicherheitsrationalität der Risikoforschung nicht zu Risiken transformieren kann (vgl. Bonß, 1997). Als komplexes, offenes System weist Natur nicht-additive Eigenschaften auf, die sie als offenen Ereignisraum charakterisieren.

Versuchen Teile der Risikosoziologie dennoch, die ökologischen Gefährdungen moderner Gesellschaften in der Absicht zu erfassen, Erwartungssicherheit zu schaffen, um dabei im handlungstheoretischen Medium instrumenteller Rationalität eine inadäquate, weil additive Handlungsheuristik auf ein offenes System mit nicht-additiven Eigenschaften zu übertragen, so haben W. Bonß et al. einen solchen Ansatz als ungenügend verworfen. Die Autoren empfehlen für eine empirische Diskursanalyse die Unterscheidung zwischen kumulativ-additiven und kontextualistisch-situativen Kontexten sozialer Sicherheitskonstruktionen (Bonß et al., 2001). Konflikte zwischen Technik und Natur wären für eine solche Diskursanalyse aufgrund des irreversiblen Charakters von Natur als kontextualistisch-situative Kontexte zu analysieren, wobei das Konzept die handlungs- und systemtheoretischen Bezüge zunächst noch vollkommen offen läßt.

Beck hat die Nebenfolgen von riskanten Entscheidungen in der Theorie reflexiver Modernisierung handlungstheoretisch zu fassen versucht. Reflexive Modernisierung stellt sich nach Beck zum einen als kontingente Folge der Modernisierung ein. Zum anderen nimmt die Moderne in den sozialen Auseinandersetzungen über Modernisierungsrisiken die Form einer reflexiven Modernisierung der Industriegesellschaft an. Beck behauptet an einigen Stellen einen Automatismus reflexiver Modernisierung und spricht sogar von einem sozialen Reflex auf (ökologische) Modernisierungsfolgen. Bezüglich der bestehenden politischen und wirtschaftlichen Ordnung radikalisiere reflexive Modernisierung die Moderne; sie löse die Industriegesellschaft auf und eröffnet den Weg in eine andere Moderne, die Beck Gegenmoderne nennt (1993, 67). Diese sei eine historische Zäsur der einfachen Modernisierung, die sich lediglich von überkommenen Traditionen emanzipiert habe. Beck spricht von einem Epochenbruch der Gesellschaft. Gegen die Modernisierungstheorie macht er geltend, daß sich in ihr unfreiwillig Innovation und Revolution synthetisieren. Eine Revolution ausgelöst durch die Nebenfolgen einfacher Modernisierung, welche hinter dem Rücken der Modernisierungsträger akkumulieren (Beck, 1993, 61 ff). Der reflexiven Modernisierung fehlt jedoch ein politisches Subjekt, wie es die einfache Modernisierung etwa mit dem Proletariat besaß. Statt zur Bildung sozialer Klassen komme es zu einer Individualisierung ökologischer Gefährdungen und sozialer Ungleichheiten. "Not ist hierarchisch, Smog ist 
demokratisch." (Beck, 1986, 48) Beck erhebt gegen die Soziologie den Vorwurf, daß sie die Folgeprobleme der Modernisierung in ihren Theorien begrenze, indem sie die Folgen nicht auf die Institutionen und Organisationen oder Teilsysteme zurückfallen lasse; Kontroll- und Steuerungsanspruch der Soziologie blieben a priori unberührt von den Nebenfolgen. "Dies liegt zum einen begründet in der Zwei-Welten-Theorie von Individuum und System, Organisation und privater Lebenswelt, die weitgehend gegeneinander verselbständigt gedacht werden." (Beck, 1993, 81) Zum anderen nehme die soziologische Modernisierungstheorie an, daß die Folgeprobleme einfacher Modernisierung immer weiter an die natürliche Umwelt abgegeben werden können (ebd.) Diese Kritik läßt sich auch gegen eine technologieorientierte Risikosoziologie anbringen, welche die Risiken alltäglichen Handelns nur unzureichend thematisieren kann. Beck integriert diesen Aspekt der Risikogesellschaft, wenn er ihre ungewissen Folgen naturalistisch auf die Gesellschaft zurückfallen sieht. Dies führe zu einer Entdifferenzierung der Sozialsysteme und einer Entgrenzung der Politik, die zur Bewältigung der Nebenfolgen einfacher Modernisierung gerade auch jenseits institutioneller Pfade in die Pflicht genommen werde (Beck, 1986, 300 ff). Es komme zur Politisierung des Alltags, zu Subpolitik und schließlich zu Metamorphosen des Staates (Beck, 1993, $204 \mathrm{ff})$.

Die Systemtheorie hat Becks Konzept reflexiver Modernisierung eine Entdifferenzierung von Theorie vorgeworfen. Dies ist auch dann nicht ganz von der Hand zu weisen, wenn man auf die verdienstvolle empirische und diagnostische Sensibilität Becks verweist. Beck kritisiert zwar den Wahrheitsanspruch der Wissenschaft (1986, 254 ff), vertraut dabei aber ganz auf die empirische Evidenz der in der Natur kontingent und notwendig erzeugten Risikofolgen. ${ }^{6}$ Zwar lassen sich die schleichenden Folgen der Risikogesellschaft nicht linear und kausal im Sinne der klassischen Naturwissenschaft erklären, doch ist die naturwissenschaftliche Erklärung von Phänomenen der zweiten Natur unerläßlich, um falsche, bestehende Praktiken zu modernisieren und damit zur reflexiven Modernisierung überzugehen. Für die Soziologie erscheint dieses Problem zunächst zweifellos nur als methodologische Frage im Rahmen einer Wissenssoziologie; gleichwohl motiviert sie zu einer theoretischen Antwort. Allein Luhmann hat den Versuch unternommen, die empirisch-sachliche Dimension zunehmender Risiken und Gefahren in der Moderne nur über eine Theorie der Beobachtung bewältigen zu wollen.

Die Systemtheorie beruht auf der Annahme einzelner, sich selbstreproduzierender (autopoietischer) sozialer Subsysteme, welche die moderne Gesellschaft konstituieren. Neben den funktionalen Subsystemen Recht, Wirtschaft, Wissenschaft, Massenmedien etc. bestehen noch Interaktions- und Organisationssysteme und Sozialsysteme des Protests und des Konflikts. Die operative Reproduktion der einzelnen autopoietischen Subsysteme folgt binären Codes, die sich von Subsystem zu Subsystem unterscheiden. Die Subsysteme stellen, da sie ihre Grenzen selbstreferentiell definieren, zueinander jeweils ebenso Umwelten dar wie die natürliche Umwelt zu

6 Aufgrund einer in der kontingenten Koevolution von Gesellschaft und Natur mitlaufenden Notwendigkeit (konstante Energie- und Massenbilanz) erscheint der systemtheoretische Begriff der Emergenz für die anthropogene Evolution von Risiken am passendsten, obwohl er die Gefahr beinhaltet, ethisch-moralische Verantwortung an der ökologischen Krise zu negieren. 
den einzelnen gesellschaftlichen Subsystemen. Und ebenso wie die Subsysteme untereinander kommunizieren, tauschen diese auch Informationen mit der Natur aus. Im Zuge der sozialen Evolution zur modernen Gesellschaft hat sich die Sinndimension, die in der Kommunikation gegenwärtig ist, sachlich, zeitlich und sozial differenziert. Die Subsysteme folgen jedoch ihrer operativen Eigenlogik, weshalb es auf der Ebene der (Gesamt)gesellschaft zu keinem problembezogenen Austausch von Informationen über die ökologische Krise kommt. ${ }^{7}$ Solchermaßen ausdifferenzierten soziale Subsysteme beobachten Realität immer nur systemrelativ, d.h. in Abhängigkeit zur codegeleiteten Operation der Systeme. Damit besteht die Gefahr, daß ein einzelner, individueller oder ein systemspezifischer Beobachtungsstandpunkt, etwa der ökonomische, die ökologische Kommunikation vereinnahmt. Wie A. Nassehi verdeutlicht hat, kann die Systemtheorie nur im Wissenschaftssystem der Gefahr einer Ontologisierung des Beobachterstandpunkts entgehen (Nassehi, 1992, 56). Daß diese Gefahr bei der Theoriekonstruktion immer gegeben ist, wird klar, wenn Luhmann die Ökologie nicht als Systemtheorie anerkennen will, da ihr keine System-Umwelt-Differenz zugrunde liege (1986, 21 Fn. 17, 39, 267). Natur und Gesellschaft sind für die Systemtheorie Luhmanns vollständig voneinander getrennt. ${ }^{8}$ "Luhmanns Umweltbegriff blendet den ökologischen Umweltbegriff zugunsten des Begriffs der Systemumwelt völlig aus." (Metzner, 1993, 171) Nur auf der kognitiven Ebene ökologischer Kommunikation tritt Natur der Gesamtgesellschaft gegenüber. Der naturalistische Aspekt der ökologischen Krise, der sich in alltäglichen Systemoperationen durch einen stofflich-energetischen Austausch mit der natürlichen Umwelt manifestiert und innerhalb des Systems nicht kontingent ist, wird aber von Luhmann gegenaufklärerisch latent gehalten. ${ }^{9}$ Insofern ist es erstaunlich, daß Luhmann die ökologische Selbstgefährdung der modernen Gesellschaft erkennt $(1986,68)$ und als theoretische Herausforderung akzeptiert hat (ebd., 247).

Es findet ökologische Kommunikation statt, die jedoch, will sie erfolgreich sein, die Resonanzbedingungen der Gesellschaft, d.h. die Kommunikationsfähigkeit der Subsysteme, beachten muß

7 Vgl. zur Frage rationaler Systeme Dorschel, Kettner (1996), die bezüglich des ökologischen Kontextes darauf hinweisen, daß die Gesellschaft nur in dem Maße rational sein könne, wie die Teilsystemrationalitäten 'welthaltig' seien. Und sie seien es zuwenig, da ihre "avancierte Autopoiesis sie daran hindert, Distanz zu ihren systemspezifisch geschlossenen systemrationalen Operationsmodus (Code + Medium) zu gewinnen" (ebd., 370 f).

8 Luhmanns dogmatische Sicht der Ökosystemtheorie wird dann auch richtigerweise von K. P. Japp (1990, 1996) völlig ignoriert. Er hat vorgeschlagen, soziologische Systemtheorie und ökologischer Umwelt über lose und feste Koppelung näher miteinander zu relationieren, ohne daß dies jedoch die Ungewißheit im Kontext von Ökosystemen überwinden kann. Genau dies ist soziologisch problematisch, da der generalisierten Ungewißheitserwartung "wenig soziale Annahmebereitschaft gegenübersteht." (Japp, 1990, 186) Zwar trifft Japp aufgrund der Ungewißheit im ökologischen Kontext durchaus weitreichende soziale und politische Feststellungen (1990, 186f), doch wechselt er scheinbar von der Beobachtung zur systemischen Operation, wenn er von Ungewißheiten im Kontext ökologischer Risiken spricht. Die Risikoproduktion der Systeme könnte durch den Wiedereintritt der Gefahr in das System verringert werden, wobei allerdings dieser Mechanismus, so Japp, vermutlich zu spät und zu langsam greifen werde. Andererseits wendet Japp gegen ein zentralisiertes, ökologisches Risikosystem wohl zu Recht ein, daß es wie die bestehenden Sozialsysteme funktionieren würde, d.h. die Risikogesellschaft nicht überwinden könnte. Gemeinsam mit W. Krohn hat Japp später versucht, der systeminduzierten Selbstgefährdung moderner Gesellschaften durch einen Rekurs auf die kultursoziologische Risikotheorie zu entkommen (Japp, Krohn, 1996). Doch müssen sie dabei eingestehen, soziologische und ökologische Koppelungsmechanismen nicht begrifflich aufeinander aufbauen zu konnten.

9 A. Metzner vertritt die Auffassung, daß Luhmann aktive Umweltmodulation schon deshalb nicht fassen könne, da der über die Organismus/Umwelt-Analogie (Maturana) eingeführte autopoietische Systembegriff die Aktivität und Passivität des Organismus zur Umwelt bereits asymmetrisch einführe; vgl. Metzner, 1993, 171f Fn 418. 
(Luhmann, 1986, 41). Luhmann hält die Erzeugung des richtigen Maßes an Resonanz für die wichtigste Bedingung zur Bewältigung der ökologischen Krise. Auch wenn Luhmann eine ökologische Selbstgefährdung nicht prinzipiell ausschließt, erscheint eine Selbstgefährdung der Gesellschaft vor allem von Kommunikation auszugehen (ebd., 68). Diese überaus eigenwillige wenn nicht bornierte Auffassung änderte Luhmann erst im Zuge der Auseinandersetzung mit Beck.

N. Luhmann hat, ganz auf der Linie des systemtheoretischen Konstruktivismus, eine strikt anthropozentrische Unterscheidung zwischen Risiko und Gefahr angeregt, die von der natürlichen Umwelt absieht (Luhmann, 1990b). Die Unterscheidung zwischen Risiko und Gefahr bezeichnet demnach die Differenz zwischen individuell gewähltem Risiko und objektiv zugewiesener oder bestehender Gefahr. Als soziologischer Begriff meint Gefahr damit nicht eine Abstufung auf der Skala von Risiko zu Unsicherheit, wie in der rechtlichen Bedeutung des Begriffs, sondern die zu beobachtenden sozialen (Neben)folgen von riskanten Entscheidungen. Für diese Differenz sprächen laut Luhmann u.a. Ergebnisse der psychologischen Risikoforschung. Dafür spricht schließlich auch seine eigene Theoriekonstruktion.

Hatte Beck von den ökologischen Risiken moderner Gesellschaften gesprochen, so führt Luhmanns Unterscheidung zwischen Risiko und Gefahr scheinbar automatisch auf die Gefährdung moderner Gesellschaften durch ökologische Risiken zurück. Dazu schließt Luhmann an die Theorie der Beobachtung an. Ein Beobachter erster Ordnung verhält sich riskant. Erst in der Reflexion auf sein Verhalten beobachtet er sich aus der Perspektive eines Beobachters zweiter Ordnung; "und erst dann kann man eigentlich von Risikobewußtsein und Risikokommunikation sprechen; denn nur dann werden die für Risiken typischen Unterscheidungen der Operation zu Grunde gelegt, daß mitberücksichtigt wird, daß sie auch eine andere Seite haben und nicht einfach nur Objekte referieren." (Luhmann, 1991, 235) Ebenso kann die Reflexion auf das riskante Verhalten eines Beobachters erster Ordnung durch einen anderen Beobachter erfolgen, der dieses Verhalten als Gefahr kennzeichnet und damit die andere Seite des Risikos benennt. Gefahren werden demnach individuell oder kollektiv zugerechnet, wobei Luhmann den Zeitpunkt der Zurechnung für ebenso unerheblich hält, wie den Unterschied zwischen Fremd- und Eigenzurechnung (ebd., 25). Die sozialen Bewegungen, die Luhmann 1986 nur widerwillig und mit Spott beobachtet hatte, eröffnen in der Soziologie des Risikos mittels 'Angstkommunikation' nun die Option, die ökologische Selbstgefährdung der Gesellschaft überhaupt zu kommunizieren. ${ }^{10}$ Die Funktion sozialer Bewegungen besteht in der Verbreitung von Beobachtungen über mögliche Gefahren, die quer zu dem stehen, "was auf Grund eines Primats funktionaler Differenzierung innerhalb der Funktionssysteme an Selbstbeschreibung anfällt." (ebd., 153) Zugleich befürchtet Luhmann aber noch immer, daß soziale Bewegungen Gefahren über Gebühr betonen könnten und zu einer Entdifferenzierung von sozialer Differenzierung führen würden. Luhmann plädiert im Sinne soziologischer Aufklärung für die wechselseitige Verständigung zwischen Entscheidern (Risiko) und Betroffenen (Gefahr), zeigt allerdings - wie im übrigen auch Beck - keine institutionellen oder

10 In Ökologische Kommunikation spricht Luhmann (1986, 238 f) von öffentlicher Angstkommunikation, die authentisch sei, aber nicht wirklich vorhanden sein müsse. 
organisatorischen Möglichkeiten auf, wie ein solcher Risikodiskurs gestaltet werden könnte (vgl. dazu Japp, 1996).

Luhmanns Unterscheidung zwischen Risiko und Gefahr weist einige sozialwissenschaftliche Vorzüge auf. So kann sie von einer kausalen Zuschreibung und von (auch damit verbundenen) erkenntnistheoretischen Problemen elegant absehen, da sie Gefahr als kontingent interpretiert. Sie gibt andererseits aber sozialintegrative Elemente wie Verantwortung und Motivation auf, indem sie allein auf risikoentscheidende und -beobachtende Systeme verweist. ${ }^{11}$ Leitsystem der soziologischen Beobachtung ist die Wissenschaft. "Entscheidend an Luhmanns Begriffsvorschlag ist jedoch, daß er sich strikt auf die Systemreferenz des Wissenschaftssystems beschränkt. Die Unterscheidung Risiko/Gefahr, die riskante Entscheidungslagen in der modernen Gesellschaft anders zu beobachten in der Lage ist als die Risiko/Sicherheits-Form, vermag es nicht, praktische Problemlösungen für die Handhabung von Risiken anzubieten." (Nassehi, 1992, 49; ähnlich auch Reese-Schäfer, 1996, 95)

Die praktische Lösung der ökologischen Krise ist anhand der Unterscheidung Risiko/Gefahr nicht in Sicht, denn der systemtheoretische Begriff des Risikos bezieht sich auf ein 'hochstufiges Kontingenzschema' (Luhmann, 1991, 25), welches Ereignis und Schaden als Kontingenzen - nicht als Notwendigkeit - fest koppelt. ${ }^{12}$ Die Unterscheidung Risiko/Gefahr erfaßt somit nicht das Verhältnis zwischen Gesellschaft und Natur, da Risiko und Gefahr nur die beobachtete Dimension der ökologischen Krise markieren, die natürliche Umwelt als unmarked space indes immer notwendig unbeobachtet bleibt. Wie wird also die ökologische Krise überhaupt beobachtet?

Luhmann hat zur Bewältigung der ökologischen Krise zwei Entwicklungsrichtungen für die Systemtheorie entworfen: 1. Es bilden sich (neue) Systeme mit hoher und doch reduzierbarer Eigenkomplexität. Offensichtlich kann dieser Weg nicht von einem Risikosystem beschritten werden, oder: 2. Die Autopoiesis wird zunehmend temporalisiert, und eine größere Zahl von Ereignissen mit Umweltkontakten geschaffen (Luhmann, 1986, 37 ff). Diesen Weg hat Luhmann vor Augen, wenn er ökologische Selbstgefährdung als temporales Problem einer nicht zu überwindenden Kontingenz formuliert. Diese fundamentale Kontingenz entsteht angesichts einer nicht näher bestimmbaren, offenen Zukunft "die Irreversibilität nur auf eine andere Weise fest[legt]: Durch Unterlassen oder durch nicht-intendierte ... Nebenfolgen des Handelns." (Luhmann, 1990b, 166) In den beiden zitierten Feststellungen Luhmanns liegt beinahe die ganze theoretische Herausforderung, die das Verhältnis von Mensch zur Natur beinhaltet, nämlich zum einen das Problem gesellschaftlicher Umweltbeobachtung angesichts möglicher irreversibler nichtintendierter Nebenfolgen menschlichen Handelns - wobei die soziologische Bedeutung von

11 Die Differenz stellt sogar die systemintegrative Funktion des Rechts, die sich an individueller Zurechnung und Kausalität orientiert, vor Probleme (vgl. Kapitel 4).

12 Dabei provozieren zeitliche Kontingenzen lediglich soziale Kontingenzen. Sinn, neben Welt und Realität Luhmanns dritter differenzloser Begriff, wird in seiner zeitlichen Dimension ausgeschöpft, in der sozialen Dimension als Folge angesehen und in der sachlichen Dimension nicht weiter thematisiert, wobei Luhmann aber implizit anzunehmen scheint, daß der Risikodiskurs die sachliche Dimension der ökologischen Krise vollständig abdeckt. Dies ist unzutreffend. 
Irreversibilität erst noch weiter zu entwickeln wäre - zum anderen das ethische Problem richtigen Handelns oder Nichthandelns angesichts der Irreversibilität von Folgen. Allerdings fällt auf, daß hier nicht von der Durchführung oder dem Unterlassen von systemgebunden Operationen die Rede ist, sondern von Handlungen. A priori scheint jeder Unterlassensanspruch, da er sich systemtheoretisch ohnehin nicht für Individuen stellt, von der Operationsweise autopoietischer Systeme abgewiesen zu werden.

Dennoch beobachtet Japp (1997b) die Ausdifferenzierung regulativer Risikopolitik. Denn die Selbstreferenz des Risikos - sowohl eine Entscheidung als auch eine Nicht-Entscheidung sei für das System riskant - wird durch die Zuschreibung von Gefahr aus der Systemumwelt aufgelöst. Das Ergebnis Unsicherheit absorbierender Operationen sei Erwartungssicherheit. Daran anschließend postuliert Japp, "daß Unsicherheitsabsorption die für einen Beobachter zweiter Ordnung virtuell sichtbare Paradoxie der Einheit von Sicherheit und Unsicherheit ist." (Japp, 1997b, 255) Die Unsicherheitsabsorption sei notwendig, da das System seine operative Entscheidungsfähigkeit erhalten müsse; sie nehme andererseits blinde Flecken für alles nicht Selektierte in den Kauf. Dies könne als kontingente, zeitlich versetzte Überraschung und Irritation auf das System zurückwirken. Es verwandele jedoch zunächst einmal Unsicherheit in Risiko. Die Zeitdifferenz zwischen systemischer Operation (Entscheidung) und Beobachtung (Reflexion) könne gesenkt werden, wenn die interne Sicherheitsproduktion neben Operationen auch Informationen generieren würde. Dies stoße jedoch an systemische Verarbeitungsgrenzen. Die systemische Unsicherheitsabsorption sei selbst riskant und könne mit Entscheidungsfolgen Betroffene belasten. "An dieser Seite der Unterscheidung können rekursive Operationen anschließen und Systeme ausdifferenzieren, die Gefährdungen anderer versichern (also Versicherungssysteme), autoritativ normieren (also staatlich-verbandliche Regulierungssysteme) und zum Gegenstand von Verhandlungen machen (also Verhandlungssysteme, Partizipation, Mediation)." (ebd., 237; kursiv i. O.) Im Sinne einer funktionaler Komplementarität entwickelten sich gefahrenabwehrende Systeme: z.B. (privat)wirtschaftliche Versicherungen, staatliche Gefahrenabwehr und Verhandlungssysteme (Verhandlungssysteme scheinen im Unterschied zu sekundär gefahrenabwehrenden Systemen originäre Risikosysteme sein zu können). Die Abgabe der Gefahrendimension an derartige Risikosysteme erlaube die komplementäre Steigerung der Risikopräferenz von Primärsystemen. Diese unsicherheitszentrierte Evolution werde durch Differenzen ermöglicht, welche Selektionsvorteile organisieren könnten. Diese würden über die Differenz von manifester (intentionaler) und latenter (nichtintentionaler) Funktion durchgesetzt werden. Dies reicht indes noch nicht zur Erklärung der historischen Herausbildung von Risikosystemen wie Japp selbst einräumt.

Die Ausdifferenzierung der Risikogesellschaft führe laut Japp zu spezifischen Risikopolitiken, die als eine ökologisch modernisierte Form einfacher Modernisierungspolitik aufträten und im politisch-administrativen System abgearbeitet werden müßten. Doch der 'loose talk' (Reese-Schäfer) des politischen Systems ist gegenüber den anderen Subsystemen (Ökonomie, Recht, etc.) ohne Verpflichtung. Bei Japp kann Öffentlichkeit qua Angstkommunikation bestehende, 
ausdifferenzierte regulatorische Systeme des politischen Systems (Verhandlungssysteme) beeinflussen, ohne dabei jedoch präventiv wirksam werden zu können. Im Gegensatz zu Willke (1992) referiert er nicht auf die Lebenswelt, sondern spart eine Erklärung der Genese erfolgreicher Risikotransformation schlicht aus. ${ }^{13}$ Zukünftige Prävention müsse, da sie ja selbst riskant sei, an der Eigenlogik der Systeme - insbesondere des Wirtschafts- und des Rechtssystems - scheitern.

Die soziologische Systemtheorie hat dies am Wirtschaftssystem empirisch aufgezeigt, wo systeminterne Versicherungen extern auferlegte (Haftungs)gefahren ökonomischer Organisationen verringern sollen (Japp, 1997a; Schmidt, 1997; Hapke, 1999). Diese Form der Bewältigung von Umweltproblemen wird von der umweltökonomischen Theorie empfohlen (Endres et al., 1992), aber auch kritisiert (Wätzold, 2000). Japp (1997a) kommt zu dem Schluß, daß Prävention ein moderner Mythos sei, der sowohl vom Wirtschaftssystem als auch von seiner Umwelt gefördert werde. Die Transformation ökologischen Nichtwissens in immer partielles, präventives Wissen lasse sich nur indirekt und evolutionär vorstellen. Sie gehe auf Irritationen und nicht auf eine Präventionsrationalität zurück. Die organisatorische Selbststeuerung ist strukturell mit Politik, Recht und Wirtschaft gekoppelt. Für die Politik bedeutet dies, so Japp, daß sie aus der Sachdimension richtiger Konzepte heraus und in die Zeitdimension auf Revidierbarkeit bedachter Nachsteuerungsoptionen hinein müsse: ${ }^{14}$ Es müßten also Haftungsobergrenzen angehoben und die Auswirkungen beobachtet werden. Immerhin empfiehlt Japp nicht, wie Luhmann (1997), wieder Grenzenwerte (Grundlage staatlicher Gefahrenabwehr) als Form präventiver Umweltpolitik.

\subsubsection{Reflexive, ökologische Modernisierung}

Die Differenz zwischen Gesellschaftssystem(en) und natürlicher Umwelt läßt sich in der stofflich-energetischen Dimension als emergente Komplexität beobachten, deren Strukturen nicht prognostiziert werden können (Funtowicz, Ravetz, 1994b). Diese emergente Komplexität hat keinen Bezug zu Risiko, welches Wissen über Folgen voraussetzt. Die koevolutionäre Emergenz ist zeitlich strukturiert, durch Notwendigkeiten bestimmt und dennoch unsicher. Zwar erzeugen stofflich-energetischen Emissionen im Sinne einer konstanten Materialbilanz notwendig quasinatürliche, ökologische Folgestrukturen (vgl. Steubing, 1995), doch diese lassen sich nur bedingt prognostizieren. Diese ökologischen Folgen bleiben von Luhmann, der in seinen Beobachtungen der Moderne die Kontingenz der Modernisierung gegen die Selbstgefährdung der Moderne verteidigt, unbeobachtet. Luhmann hält die Beschreibung der Welt als operativ erzeugte

13 Nach J. Schmidt $(1997,286)$ bestimmt die funktionale Differenzierung selbst die Möglichkeiten von Stoppregeln der sozialen Risikoproduktion.

${ }^{14}$ Grundmann hat der systemtheorischen Risikosoziologie zu Recht vorgeworfen, die in der Soziologie übliche Sach-, Zeit- und Sozialdimension auf die ersten beiden Dimension zu reduzieren und so die dritte zu vernachlässigen. "Dies scheint seinen Grund darin zu haben, daß die Soziologie einen professionellen Hang zum Konstruktivismus aufweist. Der konstruktivistische bias, sorgt dafür, daß jede Wirklichkeitswahrnehmung, auch ökologischer Risiken, als soziale Konstrukte gelten." (Grundmann, 1999, 54) In dieser Lesart seien Situationen kommunikativ erzeugt und nicht sachverhaltsbedingt. Die Sachdimension werde von den Naturwissenschaftlern durch deren Autorität bestimmt und von Sozialwissenschaftlern dann eben dekonstruiert, rekonstruiert oder konstruiert. 
Notwendigkeit in der Moderne für überholt. Becks Begriff reflexiver Modernisierung enthält dagegen Notwendigkeit, indem er nämlich das Reflexhafte, Nichtintendierte, Naturalistische an den Gefahren zweiter Ordnung betont. Becks Konzept muß gerade aufgrund der These naturalistischer Sozialfolgen als Kritik an den Theorien einfacher Modernisierung (vgl. Zapf, 1975, Zapf, 1996) gelesen werden. Allerdings bedarf dieser Ansatz der weiteren Integration in die sozialwissenschaftliche Theorie (vgl. dazu Beck, Bonß, 2001).

Von der Modernisierung funktionaler Systeme hat Offe die Modernität der Gesellschaft unterschieden (1986; vgl. auch Habermas, 1985). Für Modernisierungs- und Modernitätsprozesse würden vier Handlungsfelder bestehen: 1. materielle Reproduktion, 2. kulturelle Reproduktion 3. Politics (demokratische, beteiligungsoffene Politik) 4. public policy (politische Steuerung, Eliten). Probleme, Modernität gegen Modernisierung durchzusetzen, würden u.a. aus dem Gegensatz von Bestandsbedingungen und Handlungsmotiven und aus der Lücke zwischen design complexity und control complexity resultieren, die durch institutionelle Innovationen nicht zu schließen sei (Offe, 1986, 102 ff). Als Lösung empfiehlt Offe die Utopie der Null-Option, die an der Bedarfsseite ansetzen soll und "das erforderliche $\mathrm{Maß}$ an Fähigkeiten zur Koordination und Kompatibilitätssicherung so [herabsetzt], daß man mit den verfügbaren Steuerungskapazitäten auch tatsächlich auskommt." (Offe, 1986, 111) Null-Optionen würden dann utopisch, wenn aufgrund hoher Interdependenzen der Verzicht auf marginale Vorteile unkalkulierbare Schlechterstellung nach sich ziehen könnte, so daß die zweitbeste Lösung nicht mehr von der schlechtesten unterschieden werden könne. Offe bezieht dies auch auf umweltpolitische Zielsetzungen einzelner zu reduzierender Stoff- und Energieströme. (Er wählt das Beispiel der Verkehrspolitik). Ein Kostenausgleich zwischen kollektivem Nutzen und individueller Selbstbeschränkung lasse sich als reflexiv gewendete Null-Option der politischen Modernisierung bewältigen. Offe betont die Bedeutung der zeitlichen Dimension und plädiert für zeitliche Überschaubarkeit und Reversibilität in der institutionellen Form von Moratorien und Iterationen. Klingt hier bei Offe die ökologische Problematik schon unüberhörbar durch, wird sie doch erst in den Theorien ökologischer Modernisierung zu einem zentralen Gegenstand der Sozialwissenschaften. Dies gilt besonders für die stoffliche Dimension der ökologischen Krise.

Implizit folgt das Konzept ökologischer Modernisierung der Idee einer Null-Option: Es ist ein ökonomie- und technologiebezogenes Konzept, das von J. Huber, E. U. Simonis und M. Jänicke erarbeitet wurde. Es setzte bei der Einsicht an, daß ökologische Entlastungen (durch Umweltpolitik) regelmäßig wieder durch wirtschaftliches Wachstum zunichte gemacht wurde. Unter dem Begriff des qualitativen Wachstums wurde die Entkoppelung von Wirtschaftswachstum und Ressourceninput angestrebt, denn es zeigte sich, daß die Modernisierung innerhalb von Industrien (intrasektoraler Wandel) einer teilweisen Deindustrialisierung von umweltbelastenden Branchen überlegen war (Jänicke, 1993). Die Auswirkung von Wachstum auf die Umwelt wurde von Simonis nach drei Kategorien beurteilt: absolute Umwelteinwirkung (anhand von vier Inputs), Umweltwirkung pro Kopf und Umweltwirkung pro Einheit des Bruttosozialproduktes (BSP) (Simonis, 1988, 8 ff). Kognitiver Ausgangspunkt des Konzepts ökologischer Modernisierung ist das 
ökonomische System. Ziel ist eine präventive Umweltpolitik, welche Ressourcensteuern und Emissionsabgaben einführt, während sie gleichzeitig die Lohnsteuern senkt und dadurch Ressourceneffizienz und Arbeitsquote erhöht (Simonis, 1988, 39f). Durch Becks Theorie reflexiver Modernisierung wurde ökologische Modernisierung später offener interpretiert.

V. v. Prittwitz hat reflexive Modernisierung als Begriff angesehen, bei dem die Art und Richtung der gesellschaftlichen Reflexion noch unklar bleibe (v. Prittwitz, 1993). Er sieht reflexive Modernisierung "als einen sich auf Folgeprobleme der einfachen Modernisierung (Entkoppelung) beziehenden Innovationsprozeß, der Elemente bewußter sozialer Steuerung enthält. [...] In den Prozeß reflexiver Modernisierung fließen damit Ansätze rationaler Steuerung mit Gemeinwohlanspruch ein. Typische Ausdrucksform solcher reflexiven Modernisierung ist die Entwicklung von Politiken mit Bezug zu Folgelasten einfacher Modernisierung." (v. Prittwitz, 1993, 37) Er nennt Sozial- und Umweltpolitik als Beispiele. Die Reflexionstiefe könne als Reflexion auf Mittel, Ziele, Werte und Strukturen sehr unterschiedlich sein. Reflexion bezieht sich im Unterschied zu Beck auf bewußtes Handeln.

Im Policy-Modell der Interessenspirale kann der Prozeß reflexiver Modernisierung auf der Akteursebene erfaßt werden. Das Modell geht davon aus, daß trotz möglicher Informationsmängel, kognitiver und affektiver Differenzen ein enger Zusammenhang zwischen subjektiver Interessenwahrnehmung und situativen Interessenbedingungen besteht. Prittwitz verweist darauf, daß bestimmte allgemeine Voraussetzungen gegeben sein müssen, damit sich die Interessenspirale 'dreht'. Entgegen einer vielleicht gegebenen objektiven Betroffenheit würden nur subjektive Betroffenheiten politisch geäußert. Diese führe $\mathrm{zu}$ Präferenzen für Veränderung, deren Erfolgsaussichten mit den vorhandenen Wahrnehmungs- und Handlungskapazitäten der Betroffenen verbunden seien. Dazu zählten sozioökonomische und politisch-institutionelle Rahmenbedingungen. "Voraussetzungen für reflexive Modernisierung sind schließlich politisch-kulturelle Bedingungen eines öffentlichen Diskurses." (v. Prittwitz, 1993, 42) Unter günstigen Entwicklungsbedingungen könne Umweltpolitik so durch gesellschaftliche Reflexivität auch in andere Politikfelder (Wirtschafts-, Verkehrs-, Landwirtschafts-, Forschungs- und Außenpolitik) vordringen.

Prittwitz unterscheidet neben Gefahrenabwehr und Vorsorge auch strukturelle Ökologisierung. Auf Vorsorge (oder Prävention) würde in der Risikogesellschaft steigendes Risiko mit komplexeren Sicherheitssystemen und expandierenden Handlungskompetenzen folgen; bei der strukturellen Ökologisierung wachse die Ökologieproblematik über den Gegenstandsbereich der Naturwissenschaften hinaus und reflektiere auf (ökologische) Werte (vgl. Prittwitz, 1988). Als Strukturreflexion politischer Modernisierung (reflexive Verfahren wie Verhandlungssysteme und Policy-Netzwerke) erreiche Reflexivität ihre größte Tiefe. Die Policyanalyse zeige, daß kein Automatismus der Bewältigung von Folgen einfacher Modernisierung besteht. Reflexive Modernisierung sei kein linearer Prozeß, sondern könne beliebig viele Reflexionsschleifen durchlaufen (vgl. M. Cohen, 1997; ähnlich Jänicke, 1996, 26). Um in eine nachhaltige Entwicklung einzumünden, ist dies unerläßlich. 
Hajer hat schließlich in Abgrenzung zu v. Prittwitz' policybezogenem Konzept nicht reflexive, sondern ökologische Modernisierung als ein offenes Konzept bezeichnet und dabei besonders die soziale Dynamik herausgestrichen. ${ }^{15}$ Der semantische Kern dieser spezifischen Kommunikation bleibe aufgrund seiner Offenheit und vielfältigen Interpretierbarkeit unbestimmt (Hajer, 1997). Als dynamischer sozialer Zusammenhang sei ökologische Modernisierung nicht als Theorie, sondern als 'Diskurs' anzusehen. Hajer definiert aus einer institutionell-konstruktivistischen Perspektive "Diskurse als ein spezifisches Ensemble von Ideen, Konzepten und Kategorisierungen, das sich in einem spezifischen Set sozialer Praktiken produziert, reproduziert und transformiert und durch welches die physikalische und soziale Wirklichkeit Bedeutung gewinnt." (Hajer, 1997, 111) Diese Art der Diskursanalyse teilt mit der Diskurstheorie methodisch den verstehenden Ansatz und ebenso objektiviert sie auch Verhalten. Doch im Gegensatz zur Diskurstheorie erfolgt die sozialwissenschaftliche Objektivierung nicht rationalitäts- oder systemtheoretisch, sondern in bezug auf rote Fäden (story lines). Hajer geht von einem empirischen Diskursbegriff aus: Die soziale Dynamik ökologischer Modernisierung resultiere weniger aus einer epistemischen Rationalität der Wissenschaften, denn aus interpersonalen, sozialen Prozessen. Die Verbreitung des Konzepts ökologischer Modernisierung verdankt sich demnach dem Umstand, daß der rote Faden immer mehr Akteure einbindet. Wissenschaftler sind dabei lediglich sozial einflußreichere Akteure als andere. Hajer schließt die Bedeutung naturwissenschaftlicher Paradigmenwechsel nicht explizit aus, doch er macht solche nur aus einer wissenssoziologischen Perspektive zugänglich (Hajer, 1995, 117, 267 ff). Wie in Kapitel 2.3 gezeigt wird, läßt sich die analytische Schärfe der Diskursanalyse hier steigern.

Reflexive ökologische Modernisierung ist nach Hajer dann semantisch auf jene Gesellschaftsstrukturen zu konzentrieren, in denen festgelegt wird, was sozial-ökologische Wirklichkeit ist. Dazu solle die Diskursanalyse Expertenmeinungen sozial kontextualisieren und "Umweltpolitik zu einer Angelegenheit wohlüberlegter und -verhandelter sozialer Wahl für bestimmte Szenarien der gesellschaftlichen Modernisierung werden." (Hajer, 1997, 121) Angesichts von gravierenden Problemen mit Mediationsverfahren müsse das institutionelle Design reflexiver Verfahren genau bedacht werden. Reflexive ökologische Modernisierung ließe sich dann einer technokratischen Modernisierungsvariante gegenüberstellen, die nach einer universellen Sprache forsche, "um die Suche nach den effektivsten, effizientesten oder innovativsten Lösungen für eindeutige Probleme zu erleichtern." (Hajer, 1997, 121)

Damit scheint reflexive, ökologische Modernisierung nun als politisch-institutionelle Ausgestaltung im Sinne einer politischen Modernisierung gedacht werden zu müssen. M. Jänicke hat deshalb eine deutliche Unterscheidung zwischen politischer und ökologischer Modernisierung getroffen, und die kulturelle Bedeutung der politischen Modernisierung gegenüber einer ökologischen Modernisierung hervorgehoben. Hier läßt sich dann die Offenheit von Wissenschaften, Medien und Politikarenen ebenso analysieren wie die Offenheit des politischen-

${ }^{15}$ In Hajers früherer diskursanalytischer Arbeit (1995) hat noch das enge Konzept ökologischer Modernisierung die zentrale Position inne. 
administrativen Systems für neue Parteien, Volksabstimmungen und neue umweltpolitische Instrumente (Jänicke, 1993; Zilleßen et al., 1993).

Im Unterschied dazu betonte J. Huber vor allem die systemische Seite ökologischer Modernisierung auf Kosten partizipatorischer Bedürfnisse: Unter den Wachstumsmodellen der 70er und 80er Jahre stellten demnach die ökologischen Modernisierungskonzepte entkoppelten und quantitativen Wachstums die realpolitisch Anschlußfähigsten dar (Huber, 1993). Die Konzepte würden auf die Re-Integration der anthropogenen Stoff- und Energieflüsse in den Gesamthaushalt der Natur zielen und seien als 'lebenspraktisches Handeln' umzusetzen. Huber verortet ökologische Modernisierung zwischen bürokratischem und zivilgesellschaftlichem Handeln, das in verschiedenen sozialen Subsystemen unterschiedliche Virulenz besäße. Auf Dauer könne sich kein Subsystem von der Modernisierung abkoppeln, "sondern die (Selbst)Modernisierung jedes Subsystems gehört zum Kontext der (Selbst)Modernisierung aller anderen." (Huber, 1993, 60) Ökologische Modernisierung sei zwar an staatliche Institutionen gebunden, doch müsse sie zivilgesellschaftlich-ökonomisches Handeln integrieren, um präventiven Umweltschutz zu erreichen. ${ }^{16}$ "Es gibt keine Ökologisierung ohne die Eigeninitiative der Industrie - nicht ohne sie, nicht gegen sie, nur mit ihr, freilich auch in Auseinandersetzung mit ihr." (ebd., 68) Der Staat könne durch Setzung geeigneter Rahmenbedingungen kontextsteuernd auf die ökologische Modernisierung des ökonomischen Systems drängen, innerhalb dessen Produzenten und Konsumenten selbst den industriellen Kurs bestimmten. Huber hat diese konsumtive Effizienzstrategie ökologischer Modernisierung erst späterer durch eine Suffizienzstrategie ergänzt, d.h. durch eine Strategie, die sich auf eine 'genügsame' Lebensweise im Sinne ökologischer Konsistenz richtet. Konsument und ökologisch verantwortliches, ethisches Subjekt treten dabei wieder auseinander. Effizienz, Suffizienz und Konsistenz konkretisieren nicht mehr nur ökologische Modernisierung, sondern bereits nachhaltige Entwicklung (vgl. Huber, 1995). Nachhaltige Entwicklung geht demnach über eine ökologische Modernisierung der Industriegesellschaft insofern teilweise noch hinaus, als daß sie Suffizienz berücksichtigen soll. Allerdings führt Huber die ethisch-moralische Dimension nicht weiter aus.

Offensichtlich steht nach dem bisher Gesagten ökologische Modernisierung als umweltpolitisches Programm reflexiver Modernisierung in einem direkten Zusammenhang zur allgemeinen soziologischen Modernisierungstheorie: Die gesellschaftliche Ausdifferenzierung des ökonomischen Systems wird im Sinne einer Null-Option um die Risikodimension erweitert. Die gleichzeitig stattfindende Ausdifferenzierung des politischen Systems sichert die Reflexivität der Programmatik. Damit ist aber noch nicht gezeigt, wie die historische Entwicklung ökologischer Modernisierung in den praktischen Diskurs zur Nachhaltigkeit münden konnte, was als Voraussetzung eines diskurstheoretischen Zugangs zur Nachhaltigkeit angesehen werden muß.

${ }^{16}$ Huber verkürzt den Begriff der Zivilgesellschaft auf die Hegelsche Tradition einer marktförmig handelnden, bürgerlichen Gesellschaft. 
Diese wird erst zugänglich, wenn man sich die Entwicklungslogik ökologischer Modernisierung vergegenwärtigt. B. Gill hat vorgeschlagen, dabei mit Stufenfolgen zu arbeiten und auf streng historische Phasen zu verzichten (Gill, 1999; ähnlich auch Huber, 1993, 60 ff). Die Stufen beruhen auf qualitativ verschiedenen Wahrnehmungs- und Reaktionsweisen von Gesellschaften und orientieren sich eng an Becks Verständnis von Reflexivität. ${ }^{17}$ Gill negiert jedoch eine naturalistische, 'objektive Gegenmacht der Gefahr' (Beck). Zwar könne es beobachterunabhängige Rückwirkungen geben, bei denen naturale Reflexivität und soziale Wirkung nicht auseinanderfielen, doch werde naturale Reflexivität nicht unvermittelt von kulturellen und konstruktivistischen Perspektiven in soziale Reflexivität übertragen.

Auf der ersten Stufe ökologischer Modernisierung würden Nahfolgen bewältigt. Diese würden früh als lokale Umweltschäden wahrnehmbar, die 'reflexartige Selbstkonfrontation' evozierten. Bereits hier seien teilweise widersprüchliche Sicherheiten (als Zeichen reflexiver Modernisierung) zu beobachten. "Reflexivität als naturale Konsequenz industrieller Nebenfolgen setzt sich hier um in soziale Reflexivität im Sinne des zunächst ungelösten Konflikts zwischen Organisationen." (Gill, 1999, 185, kursiv i. O.) Damit begännen sie aber bereits für die Gesellschaft zu existieren. Man könne auch von latenter und manifester Reflexivität sprechen anstatt von naturaler oder sozialer. Die Schäden seien kognitiv noch leicht zuzuordnen, und sie seien hierarchisch. Da soziale Risiken auch heute noch immer wieder gegen Umweltrisiken ausgespielt werden würden, müsse eine immer wieder stattfindende wechselseitige Überlagerung von einfacher und reflexiver Modernisierung konstatiert werden.

Auf der zweiten Stufen träten zunehmend Fernfolgen der einfachen und reflexiven Modernisierung auf (Politik der hohen Schornsteine, FCKW). Aufgrund der steigenden Komplexität (Zeit, Raum) seien die Ursache-Wirkungszusammenhänge weniger offensichtlich als bei Nahfolgen. Die Wahrnehmung der Risiken verbessere sich aber durch Wissenschaft und Meßtechnik. Es wüchsen soziale Bewegungen. Ein Nachhaltigkeitsdiskurs setze ein. Ein Kennzeichen der zweiten Stufe reflexiver Modernisierung sei, so Gill, daß politische Entscheidungen über Abwehrmaßnahmen getroffen werden könnten, bevor es einen wissenschaftlichen Konsens gebe. Man handele hier zwar auf der Basis von Ungewißheit, aber immer noch - im Unterschied zu Stufe 3 - aufgrund einer spezifischen Hypothese, die eine diskrete Schadenwirkung postuliere und sie mit einer diskreten Ursache in Zusammenhang bringe. (Gill, 1999, 187) Umweltpolitik ist noch stark ordnungsrechtlich orientiert (Stand der Technik) und akzeptiere Restrisiken. Es würde aber bereits versucht, Grenzwertpolitik und End-of-the-pipeTechnologien durch ökologische Modernisierung zu überwinden.

Auf der dritten Stufe kommt es nach Gill schließlich zur Berücksichtigung von Nichtwissen. Ungewißheit werde explizit thematisiert. Ökologische Modernisierung versuche nun, durch Lernstrategien, die auf Sicherheitsforschung und Risikokommunikation basierten, die Kluft

17 Gill merkt an, daß der Begriff der ökologischen Modernisierung normalerweise für umfassendere auf die Gegenwartsgesellschaft bezogene Modernisierungsprozesse gebraucht werde. Er will ökologische Modernisierung hingegen enger verstehen, da sie sich dann schon früher konstatieren lasse. 
zwischen dem aktuellen Noch-Nicht-Wissen und dem Nicht-Wissen-Können zu verringern. Es würden offene Suchprozesse etabliert, "die alle möglichen - und nicht nur die bekannten schädlichen Folgen berücksichtigen sollen." (Gill, 1999, 188) Der Prozeß stoße aber an prinzipielle Grenzen, da zugleich die (zeitliche) Konstituierung des erkennenden Subjekts problematisiert werde. Diese Wendung zur Selbstreflexion werde durch die Thematisierung von Langzeitfolgen im soziologischen Gegenstandsbereich nahegelegt. Soziale Reflexivität breite sich auf die internationale Ebene aus, und es komme zur Diffusion umweltpolitischer Instrumente in den Industrieländern der OECD (vgl. auch Jänicke, Weidner, 1995)

Auf der ersten Stufe, so Gill, seien Reflexivität und Reflexion mit den Institutionen der Moderne - Wissenschaft, Recht und Ökonomie und nationalstaatliche Politik - offenbar zu bewältigen. Dagegen komme es auf Stufe 2 und 3 zu prinzipiellen Schwierigkeiten. Gill begründet dies damit, "daß die (Natur-)Wissenschaft kein einheitliches und zeitlich stabiles Wahrnehmungsschema zur Verfügung stellen kann, wodurch Ungewißheit primär offenbar wird. Wirkungsvoller als die Debatten der postempirischen Wissenschaftstheorie sind hier zweifellos die Institutionalisierung von Gegenexpertise, die Generierung neuer Erkenntnisse und - nicht zuletzt - die Dementierung von Sicherheitsbehauptungen durch reale Ereignisse." (Gill, 1999, 191) Die Institutionalisierung könne zwar von den Institutionen der Moderne noch bewältigt werden. Doch das wissenschaftliche Wissen, daß als Begründungsressource im Streit immer notwendiger werde, stelle für praktische Schlußfolgerungen keine hinreichende Grundlage mehr. Im Recht komme es zu einem Rückzug auf prozedurales Recht, in welchem die Funktion des Rechts nur darin bestehe, die Entscheidungsverfahren zu gestalten, nicht aber die Entscheidungen selbst zu programmieren, und die Ökonomie müsse die Frage nach der Versicherbarkeit potentieller Schäden verneinen. Schließlich schätzt Gill auch reflexive Politik in der Form deliberativer Konsense als wenig aussichtsreich ein, da kognitive Sicherheit, rechtliche Normierung und wirtschaftliche Kompensationsgarantien fehlten und zudem die internationale Problematik noch nicht in den Institutionen berücksichtigt sei. Dennoch hält er die Rede vom Epochenbruch für überzogen; Beck liefere nur Empirie, die Kontinuität der Basisinstitutionen der Moderne könne nicht ernsthaft angezweifelt werden. Auch Schwinn (1999) hat Becks Diagnose einer 'Zweiten Moderne' diesbezüglich kritisiert und auf die Kontinuität der Rationalitätsformen verwiesen. Widersprüche in der kapitalistischen Entwicklung seien nicht durch den Wandel der ökonomischen Rationalität aufgelöst worden, sondern durch die institutionelle Trennung von Anforderungen und Eigenlogik (Schwinn, 1999, 428 f). Insofern scheint Habermas' Forderung, das Projekt der Moderne fortzuführen und die Systemdissonanzen kommunikativ zu verflüssigen, plausibel, doch erfordert dies, wie zu zeigen ist, nicht nur eine veränderte metabolische Praxis, die am ökonomischen System ansetzen muß, sondern auch Revisionen in Habermas' Theorieprogramm 


\subsubsection{Unsicherheit und Nichtwissen}

Charakteristisch wird für die Risikogesellschaft, daß in ihr die Naturwissenschaft nicht mehr als neutrale Autorität fungiert. Die Forschungsergebnisse sind gesellschaftlich umstritten; sie fließen in Subpolitiken (Beck, 1986, 1993, 149 ff) bzw. die Wissensfabrikation von Diskurskoalitionen ein (Lau, 1989; Lau, Keller 2001). Wissenschaftler arbeiten nicht neutral, sondern folgen eigenen Interessen (Latour, 1987). Und sie verlassen die Grenzen der Labors. Dadurch setzen sie die wissenschaftliche Methodik den Unwägbarkeiten sozialer Bewertung aus: Bereits das Experiment kann zum Politikum werden, wohingegen Labortätigkeit in der Moderne immer konsequenzentlastetes Probehandeln und -denken war. Zwar greifen alle Experimente in die Wirklichkeit ein und unterliegen zeitlicher Irreversibilität. Im Labor aber bleiben die Konsequenzen klein und im methodischen Prozeß der wissenschaftlichen Kommunikation partiell von der sozialen Umwelt getrennt (Krohn, Weyer, 1989, 353). Dadurch erzeugten die Naturwissenschaften, trotz der gewaltigen Veränderungen, die sie hervorriefen, nicht soziale Konflikte, sondern trügen durch den von ihnen ausgehenden Fortschritt vielmehr zur Lösung von sozialen Problemen bei.

Die Anwendung wissenschaftlichen Wissens wurde sozialwissenschaftlich solange vernachlässigt, wie die Basisinstitutionen der Moderne (Modernisierung, Kulturkritik und Rationalisierung) ungebrochen reproduziert wurden und die Naturwissenschaften hinsichtlich der Anwendung ihres Wissens auf andere Disziplinen (Ingenieurberufe, Ökonomik, Jurisprudenz) verweisen konnten. Nach Krohn und Weyer ist jedoch die Anwendung von Wissen in der Moderne auch als Produktion von Wissen zu verstehen, da es aufgrund der beabsichtigten Anwendung zu Theorieexpansionen und -modifikationen und damit zu einer Finalisierung der Wissenschaft komme, verschiedene Disziplinen miteinander verknüpft würden und die Implementation neuen Wissens sich zugleich als systematische Erzeugung neuen Wissens darstelle (Krohn, Weyer, 1989, 356)

Von wissenssoziologischer Seite wurde die ökologische Anwendungsdimension von Wissenschaft in mehrere Richtungen erforscht. S. O. Funtowicz und J. R. Ravetz haben das Konzept postnormaler Wissenschaft (post-normal-science) entworfen (Funtowicz, Ravetz, 1992, 1993; Ravetz, 1999), das Unsicherheit und Problembezug anwendungsorientierter Wissenschaft hervorhebt. Der Begriff der postnormalen Wissenschaft knüpft an Kuhns normale Wissenschaften (normal science) an, ohne allerdings den wissenschaftstheoretischen Hintergrund voll auszuleuchten. Postnormale Wissenschaften verfolgen die Einbindung des Publikums in den wissenschaftlichen Begutachtungsprozeß (extended peer communities) und erlauben, Anschluß an Becks Subpolitik herzustellen (Healy, 1999). Funtowicz et al. unterscheiden Unsicherheit, Nichtwissen (ignorance), Unbestimmtheit (indeterminacy) und interpretieren Nichtwissen und Unbestimmtheit als Kontinuum von Risiko und Unsicherheit und potentiellem Schadensmaß. Die Übergänge zwischen den einzelnen Formen von Risiken und Unsicherheiten bestimmen Funtowicz et al. nicht wissenschaftstheoretisch. Es wird objektives Wissen bzw. Nichtwissen unterstellt. B. Wynne hat die Unterscheidung von Funtowicz et al. übernommen. Er interpretiert Unbestimmtheit 
gegenüber Funtowicz et al. jedoch stärker anwendungsbezogen. Daraus kann folgende Differenzierung abgeleitet werden (vgl. Schiller, Tänzler, 2002):

- Risiko: Das Systemverhalten ist bekannt und Endzustände können mit Wahrscheinlichkeitswerten belegt werden.

- Unsicherheit: Wichtige Systemparameter sind bekannt; es lassen sich jedoch keine Wahrscheinlichkeiten für zukünftige Systemzuständen angeben.

- Bestimmtes Nichtwissen/Unbestimmtheit (specified ignorance/indeterminacy): Sozial thematisiertes Nichtwissen oder Fehlen von Wissen, das aufgrund der Unbestimmtheit von Handlungsfolgen in offenen Systemen ex-post die methodisch bedingten Grenzziehungen der Wissenschaften relativieren kann.

- Unbestimmtes Nichtwissen (unspecified ignorance): In der Anwendung von Wissenschaft kann in der epistemischen Dimension Ungewißheit und in der sozialen, lebenweltlichen Dimension Nichtwissen auftreten.

Spezifiziertes und unspezifiertes Nichtwissen verweisen damit auf epistemologische Aspekte von Unsicherheit, wohingegen Unsicherheit durch fehlende Prognosefähigkeit in offenen Systemen charakterisiert ist. Unsicherheit bewegt sich dennoch im Rahmen der konventionellen Wissenschaftstheorie unter Einschluß einer ökosystemaren Umweltbeobachtung, während bestimmtes Nichtwissen bereits darüber hinausweist und erst unbestimmtes Nichtwissen darauf auch reflektiert. Es ist jedoch festzuhalten, daß auch Unsicherheit ex-post eine Rekategorisierung in bestimmtes Nichtwissen erforderlich machen kann. Und die singulären Fälle des Ozonlochs und des Treibhauseffektes werfen die Frage auf, ob nicht selbst Sicherheit jederzeit in bestimmtes Nichtwissen transformiert werden kann.

Krohn und Weyer (1989, 356 ff) haben die Verschiebung von Forschungsrisiken vom Labor in die Umwelt als Risikotransformation bezeichnet und als Beispiele Experimente in der realen Welt, wie z.B. gentechnische Freisetzungen und Großtechnologien genannt. Komplementär zum Vordringen der Primärwissenschaften in die Umwelt finde ein Prozeß der Risikokonstitution statt, welcher die Effekte von Naturveränderungen beobachte. ${ }^{18}$ Ein solches sekundäres Forschungsdesign, besteht z.B. mit der Umweltforschung (vgl. Küppers et al., 1978). Krohn und Weyer halten es für möglich, daß Primärforschung und Sekundärbeurteilung - als Wechselspiel zwischen Implementation und Reflexion - Teile derselben Disziplin sein können. Diese Differenz lasse sich nicht mehr als Grenzziehung zwischen Sozial- und Naturwissenschaften abbilden. Ihre Unterscheidung berücksichtigt zwar noch nicht explizit Nichtwissen oder Unbestimmtheit, dessen Bedeutung Wynne gerade auch unter Verweis auf Irreversibilität (open-endedness; Wynne, 1992, 119) für die Anwendungsdimension hervorgehoben hatte, arbeitet dieser aber entgegen.

${ }^{18}$ M. E. ist die Begriffsbildung nicht sonderlich geglückt, denn intuitiv verbindet man sicher die jeweils entgegengesetzten Phänomene mit den Begriffen und würde demnach die Risikogenese als Risikokonstitution bezeichnen und nicht als Risikotransformation. Ob damit eine konstruktivistische Auffassung zum Ausdruck gebracht werden soll, wird bei Krohn und Weyer nicht ganz deutlich. Dennoch erscheint es angebracht, der etablierten Begriffsbildung zu folgen, die konstruktivistische Konnotation hinzunehmen und im Zweifelsfall auf den Begriff der Risikogenese zurückzugreifen. 
Innerhalb der anwendungsbezogenen Wissenschaft wird nämlich interner Dissens mit der Institutionalisierung von Expertise und Gegenexpertise nach außen getragen. Die methodologischen Grundlagen der Wissenschaft gewähren keine Sicherheit über Anwendungsfolgen. Krohn und Weyer zufolge lasse anwendungsbezogene Wissenschaft das wissenschaftliche Wahrheits- und Objektivitätsmonopol ganz außer Acht. Sie ziele nicht auf sicheres Wissens, sondern auf den schnellen experimentellen Erfolg - in einer offenen Umwelt, wie hinzuzufügen ist. Herrschende Risikodefinitionen nehmen zwar wissenschaftliche Definitionen auf und wirkten so ebenso auf die Themensetzung der Forschung (Politisierung der Wissenschaft) wie auch auf die Öffentlichkeit (Verwissenschaftlichung der Gesellschaft) zurück. Risikodiskurse sind aber dadurch charakterisiert, daß die in ihnen verwandten Argumente "in einen, wenn auch möglicherweise kritischen Bezug zu einschlägigem wissenschaftlichen Wissen gebracht werden [müssen], wenn sie Geltung beanspruchen wollen." (Lau, 1989, 432) Damit muß sich die öffentliche Deliberation bei Risikodiskursen mit wissenschaftlichen Kriterien auseinandersetzen wie andererseits die wissenschaftliche Erkenntnisproduktion der Kontextualisierung unterliegt (vgl. Kollek, 1993, 32 ff).

Um die weitgesteckte Problematik der Verschiebung von Forschungsrisiken vom Labor in die Umwelt zu illustrieren, skizzieren Krohn und Weyer die wissenssoziologische Typologie eines empirischen Forschungsdesigns anhand von Risikofeldern. Sie nennen: a) Unfälle komplexer technischer Anlagen, b) Verbesserung von Prototypen, c) Langzeit- und Akkumulationseffekte d) nicht-lineare und rekursive Effekte e) explorative Forschung. Im Rahmen des Diskurses über Nachhaltigkeit sind besonders die Aspekte c), d) und e) hervorzuheben. ${ }^{19}$ Umweltpolitisch machen die ökologischen Effekte eine Prioritätensetzung erforderlich (Bechmann et al., 1994), in welcher unter prognostischer Unsicherheit der öko-soziale Erwartungsraum näher zu bestimmen versucht wird und umweltpolitische Ziele und Maßnahmen festgelegt werden. Explorative Forschung zielt dagegen auf die systematische Reduktion wissenschaftlichen Nichtwissens.

Zwar ist in den letzten Jahrzehnten die Technikfolgenabschätzung auf breiter Front institutionalisiert worden, doch nicht so die Wissenschaftsfolgenabschätzung, obwohl die ersten Konzepte parallel zur Technikfolgenabschätzung entstanden sind (vgl. Lau, Böschen, 2001). Die Wissenschaftsfolgenabschätzung stand lange im Schatten der wissenssoziologischen Erforschung der Technikfolgenabschätzung. Erst in jüngster Zeit gewinnt die sozialwissenschaftlich Erforschung des Nichtwissens an Aufmerksamkeit. Dabei tritt an die Stelle der Entgegensetzung von Experten/Wissenschaftlern und Laien im älteren Risikodiskurs nun das Nichtwissen der Experten/Wissenschaftler. Luhmann hatte über das Laienwissen ohnehin gemutmaßt, "daß die ökologische Kommunikation ihre Intensität dem Nichtwissen verdankt." (Luhmann, 1992, 154) Naturwissenschaftlich (und soziologisch) nicht aufgeklärte Laien haben demnach keine Relevanz für die systemtheoretische Forschung. Im Unterschied zu Luhmanns abwertender Feststellung zur ökologischen Kommunikation kommt sozialem Nichtwissen sehr wohl vielfach eine Präventions-

19 Dagegen können die Aspekte a) und b) eher dem Technikdiskurs zugerechnet werden, der mit dem Risikodiskurs die Annahme geschlossener technischer oder eben riskanter Systeme teilt. Allerdings haben verschiedene Autoren (z. B. Perrow, Bonß etc.) die Grenzen dieser Diskurse durch den Verweis auf eben die soziale oder naturale Umwelt dieser Systeme herausgearbeitet. 
wirkung zu, wenn es den sozial reflektiert wird (vgl. Böschen, 2002). Im Anschluß an Habermas könnte hier von einem kollektiven Bewußtsein über Grenzen wissenschaftlichen Wissens gesprochen werden, das von entsprechenden Lebensformen getragen wird. Derartige kollektive Lebensformen sind das Ergebnis von Lernprozessen und könnten eine Soziologie des Nichtwissens unterstützen. Kognitiv basieren sie etwa auf der Gewißheit einer konstanten Energie- und Materialbilanz in koevolutionären Prozessen.

Beck hat davon gesprochen, daß es der Gesichtpunkt der Verteilung, Verteidigung und (wissenschaftlichen) Erzeugung von Nichtwissen sei, "der den Fragehorizont nicht-linearer Theorien (reflexiver Modernisierung) eröffnet" (1996, 298). Nichtwissen sei ein 'Medium' reflexiver Modernisierung. Diese allgemeine Definition nimmt auf Nebenfolgen bezug, ohne daß diese notwendig als intersubjektive, kognitive Reflexion zu verstehen wären. Es könnte sich ebenso um nicht-kognitive Reflexe der Gesellschaft auf Risiken handeln. Nebenfolgen und Nichtwissen sind jedoch empirisch tatsächlich eng miteinander verflochten. Beck möchte nun diesen Umstand für die Soziologie erschließen (Beck, 1996; Beck et al, 2001). Dabei sind Aspekte des Nichtwissens immer Gegenstand der Soziologie gewesen. Durch die Unsicherheiten des Handelns im offenen System der Natur erfährt Nichtwissen aber eine neuartige, auch spezifisch ökologische Ausprägung: Nichtwissen tritt als Nicht-Antizipierbarkeit ökologischer Feed-backs auf. Nicht die Epistemologie der Sozialwissenschaften, sondern jene der Naturwissenschaften verweist auf Nichtwissen. Diesen Aspekt der ökologischen Krise, den schon Wynnes Begriff der Unbestimmtheit (indeterminacy) bezeichnete, hat Habermas bisher zu wenig beachtet. ${ }^{20}$ Er folgt in stofflich-energetischer Hinsicht notwendig aus der Thermodynamik, d.h. einer konstanten Material- und Energiebilanz.

Luhmann hat in dem Aufsatz Ökologie des Nichtwissens den Begriff des Nichtwissens nicht an die Operationen der sozialen Subsysteme, sondern an die erkenntnistheoretische Beobachtungstheorie angeschlossen. Jede Beobachtung konstituiere durch eine Unterscheidung (Einheit und Differenz) einen unmarked space, aus dem heraus der Beobachter operiere. Mittels Bezeichnungen könne er auf der einen Seite Wissen konstituieren, während der unmarked space erst durch Beobachtungen zweiter Ordnung zugänglich werde. Nichtwissen sei zwar nicht schon selbst der unmarked space, aber die andere Seite der Form des Wissens (1992, 159). Dies verweise auf das Gesellschaftssystem als System von Beobachtern. Mit der Spezifizierung relevanten Nichtwissens komme es in modernen Gesellschaften zur Ausdifferenzierung des Funktionssystems Wissenschaften, da Nichtwissen zum Anlaß von Bemühungen zum Wissenserwerb werde. Die Differenz (Grenze) zwischen Wissen und Nichtwissen könne gekreuzt werden, "entweder in Richtung auf den unmarked space des Nichtwissens, das sich mit jeder Operation reproduziert [...], oder in Richtung auf ein markiertes Nichtwissen, das selbst unterschieden und bezeichnet werden kann, etwa in der Form eines Problems." (Luhmann, 1995, 177) Für die Wissenschaft könne die Welt insgesamt kein möglicher Gegenstand sein, denn sie bleibe der unmarked space, der mit jeder

${ }^{20}$ Die Debatte in den Sozialwissenschaften bezog sich im wesentlichen auf Nicht-Intentionalität innerhalb der sozialen Welt und behandelte noch nicht die ökologischen Rebound-Probleme der Gesellschaft (vgl.die Beiträge in: Matthes, 1981; Habermas, 1984, 307 ff). 
Operation der Beobachtung die Form des Nichtwissens reproduziere (vgl. ebd., 177). In bezug auf die ökologische Umwelt der Gesellschaft führt dies zu einem scheinbaren Paradox. Denn da Beobachten ein sozialer Prozeß ist, "liegt der unmarked space in der Umwelt des Gesellschaftssystems. Zwar sammeln wir mehr und mehr ökologisches Wissen. Gerade das führt aber zum Nichtwissen über die Beziehung zwischen der Gesellschaft und ihrer ökologischen Umwelt." (Luhmann, 1992, 158) In einem phänomenbezogenen Perspektivwechsel spezifiziert Luhmann dann aber ökologisches Nichtwissen als Komplexität und raum-zeitliche Entgrenzung [aufgrund von loser Koppelung] im Verhältnis von Anthroposphäre und Natur (vgl. ebd., 167). Die Beschreibung von Raum und Zeit könne den sozialen Veränderungen folgen, "wenn sie ihr Instrumentarium prinzipiell von Einteilungen (des Seins, der Welt) auf Unterscheidungen (eines Beobachters) umstellt." (ebd., 168)

Luhmann folgt (auch) hier der Strategie, die Systemtheorie bei Vernachlässigung der sachlichen Sinndimension der ökologischen Krise zu temporalisieren. Damit kann er Kritik an den Operationen der Subsysteme vermeiden. Beinahe zwangsläufig führt ihn dies aber auf die Kontingenz der Koevolution von Natur und Gesellschaft zurück, ohne daß sein suchender Wechsel von Systemen zu Organisationen zur Absorption (ökologischer) Unsicherheit in der Gesellschaft beitragen könnte. Kontingenz erscheint Luhmann als (anthropozentrischer) Eigenwert der modernen Gesellschaft, die nicht eine Relation zwischen Gesellschaft und Umwelt meine, sondern das intransparente und deshalb produktive Verhältnis der Subsysteme zueinander (Luhmann, 1992, 93 ff). Notwendigkeiten und Unmöglichkeiten repräsentiert deshalb heute schlicht kein Ordnungsgerüst der Welt mehr, gleichviel ob Natur mit der naturalistischen Indifferenz ökologischer Gefahren zweiter Ordnung auf die Gesellschaft zurückwirkt. Notwendigkeit und Unmöglichkeit "sind nur noch Modalitäten, die man aus Zeitgründen hinzunehmen hat." (Luhmann, 1992, 127) ${ }^{21}$

Japp hat auch hier Luhmanns Ansatz aufgegriffen und zwischen gesichertem Wissen, spezifischem und unspezifischem Nichtwissen unterschieden. Gesichertes Wissen verweist auf das im Wissenschaftssystem generierte Wissen, welches für Luhmann aus kognitiven, 'lernbereiten Erwartungen' besteht. Dagegen versteht Japp unter Nichtwissen den partiellen oder kompletten Ausfall solcher Erwartungen. Spezifisches Wissen entstehe bei der Spezifizierung von Nichtwissen in Hinblick auf bestehendes Wissen. Es könne entweder in gesichertes Wissen oder in Risiko transformiert werden, wobei es aber relational bleibe. "Diese Art des Nichtwissens entsteht etwa durch die Relationierung von mehrdeutigen Schadensereignissen (z.B. toxische Kontamination) und bewerteten Beständen (z.B. Gesundheit und Besitz)." (Japp, 1997c, 290) Unspezifisches Wissen knüpft an Luhmanns (allgemeiner) Bestimmung von ökologischem Nichtwissen an: Unspezifisches Nichtwissen sei strukturell intransparent und nicht mehr hintergehbar, weil sich die Gesellschaft

${ }^{21}$ Zwar sind Luhmanns Ausführungen zu den historischen Problemen von Philosophie und Theologie mit dem Begriff Kontingenz überaus interessant, doch erweist sich Luhmanns Kontingenztheorie als irrelevant für das ökologische Problem, das nicht durch die Beobachtungsoperationen geschlossener Systemen konstituiert wird, sondern durch den materiell-energetischen Stoffstrom des offenen Gesellschaftssystems. Den Versuch einer Relationierung von Gesellschaft und Natur (historisch noch nicht: Umwelt) hatten die klassischen Konzepte von Kontingenz somit der Systemtheorie sogar voraus. 
immer schon mit der Differenz von System und Umwelt beschrieben habe. Der unmarked space des ökologischen Nichtwissens sei nicht "durch andere Wissensunterscheidungen" zu überwinden (ebd., 298). Die Einheit der Unterscheidung von System und Umwelt wird auch hier zur Grenze der Beobachtung, die immer wieder reproduziert werde und erkenntnistheoretisch-kognitiv nicht zu überwinden sei. "Ein Widereintritt (re-entry) der Unterscheidung von Gesellschaft und Umwelt auf der Seite der Umwelt würde keine zusätzliche Information erbringen, würde gar keine Kommunikation auslösen." (ebd., 297) Daher stelle sich für die Gesellschaft nur die Frage, "mit welchen Operationen das kognitiv unlösbare Problem ökologischen Nichtwissens 'produktiv' umgangen wird." (ebd., 198)

Japp unternimmt die Differenzierungen auf der Sinnebene der Systemtheorie. In der Zeitdimension würden Entscheidungen operativ getroffen. Die Gesellschaft behelfe sich mit der provisorischen Verständigung auf reversible Festlegungen. Japp geht indes nicht auf die Operation von Subsystemen - etwa Wirtschaftssystem und Wissenschaftssystem - ein, sondern weist einzig dem Politischen die Risikokommunikation zu: In der Sachdimension sollen kategorische Vermeidungsimperative vor dem Schlimmsten schützen. Die Katastrophensemantik sozialer Akteure mit der Behauptung entgrenzter Gefahren weise eine große Nähe zu der prinzipiellen Unmöglichkeit von Beobachtung auf (ebd., 306). Dies laufe auf eine komplette Negation kontingenten Wissens hinaus. Doch in der Sozialdimension werde allgemein mit Dissens auf Nichtwissen geantwortet. Gesichertes, autoritatives Wissen werde selbst zu riskant. Die Gesellschaft greife deshalb, so Japp, auf die systemtheoretische Erkenntnisoption von Entscheidung und Beobachtung zurück und etabliere einen Mechanismus, der die optionsvernichtende Rigidität von Katastrophenvermeidung austariert. In der sozialen Dimension werde die optionssteigernde Unsicherheit des Risikos in Anspruch genommen. Die Gesellschaft "wird das Großrisiko einer Ökologisierung der Wirtschaft vermeiden und anstelle dessen die Umweltpolitik auf das Maß (partieller Negationen) reduzieren, das durch die Anschlußmöglichkeiten einer 'Politik der provisorischen Verständigung gegeben ist (Katalysatoren gegen Waldsterben)." (ebd., 307) Der behauptete systemtheoretische Ausgleichsmechanismus läuft auf die Assimilation von Wissenschaft an politische Verfahren hinaus, wobei Japp die Beobachtung objektivierbarer Sachverhalte allein der Wissenschaft zuspricht (ebd., 291; bereits Japp, 1997b). ${ }^{22}$

Bereits A. Schütz (und T. Luckmann) haben in der Untersuchung der Strukturen der Lebenswelt das Thema des Nicht-Wissens aufgenommen; sie beziehen Nicht-Wissen auf Subjekte, die im Horizont des lebensweltlichen Wissensvorrats verblieben, und die Lebenswelt nicht erschließen könnten. "Der individuellen Situation in der Lebenswelt ist sowohl die relative Undurchsichtigkeit als auch die absolute Undurchschaubarkeit der Lebenswelt auferlegt." (Schütz, Luckmann, 1975, 169) Als Nicht-Wissen eines Subjekts können Schütz und Luckmann Nicht-Wissen als 'potentielles Wissen' verstehen, das sie weiter in wiederherstellbares und erlangbares Wissen unterscheiden. Erst

${ }^{22}$ Von daher ist Japp Vorwurf gegen einen 'halbierten Konstruktivismus', der von einer Realität (der natürlichen Umwelt) ausgehe, nicht nachzuvollziehen. Ein solcher muß nicht zu einer Entdifferenzierung von Handlung und Reflexion führen oder die die Objektivität wissenschaftlicher Erkenntnis bestreiten. 
in der theoretischen Reflexion "führt das Erlebnis der Unzulänglichkeit spezifischer Auslegungen zur Einsicht in die wesensmäßige Begrenztheit des lebensweltlichen Wissensvorrats überhaupt." (ebd., 174) Dies trifft den Wissensvorrat in seiner Gesamtheit und zeigt sich insbesondere bei der Bestimmung der Zukunft durch diesen Wissensvorrat. "Das Erlebnis radikaler Überraschungen verweist eindringlich auf die grundsätzliche Undurchschaubarkeit der Lebenswelt." (ebd., 173)

Habermas hat dieses Konzept intersubjektiv gewendet in die Theorie des kommunikativen Handelns aufgenommen (vgl. 1981, II, 192 ff). Die Strukturen der Lebenswelt hat er dabei 'epistemisiert' (Habermas, 1999). Eine theoretische Auseinandersetzung mit der Risikosoziologie als soziologische Gegenwartsdiagnose - oder der Wissenssoziologie erfolgte nach der wissenschaftstheoretischen Konstruktion lebensweltlicher Hermeneutik im Positivismusstreit (mit der Übernahme des Fallibilismusprinzips) jedoch nicht mehr. Andererseits hat die empirische, wissenssoziologische Diskursanalyse auch kaum Bezug zu Habermas' Theorie hergestellt (vgl. Keller, 1999, 128 ff). Dies ist erstaunlich, weil Habermas' Epistemisierung der Lebenswelt dieser sozialwissenschaftlichen Methodik prinzipiell entgegenkommt.

S. Böschen (2002, 79 ff) hat für den Anwendungskontext der Wissenschaften und der damit verbundenen Anschlußfähigkeit der Sozialwissenschaft die Bedeutung der Differenzierung von Erkenntnisgegenständen und der Koordination von Akteuren unterschiedlicher Felder hervorgehoben. Im Rahmen der Differenzierung strukturierten Metaphern (Leitbilder) den Erkenntnisprozeß. Ihr hoher Symbolgehalt prädestiniere Metaphern für den Risikodiskurs; sie fänden sich sogar in der Wissenschaft. Dies könne von heuristischen über hypothesengenerierenden bis zu theoriekonstitutiven Wirkungen reichen. Sie seien aber nicht nur für die Problemkonstitution relevant. Metaphern seien hochflexibel und könnten als Transmissionsriemen zwischen Wissenschaft und Öffentlichkeit fungieren. Es gehe dabei weniger um das Erkennen (nicht wissen können), als um das Anerkennen von Fakten (nicht wissen wollen). Für die Dynamik des Erkennens und Anerkennens sei vor allem bedeutsam, in welcher Form kognitive Ressourcen bei den Akteuren vorlägen. Im Bereich des politischen Systems erhöhten sie aber den Symbolgehalt und könnten Deliberation verstärkt expressivem Handeln aussetzen. Andererseits kann davon ausgegangen werden, das Nichtwissen im politisch-administrativen System zur Blockade von Entscheidungen führt. Einzig positives, mitunter auch im Entstehen begriffenes Wissen kann derartige Blockaden aufheben (vgl. Mayntz, 1999; Schiller, Tänzler, 2002). Böschens Diskursanalyse zufolge könnten Metaphern (Leitbilder) Nichtwissen an Wissen assimilieren und so kognitive Hürden überwinden. Doch wissenschaftstheoretisch erscheint der diskursanalytische Begriff der Metapher noch unbefriedigend, da er die diskursiven Prozesse unterhalb des mit der Diskurstheorie bestehenden kognitiven Niveaus von Gesellschaftstheorie erfaßt. Allerdings kann dem zunächst noch die skeptische Frage entgegengehalten werden, ob die Diskurstheorie tatsächlich einen sozialwissenschaftlichen 'Mehrwert' aufweist.

Wie gezeigt, haben sich die risikosoziologischen Diagnosen der Gegenwart nicht nur vom Risiko zugunsten von Unsicherheiten wegbewegt, sondern sie haben auch zunehmend die Bedeutung von Nichtwissen betont. Luhmann und Japp haben zwischen spezifischem und unspezifischen 
Nichtwissen unterschieden, wobei nur erstere Form des Nichtwissens weitere eigenständige Wissensbemühungen in Gang setze. Unspezifisches Wissen sei dagegen nicht mehr weiter zu differenzieren. Japp fordert deshalb für den aktiven Umgang mit Nichtwissen einen theoretischen Wechsel von Wissen auf Operationen. "In der Tat ist Nichtwissen als Untersuchungsgegenstand nicht unmittelbar präsent, sondern setzt sowohl einen (Selbst)Beobachter als auch ein wie immer selektives und hypothetisches Wissen oder zumindest Vermuten und Befürchten des Nichtwissens voraus." (Wehling, 2001, 469) Nicht zwingend sei jedoch die Annahme, "daß bestimmte Wissensinhalte immer schon verfügbar sein müssen, um im Kontrast dazu Nichtwissen diagnostizieren zu können." (ebd., 469) Die wissenssoziologische Hinwendung zum Nichtwissen, sollte nicht von der Schwäche der entscheidungstheoretischen Risikoforschung getragen werden, sondern einen Zugang zum Problembereich suchen, der die Ausdifferenzierung der modernen Gesellschaft auf der Ebene von Politik, Ökonomie, Naturwissenschaft und anwendungsbezogener Wissenschaft reflektiert. Trotz Japps Forderung nach einer Hinwendung der Systemtheorie zu Operationen hat diese sich bislang kaum mit dieser Aufgabe befaßt. Für die Diskurstheorie wäre dieses Programm auf das ökonomische und das politisch-administrative System zu beziehen, sowie wissenschaftstheoretisch zu reflektieren. Derart könnten dann gegebenenfalls Wissenssoziologie und Wissenschaftstheorie näher aneinander geführt werden. Es bietet sich dazu ein argumentationstheoretischer Ansatz an.

\subsection{Die Lebenswelt als Quelle von Rationalität und Relevanz?}

Habermas hat in der Theorie des kommunikativen Handelns (1981, II, 198 ff) das Lebensweltkonzept von Schütz, Luckmann und Berger wegen seines monadischen und ontologischen Aufbaus kritisiert und statt dessen vorgeschlagen, die Lebenswelt komplementär zum kommunikativen Handeln zu verstehen (vgl. auch Habermas, 1988, 87 ff). Teils wird damit die (Spach)philosophie zur Quelle von möglicher Relevanz: Die Lebenswelt ist bei Habermas nicht wie bei den Phänomenologen Prädikator einer Objektsprache, sondern reflektierend-theoretisches, kommunikatives Handeln. Sprache ist nicht Ontologie, sondern Sprachhorizont, der kommunikativ handelnd nicht überschritten werden kann. Es könnte damit aber auch die Soziologie zur Quelle der Relevanz werden: Sprache ist mit Handlungen verbunden (vgl. Tugendhart, 1985), was über die kommunikationstheoretische Begründung der Theorie des kommunikativen Handelns eine rationelle Verbindung von Expertenkommunikation und alltäglichem sozialen Handeln erlaubt (Krüger, 1990, 394). Ob nun die Philosophie oder die Soziologie als Quelle der Kritik angesehen werden soll, ist offen. Philosophisch bestehen keine Relevanzkriterien für die Präsupposition, welche die jeweils aktuelle Lebenswelt ausmacht (vgl. Psarros, 1998, 344). In Wahrheit und Rechtfertigung ist Habermas zwar auf offene Fragen des theoretischen Diskurses zurückgekommen, doch gibt er unzureichende Antworten. Er verfolgt dort den Ausbau der philosophisch-kommunikationstheoretischen Begründung der Diskurstheorie, während er die angekündigte argumentationstheoretische Fundierung des Diskurses weiter vernachlässigt. Bedauerlicherweise verfehlt, wie noch 
zu zeigen ist, das vorgestellte Rationalitätskonzept die Absicht, Rationalitätsdimension neutral zusammenzuführen, so daß praktische Fragen durch instrumentelles Handeln vorentschieden werden.

\subsubsection{Kommunikatives Handeln und Rationalität}

Zwar kann diskursive Rationalität nicht den philosophischen Begriff der Vernunft neu begründen (Schnädelbach, 1987), denn Rationalität ist selbst an Begründung gebunden (vgl. Peters, 1991, 167 ff), sie kann aber - ähnlich wie bei Apel - dem philosophischen Begriff der Vernunft ergänzend zur Seite treten (Habermas, 1981, I, 15 f und II, 583 f; Habermas, 1983, 9 ff; 11; 23; 25; 1988). Diesem Fokuswechsel von Vernunft auf Rationalität entspricht bei Habermas eine Sozialphilosophie, die nicht mehr die philosophischen Absolutheitsansprüche eines Kant oder Hegel vertreten will, sondern sich philosophisch zurücknimmt. Rationalität bietet gegenüber der Vernunft zudem den Vorteil, empirisch zugänglich zu sein. Die intersubjektive 'kommunikative Rationalität' steht bei Habermas (ebenso wie bei Apel) im Gegensatz zum selbstreflexiven Rationalitätsverständnis der Bewußtseinsphilosophie. Während jene das 'reflexive Haben ' von Vernunft im Subjekt verortet, erklärt sich Rationalität für die Universalpragmatik aus der Übernahme der Perspektive einer zweiten Person durch ein kommunikativ handelndes Subjekt: Rationalität ist nicht als introperspektivische Selbstreflexion zu verstehen, sondern als Diskurs, der sich dialogisch nach dem Modell der problematischen Geltung von Äußerungen vollzieht. "Die diskursive Thematisierung von Geltungsansprüchen, an denen sich die Rationalität unserer Äußerungen bemißt, und das reflexive Haben dieser Äußerungen stehen in einem komplementären Verhältnis: sie verweisen aufeinander." (Habermas, 1999, 103) Habermas nimmt nun an, daß sich in der kommunikativen Struktur des Sprechens verschiedene Wurzeln der Rationalität finden lassen, die selber jedoch keine gemeinsamen Ursprünge in der Diskursstruktur der Begründungspraxis oder auch in der Reflexionsstruktur der Selbstbeziehung eines an Diskursen teilnehmenden Subjekts haben. Sprache ist gegenüber der Rationalität von Subjekten neutral. "Die welterschließende Kraft der Sprache ist weder rational noch irrational; als eine Ermöglichungsbedingung für rationales Verhalten ist sie selbst a-rational." (Habermas, 1999, 133)

Habermas geht davon aus, daß "die Diskursstruktur unter den verzweigten Rationalitätsstrukturen des Wissens, Handelns und der Rede einen Zusammenhang stiftet, indem sie die propositionalen, teleologischen und kommunikativen Wurzeln gewissermaßen zusammenführt." (Habermas, 1999, 104; kursiv i. O.) Diskursrationalität bezeichnet demzufolge keine fundierende, sondern eine integrative Leistung, die drei Formen von Rationalität miteinander verbindet, nämlich die epistemische, die teleologische und die kommunikative Rationalität. Alle drei Formen sind sprachlicher Natur. Gleichwohl sei kommunikative Rationalität von Diskursrationalität zu unterscheiden, denn kommunikative Rationalität sitze der im Alltagshandeln verkörperten Sprache zwar auf, doch als Argumentationspraxis stelle sie zugleich eine Reflexionsform kommunikativen Handelns dar. 
Die erkenntnistheoretische Rationalität sei nicht einfachhin als Erkennen von Tatsachen gekennzeichnet, sondern zudem als Wissen von Wahrheit. ${ }^{23}$ So impliziere die Rationalität eines Urteils trotz der 'platonischen' - weil falliblen - Natur von Wissen "nicht dessen Wahrheit, sondern nur seine begründete Akzeptabilität in einem gegebenen Kontext." (Habermas, 1999, 107f) Da sich in der epistemischen Rationalität Sprachgebrauch und Handeln verschränkten, spricht Habermas von einer epistemischen, sich nicht selbsttragenden Kernstruktur dieser Rationalitätsform. Diese Kernstruktur erlaube dennoch ein reflexives Haben von Wissen. Die Verschränkung von Handlung und Sprache werde etwa in den Wissenschaften methodisch erzeugt. Der pragmatische Begriff erfolgskontrollierten Handelns schließt Habermas zufolge praktisches Lernen aus negativen Erfahrungen ein. Habermas baut dabei auf der von Peirce' entdeckten abduktiven Schlußmethode auf, die hypothetisch von einer Art von Fakten auf eine andere Art von Fakten schließt ${ }^{24}$ und die wissenschaftstheoretische Funktion haben, neue Hypothesen zu entdecken und aufzustellen, d.h. erkenntniserweiternd zu wirken: "Wir lernen aus Enttäuschungen, indem wir Überraschungen mit abduktiver Urteilskraft verarbeiten und das problematisch gewordene Wissen revidieren. (Auf der reflexiven Ebene der Wissenschaft werden solche produktiv zu verarbeitenden Enttäuschungen methodisch erzeugt; der Handlungsbezug der falsifizierten Enttäuschungsevidenzen verrät sich insbesondere im experimentellen Handeln.)" (Habermas, 1999, 107 f) Daß wissenschaftliche Tätigkeiten und sprachliche Kommunikation tatsächlich in dem von Habermas hier behauptet unproblematischen Verhältnis zueinander stehen, ist zu bezweifeln. Diese im Kontext der Nachhaltigkeit äußerst problematischen Annahmen werden aber sogleich noch detailliert zu betrachten sein.

Habermas zufolge ist teleologische Rationalität allem Handeln inne, denn dieses sei intentional und ziele immer auf die Realisierung eines gesetzten Zwecks. Dabei zeigten nicht faktische Handlungsfolgen in der Welt teleologische Rationalität an, sondern die intentional gewählten und eingesetzten Mittel eines Aktors mit denen dieser Ziele erreiche. "Ein erfolgreicher Aktor hat dann rational gehandelt, wenn er (a) weiß, warum er Erfolg hatte (bzw. den gesetzten Zweck unter normalen Umständen hätte realisieren können), und wenn (b) dieses Wissen den Aktor (mindestens teilweise) motiviert, so daß dieser seine Handlung aus Gründen ausführt, die zugleich deren möglichen Erfolg erklären können." (Habermas, 1999, 109) Nicht-kommunikative Handlungen sind strategisch, wenn sie auf Subjekt, und instrumentell, wenn sie Objekte abzielen. Im einfachsten Fall

${ }^{23}$ B. Peters spricht in bezug auf symbolische Gebilde und Sinngehalte von Wahrheit und Richtigkeit und nicht von Rationalität. Aufgrund des generell pragmatischen Charakters von Rationalität sei es sinnvoll, 'rational' nur auf pragmatische Kontexte, "eingeschlossen die Akzeptanz oder Beurteilung solcher Sinngebilde als wahr, richtig usw., zu beschränken." (Peters, 1991, 179) Er bezieht mit der pragmatischen Tradition Rationalität auf das Lösen von Problemen und unterscheidet mit Habermas kognitiv-instrumentelle, moralisch-praktische und evaluativ-expressive Rationalität, die in Wahrheit und Richtigkeit ihre Standards hätten. Ausgangspunkt bleibt dabei die Erklärung sozialen Handelns. Handlungsrationalität beinhalte dabei immer alle drei Aspekte von Rationalität, sonst könne nicht von rationalem Handeln gesprochen werden. Peters verweist auf die Möglichkeit von Konflikten zwischen normativer und empirisch-kognitiver Rationalität im Prozeß der Wissensbeschaffung und Wissenssteigerung, die an bestimmte Lebensbereiche mit vereinseitigter Handlungsrationalität angebunden sein könne.

${ }^{24}$ Dazu das folgende Beispiel eines abduktiven Schlusses: Wenn die Regel lautet, daß alle Bohnen aus einem Sack weiß sind und das Resultat vorliegt, daß alle Bohnen weiß sind, dann könnte es der Fall sein, daß die Bohnen aus eben jenem Sack sind. 
können Handlungen, wie etwa in der Theorie rationaler Wahl, die Form eines praktischen Schlusses haben.

Kommunikative Rationalität drücke sich, so Habermas, nicht in Sprache per se, sondern in der einigenden Kraft verständigungsorientierter Rede aus. Diese sichere für die beteiligten Sprecher gleichzeitig die intersubjektiv geteilte Lebenswelt und damit den Horizont, innerhalb dessen sich alle auf ein und dieselbe objektive Welt beziehen könnten. Dabei verbänden sich Sprache und Handlungen zu Sprechakten, die eine interpersonale Beziehung mit einer zweiten Person herstellten. Mit Sprechakten verfolge ein Sprecher das Ziel, sich mit einem Hörer über etwas zu verständigen. "Dieses - wie wir sagen wollen - illokutionäre Ziel ist zweistufig: Der Sprechakt soll vom Hörer zunächst verstanden und dann - nach Möglichkeit - akzeptiert werden. Die Rationalität des verständigungsorientierten Sprachgebrauchs hängt dann davon ab, ob die Sprechhandlungen so verständlich und akzeptabel sind, daß der Sprecher damit illokutionäre Erfolge erzielt (oder unter normalen Umständen erzielen könnte)." (Habermas, 1999, 111) Ein derartiger Erfolg bemesse sich an der intersubjektiven Anerkennung, die der mit ihr erhobene Geltungsanspruch finde, wobei dabei Habermas zufolge eine Kommunikationssituation vorauszusetzen sei, die eine vollständige Rollenverteilung zwischen erster, zweiter und dritter Person erlaube. Diese Kommunikationsvoraussetzungen relativiert Habermas jedoch in bezug auf den epistemischen und teleologischen Sprachgebrauch. Hier seien sie weniger zwingend, da die Sprecher keine illokutionären Ziele verfolgten (Habermas, 1999, 113). "Argumente und Aufforderungen sind von Haus aus pragmatischer Natur und können deshalb (anders als Aussage- und Absichtssätze) nur zusammen mit den interpersonalen Beziehungen, die ihrer Bedeutung inhärent sind, internalisiert werden. Aussagen und Absichten lassen sich des illokutionären Sinnes von Behauptungs- und Ankündigungsakten entkleiden, ohne ihre Bedeutung zu verlieren, während eine Aufforderung ohne illokutionäre Komponente selbst in foro interno keine Aufforderung bliebe." (Habermas, 1999, 115) Im Gegensatz zum nicht-kommunikativen Sprachgebrauch trete beim kommunikativen Sprachgebrauch ein Geltungsanspruch hinzu, mit dem der Sprecher den Hörer konfrontiert. Implizit solle der Hörer damit zur selben Auffassung wie der Sprecher gelangen und die von diesem erhobenen Geltungsansprüche akzeptieren. Dabei ist genau zwischen Einverständnis und Verständigung zu unterscheiden.

Einverständnis im strengen Sinne wird nur dann erreicht, wenn die Beteiligten einen Geltungsanspruch aus denselben Gründen akzeptieren können, während eine Verständigung auch dann zustande kommt, wenn der eine sieht, daß der andere im Lichte seiner Präferenzen unter gegebenen Umständen für die erklärte Absicht gute Gründe hat, d. h. Gründe, die für ihn gut sind, ohne daß sich der andere diese Gründe im Lichte eigener Präferenzen zu eigen machen müßte. Aktorunabhängige Gründe erlauben einen stärkeren Modus von Verständigung als aktorrelative Gründe. (Habermas, 1999, 116 f)

Im diskursiven Wettbewerb um das bessere Argument, stehe das einverständige Einlösen des Geltungsanspruchs so lange aus, "bis aktorunabhängige Gründe den strittigen Wahrheitsanspruch grundsätzlich für alle Beteiligten rational akzeptabel machen." (ebd., 116) 
Soziale Handlungen definieren sich dadurch, daß sich Aktoren in der Verfolgung ihrer je eigenen Handlungspläne auch an dem erwarteten Handeln anderer orientieren. Habermas schließt an Max Weber an: Von kommunikativem Handeln könne gesprochen werden,

wenn Aktoren ihre Handlungspläne über sprachliche Verständigung, also in der Weise miteinander koordinieren, daß sie dazu die illokutionären Bindungskräfte von Sprechakten nutzen (1). Im strategischen Handeln liegt dieses Potential kommunikativer Rationalität brach, und zwar auch dann, wenn die Interaktionen sprachlich vermittelt sind. Weil die Beteiligten hier ihre Handlungspläne über reziproke Einflußnahme miteinander koordinieren, wird die Sprache nicht im erläuterten Sinne kommunikativ, sondern folgenorientiert verwendet. Für die Analyse dieses Sprachgebrauchs bieten die sog. Perlokutionen einen geeigneten Schlüssel (2). (Habermas, 1999, 122)

\subsubsection{Wissenschaft, epistemische Rationalität und Argumentationstheorie}

Die Wissensfortschritte der Naturwissenschaften sind ganz wesentlich experimenteller Forschung zuzuschreiben. Trotzdem könnten naturwissenschaftliche Fragen mit sehr hoher Relevanz für die ökologische Krise mit den herkömmlichen wissenschaftlichen Methoden unbeantwortet bleiben, da sie sich nicht dazu eignen, offene, lebende Systeme zu erfassen. Experimentelle wissenschaftliche Forschung kann dann eventuell nicht durchgeführt werden, da der experimentelle Ereignisraum für Experimente zu groß ist, sich generell nicht begrenzen läßt oder Experimente wegen irreversibler Folgen moralisch umstritten sind.

Für die beobachtenden Naturwissenschaften erscheinen dagegen bestimmte epistemische Perspektiven nur unter der Annahme mehr oder weniger plausibler Voraussetzungen richtig, deren Vollständigkeit nicht behauptet werden können. Damit lassen sich derartige Theorien nicht in der Weise prognostisch anwenden, als basierten sie auf der Grundlage bewährter empirischer, nomologischer Aussagen wie sie die experimentellen Naturwissenschaften bereithalten (vgl. v. Schomberg, 1995b, 176). Während sich die beobachtenden Naturwissenschaften vor allem dazu eignen, Veränderungen ex-post zu erklären, beruht der Erfolg der experimentellen Naturwissenschaften auf prognostischen Theorien, die oft technisch anwendbar sind.

Während die beobachtenden Naturwissenschaften die Realität so belassen wie sie ist, intervenieren die experimentellen Naturwissenschaften in die Realität der Natur. Die wissenschaftliche Entwicklung schreitet mittels der Verifikation bzw. Falsifikation von Theorien durch Experimente voran. Der kritische Rationalismus hat dies mit dem Falsifikationismus und dem Fallibilismusprinzip philosophisch auf den Punkt gebracht. Diesen haben Habermas und Apel als epistemisches Prinzip in die Diskurstheorie integriert.

Gegen den kritischen Rationalismus hatte bereits Kuhn auf den Entdeckungskontext hingewiesen, innerhalb dessen wissenschaftliche Praxis abläuft (Kuhn, 1962). Dieser Entdeckungskontext des empirischen Findens von Tatsachen verläuft nach Kuhn nicht kontingent, sondern wird immer vor einem bestehenden theoretischen Hintergrund konstruiert. So entstehen in einer diskursiv strukturierten wissenschaftlichen Praxis neue Theorien, die schließlich die normale 
Forschung durchbrechen und $\mathrm{zu}$ neuen Paradigmen kulminieren. Doch Kuhns wissenschaftstheoretische These von der Ablösung alter Paradigmen durch neue ist leidenschaftlich kritisiert worden. Denn sie impliziere doch, so die Kritiker, die (radikale) Inkommensurabilität konkurrierender Paradigmen.

I. Stengers (1997) schreibt diese Kritik allein der philosophischen Reflexion zu; sie sei von den Wissenschaftlern in deren Praxis nicht geteilt worden. Auf dieser Linie schlägt sie vor, dichotomische Entgegensetzungen wie jene zwischen normaler versus post-normaler Wissenschaft oder zwischen beobachtender versus experimenteller Naturwissenschaften zu vermeiden. Statt dessen solle sowohl wissenschaftliches als auch soziales Handeln als kontextgebundene Praxis verstanden werden, die es in nichthierarchischen Kontroversen zu verteidigen gelte. Dabei versteht sie Praktiken als diskursive Lebensformen. Nach R. von Schomberg (1995b) können solche Kontroversen als argumentative Diskurse analysiert werden.

In einer solchen Analyse zeigt sich, daß in entsprechenden historischen Kontexten entgegen dem philosophischen Inkommensurabilitätsverdacht für die Wissenschaftler selbst das Problem einer Theoriewahl gar nicht besteht, da sich die Theorien tatsächlich auf verschiedene Objektbereiche beziehen (vgl. v. Schomberg, 1995b, 89). Erkenntnisfortschritt vollziehe sich, laut v. Schomberg, weniger durch rationale Theoriewahl als vielmehr durch ständige Kritik an einer artikulierten Theorie. Es vollziehe sich eine Veränderung der Sprache, indem man sich immer besser über den wissenschaftlichen Objektbereich verständige. Die theoretischen Begriffe würden in einem Verständigungsprozeß ständig modifiziert, und in einer Verschiebung der Hintergrundannahmen verlagere sich schließlich auch der Objektbereich. R. v. Schomberg schließt dabei an die argumentations- und wissenschaftstheoretischen Arbeiten Toulmins an. Dieser Verständigungsprozeß der Wissenschaften folgt bestimmten argumentativen Mustern, die v. Schomberg (1995a) zu erschließen versucht hat.

Die argumentative Praxis der Wissenschaften durchläuft demnach in epistemischen Diskursen einen Prozeß, in welchem zuerst plausible Hypothesen abduktiv abgeleitet, sodann spezielle Hypothesen rational selektiert und diese schließlich in ein Paradigma integriert werden. Die Plausibilität von Aussagen in derartigen Diskursen hänge von Präsuppositionen in den jeweiligen wissenschaftlichen Disziplinen und abduktiven Schlüssen ab. Plausible oder auch abduktive Hypothesen rekonstruiert v. Schomberg nach drei Formen: Hypothesen auf Grundlage von Analogien, Hypothesen basierend auf Attestargumenten und Hypothesen auf Grund von hypothetischen Annahmen. Im Gegensatz zu empirisch-theoretischen Diskursen sei bei plausibler Argumentation in epistemischen Diskursen weder Wahrheit noch Wahrscheinlichkeit benennbar. Vielmehr könne es zu tiefergehenden epistemischen Dissensen kommen, in deren Verlauf konkurrierende Forschungsprogramme oder gar neue wissenschaftliche Disziplinen entstehen könnten. Konkurrierende Programme zeigten Unsicherheit über die Angemessenheit der Erkenntnis auf einem bestimmten Gebiet. "Diese Unsicherheit wird zum Ausdruck gebracht in einem epistemischen Diskurs, wobei beispielsweise umstrittene Plausibilitätsansprüche auf Grund verschiedener Analogien geäußert werden: Die Argumente in einem epistemischen Diskurs haben 
eine unsicherheitskonstituierende Kraft." (ebd., 171, kursiv i. O.) Der theoretisch-empirische Diskurs bezieht sich dagegen auf die argumentative Einlösung von Wahrheitsansprüchen, die wir mittels Aussagen einfordern. Wichtigste Frage ist hierbei, welche Aussagen wir rechtfertigen können. "In einem solchen Diskurs geht es um kontroverse Aussagen, die Interpretationen akzeptierter Tatsachen bilden. Das Ergebnis eines solchen Diskurses kann man in 'Wahrheit' und 'Wahrscheinlichkeit' ausdrücken." (ebd., 167)

Eine derartige Unterscheidung zwischen epistemischen und theoretisch-empirischen Diskursen erlaubt, die auf einem prinzipiell möglichen Konsens beruhenden Ergebnisse von theoretischempirischen Diskursen zu Prämissen unseres Handelns zu machen, wohingegen die (kontroversen) Aussagen epistemischer Diskurse nicht direkt Grundlage unseres Handelns werden können. Denn es ist bei ihnen prinzipiell ausgeschlossen, einen auf Wahrheit bezogenen Konsens herbeizuführen. Statt dessen zielen Aussagen in epistemischen Diskursen in ihrer plausiblen Argumentation auf eine prospektive Kohärenz, die sich erst noch pragmatisch bewähren muß.

Versteht man nun den Entdeckungskontext von Wissenschaften in epistemischen Diskursen als kommunikatives Handeln, so beinhaltet eine verständigungsorientierte Situationsauslegung v. Schomberg zufolge: 1. die Interpretationsfähigkeit der Beteiligten, 2. die Kohärenz des Wissens mit anstehenden Entscheidungen und 3. die Orientierung an plausiblen Prinzipien. "Wissenschaftliches Handeln ist dann lediglich ein Spezialfall des kommunikativen Handelns, indem eine methodologische Einstellung gegenüber den lebensweltlichen Hintergrundannahmen eingenommen wird." (v. Schomberg, 1995b, 93) Diese Annahme scheint berechtigt, hat doch Habermas davon gesprochen, daß wir Wissen nur operativ bearbeiten könnten, "wenn es eine symbolisch greifbare Gestalt annimmt. (Auf der reflexiven Ebenen der Wissenschaft, wo es um die Aufstellung von Theorien geht, ist die Notwendigkeit der sprachlichen, gegebenenfalls der formalsprachlichen Organisation des Wissens offensichtlich.)" (Habermas, 1999, 108; Klammern i. O.). Das wissenschaftliche Wissen bleibt fallibel und gilt deshalb nicht universell als wahr sondern kontextuell als akzeptabel. Die 'platonische' Natur wissenschaftlichen Wissens impliziert aufgrund der prinzipiellen Fallibilität, "die Rationalität eines Urteils nicht dessen Wahrheit, sondern nur seine begründete Akzeptabilität in einem gegebenen Kontext." (ebd., 107 f) Rational ist es somit, wenn eine Theorie oder Hypothese im Rechtfertigungskontext der Wissenschaften aus guten Gründen akzeptiert werden kann.

Habermas trennt hier weiterhin, wie schon in der Theorie kommunikativen Handelns (1981, I, 25), zwischen Erkenntnis- und Wahrheitstheorie. Eine Beziehung zwischen Wahrheitstheorie und Erkenntnistheorie besteht lediglich über die Theorie der Rationalität, der zufolge epistemische Rationalität auf der Kritisierbarkeit von Wahrheitsansprüchen beruht. R. v. Schomberg hat deshalb angenommen, daß Habermas seiner Unterscheidung zwischen Erkenntnisansprüchen (in epistemischen Diskursen) und Wahrheitsansprüchen (in empirisch-theoretischen Diskursen) zustimmen können müßte und einen Dissens zu Habermas nur für den Fall befürchtet, daß dieser Wissenschaft generell als empirisch-theoretischen Diskurs ansehen würde (v. Schomberg, 1995b, 84). Dies scheint jedoch nicht Habermas' Position zu entsprechen: "Der organisierte Fallibilismus 
der Forschung kann den hypothetischen Umgang mit kontroversen Wahrheitsansprüchen auf Dauer stellen, weil er einer vom Handeln entkoppelten Konsensbeschaffung dient." (Habermas, 1999, 255; kursiv im Original) Diese handlungsentlastete, symbolische Konsensbildung treffe nur für die organisierte Forschung zu, nicht für die Lebenswelt als Ganze. Trifft sie aber überhaupt für die wissenschaftliche Forschung zu? Denn Naturwissenschaften mit experimentellen Interventionshandlungen tragen mittlerweile die Bürde, potentiell irreversible Prozesse zu initiieren. $^{25}$ In dem weiter oben zitierten Kurzschluß von Experiment und wissenschaftlichem Fortschritt übergeht Habermas die Möglichkeit der argumentativen Konstitution von epistemologischer Unsicherheit im Forschungsprozeß. Indem Habermas abduktive Schlüsse an die Systematik des Experiments bindet, schreibt er die soziale Konstitution der Natur den experimentellen Naturwissenschaften zu.

Im Vergleich zu Habermas spricht für v. Schombergs' argumentationstheoretischen Ansatz, daß dieser klar auf ein wissenschaftstheoretisches Problem mit großer praktischer Bedeutung ausgerichtet ist. So hat v. Schomberg die theoretischen Auseinandersetzungen zwischen Genetik und Evolutionstheorie als epistemischen Diskurses rekonstruiert (vgl. v. Schomberg, 1995b, 97 ff). Diese argumentationstheoretische Herangehensweise wird der Problematik von Irreversibilität - im phänomenologischen Sinne - insofern wissenschaftstheoretisch gerecht, als daß der Ansatz die nur prospektive Kohärenz des biowissenschaftlichen Diskurses zwischen Genetik und Ökologie als epistemische Unsicherheit kennzeichnet. Er assimiliert nicht die Argumentation über Theorien der symbolischen Repräsentation von Natur an experimentelle (Interventions-)Handlungen in die Natur. Die Argumentation des wissenschaftlichen Diskurses ist dabei sinnbezogen (Apel, 1987, Habermas, 1984, 127 ff v. Schomberg, 1995b, 29 ff). Sie beruht auf Problemen und nicht auf Prämissen, daß heißt sie ist immer in einen sprachlichen Kontext eingebunden. "[Z]u Problemen werden Sachverhalte erst im Kontext bestimmter kategorialer Reflexionshorizonte gemacht." (Kopperschmidt, 2000, 113) Eine Argumentationstheorie der Wissenschaft ließe sich eventuell auch für die Wissenschaftsfolgenabschätzung fruchtbar machen. Habermas wahrheitstheoretischer Rekurs auf die pragmatische Dimension der Verwendung des Wahrheitsprädikats berührt hingegen das Problem des Experiments nicht erkennbar.

Es bleibt darauf zu verweisen, daß im ökologischen Kontext prognostische Unsicherheit auch im Rahmen theoretisch-empirischer Diskurse fortbesteht. Diese steht prinzipiell im Einklang mit kausalen Naturgesetzen. Sie beruht auf der Offenheit von Naturprozessen. (Insofern könnte im gegebenen Kontext auch von ökologischer Unsicherheit gesprochen werden.) Diese Offenheit beinhaltet chaotisches Systemverhalten. Bei prognostischer Unsicherheit stehen nicht die einer begrenzten Vorhersage zugrundeliegenden Naturgesetze und empirischen Regelmäßigkeiten zur

${ }^{25}$ Als erste Philosophin hat meines Wissens Hannah Arendt den Begriff der Irreversibilität zur Charakterisierung menschlichen Handelns in bezug zur Natur benutzt. Während die Irreversibilität von Handlungen des Menschen im interpersonalen Kontext durch die Fähigkeit zu Vergeben bewältigt werden könne, versage diese Fähigkeit bei moderner Wissenschaft und Technik: "Modern natural science and technology, which no longer observe or take material from or imitate processes of nature but seem actually to act into it, seem, by the same token, to have carried irreversibility and human unpredictability into the natural realm, where no remedy can be found to undo what has been done." (Arendt, 1958, 238) 
Diskussion. Vielmehr kann Wissen auch unter diesen Bedingungen, die mit 'Wahrheit' verbunden sind, nicht notwendig vor nicht-intendierten ökologischen Folgen bewahren. Kontingenz wäre auch in einer vollständig naturwissenschaftlich beschriebenen Natur Bestandteil von instrumentellen Handlungen.

\subsubsection{Rationalität und Reflexivität}

In der Theorie des kommunikativen Handelns hat Habermas die Hoffnung gehegt, den Wechsel zwischen Beobachter- und Teilnehmerperspektive weitestgehend als soziologischmethodologisches Problem zu lösen, nur ergänzt durch philosophisch-rationalitätstheoretische Klärungsversuche. Habermas verbindet die Teilnehmerperspektive mit der verstehenden sozialwissenschaftlichen Methode des symbolischen Interaktionismus während er die Beobachterperspektive den Naturwissenschaften und der Systemtheorie zuschreibt. Er spricht sowohl von System- als auch von Handlungsrationalität (und bezeichnet auch Lebensformen und Wertsphären als rational.) Dabei wird der Zusammenhang zum Begriff der Rationalität nicht vollständig geklärt. Auch ist festzuhalten, daß Habermas den Dualismus zwischen Systemen und Lebenswelt nie systemtheoretisch und nach 1986 auch nicht mehr handlungstheoretisch aufzulösen versucht hat. Gleichwohl besteht ein enger Zusammenhang zwischen Rationalität und Reflexivität. Habermas hat u.a. in der später ausgearbeiteten Diskursethik wieder auf Rationalität verweisen und schließlich 1999 eine philosophische Rationalitätstheorie vorgelegt.

Die Responsivität von Gesellschaften auf Umweltkatastrophen - im Sinne einer reflexartigen Reaktionen - kann zweifellos nicht als Maßstabfür eine Rationalitätstheorie dienen. Sie könnte ebenso gut für einen u.U. erst ex-post so zu beurteilenden irrationalen Naturalismus erster Ordnung stehen. Zwar ist es, da ökologische Folgen sowohl notwendig als auch kontingent sind, unmöglich, die Folgen anthropogener Interventionshandlungen in der Natur vollständig zu antizipieren. Doch können intervenierende Handlungen auch nicht vermieden werden, da alle menschlichen Handlungen immer - in unterschiedlichen Maßen - in bestehende Natur intervenieren. Das Spannungsverhältnis läßt sich aber auf den Zusammenhang zwischen Wissenschaftstheorie und Wissenssoziologie übertragen wie dies bereits I. Stengers (1997) unternommen hat und wie es hier mit v. Schomberg argumentationstheoreitsch weitergeführt wurde.

Der Begriff der Unbestimmtheit verweist in diesem Sinne auf Notwendigkeit und spezifisches und unspezifisches Nichtwissen auf die mitlaufende Kontingenz. Alle drei Begriffe wiederum zeigen die Bedeutung der Wissenschaften für eine rationale, reflexive Gesellschaftsform auf. Für eine nachhaltige Entwicklung ist Wissenschaft vor allem in folgenden Aspekten Bedingung für Reflexivität (vgl. dazu Bechmann, Grunwald, 2002, 115 ff):

- Naturwissenschaften sind für das Erkennen von Umweltproblemen unabdingbar. Es bedarf für die gesellschaftliche Umweltbeobachtung naturwissenschaftlich-empirischer Forschung. 
- Um natürliche Prozesse in offenen Systemen evaluieren zu können, werden Simulationen und Modellierungen benötigt, die eine begrenzte Extrapolation natürlicher Prozesse in die Zukunft ermöglichen.

- Umweltveränderungen mit identifiziertem anthropogenen Ursprung gehen über rein instrumentelle naturwissenschaftliche Simulationen und Modellierungen hinaus. Zur Identifizierung von Handlungsoptionen müssen Szenarien entwickelt werden, die zumeist einen Rahmen (worst/best case) für zukünftige gesellschaftliche Entwicklungen abzustecken versuchen.

- Bei der Entwicklung von Nachhaltigkeitskriterien (Indikatoren) wird der Einbezug von sozialwissenschaftlich-ökonomischem Wissen zwingend erforderlich, um Handlungsoptionen zu finden. Dies beinhaltet eine normative Dimension.

Für das Monitoring der faktischen sozial-ökologischen Entwicklung in der Zeit sind wiederum Natur- und Sozialwissenschaften erforderlich. Gegebenenfalls erweisen sich Indikatoren als unzureichend und erfordern naturwissenschaftliches Lernen. Ebenso können sich institutionelle Pfade/Indikatoren als nicht-nachhaltig erweisen und dann soziale Lernprozesse nahelegen, die befolgt werden können. Nur wenn sowohl die natur- als auch die sozialwissenschaftliche Dimension bewältigt wird, erscheint eine nachhaltige Entwicklung möglich, die koevolutionäre Notwendigkeit und Kontingenz reflexiv vergegenwärtigt.

Dieses Wissenschaftsprogramm erfordert, wie bereits dargelegt wurde (s. S. $51 \mathrm{ff}$ ), zwar keine post-normalen Wissenschaften, wohl aber reflexive, nicht-funktionale Wissenschaften. Im strikten Gegensatz zur Systemtheorie hat Habermas immer wieder eine solches nicht-funktionales (wie auch ein nicht-positivistisches) Verständnis von Wissenschaft eingefordert. Der Philosophie kommt dabei eine begrenzte Rolle als Reflexionstheorie von Wissenschaftstheorie und Wissenssoziologie zu. Als nachmetaphysische Philosophie ist sie gekennzeichnet (vgl. Habermas, 1988, 41 ff):

- durch einen Typus der Verfahrensrationalität, wie er sich in den Naturwissenschaften entwickelt und über den Formalismus sowohl in der Moral, als auch der Rechtstheorie Einzug gehalten hat,

- durch die historischen Wissenschaften, welche die Endlichkeit gegenüber einer idealistischen, nichtsituierten Vernunft herausarbeiten,

- durch den Paradigmenwechsel von der Bewußtseins- zur Sprachphilosophie,

- und durch die Umkehr des Verhältnisses zwischen Theorie und Praxis, welches in der Moderne über das Konzept der Lebenswelt den klassischen Vorrang der vita contemplativa bestreitet.

Verfahrensrationalität in der Philosophie impliziert, daß die 'Vernünftigkeit der Inhalte' zu einer 'Gültigkeit der Resultate' schrumpft. Die Vernünftigkeit von Prozeduren soll für die Resultate verbürgen: Die empirischen und theoretischen Wissenschaften entwickeln im Forschungsprozeß gültige Erkenntnisse, während moralisch-praktische Probleme im politisch-administrativen System behandelt werden. Doch garantiert die Verfahrensrationalität in der konventionellen Sichtweise 
keine vorgängige Einheit der Erscheinungen. Im Gegenteil, zwischen den Natur- und den Geisteswissenschaften kommt es im 18. Jahrhundert zur Aufspaltung der Objektbereiche: Natur ist danach über die Beobachter-, Gesellschaft über die Teilnehmerperspektive zugänglich. Über diese Aufspaltung der Wissenschaften spannt sich bei Habermas jedoch die Lebenswelt. Diese wird zwar durch kommunikatives Handeln reproduziert, sie kann aber den methodologischen Wechsel zwischen Beobachter- und Teilnehmerperspektive - wie gezeigt - nicht vollends hinter sich lassen. Auch kommt dem Wissenschaftler gegenüber den Laien noch ein schwacher Geltungsprimat zu: Als verstehender Sozialwissenschaftler kann er die Strukturen der Lebenswelt noch narrativ vergegenständlichen. Der methodologische Wechsel zwischen Beobachter- und Teilnehmerperspektive wird so, ähnlich wie in der Systemtheorie, vor allem in eine zeitliche Differenz verwandelt. In diesem Sinne kann man davon sprechen, daß der die Vergangenheit beobachtende Sozialwissenschaftler die Strukturen der Lebenswelt versteht. Doch die Vergangenheit ist kein Paradies, aus dem man nicht vertrieben werden könnte: Habermas gewinnt aus ihr den kritischen Gehalt seiner Theorie - ohne einem Historizismus zu verfallen. Ob er diese damit allerdings als kritische Theorie etablieren kann, soll hier offen bleiben.

Im stofflich-energetischen Kontext von Nachhaltigkeit interessiert vielmehr, ob die wissenschaftstheoretische Zurückweisung der naturwissenschaftlichen Beobachtungsperspektive in der Diskurstheorie der Nachhaltigkeitsforschung den Zugang zu kybernetisch-systemtheoretischen Methoden verbaut. Sie tut dies nicht, obschon die nachdrückliche Absage Habermas an systemtheoretische Erklärungen zunächst Anderes vermuten lassen könnte. Die Theorie des kommunikativen Handelns beharrt lediglich auf der Normativität von so gewonnenen Szenarien und Indikatoren. Sie verweist auch nachdrücklich auf die Unbestimmtheit bzw. die Bedeutung von Notwendigkeit und Kontingenz in der Koevolution von Gesellschaft und Natur und damit auf die mögliche Revisionsbedürftigkeit naturwissenschaftlicher Forschung.

Bedenken gegen eine mangelnde Eignung der Theorie des kommunikativen Handelns sind vielmehr im biologischen Kontext von Nachhaltigkeit (genetisch modifizierte, freigesetzte Organismen) angebracht. Obschon zwar Habermas philosophisch das epistemologische Projekt der Moderne verabschiedet und wissenschaftstheoretisch die Beobachterperspektive eingeschränkt hat, erscheinen doch letztlich immer die Wissenschaften als Quelle von Relevanz. Doch Habermas' Einfassung der Wissenschaften in den Brunnen epistemisch-instrumenteller Rationalität ermöglicht naturalistische Fehlhandlungen. Der theoretische Kurzschluß von Sprach- und Interventionshandlungen kann praktisch irreversible Prozesse induzieren, deren Reversibilität das Fallibilismusprinzip nicht sicherstellen kann. Ebenso ist die Vorgängigkeit des Verstehens so nicht mehr gewahrt, so daß die lebensweltliche, emanzipatorische Bindung der Wissenschaften verloren geht. Es ist die Funktionalisierung der Wissenschaften zu erwarten, wenn instrumentelle Handlungen, deren Eingriffstiefe potentiell bis ans Ende der Evolution reicht, theoretisch abgezeichnet werden. Die Theorie des kommunikativen Handelns kann die Spannungen zwischen Wissenschaftstheorie und Wissenssoziologie nur dann reflexiv auflösen, wenn v. Schombergs 
Argumentationstheorie Berücksichtigung findet. Dies legt die Reformulierung von Habermas' Begriff epistemischer Rationalität nahe.

Darüber hinaus ermöglicht Habermas' bestehende Rationalitätstheorie aber durchaus reflexives soziales Handeln. Dieses besteht dem Ansatz nach insbesondere in der Unterscheidung zwischen teleologischer und diskursiver Rationalität sowie auch in den Unterschieden zwischen diskursiver und argumentativer Rationalität. Reflexives soziales Handeln wird durch die Differenz ermöglicht, die zu setzen kommunikative Rationalität gestattet. Kommunikative Rationalität ist durch in sie eingebettete Argumentation die eigentliche Reflexi 
nicht genügen, teilsystemischen Rationalitäten zu folgen, die nachgerade atopisch funktionieren (Willke). Systemische Rationalität bedarf der kritischen kommunikativen Reflexion und konstruktiven Imagination. Am Beispiel des Rechtssystems verdeutlicht: Habermas greift die Differenz zwischen Rechtssoziologie und Rechtstheorie auf und erklärt sie zu einer theorieinternen Differenz, wobei er die erreichte Ausdifferenzierung der Gesellschaft bestätigt. Er versieht jedoch Rechtsgeltung mit dem Anspruch auf Begründung und stellt sie nicht, wie die Systemtheorie des Rechts, als naiven Geltungsglauben bloß (Kieserling, 2000, 32 f). Das Recht führt so die soziale Integration der Gesellschaft auf reflexiver, d.h. systemischer Ebene fort (Habermas, 1992, 386 f).

Habermas beharrt auf der Wahrheitsfähigkeit praktischer Fragen. Die diskursive Rechtstheorie steht so einerseits in Verbindung zu Wissenschaft und Wissenschaftstheorie andererseits auch zur Lebenswelt bzw. zur solidarischen Zivilgesellschaft: Denn in der Gestalt verfassungsrechtlicher Institutionen haben Organisationen und Institutionen "den reflexiven Sinn von gegensteuernden Vorkehrungen gegen eine gesellschaftliche Komplexität, die die normativ gehaltvollen Präsuppositionen einer rechtsstaatlichen Praxis unterwandert. Diese Art der komplexitätserhaltenden Gegensteuerung ist bereits im Gegenspiel der informellen öffentlichen Meinung mit der institutionalisierten, durch Verfahren regulierten Meinungs- und Willensbildung am Werke." (Habermas, 1992, 397; Hervorhebung FS) Die Öffentlichkeit wird zur Gegeninstanz der Komplexität ausdifferenzierter Systeme und deren Selbstbezüglichkeit. Habermas hat einer solchen, normativ gesättigten Öffentlichkeit vor allem rechtstheoretisch/-soziologisch zugearbeitet. Mit Schmalz-Bruns ist aber auch darauf hinzuwirken, "daß nicht nur eine rationalitätssteigernde Herstellung der Offenheit und Öffentlichkeit von Entscheidungen ins Auge gefaßt wird, sondern daß[...] Öffentlichkeit zum privilegierten Ort der Vermittlung institutioneller Reflexivität wird." (Schmalz-Bruns, 1995a, 35) Denn Politik ist zuvorderst Praxis. Im Fall der Demokratie eine normativ auf Gleichheit beruhende Praxis von Laien, die im Kontrast zum Expertentum von Systemen steht. Ob dies immer eine kritischere Öffentlichkeit im Vergleich zu kritischen Experten impliziert, wäre empirisch zu bestimmen, ist hier aber nicht Gegenstand der Diskussion. Gleichwohl ist klar, daß Experten sich der Normativität demokratischer Gleichheit stellen müssen.

Hinsichtlich von Nachhaltigkeit lautet die Frage, wie nachhaltige Entwicklungspfade reflexiv in Systeme eingeschrieben werden können. Daß es sich bei dieser theoretischen Aufgabe der Experten zugleich auch um eine praktische Aufgabe historischen Maßstabs handelt, könnte für den Laien politisch evident erscheinen, ist es jedoch nicht vor dem Hintergrund von Habermas' Wissenschaftstheorie und Systemtheorie. Erst durch die moralische Reflexion auf ihre ethischen Grundlagen sollen moderne Gesellschaften zu Handlungsanweisungen gelangen. Habermas versteht Moral als 'Reflexionstheorie' der Ethik. Über den argumentationstheoretischen Bezug auf Vernunft löst er so die Spannungen zum systemtheoretischen Teil seiner Gesellschaftstheorie weitgehend auf. Doch letztlich führt die Diskursethik noch die - wie dargelegt - zweifelhaften rationalitätstheoretischen Annahmen fort, welche sich gegenüber dem reflexiven Zusammenspiel von Wissenschaftstheorie und -soziologie nicht eindeutig verordnen ließen. Deshalb, aber auch aus systematischen Gründen, ist im folgenden Abschnitt auf praktische Vernunft einzugehen. Erst in 
den beiden darauffolgenden Kapiteln wird die systemimmanente ökologische Kritik für die diskurstheoretische Version von Nachhaltigkeit aufgegriffen, um Ansatzpunkte für die nachhaltige Gestaltung der Interdependenz zwischen ökonomischem und politisch-administrativem System zu gewinnen.

\subsection{Diskurstheorie und praktische Vernunft}

Praktische Vernunft bezieht sich auf Handlungen, Wünsche und Ziel oder Normen (Gosepath, 1999, 7 ff). Sie rechtfertigt Handlungen durch Gründe und motiviert durch Einsicht. Praktische Vernunft ist Motiv und Verpflichtung zugleich. Wie bereits an verschiedenen Stellen deutlich geworden sein dürfte, steht Habermas' Konzept praktischer Vernunft in der Tradition des Pragmatismus. Der Pragmatismus stellt 'Probleme' in den Mittelpunkt, die unmittelbar aus Handlungssituationen erwachsen und deshalb immer etwas Objektivierendes besitzen. Für gewöhnlich nimmt das kommunikativ vermittelte, lebensweltliche Handeln seinen alltäglichen Lauf. Die Ansprüche auf Verständlichkeit, Wahrheit, Wahrhaftigkeit und Richtigkeit gelten, d. h. Handeln ist normativ - unter Anspruch auf Richtigkeit - koordiniert. Im Modus einverständnisorientierten Handelns sind normative Geltungsansprüche unproblematisch. Soziale Dynamiken, Koevolution von Mensch und Natur, Emergenz des Metabolismus zwischen sozialen Systemen und der Natur, Unfälle, Gefährdungen zweiter Ordnung etc. können die lebensweltliche Gewißheit jedoch erschüttern und dann die Neuformulierung von Normen erfordern.

Ausgangspunkt praktischer Vernunft ist der Bezug auf den Willen eines Aktors, wobei die Tatsache, daß alternative Handlungssituationen unterschiedliche Formen der praktischen Vernunft nahelegen können, bei Habermas auch zu verschiedenen Konzepten des Willens führt. In Abhängigkeit zu den jeweiligen Problemstellungen tritt die praktische Vernunft entweder in pragmatischer, ethischer oder moralischer Gestalt auf. Habermas ordnet den drei Gestalten praktischer Vernunft entsprechende Diskurs- bzw. Argumentationstypen zu, wovon lediglich der moralische Diskurs die weitreichende Anforderung nach unparteilicher Universalisierbarkeit erfüllen muß. Für die anderen beiden Diskurstypen gilt nur, daß sie intersubjektiv nachvollzogen werden können müssen. Habermas zufolge ist ein philosophischer Metadiskurs zur Wahrung der Einheit praktischer Vernunft nicht notwendig. Soziale Reflexivität entsteht nicht durch einen Metadiskurs. Die Einheit der praktischen Vernunft sei trotz ihres Auseinandertretens in ihre pragmatische, ihre ethische und ihre moralische Gestalt gewährleistet. Kants Ansatz, die Einheit des transzendentalen Bewußtseins in der Einheit der moralischen Argumentation zu wahren, sei nicht mehr möglich. Vielmehr müsse sich, so Habermas, die diskursive Moraltheorie bescheiden und auf die Rechtsphilosophie verweisen, denn für die Universalpragmatik "verlagert sich das Problem der Verständigung zwischen Parteien, deren Willen und Interessen aufeinanderstoßen, auf die Ebene der institutionalisierten Verfahren und Kommunikationsvraussetzungen für real durchzuführende Argumentationen und Verhandlungen." (Habermas, 1991, 117) 
In pragmatischen Diskursen werden Ziele und Mittel zu Bewältigung von Handlungssituationen rational festgelegt. Individuen verfügen über Präferenzen, die sie strategisch zu verwirklichen suchen. Pragmatische Imperative setzen Ursachen und Wirkungen nach Wertpräferenzen und Zwecksetzungen in Relation zueinander. Pragmatische Diskurse bleiben auf ihre mögliche Verwendung bezogen. Den Willen von Aktoren formen sie nur extern über subjektive Zwecksetzungen und Präferenzen als ein relatives Sollen. Genesis und Geltung von Zwecken sind nicht miteinander verbunden; die Gültigkeit von strategischen Empfehlungen beruht letztlich auf dem empirischen Wissen, das sie stützt. Es gibt keinen internen Bezug zwischen Vernunft und Willen, dieser ist vielmehr kontingent.

Ethische Diskurse behandeln Fragen des Guten. Das dabei berührte Selbstverständnis von Personen geht über ein nur an Präferenzen orientiertes Personenkonzept hinaus. Fragen des Guten beinhalten grundlegende Wertentscheidungen, welche die Identität von Personen betreffen. Dabei ist die eigene Identität sowohl von normativen Ich-Idealen als auch von der lebensgeschichtlichen Genese des Ichs bestimmt. In performativer Einstellung ergibt sich für ein Individuum die Perspektive, Teil einer Gruppe zu sein: ich als einer von uns. Ethische Diskurse haben insofern einen Januscharakter, als daß sich bei ihnen Genesis und Geltung nicht voneinander trennen lassen. Ein solcher ethisch-existentieller Diskurs, wie Habermas den ethischen Diskurs auch nennt, setzt bei den Adressaten das Streben nach einem authentischen Leben voraus; er ist auf das vorgängige Telos einer bewußten Lebensführung angewiesen. Damit aber bestimmen sich Vernunft und Wille gegenseitig, wobei der Wille immer in einen lebensgeschichtlichen Kontext eingebettet bleibt. Ethisches Sollen ist weder subjektiv (wie pragmatisches) noch absolut (wie moralisches), sondern soll den Willen an die Vernunft binden und ein gutes Leben ermöglichen.

Moralische Diskurse behandeln, wie dargestellt, ausschließlich den strikt universalen Aspekt der Gerechtigkeit. Nur jene Normen sind gültig, die ein gemeinsames Interesse aller Betroffenen ausdrücken. Als einer gleich allen richtet ein Individuum seinen freien Willen nach selbstgegebenen, universal gültigen moralischen Gesetzen. Dabei bezeichnet Habermas einzig jenen Willen als autonom, der sich vollständig durch moralische Einsicht bestimmen läßt. Das moralische Sollen erlaubt zwar eine universelle Orientierung; es kann aber nur in dem Maße Wirksamkeit erlangen, wie sich die Motivationskraft guter Gründe gegen die Macht anderer Motive durchsetzen kann. Ein schwacher Wille ist mitunter nur noch ein 'guter Wille': moralische Einsicht bewirkt nicht auch schon autonomes Handeln. Dennoch sind moralische Gebote unabhängig davon, ob ein Individuum die Kraft aufbringt, gemäß moralischen Geboten zu handeln. Genesis und Geltung von moralischen Geboten sind von einander unabhängig, "weil die Grundsätze einer autonom gewordenen Moral einen erkenntnisanalogen Anspruch stellen" (1991, 115). Die Aufspaltung des Willens unter unzumutbaren Bedingungen der Normenbefolgung in einen autonomen und einen empirischen Willen führt zu moralischen Lernprozessen.

Habermas' Konzeption praktischer Vernunft ist nicht leicht innerhalb der Diskurstheorie zu verorten. Gegenüber dem Handlungs- und dem Rationalitätsmodell der Theorie kommunikativen Handelns beansprucht Habermas bei seiner Dreiteilung praktischer Vernunft die pragmatische 
Tradition ausgesprochen stark. Praktische Vernunft ist - im weitesten Sinn (der pragmatischen Tradition) - auf 'politische' Probleme zugeschnitten.

Pragmatische Diskurse verweisen, sobald das eigene mit dem fremden Interesse in Einklang gebracht werden muß, auf die Notwendigkeit von Kompromissen. In ethisch-politischen Diskursen geht es um die Klärung einer kollektiven Identität, die Raum lassen muß für die Mannigfaltigkeit individueller Lebensentwürfe. Das Problem der Zumutbarkeit moralischer Gebote motiviert zum Übergang von der Moral zum Recht. Und mit der Implementierung von Zielen und Programmen stellen sich schließlich Fragen der Übertragung und der neutralen Verwendung von politischer Macht. (Habermas, 1991, 117)

Habermas' Auffächerung von Diskurstypen der praktischen Vernunft beinhaltet einige Probleme. An erster Stelle ist zu nennen, daß sie ihr Verhältnis zur rationalitätstheoretischen Einteilung von Vernunftaspekten nicht zureichend bestimmt, wie M. Kettner (1995) festgestellt hat. Habermas verbindet Rationalitätsformen und Diskurstypen nicht miteinander, sondern führt sie parallel. Das Verhältnis zwischen der rationalitätstheoretischen Einteilung von Vernunftaspekten und der Einteilung von Problemsortierungsaspekten (Diskurstypen) bleibt theoretisch unbestimmt (vgl. ebd.; Alexy, 1995a, 230). Als aporetisch bezeichnet Kettner sogar Habermas' Überlegungen zur Einheit der Vernunft, da diese weder durch den Willen, der sich mit dem Typus der Fragen ändere, noch durch eine Argumentationstheorie hergestellt werden könne. Die versäumte Ausschöpfung der Argumentationstheorie wirft so auch im Bereich praktischer Vernunft Probleme auf.

Für die Konstruktion der universalpragmatischen Theorie ergeben sich gewisse statische Schwierigkeiten, die in der weiteren Entwicklung der Diskurstheorie immer wieder zum Gegenstand der Kritik geworden sind (vgl. Alexy, 1995a, 109 ff, McCarthy, 1998, 139 f). Habermas' philosophische Entwicklung der Diskurstheorie gingen, wie dargestellt, in Teilbereichen zu Lasten des sozialwissenschaftlichen Programms. Für Habermas' Fassung der praktischen Vernunft spricht in sozialwissenschaftlicher Hinsicht, daß sich mit ihr politischdemokratietheoretische Probleme bei Absehung von möglichen rationalitätstheoretischen Problemen pragmatisch bestimmen lassen, gegen sie, daß das Verhältnis zwischen Demokratie und materieller Politik, nicht mehr näher bestimmbar ist. In der Theorie der deliberativen Demokratie etwa tritt die Frage auf, welche Form von Rationalität im politischen Diskurs wie berücksichtigt werden sollte. Die Diskurstheorie kann hierauf keine Antwort geben (so Gerstenberger, 1997, Schmalz-Bruns, 1995a). Die Bedeutung von Diskurstypen bleibt auch in der für eine nachhaltige Entwicklung wichtigen internationalen Politik unklar. Wohlgemerkt, es handelt sich hierbei nicht um ein Anwendungsproblem von Normen, sondern um eine strukturelle Schwäche der Diskurstheorie, die aber zu beheben sein dürfte. ${ }^{26}$

${ }^{26}$ Diese optimistische Einschätzung beruht darauf, daß Apel (1979, 1988b, 1995, 1996) für die Transzendentalpragmatik eine überzeugende Rationalitätstheorie präsentiert hat. 


\subsubsection{Begründung der universalpragmatischen Diskursethik}

Werden normative Geltungsansprüche in Sprechakten angezweifelt, verlangt die Diskurstheorie das Aussetzen des Handelns und die Durchführung praktischer Diskurse, in denen die konfligierenden normativen Geltungsansprüche argumentativ zu klären sind. Dabei verschiebt sich die Perspektive von der Handlungstheorie des kommunikativen Handeln zur Argumentationslogik des Diskurses (vgl. Kopperschmidt, 2000, 49). Die Logik moralischer Diskurse hat Habermas erst im Anschluß an die Theorie des kommunikativen Handelns ausgearbeitet. Die Diskurstheorie erlangt dadurch den reflexiven Status einer Diskursethik, deren zentraler Gedanke der Konsens aller Betroffenen einer Norm über deren Richtigkeit ist. Sie expliziert allgemein die formalen Argumentationsvoraussetzungen für praktische Diskurse und die Argumentationsregeln moralischer Diskurse im besonderen.

Gegenüber konkurrierenden philosophischen Ethiken wie Utilitarismus, Intuitionismus oder Emotivismus will die Diskursethik in der Nachfolge Kants eine kognitivistische Position verteidigen. Sie hält an 'einer Art von Objektivität' gültiger Normen fest. Sie verfährt nicht volitional, sondern kognitiv. Weder sind Normen nicht-wahrheitsfähiger Ausdruck bloßer Emotionen, noch sind sie strategischer Kalkulation zugänglich, noch ergeben sie sich aus unmittelbaren Evidenzen. Vielmehr unterliegt Ethik als Teil der praktischen Vernunft ebenso Diskursen wie die theoretische Vernunft. Der ethische Anspruch der Diskurstheorie steht oder fällt dann aber damit, "daß (a) normative Geltungsansprüche einen kognitiven Sinn haben und wie Wahrheitsansprüche behandelt werden können, und daß (b) die Begründung von Normen und Geboten die Durchführung eines realen Diskurses verlangt und letztlich nicht monologisch, in der Form einer im Geiste hypothetisch durchgespielten Argumentation möglich ist." (Habermas, 1983, 78) Mit einer solchermaßen kognitivistischen Ethik kann dann die für das Politische relevante Idee der Unparteilichkeit begründet werden.

Der Diskursethik zufolge darf eine Norm nur dann Geltung beanspruchen, wenn alle von ihr möglicherweise Betroffenen als Teilnehmer eines praktischen Diskurses Einverständnis darüber erzielen (oder erzielen würden), daß diese Norm gilt. Dies setzt voraus, daß bereits die Wahl von Normen begründet werden kann. Denn die argumentative Rede muß - verstanden als normengenerierender Prozeß - unwahrscheinliche Voraussetzungen zur Argumentation erfüllen. So muß die Sprechsituation unter bestimmten idealen Bedingungen stattfinden, ${ }^{27}$ die selber keine normativen, sondern nur pragmatische Gesichtspunkte enthalten. Habermas hat in Anschluß an R. Alexy (1987) nur solche Regeln als Diskursregeln zugelassen, die:

\footnotetext{
27 Habermas hatte in Wahrheitstheorien (1972, nun in: ders., 1984, 127 ff) noch eine ideale Sprechsituation expliziert, deren Voraussetzungen jedoch später als unzureichend verworfen. Demzufolge begründet die Theorie des kommunikativen Handelns nicht die Annahme einer idealen Sprechsituation!
} 
1. die Inklusion ausnahmslos aller Subjekte in den Kreis der potentiellen Teilnehmer garantieren; sofern die Subjekte überhaupt über die Fähigkeit verfügen, an Argumentationen teilzunehmen;

2. allen Teilnehmern gleiche Chancen sichern, Beiträge zur Argumentation zu leisten und eigene Argumente zur Geltung zu bringen;

3. Kommunikationsbedingungen einfordern, unter denen sowohl das Recht auf universellen Zugang zum, wie das Recht auf chancengleiche Teilnahme am Diskurs ohne eine noch so subtile und verschleierte Repression (und daher gleichmäßig) wahrgenommen werden können.

Diese Regeln sind jedoch nicht, wie bei Alexy, als definitorische Idealformen von Kommunikation zu verstehen, sondern als notwendige Präsuppositionen, die nicht bestritten werden können, ohne daß sich der Bestreiter nicht unvermeidlich in performative Widersprüche verwickelt. Ebenso wendet Habermas gegen Alexy ein, daß nicht alle real durchgeführten Diskurse diesen Regeln genügen würden, daß aber 'Regeln' auch nicht im Sinne von definierten 'Spielregeln' verstanden werden könnten, die Diskurse erst konstituierten. "Während [beispielsweise] Schachregeln eine faktische Spielpraxis bestimmen, sind Diskursregeln nur eine Form der Darstellung von stillschweigend vorgenommenen und intuitiv gewußten pragmatischen Voraussetzungen einer ausgezeichneten Redepraxis." (1983, 101)

Habermas unternimmt deshalb eine Unterscheidung in ein Diskursprinzip $>\mathrm{D}<$ und ein moraltheoretisches Universalisierungsprinzip $>\mathrm{U}<$. Letzteres ist einziger Grundsatz der Verallgemeinerung, gilt als Argumentationsregel und gehört, im Gegensatz $\mathrm{zu}>\mathrm{D}<$, zur Logik des praktischen Diskurses. Das Diskursprinzip $>\mathrm{D}<$ spricht dagegen nur die Grundvorstellung einer Moraltheorie überhaupt aus, gehört aber nicht zur Argumentationslogik. Diskursprinzip und Universalisierungsprinzip lauten wie folgt:

Aus den genannten Diskursregeln ergibt sich [...], daß eine strittige Norm unter den Teilnehmern eines praktischen Diskurses Zustimmung nur finden kann, wenn $>\mathrm{U}<$ gilt, daß heißt, - wenn die Folgen und Nebenwirkungen, die sich aus einer allgemeinen Befolgung der strittigen Normen für die Befriedigung der Interessen eines jeden Einzelnen voraussichtlich ergeben, von allen zwanglos akzeptiert werden können.

Ist nun aber gezeigt, wie der Universalisierungsgrundsatz auf dem Wege der transzendentalpragmatischen Ableitung aus Argumentationsvoraussetzungen begründet werden kann, kann die Diskursethik selbst auf den sparsamen Grundsatz $>\mathrm{D}<$ gebracht werden,

- daß nur die Normen Geltung beanspruchen dürfen, welche die Zustimmung aller Betroffenen als Teilnehmer eines praktischen Diskurses finden (oder finden könnten). (Habermas, 1983, 103; Hervorhebungen i. O.)

Derart ist die Diskurstheorie von Habermas als Diskursethik begründet worden. Die Begründung vermeidet es, Argumentationsregeln mit Argumentationsinhalten und Argumentationsvoraussetzungen kurzzuschließen. $>\mathrm{D}<$ ist die Zielbehauptung, die Habermas als Moraltheoretiker zu begründen versucht. Moralprinzipien selbst sind keine Grundsätze einer philosophischen Ethik, sondern Ergebnis des praktischen Moraldiskurses. Und an diesem kann der Moraltheoretiker nur als 
ein Partizipant unter anderen teilnehmen. ${ }^{28}$ "Der praktische Diskurs ist ein Verfahren nicht zur Erzeugung gerechtfertigter Normen, sondern zur Prüfung der Gültigkeit hypothetisch erwogener Normen." (Habermas, 1983, 132) Das Universalisierungsprinzip $>U<$ als Argumentationsregel für praktische Diskurse lasse sich, so wendet Habermas gegen die Transzendentalpragmatik ein, nicht im Sinne einer 'strengen' Begründung verstehen. Die gewählte Begründung der Universalisierungsregel sei zwar selektiv, wie Habermas einräumt, aber auch formal und präjudiziere damit keine Inhalte, wenngleich es durchaus bestimmte Gesichtspunkte ausschließe. Die Diskursethik versuche zu zeigen, daß es zu der dargestellten Art der (moralischen) Argumentation keine Alternative gibt.

Die von Habermas vorgetragene Begründungsstruktur impliziert, daß die Diskursethik auf eine ihr entgegenkommende Kognitionswissenschaften angewiesen ist, durch die sie indirekt bestätigt werden muß. Eine derartige Bestätigung erfährt die Diskursethik durch Kohlbergs Theorie der Moralentwicklung. Mit der Theorie L. Kohlbergs teilt die Diskursethik den Kognitivismus, den Universalismus und schließlich den Formalismus. Überdies beziehen sich beide Theorien auf einen idealen Rollentauschs ('ideal role-taking', G. H. Mead), der sich in der Universalpragmatik im Diskursprinzip $>\mathrm{D}<$ ausdrückt. "Der transzendentale Begründungsmodus entspricht der Einbettung des praktischen Diskurses in Zusammenhänge kommunikativen Handelns; insofern verweist die Diskursethik (und ist selber angewiesen) auf eine Theorie des kommunikativen Handelns." (1983, 141) Denn diese ist es, die unter Rückgriff auf Kohlbergs kognitivistische Moralpsychologie die Stufen des moralischen Bewußtseins rekonstruiert. Der Übergang vom normengeleiteten Handeln zum normenprüfenden Diskurs soll dabei allen Stufen der Moralentwicklung bei Kohlberg entsprechen.

Habermas verwendet die Grundbegriffe kommunikativen Handelns 'soziale Welt' und 'normengeleitete Interaktion', um Kohlbergs Moralstufen über verschiedene Sozialperspektiven auf die in der Theorie kommunikativen Handelns entwickelten Stufen der Interaktion zurückzuführen. Dabei stellt sich erst auf der sogenannten postkonventionellen Stufe der Interaktion jenes normenregulierte Handeln ein, bei dem sich Handelnde nur noch an diskursiv geprüften Geltungsansprüchen orientieren. Der zugrundeliegende 'moralische Gesichtspunkt' entspringe der in das verständigungsorientierte Handeln eingebauten Reziprozität einer im Prinzip unbegrenzten Kommunikationsgemeinschaft. Die Diskursregeln des praktischen Diskurses geben mit dem Gerechtigkeitsprinzip eine Richtlinie für ethisches Handeln vor ohne dies zu determinieren.

Allerdings dürfen die Kommunikationsvoraussetzungen (mit ihrem 'normativen' Gehalt) nicht an den verpflichtenden Gehalt von Interaktionsnormen angeglichen werden. Habermas spricht davon, daß die allgemeinen pragmatischen Voraussetzungen, die alle an Argumentationen Teilnehmenden stets machen müßten, lediglich 'den Charakter einer transzendentalen Nötigung' hätten (Habermas, 1991, 132). "Kommunikationsvoraussetzungen haben nämlich auch dann keinen regulativen Sinn, wenn sie idealisierend über die tatsächlich erfüllten Bedingungen hinausschießen. Sie konstituieren

${ }^{28}$ Vgl. Habermas, 1983, 9 ff; ähnlich auch: ders., 1983, 184. 
vielmehr als vorgreifende Unterstellungen eine Praxis, die ohne sie nicht funktionieren oder mindestens zu einer kaschierten Form strategischen Handelns degenerieren würde. Rationalitätsunterstellungen verpflichten nicht zu rationalem Handeln; sie ermöglichen die Praxis, die die Teilnehmer als Argumentation verstehen." (Habermas, 1991, 133) In der Folge dieses Bedeutungswandels hat Habermas das Verhältnis zwischen $>\mathrm{U}<$ und $>\mathrm{D}<$ umgekehrt. Leitete sich zunächst $>\mathrm{D}<$ aus $>\mathrm{U}<\mathrm{ab}$, so bezieht sich seit Faktizität und Geltung das Diskursprinzip explizit auf allgemeine Handlungsnormen, die in moralischer Hinsicht durch die Universalisierungsregel operationalisiert werden können. Dies ist auch für Beratungen des politischen Gesetzgebers oder für juristische Diskurse möglich (Habermas, 1992, 140; ders., 1996, 64). Das neu formuliert $>\mathrm{D}<$ kann nun auch unabhängig von $>\mathrm{U}<$ für Recht und Politik operationalisiert werden. Es muß demzufolge eigenständig begründet werden (vgl. dazu Apel, 1998, 727 ff). Für den Übergang von $>\mathrm{D}<\mathrm{zu}>\mathrm{U}<$ werden dann zusätzliche Prämissen benötigt.

N. Gottschalk-Mazouz hält zwei Lesenarten von $>\mathrm{D}<$ und $>\mathrm{U}<$ für möglich, die beide auf unterschiedliche Art zur verantwortungsvollen Anwendung von Normen in der Praxis führen sollen: "(1) D ist zunächst nur eine leere Formel, die moralischen Sinn erst durch eine Erläuterung qua U erhält. Ohne U könnten wir D nicht, oder jedenfalls nicht als moralisch, verstehen. Oder (2), wir können zwar D bereits als einen diskursethischen Grundsatz voll verstehen, ihn aber ohne U nicht anwenden." (2002, 89). Im ersten Fall stünde $>\mathrm{U}<$ gegenüber $>\mathrm{D}<$ in einem Explikationsverhältnis, im zweiten würde $>\mathrm{U}<$ konkrete Zielvorgaben und Methoden zur Prüfung moralischer Normen vorgeben. Beide Lesarten schlössen einander nicht aus, sie setzten aber unterschiedliche Akzente.

Die von Gottschalk-Mazouz vorgeschlagene zweite Lesart bezieht sich auf K. Günthers (1988) methodologische Ausarbeitung der Anwendung des Diskurs- und Universalisierungsprinzips. Günther hat den Begründungsdiskursen von Normen Anwendungsdiskurse zur Seite gestellt, in denen in realen Situationen unparteilich die Einschlägigkeit von Normen zu prüfen sei und mögliche Normenkollisionen behandelt werden müßten. In Anwendungsdiskursen würden alle Merkmale einer konkreten Anwendungssituation mit denjenigen Merkmalen verglichen, die Normen für ihre Anwendung in Situationen benötigen. Begründungsdiskurse würden demgegenüber hypothetische Situationen voraussetzen und nur in einer extensionalen Interpretation des Universalisierungsprinzips schon alle zukünftig möglichen Normenkollisionen einschließen (Günther, 1988, 45 ff). Diese Sichtweise hat sich Habermas für seine Rechtstheorie zueigen gemacht.

R. Alexy hat demgegenüber die Anwendung der Diskursethik ohne explizite Trennung von Begründung und Anwendung vorgeschlagen. Die in Sprechakten hervorgehobenen Ansprüche hingen nicht von den Wünschen der Sprecher, sondern von den den Sprechakten zugrundeliegenden pragmatischen 'Regeln' ab (vgl. Alexy, 1978, 165). Diese würden durch $>\mathrm{D}<$ und $>\mathrm{U}<$ als Argumentationsregel expliziert. Wenn Normen bereits bei der Begründung hinreichend speziell - in Hinblick auf alle möglichen Normenkollisionen - formuliert werden würden, würden Normen situationssensitiver, wenngleich auch unter Umständen sehr spezifisch (Alexy, 1995a, 52 ff). 


\subsubsection{Praktische Philosophie und ökologische Krise}

Allgemein ist es notwendig, angesichts der geschichtlich Herausforderung der ökologischen Krise nachdrücklich einen ökologischen Praxisbezug von der Philosophie einzufordern. Es überrascht dabei nicht, "daß die sich abzeichnende Möglichkeit einer Selbstvernichtung der Menschheit eine Provokation für die Philosophie darstellen mußte. Sie ist nicht nur eine bis dahin unerhörte Tatsache, sondern ein Faktum, das den Rahmen des traditionellen Denkens sprengt." (Bayertz, 1995, 51) Diese Provokation richtet sich natürlich ebenso an die Diskursethik.

Zwar hat die ökologische Krise eine breite Reaktion innerhalb der praktischen Philosophie hervorgerufen, doch die in großer Zahl entstandenen ökologischen Ethiken stehen teilweise in einem zweifelhaften Verhältnis zu den Errungenschaften der Aufklärung: Sie basieren in der Mehrzahl zwar auf fundiertem, ökologischem Wissen, und nur vereinzelt verlieren sie sich in Naturphilosophie, doch werden teilweise die philosophischen Begründungverpflichtungen nicht ernst genommen. Über das Ziel des Umweltschutzes wird hinausgeschossen, wenn bereits der Verweis auf den Menschen als Anthropozentrismus gebrandmarkt wird und statt dessen ein Biooder Physiozentrismus eingefordert wird. ${ }^{29}$ Dabei kann vom Menschen weder in erkenntnistheoretischer noch in ethischer Hinsicht abgesehen werden (vgl. Krebs, 1996; v. d. Pfordten, 1996). In beiden Fällen ist einzig der Mensch Träger von Wissen oder Verantwortung.

Baut eine ökologische Ethik auf einer anderen Ethik auf - wird die Ausgangsethik also 'ökologisiert' -,wird deren Struktur relevant: So sind etwa in der Diskursethik Sprecher notwendiger Ausgangspunkt für jede Ökologisierung, was zunächst einmal jede direkte Berücksichtigung nichtsprachfähiger Lebewesen ausschließt. Offensichtlich kann aber die Bezugnahme auf nichtmenschliche Entitäten die Intensität des Anthropozentrismus wesentlich einschränken. Von einer anthropozentrischen Begründung sollte daher nur dann gesprochen werden, wenn sich alle Bezüge ausschließlich auf den Menschen richten, dagegen kann von einer anthroporelationalen Theorie gesprochen werden, wenn sich wenigstens eine Bezugnahme auf den Menschen richtet und schließlich ist von einer transanthroporelationalen Gesamtbegründung (bei einer mehrstufigen Ethik) zu reden, wenn auf der ersten Stufe eine anthroporelationale oder anthropozentrische Begründung erfolgt, aber auf der zweiten Stufe die Bezugnahme nichtanthroporelational ist (v. d. Pfordten, 1996, 18 ff).

Sowohl Habermas als auch Apel haben die Diskursethik so ausgeweitet, daß nicht-diskursfähige Lebewesen ethisch zu berücksichtigen sind. Dabei erkennt Habermas 'moralanaloge' Verpflichtungen gegenüber Tieren an. ${ }^{30}$ Habermas sieht eine derartige Pflicht dadurch gegeben, daß Tiere "uns in der (wenn auch nicht vollständig ausgefüllten) Rolle einer zweiten Person entgegentreten - denen wir in die Augen sehen wie einem Alter Ego. Für viele Tiere, aber wohl

${ }^{29}$ Sinn erhalten viele bio- und physiozentrischen Positionen in erkenntnistheoretischer Hinsicht aber durchaus durch ihren Beitrag zur Dezentrierung bestehender Wissenschaftsprogramme. Sie sind als Steigerung von Wertbindung und Reflexivität zu verstehen, die auf die Seinsbindung von Wissenschaft verweisen (vgl. Krohn, 1998).

30 Habermas hatte noch in den Vorstudien $(1984,517)$ die Ausdehnung von Moral auf Tiere prinzipiell abgelehnt. 
nicht für Pflanzen gilt, daß wir ihnen gegenüber eine performative Einstellung einnehmen können." (Habermas, 1991, 224) Die moralanaloge Pflichten gegenüber Tieren sind deshalb Pflichten, die "in den Voraussetzungen kommunikativen Handelns ihre Basis haben." (ebd., 225) Dagegen sieht Habermas keine moralische Pflicht des Menschen, Pflanzen oder Arten generell zu erhalten. ${ }^{31}$ Hier verweist Habermas aber auf ethische oder ästhetische Gründe zur Bewältigung der ökologischen Krise. (ebd., 225 f)

Eine moralanaloge Pflicht der Bewahrung der natürlichen Umwelt scheint sich in der Diskursethik demnach nur auf Haus- und Zootiere zu erstrecken. Zwar kann es durchaus ethische und ästhetische Gründe für Tier- und Artenschutz in der Diskursethik geben, aber eben keine moralischen (sondern nur moralanaloge). Die Ausführungen legen nahe, daß Habermas ökologische Werte nur über (andere) substantielle ökologische Ethiken in ethischen Diskursen für generierbar hält. ${ }^{32}$ Allerdings ist die Exklusion nicht-sprachfähiger Wesen im praktischen Diskurs, nicht ohne Widerspruch geblieben (vgl. Werner, 2001), denn sie schließt zugleich jede moralische Intuition aus, die sich nicht auf Reziprozitäten beziehen läßt, - also nicht nur nichtmenschliche Lebewesen, sondern auch zukünftige Personen und Generationen, Behinderte, Föten, Kleinkinder etc. Die Interessen von gegenwärtigen und zukünftigen Personen sind als solche niemals reziprok; sie können aber auch nur in moralischen Diskursen universal thematisiert werden. Hinsichtlich zukünftiger Menschen würde sich ein restriktives Verständnis des Diskursprinzips dem Gerechtigkeitsaspekt der ökologischen Krise verschließen und die Diskursethik nur noch pragmatisch ansetzen können. Aufgrund dieser Schwäche der Diskursethik hat K. Ott (1996) einen advokatorischen, moralischen Diskurs durchgeführt, der auch zukünftige Menschen und Artenschutz universal zu begründen vermag. Es handelt sich dabei um eine anthroporelationale Version der Diskursethik. ${ }^{33}$

31 Zurückhaltend ist auch Apel (1994, 398). Besondere Aufmerksamkeit haben viele ökologische Ethiken der Frage von menschlichen Pflichten gegenüber Tieren zukommen lassen. So hat sich G. Patzig in seiner nicht-metaphysischen, deontologischen Ethik beispielsweise pro Pflichten für Tiere ausgesprochen, da kein radikaler Unterschied zwischen Menschen und Tieren bestehe; auch Tiere könnten Leid, Schmerz, Behagen und Not empfinden. Dagegen hat auch er eine moralische Verpflichtung, bedrohte Tierarten vor dem Aussterben zu bewahren, abgelehnt (Patzig, 1983). Ähnlich ist J. Feinberg (1980) Kant gefolgt und hat von Rechten in bezug auf Tiere gesprochen, die jedoch aufgrund der Asymmetrie von Mensch und Tier keine Pflichten gegenüber von Tieren seien. Während sich so Tierschutz moralisch begründet läßt, stellt sich auch für Feinberg Pflanzenschutz nur ein, wenn dies im praktischen oder ästhetischen Interesse von Menschen liegt. Eine Pflicht, bedrohte Arten generell zu schützen ergebe sich erst als abgeleitete Pflicht aus einer Verpflichtung gegenüber zukünftigen Generationen. Noch erstaunlicher ist die Wiederbelebung des Aristotelismus in neueren ökologischen Ethiken (vgl. O'Neill, 1993), muß doch der Aristotelismus grundsätzlich als (partikulare) Nahbereichsethik gelten (und die Biologie Aristoteles als überholt). Dagegen sind die dringlichsten Umweltprobleme gerade nicht im Nahbereich sondern im Fernbereich angesiedelt. Anzumerken ist also, daß die Geringschätzung des Artenschutzes (gegenüber dem Tierschutz) in den ökologischen Ansätzen der Ethik unverständlich ist. Sie geht an der Problemlage vorbei.

32 Vgl. dazu Zierhofer (1994) der aber eine Ontologisierung der Diskursethik vorschlägt und somit die Diskurstheorie kate0 10.02 372.89456 1a4Tj10.Tj0.0016 Tc -0 Tm(kat)Tj10.02 00 34.02775418016 Tc -0 Tm(10.02 00 10.02 534.21098 184.706 
Die Diskursethik zeigt, daß deontologische Ethiken tendenziell Probleme mit dem ethischen Status der belebten und unbelebten Natur haben, denn Ethiken diesen Typs sind in ihrer Begründungsstruktur bestenfalls anthroporelational. Fragen nach dem Status von Tieren oder Pflanzen lassen sich aufgrund der (von Tieren zu Pflanzen zunehmenden) Asymmetrie nur schwer hinreichend beantworten. Eine gänzlich fehlende ethisch-moralische Begründung von Tier- und Artenschutz würde Nachhaltigkeit aber normativ unterhöhlen. In bezug auf Stoffströme ist dies hier zwar von nachgeordneter Bedeutung, doch wird das zugrundeliegende Reziprozitätsproblem auch im Fall zukünftiger Generationen relevant. Da deren Interessen nicht als solche in praktische Diskurse eingehen können, bliebe ihnen (intergenerationelle) Gerechtigkeit versagt. Nur ein auf Gründen basierender 'adressaten-universalistischer' Diskurs (Gottschalk-Mazouz, 100), könnte 'normative Richtigkeit' gegen Einwände jedes sprach- und handlungsfähigen Wesens verteidigen und als solchermaßen anthroporelationale Ethik das Verhältnis zwischen Mensch und Natur prinzipiell durchaus sinnvoll anleiten. Subjekt von Verantwortung bleibt auch hier der Mensch.

Anforderungen speziell an die praktische Philosophie ergeben sich primär aus der Selbstgefährdung der Menschheit durch die Zerstörung der eigenen Lebensgrundlagen. Dieser Aspekt kann bei deontologischen Ethiken deutlich hervortreten und sollte es gestatten, in praktischen adressaten-universalistischen Diskursen zureichende Antworten zur Bewältigung der ökologischen Krise zu finden.

\subsubsection{Universale Verantwortung für Nachhaltigkeit}

W. Reese-Schäfer (1994) hat sich um kommunikative Rationalität angesichts der ökologischen Krise bemüht: Er stellt auf fehlende Üblichkeiten im Umgang mit neuen Technologien ab: Da kommunikative Rationalität sowohl für politisch-pragmatische wie für ethische Diskurse bedeutsam sei, müßten der Einführung neuer Technologien aufgrund fehlender Üblichkeiten moralische Diskurse vorausgehen. Dabei stünden ethischer und politisch-pragmatischer Rationalitätstypus im Widerstreit, wozu Reese-Schäfer auf Webers Unterscheidung zwischen Gesinnungs- und Verantwortungsethik verweist. Die deduktive Rationalität und absolute Verbindlichkeit, wie sie in den klassischen Moraltheorien zu finden sei, stehe nicht mehr zur Verfügung. Statt dessen müsse auf das Rechtssystem und die öffentlich Meinung vertraut werden.

Verantwortungsethische Politik nimmt gegenüber der (moralischen) Gesinnungsethik die abwägendere Position ein. Obwohl Reese-Schäfer keine externen (nicht-anthropozentrischen) Bewertungsstandards hinzuzieht, hält er sein Konzept für praxis-relevant. Es könne Konsequenzen in praktischen Zwangsmaßnahmen haben. Allerdings weise, wie Reese-Schäfer einräumt, die Gegenüberstellung von Gesinnungs- und Verantwortungsethik Schwierigkeiten auf, und er hat sich 
später weniger überzeugt zu der Fruchtbarkeit dieser Differenzierung geäußert. ${ }^{34}$ Auch Habermas hat eine solche Differenzierung inzwischen fallen gelassen.

Weitaus grundsätzlicher ist jedoch festzustellen, daß eine Ethik der Technik nicht mit einer Ethik der Nachhaltigkeit zusammenfällt. ${ }^{35}$ In gewisser Weise könnte einer Ethik der Technik noch ein Fortschrittsparadigma zugrunde liegen, das Verantwortung für Technologien auf den Gefährdungsaspekt reduziert und dabei von den durch Technologien induzierten Energie- und Stoffströmen absieht. Damit wird nicht bestritten, daß eine solche Ethik unmittelbare Relevanz besitzen könnte; es zeigt sich aber bereits in der einschlägigen sozialwissenschaftlichen Technologieforschung eine Vernachlässigung der metabolen Seite von Technologien.

Einen anderen diskursethischen Weg zur Begründung einer ökologischen Ethik, die einer Nachhaltigkeitsethik bisher am nächsten kommt, hat K.-O. Apel beschritten. Auf ihn geht die Ausweitung der Diskursethik zu einer Verantwortungsethik im Sinne der Zukunftsethik H. Jonas' zurück. $^{36}$ Während das universalpragmatische Universalisierungsprinzip unmittelbar die Berücksichtigung von Handlungsfolgen verlangt, hat Apel eine direkte Folgenberücksichtigung als Überlastung des Universalisierungsprinzips verworfen. Die transzendentalpragmatische Diskursethik differenziert sich statt dessen in einen Begründungsteil (Teil A) und einen verantwortungsethischen Teil B.

Bereits in seiner ersten Formulierung der Diskursethik hatte Apel zwei regulative Prinzipien angeführt, die jeder philosophischen Argumentation inne seien. "Erstens muß es in allem Tun und Lassen darum gehen, das Überleben der menschlichen Gattung als der realen Kommunikationsgemeinschaft sicherzustellen, zweitens darum, in der realen, das Überleben der idealen Kommunikationsgemeinschaft zu verwirklichen. Das erste Ziel ist die notwendige Bedingung des zweiten Ziels; und das zweite Ziel gibt dem ersten seinen Sinn, - den Sinn, der mit jedem Argument schon antizipiert ist." (Apel, 1976, 431) Apel spricht in diesem Zusammenhang davon, daß die Überlebensstrategie ihren Sinn durch eine langfristige Emanzipationsstrategie erhält. Auf diesen beiden regulativen Prinzipien basiert der verantwortungsethische Teil B der Diskursethik. Teil B umfaßt mehrere Bereiche: So besteht vor allem eine politische Verantwortung zur Herstellung von Verhältnissen, die praktische Diskurse ermöglichen und moralisches Handeln zumutbar machen, dann eine ökonomische Verantwortung die Ökonomik in die Ethik zu integrieren und schließlich eine ökologische Verantwortung.

34 "Der Fall, daß die Folgen die Gesinnungsethik bestätigen und die Verantwortungsethik widerlegen, ist übrigens nicht so ungewöhnlich, wie man eingeschüchtert durch die volltönende Verantwortungsrethorik - glauben könnte. Die Ungewißheit der Folgen macht nämlich Handlungssituationen überkomplex, wenn man sie jederzeit in wirklich verantwortlicher Weise mitbedenken und einkalkulieren will. Wenn man die Folgen so oder so nicht absehen kann, ist es unter Umständen einfacher, sich gleich an moralische Regeln zu halten." (1996, 116) Moral stellt ReeseSchäfers Ansicht zufolge allgemeine normative Unbestimmtheitspotentiale für jene Themen und Bereiche zur Verfügung, "in denen Rechtsnormen und politische Entscheidungen nicht ausreichen, sich festgelaufen haben und sich aus eigener Kraft nicht korrigieren können." (ebd., 120)

35 Keinesfalls entspricht das additive Modell in Wissenschaft und Technik bereits dann einer Verantwortungsethik der Nachhaltigkeit, wenn technologische Innovationen über Diskurse eingeführt wurden. Dies würde den Nachhaltigkeitsdiskurs kognitiv auf einen Risikodiskurs reduzieren, der 'at the end of our days' faktisch mehr Gesinnung als Verantwortung bewiesen haben könnte.

36 Zum besonders im ökologischen Kontext oft verwandten Begriff der Verantwortung vgl. Bayertz, 1995. 
Hinsichtlich des ersten regulativen Prinzips Apels fällt sogleich die Ähnlichkeit zu Hans Jonas' kategorischen Imperativ auf, daß eine Menschheit zu sein habe (Jonas, 1979, 90 ff) ${ }^{37}$ Im Gegensatz zum Prinzip Verantwortung spricht die Diskursethik nicht von einem Imperativ der Menschheitsbewahrung, sondern von der Pflicht zur Erhaltung der realen Argumentationsgemeinschaft. Diese liegt auf der Ebene des Diskursprinzips, womit sich für die Transzendentalpragmatik die begründungstheoretischen Probleme Jonas' nicht stellen. Aber für die Transzendentalpragmatik ergeben sich daraus auch völlig andere Praxisprobleme als für die Jonas'schen Ethik (vgl. Werner, 1994, 319).

Verantwortung für die Biosphäre resultiert in der transzendentalpragmatischen Diskursethik aus der Differenz zwischen idealer und realer Argumentationsgemeinschaft. Jeder Sprecher als Argumentierender gehört demnach gleichzeitig und a priori beiden Argumentationsgemeinschaften an. Diese transzendentale Differenz nennt Apel, den Widerspruch einer noch nicht entschiedenen Geschichtsdialektik, den man aushalten müsse (Apel, 1973, 430). Zwar sei diese Differenz prinzipiell nicht aufhebbar, doch sei - im Sinne einer diskursiven Verantwortungsethik - die ideale Argumentationsgemeinschaft in der realen anzustreben. Die ideale Argumentationsgemeinschaft zeichne sich durch unbegrenzte Argumentation und reversiblen Konsens der Argumentationsgemeinschaft aus. Nach Apel kann nur im Diskurs der idealen Argumentationsgemeinschaft, "der vom geschichtlich-irreversiblen Handeln des Menschen entlastet ist" (Apel, 1988, 127), das Universalisierungsprinzip einer Verantwortungsethik generiert werden. Nicht dagegen auf der Ebene der geschichtsbezogenen Anwendung dieses Prinzips. Apel hat gerade aufgrund der faktischen Unmöglichkeit unbegrenzter Argumentation (in fortschreitender Annäherung an Wahrheit) und der Irreversibilität geschichtlich situierten Handelns Diskursprinzip und Handlungsprinzip unterschieden. Das Handlungsprinzip sei zugleich auch verantwortungsethisch zu verstehen. Es umfaßt eine ökologische Verantwortung für die Biosphäre. Apel führt nicht aus, inwieweit menschliches Handeln (phänomenologisch) als irreversibel zu qualifizieren ist.

Apels ökologische Verantwortung geht über unmittelbar zurechenbare Handlungsverantwortung einzelner Subjekte, Staaten oder Generationen hinaus. Es bestehe eine prinzipielle, allgemeine Verantwortung für die natürliche Umwelt. Diese sei beteiligungsoffen und nicht teilbar. Eine enge Interpretation von Verantwortung lasse in der Ex-Post-Perspektive zwar einen teleologischen Handlungsbegriff zu. Verantwortung könne jedoch nicht teleologisch - als Ex-Ante-Perspektive begründet werden, wie dies etwa konsequentialistische Zukunftsethiken versuchen (vgl. Birnbacher,

\footnotetext{
37 Allerdings hat Jonas diesen Imperativ mit naturphilosophischen und ontologisch-metaphysischen Argumenten begründet. Und auch wenn sich diese noch quasi-intuitionistisch verstehen ließen - wenn Jonas nämlich in bezug auf die Verantwortung, die der Atmen eines Neugeborenen seiner Umwelt auferlegt, von einem ontischen Paradigma spricht (Jonas, 1979, 234 f) - begeht Jonas dennoch in beiden Fällen einen logischen bzw. naturalistischen Fehlschluß, den er wiederum erstens durch Anzweifeln dieses Prinzips relativiert und zweitens indem er den normativ-ethischen Anspruch seiner Theorie abzuschwächen scheint. So spricht er davon, daß seine Verantwortungsethik eine Art 'Notstandsethik' oder 'Vermeidungsethik' sei, die Verantwortung nicht in den Mittelpunkt der Moraltheorie rücken wolle, sondern diese zu ergänzen beabsichtige (vgl. zur Auseinandersetzung der Diskursethik mit Jonas die Beiträge in Böhler, 1994).
} 
1988). Bereits die Ex-post-Perspektive zeige, daß nicht jede kausal zuordbare Handlung auch verantwortbar gewesen sein muß. Um von Verantwortung sprechen zu können, müßten gemäß dieser Theorien alle Folgen einer Handlung kausal intendiert sein. Somit erwiesen sich konsequentialistische oder teleologische Handlungstheorien aufgrund eines zu engen Verantwortungsbegriffs als ungeeignet, normative Theorien zu begründen.

Während Verantwortung im herkömmlichen Sinne an intentionales Handeln gebunden sei, bestünde die Pointe einer Verantwortungsethik wie Jonas' Prinzip Verantwortung oder Apels Diskursethik gerade darin, daß Verantwortung sich ganz prinzipiell auf Natur erstrecke. ${ }^{38}$ Eine ökologische Verantwortungsethik, die nicht hinter Jonas' Prinzip Verantwortung zurückfallen wolle, könne sich deshalb nicht auf die intendierten ökologischen Folgen unseres Handelns beschränken, sondern müsse so gefaßt sein, daß im praktischen Diskurs näher zu bestimmende Folgen menschlichen Handelns in der Natur ausgeschlossen werden könnten. Dabei müsse kognitives Lernen aus Rückwirkungen der Natur möglich bleiben. Dergestalt könnte sich die ökologische Krise als ein rekursiver Prozeß von sozial geltenden ökologischen Normen, widerständiger Realität und Neubegründung ökologischer Normen bewältigen lassen. Ganz ähnlich charakterisiert Habermas eine rationale Lebensweise als rekursiven Lernprozeß (vgl. Habermas, 1999, 132 f). Eine derartige Vorstellung der Normenbegründung im ökologischen Kontext kann jedoch nicht mit einer 'additiven' Sichtweise begründen werden, die vom Paradigma der Irreversibilität zurückgewiesen wird. Irreversibilität verweist auf den nicht-additiven Charakter von Ökosystemen.

M. Kettner hat unter Verweis auf moralische Lernprozesse die im additiven Modell implizierte rekursive Begründung ökologischer Normen abgelehnt. ${ }^{39}$ Seine Ablehnung richtet sich insbesondere gegen (ökologische) Klugheitsethiken: "Die ökologische Modernisierung von Klugheitsdispositiven [...] läßt sich nicht einfachhin, als ein moralischer Lernprozeß abhandeln." (Kettner, 1995, 304) Jede ökologische Ethik müsse zumindest gewährleisten, daß Lernprozesse möglich seien. Zugleich muß sie allerdings auch offenlassen, was die Erhaltung der natürlichen Lebensgrundlagen des Menschen voraussetzt. Auch Apel hat darauf verwiesen, daß im Rahmen der Diskursethik ökologische Normen Gegenstand einer situativen Güterabwägung bleiben müßten (Apel, 1994, 398 f). Kurzum: die transzendentalpragmatische Diskursethik beansprucht eine bereichspezifische Relevanz für den ökologischen Kontext, in welchem reversible Handlungsnormen Lernprozesse ermöglichen soll. Die äußerst relevanten Probleme ökologischer Abwägung bzw. Anwendung können im folgenden nur angedeutet werden. Folgt man - mit Habermas - Günthers' Differenzierung von Begründungs- und Anwendungsdiskursen, kann sich die Universalpragmatik relativ unproblematisch diese theoretischen Auffassungen der Transzendentalpragmatik zueigen machen.

${ }^{38}$ Vgl. Apels allgemeine Begründung für seine Verantwortungsethik unter Bezugnahme auf intentionalistische Handlungstheorien über die eine prinzipiengeleitete Ethik hinausgehen müsse (Apel, 1988, 132) und eine spezifisch ökologische Verantwortungsethik (ebd., 179 ff; ders., 1994).

39 D. Böhler (1994, 262f) hat an der moralischen Zulässigkeit eines 'additiven Modells' mit Blick auf die Gentechnik gravierende Zweifel geäußert. 
Das hier vertretene koevolutionäre Verständnis von Natur und Anthroposphäre schließt ein 'additives Modell' von Natur aus. Naturprozesse reproduzieren sich selbstständig. Anthropogene Entwicklungsprozesse sind über eine konstante Energie- und Materialbilanz metabolisch mit den evolutionären Naturprozessen verbunden und beeinflussen diese. Nur in dieser gemeinsamen Koevolution von Mensch und Natur sind daher moralische Lernprozesse zu realisieren. Der Diskursethik zufolge müssen Normen, die Veränderungen von Naturprozessen durch den Menschen für zulässig erklären, reversibel bleiben. Nur durch moralische Lernprozesse, die (irreversible) Veränderungen der Natur kognitiv zugänglich machen, werden derartige Veränderungen im Zaum eines schwachen Naturalismus (Habermas, 1999) gehalten. Die Bestimmung irreversibler Veränderungen bedarf unter Umständen einer erheblichen naturwissenschaftlichen und phänomenologischen Rekonstruktionsarbeit durch die Philosophie. Irreversible Naturfolgen könnten ein Unterlassen von Handlungen zwingend gebieten. Allerdings erweist sich die moralische Bewertung irreversibler Veränderungen in ökologischer und sozialer Hinsicht als überaus komplex. ${ }^{40}$ Dies zeigt sich schon bei Versuchen der ethischen Bewertung von Stoff- und Energieströmen (vgl. Birnbacher, 1988, 70 ff, 208 ff).

Die ökologische Abwägung sollte deshalb anthroporelational bei möglichen Handlungsfolgen ansetzen. ${ }^{41}$ Handlungsfolgen unterliegen in zukunftsbezogener, koevolutionärer Perspektive wie gezeigt prognostischer und epistemischer Unsicherheit. D. v. d. Pfordten hat für diesen Kontext ein Kriterium der Nichtintervention in die Natur formuliert: "Die Nichtintervention in alle gegenwärtig bestehenden natürlichen Verhältnisse dient dem Menschen im Fall von Unsicherheit und Risiko alles in allem mehr als jede Intervention." (v. d. Pfordten, 1996, 260) Dabei richtet sich das Kriterium auf die Veränderung und nicht auf den Erhalt der Natur, so daß es nicht den gegenwärtigen nicht-nachhaltigen Status Quo auszeichnet. Aus dem Nichtinterventionsprinzip folgt nach v. d. Pfordten das Gebot der Nachhaltigkeit, das er allerdings nicht näher ausführt. In Verbindung mit der gebotenen Nichtverletzung anderer menschlicher Interessen an einer unveränderten Umwelt ergebe sich aus der gebotenen Nichtintervention unter Unsicherheit die Umkehr der Beweislast für potentiell umweltrelevante Handlungen. Umweltrelevante Handlungen seien grundsätzlich rechtfertigungsbedürftig (ebd., 262). Da das Universalisierungsprinzip der Diskursethik (Habermas) direkt menschliche Bedürfnisinterpretationen einschließt, folgt es der Beweislastumkehr im Sinne v. d. Pfordtens. ${ }^{42}$

40 Vgl. zu entsprechenden Ansätzen: Birnbacher, 1988.

41 Im ökologischen Kontext bedingt Habermas' moralisches Universalisierungsprinzip U unmittelbar, daß nur jene Handlungen zulässig sind, deren ökologische Folgen und Nebenwirkungen abgeschätzt werden können.

42 Allerdings wäre für den ökologischen Kontext generell zu prüfen, ob daß Universalisierungsprinzip nicht aufgrund seiner Referenz auf die unmittelbare Berücksichtigung von potentiellen Folgen und Interessen (Inklusion in den praktischen Diskurs) Moralität und Sittlichkeit kurzschließt, wie dies Apel bereits vermutet hat (1988, 1989). Bei Habermas lassen sich Interessen zukünftiger Personen in praktischen Diskursen allenfalls advokatorisch berücksichtigen. Der Umstand, daß die Unbegrenztheit der idealen Argumentationsgemeinschaft bei Apel im Prinzip auch kommende Generationen umfaßt, ist nicht so mißzuverstehen, daß dies bereits Normen zum Verhältnis zwischen Generationen konstituieren würde. Die ideale Argumentationsgemeinschaft - in ihrer Relation zur realen Argumentationsgemeinschaft - konstituiert nur das Diskursprinzip D. Daran schließt die Verantwortungsethik an. Konkrete Normen folgen aber erst aus praktischen Diskursen (vgl. auch Brumlik, 1986, 265 ff.). Die der ökologischen Krise zugrundeliegende soziale Komplexität, könnte zwar - im Sinne Habermas' - für die These einer 
Von der Pfordtens Kriterium der Nichtintervention erweist sich als relativ starkes Kriterium, das zwar bei epistemischer Unsicherheit größte Konsensfähigkeit besitzen dürfte, doch bei prognostischer Unsicherheit auf Einwände stoßen könnte: Das Kriterium würde nahezu alle umweltrelevanten Handlungen verbieten, da aufgrund der konstanten Energie- und Materialbilanz und der Offenheit des Handlungsraums 'Natur' prognostische Unsicherheit über zukünftige Folgen anthropogener Handlungen den Normalfall der Abwägung darstellt. Die diskurstheoretische Unterscheidung zwischen epistemologischer und ökologischer Unsicherheit würde gegenüber einem solchen generellen Kriterium der Nichtintervention in die Natur eine präzisere Differenzierung ermöglichen: Epistemologische Unsicherheit verbietet Handlungen generell. Unter prognostischer Unsicherheit aber wird der Situationskontextes für die ökologische Abwägung relevant, da dieser die Abschließbarkeit eines Handlungsraums bestimmt. Im Situationskontext der Abwägung sind Irreversibilität, Nicht-Intentionalität und konkrete ökologische Güter als Kriterien zu berücksichtigen.

Hinsichtlich einer nachhaltigen, koevolutionären Entwicklung erweist sich der gegenwärtige Steady-State von Ökosystemen als entscheidendes ökologisches Gut. ${ }^{43}$ Diese Bezugnahme auf den Steady State von Ökosystemen schließt irreversible Veränderung nicht prinzipiell aus, sondern verweist auf die Notwendigkeit einer anwendungsbezogenen Güterabwägung: In die eine Richtung wird der Situationskontext durch die objektivierte Welt gegeben, wobei Irreversibilität und Unsicherheit moralisch zu berücksichtigen sind; in die andere Richtung wird der Situationskontext durch die moralische Beachtung von Kontingenz in der Annahme einer prinzipiellen Unverfügbarkeit der Welt bestimmt. Nur so erscheinen nichtnaturalistische, moralische Lernprozesse denkbar, und die reflexhafte Anpassungen der Gesellschaft an anthropogene Umweltveränderungen vermeidbar.

Bewertungsunsicherheit, resultierend aus der Prognoseunsicherheit in offenen Systeme, verbleibt aber selbst in diesen Fällen bestehen, obgleich die epistemische Sicherheit theoretisch-empirischer Diskurse vorliegt. Mithin können gravierende Schwierigkeiten bei praktischen, umweltpolitischen Abwägungen bestehen (vgl. Wätzold, Simonis, 1997). Prognostische Unsicherheit kann schließlich die Möglichkeit, überhaupt legale, systemische Handlungsbereiche zu konstituieren, in Frage stellen. Auch eine ökosystemische Umweltbeobachtung kann - bei umzukehrender Beweislast nur Gefährdungsstrategien erschließen, die sich am potentiellen Schadensmaß orientieren und sozialer Komplexität gerecht zu werden versuchen. Ökologisch vermeintlich abgeschlossene

sozialen Evolution praktischer Vernunft sprechen, bei der sich das Verhältnis zwischen den pragmatischen, den ethischen und den moralischen Aspekten praktischer Vernunft wandelt (vgl. Eder, 1988), doch muß sich diese Evolution praktischer Vernunft weiterhin an Lernfähigkeit orientieren und diese dürfte in der ethischen und pragmatischen Dimension stark eingeschränkt sein.

43 Der Begriff des Steady State kommt aus der thermodynamischen Ökosystemtheorie, welche gegenüber der kybernetischen Ökosystemtheorie vor allem dynamische Instabilitäten, Bifurkationen und Entwicklungsaspekte untersucht. Dem homoeostatischen Gleichgewicht der Kybernetik wird hier ein Fließgleichgewichtszustand (steady state) gegenübergestellt, das auf der Geschichtlichkeit eines Ökosystems beruht (vgl. dazu Müller, 1997). Die Annahme starker Kausalität innerhalb eines geschlossenen, kybernetischen Systems wird fallen gelassen. Entstehende Eigenschaften von Ökosystemen werden als nicht-addierbare Ergebnisse funktionaler Interaktion und nicht als einfach-lineare Effekte bestehender Strukturen erklärt. Sie sind deshalb auch nicht vorhersagbar. 
Handlungsräume können sich ex-post doch als offene Handlungsräume erweisen und naturalistisch auf die Gesellschaft zurückwirken ohne daß u. U. noch Lernprozesse ausgelöst werden könnten. Koevolutionäre Kontingenz impliziert, daß die Unverfügbarkeit der Welt nur ex-post erkannt werden kann. Koevolutionäre Kontingenz erscheint zwar im Horizont praktischer Vernunft; sie läßt sich jedoch nicht eindeutig eingrenzen. Kontingenz bleibt vermutlich immer sowohl betreffend der Art als auch des Ausmaßes potentieller Gefährdung bestehen. ${ }^{44}$ Irreversible Gefahren und Irreversibilität erscheinen lediglich als besonderes Schadensmaß, da sie die menschliche Freiheit aller zukünftigen Generationen einschränken.

Die Diskursethik rechtfertigt Nachhaltigkeit somit als globales Moralprinzip der Vermeidung irreversibler Veränderungen der Biosphäre im gegenwärtigen Steady State. Die diskursethische Begründung zielt auf die Prävention katastrophaler sozialer Entwicklungen in der Koevolution von Gesellschaft und Natur. Sie besagt nicht, daß der gegenwärtige Steady-State nicht bereits durch extensive Stoff- und Energieströme gefährdet ist. Diese auf den Steady State und Irreversibilität in der Biosphäre verweisende Begründungsstruktur gewährleistet die Unverfügbarkeit der Natur gegenüber der Verfügbarkeit einer objektivierten Natur, d. h. Nachhaltigkeit wird von einer seienden - unter dem Paradigma von Irreversibilität eigentlich: werdenden - Natur her angegangen, die letztlich immer den Menschen einschließt, obwohl umweltgefährdende Handlungen des Menschen die koevolutionäre Zukunft von Mensch und gegenwärtiger Natur bedrohen. Natur bleibt auf den Menschen und seine Bedürfnisse bezogen. In der angewandten Ethik hat sich A. Leist (1996) mit Ansätzen zu Nachhaltigkeit auseinandergesetzt. Er unterscheidet vier Definitionen (vgl., ebd., 434 ff):

1. Eine Wirtschaftsart ist nachhaltig, wenn sie die Funktionskreisläufe der Natur nicht zerstört, sondern ihren anhaltenden Bestand sichert.

2. Eine Wirtschaftsweise ist nachhaltig, wenn sie die heute noch bestehende Natur (Funktionskreisläufe, Rohstoffe) in ihrer Existenzweise bewahrt.

3. Eine Wirtschaftsweise ist nachhaltig, wenn sie die Bedürfnisse der zukünftigen Generationen nicht gefährdet.

4. Eine Wirtschaftsart ist nachhaltig, wenn sie die Chancen der Naturnutzung der zukünftigen Generationen gegenüber den heutigen nicht verringert.

Während 1. als eine rein empirische Definition unbrauchbar sei und als anthropozentrische Wertauffassungen das Defizit aufweise, endliche Ressourcen nicht zu berücksichtigen, stelle 2. die

44 Bereits Jonas wies nachdrücklich darauf hin, daß 'Verantwortung' eine epistemologische Basis benötigt. Obwohl dieser Forderung hier gefolgt wird, ist doch festzustellen, daß die Bedeutung der Epistemologie für die Sozialphilosophie aufgrund potentiell nicht-intendierter ökologischer Handlungsfolgen immer begrenzt ist. Zwar hat Jonas die zweischneidige Rolle der Wissenschaften als Wegbereiter und Schreckensverbreiter des Fortschritts durchaus gesehen und angesichts einer limitierten Prognosefähigkeit der Wissenschaften für eine 'Heuristik der Furcht' plädiert, doch kann Jonas diese 'Heuristik der Furcht' nicht durch Verweis auf eine Zukunftsethik rechtfertigen, deren Wissensbasis die Selbstgefährdung der Menschheit ausschließen soll (Jonas, 1984, 61 ff). Die von Jonas im Gegensatz zu vielen heutigen Autoren der Nachhaltigkeit erkannten Schwierigkeit intertemporaler Kommensurabilität (Jonas, 1984, 40f), läßt sich jedoch nicht durch dieses zirkuläre Argument überwinden. Es verleitet ihn schließlich sogar dazu, autoritäre Staatsformen in Betracht zu ziehen und so einen 'katastrophischen Fehlschluß' (Reese-Schäfer) zu begehen. Es sei darauf verwiesen, daß Apel die schleichende ökologische Veränderung der conditio humana als Herausforderung der Menschheit als Selbstbehauptungssystem (Apel, 1988, 193) ansieht, ohne einen solchen Fehlschluß zu begehen. 
willkürliche Wahl eines Ist-Zustandes der Natur dar und zeige, daß aus inhaltlichen Gründen die Bezugnahme auf menschliche Interessen oder Bedürfnisse nötig sei. Die Definitionen 3. und 4. implizierten eine intergenerationell gerechte Entwicklung, ihre zweckrationale Operationalisierung sei aber problematisch. Leist schlägt deshalb folgende Definition von Nachhaltigkeit vor, die sowohl die zukünftige als auch die gegenwärtige Nutzung der natürlichen Umwelt einschränkt und so v. d. Pfordtens Nichtinterventionsprinzip material anwendbar macht (vgl., ebd., 436 ff):

5. Eine Wirtschaftsweise ist nachhaltig, wenn sie die Chancen der Naturnutzung nicht einseitig (etwa sogar exponentiell) zu Lasten der zukünftigen Generationen einschränkt, sondern langfristige intergenerationelle Gleichheit auf einem realisierbaren Niveau anstrebt.

Mit Leist ist das bisher skizzierte Konzept von Nachhaltigkeit gegen den Einwand zu verteidigen, daß die Bezugnahme auf die gegenwärtige Natur die willkürliche Wahl eines IstZustands sei. Ein solcher Einwand würde quasi eine 'ontologische Wahlmöglichkeit' unserer Naturverhältnisse unterstellen und verkennen, daß die ökologische Krise ganz wesentlich kontingenten Ursprungs ist. ${ }^{45}$ Der gegenwärtige Ist-Zustand liegt auch Definition 5. zugrunde, wird hier aber auf das Verhältnis zwischen den gegenwärtigen und zukünftigen Generationen bezogen. Die Vermeidung ökologischer Gefährdungen durch die Unterlassung von Interventionen in die Natur ist produktivistischen Zielen (intertemporaler Allokation) vorrangig. Dies vermeidet einen produktivistischen Fehlschluß, der sowohl von der begrenzten Produktivität als auch der limitierten Assimilationskapazität der Natur absieht und allein die anthropogene Produktivität zum normativen Maßstab menschlichen Handelns macht. Dies steht im Widerspruch zu den Grenzen des materiellenergetische Stoffwechsels zwischen Gesellschaft und Natur. Im liegt die Verwechslung instrumenteller Rationalität mit strategischer Rationalität zugrunde. An dieser Stelle aber wird deutlich, daß die Diskursethik nicht weiter ohne den kognitiven Gehalt der Diskurstheorie entfaltet werden kann. Es ist daher notwendig, näher auf das ökonomische System einzugehen.

\footnotetext{
45 So hat Mittelstrass auf die Wichtigkeit verwiesen, "Natur auch in technischen Kulturen wieder als etwas zu begreifen, das wir in seinen wesentlichen Formen nicht können und das gleichzeitig für ein Verständnis unseres Lebens im ganzen unverzichtbar ist." (Mittelstrass, 1987, 61)
} 


\section{Der Metabolismus mit der Natur: das Wirtschaftssystem}

\subsection{Die Wirtschaft als System der Gesellschaft}

Die neoklassischen Ökonomie beruht auf der Annahme strategisch-instrumenteller Rationalität. Dies gilt insbesondere auch für die Teilbereiche der Umwelt- und Ressourcenökonomie, die beide auf autonom entscheidende Individuen zurückgeführt werden. Rationalität wird dabei als autonome Entscheidungsrationalität gefaßt, die auf die Maximierung des individuellen Nutzens zielt. Während die Ressourcenökonomie den gegebenen Bestand an Natur gemäß einer instrumentellen Rationalität abträgt, setzt sich die Umweltökonomie mit strategischer Rationalität auseinander. Beide Formen werden als substantielle Rationalität (homo oeconomicus) verstanden.

Konträr zu instrumentellen, konsequentialistischen Ansätze beruhen systemtheoretische Ansätze auf der Differenzsetzung zwischen ökonomischem System und Umwelt. Dies kann sowohl die soziale als auch die natürliche Umwelt meinen. Im Kontext der Nachhaltigkeit interessiert aber insbesondere die Differenz zur nicht-menschlichen Umwelt (Berkes, Folke, 1992). Während also Kommunikation das ökonomische System konstituiert und entwickelt, relationiert der energetischmaterielle Stoffstrom ökonomisches System und nicht-menschliche Umwelt über die gesetzte kommunikative Differenz hinweg. Diese systemtheoretische Grundposition wird - wenn auch mit ganz unterschiedlichen Anklängen - sowohl von Luhmann als auch von Habermas vertreten.

In der ökonomischen Theorie ist die Umwelt simultan Grenze (im Sinne eines freien Gutes), KoOrganisator des ökonomischen Systems (insofern das System sich nur durch Umwelt reproduzieren kann) und schließlich Externalität als das noch nicht in die ökonomische Theorie Integrierte. Die operationale Geschlossenheit des ökonomischen Systems bedeutet somit nicht seine Isolation von der Umwelt. ${ }^{46}$ "Cette exigence conduit à rompre avec les approches qui se construisent comme objets des systèmes clos sans environnement, ou des systèmes dont l'environnement est en quelque sorte neutralisé pour les besoins de la cause scientifique - en recourant par exemple à la clause 'ceteris paribus'." (Godard, 1984, 317) Die neoklassische Interpretation der Ökonomie als geschlossenes System ohne Umwelt gerät nicht nur bezüglich des Stoffstroms in Widersprüche denn dieser verändert eine Umwelt, von der das ökonomische System abhängt -, sondern generell auch hinsichtlich der Organisation und der Regulation der Reproduktion des ökonomischen Systems (Godard, 1984). Die operational geschlossene Entwicklung des Wirtschaftssystems führt zu einer Komplexitätssteigerung des induzierten Stoffstroms gegenüber dem Input. Der ökonomische Stoffstrom ist, systemtheoretisch gesprochen, emergent. Die Vorstellung eines geschlossenen, sich autonom reproduzierenden ökonomischen Systems, wie sie die Neoklassik vertritt, ist nicht zu halten.

${ }^{46}$ Für N. Luhmanns Theorie autopoietischer Systeme gilt, daß ein System seine Umweltbeziehungen im Medium der Kausalität oder als Austauschbeziehung beobachtet, auch wenn autopoietische Systeme durch Selbstkontakt ihren Umweltkontakt ausschließlich über eigene Elemente herstellen können. 
Unter diesen Vorzeichen systemtheoretischer Kritik an der Ökonomie ist es nicht überraschend, daß auch Habermas die Wirtschaft als System verstanden hat. Insbesondere die Aussagen zur System-Umwelt-Beziehung scheinen ein wesentlicher Grund dafür zu sein, daß Habermas Systemtheorie in der Theorie des kommunikativen Handelns integriert hat. Er hat sich dabei nicht nur auf die Theorie T. Parsons', sondern explizit auch auf die Theorie autopoietischer System von N. Luhmann bezogen. ${ }^{47}$ Zumindest scheinbar kann diese durch die System-Umwelt-Differenz den Metabolismus zwischen Gesellschaft und Umwelt besser fassen als Parsons' Systemtheorie oder eine zweckrationale Handlungstheorie. Denn die Parsons'sche Theorie ermöglichte zwar die Kritik ökonomischer Rationalität, "but it did not go far enough as an analysis of the relationship between society and environment." (Turner, 2000, 252)

Die Konstruktion der Interaktionen zwischen Gesellschaft und natürlicher Umwelt wird der Theorie autopoietischer Systeme allerdings dadurch erschwert, daß die natürliche Umwelt nur eine von zahlreichen Umwelten eines Subsystems ist. Es kommt hinzu, daß die natürliche Umwelt nur als systemintern kommunizierte Umwelt aus den zahlreichen sozialen Umwelten eines Subsystem in dieses eindringen kann. Aus der System-Umwelt-Beziehung folgten deshalb bisher keine ökologisierten Eigenwerte der Systeme. Ökologische Kommunikation ist im wesentlichen vergeblich, ansonsten aber gar subsystemgefährdend (Luhmann, 1986).

Die Bewältigung der ökologischen Krise als Folge eines ökonomischen Stoffstroms erfordert jedoch von soziologischer Theorie, gesellschaftlich relevante ökologische Folgen mindestens theoretisch reintegrieren zu können. Da die Schäden, zwar oft nichtintendierten aber doch anthropogenen Ursprungs sind, müssen Handlungsmöglichkeiten offen stehen. Doch die Kontingenz des Metabolismus zwischen Gesellschaft und Natur wird von der Systemtheorie nicht auf Nachhaltigkeit bzw. zukunftsoffene Sicherheit ausgerichtet. In der Theorie der Systemtheorie wird die Internalisierung von ökologisch-systemischen Folgewirkungen nicht einmal ersichtlich (vgl. dazu näher Metzner, 1993). Hier scheint der Konstruktivismus des Theoretikers negativ zum Tragen zu kommen (so Habermas gegen Luhmann, 1985, 426 ff). Eventuell gehegte Erwartung an eine ökologisch integrative Systemtheorie hat Luhmann mit seiner Theorie des wirtschaftlichen Subsystems (1988) schließlich abgewiesen. ${ }^{48}$

Im Unterschied zu Luhmann hat Habermas festgestellt, daß sich der systemischen Handlungsrationalität kein Eigenwert zuordnen läßt. Zweckrationalität sei zwar Grundlage funktionaler Verselbständigung, doch sie sei nicht die einzige Form der Handlungsrationalität in sozialen Systemen. Die Systemrationalität des Wirtschaftssystems folge lediglich einem auf

${ }^{47}$ Allerdings ist die Theorie des kommunikativen Handelns sieben Jahre vor Luhmanns Die Wirtschaft der Gesellschaft erschienen.

48 Beckenbach hat nach dem heuristischen Ertrag eines Verfahrens gefragt, "das in dem Überstülpen einer gegenstandsunspezifischen Methodik über je spezifische Gegenstände besteht." (Beckenbach, 1989, 901) Er spricht gar von einer 'Subsumtion' der Ökonomie unter die Methodik der Systemtheorie. Dies macht er an der Differenz von Operation und Beobachtung deutlich, die Luhmann über den Markt zu integrieren versucht hat: Der Markt soll nämlich Luhmann zufolge 'innere Umwelt' des Wirtschaftssystems und nicht selbst System sein (1988, 94). Doch nur Systeme können ausdifferenziert werden! Willke (1987b) 'umgeht' dieses Problem, indem er über eine Lebenswelt (sic!) soziale Kriterien in die systemttheoretische Ökonomie einbaut. 
Nutzensteigerungen basierendem Tausch (Rentabilität). Die kritische Forderung der Theorie des kommunikativen Handelns, die systemisch kolonialisierten Bereiche der Lebenswelt kommunikativ zu verflüssigen, wird jedoch dadurch erschwert, daß Habermas weitgehend offen läßt, was Systeme jenseits von Medien noch konstituiert.

In der Theorie des kommunikativen Handelns identifiziert Habermas Systeme mit einer rein empirischen Beobachterperspektive. Dies aber wirft Probleme auf: Nicht nur die motivationale Seite ökonomischen Handelns würde negiert, sondern teilweise auch der Informationsgehalt des Stoffstroms reduziert. Denn der anthropogene Stoffstrom tritt nicht nur als rein empirisch zu beobachtende Erfahrung kontingent in der Umwelt auf, sondern geht auf Motive und Wissen zurück, was mit einer opaken Systemrationalität oder der medialen Reproduktion (Geld) allein unzureichend beschrieben wird. Obwohl das Wissen über den Stoffstrom aufgrund der empirischkontingent auftretenden Externalitäten und Gefahren unsicher ist, besteht daneben immer die Sicherheit seiner konstanten Materialbilanz. Damit wird der Stoffstrom trotz prognostischer Unsicherheiten über seine (quasi-natürliche) Wirkung und (anthropogene) Entwicklung verantwortungsethisch zugänglich. Hinsichtlich des Metabolismus ist an der Einsicht der Theorie autopoietischer Systeme festzuhalten, daß weder die Beobachtung des Systems noch der Umwelt über die dynamische Interaktion zwischen Gesellschaft und Natur nachhaltig aufklären kann, sondern nur die Beobachtung des Stoffstroms in die ökonomisches, physikalisches, chemisches, biologisches etc. Wissen eingeht. Dies ist die theoretische Argumentationslinie, die im folgenden detailliert zu entwickeln ist.

Als eine der wenigen Ökonomen hat sich A. Biesecker (1992) mit der Diskurstheorie auseinandergesetzt. ${ }^{49}$ Sie schlägt vor, das Modell des homo oeconomicus nicht aufzugeben, sondern es durch ein Modell kommunikativen Handelns zu ersetzen, welches sie in der 'Interferenzzone' zwischen ökonomischem System und Lebenswelt verordnet. Als Vorteil von Habermas' Konzeption sieht Biesecker es an, daß prinzipiell sowohl systemische Strukturen in die Lebenswelt einwandern können als auch lebensweltliche in die Systeme. Damit kann kommunikative Rationalität auch das strategische, ökonomische Kalkül ethisch-moralisch begrenzen. Sie schlägt den Wirtschaftswissenschaften pragmatisch einen methodologischen Wechsel zwischen Teilnehmerund Beobachterperspektive mit einem Primat der lebensweltlichen Analyse vor. Innerhalb lebensweltlich orientierter Grenzen - Biesecker nennt: Lohnentwicklung, Begrenzung der Arbeitszeit, Natur etc. - muß die Ökonomik dann regelhaftes Handeln ermöglichen.

Die Expansion des ökonomischen Systems durch die Schaffung von Eigentumsrechten in der Neoklassik diene nur der Wiederherstellung konkurrierender Kapitalgütermärkte und eröffne keine gesellschaftlich-lebensweltlichen Möglichkeiten, privates Eigentum bezüglich von Natur, Produktionsstrukturen etc. zu regulieren, denn einziges Kriterium des neoklassischen Ansatzes sei

${ }^{49}$ Vgl. auch die redlichen, aber doch bescheidenen transzendentalpragmatischen Ansätze von Ulrich (1987) und Apel (1988, 270 ff), die über eine Verantwortungsethik die ökonomische Eigenlogik kommunikativ verflüssigen wollen. Apel konzentriert sich dabei ganz auf das (ökologische) Modernisierungspotential des Unternehmens und findet deshalb keinen Zugang zur (ökologischen), makroökonomischen Theorie. 
das der Pareto-Optimalität (Biesecker, 1992, 41). Biesecker hält den methodologischen Individualismus für ebenso unbrauchbar wie die eigentumsrechtlich orientierten Ansätze der Neuen Politischen Ökonomie (NPÖ), die in der ideengeschichtlichen Nachfolge des Coase-Theorems Transaktionskosten ignorieren. Demgegenüber erlaubten die kulturellen Ansätze der Neuen Institutionen Ökonomie (NIÖ) die Integration von Normen in das Wirtschaftssystem über Institutionen. Die makroökonomischen Zusammenhänge müßten so nicht auf mikroökonomische Modelle zurückgeführt werden. Die ökonomische Analyse könne solche institutionellen Arrangements unter dem Gesichtspunkt ihrer Interferenz zwischen Lebenswelt und ökonomischen System untersuchen. Es bleibt jedoch darüber hinaus noch eine Differenz zu einer diskurstheoretischen Analyse des Wirtschaftssystems bestehen, da in der Diskurstheorie Normen über kommunikatives Handeln in das ökonomische System einfließen können.

Die Bestimmung der lebensweltlichen Grenzen des ökonomischen Systems verfolgt in ökologischer Hinsicht Umwelt- und Ressourcenökonomie und ökologische Ökonomie. Diese Teildisziplinen weisen im Diskurs zur Nachhaltigkeit einen methodischen Pluralismus auf, der zunächst einmal nicht in Frage zu stellen ist (Norgaard, 1985). Im Verlauf des Diskurses zur Nachhaltigkeit zeigten einige Ansätze jedoch Rechtfertigungsprobleme.

Dies betrifft die mikroökonomische Rationalität als Grundlage einer nur makroökonomisch zu verwirklichenden nachhaltigen Entwicklung. Es betrifft aber zumindest teilweise auch Versuche, absolute ökologische Grenzen auszuzeichnen. Die Orientierung auf die Lebenswelt darf den Konzeptionen zur Nachhaltigkeit nicht verloren gehen. Ökologischen Indikatoren fällt dabei sowohl die Aufgabe zu, den Diskurs zur Nachhaltigkeit anzuleiten, als auch zur 'Selbsterziehung' der Gesellschaft beizutragen. Die im folgenden begründete Fokussierung auf den Stoffstrom ist in diesem Sinne zugleich Beobachtung der dynamischen Innovation von Stoffen in der Ökonomie, der ökologischen Austauschprozesse (Ökosystembeobachtung) und der rationalen lebensweltlichen Reflexion auf den Metabolismus zwischen Ökonomie und Natur. Umwelt und ökonomisches System werden so nicht nur über den Stoffstrom relationiert, sondern auch moralisch-lebensweltlich bewertet.

\subsection{Umwelt- und Ressourcenökonomie und nachhaltige Entwicklung}

In der politischen Debatte wird oft die Vermutung geäußert, daß das Nachhaltigkeitspostulat auf der ökonomischen Tradition nachhaltiger Bewirtschaftung aufbaut. Dies ist jedoch nur teilweise zutreffend. $^{50}$ Die Brundtland-Kommission hat in ihrer universale Geltung beanspruchenden Konzeption 'nachhaltiger Entwicklung' die gleichrangige Berücksichtigung sowohl von Entwicklung als auch von ökologischen Grenzen formuliert. Output und Input des ökonomischen Prozesses sind normativ gleichwertig auf soziale Entwicklung bezogen. Hinzu kommt, daß beide

${ }^{50}$ Zur Geschichte von Nachhaltigkeit in der Ökonomie vgl. Nutzinger, Radke, 1995. 
Kriterien global zu verstehen und auf zukünftige Generationen zu beziehen sind. Nachhaltige Entwicklung schließt demnach internationale und intergenerationelle Gerechtigkeit mit ein. Dies ist eine große Herausforderung für die Ökonomik - vermutlich die größte seit der sozialen Frage -, denn sowohl für die neoklassische Ressourcen- als auch die Umweltökonomie stellt eine effiziente Allokation kein Umweltproblem dar, selbst wenn es zu einer Übernutzung von Ökosystemen kommt. Aus ökonomischer Sicht bestehen Umweltprobleme nur als Folge der ineffizienten Allokation von Naturgütern (vgl. Vornholz, 1997, 42 f).

Während in der Klassik Natur als absolute Grenze der Wirtschaft angesehen wurde, wird die Knappheit der Natur in der Neoklassik durch die intertemporalen Allokation der natürlichen Ressourcen als relative bestimmt. Die Hierarchie der klassischen Produktionstheorie wurde im Lauf der Zeit durch die individualistisch-marginalistische Neoklassik verdrängt (vgl. Christensen, 1989). Knappe Ressourcen wurden entsprechend den Präferenzen von Individuen nachgefragt. Nachhaltige Bewirtschaftung erneuerbarer Ressourcen und Abbau endlicher Ressourcen werden von der Ressourcenökonomie beschrieben.

Der Rückgriff auf Ressourcen konstituiert den ökonomischen Prozeß und zugleich immer auch einen Energie- und Materiestrom, dessen Folgen erst mit der Herausbildung der Umweltökonomie Gegenstand der ökonomischen Theorie wurde. Die Eigenschaften des Stoffstroms sind dabei für die Ökonomie nur als ex-post beobachtete Externalität relevant, obwohl der Stoffstrom die gesamte materielle Reproduktion der Gesellschaft durch das ökonomische System umfaßt und hierarchische Strukturen hat. Die Ressourcenökonomie konzipiert optimale wirtschaftliche Wachstumspfade. Die Umweltökonomie behandelt die ex-post beobachteten gesundheitlichen und ökologischen Folgen. Diese sollen mit Steuern (nach Pigou) oder Eigentumsrechten (nach Coase) dergestalt internalisiert werden, daß die Optimalität der intertemporalen Allokation gemäß der ressourcenökonomischen Modelle gewährleistet bleibt.

Im Sinne der neoklassischen Ressourcenökonomie ist 'Entwicklung' rein materiell auf Wohlfahrt zu beziehen, welche utilitaristisch oder distributiv (Solow bzw. Rawls) als nicht sinkende Wohlfahrt formuliert wird. ${ }^{51}$ Die so formulierten Theorien intertemporaler Allokation behandeln die Nutzung von Ressourcen als reines Cake-eating-Problem. Natur wird als Bestand modelliert, der intertemporal zu konsumieren ist. Ressourcen aus der Natur treten als Produktionsfaktor auf, dessen optimale intertemporale Allokation die Umweltökonomie über die Zeit garantiert. Unsicherheit besteht diesen Modellen zufolge im wesentlichen nur über den tatsächlichen Umfang des Ressourcenpools. Irreversibilität wird als Erschöpfung endlicher Ressourcen modelliert, die von der sozialen Diskontrate beeinflußt wird. Diese wirkt sich auch auf die Erntequote nachwachsender Ressourcen und damit auf deren Erhalt bzw. irreversible Zerstörung aus. Diese Ressourcen werden im Produktionsprozeß neben anderen Faktoren verwandt, welche einander substituieren können. Die Substitutionselastizität der Produktionsfaktoren (Arbeit, Kapital, Land/Ressource) wird durch hypothetische Produktionsfunktionen bestimmt, welche auf äußerst optimistischen und teilweise

51 Eine Einführung und Übersicht über die verschiedenen Definitionen bietet Feess-Dörr et al., 1993. 
physikalisch nicht haltbaren Annahmen bezüglich der Elastizität der Substitution basieren. Gemäß der zugrunde gelegten Produktionsfunktionen erfolgt die Maximierung des Gegenwartswertes. Als Zeithorizont wählen die Modelle i.d.R. Unendlichkeit.

Im Rahmen der neoklassischen, intertemporalen Modellen der Ressourcenökonomie wurde nicht ökonomisches Wachstums, sondern 'Diskontierung' als ethisches Problem diskutiert. ${ }^{52}$ In Hinblick auf Nachhaltigkeit (und intergenerationeller Equity) hat eine Diskontrate ambivalente Auswirkungen, da eine positive Diskontrate einen schnelleren Abbau endlicher Ressourcen zur Folge hat und nur eine Nulldiskontrate eine ewig konstante Ernte nachwachsender Ressourcen erlaubt, wohingegen Diskontierung für (ökoeffizientere) Investitionen attraktiv ist (vgl. Ströbele, 1991; Norgaard, Howarth, 1991). Schließlich ist aber gezeigt worden, daß auch eine Nulldiskontrate nicht notwendig den Weg in die Umweltkatastrophe verhindern kann (Radke, 1995, 208 f). Die Modelle garantieren nicht die nachhaltige Bewirtschaftung nachwachsender Ressourcen (Erhalt des Bestandes) und abstrahieren in der Regel von den Folgen der Nutzung endlicher Ressourcen (Abfall, Emissionen). Wird die Assimilationsfunktion der Natur als Produktionsfaktor doch berücksichtigt (Siebert, 1981), ergibt sich daraus die Substitution des Naturkapitals durch produzierte Kapitalgüter, was die viel grundsätzlichere Frage nach der Substituierbarkeit von Natur durch Kapital aufwirft.

Obwohl die Modelle offensichtlich Zeit zum Gegenstand haben, abstrahieren sie von den realen zeitlichen Umständen des ökonomischen Prozesses. Die unzureichende Konzeptionalisierung der Zeit in der Neoklassik betrifft sowohl den ökonomischen Prozeß selbst, der zumeist mechanistischreversibel gedacht wird, als auch die Umweltschäden, welche für internalisierbar und damit für reversibel gehalten werden (vgl. dazu Godard, Salles, 1991). Die Modelle sehen von Unsicherheit in der Entwicklung von ökonomischem System und natürlicher Umwelt ab, obwohl sie eine intertemporale Perspektive einnehmen. Sie verkennen dabei den emergenten Charakter des ökonomischen Outputs als Stoff- und Energiestrom. Intertemporal stellt Natur nicht einen Bestand, sondern einen wandelbaren Strom an Funktionen (Assimilationsfunktion und Nutzenfunktion) bereit. Die den Modellen intertemporaler Allokation zugrunde gelegten Produktions- bzw. Wohlfahrtsfunktionen legen dagegen einen Bestand zugrunde und werden über alle Generationen hinweg verfolgt, ohne daß dies adaptives ökonomisches oder ökologisches Lernen ermöglichen könnte.

In der intertemporalen Allokation von endlichen Ressourcen treten externe Effekte auf, die gemäß der Neoklassik in den Markt internalisiert werden müssen, um ein langfristiges Marktgleichgewicht herzustellen. Die Umweltökonomie behandelt die speziellen Fälle externer Effekte mit umweltschädigenden Wirkungen. Die Umweltökonomie internalisiert entstehende Umweltschäden, indem sie Umweltschäden monetär erfaßt und dem Verursacher bzw. den Verursachern die volkswirtschaftlichen Kosten in Rechnung stellt. Innerhalb der ökonomischen Theorie konkurrieren die bereits angesprochenen zwei Lösungen zu diesem Problem miteinander:

52 Birnbacher, 1988, 101 ff; Rawls, 1971, 293 ff 
die Belastung des Verursachers durch eine staatliche Steuer in der Höhe der marginalen Schadenskosten nach dem Vorschlag A. C. Pigous und private Verhandlungen über das Ausmaß der externen Effekte im eigentumsrechtlichen Ansatz von R. Coase. Der Ansatz von Pigou wurde 1946 veröffentlicht, der von Coase 1960 (vgl. Mishan, 1971). Beide Ansätze werden häufig in einem Atemzug als Lösung des Umweltproblems genannt und theoretisch für gleichwertig gehalten, da beide die Optimalität der Allokation proklamieren. Allerdings ist Coase' Theorem für die praktische Umweltpolitik bedeutungslos geblieben, - was nicht nur an seiner verteilungspolitischen Dimension liegen dürfte.

Nach Coase (1960) haben ökologische Probleme die statische Struktur einer Tragödie der Allmende (Gefangenendilemma). Die Tragik kann Coase zufolge durch die (staatliche) Vergabe von Eigentumsrechten verhindert werden. Die Ökonomie der Eigentumsrechte besagt, daß ein Arrangement von Eigentumsrechten das zu einer ineffizienten Allokation von frei zugänglichen Ressourcen führt, bei der alle schlechter gestellt sind, durch Pareto-bessere Allokationen aufgehoben werden könne. Dazu müßten Eigentumsrechte (durch den Staat) definiert oder umdefiniert und (durch Private) getauscht werden können. Coase' zentrale Einschränkung ist, daß dabei keine Transaktionskosten anfallen und die Einhaltung der neuen Eigentumsordnung extern überwacht wird. Als umweltökonomische Antwort auf die ökologische Krise kann das Coase Theorem deshalb keinesfalls dienen, da hierbei die Informationskosten hoch sind und die Probleme dynamisch. Das Coase Theorem deutet (ökologische) Probleme instrumenteller Rationalität in (soziale) Probleme strategischer Rationalität um und verkennt so systemtheoretische Einsichten in System-Umwelt-Beziehungen.

Der handlungstheoretische Gehalt des Coase-Theorems wirft sogar die Frage auf, ob - im Sinne individueller Folgenverantwortung - das Verursacherprinzip noch Gültigkeit beanspruchen kann. ${ }^{53}$ Dies betrifft sowohl die ethische als auch die ökonomische Tradition: Für den methodologischen Individualismus ist die strikte Trennung zwischen Daten- und Wahlbereich konstitutiv. Der Wahlbereich ist durch isolierte, (atomisierte) Einzelentscheidungen freien Tauschs charakterisiert, die durch das Gleichgewicht des Marktes integriert sind. In der Allokationsperspektive, der das Coase' Theorem folgt, ergibt sich das Optimierungshandeln durch rationale, individuelle Marginalkalküle, d.h. das Handeln von Individuen ist intentionales, nutzenmaximierendes Handeln. Soziale Verselbständigung in Abweichung zum Marktgleichgewicht wird in der neoklassischen Ökonomie im Gegensatz zur Soziologie nicht verfolgt. Coase vollzieht nun mit seinem Theorem eine Dualisierung der neoklassischen Modellogik, indem eine explizit zentralistische Entscheidungsfindung über umweltbezogene Anreize eingeführt wird. Individuelle Nutzenmaximierung und gemeinwohlorientierte Entscheidungsfindung über Umweltgütern treten sich gegenüber. Diese Annahme behauptet implizit die Substituierbarkeit von Umwelt- und NichtUmweltgütern, die durch einen externen Regulator (zeitlos) optimiert wird. F. Beckenbach hat

53 Dies gilt über die rechtliche Unterscheidung zwischen Kausalität und Verschuldung (wie u.a. im Umwelthaftungsrecht) hinaus, denn das Coase-Theorem beruht auf dem intentionalen Handlungsmodell des homo oeconomicus. 
darauf hingewiesen, daß diese Dualisierung zu inkonsistenten Resultaten führen muß, wenn sie der Umwelt die Eigenschaft eines öffentlichen Gutes zuweist (Beckenbach, 1991b). Die Annahme vollständiger Information und die Erweiterung des Allokationsmodells um die Umweltnutzung ist aufgrund des Informationsproblems (asymmetrische Informationsverteilung zwischen Verschmutzer und Geschädigtem unter epistemologischer und ökologischer Unsicherheit) nicht kompatibel (ebd., 111). ${ }^{54}$ Und selbst wenn das Informationsproblem nicht existieren würde, stellte sich noch immer das Reziprozitätsproblem (Coase), denn nicht nur die Nutzungsansprüche des Schädigers, sondern auch die des Geschädigten sind Teil des Allokationsproblems: Individuelles Handeln wird hier erst durch das Handeln anderer rational, d.h. es ist nicht-kooperativ und strategisch. Coase unterstellt privaten Verhandlungen dagegen einen kooperativen Charakter, indem er sie in einen pareto-optimalen Vertragsabschluß enden läßt. Coase konstituiert zwei Märkte: einen Markt für Güter, auf welchem sich Preise parametrisch bilden, und einen für Nutzungsrechte, als zweiseitiger Verhandlungsmarkt (barter) mit strategischer Preisbildung. ${ }^{55}$ Für die Gleichgewichtslösung ergeben sich daraus gegensätzliche Forderungen: Während der Gütermarkt eine möglichst große Teilnehmerzahl erfordert, gilt für den Verhandlungsmarkt von Nutzungsrechten das Gegenteil. Die Wahrscheinlichkeit, daß dort effiziente Entscheidungen getroffen werden, ist um so geringer, je größer die Anzahl der Geschädigten ist.

Der Optimalitätsanspruch, den das Coase Theorem für die intertemporale Allokation erhob, ist aufgrund dieser Probleme fallen zu lassen. Von Baumol und Oates wurde derselbe Anspruch hinsichtlich der Pigou-Steuer schon früher (und teilweise unter Verweis auf Coase' fehlerhaftes Theorem) explizit aufgegeben, denn der Umstand, daß die Pigou-Steuer dem Grenzschaden im späteren Pareto-Optimum entsprechen muß, führt ökonomische und ökologische Unsicherheit in das Modell ein (Baumol, Oates, 1975, 160 f). Das Coase' Theorem ist somit nicht nur wegen seiner möglichen Verteilungswirkung brisant und mit hohen politischen Transaktionskosten verbunden (vgl. Scharpf, 2000, 204 ff), sondern es läuft sowohl der ethischen und als auch der neoklassischen ökonomischen Tradition entgegen. Seine Übernahme in die sozialwissenschaftliche Theorie (vgl. Luhmann, 1986, 29 ff) importiert somit stark normative Implikate, die einem produktivistischen Fehlschluß unterliegen, denn Coase formuliert eine intergenerationelle Verteilungsfrage in eine intertemporale Allokationsfrage um, die vom Umfang (scale) des Wirtschaftssystems gänzlich abstrahiert.

Angesichts der Probleme der Ökonomie, Konzepte und Theorien zur systeminternen Bewältigung der ökologischen Krise auszuarbeiten, haben Baumol und Oates einen umweltpolitischen Ansatz ausgearbeitet, der diesen Anspruch a priori fallen läßt (Baumol, Oates, 159 ff). Charakteristisch für diesen sogenannten Preis-Standard-Ansatz ist, daß er nicht auf Präferenzen

${ }^{54}$ Wenn der Geschädigte zugleich Schädiger ist, wird er seine Umweltnutzung maximieren und eine umweltbezogene Präferenzartikulation unterlassen. Ist er ausschließlich Geschädigter, kann er, da keine marktlichen Sanktionsmechanismen gegen simulierte Präferenzen bestehen, den Schaden übertreiben.

55 Bei parametrischer Anpassung nehmen Akteure die Aktivitäten und Ergebnisse anderer Akteure als Daten hin und beziehen sie in ihre eigene Handlungsstrategie ein, ohne ihrerseits das Verhalten anderer (eventuell argumentativ) beeinflussen zu wollen. 
basiert, sondern durch politische Vorgabe definiert ist und eine (volkswirtschaftlich) kostenminimale Lösung darstellt. Zur Implementation des Ansatzes werden umweltpolitische Standards durch eine politische Instanz gesetzt, d. h. Emissionsmengen regulativ vorgeschrieben. Dazu werden vom Staat entweder Steuern erhoben oder Zertifikate ausgegeben. Beide Varianten des Preis-Standard-Ansatzes werden in einem ordnungspolitischen Rahmen nachhaltiger Entwicklung eingeordnet (Zimmermann, Hansjürgens, 1998). ${ }^{56}$

Während Steuern der ökonomischen Tradition der Pigou-Steuer folgen, sind Zertifikate, eine zurückhaltendere Variante der Coase'schen Verhandlungslösung. Im Unterschied zum CoaseTheorem hat die Spieltheorie eine strategischen Begründung für Zertifikatverhandlungen geliefert. Anstatt eines zentralen Regulators stellt sich die Allokationsaufgabe vor dem Hintergrund sozialer Dilemmatasituationen. Diese werden in Erweiterung der neoklassischen Umweltökonomie sowohl von der Neuen Politischen Ökonomie als auch von der Neuen Institutionenökonomik beschrieben. Beide Ansätze untersuchen für die Umweltökonomie relevante, strukturelle Phänomene sozialer Verselbständigung. Von der Neuen Institutionenökonomik werden positivistische Modelle entworfen, welche kollektive Entscheidungssituationen thematisieren und die institutionelle Steuerbarkeit von Zertifikaten verfolgen (Bonus, Häder, 1998). Daneben sind Institutionentransfers diskursanalytisch erklärt worden (Scherrer, 2001). Diskurstheoretisch ist aber zunächst einmal nicht empirisch auf institutionelle Diffusionsprozesse $\mathrm{zu}$ verweisen, sondern auf den universalen normativen Geltungsanspruch von Nachhaltigkeit, wohingegen die institutionelle und instrumentelle Ausgestaltung Gegenstand von Anwendungsdiskursen ist.

Unter Informationsaspekten liegt es für die umweltpolitische Instrumentenwahl nahe, auf Zertifikate zurückzugreifen, da diese die Wahl der jeweils geeigneten Form der Emissionsvermeidungen dem einzelnen Unternehmer belassen, während bei Abgaben das dezentrale Wissen der Emittenten z. T. erst wieder zum Staat transferiert werden muß. Das politische System muß bei Abgaben nicht nur unter ökologischer Unsicherheit, sondern auch unter ökonomischem Risiko (Anpassungskosten) entscheiden. Für Zertifikate ist dagegen kein (ökonomisches) Wissen über Schadenskosten erforderlich, da allein Schadensmengen festgesetzt werden. Diese können in einem iterativen Lernprozeß erschlossen werden.

Für Zertifikate spricht auch, daß sie im Gegensatz zu Abgaben nicht von intertemporalen ökonomischen Entwicklungen wie Wachstum und Preisinflation abhängig sind. Eine Inflation der Preise verringert den realen Wert von Abgaben, und eine wachsende Produktion würde bei konstant zu haltenden Immissionslasten eine wachstumsproportionale Anhebung der Abgaben nach sich ziehen müssen. In beiden Fällen würde die Erhöhung der Abgaben allein aus der Entwicklung des Wirtschaftssystems resultieren und nicht aus der Verschärfung von Umweltstandards. Abgaben zeitigen gegenüber Zertifikaten folglich höhere politische Transaktionskosten.

Schließlich können Zertifikatsysteme auch spezifischer auf räumliche Umweltprobleme eingehen als Steuern. Zertifikatsysteme können sowohl bei Emissionen, als auch bei Immissionen

\footnotetext{
${ }^{56}$ Vgl auch die Rolle von Zertifikaten und Abgaben in den ordnungsökonomischen Studien in: Gerken, 1996.
} 
ansetzen und u. a. damit räumlichen Aspekten in der Umweltpolitik angemessen Rechnung tragen. Die politische Zielformulierung kann 'Umweltregion' und 'Marktregion' über verschiedene Ausgestaltungen des Zertifikatsystems zueinander in Beziehung setzen (Karl, 1998). Allerdings können Probleme entstehen, wenn staatliche Institutionen (Föderalismus) und die problemspezifische Umweltregion nicht zusammenfallen.

Einen Nachteil allerdings weisen Zertifikate gegenüber Steuern auf: Sie führen im Markt zu vergleichsweise höheren Transaktionskosten. Diese entstehen aus der betrieblichen Anpassung an die staatliche Zielsetzung, da gegenüber einer Steuer eine marktinterne Koordination von Zertifikattransfers notwendig wird. Derartige wettbewerbspolitische Bedenken gegen Zertifikate lassen sich jedoch durch entsprechende institutionelle Ausgestaltung weitestgehend ausräumen (Weimann, 1998). Sie verweisen aber auf die immer gegenwärtige Gefahr eines Vollzugsdefizits bei ungenügender staatlicher Kontrolldichte.

Generell können Emissionszertifikate so ausgegeben werden, daß für die privatwirtschaftlichen Akteure hinreichende Planungssicherheit besteht. Die Ausgabe kann sowohl durch Ersteigerung von Zertifikaten (als Voraussetzung des behördlich erlaubten Betriebs) als auch durch 'Grandfathering', d. h. durch die status-quo-orientierte Ausgabe von Zertifikaten an Emittenten geschehen. Als Problem des Grandfathering kann auftreten, daß mit der Ankündigung einer Zertifikatlösung, der Ressourcenverbrauch bzw. der Emissionsausstoß zunimmt.

Beim Grandfathering legt der Staat eine zeitliche Abwertung der Zertifikate fest, welche die Gesamtemissionsmenge entsprechend begrenzt und den Firmen die Deckung ihrer Emissionen durch Zertifikate vorschreibt, so daß sie entsprechend der Abwertung entweder Reduktionen vornehmen müssen, oder zusätzlich Zertifikate von anderen Firmen aufkaufen müssen. Bei der Versteigerung wird von vornherein nur die Zielmenge an Zertifikaten ausgegeben.

Theoretisch würden sich für Zertifikate gleichgewichtige Lösungen ergeben können, wenn Zertifikatmärkte ohne Marktversagen als ideale Märkte funktionieren könnten. Marktversagen ist jedoch, wie das Coase Theorem zeigte, bei der Konstituierung öffentlicher Umweltgüter praktisch unvermeidlich, da die Teilnehmerzahl bei öffentlichen Umweltgütern groß ist. Die Preis-StandardLösung berücksichtigt diese Probleme nicht und überschreibt die ordnungsrechtliche Konstitution des Umweltschutzes dem politisch-administrativen System. Zertifikate und Abgaben fungieren innerhalb eines solchen Rahmens als zweitbeste Lösung.

Dennoch stellen sie weitere Anforderungen, so an die Homogenität des handelbaren Umweltgutes. Ursache und Wirkung müssen in einem hinreichend ähnlichen, d.h. standardisierbaren Verhältnis stehen. Ist dies wie bei 'hot spots' nicht der Fall und lokale oder zeitliche Konzentrationseffekte übersteigen die zugrunde gelegte standardisierte Wirkung der Einheiten, verlieren Zertifikaten ihre ökonomische Effizienz als Second-Best-Lösungen. Dennoch ist das Anwendungsfeld von Zertifikaten, ebenso wie von Abgaben, weitgefaßt (allgemein: Klepper, 1998). Zur Diskussion gestellt wurden etwa Zertifikate im Verkehrsbereich (Köhn, 1996, Junkerheinrich, 1998) oder im Siedlungsbereich (Bizer, 1996). 
Zertifikate und Abgaben beruhen allgemein auf ex-post erkannten Umwelt- oder Gesundheitsschäden, die vom politisch-administrativen System gegenüber dem ökonomischen System implementiert werden. Sie begründen, dem Ansatz von Baumol und Oates folgend, nicht präventive Umweltpolitik, sondern versuchen, eingetretene Umweltschäden zu beheben oder finanziell auszugleichen. Mit dieser Ex-post-Perspektive kann auch ein detailliertes System von Zertifikaten und Abgaben eine nachhaltige Entwicklung nicht gewährleisten (Streissler, 1993).

Andererseits reduzieren Zertifikate und Abgaben die (stofflichen) Emissionen des ökonomischen Systems potentiell kostenminimal. Sie müssen dabei nicht ex-post ausgerichtet sein. Stoffliche Reduktionsziele können im Rahmen eines Diskurses über Nachhaltigkeit bestimmt werden, so daß Zertifikaten auch für die eine präventive Politik der Nachhaltigkeit eine wesentliche Rolle zukommen kann. Zertifikate und Abgaben müßten dafür beim Input ansetzen, wie dies etwa $\mathrm{CO}_{2}$ Steuern aufgrund des linearen Zusammenhangs zwischen Input und Output bereits tun. Im Sinne einer Dematerialisierungspolitik sind Zertifikate im Bereich des internationalen Klimaschutzes, allgemein bei stofflichen Immissionen und - hinsichtlich des Inputs - für natürliche Ressourcen diskutiert worden.

Hinsichtlich der Internalisierung und der Prävention von Umweltschäden wird von ökonomischer Seite besonders auf das Haftungsrecht hingewiesen. Dabei ist zwischen Verschuldungs- und Gefährdungshaftung zu unterscheiden. Der Haftungsfall tritt bei der Verschuldungshaftung dann ein, wenn der Betreiber einer Anlage eine ungesetzliche Emission verschuldet hat. Der Staat hat also bei der Verschuldungshaftung ein Emissionsniveau bestimmt, das eine legale Abgabe von Emission im Normalbetrieb gestattet. Diese Form der Internalisierung folgt dem Preis-Standard-Ansatz. Das Haftungsrecht soll darüber hinaus zur Reduktion von Emissionen anreizen und bei schuldhaften Unfällen eine Entschädigung der Opfern sicherstellen. Bei der Gefährdungshaftung muß der Verursacher für alle auf sein Handeln zurückgeführten Schäden Schadensersatz leisten. Der Schadensfall tritt unabhängig von der privat getroffenen Vorsorge bzw. unabhängig von einem Verschulden ein. Die Gefährdungshaftung weist Parallelen zur eigentumsrechtlichen Internalisierung nach dem Verursacher-Prinzip auf. Der Emittent muß dem Geschädigten den Schaden voll ausgleichen.

Beide Versicherungstypen führen theoretisch zum gleichen allokativen, pareto-optimalen Ergebnis. Sie unterscheiden sich jedoch grundlegend in ihren distributiven Auswirkungen, da die Verschuldungshaftung nur einen Ausgleich für Emissionen oberhalb des gesetzten Standards verlangt. Die von Emissionen Betroffenen müssen den Schaden bei nicht schuldhaftem Handeln im Normalbetrieb hinnehmen. Allerdings liegt hier derselbe Zusammenhang zwischen Allokation und Distribution vor wie beim Coase-Theorem. Langfristig erhöht die Gefährdungshaftung den Preis von Gütern, was zu einem geringeren Produktionsniveau und demnach auch Emissionsniveau der Industrie gegenüber der Verschuldungshaftung führt.

Das Modell beruht jedoch offensichtlich auf eine Reihe äußerst restriktiver Voraussetzungen (vgl. Endres, 1994, 68 f): 1. Es wird vollständige Information vorausgesetzt. 2. Die politischadministrativen Institutionen können das Emissionsniveau der Verschuldungshaftung pareto- 
optimal bestimmen. 3. Der Markt ist durch vollständige Konkurrenz charakterisiert. 4. Schäden und Schadensersatzzahlungen sind identisch und kommensurabel. Unter praktisch-realen Bedingungen kommt es dagegen zu Abweichungen zwischen Schadenshöhe und Schadensersatzzahlungen, so daß Emittenten eine Diskontierung des Schadens vornehmen. Dies läßt sich u.a. zurückführen auf Wirkungsbrüche durch Beweislastprobleme und Haftungsbegrenzungen und hat zur Folge, daß die Internalisierung externer Effekte durch Haftung nicht erreicht wird.

F. Söllner hat darauf hingewiesen, daß die praktische Umweltpolitik regelmäßig eine unterschiedliche Behandlung von kontinuierlichen Emissionen und Unfällen aufweise (Söllner, 1997). Der ökonomischen Theorie zufolge können sowohl Zertifikate und Steuern (ex-ante Anreize) als auch Haftung (ex-post Anreize) Umweltprobleme pareto-optimal internalisieren. Praktisch aber werde in der Umweltpolitik eine Regulierung favorisiert, die mittels Steuern oder Zertifikaten kontinuierliche Emissionen reduziert und über Haftungsregeln Unfälle vorbeugen will. Für die Umweltqualität sei es allerdings gleichgültig, ob Emissionen geplant oder zufällig geschehen würden. Deshalb untersucht Söllner, ob Zertifikate (Preis-Standard-Ansatz) Haftungsregeln ersetzen könnten und kommt zu dem Schluß, daß eine kostenminimale Lösung, wie allgemein bei Zertifikaten, bei mehreren involvierten Stoffen (zwei) und bei räumlichen Unterschieden zwischen Emissionen und Immissionswirkung erwartet werden kann, daß aber in der zeitlichen Dimension von Zertifikaten Probleme auftreten: Generell sind stabile Preise um so wahrscheinlicher, je länger Zertifikate gültig sind, wobei auf großen Märkten die Zertifikatdauer wiederum begrenzt wird, ohne die Preisstabilität zu gefährden. Bei dünnen Märkten sind jedoch kostenminimale Lösungen schwieriger zu gewährleisten, da Unfall-Emissionen stark variieren und somit die tatsächlichen Emissionen den erwarteten erst über lange Zeiträume entsprechen. Dies kann die ökologische Zielsetzung gefährden, so daß hier eine Priorität gesetzt werden muß. Schließlich kann in der Praxis die räumliche nicht immer von der zeitlichen Ausgestaltung des Zertifikatsystems getrennt werden. Und wie allgemein beim Zertifikatsystem kann ein begleitendes ordnungsrechtliches Instrumentarium gegen gefährdende Unfälle unerläßlich sein.

Haftungsregeln seien dagegen Alles-oder-nichts-Instrumente bei denen es keine Second-bestEffizienz gebe, wenn sie Pareto-Optimalität verfehlten. Zertifikate (und andere präventive Instrumente) würden dagegen immer kosteneffektiv sein, da sie auf die dezentralen Informationen der Firmen (über Kostenvermeidung) zurückgreifen würden und diese nicht zentral, wie bei Haftungsregeln, antizipieren müßten. Zudem seien Schadenskosten dem administrativen System eher bekannt als Firmen und Haushalten. Haftungsregime könnten dagegen nur dezentral (rule of negligence) oder zentral (strict liability) ausgestaltet werden.

Ein System von Haftungen mündet demnach nicht auf einen volkswirtschaftlichen First-bestPfad der Nachhaltigkeit ein. Gleichwohl wird Haftung immer wieder als Instrument präventiver Umweltpolitik empfohlen. Inwieweit kann es einem solchen Präventionsanspruch gerecht werden? Da eine Gefährdungshaftung weniger Informationsaufwand für das politisch-administrative System beinhaltet als eine Verschuldungshaftung, scheint sie sich für Ziele präventiver Umweltpolitik a priori besser zu eignen als eine Verschuldungshaftung. Denn ein solches Haftungssystem ist 
zukunftsgerichtet und muß sich nicht nur unter ökologischem Risiko, sondern auch unter ökologischer Unsicherheit bewähren. Die verschiedenen Formen ökologischer Unsicherheit aber erhöhen die Gefahr von Wirkungsbrüchen und vergrößern in der Folge die Schadensdiskontierung durch die Verursacher. Unter den Wirkungsbrüchen leidet folglich die ökonomische Effizienz. Ebenso wird die ökologische Effektivität von Gefährdungshaftungen durch das Wirtschaftswachstum gefährdet. Dennoch geht vom Haftungsrecht unter ökologischer Unsicherheit eine dynamische Anreizwirkung aus, die einen strukturellen Wandel in Richtung ökologischer Sicherheit unterstützt.

Beiden optimalitätsorientierten Ansätzen der Umweltökonomie, sowohl der Pigou-Steuer als auch den Coase-Verhandlungen, ist ein fehlender Bezug zur umweltpolitischen Praxis vorgeworfen worden (vgl. Dietz, Straaten, 1991). Sie behaupten die Möglichkeit einer internen, intertemporalen Lösung der ökologischen Krise durch den Markt, wenn der Staat nur die entsprechende Serie von steuer- oder eigentumsrechtlichen Grundsatzentscheidungen fällt. Die empirische Erfahrung mit 30 Jahren Umweltpolitik geben jedoch keinen Hinweis auf marktwirtschaftliche (Selbst)Regulation qua Pigou-Steuer oder Coase-Verhandlungen. Die Bestandsaufnahme von implementierten Zertifikaten und Abgaben nach dem Preis-Standard-Ansatz fällt demgegenüber zwar positiver aus, entspricht jedoch keinesfalls dem ökologischen Problemdruck (Michaelis, 1995). Dies führt zu der Frage, wieso die Umweltökonomie so selten angewandt wird und die von ihr empfohlenen Instrumente auf so viel gesellschaftlichen Widerstand stoßen, wobei der Widerstand sowohl von produzierender als auch von konsumierender Seite mobilisiert wird. Die Antworten von ökonomischer Seite verweisen zur Erklärung umweltpolitischen Stillstands zumeist auf die Strukturen des politischen Prozesses (Stavins et al., 1997; Frey, Schneider, 1997; Horbach, 1992). Welche Institutionen der Marktwirtschaft für eine nachhaltige Entwicklung reformiert werden müssen, um einen (selbst)gefährdenden sozio-ökologischen Stillstand zu überwinden, wird nur selten thematisiert (Opschoor, 1996). Möglichkeiten der Konsum- und Kulturkritik bleiben, nicht zuletzt aufgrund der vermeintlichen Objektivität von souveränen Präferenzen (Norton, et al., 1998) oder Marktstrukturen (Söderbaum, 1994), in der neoklassischen Lehre unausgeschöpft. Wie man vom kostenorientierten Ansatz der neoklassischen Umweltökonomie zu einer am Wert der Natur orientierten ökologischen Ökonomik kommt, wird kaum reflektiert.

Keine der drei Konzepte (Coase, Pigou, Preis-Standard-Ansatz) entspricht diesen Bedingungen im Sinne einer gleichgewichtigen, intertemporalen Allokation. Für die Pigou-Steuer-Lösung erweisen sich die externen ebenso wie die internen Unsicherheiten des Wirtschaftssystems als zu groß. Und im Fall von Nutzungsrechten (Coase) ebenso wie im Fall von öffentlichen Gütern (PreisStandard-Lösung) hat die Erhöhung der Anzahl der Teilnehmer genau den gegenteiligen Effekt wie im Fall von privaten Gütern. Es ist damit in beiden Fällen nicht garantiert, daß die beste Ergänzung versagender Privatgütermärkte Märkte für öffentliche Güter sind. In allen drei Lösungsansätzen kann der Markt keine endogene Lösung generieren.

Nicht zuletzt aufgrund der Probleme, die optimale intertemporale Allokation umweltökonomisch zu sichern, ist das Modell nachhaltigen Wachstums (Solow-Hartwick-Modell) seit den 70er Jahren 
Zielscheibe ökologischer Kritik gewesen. Die praktische Umweltpolitik und die theoretische Arbeit zur Internalisierung von Umweltschäden haben gezeigt, daß eine notwendige Voraussetzung von ökologischen Gütern zumeist nicht erfüllt wird, nämlich die von Homogenität, d. h. von marginal und kontinuierlich zu bemessender Quantität von Natur. Die Anforderung der Homogenität wird von Umweltgütern regelmäßig in räumlicher und zeitlicher Hinsicht durchbrochen. Aufgrund dieser empirisch-umweltpolitischen Probleme ist besonders die Prämisse des homogenen Kapitalstocks kritisiert worden. Diese behauptet die Substitution von natürlichem durch produziertes Kapital gemäß der zugrunde gelegten Produktionsfunktion. In Erweiterung dieser Problematik ist kritisch zu sehen, daß die Hartwick Regel an Preise gebunden ist und nicht an die natürliche Umwelt. Für einen erweiterten intertemporalen Allokationspfad gemäß der Solow-Hartwick Regel muß der gesamte Kapitalstock (also mit allen Naturgütern) vollständig monetär erfaßt sein, da sich ansonsten Investitionen und Wertminderungen nicht entsprechen können und damit das intertemporale Optimum verfehlt werden würde (vgl. Common, Perrings, 1992, 13 ff; Dubourg, Pearce, 1996). Dies bedeutet, daß die gesamte belebte Umwelt kommensurabel gemacht werden müßte. Simulierte Märkte für Umweltgüter, wie beim Preis-Standard-Ansatz, sind nicht ausreichend, um ein intertemporales Optimum zu erzielen; denn obwohl der Preis-Standard-Ansatz theoretisch ein vollständiges System von Märkten etablieren kann, die auch mit einem augenblicklichen ökonomischen Gleichgewicht übereinstimmen können, resultiert daraus für die globalen Ressourcen entweder ein ineffizienter oder ein unrealisierbarer Zeitpfad (Radke, 1995). Der Wachstumstheorie gelingt es nicht, die neoklassische Reproduktion des ökonomischen Systems so zur natürlichen Umwelt in Beziehung zu setzen, daß eine nachhaltige Reproduktion der Gesellschaft in der natürlichen Umwelt zu erwarten wäre. Alle empirischen Beobachtungen sprechen dagegen, daß die ökologische Krise der Menschheit seit Formulierung der oder gar durch die Wachstumstheorien entschärft worden wäre. ${ }^{57}$

Zur Wahrung einer minimalen Form ökologischer Nachhaltigkeit ist die Erhaltung bestimmter Funktionen der Natur als notwendige, minimale Bedingung anzusehen. Deren nähere Bestimmung fällt zusammen mit der Beobachtung des emergenten Outputs des ökonomischen Systems, sprich seines Stoffstroms. Mit der ökologisch motivierten Berücksichtigung des Stoffstroms findet ein zentraler Gegenstand der Naturwissenschaften Eingang in die Ökonomie. Einen wesentlichen Schritt zur Integration des Stoffstroms in das Theoriegebäude der Ökonomie hat die ökologische Ökonomie geleistet. ${ }^{58}$

Diese unterscheidet sich in ihrer Behandlung von Natur fundamental von der neoklassischen Umwelt- und Ressourcentheorie, so daß von einem Paradigmenwandel in der Ökonomie gesprochen werden kann. Allerdings ist die Übertragung des Kuhnschen Paradigmabegriffs auf sozialwissenschaftliche Sachverhalte wissenschaftstheoretisch problematisch. Aufgrund des zentralen Stellenwertes von Unsicherheit und Irreversibilität im Konzept der Nachhaltigkeit wurde

\footnotetext{
57 Tatsächlich wurden die dogmatischen Wachstumstheorien alle erst nach Erscheinen von D. Meadows' Studie über die Grenzen des Wachstums (1972) entwickelt!

58 Vgl. zu ihrer Geschichte Martinez-Alier, Schlüpmann, 1987.
} 
wiederholt auch gefordert, die ökologische Ökonomie als eine postnormale-Wissenschaft (postnormal-science) zu betreiben (Funtowicz, Ravetz, 1994a; Luks, 1996). Dies solle sich insbesondere ökologischen Verteilungsfragen (life-support-systems, natural assessments) und Externalitäten annehmen (Funtowicz et al., 1997). Postnormale-Wissenschaft wird als praxisbezogene Wissenschaft angesehen, die nicht mehr dem Kuhnschen Entwicklungsmodell folgt soll. Im Rahmen der Kuhnschen Theorie wäre die Rede von einem Paradigma der ökologischen Ökonomie angesichts Kuhns Zurechnung der Ökonomie zu den Sozialwissenschaften zweifellos rhetorisch (Turner et al., 1997). Doch die Rede von einem Paradigma der ökologischen Ökonomie kann den starken Anspruch der naturwissenschaftlichen Fundierung für sich geltend machen (Christensen, 1989). Dies unterscheidet die ökologische Ökonomie nicht nur von der neoklassischen Ökonomie, sondern auch von jeder anderen sozialwissenschaftlichen Theorie. Insofern ist der auch allgegenwärtige Paradigmabegriff nirgendwo sonst in den Sozialwissenschaften besser angebracht als in bezug auf die ökologische Ökonomie.

Die Neoklassik steht dagegen im Teilbereich der Ressourcenökonomie in ungebrochener Folge der fortschrittsoptimistischen Wachstumstheorie. Sie verkennt und ignoriert dabei naturwissenschaftliche Fakten, und zieht sich dann auf ihre mechanistischen und deduktiven Kernaussagen zurück (Daly, 1995). Diese Litanei wird inzwischen von einzelnen neoklassischen Umweltökonomen unterbrochen und eine ökologisch 'aufgeklärte Neoklassik' eingefordert (Gawel, 1996). Trotz der damit verbundenen Einschränkungen des Erklärungsanspruchs bleibt das Verhältnis zwischen Umwelt- und Ressourcenökonomie in der neoklassischen Ökonomie ungeklärt. Die ökologische Ökonomie kann zeigen, daß der von Umwelt- und Ressourcenökonomik nur implizit behandelte Energie- und Materiestrom Eigenschaften besitzt, welche eine legitime Separierung der beiden Bereiche in der Neoklassik widerlegen. Der neoklassischen Umwelt- und Ressourcenökonomie stehen somit noch Lernprozesse bevor, die vor allem die naturwissenschaftlichen Beschränkungen ökonomischer Prozesse betreffen. ${ }^{59}$ Allerdings steht auch die ökologische Ökonomie vor wissenschaftstheoretischen und forschungspraktischen Herausforderungen, welche neben der Operationalisierung ihrer naturwissenschaftlichen Erkenntnisse insbesondere die Motivation der Wirtschaftsakteure betreffen (Duchin, 1996). Aus politikwissenschaftlicher Sicht erscheinen die motivationalen Aspekte als das zentrale Problem von Nachhaltigkeit.

Es bietet sich für die folgende Darstellung an, der üblichen Unterscheidung zwischen starker und schwacher Nachhaltigkeit im Rahmen der ökologischen Ökonomie zu folgen und ganz auf die Darstellung von solchen (neoklassischen) Positionen in der Ökonomik zu verzichten, welche gegen die empirische Evidenz die Notwendigkeit eines Nachhaltigkeitsdiskurses nicht einmal anerkennen. $^{60}$

59 So sparen etwa die Standardlehrbücher zur Umwelt und Ressourcenökonomie von A. Endres (1994 u. 1995) die Diskussion entropischer Aspekte des ökonomischen Prozesses ganz aus.

60 Damit folgt die Arbeit nicht R. Steurers (2001) Dreiteilung von schwacher, ausgewogener und starker Nachhaltigkeit. Diese Trias kann zwar die Kontinuität zwischen der Wachstumsdebatte der 70er und dem Nachhaltigkeitsdiskurs seit den 80er Jahren klar aufzeigen und damit die ökonomistische Prägung des Nachhaltigkeitsdiskurses 


\subsection{Thermodynamik und die Grenzen der Ökonomie}

Durch die ökologische Kritik des Solow-Hartwick Modells wurde die Wachstumstheorie mit physikalisch-ökonomischen Theorien konfrontiert, die den Markt als zeitlich gerichtetes System eines durch thermodynamische Gesetzlichkeiten charakterisierten Metabolismus zwischen Wirtschaftssystem und Natur verstehen. Aus der Kritik bildete sich der Ansatz der ökologischen Ökonomie heraus (vgl. Constanza et al., 1991; Constanza et al., 2001; Proops, 1989; Duchin, 1996, Siebenhüner, 1996; Gowdy, Carbonell, 1999). Im Unterschied zur neoklassischen Ökonomie berücksichtigt die ökologische Ökonomie die physikalische, thermodynamische Theorie explizit. Die Physik der Thermodynamik ist relevant für die Gesetzmäßigkeiten der Transformation von Energie in Materie (und umgekehrt), die Zusammenführung von Ressourcenallokation und Umweltverschmutzung und die Erklärung der Irreversibilität des ökonomischen Prozesses (vgl. Vornholz 1997). Im Sinne der Persistenz physikalischer Bewegungsformen in allen höheren Bewegungsformen können thermodynamische Gesetze niemals verletzt werden (Ebeling, 1991, 344). Sie beschreiben demnach auch fundamentale Beschränkungen des ökonomischen Prozesses.

Die systematische Beschreibung des ökonomischen Prozesses als entropischer Prozeß ist zentraler und damit fundamentaler Gegenstand der ökologischen Ökonomie geworden. Erstmals wurde der Ökonomie 1971 durch Georgescu-Roegen als durch thermodynamische Gesetze limitierten Prozeß beschrieben. ${ }^{61}$ Nach dem ersten Hauptsatz der Thermodynamik können Energie und Materie weder geschaffen, noch zerstört werden. Energie und Materie lassen sich nur transformieren, wobei die Transformation weniger geordnete Formen nach sich zieht. Nach dem zweiten Hauptsatz der Thermodynamik steigt die Entropie in einem geschlossenen System kontinuierlich bis zu seinem Maximum, dem thermodynamischen Gleichgewicht, an. Entropie bezeichnet dabei das Maß an Ordnung, bzw. das Maß gebundener Energie. Georgescu-Roegen machte als erster beide thermodynamischen Gesetze für den ökonomischen Prozeß geltend (vgl. Georgescu-Roegen, 1994). Der ökonomische Prozeß greift demnach permanent auf ungebundene Energie zurück und hält seine Strukturen durch die permanente Verteilung gebundener Energie aufrecht (Dissipation). Entropisch besehen ist der ökonomische Prozeß ein defizitärer Prozeß, der auf die absolute Knappheit von Energie für menschliche Tätigkeiten verweist. Dabei liegt ihm ungebundene Energie nur in zwei Formen vor: als energetischer Bestand (Biomasse, Kohle, Gas, Öl und Uran) und als energetischer Fluß (Gezeiten, Sonnenenergie und ihre Dissipationsformen Windund Wasserenergie) (vgl. Hubbert, 1994). Der ökonomische Dissipationsprozeß ist zeitlich gerichtet; er ist irreversibel.

Bezogen auf Energie war Georgescu-Roegens Kritik an der neoklassischen Theorie stichhaltig. Er hatte aber auch die Dissipation von Materie im ökonomischen Prozeß direkt thermodynamisch

insgesamt nachweisen. Der integrative Ansatz fordert jedoch keine Lernprozesse seitens jener Ökonomen ein, die Nachhaltigkeit schlicht ablehnen. M. E. sind die entsprechenden Ansätze im Grunde nur noch über eine Ideologiekritik zugänglich, denn sie streben aus der ökonomischen Perspektive eine Totaldeutung der Welt an; vgl. dazu Habermas, 1981, II, 519 f.

61 Zur Wirkung des Ansatzes von N. Georgescu-Roegen in der Ökonomie vgl. Cleveland, Ruth, 1997. 
zu begründen versucht. Dies wurde in der Physik jedoch nicht bestätigt. Unmittelbar durch die gleichgewichtsnahe Thermodynamik kann nur die energetische Begrenzung des ökonomischen Prozesses begründet werden (vgl. Cleveland, Ruth, 1997, 209 ff). Erst später wurde der mittelbare Zusammenhang zwischen dem Energie- und Materiestrom im ökonomischen Prozeß durch M. Faber, H. Niemes und G. Stephan hergeleitet (Faber et al., 1987; auch Stephan, 1992). Diese Herleitung beruht auf der Annahme einer Materiekonzentration in der extrahierten Ressource gegenüber dem Ausgangsgestein. Zur produktionsnotwendigen Erhöhung der Konzentration ist ein Energieeinsatz erforderlich, der im Verlauf des Abbaus logarithmisch zunimmt. (Das Modell bezieht sich dabei auf die Annahmen der Ressourcenökonomie, demzufolge im Verlauf der Ressourcenextraktion zunächst immer Lager höherer Qualität abgebaut werden.) Bezüglich des Solow-Hartwick-Modells konnte damit gezeigt werden, das dieses einen logarithmischen Anstieg des Energieverbrauchs beim Abbau unberücksichtigt gelassen hat. Im Gegensatz zum Konzept relativer Knappheit der neoklassischen Ökonomie verweist dies auf absolute Knappheit bezüglich der endlichen, energetischen Ressourcen. Energie und Ressourcenextraktion stehen in einem hierarchischen Verhältnis. Damit konnte die Annahme absoluter Knappheit indirekt in bezug auf Materie bestätigt werden.

Die Herleitung energetischer Prozesse durch die gleichgewichtsnahe Thermodynamik geschlossener Systeme weist jedoch Grenzen auf. Offensichtlich finden alle anthropogenen und ökologischen Prozesse nicht in isolierten Systemen, sondern in offenen Systemen statt, auf welche die klassische Thermodynamik nur sehr eingeschränkt bezogen werden kann. Zur Beschreibung offener Systeme wie dem ökonomischen ist hingegen die gleichgewichtsferne Thermodynamik relevant. Sie ermöglicht die physikalische Erklärung von Dissipationsphänomenen. Offene Systeme erzeugen und erhalten ihre Strukturen fern des thermodynamischen Gleichgewichts durch die ständige Dissipation von Energie und Materie, die sie aus der Umwelt des Systems beziehen. Dabei wird die Entropie in der Umwelt des offenen Systems erhöht, wobei die Entropieerhöhung um so größer ist, je weiter das offene System vom Gleichgewicht entfernt ist. Offene Systeme zeichnet Zeitlichkeit aus, d. h. ihre Strukturen prägen sich an Bifukurationen nicht-deterministisch und irreversibel aus. Prinzipiell können sie in der Physik und der Chemie durch nicht-lineare partielle Differentialgleichungen beschrieben werden, - was in der Ökologie und der Biologie nicht möglich ist (Binswanger, 1994, 168).

Für die ökologische Ökonomie erweisen sich Modelle interessant, die sich auf derartige dissipative Strukturen, d.h. die gleichgewichtsferne Thermodynamik, beziehen (Binswanger, 1994, 165 ff, Heinemann, 1994; Der, 1994). Dissipative Strukturen stellen insofern eine vielversprechende Heuristik dar, als daß in ihnen ein Fließgleichgewicht in Form eines kontinuierlichen Energie- und Materiestroms aufrecht erhalten wird, was zunächst auf einer rein deskriptiven Ebene Ähnlichkeiten zum ökonomischen Prozeß aufweist. Die gleichgewichtsferne Thermodynamik erlaubt aber auch die fundamentale Aussagen über den ökonomischen Prozeß, daß der im ökonomischen System aktivierte Stoffstrom nicht nur irreversibel ist, sondern auch 
degradiert (Binswanger, 1994). Der Stoffstrom kann zwar durch Recycling länger erhalten werden, doch müssen dazu ständig neue Materialien und Energie hinzugefügt werden.

Die qualitativen Aussagen der gleichgewichtsfernen Thermodynamik betreffen sowohl die InputSeite als auch die Output-Seite des ökonomischen Systems und weisen damit vom additiven Modell der Umwelt- und Ressourcenökonomik weg. Allerdings zeigt sich auf der Output-Seite des ökonomischen Prozesses auch, daß der Entropieansatz die äußerst vielfältigen Phänomene der Naturzerstörung nur unvollständig beschreibt. Denn die Umweltwirkung des entropischen Stoffstroms unterliegt prognostischer oder ökologischer Unsicherheit, die allenfalls sehr eingeschränkt als ökologisches Risiko modelliert werden kann, bzw. prognostizierbar ist (s. S. 51 ff). Die unsicheren Folgen des Stoffstroms werden erst ex-post in der Natur sicher beobachtbar. Einer umfassenderen naturwissenschaftlichen Perspektive auf ökonomische Prozesse stehen auch quantitative Probleme entgegen, Entropie im ökonomischen System zu messen (vgl. Ebeling, 1991, 1994) Es besteht insbesondere eine Informationsasymmetrie zwischen stofflichem Input und seinem Output, da es unter den Stoffen zu Synergien und zwischen den Stoffen und natürlicher Umwelt zu komplexen Assimilations- und Reaktionsprozessen kommen kann. Qualitative Analysen untersuchen den Stofffluß chemisch-physikalisch und toxikologisch, quantitative Analysen bemühen die Thermodynamik nur indirekt über die Annahme einer konstanten Materialbilanz.

Obwohl also die Thermodynamik nicht überall zur Untersuchung ökonomisch-ökologischer Prozesse herangezogen werden kann, erklärt sie das ökonomische System als einen den physikalischen Gesetzmäßigkeiten folgenden Prozeß. So ermöglicht die thermodynamisch begründete Konstanz der Materialbilanz eine näherungsweise Beschreibung des Stoffstroms (Ayres, Martinás, 1995), der in seiner ökologischen Wirkung somit zwar prognostischer, nicht jedoch epistemologischer Unsicherheit unterliegt. ${ }^{62}$ Damit stellt sich die vermeintliche Singularität von Externalitäten ganz im Gegensatz zur neoklassischen Lesart im materiell geschlossenen System der Erde als Regelfall des ökonomischen Prozesses dar (Ayres, Kneese, 1989). Wenn Umweltpolitik unter Unsicherheit implementiert wird, betrifft diese Unsicherheit nicht Naturgesetze, sondern die Prognosegrenzen naturwissenschaftlicher Modelle. Die Entwicklung von Wirtschaftssystemen und die Komplexitätsreduktionen in Ökosystemen steht in einer ständigen Wechselbeziehung, "die sich ohne das Entropiegesetz und die darauf aufbauenden Evolutionstheorien nicht verstehen läßt." (Binswanger, 1994, 195) Damit lassen sich bereits weitreichende Ansprüche an eine Reform des ökonomischen Systems verbinden (vgl. Pastwoski, 1994).

Doch einem durchgehend thermodynamischen Ansatz sind nicht nur hinsichtlich der Analyse der Stoffströme Grenzen gesetzt. Er kann auch unmittelbare anthropogene Umweltwirkungen wie Waldrodung, Artensterben nicht beschreiben. Diese sind nur in kulturellen Kontexten zu verstehen und lassen sich nicht auf ein 'entropisch-physikalisches Weltbild' zurückführen. Historisch wurden in der biologisch-ökosystemischen Dimension die Umweltprobleme (Ozonschicht, Klima, Wald, Boden etc.) derart akut, daß die von der Neoklassik verdrängte Thematik absoluter

${ }^{62}$ Vgl. zu den prognostischen Möglichkeiten einer ökologischen Ökonomie Ramos-Martín, 2003. 
Ressourcenknappheit umgehend wieder an Bedeutung gewann und als zu erhaltendes Naturkapital nunmehr die Assimilationsfunktion der Natur zum Gegenstand der Ökonomik machte.

\subsubsection{Naturkapital und schwache Nachhaltigkeit}

Das Konzept des Naturkapitals, welches zuvorderst von der sogenannten 'Londoner Schule' entwickelt wurde, hat sich in ihrem Beitrag zum Nachhaltigkeitsdiskurs einerseits weiter an der neoklassischen Wachstumsposition orientiert, andererseits bereits Einsichten der ökologischen Ökonomie aufgenommen. Die Definition von nachhaltiger Entwicklung des Brundland-Berichts wird wie beim Solow-Hartwick-Modell noch utilitaristisch interpretiert: Nachhaltigkeit beruhe auf einer im Zeitablauf nicht-sinkenden gesellschaftlichen Wohlfahrt. Andererseits wird die strikte Erhaltung von einigen Naturgütern als notwendig angesehen: Der natürliche Kapitalstock ist konstant zu halten und damit Nachhaltigkeit im starken Sinne zu verwirklichen (strong sustainability). Damit werden nicht nur Konsumentenpräferenzen als wohlfahrtsstiftend angesehen, sondern auch unmittelbar Ressourcenbestände. Im Unterschied zur Mehrzahl der neoklassischen Modelle wird Natur so als Produktionsfaktor in die Wohlfahrtstheorie aufgenommen. Nachhaltigkeit wird dann durch die Konstanz des ökonomischen Wertes von Naturkapital operationalisiert. Bedeutsam ist das Konzept der Londoner Schule vor allem deshalb, weil es operationalisierbar ist und bereits zur Modifikation volkswirtschaftlicher Rechnungssysteme geführt hat.

Die Ökonomie wird von der Londoner Schule - im Sinne Bouldings - als zirkuläres, mit der Umwelt vernetztes Wirkungsgefüge verstanden. Die verschiedenen Vermögensbestandteile an menschgeschaffenen Kapital, Humankapital und natürlichem Kapital sind interdependent. Dies schränkt die Substitution von Kapitalgütern ein. Insbesondere Naturkapital ist oft nicht substituierbar und zudem oft multifunktional. Da die Umwelt ein offenes und komplexes System ist, herrscht Unsicherheit über genaue Wirkungszusammenhänge und mögliche irreversible Effekte von Immissionen. Aus diesen ökologischen Bedingungen wird die Forderung abgeleitet, den natürlichen Kapitalstock konstant zu halten.

Die natürliche Umwelt wird als Bestand von Gütern angesehen, mit dem weitere Güter produzieren werden können. Natur ist Produktionsfaktor, der sich nach Überzeugung von El Serafy theoretisch sogar als öffentliches Gut ohne Marktpreis erhalten ließe, aus praktischen Gründen aber als Naturkapital behandelt wird (El Serafy, 1991, 169 f). Dies muß in seinem ökonomischen Wert bewahrt werden. Naturkapital ist in die Berechnung des Bruttosozialprodukts (BSP) einbezogen worden. $^{63}$

63 Der dabei zugrunde gelegte Hicksche Einkommensbegriff bezeichnet die Menge des Konsums eines Staates, die er innerhalb einer Periode konsumieren kann, ohne daß sein Wohlstand am Ende der Periode gegenüber jenem zu Beginn sinkt. 
Im Ansatz der Londoner Schule ist schwache Nachhaltigkeit (weak sustainability) kein hinreichendes Kriterium für Nachhaltigkeit, da sinkende Naturbestände durch andere Kapitalformen gemäß der beibehaltenen neoklassischen Produktionsfunktionen substituiert werden können. Gleichwohl fungiert aufgrund der intertemporalen Wohlfahrtsannahmen das Wachstum des BSPs (noch) als notwendiges Kriterium (vgl. zur Kritik des BSPs als Wohlfahrtsindikator und zu Alternativen: Costanza et al., 2001, 133 ff). Dabei wird Wachstum begrenzt durch einen sinkenden Ressourceninput und den Erhalt des natürlichen Kapitals. ${ }^{64}$ Dies macht die ökologische Modifizierung der volkwirtschaftlichen Gesamtrechnung (VGR) notwendig. El Serafy hat für das BSP die Berücksichtigung von Erträgen aus erschöpfbaren Ressourcen als Einkommen angeregt. Dazu unterteilt er die Erträge aus erschöpfbaren Ressourcen in einen Einkommens- und einen Kapitalteil. Das Einkommen bezieht sich auf jenen Teil der Erträge, der über einen unendlich langen Zeitraum jährlich unter der Bedingung verbraucht werden kann, daß die verbleibenden Erträge in erneuerbare Ressourcen investiert werden. Die Summe der Erträge aus den erneuerbaren Ressourcen und den jährlichen Investitionen in erneuerbare Ressourcen ist so hoch, daß mit der Erschöpfung der endlichen Ressource die erneuerbare Ressource ein Einkommen bereitstellt, das dem aus den endlichen Ressourcen entspricht. Dies überführt eine endliche Reihe von Erträgen aus einer Ressource, die diese erschöpfen, in eine unendliche Reihe echten Einkommens, so daß sich der Kapitalwert beider Reihen letztlich entspricht. Dies zielt auf starke Nachhaltigkeit und relativiert die mit dem Rückgriff auf die Wachstumstheorie unterstellte vollständige Substituierbarkeit von menschgeschaffenem und natürlichem Kapital.

Ökologische Indikatoren als Ergänzung der Messung des Bruttoinlandsproduktes (BIP) erfassen zwar die Einkommensentwicklung genauer, erlauben jedoch keine sicheren nachhaltigkeitspolitischen Empfehlungen. Deshalb verfolgen -orientiert an El Serafy - Pearce und Atkinson ein Konzept angepaßter Ersparnisse (adjusted savings) und Hamilton eines echter Ersparnisse (genuine savings). Explizit als ökonomischer Indikator schwacher Nachhaltigkeit dient das Konzept echter Ersparnis, das sich am Einkommensbegriff von Hicks orientiert. Demnach bestehen langfristig nur solche, als 'wahres Einkommen' zu bezeichnenden Geldströme, die ohne Verzehr von Kapitalgütern einschließlich Naturkapital erzielt werden können. Die echte Ersparnis benennt also den Teil des volkswirtschaftlichen Outputs, der nicht konsumiert oder für Abschreibungen aufgewandt wird, sondern für die Vermehrung zukünftigen Wohlstands zur Verfügung steht. Dies bezieht sich aber auch auf natürliches Kapital. Ausgehend vom BIP sind Abschreibungen auf natürliches Kapital in die volkwirtschaftliche Gesamtrechnung einzubeziehen. Dazu werden natürliche Rohstoffe und Umweltverschmutzung in der VGR berücksichtigt, d.h. ihre Nettobeträge ebenso wie Konsum und Abschreibungen von produziertem Kapital vom BIP abgezogen.

Echte Ersparnis erfaßt auf diese Weise die Erschöpfung von Ressourcen und die Akkumulation von Emissionen. Die berechnete echte Ersparnis gilt aber nur als schwach nachhaltig, weil die Methodik implizit die Substituierbarkeit von Kapitalgütern annimmt. Sie legt im Gefolge der

${ }^{64}$ Die erste Bedingung geht über A. Endres' Konzeptionalisierung von nachhaltiger Entwicklung hinaus, die intersektorale Substitution (zwischen natürlichem und produziertem Kapital) erlaubt; vgl. Endres, 1993. 
Neoklassik eine unbegrenzte Substitutionselastizität zwischen natürlichem und produziertem Kapital zugrunde (Pearce, Atkinson, 1993, 103 ff und Pearce et al., 1996). Echte Ersparnis verfehlt schwache Nachhaltigkeit dann, wenn sie über mehrere Perioden negativ ist, so daß der Bestand an Kapitalgütern dauerhaft abnimmt. Die mit dem Ansatz verbunden Monetarisierungsprobleme werden prinzipiell als lösbar angesehen. ${ }^{65}$

Der Indikator echter Ersparnis ist bereits praktisch angewandt worden (Hoffmann, Radke, 2000, 149 ff). Zur Erfassung der sozialen Dimension schwacher Nachhaltigkeit hat man seitens der Londoner Schule neben dem BIP den Human Development Index (HDI) der Vereinten Nationen hinzugezogen und u.a. für eine umweltbezogene Erweiterung plädiert. Als ökologische Indikatoren starker Nachhaltigkeit wird der Aufbau eines Umweltinformationssystems in Erweiterung des Pressure-State-Response-Ansatzes (PSR-Ansatz) der OECD um einen Impact-Aspekt vorgeschlagen (PSIR-Ansatz). Vertreter des Naturkapital-Ansatzes bestreiten nicht die grundsätzliche Möglichkeit und ev. sogar Notwendigkeit, darüber hinaus Nachhaltigkeit makroökonomisch geltend zu machen. Sie sind allerdings ausgesprochen skeptisch bezüglich der Operationalisierbarkeit starker Nachhaltigkeit. ${ }^{66}$

Während die Feinsteuerung der Umweltqualität von Ökosystemen direkt an den Akzeptoren (impacts) ansetzen muß und dazu kleinräumiger und komplexer Umweltinformationssysteme bedarf, kann die Grobsteuerung der Umweltqualität bei den Inputs (z.B. Energie, Stoffe) und Outputs (z.B. Emissionen) der Verursacher ansetzen. Im Kern verfolgt eine solche Strategie die Ermittlung und Einhaltung kritischer Belastungswerte als Indikatoren für die ökologische Aufnahmekapazität. Da kritische Belastungswerte nicht für alle Akzeptoren ermittelbar sind und die Zurechnung auf einzelne Verursacher aufgrund komplexer Ursache-Wirkungs-Zusammenhänge teilweise nicht möglich ist, kann es, insbesondere im vorsorgenden Umweltschutz, opportun sein, eine Grobsteuerung mit Hilfe geeigneter Input- und Outputgrößen des Produktionsprozesses zu verfolgen. (Ewers, Rennings, 1996, 430)

Wie eine derartige Grobsteuerung umweltpolitisch und makroökonomisch aussehen soll, wird jedoch nicht entwickelt.

Das ökonomisch orientierte Konzept nachhaltiger Entwicklung strebt die Erweiterung der VGR zu einer Umweltökonomischen Gesamtrechnung (UGR) an, welche die Berechnung eines nachhaltigen Einkommens ermöglicht und so Wohlfahrtsveränderungen korrekter abbilden soll als das BSP. Die Crux schwacher Nachhaltigkeit aber ist die Annahme, daß lediglich die Summe von Naturkapital und produziertem Kapital konstant gehalten werden muß, um die Wohlfahrt zu sichern. Dies impliziert, daß Naturkapital und produziertes Kapital substituierbar sind. Um diese These wieder zu relativieren, wird mitunter pragmatisch auf Indikatorensysteme zurückgegriffen, welche die spezifischen Umweltschäden genauer zu fassen versuchen. Sollen dabei aber nicht monetäre und physische Indikatoren völlig unverbunden nebeneinander stehen, sondern Substitution partiell zugelassen werden, können mehrere physische Bestandsniveaus nachhaltige Korridore festlegen, innerhalb derer Kompensation für sinkende monetäre Werte und nicht

65 Vgl. aber zu den Problemen der Monetarisierung von Umweltgütern: Schulz, 1987, Gronemann, Hampicke, 1997.

66 Die Skepsis schlägt dann aber um in volkswirtschaftliche Indikatorsysteme, die aufgrund heterogener und teilweise antagonistischer Zielsetzung kaum Orientierungshilfe für die (Umwelt)politik bieten (vgl. Bartelmus, 1998). Zur Ausgestaltung bestehender Indikatorensysteme in Richtung Nachhaltigkeit vgl. auch Spangenberg, Bonniot, 1998. 
reflektierte Wohlfahrtsverluste möglich (und erforderlich) ist (vgl. zum Konzept von Endres und Radke: Radke, 2001). Die Hierarchie zwischen physischen Bestandsniveaus und nachhaltigen, monetär erfaßten Korridoren verweist wiederum auf starke Nachhaltigkeit.

Seitens der Londoner Schule wird starke Nachhaltigkeit über ökologische Tragfähigkeit (carrying capacity) und, mit stärkerem Interesse, über die elastische Stabilität von Ökosystemen (resilience) zu konzeptionalisieren versucht (vgl. Pearce et al., 1996). Als Zielgrößen werden dazu im ersten Fall Nahrungsmittelproduktion, Wassernutzung und Brennholzernte angesehen, im zweiten Biodiversität. Alle diese Größen sind aus unterschiedlichen Gründen gegenwärtig nur schwer zu bestimmen und als Indikatoren auch nicht unangefochten (vgl. Pearce, Atkinson, 1993).

Das Konzept des Naturkapitals versucht, verschiedene fundamentale Funktionen der Natur zu benennen und zu operationalisieren. Das Konzept ist in diesem Sinne funktional-reduktionistisch. Es zeigt aber auf, daß der Gesellschaft notwendig Probleme entstehen, wenn anstatt von Einkommen Kapital konsumiert wird. Dies gilt auch für Naturkapital, und insofern stellt der Begriff eine nützliche Metapher dar. Seine präanalytische Konzeption (preanalytical vision) erkennt die Probleme von Substitutionsfähigkeit und Komplementarität ökologischer Funktionen sowie ökologische Unsicherheit zwar an (vgl. Bartmann, 2001), doch bezieht sich schwache Nachhaltigkeit zunächst nur auf ökologisch erweiterte ökonomische Indikatoren, welche die Substitution von Naturkapital nicht beschränken. Starke Nachhaltigkeit soll als konstantes Naturkapital ermöglicht werden; dies ist aber in der statischen Perspektive des Ansatzes ungleich schwerer zu operationalisieren als schwache Nachhaltigkeit, die auf bestehende ökonomische Indikatoren Bezug nehmen kann. Alle Versuche, starke Nachhaltigkeit operational zu fassen, kämpfen mit gravierenden Problemen, die u.a. auch auf prognostische Unsicherheit in der Ökosystemanalyse zurückzuführen sind

Andererseits weist das modifizierte Indikatorensystem schwacher Nachhaltigkeit Mängel auf, die bereits minimalen Forderungen von Nachhaltigkeit (im Sinne eines menschlichen Selbstbehauptungssystems) nicht entsprechen müssen. Wenn die empirische Anwendung des Indikatorensystems auf die Weltökonomie diese für die 80er Jahren als schwach nachhaltig auszeichnet, sind erhebliche Zweifel hinsichtlich der ökologischen und sozialen Relevanz des Indikatorensystems angebracht. Martinez-Alier hat darauf hingewiesen, daß schwache Nachhaltigkeit auf der globalen Ebene allein von der Sparrate einiger reicher Volkswirtschaften bestimmt werden kann, wenn diese die Sparrate nicht-nachhaltiger Volkswirtschaften vollständig kompensieren können (Martinez-Alier, 1995). Daraufhin ist das Modell schwacher Nachhaltigkeit auf offene Volkswirtschaften ausgedehnt worden (Proops, Atkinson, 1998), was jedoch weder seine grundlegenden Probleme lösen kann, noch den distributiven Fragen im internationalen Kontext gerecht wird (O'Connor, Martinez-Alier, 1998).

Auf das grundlegende theoretische Probleme des Ansatzes, Natur als Kapital im Sinne der Neoklassik zu behandeln, ist schon frühzeitig hingewiesen worden (Victor, 1991). Die Indikatoren des Naturkapitalansatz beziehen sich auf das BSP bzw. BIP. Dieses ist entweder ökologisch zu korrigieren (durch die Monetarisierung von potentiell immer weiteren Naturfunktionen) oder gemäß 
der verschiedenen Ersparnisformen (nach Hartwick, Pearce und Atkinson oder Hamilton) zu bereinigen. Die für den theoretischen und praktischen Wert der Indikatoren schwacher Nachhaltigkeit relevante Frage ist, wie man vom Bruttosozialprodukt als Maßstab des wirtschaftlichen Outputs der Gegenwart, zu (Netto)Ersparnissen oder einem grünen Nettosozialprodukt als Indikator für zukünftige Wohlfahrtsniveaus gelangen kann, wenn diese Indikatoren schwacher Nachhaltigkeit relativ zum gegenwärtigen Niveau des Konsums stehen, dieses aber nicht nachhaltig ist.

S. Faucheux et al. (1997) haben schwache Nachhaltigkeit modelliert und als nicht nachhaltig verworfen. Für die zugrunde gelegten Indikatoren müßten die korrekten relativen Schattenpreise des zur Disposition stehenden Naturkapitals bekannt sein (d.h. die intertemporale Produktionsmöglichkeitsgrenze sowohl für die ökonomische Produktion als auch für die ökologischen Funktionen). Dies impliziert Wissen über Substitutionselastizität und technologischen Wandel. Die Autoren verweisen darauf, daß entsprechendes empirisches Wissen über (ökonomische) Substitutionselastizitäten überhaupt nur sehr eingeschränkt (für einige wenige Sektoren und Inputs) vorhanden ist und für ökologische Substituierbarkeit überhaupt noch nicht bestimmt wurde. Kritik am Konzept schwacher Nachhaltigkeit ist auch von anderer Seite geäußert worden und geht in eine ähnliche Richtung (Martinez-Alier, 1995, 5 ff; Hinterberger et al., 1997; Hinterberger, Wegener, 1997; Funtowicz, O'Connor, Ravetz, 1997, 90). Damit stellt sich wiederum die schon in der wachstumstheoretischen Debatte aufgetretene Frage, ob Nachhaltigkeit der Ökonomie und ökonomische Nachhaltigkeit nicht gegensätzliche Paradigmen sind (Klaasen, Opschoor, 1991).

\subsubsection{Der nachhaltige Umfang des Wirtschaftssystems: Scale}

Das Ungenügen mit der bisherigen Konzeptionalisierung von Nachhaltigkeit als schwache Nachhaltigkeit hat zu einem Konzept geführt, daß den physischen Umfang des Wirtschaftssystems, die Skalierung (scale), im Sinne von Nachhaltigkeit zu bestimmen versucht. Im Gegensatz zu der auf individuelle Präferenzen zurückgeführten relativen Knappheit in der neoklassischen Theorie beharrt das Steady-State-Konzept von H. Daly auf einer absoluten Knappheit der Ressourcen (Daly, 1990). Diese wird auf die bereits erläuterten thermodynamischen Restriktionen zurückgeführt. Es unterscheidet sich aber auch vom Konzept schwacher Nachhaltigkeit, welches das Umweltproblem aus der Perspektive effizienter Allokation betrachtet. Doch weder die effiziente intertemporale Allokation von Ressourcen noch die zirkuläre Suche nach der richtigen sozialen Diskontrate können die Probleme intergenerationeller Gerechtigkeit lösen, da sich Gerechtigkeit immer auch auf die gegenwärtige Eigentumsordnung bezieht. Externe Kosten können zwar als Indikatoren hilfreich sein, sie können jedoch nicht die Frage gerechter (intra- und intergenerationeller) Verteilung oder ökologischer Tragfähigkeit beantworten. Die ökologische Korrektur von nationalen und internationalen Bilanzierungssystemen garantiert nicht notwendig Nachhaltigkeit, da das Preissystem nur relativ ist. 
Daly unterscheidet in seiner Theorie zwischen Allokation, Verteilung und Umfang (scale). ${ }^{67}$ Die ersten beiden Kriterien sind in der Ökonomie allgemein anerkannt. Allokation bezieht sich auf die relative Zuteilung eines Stoffstroms auf verschiedene Verwendungszwecke. Diese werden durch individuelle Präferenzen bzw. durch die Zahlungsbereitschaft bestimmt. Eine effiziente Allokation ist pareto-optimal. Verteilung ist eine Zuteilung von Gütern, die gemäß eines Kriteriums gerecht oder fair ist. Das Rawls'sche Verteilungskriterium ist hier als das wohl prominenteste zu nennen. Neu in der Ökonomie ist das dritte Kriterium. Umfang bezieht sich laut Daly auf das physische Volumen des Stoffstroms (physical volume of the throughput). Dieses wird in absoluten physischen Einheiten gemessen. Gleichwohl beruht die Bedeutung des Umfangs auf der Assimilationsfähigkeit der Natur. "Scale is measured relative to the ecosystem rather than to the prevailing market prices and monetary rate of return within the economy. The primary reason for the scale criterion is the long-term sustainability of the human economy within environmental limits; the primary reason for allocative efficiency is the maximization of the present value of wealth in an economy. A sustainable scale should be viewed as a constraint on the maximization of present value, not as a consequence of it." (Foy, Daly, 1992, 299; meine Hervorhebung) Daly vergleicht den Umfang auch mit der Freibordmarke eines Schiffes (plimsoll line), welche dessen maximale Beladungskapazität anzeigt. Wird das Schiff über diese Grenze hinaus beladen, geht es unter, gleichgültig, ob die Beladung (Allokation) optimal erfolgte. Als Beispiele für den Umfang führt Daly Zertifikate an. Diese seien nicht marktwirtschaftliche Instrumente wie die neoklassische Umweltökonomie glauben machen will, sondern beruhten auf einer politischen Entscheidung über den Umfang der Emission.

Die neoklassische Theorie sehe in zweierlei Hinsicht vom Umfang des ökonomischen Systems ab. Erstens gehe sie davon aus, daß die Ressourcen- und Assimilationskapazität in Relation zum Wirtschaftssystem grenzenlos sei und zweitens der Stoffstrom unendlich klein sei, d.h. Natur nur ein Wirtschaftssektor unter anderen sei, der über mikroökonomische Allokationsinstrumente gesteuert werden könne. Während Allokation in Märkten über Angebot und Nachfrage und Verteilung über Steuern gesteuert werde, bestehe für die Skalierung kein eigenständiges Steuerungsinstrument. Den Externalitäten des Stoffstroms sei nicht mit einzelnen mikroökonomischen Allokationsentscheidungen beizukommen, wenn andere ökonomische Ziele Wachstum verfolgten und so den Umfang vergrößerten. Daly zufolge benötigt die Konzeptionalisierung des Umfangs eigenständige makroökonomische Instrumente. Deren Entwicklung hält er für eine zentrale Aufgabe der ökologischen Ökonomie. Dalys Präzisierungen des Umfangs führten zu folgenden Managementregeln von Nachhaltigkeit:

- Der Umfang des ökonomischen Systems ist auf die Tragfähigkeit der Erde auszurichten. Bei einem optimalen Umfang würden sich die langfristigen marginalen Kosten der Ausweitung

${ }^{67}$ Vgl. Daly, 1992. 'Umfang' scheint eine zutreffende Übersetzung von 'scale' zu sein, wenn man den absoluten Charakter von 'scale' betont; will man hingegen den relativen Charakter von 'scale' hervorheben, bötet sich eher 'Skalierung' an. Allerdings könnte dies eine Skalierung relativ zur Ökonomie suggerieren, wohingegen Daly Skalierung auf die Tragfähigkeit der Lebenserhaltungssysteme (Ökosysteme) bezieht! 
mit dem marginalen Nutzen decken. Ein optimaler Umfang würde sowohl Effizienz als auch Suffizienz beinhalten.

- Technischer Fortschritt sollte effizienzsteigernd sein und nicht den Umfang des Stoffstroms erhöhen. Dazu müßten die Kosten für Ressourcen erhöht werden.

- Erneuerbare Ressourcen sollten sowohl in ihre Senken- als auch in ihrer Quellenfunktion gewinnmaximierend nachhaltig bewirtschaftet werden, d.h. die Erntequote darf die Regenerationsquote nicht überschreiten und die Assimilationsgrenzen müßten eingehalten werden. Dazu muß sich gegebenenfalls von dem Ziel der Gegenwartswertmaximierung (present value maximization) gelöst werden.

- Erschöpfbare Ressourcen sollten mit einer Rate abgebaut werden, die der Regenerationsquote nachwachsender Ressourcen entspricht. Die Einnahmen der Ressourcenextraktion sollten in einen Einkommens- und einen Kapitalanteil zerlegt werden. Damit könne nach der Erschöpfung der Ressourcenlagerstätte auf nachwachsende Ressourcen zurückgegriffen werden, die über jährliche Investitionen des Kapitalanteils finanziert worden seien. Die jährliche Nutzungsrate der nachwachsenden Ressource muß dem Einkommensanteil der ursprünglich konsumierten endlichen Ressource entsprechen. (Daly bezieht sich hier auf El Serafys Modifikation des volkswirtschaftlichen Rechnungssystems).

Es dürfte offensichtlich sein, daß Daly trotz seiner Abgrenzung zum Konzept schwacher Nachhaltigkeit auf sehr ähnliche Operationalisierungsprobleme trifft wie deren Vertreter. Die Probleme beruhen teilweise auf der Unmöglichkeit, ein statisches Optimum für den Umfang zu definieren. Dies legt zwar bereits Dalys Definition des Umfangs (absoluter Stofffluß relativ zur Biosphäre) nahe, doch Daly beachtet den Stoffstrom nicht näher, sondern sucht vergeblich (operationalisierbare) ökologische Limits - in der Umwelt des Systems, ließe sich systemtheoretisch hinzufügen. Daly argumentiert nicht moralisch, sondern naturwissenschaftlich, doch als Politikempfehlungen sind die genannten makroökonomischen Managementregeln nur bedingt zu gebrauchen.

F. Luks und M. Stewens haben darauf hingewiesen, daß Dalys Konzept des optimalen Umfangs in mehrerer Hinsicht mißverständlich sein könnte (Luks, Stewens, 1999). So suggeriere die Isolierung des Umfangs von allokativen und distributiven Zielen eine normative Hierarchie, welche die Trias von ökologischen, ökonomischen und sozialen Zielen der Nachhaltigkeit aufbreche. Auch wenn dieser Einwand zu relativieren ist, ${ }^{68}$ bleiben für die ökologische Ökonomie Probleme mit Dalys Konzept der Skalierung bestehen. Denn Daly folgt mit seiner strikten Unterscheidung seinerseits der lebensweltfernen neoklassischen Trennung zwischen Distribution und Allokation. Dagegen führt Stewens zu Recht an, daß eine ökologische Wirtschaftspolitik die Trade-Offs zwischen verschiedenen interdependenten Zielen nicht vernachlässigen dürfe. So sei auch eine den

${ }^{68}$ Dalys Beharren auf die Eigenständigkeit des Umfangs gegenüber ökonomischen Zielen könnte umgekehrt auch die Frage aufwerfen, wieso ökonomische Ziele der Nachhaltigkeit überhaupt von sozialen Zielen der Nachhaltigkeit getrennt behandelt werden, wenn doch die Ökonomik die soziale Welt ausnahmslos in Präferenzen fundiert. Ideologiekritisch würde die Frage also lauten, wieso Nachhaltigkeit dann nicht auf eine ökologische und soziale Zielsetzung, die institutionell zu verankern wäre, vereinfacht werden kann? 
Umfang verringernde Reduktion des Stoffstroms auf politische Zustimmung und funktionierende Märkte angewiesen. Beides werde in ganz erheblichem Maße von distributiven Aspekten einer Implementation bestimmt. Die Vorstellung einer linearen Entscheidungshierarchie (Distribution von Eigentumsrechten und daran anschließende Allokation von Gütern und Einkommen) sei weder zweckmäßig noch empirisch zutreffend. Schließlich würde selbst die umweltpolitische Implementation biophysikalischer Indikatorensysteme distributive Aspekte (wie etwa regressive Effekte auf die Verteilung von Einkommen) einschließen (Luks, Stewens, 1999).

Geht man auf Dalys ursprüngliches Steady-State Konzept zurück, kennzeichnet dieses nicht eine stetige Wachstumsrate wie die neoklassische Wachstumstheorie (alias Umwelt- und Ressourcenökonomie), sondern ein konstanter Energie- und Materiestrom (throughput), der den absoluten Umfang des Wirtschaftssystems relativ zur nichtmenschlichen Umwelt bestimmt. Boulding (1973) hatte demgegenüber in seiner klassischen, ökonomischen Arbeit zum kommenden Raumschiff Erde den Durchfluß (throughput) als Energie-, Materie- und Informationsfluß bezeichnet. Davon hat Boulding den Informationsfluß als den wichtigsten angesehen. Mit der thermodynamischen Fundierung der ökologischen Ökonomie wird der Energie- und Materiestrom zur wichtigsten Bestimmungsgröße des Umfangs, wohingegen Informationen (über die ökologische Wirkung des Stoffstroms) angesichts von epistemischer und prognostischer Unsicherheit als sekundär anzusehen sind. Zentral ist somit der Stoffstrom und nicht unmittelbar die ökologischen Grenzen des Wachstums.

Das Steady-State-Konzept unterscheidet sich genau in dieser Hinsicht von den produktionstheoretischen Annahmen der Klassiker über die Grenzen des Wirtschaftssystem. Denn diese nahmen für den Steady-State die Stationarität von Kapital, Bevölkerungswachstum oder Nahrungsmittelproduktion an. (Auch unterscheidet sich der Steady-State von neueren produktionstheoretischen Modellen. ${ }^{69}$ ) Das Skalierungskonzept von Daly hat aber nur dann Ähnlichkeiten mit einem solchen stationären Zustand der Klassiker, wenn physische Begrenzungen tatsächlich zu einer Stationarität von Wertgrößen, wie etwa dem Sozialprodukt, führen.

\subsubsection{Der historische Stoffstrom des ökonomischen Systems}

Mitte der 80er Jahre wurde aufgrund empirischer Untersuchungen erstmals die These einer Entkoppelung von Wirtschaftswachstum und Ressourcenverbrauch formuliert. Die damalige Studie untersuchte den Verbrauch von Zement, Stahl, Ammoniak, Papier, Chlor, Aluminium und Ethylen in den USA über einen fast 100jährigen Zeitraum. Ähnliche Ergebnisse lieferten Trendanalysen für Deutschland, Frankreich und Großbritannien, die den Zeitraum seit den 50er Jahren analysierten (Jänicke, 1998, 2).

${ }^{69}$ S. Hofmeister, die ein solches produktionstheoretisches Modell vertritt (Hofmeister, 1998), hat darauf hingewiesen, daß Daly Naturkapital als (unproduktive) Bestandsgröße interpretiert und damit über die reproduktiven Eigenschaften sowohl von Natur- als auch Humankapital hinwegsehe (Biesecker, Hofmeister, 2001). 
Die beobachtete Entkoppelung ließ sich als inverse U-Kurve beschreiben, die später unter dem Namen ökologische Kuznets-Kurve (ÖKK) firmierte. Die Hypothese lautet, daß in frühen wirtschaftlichen Entwicklungsstadien die Umweltbelastung stärker zunimmt als das Einkommen und daß sich diese Relation abschwächt und ab einem gewissen Punkt eigenständig umkehrt. Die Entwicklung erfolgte demnach unabhängig von (umwelt)politischer Steuerung. ${ }^{70}$ Eine Reduktion der Materialintensität wurde für ganz verschiedene Materialien (Blei, Kohlenmonoxid, Stickstoffverbindungen, Schwefeldioxid, Oxid, suspended particulate matter, etc.) und für mehrere Länder (OECD-Länder) bekräftigt. Einige Studien zeigten darüber hinaus sogar eine absolute Reduktion des Materialinputs und gingen damit noch über die Hypothese sinkender Materialintensität hinaus. Als Gründe für den Rückgang des Ressourceninputs wurden genannt: Substitution traditioneller Materialien, höhere Effizienz der Materialien, höhere Effizienz der Produktion und Zunahme dienstleistungsintensiver Güter bei gleichzeitiger Abnahme materialintensiver Güter.

Dagegen haben weitere Studien gezeigt, daß Länder der 3. Welt und des ehemaligen COMECON keine derartige Entkoppelung durchlaufen sind. In diesen Ländern konnte die Ressourcenproduktivität somit nicht gesteigert werden. Auch wurde die ÖKK-Hypothese schon früh mit der Prognose konfrontiert, daß das langfristige Wirtschaftswachstum die Ressourcenproduktivität wieder ausgleichen würde und die ökologische Belastung wieder ansteigen würde (N-Kurve). Als Erklärung für die unterbliebene Entkoppelung in der 3. Welt wurde auf die offene Weltwirtschaft verwiesen. Lediglich in geschlossenen Volkswirtschaften entsprechen sich Ressourceninput und Emissionen und Abfall langfristig. Es könnte bezüglich der 3. Welt ein Phänomen des Umweltbelastungsimports stattgefunden haben. Dem entspricht ein Umweltbelastungsexport seitens der Industrieländer. Während M. Jänicke gegen die These einbringt, daß es bis heute zu keiner relevanten Verlagerung von Grundstoffindustrien in die Entwicklungsländer gekommen sei, sehen S. de Bruyn et al. schwache Indikatoren sowohl für als auch gegen eine solche Annahme (jeweils abhängig vom Stoff und Land) (vgl. Jänicke, 1998, 10; de Bruyn et al, 1997, 206). Insgesamt sei die Datenlage jedoch zu schlecht, um Verschiebungen der Umweltbelastungen zwischen offenen Volkswirtschaften beurteilen zu können.

Um den empirischen Zusammenhang zwischen Material- und Energieinput und Wirtschaftswachstum zu bestimmen, haben S. de Bruyn et al. mehrere Modelle entwickelt, von denen das erste eine einfache Korrelation von Wachstum und Materialinput nachstellt, das zweite eine Steigerung der Ressourcenproduktivität annimmt (ÖKK-Hypothese) und das dritte ein sinkendes Materialinput als Funktion des Wirtschaftswachstums und des Einkommensniveaus ansieht. Das Ergebnis bestätigt das dritte Modell, nach welchem die Steigerung der Ressourcenproduktivität durch das Einkommensniveau in wachsenden Volkswirtschaften erklärt wird. Dies bedeutet auch, daß reiche Staaten größere Ressourcenproduktivitätssteigerungsraten erzielen als arme (vgl. de Bruyn, et al.,

\footnotetext{
70 Als lange Zeit einziges Land verfolgte Japan in den 70er Jahren - als Reaktion auf die Ölkrise - eine Industriepolitik, die für einzelne Branchen präzise Reduktionsziele festlegte. Diese Strukturpolitik hatte eine vielbeachtete Reduktion der Umweltbelastung zur Folge (vgl. G. Foijanty-Jost, 1991).
} 
1997, 210 ff). Unter Verwendung des dritten Modells prüfen die Autoren schließlich die Möglichkeit nachhaltiger Entwicklung, d.h. eines konstanten Materialinputs (als Annäherung an Nachhaltigkeit). Sie kommen zu dem Ergebnis, daß Wachstumsraten von 3 \%, wie sie die Brundtland-Kommission für die entwickelten Länder als nachhaltig annahm, in Wahrheit nicht nachhaltig sind. ${ }^{71}$ Nun ist das Modell rein deskriptiv und untersucht beispielsweise nicht den Einfluß von Umweltpolitik. ${ }^{72}$ Es legt aber dringend nahe, daß ein autonomer technischer und struktureller Wandel sich nicht nachhaltig entwickeln wird.

Alle jüngeren Studien, die im Ergebnis die Kuznets-Kurven-Hypothese bestätigen, beziehen ihren methodologischen Ansatz auf ausgewählte Stoffe, nehmen diese als Indikatoren für Umweltbelastungen und korrelieren sie mit der jeweiligen Einkommensentwicklung. Dies gilt auch für die letztgenannte Studie. De Bruyn et al. haben in einem weiteren Aufsatz bemängeln, daß die Ergebnisse der optimistischen ÖKK-Studien nicht nur von den zugrunde gelegten Stoffen abhingen, sondern auch von den zugrunde gelegten Modellen (de Bruyn et al., 1998). So habe der gewählte Zeitraum einen erheblichen Einfluß auf das Ergebnis. Die inverse U-Kurve könnte sich bei längerem Untersuchungszeitraum als N-Kurve darstellen, d.h. die Ressourcenproduktivität wieder gesunken sein. ${ }^{73}$ Eine derartige N-Kurve scheint auch ihre Untersuchung der Schadstoffe $\mathrm{CO}_{2}$, $\mathrm{NO}_{\mathrm{X}}$ und $\mathrm{SO}_{2}$ nahezulegen. De Bruyn hat diese N-Kurve evolutionsökonomisch erklärt. ${ }^{74}$ "The environmental implication is that the often promoted argument that economic growth can be beneficial to environmental quality is probably invalid. If the $\mathrm{N}$-shaped figure holds for aggregated material input, a similar development should be traced for aggregated environmentally relevant output (emissions and waste) by virtue of the mass balance principle" (de Bruyn, 1999, 17)

Für eine umfassende Politik der Dematerialisierung ist der Nachweis von Reduktionspotentialen einiger Stoffe weder ausreichend noch notwendig zielführend. Vielmehr ist für eine Dematerialisierungspolitik der Nachhaltigkeit Wissen über den gesamten, aggregierten Materialaufwand einer Wirtschaftsregion bzw. Volkswirtschaft erforderlich. Dieses ist erstmals in einer Studie von A. Adriaanse et al. bereitgestellt worden, die für Deutschland, Japan, die Niederlande und die USA den Globalen Materialaufwand (GMA) in den Jahren von 1975 bis 1995 ermittelt hat (Adriaanse et al., 1998). Das Maß des Globalen Materialaufwands bezeichnet die Summe der natürlichen stofflichen Ressourcen, die jährlich für die wirtschaftliche Aktivität eines Landes in Anspruch genommen werden. Im Gegensatz zur VGR erfaßt es auch jene ökologische relevanten Aktivitäten der Ressourcenmodifikation, die keine Warenform annehmen oder nicht gehandelt werden, da sie etwa noch nicht als Materialinputs dienen oder als freie Güter behandelt

${ }^{71}$ In ihrer späteren Studien geben die Autoren die Rate nachhaltigen Wachstums in Relation zu $\mathrm{CO}_{2}$ Emissionen wie folgt an: NL 1,8 \%, UK 1,8 \%, USA 0.3 \%, BRD 2.9 \% beim zugrundegelegten Einkommensniveau des Jahres 1990; de Bruyn et al., 1998, 172.

72 Außerdem trifft es diese Aussagen auch nur auf der Basis dreier Inputs, wobei allerdings mit Energie zumindest das ökologisch und ökonomisch wichtigste Input erfaßt wurde. (Die beiden anderen sind Stahl und Zement.)

73 Auch M. Jänicke bestätigt eine N-Kurven-Entwicklung des ökonomischen Stoffstroms; Jänicke, 1998, 10.

${ }^{74}$ Der Prozeß technischen Wandels erfolge nicht gleichmäßig, sondern durch ein Disequilibrium und einen evolutionären Lern- und Selektionspfad. Dagegen folge in Gleichgewichtsphasen die Entwicklung des Ressourceninput dem Wachstum. Der inversen U-Kurven-Entwicklung folgt, so die Hypothese, eine weitere Phase der Rematerialisierung. 
werden. Diese nichtmonetarisierten Materialströme werden auch als 'ökologische Rucksäcke' bezeichnet und machen in den untersuchten Ländern 55 -75 Prozent des GMA aus. Nur der restliche Prozentsatz des GMA geht überhaupt als Direktes Materialinput (DMI) in die Produktion ein. Der GMA ist als ökologischer Indikator deshalb interessant, weil er nicht auf die Substitution der heimischen Güter durch importierte Güter reagiert und die Substitution unterschiedlichster Materialien gegeneinander ermöglicht. ${ }^{75}$

Anhand des Verhältnisses von GMA zum BIP bestimmen Adriaanse et al. die Materialintensität bzw. die Ökoeffizienz der Volkswirtschaft. Der Indikator zeigt ein Absinken der Materialintensität für alle vier Volkswirtschaften, d.h. einen Anstieg der Ökoeffizienz. Dies scheint eine Entkoppelung von Wirtschaftswachstum und Materialbewegung nahezulegen. Die traditionelle Kennzahl für Ökoeffizienz, das Verhältnis von DMI zum BIP, relativiert diese Aussage jedoch teilweise. $^{76}$ Zwar läßt sich für den gesamten Zeitraum noch immer ein deutlicher Rückgang der Materialintensität der direkten Inputs belegen, doch entwickeln sich Wirtschaftswachstum und Ressourceninput in allen Ländern über Phasen von 5 - 10 Jahren hinweg praktisch konstant. Demnach scheinen, so das Fazit der Autoren, technischer Fortschritt und ökologischer Strukturwandel in ausgesprochenen Schüben zu erfolgen. ${ }^{77}$

Die Analyse des Stoffstroms des ökonomischen Systems ist Grundlage für eine erfolgreiche Stoffstrompolitik. Sie ist aber gleichzeitig limitiert. So können nur für einige Stoffe überhaupt entsprechend lange Datenreihen zusammengetragen werden. Die ökonomische Relevanz der untersuchten Stoffe, ihre Substitutionselastizität, ist aufgrund der qualitativen Lückenhaftigkeit der Daten nur sehr schwer zu disaggregieren. Die Analyse des Stoffstroms bietet dennoch die Möglichkeit, die Produktionsfunktionen, mit denen in allen ökonomischen Ansätzen von der Neoklassik bis zur Stoffstromökonomik modelliert wird, gegebenenfalls zu revidieren und auf eine empirische Basis zu stellen (van den Bergh, 1999). Dies kann auch bei der Beantwortung der Frage nach Substituierbarkeit und Komplementarität von Naturkapital und produziertem Kapitalbestand hilfreich sein. Gleichzeitig muß betont werden, daß die Analyse des Stoffstroms nicht normative Voraussetzung einer Nachhaltigkeitspolitik ist. Denn die Diskussion über realistische Substitutionspotentiale und empirisch-naturwissenschaftlich fundierte Produktionsfunktionen steht nicht immer in direktem Zusammenhang mit den gegenwärtigen ökologischen Problemen. Diese besitzen, wie etwa im Fall von Ozonloch und Treibhauseffekt, eine Objektivitätsstruktur, die sie kausal an Stoffströme rückkoppelt, doch ihnen ist auch ein Problemdruck inne, der eine Reduktion der verursachenden Stoffe zwingend erfordert. Dieses Ziel einer Reduktion von $\mathrm{CO}_{2}$ und FCKWs besagt aber wenig über die ökonomischen Charakteristika dieser Stoffe (einschließlich ihrer Substitutionselastizitäten). Diese Stoffe mögen sogar Eigenschaften aufweisen, angesichts derer

75 So erlaubt der Indikator auch die Substitution von endlichen durch nachwachsende Ressourcen. Gleichwohl ist der GMA als Indikator von Nachhaltigkeit noch immer stärker als das Kriterium schwacher Nachhaltigkeit der Londoner Schule, da es bei der Nutzung von Naturkapital nicht die Komplementarität übergeht (so Bartelmus, Vesper, 2000, $19 \mathrm{f})$.

${ }^{76}$ Adriaanse et al. (1998, 35) interpretieren das Verhältnis von DMI zum BIP als Indikator für "den Einfluß des technischen Fortschritts, der betrieblichen Praxis und des Strukturwandels auf die Effizienz der Materialnutzung."

77 Damit wird die These einer post-materialistischen Gesellschaft (Ingelhart) stark relativiert. 
sich ökonomische Instrumente als ineffektiv erweisen, so daß umweltpolitische Steuerung zwingend auf ordnungsrechtliche Instrumente (Verbot) zurückgreifen muß. Van der Voet et al. haben dies etwa in bezug auf Cadmium, Stickstoff- und Chlorverbindungen sowie fossile Brennstoffe festgestellt (van der Voet et al., 1995). Dabei schließen die Autoren für Stoffe mit den Produktionscharakteristika von Cadmium und Chlorverbindungen jede Form ökonomischer Instrumente aus. ${ }^{78}$ Die Singularität durchbricht die ökonomische Modellierung und widerlegt daraus abgeleitete sozioökonomische Prognosen. Aggregierende Produktions- und Wohlfahrtsfunktionen können immer von der harten, singulären Realität stofflicher Wirkungen in der natürlichen Umwelt widerlegt werden. Sicherheit ist in diesem Sinne für die Risikogesellschaft nicht mehr zu haben Vorsorge mittels (hoch)aggregierter ökologischer Indikatoren jedoch schon.

\subsection{Die Emergenz des ökonomischen Stoffstroms}

Angesichts des Problems der Nachhaltigkeit erweist sich nichts weniger als die konsequentialistischen Grundlagen der Ökonomie als problematisch. ${ }^{79}$ Auf der Grundlage eines sich wandelnden Inputs wird ein (kollektiver) Nutzenstrom extrapoliert, der vom kontingenten Output solange absieht, bis dieses (erst wissenschaftlich, dann öffentlich und schließlich volkswirtschaftlichpolitisch) als negativ anerkannt wird. Sodann wird eine erneute (ökonomische) Extrapolation erforderlich. Auch das Konzept des Naturkapitals folgt noch dieser Logik, nur das es die gegenwärtig bekannten ökologischen Folgen des Outputs anerkennt und zur Grundlage des Schutzes (der Konstanz) von Naturkapital macht. Jedoch bereiten diese epistemologischen Prämissen die ökonomische Theorie nicht auf die selbstproduzierten Überraschungen der ökonomischen Entwicklung vor. Der Hiatus zwischen Theorie und kontingenter Entwicklung ist eine zeitliche Differenz, die eine permanente Revision der Theorie notwendig macht, ohne sie doch einem Falsifikationsprinzip zu unterwerfen. Die Theorie basiert nicht auf kognitivem Lernen; sie ist nicht empirisch-induktiv sondern theoretisch-deduktiv. Der Kern dieses epistemologischen Problems besteht in der dynamischen, nicht antizipierbaren Produktion von Unsicherheiten im ökonomischen Prozeß selbst. Ökonomischer Fortschritt impliziert eine Komplexitätssteigerung des induzierten Stoffstroms, ohne dessen Folgen für die Umwelt antizipieren zu können.

Der induzierte Stoffstrom verweist nicht auf die Konstanz des natürlichen Kapitalstocks, sondern auf eine doppelte Unsicherheit: zum einen hinsichtlich der Substituierbarkeit und Homogenität von Naturkapital (Bartmann, 2001) und zum anderen bezüglich des emergenten Stoffstroms, der durch Innovationen evolutionäre Risiken und Unsicherheiten produziert (vgl. Krohn, Krücken, 1993). Der erste Aspekt betrifft die Ressourcenfunktion von Natur, der zweite die von der Umweltökonomie

${ }^{78}$ Zur ökologisch-ökonomischen Modellierung umweltpolitischer Steuerung dieser hochproblematischen Stoffe vgl. Guinée et al., 1999.

${ }^{79}$ F. Hackl (2000) irrt, wenn er die neoklassische Ökonomie als in sich konsistentes und geschlossenes Theoriegebäude darstellen will, daß einer qualitativen Bewertung nicht zugänglich sei. Daß ihm die ökologische Ökonomie nur gleichwertig erscheint, beruht auf seiner Verwechslung von epistemologischen und ethischen Positionen innerhalb der ökologischen Ökonomie. 
beschriebene Senken- oder Assimilationsfunktion der Natur. Insofern von beiden Funktionen zusätzlich noch eine Lebenserhaltungsfunktion unterschieden wird, ist auch diese mit Unsicherheit belegt. Durch Unsicherheit eingeschränkt sind schließlich auch direkte Wohlfahrtsfunktionen der Natur. ${ }^{80}$ Diese ökologische Unsicherheit müßte von Theorien intertemporaler Allokation zwingend berücksichtigt werden. Statt dessen übergehen neoklassische Ansätze systematisch Unsicherheit und fundieren ihre Modelle auf einer positivistisch gedachten, objektiven Welt, die durch instrumentelle Rationalität sicher und verfügbar gemacht werden soll. Diese Form der Rationalität abstrahiert systematisch von moralischen, ethischen, faktischen und epistemologischen Aspekten der Welt. Für den Nachhaltigkeitsdiskurs ist dabei die Abstraktion von den epistemologischen Aspekten der Welt besonders folgenreich. Denn neoklassische Ansätze übergehen Unsicherheit als grundlegende Tatsache der Interaktion zwischen ökonomischem System und natürlicher Umwelt. Sie mißachten zudem auch die zeitlichen Aspekte.

\subsubsection{Rationalität angesichts von Irreversibilität und emergenter Unsicherheit}

Solange die ökonomische Theorie Natur als reines Cake-eating-Problem modellieren und von weitgehend sicheren Kontexten ausgehen kann, erscheint die Unterstellung instrumenteller Rationalität in der Ökonomie plausibel. Erst über Externalitäten finden Unsicherheit und Risiko als strategische Entscheidungssituation intentionalen Handelns Berücksichtigung in der Ökonomik. "Here the emphasis is placed on finding the best outcomes through constrained optimization. In this framework, individual or collective rationality is identified with constrained maximization of an objective function. As an extension to situations of risk and of uncertainty, the same choice paradigm may be elaborated in terms of constrained maximization of expected values of outcomes based on application of probability theory." (Faucheux et al., 1997, 55) Gemäß der Entscheidungstheorie benötigen Risikoentscheidungen Informationen über die Eintrittswahrscheinlichkeit von verschiedenen Zuständen und den jeweils dazugehörigen Erwartungswerten. Risiko benötigt ex-ante Wissen über Handlungsfolgen, die nicht generalisiertes Wissen, sondern statistische Daten voraussetzen, die ihrerseits nur ex-post generiert worden sein können. Dazu muß ein stationärer, stochastischer Prozeß vorliegen, der diese Daten zu generieren erlaubt. Im Fall von Unsicherheit fehlen dagegen diese Informationen über Eintrittswahrscheinlichkeit und Erwartungswert ganz oder teilweise. ${ }^{81}$ Es gibt eine Reihe verschiedener, formaler Regeln, unter Risiko und Unsicherheit zu entscheiden (vgl. dazu Wätzold, 1998, 75 ff). Die

${ }^{80}$ Daneben ließen sich weitere Funktionen der Natur anführen, wie die Leistungen für Produktion und Konsum ohne Abbau, die Selbstorganisationsfähigkeit von Ökosystemen der Natur, komplexe Strukturen auszubilden etc. Dabei wird deutlich, daß Funktionen der Natur vielfältig und epistemisch unsicher sind, was nicht nur die Monetarisierbarkeit der natürlichen Umwelt unmöglich macht, sondern Unsicherheit für jede ökonomische Theorie der Nachhaltigkeit zentral werden läßt.

81 Die normative Baynes'sche Entscheidungstheorie hält eine solche Differenzierung für überflüssig, da Unsicherheit immer durch subjektive Folgenabschätzung geprägt sei, so daß Risiko entweder eine überflüssige Kategorie sei oder zu Unsicherheit reduziert werden könne. Gemäß dieser Position führte eine Unterscheidung zwischen verschiedenen Formen von Unsicherheit nur Wahrscheinlichkeiten höherer Ordnung ein, die sich zu Wahrscheinlichkeiten 1. Ordnung zusammenfassen ließen, und brächte ein Problem unendlichen Regresses mit sich; vgl. Vercelli, 1995. 
anspruchsvollen Voraussetzungen von umweltpolitischen Risikoentscheidungen sind in offenen Systemen nur seltenst erfüllt. Es wäre dann von Unsicherheit auszugehen, doch greift die Umweltökonomik hier regelmäßig auf die Bayes'sche Theorie zurück und nimmt subjektive Abschätzungen vor. Damit verwandelt sie einen offenen in einen geschlossenen Ereignisraum, und trifft zugleich normative Aussagen, die von Komplexität und Irreversibilität absehen. ${ }^{82}$ Die Bayes'sche Entscheidungstheorie vertritt im Grunde ein Laplace'sches Weltbild. Dies verbaut ihr u.a. die Möglichkeit des Lernens, denn in Situationen von Unsicherheit sind (erst ex-post als solche erkannte) Fehlentscheidungen unvermeidbar.

Grundsätzlich läßt sich zwischen mehreren Formen ökologischer Unsicherheit unterscheiden. F. Wätzold nennt Schadensunsicherheit, Synergieunsicherheit, Akkumulationsunsicherheit und räumliche sowie zeitliche Diffusionsunsicherheit (Wätzold, 2000, 24 ff). Unsicherheit kann unter Umständen durch gezielte Forschung in objektives Risiko transformiert werden. Der Umweltforschung sind jedoch in offenen, natürlichen Systemen Grenzen gesetzt, so daß Umweltpolitik in den meisten Fällen unter Bedingungen ökologischer Unsicherheit implementiert werden muß.

A. Vercelli hat zwischen weicher und harter Unsicherheit unterschieden. "Uncertainty may be defined as 'soft' whenever it is adequately described by a unique distribution of additive probabilities which is considered fully reliable. On the contrary, uncertainty may be defined as 'hard' whenever its representation involves non-additive probabilities and/or a plurality of probability distributions, none of which is fully reliable." (Vercelli, 1995, 256) Unsicherheit steht dabei in unmittelbarem Verhältnis zur Offenheit und Irreversibilität natürlicher Prozesse. Durch das Input an endlichen und nachwachsenden Ressourcen, seine hierarchische Produktionsstruktur und sein Output erweist sich aber auch der ökonomische Prozeß als irreversibel. Irreversibel ist trotz partieller Freiheitsgrade schließlich die Koevolution von ökonomischem System und natürlicher Umwelt. Dieser ökonomische Begriff der Irreversibilität (Godard, Salles, 1991) geht z.B. über den neoklassischen Ansatz eines Optionswertes hinaus (vgl. Krutilla, Fisher, 1975), der Natur einen Wert für eine optionale Entwicklung zuspricht. Das ökonomische Entscheidungsproblem erlaubt unter irreversiblen Bedingungen kein sicheres instrumentelles Lernen:

Irreversibility makes the stochastic process non-stationary, and, whenever the features of irreversibility are clouded by hard uncertainty there is no way to transform the non-stationary stochastic process into an equivalent stationary stochastic process. Since this is the case with sustainable development models, it is not possible to rely on the criterion of substantive rationality nor on received decision theory, which are based on this criterion of rationality just as much as is orthodox economic theory. (Vercelli, 1998, 264)

Von Unsicherheit kann weiter noch 'ignorance' (Nichtwissen) unterschieden werden. "The case of complete ignorance which constitutes the upper limiting case of strong uncertainty arises when none of the postulated probability distributions is reliable" (Froger, Zyla, 1998, 281). Ignorance

${ }^{82}$ Hier sind beide Aspekte von Irreversibilität gemeint: der Zeitverlauf ökonomischer Handlungssequenzen und mögliche grenzenlose, selbstreproduzierende Veränderungen der Natur. 
bleibt in dieser Definition noch relativ unbestimmt. O'Connor hat bezüglich von Koevolution und Komplexität zwei Formen von Unbestimmtheit unterschieden, auf die S. Faucheux und G. Froger (1995) sich zur Bestimmung von Unsicherheit und Nichtwissen beziehen. Demnach bestehe eine ontologische Unbestimmtheit, welche die Realität oder die Situation beschreibt, und eine zeitliche Unbestimmtheit, die auf eine offene Zukunft verweist (O'Connor, 1994). Mit anderen Worten verweist ontologische Unbestimmtheit auf die natürliche Umwelt und die Komplexität derselben und zeitliche Unsicherheit auf die Temporalisierung sozialer Systeme. Dabei entspricht die von O'Connor sogenannte ontologische Unbestimmtheit dem, was hier zuvor allgemein als Unbestimmtheit bezeichnet wurde. Es bietet sich für die ökologische Ökonomie an, auf ontologische Aussagen zu verzichten und statt dessen die diskursanalytische Differenzierung zwischen Unsicherheit und Nichtwissen zu übernehmen, die sich an der argumentationstheoretischen Unterscheidung von prognostischer und epistemischer Unsicherheit orientiert. Im diskurstheoretischen Ansatz kann unspezifisches Nichtwissen (ignorance) mit epistemologischer Unsicherheit identifiziert werden. Dies verweist die Ökonomik auf Unsicherheiten in den Naturwissenschaften und zwingt ihr so eine begrenzte Reflexivität auf: Diese manifestiert sich etwa in der Debatte um endogenen Grenzen der Versicherbarkeit neuer Technologien (ohne staatlich festgesetzte Haftungsobergrenzen). Ferner können schwache und starke Unsicherheit auf prognostische Unsicherheit bezogen werden, die trotz limitierter Prognosekraft auf sicherem naturwissenschaftlichem Wissen beruht. Kurzum: Starke und schwache Unsicherheit sowie Unkenntnis können problemlos im Rahmen kommunikativen Handelns verordnet werden und sind rationalitätstheoretisch zugänglich.

Wenn Unsicherheit dergestalt in den Vordergrund von Nachhaltigkeit gestellt wird, wächst die Bedeutung des Stoffstroms für die Ökonomik. Für die ökologische Ökonomie öffnet sich das Untersuchungsfeld zu beiden Seiten dessen Emergenz: Die Institutionen sowohl des ökonomischen und des administrativen Systems bleiben relevant, sie interagieren mit der natürlichen Umwelt, die ebenfalls weiterhin Gegenstand der Analyse bleibt. Im Unterschied zu Ressourcen- und Umweltökonomie aber folgt die Analyse der irreversiblen, stofflichen Koevolution nicht dem Paradigma instrumentell-ökonomischer Rationalität, da dies die verschiedenen Formen von Unsicherheit in der Interaktion zwischen ökonomischem System und natürlicher Umwelt übergehen würde. S. Faucheux, G. Froger und G. Munda stellen fest, daß

[m] uch of the uncertainty emerges from unforeseeable qualitative changes in economic and biological systems, which are not due to stochastic variability but to integral shifts in behavioral patterns including changes in policy institutions. In such cases the interactions between the economy and the natural environment cannot be defined as a system's optimal trajectory within a given (stochastic) parameter space, but (preserving the vocabulary of optimization) as a set of sequential, optimality regimes governed by sometimes dissipative structures. The decision problems get much more complex since the option set can change endogenously, due to the effects of past decisions and as a consequence of complex interactions between the economy and the environment. (Faucheux, Froger, Munda, 1997, 53 f)

S. Faucheux, G. Froger und J.-F. Noël (1993) haben sich die Aufgabe gestellt, die Koevolution zwischen ökonomischem System und natürlicher Umwelt in eine makroökonomische Theorie von 
Nachhaltigkeit zu integrieren. Die Struktur der ökologischen Krise weist eine eindeutige, hierarchische Struktur auf und kann die ökologische Ökonomie partiell thermodynamisch begründen. Energetische und materielle Beschränkungen sind zu beachten, sofern die systemische Entwicklung sich nicht selbstgefährden soll. J. Gowdy hat ebenso nachdrücklich wie Faucheux und Froger alle Versuche zurückgewiesen, (energetisch-materielle) Hierarchien innerhalb der Ökonomie auf mikroökonomische, instrumentell-rationale Theoreme zurückführen zu wollen. Statt dessen fordert er eine explizit Trennung von mikro- und makroökonomischer Theorie für eine nachhaltige Entwicklung ein. ${ }^{83}$

\subsubsection{Die Rationalität nicht-ökonomischer Indikatoren der Nachhaltigkeit}

Die praxistauglichste Differenzierung zwischen Mikro- und Makroökonomie liegt gegenwärtig wohl mit dem MIPS-Konzept (Materialintensität Pro Serviceeinheit) vor. Das vom Wuppertaler Institut für Klima, Umwelt und Energie entwickelte Konzept setzt an aggregierten ökologischen Kategorien an (Schmidt-Bleek, 1998). Das MIPS-Konzept bezieht sich nicht direkt auf ökonomische oder ökologische Systemgrößen, sondern macht Unsicherheit zum Ausgangspunkt der Theoriebildung (Hinterberger, Wegener, 1997). Der Mangel an vollständigem Wissen über die ökologischen Auswirkungen der ökonomischen Aktivität, die immer bestehende Möglichkeit, aufgrund neuer Erkenntnisse die bisherige Umweltpolitik revidieren zu müssen und die ungewissen (revidierbaren) Prozesse demokratischer, umweltpolitischer Mehrheitsfindung begründen in diesem Ansatz Unsicherheit. Das Wuppertaler Konzept ist somit stark praktisch orientiert und bezieht sich im Unterschied zur Theorie Faucheux' et al. allein auf Quantitäten des stofflichen Inputs in das ökonomische System (Hinterberger et al., 1996). Da der MIPS-Ansatz leichter darstellbar ist und sich die zugrunde gelegten Indikatoren bislang empirisch bewährt haben, wird nur er an dieser Stelle expliziert. $^{84}$

Die ökologischen Kategorien setzen an der Schnittstelle zwischen Ökosphäre und Anthroposphäre an, genauer gesagt an der Inputseite der Anthroposphäre. Für diesen inputorientierten

83 "A fruitful way to approach this is to return to one of the basic ideas in economic theory, namely, the distinction between macro- and microeconomics. If we drive a wedge between theories of efficiency at the firm level, and theories of macroeconomic behavior, perhaps another wedge can be driven between the macro economy and its surrounding social and environmental systems" Gowdy, 1999, 76.

${ }^{84}$ Energetische Bewertungsmethoden gehören wie das MIPS-Konzept zu den nicht-präferenzbasierten Bewertungsmethoden. Einige dieser Methoden wie natural assets accounting, energy/material balances und life-cycle analysis sind in Kosten-Nutzen-Analysen integriert worden (vgl. dazu näher Bouman et al., 2000). Für die Konzeption von Nachhaltigkeit sind energetische Bewertungsmethoden deshalb interessant, weil sie 1. eine starke physikalische Fundierung aufweisen, 2. eine hohe ökologische Relevanz (nicht nur für den Treibhauseffekt) besitzen und 3. der Energieverbrauch starke Parallelen zur ökonomischen Preisbildung aufweist, d.h. Energie ein zentraler Produktionsfaktor ist. Sie bieten damit die Möglichkeit, nachhaltige Entwicklung wie beim MIPS-Konzept, jedoch potentiell mit höher analytischer Präzision, auf makroökonomischer Ebene zu verfolgen. Die physikalischenergetische Fundierung nicht-präferenzbasierter Bewertungsmethoden ermöglicht es ebenfalls, absolute Knappheit zum Gegenstand von Nachhaltigkeit zu machen. Ein besonders entwickeltes energetisches Konzept wurde am Centre Economic-Espace-Environment an der Universität Paris I unter anderem von S. Faucheux entwickelt (Faucheux, 1994; Faucheux, Pillet, 1994; Faucheux. Froger, 1995, Faucheux, Froger, Munda, 1997). Aufgrund seiner Komplexität soll hier jedoch nicht näher darauf eingegangen werden, obwohl es gegenwärtig das vielleicht vielversprechendste Konzept der Nachhaltigkeit darstellt. 
Ansatz wird Simplizität geltend gemacht: Während auf der Inputseite 50 - 100 verschiedene Stoffe in das ökonomische System Eingang finden, stehen dem auf der Outputseite allein aus der chemischen Industrie rund 100.000 im Handel befindliche Substanzen gegenüber, die mit weiteren Emissionen und der Ökosphäre interagieren. Ferner sind die Eintrittsstellen in die Anthroposphäre gegenüber den Austrittspunkten in die Ökosphäre überschaubar.

Die Materialinputs werden nach fünf Kategorien ausgewiesen, wovon die letzten beiden, Wasser und Luft, in der Bilanzierung getrennt aufgeführt werden. Diese Kategorien sind im einzelnen (Schmidt-Bleek et al., 1998, 34 f):

- Abiotische Rohstoffe

(mineralische Rohstoffe, fossile Energieträger, nicht verwertete Rohförderung, bewegte Erde)

- Biotische Rohstoffe (pflanzliche Biomasse aus Bewirtschaftung, Biomasse aus nicht bewirtschafteten Bereichen)

- Bodenbewegungen in der Land- und Forstwirtschaft

(mechanische Bodenbearbeitung, Erosion)

- Wasser

(Oberflächenwasser, Grundwasser, Tiefengrundwasser)

- Luft

(Verbrennung, chemische Umwandlung).

Diese Kategorien werden durch eine Reihe von Konventionen ergänzt, welche die Analyse der Materialintensität auf verschiedenen Ebenen ermöglichen. Diese kann wie etwa beim Produktlebenszyklus ein einzelnes Produkt sein. Dazu bestimmt etwa Konvention Nr. 4, daß bei der Berechnung der Materialinputs für einen bestimmten Produkttyp zunächst die zu erbringende Dienstleistung definiert wird, und dann entweder marktübliche Produkte, die diese Dienstleistung erfüllen, für die Analyse ausgesucht oder neuentwickelte Produktkonzepte und Prototypen hinsichtlich ihrer Materialintensität für den zu schätzenden Lebenszyklus untersucht werden. Konvention Nr. 5 ermöglicht die Übertragung auf einen zu bestimmenden Wirtschaftsraum und den dazugehörigen Markt, so daß man den bereits erwähnten Globalen Materialaufwand als Indikator erhält. Die lebenszyklusweite Berechnung der Materialintensität von Produkten, Infrastrukturen und Dienstleistungen wird dadurch erleichtert, daß das Wuppertaler Institut den Materialbedarf für einige immer wiederkehrende Serviceleistungen systemweit berechnet hat. So erhält man die sogenannten Input-Module, die für die Bereitstellung von Elektrizität, Transport (Fracht und Person), Recycling und Entsorgung, Verpackung, Wohnungen, Verwaltung, Produktionsanlagen und Groß- und Einzelhandel existieren.

Dematerialisierung zielt auf die absolute Reduktion des Energie- und Materiestroms und damit auf eine Verkleinerung des Umfangs. Dies soll bestehende Umweltschäden beseitigen - soweit diese nicht irreversibel sind - und weiteren potentiellen Schäden vorsorgen. Die herkömmlichen umweltökonomischen Instrumente der Umweltpolitik sind auf Dauer erfolglos, da die mit der Internalisierung verbundenen Interventionen nur kurzzeitige ökologische Revisionen darstellen, 
welche die marktwirtschaftliche Allokation stören können. Da es im ökologischen Kontext systematisch zu Marktversagen kommt, muß das Internalisierungskonzept, sofern es für die Umweltpolitik relevant bleiben soll, neu interpretiert werden. Die Ineffizienz von Märkten könnte Resultat von Transaktionskosten sein, was die Akteure des ökonomischen Systems davon abhält, Tauschgewinne privat auszuschöpfen. Ebenso könnten Interventionen teurer sein als allokative Verbesserungen. Nur ein detailliertes System von Pigousteuern wäre dem Konzept kurzfristigen Marktversagens überlegen. Das MIPS-Konzept kann direkt auf das ökonomische System bezogen werden, so daß das Konzept auf der Mikro-, der Meso- und der Makroebene angewandt werden kann. Auf der Mikroebene kann MIPS als Indikator bei der Materialauswahl und bei der Produktentwicklung dienen und als Basis der Umweltkostenrechnung und des Öko-Audits dienen. Auf der Mesoebene kann die Materialitätsanalyse (MAIA) auf Wirtschaftsräume, Wirtschaftssektoren und auf Bedarfsbereiche bezogen werden. Dies kann auch auf der Makroebene geschehen, indem die Materialintensität auf die gesamte Volkswirtschaft bezogen wird.

Das MIPS-Konzept ist einer der wenigen Ansätze im Diskurs über Nachhaltigkeit, der Suffizienz und Effizienz gleichrangig nebeneinander stellt. Hierbei ist die Bezugnahme der Materialintensität auf Serviceeinheiten wichtig, denn dies stellt der Mikroökonomie direkt einen Suffizienzansatz zur Verfügung. MIPS definiert Serviceeinheiten als "Nutzungen, die mit der Verfügung (Eigentum, Besitz oder Nutzungsrechte) über ein Gut verbunden sind." (Konvention Nr. 72; Schmidt-Bleek et al., 1998, 68) Damit wird der ökonomische Sinn von Dienstleistungen im MIPS-Konzept erweitert und umfaßt Nutzungen, "die man von den jeweiligen Produkten (und Infrastrukturen) 'abrufen' kann, um menschliche Bedürfnisse zu befriedigen." (ebd.) Es werden somit auch Produkte und Infrastrukturen als Dienstleistungen verstanden. ${ }^{85}$ Da MIPS den lebenszyklusweiten Ressourcenund Energieverbrauch eines Produktes bzw. einer Dienstleistung erfaßt, können subjektive Bewertungen über vergleichbare Serviceeinheiten ökologisch objektiviert werden. Dies erleichtert die Formulierung von Einsparungspotentialen, da nicht mehr unspezifische Produkte, sondern spezifische Bedürfnisse in den Vordergrund gestellt werden (vgl. Föhlich et al., 1999-2000, 20). Das MIPS-Konzept erlaubt so den dynamischen Vergleich der Ökoeffizienz von Dienstleistungen durch Konsumenten (etwa zwischen Car-Sharing und Privat-Pkw) und beschränkt sich nicht auf den Vergleich gleicher Produkte (Treibstoffverbrauch verschiedener Pkw-Typen). Zahlreiche staatliche und private Normen könnten durch das MIPS-Konzept ökologie- und konsumorientiert an Aussagekraft gewinnen. Auf der Mesoebene können methodisch sowohl Suffizienzansätze mit Daten unterstützt werden als auch Effizienzstrategien der Makroebene.

R. Bleischwitz hat im Anschluß an das MIPS-Konzept eine Theorie der Ressourcenproduktivität formuliert. So wie Arbeitsproduktivität als volkswirtschaftliche Kennzahl das Verhältnis von Arbeit zum Bruttoinlandsprodukt angibt, so benennt Ressourcenproduktivität das Verhältnis von Materialinput und ökologisch korrigiertem Bruttoinlandsprodukt. Die Produktivität einer Volkswirtschaft ließe sich dem Verhältnis eines ökologisch korrigierten BIPs und den spezifischen,

${ }^{85}$ Die Serviceeinheit des MIPS-Konzepts entspricht der funktionalen Einheit in der Ökobilanzierungsmethodik. 
getrennten Meßgrößen für Arbeit, Kapital und Ressourcen entnehmen. Dabei soll die Ressourcenproduktivität anhand des aggregierten Ressourceneinsatzes ermittelt werden (Bleischwitz, 1998, 119) Zu unterscheiden ist dann zwischen einer Steigerung der Ressourcenproduktivität (relative Reduktion des Materialinputs) und einer Dematerialisierung (absolute Reduktion des Materialinputs).

Die Stoffstrombilanzierung nach der Materialintensitätsanalyse faßt bislang zumeist medial und sektoral zerstreute Informationen zu einer kohärenten Übersicht des Belastungszustandes der Umwelt zusammen. Dies stellt einerseits einen hochaggregierten Indikator für die ökologische Bewertung dar, andererseits kann dieser Indikator sowohl auf mikro- als auch auf makroökonomische Zusammenhänge bezogen werden, ohne dabei vom ökonomischen System ähnlich homogenisiert zu werden wie monetarisierte Umweltgüter (vgl. Seidel, 2001). Da das MIPS-Konzept auf den Fluß und nicht auf den Bestand ausgerichtet ist, unterscheidet es sich nicht nur von der Neoklassik, sondern auch vom Naturkapital-Ansatz (Hinterberger et al., 1997). Hinsichtlich des Diskurses zur Nachhaltigkeit kann das MIPS-Konzept aufgrund seiner Orientierung am Stoffstrom als Operationalisierung des Umfangs des ökonomischen Systems (Daly) angesehen werden (Luks, 1999). Es erfaßt den dynamischen Fluß des ökonomischen Systems und ist insofern auch ein richtungssicherer Indikator, als daß es keinen direkten Bezug auf die Umwelt nimmt, - was der Koevolution von System und Umwelt auch nicht gerecht werden würde. MIPS bezieht Nachhaltigkeit auf die emergente Komplexität zwischen Anthroposphäre und natürlicher Umwelt. Damit ist es auf eine nachhaltige Entwicklung des Stoffstroms ausgerichtet. Gleichzeitig ist die Messung der Materialintensität über die zugrundeliegenden Kategorien indirekt an wesentliche Umweltproblem zurückgebunden.

Allerdings hat diese Konzeption von Nachhaltigkeit noch einige Schwächen, was bei einem hoch aggregierten Indikator wie der Materialintensität wenig überrascht. Zunächst einmal umfaßt MIPS nicht alle Formen der Umweltzerstörung: So wird die Freisetzung gentechnisch veränderter Organismen in die Biosphäre und der Verlust von Biodiversität nicht oder nicht angemessen erfaßt. Der erste Mängel kann durch das diskursethisch gebotene Nichthandeln bei epistemischer Unsicherheit beseitigt werden. Sofern das Artensterben nicht über die MIPS-Kategorien 2 und 3 abgemildert wird, bietet die Diskursethik nur eine schwache Basis zu einem weitergehenden Schutz der Biodiversität. Dies geht zu Lasten der Diskursethik und stellt ihr eine noch zu lösende Aufgabe. Neben diesen Problemen verbleibt noch die offene Bewertungsfrage der MIPS-Methodik. Mit MAIA wird lediglich eine Analyse der Materialintensität durchgeführt. Die Analyse ist im wesentlichen quantitativ, sie enthält nur über die grundsätzliche Festlegung der Kategorien einige qualitativen Elemente. So sind die Kategorien um die Kategorie 'Fläche' ergänzt und die Zählweisen für die Kategorien 'Wasser' und 'Erdbewegungen in der Land- und Forstwirtschaft' modifiziert worden. Weitere Veränderungen der Zählweise würden wissenschaftlichen Fortschritt widerspiegeln und wären insofern zu begrüßen. Dazu gehört auch die Diskussion um eine Gewichtung der Kategorien, angesichts unterschiedlicher, mit den Kategorien verbundener ökologischer Auswirkungen in verschiedenen Ökosystemen der Erde (Bedeutung von Wasser in 
ariden oder humiden Gebieten). Es unterbleibt aber eine generelle Ausführung oder Bewertung von Reduktionszielen. Zwar können explizite Bewertungen im MIPS-Konzept sowohl auf das Input als auch auf das Output hin erfolgen, wobei sich das Konzept wiederum flexibel gegenüber anderen Indikatorensystemen erweist (vgl. Fröhlich et al., 1999-2000, 50 ff), doch das MIPS-Konzept selbst enthält sich der Festlegung von konkreten Dematerialisierungsraten. ${ }^{86}$

Als weiterer Punkt ist festzustellen, daß Gefahrenaspekte der Risikogesellschaft nicht direkt vom MIPS-Konzept erfaßt werden. Das MIPS-Konzept ermöglicht weder eine Chemikalienbewertung noch eine Bewertung von Technologien. Hier scheint eine inputorientierte Erweiterung der MAIAMethodik denkbar, die sich auf Gefahrenstoffe/toxische Substanzen, den Lebenszyklus oder die Verbreitungsmenge ausrichten könnte. Allerdings sind diese Erweiterungen noch nicht erfolgt, und sie werden einen Gefährdungsansatz auch nicht grundsätzlich überflüssig machen können. ${ }^{87}$ Vielmehr scheint ein Gefährdungsansatz zur Ergänzung des MIPS-Konzept unerläßlich zu sein.

\subsection{Stoffstrommanagement und Ordnungspolitik}

D. Hecht hat ein ordnungspolitisches Konzept der Stoffstromsteuerung vorgestellt, in welchem das ökonomische Subsystem als zentraler Ort der demokratischen, gesellschaftlichen Selbststeuerung ausgezeichnet wird. Dort bildeten sich Preise, in die dezentrales Wissen einfließe. Ebenso generiere Wissen Regeln, die das Miteinander auf Märkten koordinieren. Hecht nennt als Regeln: Privateigentum, Verträge, Haftung, die Verhütung von Gewalt und Betrug sowie die Sicherung des Wettbewerbs. Er gesteht zu, daß Ziele der Stoffnutzung bei ökologischen Grenzen mit Abstrichen zu versehen seien und nähert sich teilweise der Position starker Nachhaltigkeit. Der (Heraus)Forderung einer makroökonomischen Dematerialisierungspolitik, der er zentralistische Planung unterstellt, stellt er eine liberale, stoffliche Ordnungspolitik entgegen. Dabei versteht Hecht Ordnungspolitik als Politik, die "über einmalige Akte der Rechtsetzung Regeln für privates - und auch staatliches - Handeln vorgibt, die den Bereich zulässiger Handlungen beschränken." (Hecht, 1999, 14)

Bei der Begründung einer liberalen stofflichen Ordnungspolitik geht Hecht von der zentralen Institutionen des Libertarismus aus, dem Eigentumsrecht. Für Hecht ist die eigentumsrechtlich abgesicherte Nutzung endlicher Ressourcen angesichts der davon ausgehenden ökologischen Probleme mit der Aufgabe versehen, die Folgen der entstehenden Emissionen (und auch Abfällen, die Hecht aber vernachlässigt) abzuschätzen und zu internalisieren. Die ökologische Verantwortung des Eigentums an Ressourcen will Hecht durch Kostenzurechnung erreichen. Für die staatliche Politik ergebe sich daraus die Aufgabe, "private oder staatliche Eigentumsrechte an Stoffvorräten [zu] schaffen, die entweder einen Ausschluß der Nutzung konkurrierender Dritter durch Private

\footnotetext{
${ }^{86}$ Allerdings haben prominente Vertreter einer Dematerialisierung konkrete Zahlen genannt: So spricht sich E. U. von Weizsäcker (1995) für den Faktor 4 aus, und Schmidt-Bleek (1998) für einen Faktor 10; vgl. dazu auch Reijnders, 1999.

87 So auch Meyerhoff, Petschow 1996, 187.
} 
oder durch Kollektivrepräsentanten ermöglicht. Diese Eigentumsrechte müssen an den Ressourceneigenschaften orientiert und so ausgelegt sein, daß sie vom Inhaber kontrolliert werden können." (Hecht, 1999, 166) Dazu müßte schon bei der Konstitution des Ressourcenmarktes Wissen über Ressourcen einfließen. Dies wird jedoch erst im Zuge der Verwendung der Ressource in der Produktion und als Externalität bzw. Müll generiert. Wie Verantwortung für unbekannte und bekannte ökologische und gesundheitliche Folgen von Ressourcen durch die Produktionskette hindurch an die Eigentümer zurückgegeben werden soll, bleibt zunächst offen.

Für ökologische Kollektivgüter sei eine einzelwirtschaftliche Kostenzurechnung (Nutzen/Schaden) von staatlicher Seite zu ermöglichen. Es sei nicht wie in den intertemporalen Maximierungsmodellen von einem unendlichen Planungshorizont auszugehen, sondern es bildeten sich aufgrund der angenommenen künftigen Angebot-Nachfrage-Konstellation zusammen mit der Diskontrate faktische Erwartungen. Dieser Kurzsichtigkeit des Marktes stellt Hecht die Unzulänglichkeiten des Staates entgegen: Eine zentralisierten, staatlichen Steuerung der Stoffentnahme durch Verstaatlichung der Rohstoffe oder durch eine Steuerung über ressourcenpolitische Instrumente wie Abgaben und Lizenzen brächten Probleme, "da Entnahmeoder Aufstockungsentscheidungen nicht mehr von vielen Akteuren mit unterschiedlichem Wissen, divergierenden Risikoeinstellungen und verschiedenen Erwartungen über die Zukunft getroffen werden, sondern von einer einzigen Organisation, genauer von den Entscheidungsträgern in dieser Organisation." (Hecht, 1999, 170) Dies sei nur von Vorteil, wenn die Regierung oder die Behörden über einen Wissensvorsprung gegenüber den Privaten verfügen würden. "Davon ist in der Regel nicht auszugehen. [...] Sinnvoller ist eine Bekanntmachung zentral verfügbarer Information, so daß sie mit dezentral verteiltem weiteren Wissen kombiniert werden können und zu unterschiedlichen Bewertungen der Zukunft führen." (ebd.) Obwohl Hecht die Schwächen der neoklassischen, intertemporalen Stoffallokation anerkennt, leitet er eine stoffliche Ordnungspolitik individualistisch her. Der Individualismus wendet sich nun normativ: "Sollen in einer Gesellschaft aber individuelle Präferenzen Entscheidungen determinieren, muß Myopie akzeptiert werden." (Hecht, 1999, 177)

Darauf aufbauend, entwirft Hecht eine vorgeblich positivistische Experimentiergesellschaft, die Wissen durch die experimentelle Verwendung von Stoffe generiere. Er schränkt aber ein, daß kollektive Güter der Experimentiergesellschaft entzogen werden müßten. Ohne Kausalitätsprobleme oder Transaktionskosten zu berücksichtigen, erwartet Hecht, daß sich bereits durch Wissen über Schadstoffe das Output verteuere. "Sofern Schadeffekte von Stoffen bekannt werden und das Wissen darum zu einer geringeren Verwendung dieser Substanzen führt, werden bei einer zunächst relativ hohen Stoffeinbringung die steigenden Schäden zu einer stärkeren Begrenzung der Nutzung von der Outputseite her führen. So gesehen werden die Folgen der Ineffizienzen beim Input durch eine effiziente Outputsteuerung aufgefangen." (Hecht, 1999, 226; kursiv FS) Nur scheinbar beruht die effiziente Outputsteuerung auf marktwirtschaftlicher Selbstregulation:

Der Staat soll derartiger Fehlallokation entgegenwirken, indem er kurzfristig orientierte private Entscheidungen korrigiert und Regeln und Bedienungen dafür schafft, "daß sich private Präferenzen zugunsten längerfristig ausgerichteten Handelns am Markt umsetzen kann." (Hecht, 1999, 186) 
Hecht verweist dazu auf Grundlagenforschung, Finanzierung von Substitutionsforschung und der Erforschung und Entwicklung stoffsparender Techniken etc. Um die Sicherheitsbedürfnisse von Privaten bezüglich des Stoffflusses zu erfüllen, seien Öko-Audits oder ökologisch orientierte Unternehmensbewertungen ausreichend (vgl. Hecht, 1999, 187). Damit verbleiben jedoch noch immer ökologische Kollektivgutprobleme und die Frage, wie diese zu bewältigen sind. Diese Rolle spricht Hecht dem Staat zu, schränkt aber sogleich ein, daß an der Wiederwahl interessierte Politiker einen kürzeren Planungshorizont aufwiesen als Private und deshalb kaum besser handeln könnten (vgl. Hecht, 1999, 190). ${ }^{88}$

Hecht spricht davon, daß das ökonomische System derartig vielfältiges Wissen (und Schäden) produzieren könne, daß eine Extension des Regelsystems notwendig werde. ${ }^{89}$ Die Vielzahl von Stoffen und Wirkungen, die Schwierigkeiten, Inhaltsstoffe von Produkten und in Umweltmedien zu erkennen, und die Probleme bei der Bestimmung von Schadensquellen, stellten eine alleinige Koordination der Stoffeinbringung und -nutzung über die Grundbausteine des Marktsystems in Frage. Deshalb könnten ressourcenpolitische Instrumente zur Beeinflussung der Entnahmemengen von Ressourcen eingesetzt werden. "Diese beinhalteten unter anderem Entnahmelizenzen, die zum Abbau bestimmter Vorkommen berechtigen oder maximale Entnahmemengen pro Periode festlegen, Versteigerungen, wenn der Staat das Eigentum an den Ressourcen hält, Ge- und Verbote, Abgaben und anderes." (Hecht, 1999, 193) Es sind also zusätzliche Regeln erforderlich, die das Inverkehrbringen, die Nutzung und den Verbleib von Stoffen und aus Stoffströmen resultierende Schäden regeln. Kriterium der Legitimation derartiger Regeln ist nach Hecht der Schutz vor negativen Stoffwirkungen auf der einen Seite und nicht zu starke Beschneidung der positiven Effekte der Stoffnutzung auf der anderen. Hecht führt an, daß sich Regelsysteme immer erst im Laufe der Zeit als zieladäquat oder nicht-zieladäquat erwiesen, woraus er einen Spielraum für eine Vielfalt von Institutionen ableitet.

Dies zielt indes nicht auf die institutionelle Ausgestaltung von Nachhaltigkeit. Hecht übergeht geflissentlich die bisherigen Operationalisierungsversuche von Nachhaltigkeit und führt keine Institutionen an, die explizit den nicht-nachhaltigen Stoffstrom reduzieren könnten und somit Nachhaltigkeit gewährleisten würden. Er übergeht das physikalisch-chemische Begründungsniveau der ökologischen Ökonomie und fällt damit hinter den Nachhaltigkeitsdiskurs zurück, was u.a. bei seiner Unterscheidung zwischen essentiellen und inessentiellen Ressourcen, wo er sich auf die utilitaristische Ethik Birnbachers beruft, ebenso deutlich wird, wie bei der von Hecht verworfenen aber dennoch als Blaupause dienenden neoklassischen Ressourcenökonomie. Der fehlende Nachhaltigkeitsbezug von Hechts stofflicher Ordnungspolitik hat hier seinen Ursprung.

Die pragmatische Annäherung an die stoffliche Dimension des ökonomischen Systems läßt sich nicht mit einer normativen Superiorität des präferenzbasierten Individualismus und subjektiver

${ }^{88}$ Diese Befürchtung wird auch in der Nachhaltigkeitsstudie des Rheinisch-Westfälischen Instituts für Wirtschaftsforschung in Essen vertreten und als Beschränkung für die Korrektur eines defizitären Preissystems durch das politische System gesehen; vgl. Klemmer et al., 1996, 319 ff.

89 Dies erinnert an Buchanans (1975) Theorie konstitutioneller Revolutionen. 
Risikoentscheidungen begründen. Hecht mißversteht aufgrund seiner individualistischen Mikrofundierung das ökonomische System als einen intentionalen Suchprozeß, der nur an wenigen Stellen durch nicht-intendierte Externalitäten und strukturellen Ineffizienzen der Ressourcennutzung durchbrochen wird, und durch Wissen wieder internalisiert werden kann. Dies erklärt keinesfalls die gewöhnlich dem politischen System zugeschriebenen Probleme, umweltökonomische Instrumente überhaupt anzuwenden. Wissen motiviert auch innerhalb des ökonomischen System noch keinesfalls zu Handlungen! Offensichtlich sperrt sich die ökonomische und politische Wirklichkeit dieser ordnungspolitischen Theorie. Es bleibt offen, wie ökonomische und staatliche Regeln aus dem gleichen Suchprozeß heraus generiert werden könnten. Hecht diagnostiziert zwar einen Hiatus zwischen ökonomischer Empirie und ökonomischer Theorie, doch seine pragmatische Inanspruchnahme von Wissen und Rationalität verfehlt eine nachhaltigkeitsgerechte Zielsetzung systematisch und kann eine stoffliche Ordnungspolitik nicht begründen.

Grundfrage einer Ordnungspolitik der Nachhaltigkeit ist die Reform der Wirtschaftsverfassung. Die Notwendigkeit zur Ordnungspolitik ergibt sich aus der Sicht des ökonomischen Systems aus der Abwesenheit theoretischer erstbester Lösungen. Aus diesem Grund sind Kriterien für zweitbeste Lösungen zu benennen, die eine möglichst ordnungskonforme Politik der Nachhaltigkeit ermöglichen (so Rennings et al., 1996, 233 f). Um Nachhaltigkeit durchzusetzen, müssen vom Staat gezielt Institutionen geschaffen werden, welche auch den Prinzipien der Marktwirtschaft Rechnung tragen sollen.

Für eine derartige institutionellen Reformen zur Nachhaltigkeit stehen in der ökonomischen Tradition die ordnungspolitischen Konzeptionen von F. A. von Hayeks, M. Buchanan und W. Eucken bereit, die wesentlichen Kriterien einer funktionsfähigen Markwirtschaft zu benennen versucht haben. Da keiner dieser drei Ordnungstheoretiker als Verfechter von Umweltpolitik oder gar Nachhaltigkeit gelten kann, ist anzunehmen, daß ihr Reiz für ökologische Ordnungstheoretiker auf die ökonomische Methodik zurückzuführen ist, die sich erfolgversprechend auf das Problem der Nachhaltigkeit anwenden läßt. Bei Hayek ist Wissen und die Evolution der Wirtschaft zentral (vgl. Hinterberger, 1996). Hayek nimmt an, daß Wissen über konkrete Tatsachen der Zeit und des Raums grundsätzlich nicht zentral bearbeitet werden kann und daß deshalb ein evolutionäres, nicht reguliertes ökonomisches System, der Kapitalismus, die beste Gesellschaftsform sei. Wie soeben dargestellt, hat sich Hecht an Hayek orientiert. Der Wissensaspekt wird auch in der evolutorischen Ökonomie aufgenommen und ist in bezug auf Nachhaltigkeit modelliert worden (Beckenbach, 1996, Pasche, 1994). Auf Buchanan geht die Neue Politische Ökonomie (NPÖ) zurück, welche strukturelle Grenzen des politisch-administrativen Systems und die Legitimation staatlicher Interventionen in den Markt analysiert hat. Einer erfolgreichen Ordnungspolitik stehen auf Seiten des politisch-administrativen Systems beschränkte Öffentlichkeitsperioden, Wahlzyklen, RentSeeking und budgetmaximierende Bürokratien entgegen (Horbach, 1992; Holzinger, 1987). Schließlich ist Eucken zu nennen, der den Staat explizit als Ordnungshüter des ökonomischen Wettbewerbs einfordert und einen funktionsfähigen und menschenwürdigen Ordnungsrahmen für die Marktwirtschaft als unerläßlich ansieht. Neben konstitutiven Prinzipien der Wirtschaftsordnung 
sichern regulierende Prinzipien die Funktionsfähigkeit der Wettbewerbsordnung. (Auf Eucken baut der Vorschlag einer ökologischen Wirtschaftspolitik von F. Hinterberger, F. Luks und M. Stewens auf.)

Gegen den Hintergrund der ordnungspolitischen Theorien von Hayek, Buchanan et al. (Ökonomische Theorie der Politik) und Eucken haben Gerken und Renner versucht, eine systematische Einschätzung der Konformität umweltpolitischer Instrumente zu unternehmen (nach Gerken, Renner, 1996, 69):

\begin{tabular}{|c|c|c|c|}
\cline { 2 - 4 } \multicolumn{1}{c|}{} & Eucken & Hayek & Buchanan et al. \\
\cline { 2 - 4 } Umweltabgaben & 0 & 0 & - \\
\cline { 2 - 4 } Subventionen & - & - & + \\
\hline Umweltzertifikate & + & + & ++ \\
\hline Haftungsrecht & ++ & ++ & 0 \\
\cline { 2 - 4 } $\begin{array}{c}\text { Ordnungsrecht } \\
\text { freiwillige }\end{array}$ & + & - & -- \\
\cline { 2 - 4 } $\begin{array}{c}\text { Selbstverpflichtung } \\
\text { informatorische } \\
\text { Instrumente }\end{array}$ & + & + & 0 \\
\cline { 2 - 4 } & + & ++ & \\
\hline
\end{tabular}

$++=$ sehr gut geeignet, $+=$ gut geeignet, $0=$ geeignet, $-=$ schlecht geeignet, $--=$ ungeeignet

Letztlich halten Gerken und Renner jedoch alle drei Referenzsysteme für wenig brauchbar, um die ordnungspolitische Aufgabe einer Politik der Nachhaltigkeit zu bewältigen ${ }^{90}$ : Sie verweisen statt dessen auf die drei Säulen der Nachhaltigkeit, also auf die sozialen, die ökonomischen und die ökologischen Teilziele.

Eine direkte Bestimmung von Kriterien für einen ökologischen Ordnungsrahmen wird so unumgänglich. M. Stewens hat instrumentelle Subsidiarität, Praktikabilität der Instrumente, Funktionsfähigkeit der Märkte und des Preismechanismus ${ }^{91}$, Innovationsanreize und die Möglichkeit zur Dosierung der Maßnahmen als Maßstäbe einer ökologischen Ordnungspolitik

90 Dabei bemängeln sie die Fixierung Hayeks und Euckens auf die ökonomische Teilordnung und charakterisieren dies als externe Bewertung. Die Bewertung einer nachhaltigen Ordnung müsse demgegenüber auf Präferenzsouveränität fußen und insofern eine innere Bewertung ermöglichen. Gerken und Renner skizzieren Nachhaltigkeit dann als Urzustand à la Buchanan und Rawls, wobei als Gegenstand der Wahl die ordnungstheoretischen Konzepte der Nachhaltigkeit auftreten. Die Ungewißheit über Präferenzen bezüglich des Verhältnisses der drei Teilordnungen von Nachhaltigkeit könne nur durch die Generierung von Wissen im (nunmehr: umweltpolitischen) Wettbewerb überwunden werden. Da der politische Wettbewerb defizitär sei - weshalb Gerken und Renner u.a. für eine ökologische Verfassungsreformen plädieren - müsse Reformdruck in einem zwischenstaatlichen, politischökonomischen Ordnungswettbewerb erzeugt werden. Doch entgegen dieser Annahme ist ein internationaler Wettbewerb um die effizienteste Umweltordnungspolitik angesichts des Gefangenendilemmas bei der Etablierung internationaler, öffentlicher Güter nicht zu erwarten.

91 Stewens lehnt deshalb auch Ressourcenquoten ab, für die H. Daly plädiert hatte; vgl. Daly, 1991, $61 \mathrm{ff}$. 
genannt (Stewens, 1999-2000, 15 ff). Kurz et al. nennen als Prinzipien eines ordnungspolitischen Ansatzes ebenfalls die Funktionsfähigkeit des Preissystems, daneben die Freiheit des Wettbewerbs (verstanden als jeweils zu qualifizierende Wahlfreiheit der Konsumenten, Dispositionsfreiheit der Produzenten und Offenheit des Marktes), Privateigentum, Haftung, konstante Wirtschaftspolitik, korrigierte VGR und Berücksichtigung sozialer, politischer und ökonomischer Interdependenzen (Kurz et al., 1996, 120 ff). Klemmer et al. (1996) verweisen insbesondere auf die Koordinationsund die Selektionsfunktion des Marktes, die ein ordnungspolitischer Nachhaltigkeitsrahmen gefährden würde. Allerdings ist die These einer Entmachtung der Ökonomie "bei der neben einer mit großen Risiken verbundenen Strangulierung der Wirtschaft auch die Marktwirtschaft auf der Strecke bleiben muß" (Klemmer, 1996, 18) normativ. Das bisherige ökologische Versagen des Marktes wird nicht durch ein ähnliches umweltpolitisches Versagen des Staates legitimiert. Im Gegenteil sollte sich die ordnungsrechtliche Diskussion der normativen gesellschaftlichen Zielfindung öffnen (vgl. Becker Soest, Wink, 1996). Rennings et al. haben festgestellt, daß eine am Leitbild der nachhaltigen Entwicklung ausgerichtete Wirtschaftspolitik zu kurz greift, "wenn sie sich lediglich mit Fragen der effizienten Allokation von Gütern auf Märkten befaßt." (Rennings et al., 1996, 268) Eine Ordnungspolitik der Nachhaltigkeit müsse vielmehr die Frage des Umfangs (Daly) wirtschaftspolitisch thematisieren und zweit- und drittbeste Lösungen konsensfähig machen, da erstbeste Lösungen systematisch versagten. Sie haben die Instrumente einer Ordnungspolitik der Nachhaltigkeit nach folgenden Kriterien beurteilt: Effektivität (Zielkonformität), Erforderlichkeit (Systemkonformität), ökonomische Effizienz und institutionelle Beherrschbarkeit.

Das ordnungsrechtliche Instrumentarium stellt ihrer Einschätzung zufolge die sicherste Maßnahme zur akuten, lokalen Gefahrenabwehr dar, da sie den Normadressaten bindende Restriktionen vorschreibt. Demgegenüber erlauben Abgaben und Zertifikate Anpassungsreaktion der Unternehmen; sie kommen vor allem bei der Reduktion von Emissionsflüssen und im vorsorgenden Umweltschutz zum Einsatz. Für die Behörden sind Zertifikate vergleichsweise weniger informationsaufwendig. Theoretisch ließen sich von Subventionen ähnliche Effekte erhoffen; allerdings würden sie hohe Informationsanforderungen stellen und langfristig falsche Preissignale aussenden und zu ökonomischer Ineffizienz führen. In der Praxis werden Subventionen nur zur Unterstützung umweltpolitischer Maßnahmen eingesetzt. Das Haftungsrecht kann das umweltpolitische Instrumentarium dort ergänzen, wo für eine staatliche Nachhaltigkeitspolitik keine Informationen über Umweltschäden vorliegen oder reparable Umweltschäden vermieden werden sollen. Die Verschuldungshaftung kann nur Anreize bieten, die gesetzlichen Standards einzuhalten, wohingegen die Gefährdungshaftung Anreize zur Vermeidung von Schäden entfalten soll. Allerdings kann ein System von Gefährdungshaftungen keine politisch erwünschten Emissionsminderungsziele umsetzen, da sich das Niveau der Umweltqualität marktendogen einstellt (Wätzold, 1998, 2000). Auch weisen Rennings et al. auf die praktischen Beschränkungen der Gefährdungshaftung hin, die eine verursachergerechte Zurechenbarkeit erheblich erschweren. Im Bereich des vorsorgenden, unterhalb der Gefahrenschwelle ansetzenden Umweltschutz erweist sich das Haftungsrecht rechtlich als ungeeignet (vgl. Lübbe-Wolff, 1995, 52 f). 
Rennings et al. halten am Verursacherprinzip orientierte ökonomische Instrumente (Abgaben, Zertifikate) für systemkonformer als ordnungsrechtliche Gebote, denn Umweltabgaben würden gegenüber Auflagen größere Verhaltensspielräume eröffnen, obwohl sie breiter wirkten. Am vorteilhaftesten beurteilen auch sie Zertifikate. Freiwillige Selbstverpflichtungen könnten langfristig nicht das Gemeinwohl wahren, und seien auf Branchenebene nur dann marktkonform, wenn branchenintern auf Marktmechanismen (z.B. private Zertifikate) zurückgegriffen werden würde. Es gebe aber aufgrund des Einzelfallcharakters von Selbstverpflichtungen durchaus kartellund wettbewerbsrechtliche Bedenken.

Die ökonomische Effizienz von Auflagen ist gering, da sich sowohl auf der gesamt- als auch auf der einzelwirtschaftlichen Ebene keine statische Allokationseffizienz erzielen läßt. Da sie keine (umwelttechnische) Innovationsdynamik induzieren können, sind sie auch dynamisch ineffizient. Die allokativen Vorteile der ökonomischen Instrumente basieren auf ihrem geringen Informationsbedarf. Abgaben weisen Kostenvorteile für die Unternehmen auf und können dynamische Anreize für umwelttechnologische Innovationen vorweisen. Dies wird Zertifikaten mitunter abgesprochen, da Zertifikatpreise bei technischem Fortschritt fallen und bei gleichbleibender Zertifikatmenge weitere mögliche Innovationen unterbleiben. Außerdem können bei der räumlichen Ausgestaltung von Zertifikatsystemen Konflikte zwischen ökologischer und ökonomischer Zielsetzung auftreten, die - je nach dem - zu Lasten der ökonomischen Effizienz führen könnten. Freiwillige Instrumente können bei bestimmten Regelungen effiziente Instrumente sein; sie müssen jedoch das Trittbrettfahrerproblem lösen, das mit der Zahl der Akteure und der Heterogenität der Branche wächst. Da sich keine einheitlichen Preise für die Umweltnutzung einstellen, ist eine effiziente Allokation nicht zu erwarten. Auch stellen sich keine dynamischen Anreize zur Entwicklung von Umwelttechniken ein.

Die Umweltpolitik hat bisher aus vielfältigen Gründen vornehmlich ordnungsrechtliche Auflagen implementiert. Diese boten jedoch Raum für erhebliche Fehlentwicklungen sowohl des politisch-administrativen Systems (Vollzugsdefizit) als auch des ökonomischen Systems (Ineffizienz). Absehbar führt eine auflagenzentrierte Umweltpolitik bei anhaltendem Wirtschaftswachstum ihr eigenes Versagen herbei, indem sie Rechtssystem und ökonomisches System mit Detailregulierungen zu blockieren droht. Gegen Abgaben und Zertifikate bestehen aber erhebliche Widerstände seitens des ökonomischen und des politisch-administrativen Systems. Abgabepflichtige Wirtschaftsakteure und Rennings et al. zufolge auch ordnungsrechtlich kooperierende Genehmigungsbehörden gehören zu den Gegnern von Umweltabgaben. Die Verselbständigung des polisch-administrativen Systems scheint den Autoren sogar insoweit möglich, als daß bei Umweltabgaben das ökologische Lenkungsziel ganz hinter die Betrachtung der Steuer als Einnahmequelle des Staate zurücktreten würden (Rennings et al., 1996, 267). Freiwillige Selbstverpflichtungen sind schwer zu implementieren und im Vollzug schwer zu kontrollieren. Der Schatten staatlicher Intervention mag den geringen Anreiz zur Selbstverpflichtung zwar erhöhen, doch löst er weder das Koordinations- noch das Kontrollproblem, da die vereinbarten Ziele i.d.R. rechtlich nicht verbindlich sind. 
J. Minsch hat ein Konzept ökologischer Grobsteuerung vorgestellt, welches das Ordnungsmodell von Rennings et al. z.T. konkretisiert (Minsch, 1994). Die Grobsteuerung konzentriert sich auf wenige strategische Inputs, um die gegenwärtigen quantitativen Ursachen ökologischer Gefährdung zu beseitigen. Dazu sei eine ökologische Rahmenordnung zu realisieren, "die einen marktwirtschaftlichen Suchprozeß in Richtung nachhaltiger Entwicklung initiiert." (ebd., 23) Eine derartige ökologische Grobsteuerung soll eine Inputorientierung aufweisen, die bei der Wirk-, Material- und Raumursache der Naturschädigung ansetzt. Sie habe eine quantitative Perspektive, da ökologische Gefährdung primär ein Mengen- und Größenproblem sei, und gestatte dem ökonomischen System eine offene Anpassung an den ordnungspolitischen Rahmen. Diese Offenheit gelte auch im größeren Kontext der gesellschaftlichen Zielsetzung nachhaltiger Entwicklung. Als zentralen Ansatzpunkt nennt Minsch Energie und daneben Material und Abfall sowie Raum mit seinen Elementen Boden, Landschaft und Verkehr. Auf einer der quantitativen Ebene nachgeordneten Ebene soll von der Umweltpolitik eine ökologische Feinsteuerung implementiert werden. Die Instrumente einer solchen inputorientierten, umweltpolitischen Grobsteuerung könnten nach Stewens (1999-2000, 5) bei 1. der Ressourcenentnahme; 2. einzelnen gefährlichen Stoffen; 3. der Senkung der Emissions- und Abfallströme und 4. Immissionen ansetzen.

Die ökologische Grobsteuerung folgt den etablierten Politikfeldern mit den darin bestehenden Ministerien. Sie führt zu keiner Aufgabenentlastung der administrativen Institutionen, sondern zu einer Neuordnung, die ihre potentielle Konfliktstellung zu anderen Politikfeldern und Ministerien nicht reflektiert. ${ }^{92}$ Es ist in diesem Zusammenhang nicht ersichtlich, welche Indikatoren bzw. welches Indikatorensystem eine kohärente ökologische Grobsteuerung mit Inputorientierung gewährleisten soll, denn die ökologischen Problemfelder müssen erst wieder (mit entsprechenden politischen Transaktionskosten) an das ökonomische System akkomodiert werden. Eine Stoffstrompolitik nach dem MIPS-Konzept kann demgegenüber die notwendige Kohärenz der ökologischen Zielsetzung gewährleisten und direkt auf das ökonomische System bezogen werden.

Wesentlich für einen solchen Ansatz ist ein ökologisch-ordnungspolitischer Rahmen, der Nachhaltigkeit möglichst einfach und kohärent umsetzt. Dieser wird von F. Hinterberger, F. Luks und M. Stewens nicht wie im Konzept konstanten Naturkapitals statisch definiert, sondern dynamisch durch ökologisch-ökonomische Leitplanken innerhalb derer nachhaltige Entwicklung verlaufen soll. Darin fungiert das MIPS-Konzept als ökologisches Leitbild. Eine Schlüsselrolle bei der Umsetzung von Nachhaltigkeit übernehmen Institutionen, welche die Entwicklung einerseits beschränken und andererseits überhaupt erst ermöglichen. Diese Doppelrolle, die auch dem Rahmen insgesamt zueigen ist, resultiert aus der Beschränkung und Stabilisierung von Erwartungen durch Institutionen. Institutionen entwickeln sich pfadabhängig, so daß Erwartungen mit dem Nachhaltigkeitspfad von Institutionen verbunden werden können. Indem der Rahmen eine ökologische Grobsteuerung verfolgt, werden (nicht nachhaltige) Handlungsoptionen entwertet und gleichzeitig (nachhaltige) Handlungsoptionen durch das Leitbild stabilisiert. So erklärt

${ }^{92}$ So beziehen sich (Meyerhoff, Petschow, 1996 a) auf das Konzept der ökologischen Grobsteuerung, um den Unterschied zwischen einer Politik der Nachhaltigkeit und der traditionellen Umweltpolitik herauszuarbeiten. 
beispielsweise nur der gesellschaftliche Konsens über die Notwendigkeit zur Müllvermeidung die erstaunliche Bereitschaft zur privaten Müllsortierung. Ebenso kann das MIPS-Konzept auf allen gesellschaftlichen Ebenen seine Leitbildfunktion entfalten. Als Steigerung der Ressourcenproduktivität, d. h. mit einer Senkung der Materialintensität in Produktion und Konsum, eröffnet das Leitbild auf breiter gesellschaftlicher Basis Positivsummenspiele mit ökologischem Mehrwert. Dies entspricht als Dematerialisierung der Nachhaltigkeitszielsetzung der Leitplanken und wird mit der gleichen Methodik verwirklicht. Dabei ist klar, daß eine ökologische Grobsteuerung Umweltpolitik zwar entlasten, kaum aber erübrigen wird, da sich auch nachhaltige Technologien und ressourceneffiziente Innovationen als gefährlich erweisen könnten (wie etwa das Beispiel der Chlorchemie zeigt). ${ }^{93}$

Man kann also von einer Nachhaltigkeitspolitik nicht erwarten, daß wir die Risikogesellschaft augenblicklich hinter uns lassen. Man sollte allerdings von ihr erwarten können, daß sie die ökologische Selbstgefährdung moderner Gesellschaften langfristig mit entschärfen kann, und das sich dadurch moderne Gesellschaften wieder eine Zukunft eröffnen und das ökonomische System an die Lebenswelt zurückgebinden.

\subsection{Eine inputorientierte Ordnungspolitik der Nachhaltigkeit}

Stoffstrommanagement ist zunächst die Verlängerung der ökonomischen Selbstorganisation des Umweltproblems vom Unternehmen zur Wertschöpfungskette. Teilweise entstehen die vertikalen Kooperationen des Stoffstrommanagements im Gegensatz zur Umweltpolitik vom Ende der Kette her, also der Konsumentenseite. Diese Strukturen des Stoffstrommanagements lassen unmittelbar die Entstehung von Netzwerken zum Management von Stoffströmen erwarten. Für ein autonom entstehendes Stoffstrommanagement lassen sich intrinsische ökonomische Motive finden (vgl. Zundel et al., 1998, 334). Doch hängt die wirtschaftsinterne Kooperation von Unternehmen bereits in der statischen Perspektive von einer Reihe von Faktoren ab. ${ }^{94}$

1. Die Höhe der erwarteten Kooperationsgewinne als Gewinnzuwachs gegenüber anderen Handlungsalternativen bestimmt darüber, ob Kooperationen zustande kommen.

2. Die Verteilung der erwarteten Gewinne und Verluste zwischen den Kooperationspartnern bestimmt deren Bereitschaft zu kooperieren. Sowohl Positiv-, als auch Negativ- und Nullsummenspiele sind etwa in Kooperationen entlang von Produktionslinien möglich. Kommen bei ungleichen Kosten keine Ausgleichszahlungen zustande (Kaldor-HicksKriterium), kann mögliche Kooperation insgesamt ausbleiben.

3. Die Höhe der Transaktionskosten (Verhandlungskosten, Implementationskosten etc.) ist ebenfalls relevant und kann gerade im Entsorgungsbereich prohibitiv hoch sein.

93 Ähnlich auch die These von Meyerhoff, Petschow, 1996 b.

94 Ich folge in der Darstellung Zundel et al., $324 \mathrm{f}$. 
4. Die Risikoeinschätzung in bezug auf eine Kooperation (Vertrauenswürdigkeit der Partner, kartellrechtliche Probleme, Optimierung gegenüber Innovation) ist eine weitere Erfolgsbedingung für das zwischenbetriebliche Stoffstrommanagement.

5. Schließlich hat die Verteilung von Marktmacht entlang der Wertschöpfungskette einen erheblichen Einfluß auf das Gelingen von Kooperation. Ohne die dominanten Akteure können Kooperationen kaum zustande kommen.

Und aus dynamischer Perspektive sind folgende Faktoren hinzuzufügen:

6. Eine ökologisierte Endnachfrage hat erheblichen Einfluß auf das Entstehen von Kooperationen entlang der Wertschöpfungskette, wobei die direkt mit der Endnachfrage konfrontierten Händler/Unternehmer stärkeren ökonomischen Druck verspüren, ohne allzu große ökologische Optimierungspotentiale zu haben. Unternehmen am Beginn der Wertschöpfungskette weisen demgegenüber größere Optimierungspotentiale auf, haben jedoch geringere ökonomische Anreize, die Optimierungspotentiale auch auszuschöpfen.

7. Die politische Internalisierung externer Effekte - insbesondere durch die Verschärfung der Abfallgesetzgebung und die Verteuerung natürlicher Ressourcen - schaffen einen Anreiz zum Management von Stoffströmen, wenn man zwar von den damit verbundenen Kosten betroffen ist, jedoch nicht über die möglichen Optimierungspotentiale disponieren kann.

Ein selbstorganisiertes Stoffstrommanagement könnte sich vor allem in solchen Bereichen einstellen, wo sich durch First-Mover-Vorteile oder Skalenerträge (economics of scale) gruppale Kollektivgüter bilden können. Diese würden sich zusätzlich zu bestehenden ökonomischen Strukturen entwickeln: Im Stoffstrommanagement sind neben den traditionellen horizontalen Verbandsstrukturen (der Branchen) als organisatorische Innovation auch vertikale Kettenstrukturen (zwischen Branchen) zu erwarten. Bestehende horizontale Verbandsstrukturen würden im Stoffstrommanagement durch vertikale ergänzt werden. Derartige Kettenverbände weisen im allgemeinen Netzwerkstrukturen auf.

Die Entstehung solcher Verbände läßt sich zuerst für den Bereich der Normierung erwarten, wo TÜV und DIN als Beispiele für gelungene Selbstregulation genannt werden. S. Frick hat die Hoffnung geäußert, daß sich hier ein einheitliches Informationssystem (MIPS oder Integrated Substance Chain Management) durchsetzen könnte (Frick, 1996, 312 ff). Dies könnte potentiell bereits gemeinwohlförderlich im Sinne einer Dematerialisierung sein. Aber schon für etwas komplexere Verhandlungssysteme kann aufgrund von Erfahrungen aus anderen Politikfeldern eine Störung der funktionalen, ökonomischen Selbstregulation erwartet werden.

In der Produktion wird das Materialinput der Wirtschaft von Firmen weiterverarbeitet. Es entstehen neue Stoffe und Produkte, über welche zunächst einmal die Hersteller alle relevanten Informationen besitzen. Das Management der Stoffströme setzt bei den Firmen an und hält diese dazu an, freiwillig Informationen über Stoffströme zu sammeln und entlang der Produktionsketten miteinander zu kooperieren. Das Management von Stoffströmen ist erst einmal Aufgabe der wirtschaftlichen Akteure. Der Staat kann dies unterstützen, indem er die Bedingungen des 
Stoffstrommanagements gestaltet. Dazu gehörenvor allem auch einheitliche Standards, die mikround makroökonomische Zielsetzungen miteinander verbinden. ${ }^{95}$ In Teilen ist das Stoffstrommanagement über Öko-Audit und Produktnormen bereits Bestandteil der Umweltpolitik geworden. Erfolgreiche politische Steuerung (zum Management einzelner Stoffe) könnten die Umweltpolitik insgesamt beleben, indem sie die Motive der Akteure fördert, allokationseffiziente Instrumente zu implementieren. Daraus läßt sich jedoch kein mikroökonomisches Primat nachhaltiger Entwicklung ableiten.

Zwar vermengen sich bereits im Konzept des Stoffstrommanagements ökonomisches und politisch-administratives System (vgl. BT, 1993), doch das Stoffstrommanagement verfolgt eine rein prozedurale, im Wesentlichen nicht-hierarchische Steuerung, die sich auf die Bewältigung produktionsspezifischer Probleme ausrichtet. Eine Politik der Dematerialisierung (absolute Reduktion des Stoffstroms) geht dagegen erkennbar über ein solches Stoffstrommanagement hinaus. Allerdings übersteigt auch die Komplexität der Input-Stoffströme in einigen Bereichen (noch) die Informationsbasis des Staates.

Sofern Stoffströme unter dem Wachstum der Wirtschaft weiter quantitativ und qualitativ anschwellen, wird die Implementation von Umweltpolitik zunehmend schwieriger. Nur innerhalb eines ökonomisch-ökologischen Ordnungsrahmens läßt sich die Anreizstruktur des Wirtschaftssystems durch die Abschaffung ökologisch falscher Subventionen und durch am Input ansetzende Steuern/Zertifikaten nachhaltig verändern. Dazu bietet sich das MIPS-Konzept an. Das Materialinput wird als Umweltbelastungspotential einer Volkswirtschaft verstanden, das durch eine Energiesteuer und ergänzenden Stoffsteuern/-zertifikate gesenkt werden kann. Eine Inputsteuerung entlastet die konventionelle, einzelfallorientierte Umweltpolitik und steht zwar über eine konstante Materialbilanz noch im Zusammenhang zum Verursacherprinzip, verweist jedoch stärker auf das Vorsichtsprinzip, welches bereits die Theorie präventiver Umweltpolitik mitbegründete (vgl. Simonis, 1988).

Theoriengeschichtlich steht das MIPS-Konzept nicht in direktem Zusammenhang zu präventiver Umweltpolitik. Es kann gegenüber Umweltpolitik allgemein eine gewisse Unabhängigkeit geltend machen, denn es entspringt dem universalen Nachhaltigkeitsdiskurs und bezieht sich als ordnungspolitische Theorie einer ökologischen Wirtschaftspolitik auf das ökonomische System insgesamt. Dennoch impliziert es keine Nachhaltigkeitspolitik, welche die ökologisch-ökonomische Zielfindung externalisiert und damit die Umweltpolitik von den Füßen auf den Kopf zu stellen beabsichtigt (so Weiß, 1996). Sie ist auf ihr entgegenkommende Lebensformen angewiesen und begründet sich nicht mit endogenen, pareto-aggregierten Präferenzen, die Politik und Ökonomie in Eins setzen. Inwieweit innerhalb eines ökonomisch-ökologischen Ordnungsrahmens dann Negativsummenpolitiken zustimmungs- und implementationsfähig sein können, ist keine Frage per

95 Zur betriebswirtschaftlichen Anwendbarkeit des MIPS-Konzepts vgl. Haake, 1999. 
se konsumatorischer Präferenzen, sondern eine des institutionellen Arrangements und der sozialwissenschaftlichen Empirie. ${ }^{96}$

Eine ökologische Wirtschaftspolitik der Nachhaltigkeit wäre ein historisches Novum. Die funktionale Differenzierung der Moderne ist vom politisch-administrativen und vom kapitalistischen, ökonomischen System bestimmt. Die Ausdifferenzierung moderner Gesellschaften erfolgte bis vor drei Jahrzehnten ohne Beobachtung der Veränderungen in der Umwelt, da sich das kapitalistische Wirtschaftssystem vermeintlich weitgehend geschlossen reproduzierte. Gleichzeit aber steht das ökonomische System im stofflich-energetischen Austausch mit der natürlichen Umwelt und produziert so Umweltprobleme. Bisher hat sich keine dauerhafte reflexive ökologische Kommunikation ausdifferenziert, welche die Reproduktion der gesellschaftlichen Subsysteme langfristig sichern könnte. Nach Luhmann ist dies auch nicht zu erwarten. Gleichzeitig aber wächst der mit den ökologischen Problemen verbundene Problemdruck: In den meisten westlichen Industrieländern steigen seit mehreren Jahrzehnten die externen Kosten schneller als die Wohlfahrtseffekte (vgl. Leipert, 1989). Dies erweist sich als schleichende Gefährdung der gesellschaftlichen Differenzierung. Im Gegensatz zur Diskurstheorie ist die Systemtheorie aufgrund der Konstruktion ihrer Theorie nicht in der Lage, dieser Gefahr zu begegnen.

Hinterberger und Welfens (1996) haben aufgrund der Schwäche outputorientierter Umweltpolitik, langfristige Nachhaltigkeitsziele zu verfolgen, eine inputorientierte Umweltpolitik gefordert, die bei der Reduktion von Stoffströmen ansetzt. Dies kann als originäre Politik der Nachhaltigkeit angesehen werden. Als Gründe für eine inputorientierte Umweltpolitik nennen sie, daß diese

- bei den Ursachen ansetze,

- die ökologischen Auswirkungen von menschlichen Aktivitäten umfassend analysieren könne,

- begrenztem ökologischem Wissen besser gerecht werden,

- effizienter sei als konventionelle Umweltpolitik,

- Anreize für ressourcensparenden technischen Fortschritt (von der Rohstoffentnahme bis zur Entsorgung) schaffe,

- wettbewerbsfördernd und damit innovationsstimulierend sei,

- Produzenten und Konsumenten bessere Informationen über ihre Umweltbelastungen erhielten,

- und die Daten im Bereich der (potentiellen) Umweltbelastung einfacher zu erfassen seien.

Diese Punkte deuten auf eine an Stoffströmen ausgerichtete Nachhaltigkeitspolitik hin, welche auf die Unterstützung freiwilliger Veränderungen und Veränderung der marktwirtschaftlichen

${ }^{96}$ So verweisen F. Hinterberger und F. Luks (1998) auf die Notwendigkeit, mit den drei Dimensionen von Nachhaltigkeit (Soziales, Ökologie, Ökonomie) Politikziele zu verbinden, die sich praktisch umsetzen lassen. Sie nennen Wettbewerbsfähigkeit, Beschäftigung und Reduktion des Materialinputs als interdependente Politikziele und erweitern das Dreieck der Nachhaltigkeitsdimensionen zu einer Pyramide mit dem institutionellen Arrangement als (nichthierarchische) Spitze. 
Anreizstrukturen hinwirkt. Als Instrumente einer derartigen Politik kommen Produktkennzeichnungen, Öko-Audit, Erziehung und Weiterbildung aber auch veränderte Eigentumsrechte entlang der Nutzung von Gütern (Rücknahme- und Entsorgungspflichten) in Betracht.

Für Akteure des ökonomischen Systems weist ein ökologischer Ordnungsrahmen auf Basis eines gesellschaftlich näher zu bestimmenden Dematerialisierungsziels Vorteile gegenüber dem umweltpolitischen Status Quo auf (vgl. Hinterberger et al., 1996, 265 f):

- In der koevolutionären Perspektive ist offensichtlich, daß nicht nur das wachsende ökonomische System die Umwelt transformiert, sondern daß die veränderte Umwelt ihrerseits auf den ökonomischen Prozeß zurückwirkt. Eine Dematerialisierung verringert das Risiko zukünftiger Umweltschäden und des damit verbundenen Risikos für die Akteure des ökonomischen Prozesses.

- Die mit der Dematerialisierung verbundene Rahmensetzung sichert die Erwartungen der Wirtschaftssubjekte und erleichtert langfristige Investitionsentscheidungen, da ex-post durchzuführende umweltpolitische Maßnahmen unwahrscheinlicher werden.

- Bei fortgesetztem ökonomischen Wachstum wird die Umweltpolitik zu einem Netz von Regulierungen führen, das die Freiheitsgrade der einzelnen Akteure verringert. Dagegen impliziert eine Dematerialisierung eine vergleichsweise geringe Regulationsdichte.

- Eine Politik der Dematerialisierung erfordert eine strikte Wettbewerbspolitik, da sie auf effizienzsteigernde Innovationen angewiesen ist.

- Ein ökologischer Rahmen der Dematerialisierung schafft größere unternehmerische Handlungsspielräume, da er keine Vorgaben hinsichtlich von Technologien und ökonomischen Strukturen macht.

Als weitgehend kostenloses oder mit zu geringen Kosten belegtes Gut tritt das Ziel eines nachhaltig genutzten Naturhaushalts weder als Produktionsfaktor noch als qualitativer Bestandteil des Produktionsergebnisses in Erscheinung.

Die Inanspruchnahme von Leistungen des Naturhaushaltes substituiert umgekehrt sogar die kostenwirksamen Faktoren Kapital und Arbeit und entlastet die Unternehmen. Gleiches gilt für das soziale Kapital einer Gesellschaft. Die betriebliche Rationalität einer Kostensenkung durch Externalisierung steht somit in einem Spannungsverhältnis zu dem Ansatz der Internalisierung externer Kosten. So erklärt sich der vermeintliche Widerspruch zwischen steigender Produktivität bei gleichzeitig steigenden Folgekosten: sie sind Zwillingserscheinungen, solange keine ordnungspolitische Veränderung der ökonomischen Rahmenbedingungen erfolgt. (Bleischwitz, 1998, 97 f)

Solange die Steigerung der Arbeitsproduktivität zentrale Größe für das ökonomische System ist, wird die wirtschaftspolitische Zielsetzung eines hohen Beschäftigungsstandes weiterhin einen großen Wachstumsdruck ausüben. Dies würde sich ändern, wenn der technologische Fortschritt auf die Steigerung der Ressourcenproduktivität ausgerichtet werden könnte.

Die makroökonomische Analyse des GMA zeigt eine Entkoppelung von Wachstum und Ressourcenverbrauch. Dies kann zwar nicht als Bestätigung der Kuznet-Kurve-Hypothese angesehen werden, zeigt aber, daß in den Jahren 1960-1990 in der Bundesrepublik ein Anstieg der 
Ressourcenproduktivität bereits ohne explizite politische Steuerung stattgefunden hat. Vergleichsweise stärker stieg in diesem Zeitraum noch die Arbeitsproduktivität. Eine andere Ausrichtung des technischen Fortschritts weg von Arbeits- hin zu Ressourcenproduktivität erscheint angesichts der Relation zwischen Arbeitszeitentlastung und Einkommenszuwachs sehr wohl möglich (Hinterberger, Luks, 12 ff; Hans Böckler Stiftung, 2000). Dazu muß das Materialinput als Kostenfaktor mit Abgaben belastet werden.

Der Abgabenpfad einer solchen am Input ansetzenden Internalisierungsstrategie folgt nicht den kontingent auftretenden externen Kosten, sondern könnte mit Bleischwitz' Grenzproduktivitätstheorie verknüpft werden (vgl. Bleischwitz, 1998, 168 ff). Die Höhe des schrittweisen Preisanstiegs richtete sich autonom nach den durchschnittlichen Produktivitätsanstiegen und müßt nicht notwendigerweise wie beim Preis-Standard-Ansatz dem politischen System überantwortet werden. Dem Pfad des Preisanstiegs sollten langfristige Durchschnittswerte des Produktivitätsanstiegs zugrunde gelegt werden. Die Stoffstromökonomik kann damit einen endogenen Pfad nachhaltiger Entwicklung für das ökonomische System aufzeigen. Das ist mit der Erwartung verbunden, daß sich eine stoffliche Politik der Nachhaltigkeit weitgehend unabhängig vom politisch-administrativen System vollziehen könnte. Gawels Einwand gegen eine Stoffstromökonomik, daß diese eine undifferenzierte Tonnenreduzierung betreibe, weil sie "auf (im besten Sinne streng effizienzgeleitete) Bewertungsregeln umweltpolitischer Einschränkungen des Wirtschaftens" verzichte (Gawel, 1998, 184; zur Gegenkritik Hinterberger et al., 1999), kann also mit dem Verweis auf den Internalisierungspfad der Grenzproduktivitätstheorie entkräftet werden. Auch wird die offene, normativ-politische Bewertungsfrage des MIPS-Konzepts in den Hintergrund gedrängt. Ein Steuerpfad entlang der Grenzproduktivitätszuwächse unterscheidet sich konzeptionell grundlegend vom Meritorisierungsansatz, denn dieser behandelt Natur ontologisch als öffentliches Gut während jener kognitiv auf das ökonomische System zurückverweist. Gleichwohl wird die politische Dimension nur entschärft, nicht aufgehoben, denn auch endogen ermittelte Steuern sind erst noch vom politisch-administrativen System zu implementieren.

Als Ergänzung zu den bekannten ökonomischen Instrumenten der Umweltpolitik sind Materialinputsteuern/-zertifikate (MISZ) vorgeschlagen worden. ${ }^{97}$ Diese würden sich zwischen eigentumsrechtlichen Formen der Inputsteuerung befinden (vgl. Ströbele, 1998), da sie weder originär am Aufkommen einer Knappheitsrente interessiert sind, noch sich auf Internalisierung von externen Effekten beschränken würden. Als rechtliche Bemessungsgrundlage von MISZs würde sich das jeweilige Materialinput einer Unternehmung oder Institution empfehlen (Stewens, 1996, 182 f). Der Steuersatz bzw. die Zertifikatentwertung würde entlang eines Pfades ansteigen müssen. Stewens geht von einem unbestimmten, aber überproportionalen Anstieg aus. Nach Bleischwitz wäre die Grenzproduktivitätstheorie als Zielpfad heranzuziehen. Die Steuersätze für einzelne Stoffe

97 Vgl. dazu auch Bruvoll, Ibenholt, 1998, Bruvoll, 1998. 
müßten die Steigerung der Ressourcenproduktivität unter Berücksichtigung von spezifischen Elastizitätsanalysen ermöglichen. ${ }^{98}$

Eine auf solche Weise über Steuern am Input ansetzende Politik der Nachhaltigkeit dürfte vielfältigen Widerständen und skeptischen Einsprüchen ausgesetzt sein (so Jänicke, 1998, 13 f; Reijnders, 1999, 18 f). Dies wurde spätestens in der Debatte um die Ökosteuer deutlich, welche sich vom Preis-Standard-Ansatz abwendete und sich auf Makroneutralität reduzierte (Richter, 1995, 207 ff). Damit wurde das theoretisch neutrale Allokationsziel der Umweltökonomie mit der politischen Restriktion marktwirtschaftlicher Stabilität versehen und in der Folge immer mehr als Verteilungsproblem interpretiert. Daraus resultiert die Befürchtung, daß eine stabilitäts- und verteilungspolitische Neutralität, wie sie Stewens eingefordert hat, vom globalen Pfad der Nachhaltigkeit abweichen könnte, wenn die reale Substitution von Ressourcen durch institutionellen und technologischen Wandel keine Dematerialisierung zeitigt. Gelingende Nachhaltigkeit ist ein unsicheres Projekt, das sich massenwirksam entwickeln muß. Ihre rechtlichen Bedingungen und ihre öffentlich-politische Durchsetzbarkeit sind in den folgenden Kapiteln auszuführen.

98 Stewens weist darauf hin, daß Elastizitätsanalysen sich als schwierig erweisen würden, weil hinsichtlich der Produktion mit sektoral verzerrenden Durchschnittselastizitäten gearbeitet werden müßte und die Bestimmung der Nachfrageelastizität problematisch seien, weil sich die Materialinputs nicht direkt einzelnen Gütern zurechnen ließen; vgl. ebd., 184 Fn. 18. 


\section{Politisch-administratives System als Umweltstaat}

\subsection{Legitimität und Begründung von Demokratie und Rechtssystem}

Demokratische Institutionen beziehen ihre unproblematisierte Annerkennung im alltäglichen Leben wesentlich "aus dem Kongruenz- und Korrespondenzerlebnis ihrer organisatorischen Beschaffenheit wie ihrer politischen Handlungsbestimmungen mit den lebensweltlichen Kontexten alläglicher Kommunikation." (Bermbach, 1991, 245) In einer durchgängig rationalen Alltagsgesellschaft interagierten soziale, kommunikative Lebensformen zwanglos über einen politischen Pluralismus demokratisch. In der diachronen und der spatialen Dimension auftretende kontingente Probleme könnten konfliktfrei gelöst werden. Die Integration der Gesellschaft könnte vollständig durch soziale Verfahren in den demokratischen Nationalstaaten und deren internationaler Kooperation erfolgen. B. Peters hat in soziologischer Hinsicht zwischen fünf Typen von Verfahren unterschieden: ${ }^{99}$

1. Technische Verfahren sind Handlungsschemata, welche die objektive oder soziale Welt verändern, ohne dabei direkt auf Verständigung, Überzeugungen oder Vereinbarungen zu beruhen, etwa technische Regeln, Technologien, Strategien, technisch, medizinische oder therapeutische Verfahren und technisches Problemlösen.

2. Symbolische Operationen sind Denk- oder Sprachvorgänge, welche auch monologisch anhand von Basisregeln (z.B. Logik, Mathematik, Grammatik, Semantik) vollzogen werden können, bzw. mathematische Lösungen, logische Entscheidungsverfahren, Übersetzungsverfahren, juristische und andere Methodenlehren.

3. Diskurse sind soziale Prozesse oder Interaktionen, bei denen Argumente ausgetauscht werden.

4. Untersuchungen lassen sich als Verfahren zur Urteils- oder Erkenntnisbildung über Sachverhalte charakterisieren. Von bloßen symbolischen Operationen und Diskursen sind sie zu unterscheiden, da sie auch praktische Aktivitäten zur Informationsgewinnung einschließen. Sie sind nur insofern Verfahren, als daß die Gültigkeit der Ergebnisse nachvollzogen werden kann.

5. Beschlußverfahren bezeichnet soziale Interaktionsschemata, die handlungsrelevante Verbindlichkeiten schaffen, wobei diese Verbindlichkeiten nicht allein auf geteilten Überzeugungen in der Sache beruhen, sondern etwa auf der Autorität des Verfahren (wie z.B. im Vertragsrecht, Satzungsrecht etc.)

Außer Diskursen beschränken alle aufgeführten Verfahren Argumentationen und damit die Möglichkeiten kommunikativen Handelns. ${ }^{100}$ Das Verhältnis zwischen Gesellschaft und demokratischen Institutionen kann bereits deshalb nicht vollständig in der Lebenswelt situiert sein.

99 Ich orientiere mich hier zwar an dem Schemata in Peters (1991, $233 \mathrm{f})$ folge ihm aber nicht exakt.

100 Die Diskursethik wird, worauf Keller und Hajer (1996) hingewiesen haben, häufig als eine Theorie mißverstanden, die soziale Konflikte durch unmittelbare, konsensuale Verfahren lösen will. Eine solche Interpretation ist aber falsch. 
Dennoch ist Verfahren nicht per se ein systemischer Charakter zueigen. In der Theorie des kommunikativen Handelns übernehmen erst Medien die strukturbildende Wirkung von Institutionen im Sinne von Rationalisierungsprozessen, welche Systemimperative gegenüber der Lebenswelt zur Geltung bringen. Wie erläutert, unterscheidet Habermas zwischen ökonomischem und politischadministrativen System. Die Theorie des kommunikativen Handelns geht kaum auf politische Institutionen und die von ihnen begründeten Verfahren ein. Die Frage der Legitimität der Demokratie stellt Habermas in der Theorie des kommunikativen Handelns noch nicht. ${ }^{101}$ Für die politische Theorie allgemein und die Demokratietheorie im besonderen besteht nun das Problem, daß die in der Theorie des kommunikativen Handelns explizierten Rationalitätstypen und deren Zuordnung sich allenfalls analytisch behaupten lassen, empirisch aber zweckrationales und kommunikatives Handeln ebenso integriert wie synthetisiert sind. Eine theoretische Rekonstruktion demokratischer Verfahren durch strategische Rationalität scheidet damit von vornherein aus.

Die idealen Bedingungen praktischer und theoretischer Diskurse finden im politischen Handlungsraum kaum hinreichende Verwirklichungschancen (vgl. Greven, 1991; Bermbach, 1991). Die Formen gesellschaftlicher Integration - funktionale Koordination, moralische Integrität und expressive Gemeinschaft (vgl. Peters, 1993, 96 ff) - sind im politischen Handlungsraum eingeschränkt. Dieser wird durch symbolische, distributive und sozialisatorische Prozesse sozial konstituiert. Recht und Politik werden durch diese Prozesse limitiert; gleichwohl kann das politischadministrative System auf die Formen der sozialen Integration einwirken. Es kann das Wirtschaftssystem und das Rechtssystem koordinieren; es kann die moralische Integration durch das Rechtssystem gewährleisten; es kann die expressive Gemeinschaft durch Recht regulieren (vgl. Peters, 1993, 353). Dabei resultieren politiktheoretisch die stärksten Probleme aus der Frage nach dem rechten Verhältnis von Gesellschaft, Recht und Demokratie.

Die Diskurstheorie hat für diese Fragen mehrere Antworten entwickelt. Apel (1992) formuliert eine politische Verantwortungsethik, die er jedoch institutionell bisher weitgehend unbestimmt gelassen hat. R. Alexy (1978) hat eine Theorie des juristischen Diskurses formuliert, die den Nachteil aufweist, den politischen Handlungsraum rein rechtlich bestimmen zu wollen. Dagegen bestimmt Habermas in seiner Rechtstheorie Faktizität und Geltung Politik und Moral getrennt. ${ }^{102}$ Die Universalpragmatik reformuliert dabei die klassische Frage nach der Legitimität von Herrschaft: Legitime, rechtliche Herrschaft wird nicht mehr aus einem Naturzustand voller anthropologischer Ängste oder Hoffnungen abgeleitet, sondern muß sich - soziologisch informiert - selbst im Medium des Rechts erzeugen. Das Medium steht quasi a priori; es ist jedoch nicht prädiskursiv, denn natürlich finden sich in der Lebenswelt immer Diskurse, die asymmetrische Sozialbeziehungen abarbeiten. Eine freie, rechtlose Herrschaft erscheint nur schwer denkbar, da sich auch asymmetrische Sozialbeziehungen in universellen Diskursen legitimieren müssen. Dies scheint ohne den Rückgriff auf das Medium des Rechts nicht möglich zu sein, da sich

101 Als Legitimationsquellen der Demokratie lassen sich der Theorie des kommunikativen Handelns nur die historische Entstehung und die Bindung an Argumentation entnehmen, vgl. Bermbach, 1991.

102 Vgl. zur Diskussion über Habermas' Rechtstheorie: Alexy, 1985, 109 ff; Blanke, 1994; Arato, 1998; Forbath, 1998; Günther, 1994; Hupke, 1994; Reese-Schäfer, 1997, 150 ff; Rehg, 1998, Rosenfeld, 1998. 
Sozialbeziehungen nicht nur spontan entfalten, sondern sich auch verfestigen, d.h. institutionalisieren.

Habermas' Diskurstheorie erklärt die Legitimität der Legalität mit Hilfe ihrerseits rechtlich institutionalisierter Verfahren und Kommunikationsvoraussetzungen. Diese begründen die Vermutung, "daß die Prozesse der Rechtssetzung und Rechtsanwendung zu rationalen Ergebnissen führen." (Habermas, 1992, 499) Habermas' Bezugnahme auf die praktische Vernunft zeichnet seine Rechtstheorie als prozedurale aus. Legitimation wird nicht durch Verfahren - wie bei Max Weber und Niklas Luhmann - erzeugt, sondern die Rationalität von Prozeduren wird zur Quelle der Legitimität. ${ }^{103}$ Eine politische Ordnung ist Habermas zufolge nur dann als legitim anzuerkennen, wenn sie unsere rational begründete Zustimmung verdient und in diesem Sinne substantiell rational ist. Könnten Rationalitätstypen und formale Verfahren vollständig zusammenfallen, wäre normative Gesellschaftstheorie als reine Demokratietheorie möglich. Habermas' Rationalitätsbegriff ist jedoch weiter. Er beruht auf der Möglichkeit einer argumentativen Vergesellschaftung. Rationalität umfaßt wie gesehen epistemische, teleologische und kommunikative Elemente und kann im praktischen Diskurs zu moralischen Konsensen führen. Positives Recht dient der Ergänzung moralischer Konsense (vgl. Habermas, 1996, 296 ff). Denn rechtliche Regelungen berühren nicht nur moralische Fragen im engeren Sinne, sondern auch pragmatische und ethische sowie Kompromisse zwischen gegensätzlichen Interessen. Rechtliche Regelungen sind wie der demokratische Prozeß insgesamt sozial situiert.

Habermas entwirft Demokratie damit nur noch als regulatives Prinzip und nicht mehr als Volkssouveränität. Während Diskurse ganz dem zwangslosen Zwang des besseren Arguments unterliegen, wird dieser Wettstreit um das bessere Argument politisch mit Hilfe des Rechtsmediums in Faktizität und Geltung als radikale Demokratie rekonstruiert. Die diskurstheoretische Rekonstruktion des Rechts hat nur den Stellenwert einer Bedeutungsexplikation (Habermas, 1992, 166). In den Anwendungsdiskursen des demokratischen Rechtsstaats (Günther, 1988) erscheint die diskursive Form im Rechtssystem als Spannung zwischen Faktizität und Geltung.

Die Begründung von staatlicher Herrschaft und Zwang durch die politische Philosophie der Neuzeit erübrigt sich damit nach Habermas als eigenständiges philosophisches Unternehmen (vgl. Habermas, 1992, 677). Auch der kontrafaktische Zustand einer herrschaftslosen Gesellschaft erscheint in einer immer schon sozial und kommunikativ verfaßten Welt nicht denkbar. Dies schließt faktisch keine Theorien oder Utopien des Politischen aus, doch diese dürften sich nur schwer diskursiv rechtfertigen lassen. An der normativen, diskurstheoretischen Rekonstruktion des demokratischen Rechtsstaats müssen sich somit alle anderen Entwürfe politischer Herrschaft messen lassen und die Diskurstheorie des Rechts muß ihrerseits allen Einwänden standhalten können.

103 Zur Kritik Habermas an verfahrensbegründeten Legitimitätsvorstellungen vgl. Habermas, 1976, 271 ff., 1981 , I, 354; 1981, II, 266. 


\subsubsection{Die Konstruktion der Diskurstheorie des Rechts}

In seiner Rechtstheorie Faktizität und Geltung geht Habermas nicht von einem hierarchischen Verhältnis von Moral zum Recht aus, sondern stellt sowohl Moral als auch Recht unter ein 'sparsames' Diskursprinzip $>\mathrm{D}<$ das den Sinn postkonventioneller Begründungsanforderungen zum Ausdruck bringen soll. Dieses postkonventionelle Begründungsniveau ist zum einen das historische Zwischenresultat im Prozeß der Aufklärung; zum anderen ist es Ergebnis der diskurstheoretischen Bemühungen Apels und Habermas', ein derartiges Begründungsniveau zu explizieren (Habermas, 1976). Als historisches Zwischenergebnis bringt es die Stufen der Rechtsentwicklung zum Ausdruck (vgl. Habermas, 1981, II, 260). In modernen Gesellschaften sind Rechtsinstitutionen reflexiv zugänglich. Bestehende Institutionen können nicht mehr per se als legitim gelten. "Rationalitätsstrukturen, die sich im Bereich des moralischen Bewußtseins bereits vorgängig ausgebildet haben, verkörpern sich in der Moderne institutionell und führen dazu, daß auch vorgegebene Normen und das gegebene formale, positiv gesetzte Recht auf Begründung hin hinterfragbar werden." (Welz, 2001 340) Diese Begründung erfaßt das Rechtssystem und seine legitimationswirksamen Basisinstitutionen (Grundrechte und Prinzip der Volkssouveränität) als ganzes.

Das postkonventionelle Begründungsniveau verbietet auch einen Rückgriff auf eine metaphysische Begründung. Dieses Ansinnen wird von J. Rawls geteilt. Doch während dieser den Liberalismus nichtmetaphysisch begründen will (Rawls, 1992, 1993), strebt Habermas eine nachmetaphysische Begründung an (Habermas, 1988). Der Liberalismus begnügt sich damit, daß die Philosophie das Politische beläßt, wie es ist und vertraut dabei auf den demokratischen Konsens. Auch die Diskurstheorie nimmt diesen in Anspruch, wenn sie auf ihr entgegenkommende Lebensformen verweist. Nur versucht sie, eine philosophische Verfahrensrationalität zu entwerfen, die auch ethische Fragen noch für wahrheitsfähig im Sinne der Konsenstheorie der Wahrheit hält. ${ }^{104}$ Sie muß im Philosophischen daher weder auf Metaphysik noch auf Toleranz zurückgreifen, um dem Faktum des ethischen Pluralismus gerecht zu werden.

In der Sprache kann, wie schon in Kapitel 2 ausführlich dargestellt, Intersubjektivität aufgezeigt werden, die in der Lebenswelt situiert ist und dort einen Kreisprozeß in Gang setzt, in welchem sprach- und handlungsfähige Subjekte sich zur Sprache sowohl autonom als auch abhängig verhalten: "Sie könne sich der grammatischen Regelsysteme, die ihre Praxis erst möglich machen, auch zu eigenen Zwecken bedienen: Beide Momente sind gleichursprünglich." (Habermas, 1988, 51) Durch diesen Kreisprozeß zwischen von Kommunikationsteilnehmern vorgefundener, sprachlich strukturierter Welt und den Ja/Nein-Stellungnahmen der Kommunikationsteilnehmer zu kritisierbaren Geltungsansprüchen wird das transzendentale Subjekt vollständig ersetzt. Trotz differierender Sprecherperspektiven setzt Sprache nämlich Konsensorientierung voraus. Dies wird vom Diskursprinzip wiedergegeben. Ein sprachlich erzielter Konsens zwischen den Kommunikationsteilnehmern tilgt aber nicht die Differenz der Sprecherperspektiven. Die Art der

104 Sie kann damit einer Tyrannei der Wahrheit (gegen demokratische Entscheidungen) entgehen vgl. Dietz, 1995. 
gültigen Gründe, die sich aus der Logik der jeweiligen Fragestellung ergeben (bzw. durch die das Diskursprinzip operationalisierende Argumentationsregeln), zeigen die weitere Ausdifferenzierung des Diskursprinzips an.

Das auf diesem postkonventionellem Begründungsniveau liegende Diskursprinzip ist, wie Habermas in Faktizität und Geltung anführt, nicht neutral, sondern insofern bereits normativ, als daß es den Sinn der Unparteilichkeit praktischer Urteile überhaupt expliziert. Das Diskursprinzip lautet wie gehabt: "Gültig sind genau die Handlungsnormen, denen alle möglicherweise Betroffenen als Teilnehmer an rationalen Diskursen zustimmen könnten." (Habermas, 1992, 138) ${ }^{105}$ Dabei sind die Art der Themen und Beiträge und die Sorte der Gründe nicht a fortiori eingeschränkt. Gültig meint hier noch einen unspezifischen Sinn von normativer Gültigkeit, "der gegenüber der Unterscheidung von Moralität und Legitimität noch indifferent ist." (Habermas, 1992, 138) Praktische Fragen lassen sich nach Habermas grundsätzlich unparteilich und rational entscheiden, da "das Prinzip selber in den symmetrischen Anerkennungsverhältnissen kommunikativ strukturierter Lebensformen fundiert ist." (Habermas, 1992, 140)

Im Diskursprinzip verzweigen sich allgemeine Handlungsnormen in moralische und juridische Regeln, wobei sich die juridischen Regeln unmittelbar auf demokratische Entscheidungsverfahren beziehen. Dagegen dient das Moralprinzip als Argumentationsregel ausschließlich der Urteilsbildung (des Wissens).

Das Moralprinzip ergibt sich [...] erst aus einer Spezifizierung des allgemeinen Diskursprinzips für solche Handlungsnormen, die allein unter dem Gesichtspunkt gleichmäßiger Interessenberücksichtigung gerechtfertigt werden können. Das Demokratieprinzip ergibt sich aus einer entsprechenden Spezifizierung für solche Handlungsnormen, die in Rechtsform auftreten und mit Hilfe pragmatischer, ethisch-politischer und moralischer Gründe - und nicht allein aus moralischen Gründen - gerechtfertigt werden können. (Habermas, 1992, 139)

Diese Differenzierung beinhaltet die ebenfalls normative Annahme, daß moralische und staatsbürgerliche Autonomie gleichursprünglich sind und daß die staatsbürgerliche Autonomie zwingend an demokratische Verfahren gebunden sein muß. Allerdings liegt das Diskursprinzip auf einer anderen Ebene als das Moralprinzip, da es nicht wie das Moralprinzip als Argumentationsregel für rationale Entscheidungen moralischer Fragen fungiert, sondern die Möglichkeit der rationalen Entscheidung praktischer Fragen überhaupt voraussetzt. Dabei können alle Arten von Gründen für die Legitimität von Gesetzen geltend gemacht werden. Das Demokratieprinzip beantwortet nämlich nicht die Frage, "ob und wie politische Angelegenheiten überhaupt diskursiv bearbeitet werden können." (Habermas, 1992, 142) (Dies müßte, laut Habermas, vorab argumentationstheoretisch geklärt werden, wobei Habermas diese Klärung jedoch ausspart.) Während das Moralprinzip somit die interne Verfassung eines bestimmten Argumentationsspiels - hier: des moralischen - bestimmt, "bezieht sich das Demokratieprinzip auf die Ebene der äußeren, d. h. handlungswirksamen Institutionalisierung der gleichberechtigten Teilnahme an einer diskursiven Meinungs- und Willensbildung, die sich in ihrerseits rechtlich

105 Allerdings hat Habermas das Verhältnis zwischen Diskurs- und Moralprinzip umgekehrt. 
gewährleisteten Kommunikationsformen vollzieht." (Habermas, 1992, 142) Darüber hinaus "muß das Demokratieprinzip nicht nur Verfahren legitimer Rechtsetzung festlegen, sondern die Erzeugung des Rechtsmediums selber steuern" (Habermas, 1992, 142), denn Rechtsnormen stellen zugleich eine intentional erzeugte und eine reflexive, auf sich selbst anwendbare Struktur von Handlungsnormen dar. Sekundäre Regeln erlauben die Erzeugung von primären Regeln der Verhaltenssteuerung.

Legalität dient dabei nicht der Einschränkung von Moralität, sondern deren Ergänzung. Die postkonventionelle Moral ist auf mehr als die Internalisierung von moralischer Motivation bei Handelnden angewiesen, da gute Gründe allenfalls eine schwache Motivationskraft für die Persönlichkeit besitzen. Moral ist im Gegensatz zum Recht primär Wissenssystem und bietet von insofern eine unzureichende Handlungsorientierung. Zudem beinhalten moralische Handlungsgründe für das Individuum nicht nur Geltungs-, sondern auch Anwendungsprobleme. Moralisch urteilende und handelnde Personen stehen nämlich unter enormen kognitiven, motivationalen und organisatorischen Anforderungen, von denen sie nur als Rechtsperson entlastet werden können. Das Rechtssystem erhält deshalb eine ergänzende Funktion zur Moral, denn es ist Handlungs- und Wissenssystem zugleich. Durch die Handlungsregulative des Rechtssystems kann Moral auch persönlichkeitsextern wirksam werden. "Weil Motive und Wertorientierungen im Recht als Handlungssystem miteinander verschränkt sind, kommt den Rechtssätzen die unmittelbare Handlungswirksamkeit zu, die moralischen Urteilen als solchen fehlt." (Habermas, 1992, 146) Überdies unterscheidet Rechtsregel von Regeln der Moral auch, daß diese die Interaktion von Individuen einer konkreten Gemeinschaft regeln, während jene die Interaktion zwischen sprachund handlungsfähigen Subjekten überhaupt festlegen. Den universalen Absolutheitsanspruch moralischer Normen und die Unbestimmtheit ihrer Anwendung ergänzt Habermas durch ein nach Universalität strebendes, intersubjektiv reproduziertes demokratisches Rechtsystems. Dazu rekonstruiert Habermas die liberale Gewaltenteilungslehre innerhalb eines diskursiven Prozeßmodells:

Dabei funktioniert das Prinzip der Volkssouveränität als zentrales Scharnier zwischen dem System der Rechte und dem Aufbau eines demokratischen Rechtsstaats in der Praxis eines demokratischen Verfahrens. Diese Praxis wird durch das parlamentarische Prinzip konkretisiert, daß seinerseits (u. a.) das Mehrheitsprinzip umfaßt. Diese Praxis enthält aber auch das Prinzip der Gewährleistung autonomer Öffentlichkeiten und - in der Staatsrechtstradition - das Prinzip der Trennung von Staat und Gesellschaft. Ein politischer Pluralismus ergibt sich schon aus der Logik der Diskurse. Er verweist auf den Grundsatz der Parteienkonkurrenz (Habermas, 1992, 208 ff). Die Prinzipien beschreiben nicht nur ein einfaches deliberatives Verfahren, sondern implizieren eine normative Form von Öffentlichkeit.

Die Ergebnisse des deliberativen Verfahrens, allgemeine Gesetze, unterliegen eigenen Prinzipien, die sich auf die Anwendungsdimension des deliberativen Prozesses beziehen. Es sind dies das Prinzip der Gewährleistung eines umfassenden individuellen Rechtsschutzes, das Prinzip der Bindung der Justiz und der Verwaltung an geltendes Recht bzw. dem Gesetzesvorbehalt für das 
Handeln der Verwaltung sowie das innerstaatliche Willkürverbot. Der Rechtsstaat institutionalisiert damit den Gebrauch kommunikativer Freiheiten; andererseits reguliert er auch die Umsetzung kommunikativer in administrative Macht. Die zielverwirklichende administrative Macht ist über das Recht mit kommunikativer Macht rückgekoppelt (Habermas, 1992, 231). Und nur diese Rückbindung an die rechtsetzende kommunikative Macht erlaubt die Infusion von Sinn in das Handeln der administrativen Macht. An dieser notwendigen Rückkoppelung findet argumentationslogisch besehen - auch die Rechtsfortbildung ihre Legitimationsgrenze (vgl. Habermas, 1992, 235).

Zur Wahrung dieser Rückkoppelung bezieht sich das System der Rechte gleichgewichtig sowohl auf die private als auch auf die öffentliche Autonomie der Bürger. Im Gegensatz zur liberalen Tradition ist die private Autonomie der Bürger nicht auf die subjektive Handlungsfreiheit vereinzelter Aktoren zugeschnitten, sondern auf kommunikative Freiheit: "[D]ie im verständigungsorientierten Handeln wechselseitig vorausgesetzte Möglichkeit, zu den Äußerungen eines Gegenübers und zu den damit erhobenen, auf intersubjektive Anerkennung angewiesenen Geltungsansprüche Stellung zu nehmen" (Habermas, 1992, 152), beinhaltet illokutionäre Verpflichtungen, welche nur durch die private Autonomie von Rechtssubjekten ausgesetzt werden. Als Rechtssubjekte, und nur als solche, müssen sprachfähige Individuen nicht Rede und Antwort stehen oder für ihre Handlungspläne öffentlich akzeptable Gründe liefern; sie sind zum Ausstieg aus dem kommunikativen Handeln berechtigt. (Auf den Begriff der kommunikativen Freiheit wird noch näher einzugehen sein.)

Auf Individuen als moralische Gesetzgeber verweist dagegen die Aufgabe, die Freiheit eines jeden mit der gleichen Freiheit aller begründen zu können. Dabei adressieren die Rechtssubjekte quasi eine politische autonome Rechtsetzung an sich selbst. Die Idee der Selbstgesetzgebung von Bürgern kann dabei jedoch nicht, wie bei Kant, auf die moralische Selbstgesetzgebung einzelner Personen zurückgeführt werden, sondern muß so gefaßt sein, daß die rechtlichen Institutionen diskursive Kommunikationsformen im Sinne des Diskursprinzips ermöglichen. Da dem Rechtsystem immer auch die Möglichkeit von Rechtszwangs inne ist, darf legitimes Recht nicht die rationalen Motive für Rechtsgehorsam zerstören. "Rechtsnormen müssen aus Einsicht befolgt werden können." (Habermas, 1992, 154) Die diskursive Freiheit kann sogar soweit gefaßt sein, daß im Einzelfall die performative Einstellung zum Recht zugunsten der objektivierenden Einstellung eines nutzenkalkulierenden und willkürlich entscheidenden Aktors aufgegeben wird. Sie muß sogar soweit gefaßt sein, denn im Gegensatz zu reziprok von Sprecher und Hörer bestätigten Handlungsnormen enthalten Rechtsnormen keine Verpflichtung für Aktoren, sich die angeführten Gründe für zukünftige Handlungen anzueignen, d. h. Rechtsnormen müssen nicht 'zwanglos zwingend' zu Motiven für Aktoren werden. Dennoch bleibt Moral mit dem Rechtssystem intern verknüpft und strahlt über das Recht auf alle Handlungsbereiche aus, "sogar auf jene systemisch verselbständigten Bereiche mediengesteuerter Interaktion, die die Akteure von allen moralischen Zumutungen, außer der einzigen eines generalisierten Rechtsgehorsams, entlasten." (Habermas, 1992, 150) 
Recht ergänzt kommunikatives Handeln als Symbol- und Handlungssystem. Als Symbolsystem umfaßt es eine bestimmte, intern strukturierte Menge von Normen, Prinzipien, Grundbegriffen, Methoden, Hintergrundtheorien und anderen symbolischen Elementen. Recht offenbart sich als Sinn von Texten, Aussagen, Handlungen etc.. Als Handlungssystem tritt Recht in Aktivitäten zur Produktion oder Reproduktion dieses Sinn- und Symbolsystems hervor. Recht erscheint als ein Handlungszusammenhang, in dem sich soziale Aktivitäten sich intentional auf Recht beziehen oder am Recht orientieren. Das Handlungssystem schließt insofern das Symbolsystem ein, als daß die Akteure sinnhaft in bezug auf das Rechtssystem handeln. Das Rechtssystem weist (als System) auch nichtintentionale Strukturen auf; als Teilsystem des historischen Ausdifferenzierungsprozesses wäre dies im Gegensatz zu den intentionalen Strukturen der Lebenswelt sogar zu erwarten. Systemische Mechanismen verknüpfen Handlungen und Entscheidungen miteinander und führen zu nichtintendierten Folgen. Im politisch-rechtlichen Subsystem, wird dies vor allem an Institutionen und sozialen Prozessen deutlich, die als Handlungssysteme neben intentionalen auch nichtintentionale Mechanismen aufweisen. Im Staat ist das Rechtssystem als Handlungssystem Teil des politischen Systems. Als Normensystem reicht das Recht weiter, "weil Recht ein Strukturelement auch von vielen nichtpolitischen Institutionen ist." (Peters, 1991, 32)

Habermas unterscheidet in Faktizität und Geltung im Anschluß an die Theorie kommunikativen Handelns zwischen zwei über ein Kontinuum gestreute Handlungstypen, die sich aufgrund der erwartungsstabilisierenden Handlungskoordination ergeben, nämlich wertorientiertes und interessengeleitetes Handeln. Erster beruht auf einem Wertekonsens, zweiterer auf einem Interessenausgleich. Auf der ersten Stufe eines historisch-genetischen Modells der Entwicklung der Systeme von Recht und Macht erfolgt eine Autorisierung von Macht durch sakrales Recht, während sich gleichzeitig eine Sanktionierung von Recht durch soziale Macht vollzieht. Erst auf der zweiten Stufe verbinden sich staatliches Recht und politische Macht gleichursprünglich zu einer im strikten Sinne staatlich organisierten Herrschaft. Das Recht legitimiert nicht mehr nur die politische Macht, sondern die politische Macht kann auch instrumentell auf das Recht als Organisationsmittel zurückgreifen. Schließlich bildet sich in der Moderne - und erst hier - die politische Herrschaft in Form des positiven Rechts als legale Herrschaft heraus. Politische Macht berücksichtigt nun die systemische Eigenfunktion des Rechts insofern, als daß Rechtssicherheit hergestellt wird. Das Recht stellt nun seinerseits sekundäre Regeln (Kompetenz- und Organisationsnormen) zur Stabilisierung der Eigenfunktion staatlicher Macht zur Verfügung. Die entstandene Legitimationslücke im nicht geschlossenen Kreislauf zwischen instrumenteller Macht und instrumentalisiertem Recht sollte der Rückgriff auf praktische Vernunft schließen. Diese sei jedoch selbst noch weitgehend "im dogmatischen Bann der überlieferten Konstruktion einer aus überpositiviertem Recht autorisierten Herrschaftsmacht befangen" geblieben (Habermas, 1992, 182). Erst durch die freie diskurstheoretische Herausbildung kommunikativer Macht, kann die Legitimationslücke im modernen Verhältnis zwischen Macht und Politik vollständig geschlossen werden. Kommunikative Macht entspringt jedoch nur Strukturen unversehrter Intersubjektivität, die ihrerseits rechtlich zu schützen sind. "Diese Verschränkung von diskursiver Rechtsetzung und 
kommunikativer Machtbildung erklärt sich letztlich daraus, daß die Gründe im kommunikativen Handeln eben auch Motive bilden." (Habermas, 1992, 188)

Habermas stellt den internen Zusammenhang von Recht und Moral über das Demokratieprinzip sicher, in welchem sich Diskursprinzip und Rechtsform verschränken. Diese Verschränkung erlaubt die logische Genese von Rechten, mit ihrer schrittweisen Rekonstruktion. Während die Rechtsform die soziale Verhaltenserwartung stabilisieren soll, kann mit dem Diskursprinzip die Legitimität von allen Handlungsnormen geprüft werden. Das Demokratieprinzip ist dabei jedoch nur Kern eines Systems von Rechten. "Die logische Genese dieser Rechte bildet einen Kreisprozeß, in dem sich der Kode des Rechts und der Mechanismus für die Erzeugung legitimen Rechts, also das Demokratieprinzip, gleichursprünglich konstituieren." (Habermas, 1992, 155) Für die verfassungsgebende Praxis ist das Diskursprinzip alleine nicht ausreichend. "Vielmehr bedürfen genau die Kommunikationsformen, in denen sich ein vernünftiger politischer Wille auf diskursive Weise soll bilden können, selber der rechtlichen Institutionalisierung." (Habermas, 1992, 670) Die Wahl des Rechtsmediums steht den kommunikativ Handelnden in diesem spezifischen Sinne deshalb nicht mehr frei. Habermas hat folgende Grundrechte für unabdingbar erklärt:

1. Grundrechte, die sich aus der politisch autonomen Ausgestaltung des Rechts auf das größtmögliche Maß gleicher subjektiver Handlungsfreiheiten ergeben.

2. Grundrechte, die sich aus der politisch autonomen Ausgestaltung des Status eines Mitglieds in einer freiwilligen Assoziation von Rechtsgenossen ergeben.

3. Grundrechte, die sich unmittelbar aus der Einklagbarkeit von Rechten und der politischen autonomen Ausgestaltung des individuellen Rechtsschutzes ergeben.

4. Grundrechte auf die chancengleiche Teilnahme an Prozessen der Meinungs- und Willensbildung, worin Bürger ihre politische Autonomie ausüben und wodurch sie legitimes Recht setzen.

5.Grundrechte auf die Gewährung von Lebensbedingungen, die in dem Maße sozial, technisch und ökologisch gesichert sind, wie dies für eine chancengleiche Nutzung der 1. bis 4. genannten bürgerlichen Rechte unter gegebenen Verhältnissen jeweils notwendig ist.

Dabei ergeben sich die Punkte 1. - 3. aus der Anwendung von $>\mathrm{D}<$ auf das Rechtsmedium bzw. auf Bedingungen der horizontalen Vergesellschaftung überhaupt; ad 1. gleiche subjektive Handlungsfreiheiten ergeben sich nicht allein im Hinblick auf die Form subjektiver Rechte, sondern erst mit Hilfe von $>\mathrm{D}<$ als gleiche Handlungsfreiheiten; ad 2. Recht normiert im Gegensatz zur Moral nicht Interaktion überhaupt, sondern jene einer konkreten Gemeinschaft; ad 3. die rechtliche Institutionalisierung des Rechtskodes erfordert eine Rechtswegegarantie ohne die kein legitimes Recht entstehen kann; ad 4. Bürger selbst müssen sich - als Verfassungsgeber - das Diskursprinzip in der rechtlichen Gestalt des Demokratieprinzips geben; was vor allem bedeutet, daß der öffentliche Gebrauch kommunikativer Freiheiten rechtlich gesichert werden muß (vgl. Habermas, 1992, 162)

Habermas wählt mit der Ausdifferenzierung des Diskursprinzips in Moral- und Demokratieprinzip eine konstruktivistische Perspektive auf das Rechtssystem. Recht und Moral sind unter dem 
Diskursprinzip miteinander verschränkt, gegeneinander jedoch zugleich abgegrenzt. Die Differenz zwischen Recht und Moral ist eine Errungenschaft der Moderne (vgl. dazu Günther, 1988, 314 f; Maus, 1989). Sie ist aber zugleich auch ein Problem, da selbst rechtlich hinreichend gesicherte Prozeduren nicht zwingend ein vernünftiges Ergebnis garantieren. Alexy hat deshalb die Diskurstheorie als "eine nicht entscheidungsdefinite Theorie" bezeichnet und dafür drei Gründe genannt: 1. Sie treffe keine Festlegungen hinsichtlich der Ausgangspunkte der Prozedur; 2. Die Diskursregeln legten nicht alle Argumentationsschritte fest; 3. Eine Reihe von Regeln sei nur approximativ erfüllbar (Alexy, 1995a, 112). Diese Probleme treten in der diskurstheoretischen Demokratietheorie erneut wieder auf (vgl. Bermbach, 1991; Greven, 1991; Nullmeier, 1995). Habermas konstruiert den demokratischen Rechtsstaat als Prozedur im Medium des Rechts, ohne die argumentative Offenheit oder Geschlossenheit der durch Recht institutionalisierten Verfahren und Verhandlungssysteme detailliert aufzuzeigen. Für das Rechtsystem entwirft er allerdings eine kommunikative Struktur, die eine deliberatives Prozedur demokratischer Selbstregierung ermöglicht (vgl. dazu auch Peters, 1991, 227 ff).

Kommunikatives Handeln ist nicht nur funktional auf demokratische Rechtssetzung angewiesen, um sich stabilisieren zu können, sondern hat als kommunikative Macht auch einen kognitiven Aspekt: kommunikatives Handeln ermöglicht die rationale Willensbildung. (Daneben kann kommunikatives Handeln über intersubjektiv geteilte Überzeugungen, die zumindest als schwach motivierende Gründe wirken, motivieren.) In normativer Hinsicht nimmt Deliberation über den Begriff der praktischen Vernunft sowohl Elemente des liberalen Traditionsbestands als auch solche des Republikanismus auf und verbindet sie zu einer idealen diskursiven Prozedur der Beratung und Beschlußfassung. Wie der Republikanismus fordert das diskurstheoretische Verständnis deliberativer Politik für die Rechtsgemeinschaft zwar auch einen diskursiven Modus, doch erstreckt sich die Vergesellschaftung nicht auf die Gesellschaft im Ganzen, sondern nur auf das rechtstaatlich verfaßte politische System. Dieses bleibt in die Gesellschaft eingebettet. Die diskurstheoretische Fassung der Idee der Volkssouveränität ist so nicht unmittelbar auf den Willen der Staatsbürger bezogen (vgl. Habermas, 1992, 366) obschon volitive Elemente in Rechtsnormen eingehen. Die demokratietheoretische Perspektive, die Habermas an das problemabhängige Willenskonzept praktischer Vernunft anschließt, enthält einen "entsubstantialisierten Begriff der Volkssouveräntität, nach dem sich die staatliche Politik und demokratische Selbstbestimmungsansprüche über die prozedurale Rationalität diskursiver Verfahren vermitteln." ( Schmalz-Bruns, 1995a, 105)

Eine diskursive Theorie demokratischer Deliberation ermöglicht die öffentlich-argumentative Auseinandersetzung über Fragen des kollektiven Lebens. Sie greift dabei, wie kaum anders zu erwarten, auf wesentliche Traditionsbestände der Demokratietheorie zurück: Demokratie beinhaltet demnach ein starkes Konzept von Gleichheit der Staatsbürger, eine auf das Gemeinwohl gerichtete, öffentliche Deliberation und eine kollektive Identität der Bürger, die auch deren Interessen formt (Cohen, 1997, 144). Deliberative Politik behält dabei die Verfassung, die deliberative Politik ermöglicht, fest im Blick. Dennoch dient die Vorstellung eines idealen deliberativen Verfahrens als Kontrastfolie zur institutionalisierten Verfassungsrealität. Das demokratische Verfahren steht als 
deliberatives Verfahren im Mittelpunkt; es dient nur mittelbar zur Sicherung substantieller Ergebnisse. Deliberation beansprucht primär die Aufrechterhaltung des demokratischen Legitimationszirkels durch den reflexiven Bezug auf das Rechtssystems: "Konstitutiv für die deliberative Politik ist, daß die Bürger der strukturellen Nötigung ausgesetzt sind, für ihre Belange öffentliche Rechtfertigungsgründe zu formulieren, d. h. Gründe, die den begrenzten Horizont privatsprachlicher Selbstbezüglichkeit transzendieren und gesellschaftsweit verkehrsfähig sind." (Gerstenberger, 1997, 15f)

Eine Theorie der Deliberation muß sich zwingend mit zwei Aspekten auseinandersetzen: Die Normativität von Deliberation muß klar gekennzeichnet sein. Und sie muß die Leistung deliberativer Öffentlichkeit empirisch richtig einschätzen (vgl. Peters, 2001). Die Steigerung der Rationalität öffentlicher Meinungs- und Willensbildung wird oft als wesentliche Leistung von Deliberation angeführt. Deliberation führt demnach zu einer Selbstaufklärung der Beteiligten. Sie wird aber vermutlich allenfalls indirekt zu einer Rationalisierung politischer Entscheidungsprozesse führen, die nur zum Teil öffentlich sind. Trotzdem wird Deliberation als sozialintegrative Prozedur dabei zur Quelle politischer Legitimität.

Wenn die normative Bewertung an die sozialintegrativen Eigenschaften von Deliberation anschließt, wird dieser ein Eigenwert zugesprochen. Andererseits kann aber auch die in deliberativen Prozeduren vorhandene instrumentelle Dimension herangezogen werden, um die Qualität politischer Entscheidungen normativ zu beurteilen. Diese Unterscheidung zwischen begrifflichen oder normativen Beziehungen und empirischem Ursache-Folgeverhältnis wird nicht in allen Ansätzen klar getroffen. (ebd., 657) Wie noch in Kapitel 4 deutlich werden wird, leidet die empirische Forschung daran, daß sie in der Regel "wenig Aufschlüsse über die variablen empirischen Bedingungen [gibt], welche für die Öffnung und Schließung von Diskursmöglichkeiten in heutigen Öffentlichkeiten und für die Variation des Rationalitätsniveaus und der Leistungsfähigkeit öffentlicher Diskurse verantwortlich sind." (ebd., 664)

Die idealisierten Prozeßbedingungen deliberativer Willensbildung, wie sie Habermas in Faktizität und Geltung ausführt, finden sich nur selten unvermittelt in der politischen Realität komplexer Gesellschaften. Auch präjudizieren selbst ideale argumentative Prozeßbedingungen nicht, daß gute Gründe schon zu einem einzigen richtigen Ergebnissen führen. ${ }^{106}$ Vielmehr scheint sich die politische Welt durch ein Faktum des Pluralismus (Rawls) auszuzeichnen, das nach Toleranz anstatt nach universalen Werten zu verlangen scheint. Habermas hat für all jene Fälle, in denen sich kein verallgemeinerbares Interesse oder ein einzelner Wert vorrangig diskursiv

106 Vgl. R. Alexy, 1995, 109 ff., ähnlich B. Peters, 1991, 258 ff; so im Grunde auch Rawls in Reply to Habermas (1993, 372 ff). Offe hat erhebliche Zweifel angemeldet, daß demokratisch-rechtstaatliche Verfahren in der Lage sind, "selbst in Kombination mit den kognitiv-moralischen Dispositionen des Publikums, d. h. mit verbreiteten Tugenden einer republikanischen politischen Kultur, ausreichen, nicht nur dem jeweils 'besseren' Argument zu Anerkennung und Geltung zu verhelfen, sondern auch noch (hinreichend) 'gute' Argumente zu generieren", (Offe, 1989, 757f) die in der Lage sind, die ökologischen Dilemmatasituationen theoretisch zu überwinden, damit sachliche, zeitliche und soziale Interdependenzen und Folgen des Handelns so umfassend berücksichtigt werden, "daß sie nicht bloß zu irgendwelchen, sondern zu adäquaten Selbstbindungen der Art führen, daß das aus ihnen folgende Handeln auch im antizipierten Rückblick noch verantwortet werden kann, nicht aber bereut werden muß." (ebd., 758) 
auszeichnen läßt, versucht, angemessene Verfahren und organisatorische Formen demokratischer Willensbildungsprozesse zu bestimmen, die im Rahmen der idealisierten Prozeßbedingungen verbleiben.

In einem ersten Schritt zeichnet Habermas die argumentationslogisch angelegten politischen Meinungs- und Willensbildungsprozesse nach. Diese orientieren sich, obwohl zunächst analytisch eingeführt, an den drei bekannten Diskurstypen praktischer Vernunft und den ihnen korrespondierenden Willenskonzepten. Zwar gibt allein die bedingungslose Berücksichtigung der Interessen aller Betroffenen im moralischen Diskurs den Maßstab für die Legitimität von Herrschaft ab. Doch haben moralische Gründe ihrerseits keine ausreichende Selektivität bei der Lösung anstehender Probleme. Deshalb muß von praktischer Vernunft in der ganzen Breite Gebrauch gemacht werden. Die weiteren zu berücksichtigenden Gründe hängen indes vom Kontext ab und haben deshalb nur relative Geltung. Danach sehen pragmatische Diskurse ganz von ethischen oder moralischen Gründen ab. In pragmatischen Diskursen werden nur Fragen behandelt, die fundamentale Werte unberührt lassen. Es geht um Strategien zur Erreichung von Zwecken. In ethischen Diskursen werden nur Fragen geklärt, welche die gemeinsam zu verwirklichende Lebensform betreffen bzw. die Frage aufgreifen, ob die (pragmatisch) gewählten Strategien den ethischen Idealen einer konkreten Gemeinschaft entsprechen. Trotz der Berücksichtigung von nichtmoralischen Gründen beanspruchen Rechtsnormen, mit Moralnormen überein zu stimmen, also nicht gegen sie zu verstoßen. Gegenüber dem motivierenden Gehalt universaler moralischer Handlungsnormen behalten Rechtsnormen jedoch wegen der nur relativen Geltung immer auch ein partikulares Moment.

Diese variable Konstellation von Willen und Vernunft beansprucht die diskursive Bildung eines gemeinsamen politischen Willens vollständig $\mathrm{zu}$ erfassen und dabei alle Betroffenen einzuschließen. Das diskurstheoretische Prozeßmodell besteht nun in einer hierarchischen, rekursiven Anordnung der Diskurse praktischer Vernunft, bei der auf jeder Ebene entschieden wird, auf welcher Ebene die Kontroverse mit Gründen fortzusetzen ist. ${ }^{107}$ (Habermas, 1992, 203 f)

Ist durch diesen diskursiven Prozeß ein politischer Wille zustande gekommen, so muß dieser in der Sprache des Rechts formuliert werden. Während die prozeduralen Voraussetzungen nicht beliebig sind, kann dies wohl für den Inhalt des Gesetzes gelten. Aber die Diskurse praktischer Vernunft sind auch in das Rechtssystem eingebettet; und zwar so, daß sie weder "das Argumentationsspiel [...] sistieren noch den Rechtskode [...] sprengen." (Habermas, 1992, 219) Die rechtliche Institutionalisierung der unvollständigen Verfahrensrationalität von Diskursen könne diese in eine quasireine Verfahrensgerechtigkeit - so Habermas im Anschluß an Rawls' Begrifflichkeit - verwandeln. Das erlassene Gesetz bedarf aber der Normenkontrolle, welche die Einfügung in das bestehende Rechtssystem sicherstellen soll. Derart kann sich der politische Willen kohärent in das bestehende Rechtssystem einfügen, so daß schließlich Rechtssicherheit

107

Habermas hat die direkte Zuordnung von Diskurstypen der praktischen Vernunft zu bestimmten Politikfeldern im Nachwort zur vierten Auflage von Faktizität und Geltung zurückgenommen und angemerkt, daß politische Fragen so komplex seien, daß sie alle drei Aspekte praktischer Vernunft enthielten; vgl. Habermas, 1992, 667 Fn. 3. 
gewährleistet bleibt. Darüber hinaus findet sich auch eine argumentationslogische Arbeitsteilung zwischen juristischen Diskursen, die sich auf die Anwendung von Normen bezieht, und der Rationalität der Verwaltungstätigkeit, die durch pragmatische Diskurse gesichert wird. (Habermas, 1992, 229)

Die Etablierung staatlicher Herrschaft im Medium des Rechts spiegelt dabei die Möglichkeit praktischer Vernunft überhaupt wider. Die kommunikative Macht von Majoritäten muß sich jedoch an der universalen Geltung moralischer Gründe messen lassen. Dies unterscheidet die diskurstheoretische Fassung der praktischen Vernunft sowohl von den liberalen Konzeptionen als auch von den republikanischen. Weder bezieht sich die praktische Vernunft unmittelbar auf universale Menschenrechte, noch auf konkrete Formen von gemeinschaftlicher Sittlichkeit. Vielmehr fordert praktische Vernunft demokratische Verfahren, welche die drei Diskurstypen praktischer Vernunft in Relation zueinander setzten. "Dieses demokratische Verfahren stellt einen internen Zusammenhang zwischen pragmatischen Überlegungen, Kompromissen, Selbstverständigungs- und Gerechtigkeitsdiskursen her und begründet die Vermutung, daß unter Bedingungen eines problembezogenen Informationszuflusses und sachgerechter Informationsbearbeitung vernünftige bzw. faire Ergebnisse erzielt werden." (Habermas, 1992, 359)

So müssen insbesondere Verhandlungen, als vorherrschende Form der politischen Konsensbildung, über ihren pragmatischen Vernunftaspekt hinaus in das Prozeßmodell zurückgeholt werden können. Der Rückgriff auf Verhandlungen würde, wie Habermas einräumt, notwendig die Kette einer diskursiven Willensbildung zerreißen, wenn nicht das Diskursprinzip durch "Verfahren, die die Verhandlungen unter Fairness-Gesichtspunkten regulieren," (Habermas, 1992, 205) doch noch indirekt zur Geltung gebracht werden könnte. Darüber hinaus bleiben faire Verfahren aber auch normativ abhängig von der konsensualen Zustimmung durch moralische Diskurse. Zwar sichern faire Verfahren die gleiche Vertretung von Betroffenen, nicht aber ein Einverständnis wie zwischen den Teilnehmern eines Diskurses; sie sind also Diskursen nicht vergleichbar. "Zudem sind Verhandlungen erst dann zulässig und erforderlich, wenn partikulare, also keine verallgemeinerungsfähigen Interessen im Spiel sind, was wiederum nur in moralischen Diskursen geprüft werden kann." (Habermas, 1992, 206) Und was für den pragmatischen Aspekt praktischer Vernunft gilt, ist ebenso für den ethisch-politischen Aspekt praktischer Vernunft gültig. Auch dieser bleibt auf moralische Diskurse verwiesen. Das demokratische Verfahren hat damit lediglich - aber zugleich auch immerhin - die Vermutung praktischer Vernunft für sich. Die Mehrheitsregel, als Kern des demokratischen Verfahrens "behält eine interne Beziehung zur Wahrheitssuche dadurch, daß die mit Majorität getroffene Entscheidung nur eine Zäsur in einer fortlaufenden Diskussion bildet und gleichsam das interimistische Ergebnis einer diskursiven Meinungsbildung festhält. Dann muß die Mehrheitsentscheidung freilich unter der Prämisse zustande kommen, daß die Streitgegenstände in qualifizierter Weise, eben unter den Kommunikationsvoraussetzungen eines entsprechenden Diskurses erörtert worden sind." (Habermas, 1992, 220) Deshalb sollten Mehrheitsentscheidungen reversibel sein, denn nur so könnten Minderheiten ihr Einverständnis zur Ermächtigung der Majorität geben und die Chance gewahrt wissen, in Zukunft mit besseren 
Argumenten die Mehrheit zu gewinnen und die getroffene Entscheidung zu revidieren. Der Unbedingtheitsanspruch der Reversibilität des Moralprinzips ist somit im politischen System nur noch eingeschränkt zu finden.

Die von Habermas angesprochene prinzipielle argumentationslogische Offenheit bei der Verteilung von Zugriffsmöglichkeiten auf verschiedene Sorten von Gründen (vgl. Habermas, 1992, 235 f) schließt dezentrale Formen der Willensbildung nicht aus (dagegen: Schmalz-Bruns, 1995a, 109, vgl. auch ders. 1995b). Habermas führt schließlich eine Reihe von möglichen Reformen zur weitergehenden Demokratisierung des Rechtsstaates an (vgl. Habermas, 1992, 517 ff). Doch wie bereits B. Peters festgestellt hat, würfe die Integrationsfähigkeit deliberativer Politik allein schon aufgrund der zu erwartenden vernünftigen Qualität der Ergebnisse Probleme auf. Habermas könne deshalb das Prinzip der Volkssouveränität kaum noch als zentrale Legitimationsformel der modernen Demokratie anbringen, sondern nur noch als regulative Idee (Peters, 1991, 269 ff).

\subsection{Die Entwicklung des Umweltrechts aus der Gefahrenabwehr}

Unter formalen Gesichtspunkten ist die Entstehung des Umweltrechts ein großer Erfolg: Innerhalb nur weniger Jahrzehnte entstand seit Anfang der 70er Jahre ein neues Politikfeld, ${ }^{108}$ mit einem völlig neuen Rechtsbereich, dessen Kodifikation in einem Umweltgesetzbuch gegenwärtig für die Bundesrepublik erarbeitet wird. Grob gliedert sich das Umweltrecht in die Bereiche Immissionsschutz, Abfallbeseitigung, Naturschutz und Gentechnik. Dabei unterteilt sich das Immissionsschutzrecht weiter in Gewässerschutz, Bodenschutz und Luftreinhaltung.

Bei der Erschließung des neuen gesellschaftlichen Politikfeldes 'Umweltschutz' hat man für das zu entwickelnde Umweltrecht auf das Polizeirecht zurückgegriffen. Der liberale Staat garantiert an erster Stelle 'Sicherheit' als Rechtssicherheit und öffentliche Sicherheit, die durch die im Polizeirecht beschriebene Gefahrenabwehr auch autoritär gewahrt werden konnte. In der umweltpolitischen Gesetzgebung wurde dieses Sicherheitsmodell auf das Anlagen- und das Umweltrecht ausgedehnt. Das Gefahrenrecht des Anlagen- und Immissionsschutzrechts knüpfte begrifflich und dogmatisch an das bestehende Polizeirecht an. Risiken und Gefahren sollten so vom öffentlichen Leben abgewendet werden.

Die rechtlichen Begriffe der Gefahr und des Risikos weichen von der soziologischen Bedeutung ab. Risiken setzen im Rechtssystem Erkennbarkeit voraus. Es muß eine bestimmte Quelle existieren, von der eine mögliche Schädlichkeit ausgehen kann. Dies muß objektiv, d.h. über die konkrete Situation hinaus, feststellbar sein. Von der 'Eignung zur Schädlichkeit' einer Quelle kann bei einem begründeten Verdacht ausgegangen werden, d.h. wenn eine hinreichende Wahrscheinlichkeit besteht. (Unterhalb dieser Schwelle besteht eine Schädlichkeitsunsicherheit.) Die objektive Risikobestimmung erfolgt über das Bayes-Kriterium als Produkt aus

${ }^{108}$ Zur Geschichte der Umweltpolitik in der Bundesrepublik vgl. Hucke, 1990; Wilhelm, 1994. 
Eintrittswahrscheinlichkeit und Schadensmaß in einem zugrunde gelegten Zeitraum (s. S. 26, 108). Erfahrungsgrundsätze und spezielle Ermittlungsmethoden sollen als Grundlage der Bestimmung der Eintrittswahrscheinlichkeit dienen, wobei nach herrschender juristischer Meinung in der Regel die qualitative Bestimmung ausreichend ist, da bei zukünftigen Ereignisabläufen Unsicherheit als unvermeidbar akzeptiert wird. ${ }^{109}$ Das Schadensausmaß orientiert sich am normalen Bestand einzelner Rechtsgüter und kann zeitlich und örtlich variieren. Die Schwere des Schaden wird durch seine qualitativen und/oder quantitativen Elemente bestimmt. Das qualitative Element (Schadensgewichtung) folgt der Wertigkeit eines Schutzgutes in der Rechtsordnung und der Intensität des Schadens. Das quantitative Element bezieht sich auf die Zahl der beeinträchtigten Güter.

Der Rechtsbegriff des Risikos bezieht sich auf Urteile über Schadensereignisse, die hinreichend wahrscheinlich oder bloß möglich sind, der Begriff der Gefahr auf administrative Urteile über Tatbestandsvoraussetzungen, die staatliche Intervention erfordern. Objektiv, d.h. in kausaler Hinsicht, sind Risiken und Gefahr nicht voneinander zu unterscheiden. Gefahr stellt sich rechtlich nicht als Kausalzusammenhang zwischen einem heutigen und einem zukünftigen Schadensereignis dar, sondern als administratives Urteil über einen derartigen Zusammenhang. Gefahr wird dann eine rechtliche Tatsache, wenn ein subjektives, administratives Urteil über einen vermeidlichen Kausalzusammenhang getroffen wird. Abgeschwächt davon besteht ein Gefahrenverdacht, wenn sich keine kalkulierende Wahrscheinlichkeitsannahme treffen läßt, wenn also nicht wie bei Gefahr prognostische Unsicherheit, sondern Nichtwissen über einen Sachverhalt und dessen kausalen Zusammenhang mit anderen Sachverhalten vorliegt. Der Begriff des Gefahrenverdachts ist ebenfalls nicht epistemisch, sondern dogmatisch fundiert: 'Lebenserfahrung', 'Erfahrungssätze' und 'hinreichende Wahrscheinlichkeit' und im Umweltrecht neben normativen Erkenntnisstandards auch Statistiken konstituieren die entsprechenden Eingriffstatbestände der Verwaltung.

Das dogmatische Modell der Gefahrenabwehr, bei dem die Grenze zwischen sozialadäquaten zivilisatorischen Risiken und Gefahren als Tatbestandsvoraussetzung für ordnungsrechtliche Interventionen durch technisch Sicherheitsnormen gezogen werden, reklamierte die Gewährleistung ökologischer Sicherheit. In empirischer Hinsicht hat die Policyforschung ein umweltpolitisches Vollzugsdefizit durch die Verwaltung konstatiert, und eine Lücke zwischen akklamiertem normativen Anspruch des Umweltrechts und dessen Steuereffektivität aufgezeigt (Mayntz, Hansmeyer 1978). In theoretischer Hinsicht hat der Risikodiskurs die Versuche der Rechtsdogmatik, epistemologisch zwischen Risiken und Gefahren zu unterscheiden, scheitern

109 Die rechtliche Bedeutung des Risikobegriffs schließt laut M. Kloepfer immer die Unsicherheit von Prognosen mit ein und findet in den Begriffen ,Schädlichkeitsmöglichkeit' und ,Wirkungsmöglichkeit' Ausdruck. Allerdings könnten dabei die einzelnen Faktoren nicht mehr hinreichend bestimmt werden, so daß ein potentielles Risiko zur Grundlage administrativen Handelns werden könne. Die Tatsache, daß in offenen Systemen bzw. bei offenen Ereignisräumen allen Prognosen über Risiken Unsicherheit anhaftet, macht die Abgrenzung von Gefahr und Gefahrenverdacht anhand zu bestimmender Gefahrenschwellen erforderlich. Die Bestimmung des Risikos mit ungeklärten Faktoren erfolgt nach der gleichen Formel wie bei eindeutigen Faktoren. Erst wenn ein Risiko nicht durch ein hinreichend abgesichertes Wahrscheinlichkeitsurteil quantifiziert oder qualifiziert werden kann besteht Unsicherheit. 
lassen. Die soziologische Risikoforschung legte im Gegensatz zu den juristischen Annahmen die Inkommensurabilität von Risiken nahe. Sie verwies bezüglich von Risiko nachdrücklich auf die Relevanz des sozialen und ökologischen Kontextes, der das jeweilige Problemfeld normativ auflädt. Die Quantifizierung von Risiken im Sinne formaler Entscheidungskriterien wie dem BayesKriterium erscheint deshalb vergeblich. Die Rechtfertigung von riskanten Strategien ist vielmehr kontextabhängig. Zurück blieb eine der administrativ-politischen Entscheidung von der Rechtsdogmatik beigemischte Normativität.

Diese Normativität wurde durch unbestimmte Rechtsbegriffe gefördert, die etwa auf den 'Stand der Technik' (§ 5 Abs. 1 Nr. 2 BImSchG), 'Stand der Wissenschaft und Technik' (§ 7 Abs. 1 Nr. 3 AtomG), 'allgemein anerkannten Regeln der Wassertechnik' (§ 7a WHG) etc. verweisen, ohne damit den Prozeß der untergesetzlichen Grenzwertfixierung bzw. einzelne Verwaltungsentscheidungen hierzu determinieren zu können. Um die normative Aufladung des Rechts nicht weiter zu fördern, kam es in den 70er Jahren zu einigen Urteilen, welche die Kritik am Konzept der Grenzwerte ernst nahmen und sich auch angesichts der problematischen Frage der Gewaltenteilung ein richterliches 'self-restrain' auferlegten. Diese Rechtsprechung wurde jedoch vom Bundesverfassungsgericht "mit rechtsdogmatisch nicht unproblematischen Konstruktionen zur richterlichen Selbstbeschränkung", so R. Wolf (1991, 403), wieder zurückgenommen. Im gleichen Zug erhöhte das Gericht die prozedurale Zugangsschwelle.

Praktisch relevant wurde die Diskussion um Grenzwerte dort, wo die Begriffe nicht mehr als inhaltliche Maßstäbe an die Technik, sondern als Filter für den Individualrechtschutz begriffen wurden. So verschob die Differenzierung des BVerfG zwischen Gefahrenabwehr und Gefahrenvorsorge die vorsorgende Umweltpolitik in den rechtsfreien Raum, denn gemäß dieser Judikatur schützten alleine Grenzwerte individuelle Rechte, während das Minimierungsgebot (der StrSchV) ausschließlich dem Schutz der Allgemeinheit diente. Normativ hochangereichert ist ferner der vom BVerfG konstruierte Begriff des Restrisikos, welcher die Schwelle der Eintrittswahrscheinlichkeit eines Schadens meint, "unterhalb derer im Hinblick auf die prinzipielle Knappheit von Ressourcen Schutzvorkehrungen nicht mehr geboten sind, weil die Verwirklichungswahrscheinlichkeit der dort angesiedelten Schadensmöglichkeiten als so gering angesehen wird, daß Schäden zwar noch theoretisch, aber nach dem Maßstab praktischer Vernunft auszuschließen sind." (BVerfGE 49, 89, 135 f) Mit diesem verfassungsgerichtlichen Urteil wurde das Legitimationsdefizit negiert, welches sich mit der Anwendung unsicherer, irreversibler Technologien aufgetan hatte. ${ }^{110}$ Das Bundesverfassungsgericht sprach der Politik als aktivem Förderer der Atomtechnik damit eine dezisionistisch legitimierende Rolle zu und entband den Gesetzgeber zugleich von jeder Pflicht, eine Setzung der notwendigen Grenzwerte selbst vorzunehmen und diese nicht länger den nachgeordneten Instanzen zu überlassen. Das verfassungsrechtliche Urteil hatte innerhalb des Rechtssystems zur Folge, daß Wertentscheidungen

110 Dagegen beschreibt Restrisikos nach M. Kloepfer (1993, 66) das angesichts der staatlichen Schutzpflicht noch erlaubte Risiko, dem keine eigenständige normative Bedeutung für staatliches Handeln unter Unsicherheit zukomme, da der Begriff keine Aussage über die Möglichkeit des Staats zur Begrenzung von Risiken enthalte. Restrisiko erfasse nur abstrakt das rechtlich zwingend gebotene Maß an Sicherheit. 
(ex-post) dem Gesetzgeber zugeschrieben werden konnten, während die Tatsachenermittlung weiter den empirischen Naturwissenschaften zukommen sollte. "Doch diese Repolitisierung führte bisher nur zu einer Renaissance der Lehre von der Dezision, ohne neue Dimensionen von Entscheidungsrationalität zu erschließen." (Wolf, 1991a, 396) Die Lücke in der Entscheidungsrationalität des politisch-administrativen Systems blieb bestehen. Sicherheit wurde durch Störfälle und Umweltschäden herausgefordert und das polizeilich-behördliche Konzept der Gefahrenabwehr auf entsprechende Sachverhalte angewandt, ohne daß (ökologische) Sicherheit geschaffen werden konnte.

Umweltrechtler haben diese problematischen Begriffe (Gefahr, Risiko, Restrisiko) in Verbindung mit der umweltrechtlichen Prinzipientrias (Verursacher-, Kooperations- und Vorsorgeprinzip) zu systematisieren versucht. R. Wahl und I. Appel schlagen vor, daß dreistufige Gefahrenmodell (des Immissionsschutzrechts, des Wasser- und des Strahlenschutzrechts) terminologisch neu zu fassen und gesteigertes Umweltrisiko (Gefahr), einfaches Umweltrisiko (Vorsorgebereich) und Restrisiko zu unterscheiden. Dies würde zu einer begrifflichen Konkretisierung unter dem Oberbegriff des Risikos führen, was Gefahrenabwehr und Vorsorge verbinden könnte (Wahl, Appel, 1995, 96 ff.) Als Problem erscheint allerdings die dualistische Struktur im Atom- und Gentechnikrecht: Das Gentechnikrecht verfolgt das Konzept einer einheitlichen Risikoabwehr in einem zweistufigen Modell der Sicherheitsdogmatik, daß aber nicht mehr tatbestandlich zwischen Gefahrenabwehr und Vorsorge unterscheidet (Wahl, Appel, 1995, $104 \mathrm{ff}$.$) .$

Im Umweltrecht verknüpfen Rechtsnormen Tatsachen mit Rechtsfolgen, wobei die zugrunde zu legenden Tatschen zumeist erst noch durch Rechtsverordnungen näher bestimmt werden. Für das Rechtssystem als ganzes implizierte diese Form des Rechts eine Referenz auf Wissensregeln zweiter Ordnung und eventuell gar einen Rückgriff auf rechtsexternes Wissen. ${ }^{111}$ Im klassischen Sicherheitsrecht wurde ein solcher Rückgriff auf externes Wissen weitgehend vermieden; im Umweltrecht dagegen wurde er zur Regel. Die juristischen Wissensregeln zweiter Ordnung orientieren sich im Umweltrecht dabei an einem naturwissenschaftlichen Kausalitätsverständnis, das dem physikalischen Weltbild der Mechanik folgt und das die Reversibilität von Ereignissen und Abläufen annimmt (Preuß, 1994, 534 f). Dies gilt selbst noch für das Gentechnikrecht. Damit aber kann das Rechtssystem nicht plausibel zu einem einheitlichen Wissenssystem geschlossen werden. Die juristischen Wissensregeln zweiter Ordnung beruhen auf falschen epistemologischen Prämissen. Auch sind sie demokratietheoretisch problematisch.

Die Wissensregeln werden gemäß den Umweltgesetzen durch die Setzung von Umweltstandards (Technische Anleitungen) generiert, welche vom Parlament an entsprechende, nachrangige Normungsgremien der Umweltverwaltung abgetreten werden (vgl. Mayntz, 1990, Jänicke et al., 2000, 178 ff). Dem rechtspositivistischen Rationalitätsmodell des Rechtssystems zufolge stehen

111 Vgl. dazu Teubner (1990b) für die Systemtheorie, der aber bezüglich des umweltrechtlichen Kausalitätsproblems scheinbar keine Lösung für möglich hält (1997) und damit Luhmann (1997) folgt. 
Standards auf der unteren Ebene einer mehrstufigen Normenpyramide. Dieses Modell verspricht eine Zunahme der Flexibilität und Anpassungsfähigkeit an technische Neuerungen auf den unteren Stufen, während die Normenspitze langfristige Gültigkeit beansprucht (Marburger, Gebhard, 1993). Grundlegendes Strukturmerkmal ist die Annahme der Subsumtionsfähigkeit eines Sachverhaltes unter eine Norm und damit die Isolierung von einzelnen, tatsächlich aber vernetzten ökologischen Wirkungen. Das Modell übersieht die Kluft zwischen juristischer Normenexegese und naturwissenschaftlichem Sachverstand. "Neben und außerhalb der politischen Ordnung und des positiven Rechts hat sich ein zweiter Kosmos von Normen entfaltet, der im sozialen Leben das Recht bei weitem übertrifft." (Wolf, 1991a, 388) ${ }^{112}$ Juristisches Regelsystem und gesellschaftliches Wissenssystem entfernen sich im Umweltrecht zunehmend voneinander; das Rechtssystem entwickelt sich scheinbar selbstreferentiell ohne angemessenen epistemologische Bezug fort.

\subsubsection{Staatliche Sicherheitsgewähr und 'freisetzendes' Technikrecht}

Das Modell der Gefahrenabwehr soll gefährdete Sicherheit wiederherstellen oder in Ansätzen der Bedrohung von Sicherheit durch vorsorgende Maßnahmen zuvorkommen. Das Modell richtet sich offensichtlich an den Folgen von individuellen und kollektiven Handlungen aus, die als Tatsachenbestände zur legalen Grundlage behördlicher Reaktionen werden. Es ist das zentrale Modell für das traditionsreiche Technikrecht und das junge Umweltrecht gewesen. Dabei wurde die Annahme, daß Techniken geschlossene Systeme seien, auch auf ökologische Sachverhalte übertragen. Den technischen Standards des Technikrechts entsprechen im Umweltrecht Grenzwerte, die ein sozialadäquates Belastungsniveau festlegen.

Forsthoff hat in seiner Staatstheorie der Industriegesellschaft vor dem Hintergrund der ökologischen Krise bereits die technische Realisation kritisiert. Die gesellschaftlich noch nicht gefaßte technische Realisation sei Seinsvergessen (Heidegger) und geleitet von der erkenntnistheoretischen Frage der Machbarkeit. Als falsch bezeichnet er Verständnisse von Technik, die diese als Befriedigung von bereits vorhandenen und zukünftiger Bedürfnissen oder als Ausdruck der Produktionsverhältnisse begreifen wollten. Technik realisiere sich vielmehr um ihrer selbst willen (Forsthoff, 1971, 41). Forsthoffs Kritik der technischen Realisation folgt schließlich der Anerkennung der Technik als Machtinstrument der Normen interpretierenden Elite (Forsthoff, 1971, 33 f, 165 ff). Dabei tritt die ökologische Kritik an der Technik, der Forsthoff in weiten Teilen zugestimmt hat - obwohl er ökologische Interessen, die allgemeine Interessen seien, in einer pluralistischen Demokratie für nicht durchsetzungsfähig hält - hinter die ontologische Affinität von Macht und Technik zurück. Recht und Technik wird eine ontologische Wesensantinomie

112 Dies hat auch Folgen im Rechtssystem "Die herrschaftliche Geometrie der im Bild der Normenpyramide symbolisierten Legeshierarchie von Verfassung, Gesetz, Verordnung, Verwaltungsvorschrift und technischer Regel löst sich in polyzentrischen Netzwerken von rechtsförmigen und technischen Normenbeständen auf, die nicht mehr einer gleichgerichteten Regelungslogik folgen müssen" Wolf, 1992, 84. 
zugesprochen, insofern beide zum Integral sozialer Herrschaft werden. ${ }^{113}$ Doch eine solche pragmatische Rechtskonzeption führt letztlich zu einer Instrumentalisierung des Rechts, welche zwangsläufig die Integrationsleistung des Rechts herabsetzt (vgl. Wolf, 1986, 246 f). An der Integrationsleistung des Rechts ist jedoch festzuhalten und d.h. auch, eine Instrumentalisierung des Rechts bei der Technikentwicklung ist zu verhindern.

Das Technikrecht hat bei den Genehmigungsbehörenden zu einer Entscheidungspraxis geführt, die sich auf den 'wissenschaftlich-technischen Sachverstand' zurückzieht. Der hinzugezogene wissenschaftlich-technische Sachverstand erweist sich als in dieser Entscheidungspraxis wesentlich robuster gegenüber rechtlicher Kontrolle als die Abwägungsprozesse der Planfeststellungs- und Bauplanungsbehörden. Wolf konstatiert für das Rechtssystem dieselben Folgen wie die sozialwissenschaftliche Technikforschung. "Technik reglementiert sich zunehmend durch disziplineigene Sicherheitskonzepte und Risikobewertungen selbst. Sie substituiert die traditionellen Methoden der polizeilichen Gefahrenabwehr." (Wolf, 1986, 242) Es bilden sich informelle Kooperationsformen zwischen Wissenschaftlern, Ingenieuren und Beamten heraus (Bohne, 1992, Schneider, 1992). Die Maßstäbe für die rechtliche Inhaltskontrolle der Technik werden zunehmend an die Naturwissenschaften abgegeben, da die rechtsnormengeleiteten Kontrollmöglichkeiten fehlen und auch nicht durch eine umweltrechtliche Materialisierung des Rechts einzuholen sind. Die fehlende rechtliche Kontrolle umstrittener Technologien der Risikogesellschaft erweist sich nicht als fehlerhafte Praxis der Rechtsanwendung, sondern als Schwäche des Rechtssystems insgesamt (Wolf, 1991a). Mit den gefundenen gerichtlichen Bewertungen von sozialen Konflikten um Techniken kann sich zwar die Dogmatik zufrieden geben, doch die Autorität der Jurisprudenz leidet ebenso wie die Legitimität des politisch-administrativen Systems (vgl. Nocke, 1988). Die erkenntnistheoretischen Prämissen für den Bereich der Technik können mittlerweile als durch die Risikoforschung widerlegt gelten. Um so weniger kann man die Richtigkeit dieser Prämissen im ökologischen Kontext offener Systeme unterstellen. Trotzdem haben sich Gesetzgebung und Rechtssprechung weiterhin lange auf Grenzwerte konzentriert. Innerhalb des Rechtssystems zeigte sich dabei aber, daß die Sicherheit des Rechts nicht identisch ist mit der Sicherheit von Rechtsgütern und daß das Rechtssystem selbst Unsicherheiten etwa durch unbestimmte Rechtsbegriffe erzeugen kann.

Beispielsweise statuiert das Abfallrecht den Unterschied zwischen 'Produkt' und 'Abfall' und darauf aufbauend eine Abfallhierarchie, die von der 'Vermeidung' über eine 'Verwertung' zur 'Beseitigung' hin abfällt. Die einzelnen Abgrenzungen sind jedoch rechtlich unbestimmt. Diese Unbestimmtheit der Begriffe wird auch durch die Differenzierung des Verwertungsbegriffs in die 'stoffliche' und die 'thermische Verwertung' (§ $6 \mathrm{KrW}-/ \mathrm{AbfG}$ ) und weitere Kriterien (wie Heizwert,

113 Auch der gegenwärtige sozialwissenschaftliche Risikodiskurs ist durch die Tendenz charakterisiert, Technologieentwicklung als quasi-natürlichen Prozeß zu beobachten (Evolution von Technik). Doch die theoretische Perspektive einer selbstreferentiellen Technikentwicklung kann die Differenz von Natur und Gesellschaft letztlich nur naturalistisch auflösen. Sie übergeht moralische Verantwortung. B. Latour hat diese These am nachdrücklichsten vertreten und trotz gänzlich anderen Intentionen als Forsthoff letztlich auch in der (variablen) Ontologie Zuflucht gesucht (Latour, 1995; kritisch dazu: Werle, 2000). 
§ 6 II, 2, und Umweltverträglichkeit, § 5 IV) noch nicht hinreichend präzise aufgelöst, um rechtliche Abwägungen determinieren zu können. Dem Abfallrecht ist damit rechtlich kein ökoeffizienter Entwicklungspfad eingeschrieben. Für die wirtschaftenden Regelungsadressaten, denen das Abfallrecht zunächst einmal als Verfügungsrecht gegenübertritt, eröffnet dies die Möglichkeit zu erfolgversprechenden Klagen mit der Folge ansteigender Transaktionskosten für das politisch-administrative System. Ähnliche Probleme ergeben sich im anlagenbezogenen Umweltrecht.

Durch neue Technologie eröffnete Gefährdungsstrategien müssen Konsequenzen für politische Theorie und normative Demokratietheorie zeitigen (so Hegemann, 2000). Die Einführung neuer Techniken und Technologien stellt sich als legitimatorische und steuerungstechnische Herausforderung für die Demokratie dar. Folgt man den in Kapitel 1 dargelegten ethischen Überlegungen, so muß nach dem angesprochenen Modell Reese-Schäfers vor der Einführung neuer Technologien ein moralischer Diskurs erfolgen. ${ }^{114}$ Dieser soll die mit der neuen Technologie verbundenen Risiken zum Gegenstand haben und mögliche Gefahren antizipieren und neue Handlungsbereiche öffnen oder schließen. ${ }^{115}$ Es wird eine erweiterte Kontrolle der Technik angestrebt. Diese wird als Vorsorge auf die technologische Entwicklung insgesamt ausgeweitet. Die Kritik am Recht im Angesicht der Risikogesellschaft moniert folgende Probleme (vgl. Wolf, 1986, 249 ff): 1. Unbestimmtheit der Normen in bezug auf ihren Regelungsgegenstand, 2. Unbestimmtheit der Regelungsadressaten oder Normensubjekte angesichts von Gefährdungs- und Risikolagen, deren haftungsbegründende oder -ausfüllende Kausalbeziehung undurchschaubar, unkontrollierbar und damit unregulierbar geworden ist, 3. mangelnde Normenkenntnis und -erkennbarkeit, Normenbeachtung und -akzeptanz (weshalb oft paktierendes Recht empfohlen werde).

Denninger hat weder die Prämissen einer ontologischen Beschreibung von Technologie noch die These des Versagens des Rechtsystems geteilt. Er hält dem drei optimistische Prämissen entgegen: "1. Recht ist (auch heute noch) ein taugliches Mittel zur Steuerung des technologisch-sozialen Entwicklungsprozesses, 2. Politik will sachverständig (wissenschaftlich) 'beraten' sein, 3. Wissenschaft ist in der Lage, die Entscheidungsträger der Politik sachverständig zu 'beraten'." (Denninger, 1989, 645) Sein Technologiekonzept führt das angedeutete Diskursmodell der Technologiesteuerung näher aus. Versucht man Technologiesteuerung in der Grundrechtsdimension zu erfassen, träten drei grundlegende strukturelle Schwierigkeiten auf (vgl. ebd., 650 ff):

1. Verständigungsschwierigkeiten zwischen Juristen und Techniker (Maße und Meßwerte lassen sich nicht ohne unbestimmte, mit richterlicher Wertung auszufüllende Rechtsbegriffe in Gesetze fassen),

\footnotetext{
114 Einen Überblick über Beteiligungsverfahren bei technologie- und umweltpolitischen Entscheidungsprozessen gibt Priscoli, 1993.

115 Vgl. aber die Einschätzungen von Marcinkowski, 2000, Martinsen 2000, Canzler, Dierkes, 2000.
} 
2. Konsensual- und Kognitionsprozesse sind nicht klar voneinander zu isolieren, so daß etwa der 'Gemeinwohlbegriff' nicht mehr brauchbar sei und man auf den 'wissenschaftlichen Sachverstand' zurückgreifen müsse; dies erlaube schließlich

3. dem Gesetzgeber eine hohes Maß an Gestaltungsfreiheit, was auch für die Formen der Beteiligung an den Normsetzungsverfahren gelte. In diesen demokratietheoretisch relevanten Verfahren gelte immer auch, daß die willensbezogenen und die kognitiven Komponenten in jeder Phase der technologischen Normsetzung und -konkretisierung gefunden werden müssen.

Gemeinwohlorientiertes Technikrecht muß dann technologisch richtig in bezug auf die zu regelnde einzelne Technik und in seinen grundlegenden Entscheidungen in dem Sinne gemeinwohlverträglich sein, daß diese Entscheidungen in einem Verfahren gefällt werden, das Alternativen geprüft hat. Da es keine verfassungsrechtliche Verpflichtung des Gesetzgebers zur Fixierung von Umweltstandards gibt, ist dieser gehalten, "durch prozedurale Garantien den Prozeß und die Organisation der untergesetzlichen Normsetzung vorzugeben." (Wolf, 1990, 384) Schließlich kommt - idealiter - gemeinwohlrichtiges Technologierecht nur zustande, wenn es im Hinblick auf die demokratische Allgemeinheit durch das Verfahren seiner Erzeugung in vollem Maße als repräsentativ und demgemäß legitim gelten kann (Denninger, 1989, 655 f). Denninger denkt hier nicht nur an die Repräsentation gesellschaftlicher Pluralität in rechtsgesteuerten Verfahren der Normensetzung, sondern auch an Gegenmacht- und Gegeninformationsbildung. Hier wären parlamentarische Enquete-Kommissionen zu nennen (vgl. Euchner et al., 1993). Preuß hat zusätzlich noch die Bedeutung der Reversibilität von Technik hervorgehoben (Preuß, 1994, 543).

Das Konzept setzt nicht auf den Ausbau des Individualrechtsschutzes, sondern auf die objektivrechtliche Ausdehnung des Umweltschutzes. Die inhaltliche Objektivierung ursprünglich rein individuell subjektiver Grundrechtspositionen kann nur prozedural aufgefangen werden und zwar durch Staatszielbestimmung und Gesetzgebungsaufträge. Die prozedurale Normierung ist aber nur tentativ zu normieren. Die Ablösung vom Rechtssubjekt erfolgt sowohl beim Betroffenen als auch beim Verursacher. Sie verweist bei der Herausbildung kollektiver Güter auf eine pluralistische Demokratietheorie.

Obwohl es das Rechtssystem der Risikogesellschaft nicht auf neue epistemische Grundlagen stellt, vergrößert Denningers Konzept die Legitimität des Technikrechts. Die 'Richtigkeitsgewähr' des Rechts verschiebt sich von normierten Ge- und Verboten zur 'richtigen' Normierung von Geund Verboten. Dies konstituiert ein Element rechtlicher Rationalität. Teilweise als Begleiterscheinung dessen wird aber 'Verrechtlichung' weiter zunehmen. Dies ist bereits für fast alle Rechtsbereiche der Technikentwicklung konstatiert worden. Die richterliche Kontrolldichte wird demgegenüber an Bedeutung verlieren. In diesem Konzept stehen generell nicht Grundrechtspositionen im Mittelpunkt, sondern die objektivrechtliche Ausweitung des 
Umweltschutzes über Staatsziele bzw. Staatsaufgaben ${ }^{116}$ In diesem Bereich wird der Status Quo fortgeführt: Nur ein kleines Segment der verrechtlichten Technikentwicklung ist durch Drittbetroffenenschutz der gerichtlichen Kontrolle zugänglich.

Eine Vorhersage über die Verfassungsverträglichkeit technologischer Entwicklung, basierend auf freisetzendem Recht (Wolf), scheint aufgrund der Gestaltungsspielräume und der Anpassungsfähigkeit des Rechts kaum möglich. Freisetzendes Recht könnte einen Entwicklungspfad ermöglichen, der zwar direkt keine gefährdenden Technologien hervorbringt, gleichwohl aber indirekt nachhaltige Entwicklung durch die damit verbundene Expansion der Stoffund Energieströme verfehlt. Indem Denningers Konzept Technik einem legitimationsfördernden Verfahren der vorsorgenden Risikokontrolle unterwirft, könnte es allerdings als eingrenzendes Recht (Winter) ${ }^{117}$ richtungssicher auf Nachhaltigkeit hinwirken. Gelungene Techniksteuerung könnte dann, so die optimistische These, Umweltpolitik entlasten. Technik könnte als 'systemisches Umweghandeln' (Preuß) verstanden werden, bei welchem durch funktionelle Differenzierung ein sozialer Prozeß organisiert wird, der die technisch-soziale Wirkungsmöglichkeiten steigert. Doch mit der Schaffung neuer Optionen erhöht sich auch der Bedarf an Kooperation und organisatorischer Koordination und damit die Möglichkeiten von Fehlern und Irrtümern. In der Geschichte der Regulierung von Technik, die neben dem Schutz der menschlichen Gesundheit seit den 70er Jahren zunehmend auch den Umweltschutz umfaßt, zeigt sich eine zunehmende, wissensbedingte Verschiebung im staatlichen Regulierungsmodell. "Je größer dabei der Wissensvorsprung der Regelungsadressaten vor der staatlichen Aufsichtsbehörde und je mehr wissenschaftlich-technischer Sachverstand nötig ist, um Risiken und die Möglichkeiten ihrer Minderung einzuschätzen, um so mehr nähert sich die staatliche Regulierung dem Modell regulierter Selbstregulierung an." (Mayntz, 2000, 13 f.) ${ }^{118}$

Freisetzendes Recht transformiert die generelle Handlungserlaubnis des modernen Rechts in eine qualifizierte Erlaubnis und führt Technik so in das Rechtssystem ein. Die qualifizierte Erlaubnis konstituiert rechtliche Verantwortung und reklamiert moralische und ethische Neutralität. Teilweise sichert sie bestehende Grundrechtsvoraussetzungen, indem es wissenschaftliche Forschung oder einen Markt ermöglicht und technologische Entwicklungen unter Rechtssicherheit stellt (vgl. Kloepfer, 1998, 131f). So gewährt etwa das BImSchG einen weitreichenden Bestandsschutz für Anlagen, der, rechtssoziologisch besehen, bereits in der Genehmigungsphase mit der Möglichkeit zum Ausschluß der Öffentlichkeit (Präklusion nach §10 III 3 BImSchG) einsetzt aber erst mit der einmal erteilten, unanfechtbaren Genehmigung materielle Form erhält. Der Bestandsschutz sichert

${ }^{116}$ Vgl. zur Staatsaufgabe ,Risikovorsorge/Umweltschutz': Czada, 2000; Kirchgässner, 1994; Preuß, 1994a; Wahl, 1990 und allgemein zur Debatte über wachsende Staatsaufgaben: Grimm, 1990; Günther, 1990; Schulze-Fielitz, 1990.

117 M. Kloepfer (1998) übernimmt diese Unterscheidung von Recht der Technikkontrolle und der Technikermöglichung.

118 Werle, der ebenfalls zwischen freisetzender und eingrenzender Technik unterscheidet, versteht kodifizierte technische Normen als revidierbares Ergebnis eines Entscheidungsprozesses und nicht als emergente Phänomene. Sowohl Absender als auch Adressaten solcher technischen Standards sind individuelle oder kollektive Akteure. Es sei analytisch weiter zwischen Setzung, Implementation und Durchsetzung von technischer Normen zu differenzieren; Werle, 1995. 
den Betreiber einer genehmigten Anlage vor den Rechtsansprüchen Dritter. Das Genehmigungsverfahren einer Anlage nach BImSchG entscheidet somit nicht nur gegenüber dem Antragsteller sondern auch gegenüber Dritten. Insofern läßt sich feststellen, daß "das freisetzende Recht [...] am Prozeß der Technikentwicklung teil[nimmt], indem es sich selbst für technikneutral erklärt." (Wolf, 1992, 81) Eine Neutralität freisetzenden Rechts muß jedoch angezweifelt werden, wenn dies mit der Ausweitung des anthropogenen Stoff- und Energiestroms einhergeht, welcher die gesellschaftlichen Naturverhältnisse dynamisiert. Zwar erfolgt die Genese ungefährlicher Technik unter epistemologischer Sicherheit (vgl. Kapitel 2.3.2), sie schafft jedoch allein aufgrund des stofflichenergetischen Aspekts koevolutionäre Unsicherheiten, die das Sicherheitsversprechen des Rechtssystems latent bedrohen. Bisher haben sich bis auf wenige Ansätze im Umweltverträglichkeitsgesetz Kriterien für die Technikbewertung wie Fehlerfreundlichkeit, Reversibilität, Lernfähigkeit, Diversifizierung und Diskursorientierung kaum etablieren können (vgl. Wolf, 1992, 83). Dies gilt auch für Maßstäbe der Ökoeffizienz. Das Ignorieren dieser Kriterien aber reißt eine soziale Modernisierungslücke auf, die nicht nur den traditionellen Bestand an rechtsstaatlichen Verfahren, sondern implizit auch alle Überlegungen zu Risikoanalysen, Umweltverträglichkeitsprüfungen und Technikfolgenanalysen als aufwendige Projekte gesellschaftlicher Modernisierung in Frage stellt (Wolf, 1992, 88).

Das Umweltrecht enthält darüber hinaus Rechtsinstitute - wie etwa das GenTG -, die zum Funktionskreis des 'freisetzenden Rechts' zählen und epistemologisch unsicher sind (vgl. Schiller, Tänzler, 2002). Dem freisetzenden Recht liegen hier soziale Technisierungskonflikte voraus, die vermutlich deshalb nicht versöhnlich beigelegt werden können, weil Wissen epistemisch unsicher ist, - so die These im Anschluß an die in Kapitel 2.3.2 vertretene argumentationstheoretische Differenzierung. Bei Mißachtung epistemischer Unsicherheit durch freisetzendes Technikrecht können - wie im Fall freigesetzter GMO - auch partizipatorische Verfahren Konflikte nicht legitim schlichten (Jansen, 2000; Saretzki, 1996b). Das Recht reklamiert durch gesetzte Verfahren zwar auch hier noch die ethische Neutralität der Technik. Doch die generalisierte soziale Autorität des Rechts gibt noch keine Auskunft über die rationale Legitimität des Rechts. ${ }^{119}$ Insofern scheint Denningers optimistische Konzeption im Fall des GenTG bereits partiell revisionsbedürftig.

Im Gegensatz zum freisetzenden Recht steht eingrenzendes Recht am Ende einer Abfolge von Innovations- und Implementationsprozessen, dessen Ausgestaltung durch rechtsförmige Instrumente primär Folgen bewältigen soll, doch sekundär ebenfalls die Entwicklung nach Maßgabe der gesetzlichen Voraussetzungen freigibt. So geben z. B. administrative Genehmigungen Anlagen weitreichenden Bestandschutz. Die Normativität steigert sich meist zum Ende der Entstehung von Technikrecht hin, also im Funktionskreis eingrenzenden Rechts. Von umweltrechtlicher Seite sind befristete Gesetze und Genehmigungen vorgeschlagen worden, welche die Flexibilität und Lernfähigkeit der Verwaltung (Ladeur, 1995, 118 ff; Steinberg, 1998, 171 ff) erhöhen sollen.

119 Preuß (1994) zufolge gefährde bereits die gegenwärtig praktizierte Inanspruchnahme wissenschaftlichen Sachverstands im Rechtssystem und insbesondere im Umweltrecht die soziale Differenzierung. Es würde epistemologische Unsicherheit mißachtet und dadurch die Wissenschaften politisieren und deren Autonomie gefährden. Diese Entdifferenzierung finde bereits im Rechtssystem statt und nicht erst in einer politisierten Öffentlichkeit. 
Allerdings steht zu befürchten, daß diese selbst dann zu Lasten der Dignität des Gesetzes gehen, wenn die normativen Technisierungskonflikte zuvor beigelegt werden konnten. Gerade im Umweltrecht finden sich viele Rechtsinstrumente, die unter 'eingrenzendes Recht' fallen. Dieses eingrenzende Recht muß nicht unwirtschaftlich sein; als eingrenzendes Umweltrecht kann es sogar gegen den ökonomischen Vorwurf des Innovationshemmnisses verteidigt werden (Lübbe-Wolff, 2000). Technik- und Umweltrecht ist an den Prozeß der Technikgenese rückgekoppelt; eingrenzendes Umweltrecht steht der Technikgenese nicht entgegen. ${ }^{120}$

Zweifellos muß der Nachhaltigkeitsdiskurs qualitative Aspekte, sprich emergente Risiken oder Unsicherheiten, direkt erfassen, da eine Vielzahl von Risiken primär soziale und erst sekundär ökologische Folgen beinhalten und technologisch-systemisch fixiert sind. Die Entwicklung neuer Technologien ist, ein komplexer Prozeß, dessen endogenen und exogenen Elemente sich kaum voneinander trennen lassen. Wissenschaftliche, ökonomische, kulturelle und politische Faktoren stehen miteinander in Wechselwirkung. Die endogene Entwicklung beruht auf der Logik des gegenwärtigen technischen Artefaktpools; die Entwicklung unterliegt aber eben auch exogenen Einflüssen. Die Hoffnung, daß sich über technologische Innovationen selbststeuernd eine nachhaltige Entwicklung einstellt, dürfte sich nicht erfüllen, denn die Entwicklung von Technologien zielt nicht endogen auf Substitution im Sinne ökologischer Modernisierung (Ressourcenproduktivitätsgewinne). Dies scheint nachdrücklich für eine steuerungstheoretische Fortorientierung vom anlagenbezogenen Technikrecht zum ordnungspolitischen Umweltrecht zu sprechen. Als rationales Kriterium der Legitimation dient hierbei die absolute Senkung des Stoffstroms, d.h. die Entkoppelung von ökonomischem Wachstum und Ressourcenverbrauch. Für die qualitativen Aspekte des Stoffstroms bietet indes die Technikdebatte einen Ansatzpunkt, der die endogene Entwicklung von Technologie in einen moralischen Diskurs einmünden läßt.

Wie Wolf (1992) festgestellt hat, werde eine Konvergenz sozialwissenschaftlicher Theorieansätzen und Forschungslinien zum Thema 'Recht und Technik' allein von der Rechtsdogmatik unterstellt, sei aber de facto nicht gegeben. Steuerungstheoretische und politikwissenschaftliche Ansätze zeigten vielmehr eine große Vielfalt von Forschungsansätzen und keine nennenswerten Verbindungslinien zur juristischen Diskussion (vgl. aber Bandelow, 2000). Bisher zeichnen sich in den Sozialwissenschaften erst Ansätze zu einer Typologie rechtsförmiger Interventionsniveaus ab, die alle noch spezifischen Politikfeldern zuzuordnen sind. Am ehesten läßt sich eine soziale Steuerung der (freisetzenden) Technikentwicklung noch für den Bereich technischer Normen nachweisen (Eichner, Heinze, 1991; Voelzkow, Eichner, 1992). Die Selbstorganisationshypothese läßt sich dagegen nicht auf den Bereich der freisetzenden Gentechnik übertragen, der durch tiefe Konflikte charakterisiert ist (Jansen, 2000). Die These der rechtlichen Steuerbarkeit von Technik scheint sich durch freigesetzte, irreversible Technologien (Atom- und Gentechnik) als Naturalismus zu negieren. Im Unterschied dazu finden (eingrenzende) Umweltnormen durchaus Verbreitung (Voelzkow et al., 1987). Eine vergleichende Evaluation der

${ }^{120}$ Daß die Entwicklung von Technologie nicht vollständig durch Technikrecht gesteuert wird, zeigt sich daran, daß die Entwicklung auch durch andere Rechtsgebiete geprägt wird. 
divergierenden Steuerungsansätze, könnte zwar einen möglichen Zugang sozialwissenschaftlicher Forschung zum Thema bieten, fand jedoch bisher noch nicht systematisch statt (Werle, Rammert, 1994). Der nähere Zusammenhang zwischen Regelungsintensität und Steuerungseffektivität ist bisher nur in diesem Funktionskreis für einige wenige Politikfelder erforscht worden. Für den neuen Bereich einer nachhaltigen Stoffpolitik meines Wissens noch überhaupt nicht.

\subsubsection{Unsicherheit im Recht}

Auf dem vermeintlich sicheren epistemischen Grund des Gefahrenmodells konnte das Rechtssystem Unsicherheit noch als eine Möglichkeit mit geringer Wahrscheinlichkeit behandeln (vgl. Kloepfer, 1993). Die modernen Risiken jenseits der Lebenserfahrung gehen jedoch über den Gefahrenverdacht hinaus, gleichviel ob dieser dogmatisch der Gefahrenabwehr oder der Vorsorge zugerechnet wird. Dies gilt selbst für die vergleichsweise trivialen Bereiche des Technikrechts (vgl. Wahl, Appel, 1995, 92 f.). In komplexeren Bereichen geht das Rechtssystem von der individuell zurechenbaren und begrifflich bestimmbaren Gefahrenabwehr $\mathrm{zu}$ einer sozialgestaltenden Risikovorsorge über, welches (epistemisch überholte) Kausalitätsanforderungen durch theoretisch konstruierte, hypothetische Ereignisabläufe ersetzen muß (vgl. Teubner, 1997). Parallel dazu findet eine Ausweitung der Schutzgüter etwa im Pflanzenschutzgesetz ( $\$ 15$ Abs. 1 Nr. 3b) oder im

Gentechnikgesetz (§ 1) statt, ${ }^{121}$ was für das Rechtssystem das gravierende Problem mit sich führt, Tatbestände und Grenzen der Vorsorge zu bestimmen.

K. H. Ladeur hat aus systemtheoretischer Sicht die damit verbundenen rechtsimmanenten Herausforderungen des Umweltrechts $\mathrm{zu}$ bewältigen versucht. Zentral wird in Ladeurs rechtstheoretischer Staatskonstruktion Ungewißheit, die zunächst einmal allgemeines Kennzeichen der gesellschaftlichen Evolution sei: Sie sei ebenso Teil des wirtschaftlichen Subsystems wie des Subsystems 'Recht'. Ladeur möchte ein relationales Paradigma prozeduraler Rationalität etablieren, welches Ungewißheit als grundlegende Tatsache der Gesellschaft akzeptiert und "eine neue Allgemeinheit nur noch in einer Metaregel der Erhaltung der Selbstmodifikationsfähigkeit der pluralen Gesellschaft" findet (Ladeur, 1990, 205). Dabei hypostasiert Ladeur jedoch Unsicherheit dergestalt, daß sie einen ontologischen Status erhält. Eine unmittelbare Folge davon ist, daß Ungewißheit politische Steuerung erübrigt. Politik müsse durch eine Steigerung der Interdependenzoptionen (Relationierung) zwischen gesellschaftlichen Systemen ersetzt werden. Der Staat habe lediglich dezentral verteiltes Wissen (von Individuen) so zu verknüpfen, daß es in und durch Organisationen behandelt werden könne, d.h. der Staat solle Informationen der internen und externen Umwelt von Organisationen relationieren. Dies gelte insbesondere mit Blick auf die ökologische Krise: "Es wäre zu fragen, ob und wie das in Organisationen produzierte Wissen stärker durchlässig gemacht werden kann für die Vermeidung von nichtintendierten kollektiven negativen Effekten." (Ladeur, 1990, 207)

${ }^{121}$ Hier wird der 'Naturhaushalt' (PflSchG) oder 'die sonstige Umwelt in ihrem Wirkungsgefüge' (GenTG) zum Schutzgut der Rechtsordnung. 
Der Staat könne nicht mehr auf substantielle, ergebnisorientierte Rationalität zurückgreifen; Unsicherheit, die sowohl in den sozialen Umwelten als auch in der nichtmenschlichen Umwelt zu beobachten sei, schränke jedes planerische Entscheiden ein. Deshalb sollten sich administrative Entscheidungen an Organisationen orientieren, deren Beziehungsnetzwerke in rechtlichen Abwägungsprozessen abzubilden seien. Die Bildung der Kategorie des Normalzustands erfolge über soziale Konventionen. Als solche bezeichnet Ladeur so grundverschiedene Güter wie Eigentum und Gesundheit etc., die sowohl privatrechtlich wie öffentlich-rechtlich definiert sind. Auf derartigen Konventionen will Ladeur dann seine Rechtsregeln aufbauen. Er knüpft dabei an Hayek an: Eigentum und Patentrechte erlaubten eine hierarchische Gestaltung der Gesellschaft bei gleichzeitig dezentral organisierter Produktion und Innovation (Ladeur, 1995, 45 ff). ${ }^{122}$ Das Rechtssystem solle sich laut Ladeur über Eigentumsrechte und nicht über Verträge auf Netzwerke beziehen, denn Eigentumsrechte würden ein statisches Element in einer für das Rechtssystem ansonsten zu dynamischen Wirtschaft etablieren (Ladeur, 1994, 316).

Im öffentlichen Recht blieben Konventionen dagegen meist unausgesprochen, da das Konzept 'Sicherheit' dem Staat ein Monopol (in der Gefahrenabwehr) zuschreibe, in welches das Privatrecht (und auch das Individualschutzrecht) faktisch nicht eindringen könne. Auch das Gefahrenmodell baue auf diesen sozialen Konventionen auf, indem etwa das Polizeirecht Eingriffsnormen vorschreibt, die sich auf Eigentum, Gefahr im Verzug (Bayes-Kriterium) etc. beziehen. Auch im Technikrecht wurde die Bezugnahme auf soziale Normen angestrebt, weil sie die Erzeugung von Erfahrung (als induktive und deduktive Varianten von Wissen) ermöglichten.

Auf der Suche nach Sicherheit müsse die Generierung von Wissen die soziale Akzeptanz von Risiken beachten und Stoppregeln einführen, die das Gefahrenmaß reduzieren. Diese Stoppregeln sollten jedoch nicht Individual- oder Grundrechten folgen, so Ladeur, sondern die lernende Generierung von Wissen ermöglichen. Pragmatische Stoppregeln seien notwendig, um Gefährdungen bei der Suche nach Sicherheit zu begrenzen und große Gefahrenpotentiale in kleine zu zerlegen (z. B. durch die räumliche Diffusion der Risiken). Risiken könnten nicht gegen ein einzelnes, rechtlich geschütztes Gut abgewogen werden, egal wie gründlich und weit die Risiken verteilt werden würden. Denn Risiken hätten eine naturalistische Dimension, die das Rechtssystem zu zivilisieren versuche, die aber letztlich doch der Natur zugeschrieben würden. "This spontaneously generated strategy for the avoidance of risks is also transferred back to nature." (Ladeur, 1994, 309) ${ }^{123}$ Unter der Hand verwandelt Ladeur den systemtheoretischen Naturalismus 2. Ordnung in einen Naturalismus (1. Ordnung) und hebt damit zugleich den Rexflexivitätsanspuch der Systemtheorie auf.

${ }^{122}$ Ladeur lehnt in diesem Zusammenhang zudem explizit marktkonforme wie auch ordnungsrechtliche Instrumente als nicht ausreichend komplex ab.

123 Ladeur spricht in diesem Zusammenhang von einer unvermeidlichen Erzeugung von Entropie, die Ökosysteme durch Disturbationen belaste und erkennt die Gefahr an, die sich aus Akkumulationsschäden in der Umwelt ergeben können. Diese seien potentiell in der Lage, die Grenzen des generierten Risikos zu durchbrechen und würden so zu epistemischen Risiken anwachsen. 
Ein solcher Naturalismus lehnt die Schließung der Lücken zwischen Rechtssystem und Entscheidungsrationalität(en) kategorisch ab: soziale Akzeptanz ist allein schon demokratietheoretisch ein höchst problematischer Begriff. Die Systemtheorie folgt mit dem Verweis auf die Akzeptanz von Risiken der kulturalistischen Risikoforschung, welche in den objektiv erhöhten Gefahrendimensionen der Moderne bisher nichts generell Neues zu erblicken vermag (vgl. Kerwer, 1997, 253 f). Für die Systemtheorie ist die Übernahme des Akzeptanzbegriffs aus theorieinternen Gründen indes mit der Notwendigkeit verbunden, 'soziale Akzeptanz' differenzierungstheoretisch auszuformulieren. Die soziale Akzeptanz technologischen Fortschritts würde dabei wesentlich durch die Autorität der Wissenschaft hergestellt. Sie trifft dabei aber auf das Problem, daß im Zuge der Ausdifferenzierung in der Moderne wissenschaftliches Wissen selbst unsicher wird, da Wissenschaft nicht mehr als neutrale kognitive Operation konstruiert werden kann. Ladeur versucht genau diesem Problem dadurch zu entgehen, daß er das administrative Handeln auf Organisationen und Netzwerke bezieht.

Für den Staat sollen Markt und Organisationen die Fähigkeit zur politischen Selbst- und Fremdbeobachtung erhöhen. Die interne Umwelt des Staates werde wiederum von der Verwaltungsorganisation determiniert. ${ }^{124}$ "Für den Staat ergibt sich daraus [aus der Wissensbereitstellung durch Markt und Organisationen] die Notwendigkeit, seine eigene interne Umwelt bei der Formulierung von Aufgaben und vor allem die der (ihrerseits überwiegend) organisierten Adressaten von Programmen mit zu berücksichtigen." (Ladeur, 1990, 208) Denn das staatliche Wissen sei immer unvollständig; es sei der "Distribution über Netzwerke geschuldet" (Ladeur, 1995, 132).

Zur Generierung umweltrechtlich relevanten Wissens spricht sich Ladeur für eine Prozeduralisierung und Flexibilisierung der Netzwerke aus, sofern dadurch nicht Firmen hierarchisch reguliert werden würden, so daß sie ihre Eigendynamik einbüßten. Statt dessen solle man über rechtliche Normen firmeninterne Umweltmanagementsysteme errichten, die Informationen über Risiken bereitstellten oder firmenexterne, privatwirtschaftliche Umweltberatung vorschrieben. Ladeur sieht nämlich ein Paradox der bisherigen umweltpolitischen Regulierung darin, daß diese, ohne selbst Wissen zu produzieren, betriebsinternes Wissen unterdrücken habe. Wissen müsse demgegenüber als öffentliches Gut angesehen werden, das Firmen und Staat durch gegenseitigen Tausch erst bereitstellen würden. ${ }^{125}$ Ähnlich hat auch Willke argumentiert (1992, 200; 1995, 105). Beide übersehen die Bedeutung des Informationsdilemmas für das Verhältnis zwischen politischenadministrativem und ökonomischem System. Sie ignorieren, dass es in bestimmten Situationen auch rational ist, Informationen zu verbergen (vgl. Keck, 1987, 142 ff).

Selbstorganisiertes Wissen über Stoffströme hat, einmal öffentlich gemacht, empirisch den Charakter eines kollektiven Gutes, dessen Bereitstellung ein Motivationsproblem (Gefan-

${ }^{124}$ Hier erliegt auch Ladeur der bereits erwähnten systemtheorischen Aporie, das Informationsgefälle (Komplexität) von der nichtmenschlichen Umwelt zum sozialen System auf eine antropozentrische 'interne Umwelt' umzumünzen, deren Komplexität sich koevolutionär mit der Systemkomplexität entwickeln soll - aber nicht kann.

125 Dieses Wissen bezieht sich scheinbar überwiegend auf Stoffe; aber Ladeur verweist auch auf gentechnisch veränderte Lebewesen. 
genendilemma) in sich birgt: Dieses wird insbesondere bei Wissen über negative Wirkungen und Gefahrenpotentiale deutlich. Privates Wissen bildet dann u.U. gar kein öffentliches Gut aus. Zu einem öffentlichen Gut wird Stoffwissen, wenn es unmittelbar zur Kostenminimierung beiträgt und mit geringen Transaktionskosten bereitgestellt werden kann. Dies kann sicher teilweise für das Leitbild der Dematerialisierung erwartet werden, da sich First-mover-Vorteile von Unternehmen und makroökonomische Leitbilder durch gleiche stoffliche Indikatoren decken. Hinsichtlich dieses Indikatorensystems ist das zugrunde gelegte Wissen ein öffentliches Gut und vollständig gesellschaftsweit präsent. Es ist ein öffentliches Informationssystem das von Netzwerken in Anspruch genommen werden kann. Es ist nicht, wie Ladeur es seiner Systemtheorie des Rechts zugrunde legt, ein beschränktes kollektives Gut mit unterschiedlichen Öffentlichkeitsgraden, das überhaupt nur von Netzwerken generiert werden könnte.

Die Ladeurs Konzeption zugrundeliegenden Abwägungen im Rechtssystems treffen überdies auf die Schwierigkeit, technisch-wissenschaftlichen Sachverstand anrufen und diesen in bezug auf die Subsysteme angemessen anwenden zu müssen. Dabei wären Risikoanalysen anzustellen, die sektorale, wirtschaftliche Ansprüche mit- oder gegeneinander abwägen müßten. Ladeur nennt als Beispiel die (umweltpolitische) Abwägung zwischen den Stoffströmen der Chemieindustrie und der Landwirtschaft. Weshalb jedoch eine derartige rechtliche Abwägung mit ihren tiefgreifenden politischen Implikationen nicht die Autonomie des Wirtschaftssystems bedrohen soll, wäre, da Ladeur keine integrativen Indikatoren nennt, erst noch systemtheoretisch auszuführen.

Mittels des Begriffs epistemischen Risikos verknüpft Ladeur Rechtssystem und Wissenschaft (Ladeur, 1994, 309 ff). Das Faktum technischen Risikos wird dabei von Ladeur zu einer Norm erklärt. Epistemisches Risiko sei als eigenständiger Normentypus zu sehen, der notwendig aus der Komplexität von Technologien resultiere. Ladeur gelingt es so, Forsthoffs fatalistische Affirmation der Technik noch zu überbieten. Um sich als eigenständiges Subsystem weiterhin reproduzieren zu können, sei das Wissenschaftssystem auf experimentelle Netzwerke angewiesen, die Risiken zulassen müßten, auch wenn deren Ausmaß erst zu einem späteren Zeitpunkt genau zu bestimmten seien. Nur so sei die Wahrheitsfunktion von Wissenschaft zu sichern und Unsicherheit zu bewältigen. Auch könne das Wissenschaftssystem so gegen eine Blockade durch soziale Werte gesichert werden. In ihren technischen Dimensionen seien Stoppregeln dann wieder pragmatisch zu bestimmen (Ladeur, 1994, 311; vgl. auch ders., 1995, 84 ff).

Ladeur erblickt die Lösung des Problems riskanter Wissensgenerierung im Wissenschaftssystem selbst, nämlich in der Risikoforschung, welche die epistemischen Risiken richtigerweise als Unsicherheit in der Wissenschaft thematisieren würde. Gegen epistemische Risiken dürften aber (soziale) Werte nicht mehr geltend gemacht werden, da ansonsten das Wissenssystem der Gesellschaft beschädigt werden könnte. An die Wissenschaft, als Wissenssystem, schließe das Rechtssystem, als Handlungssystem, pragmatisch mit Stoppregeln an, die das generierte Wissen durch Prozedursalisierung harmonisieren würden (Ladeur, 1994, 311). Stoppregeln, die scheinbar durchweg technischer Natur sind, könnten dabei sowohl besser an technische Innovationen anknüpfen als auch allgemein das Unerwartete besser akkommodieren. Staatliche Risikopolitik 
sollte nicht von Fall zu Fall oder - wie im Chemikalienrecht - von Stoff zu Stoff operieren, "rather in each case the possibility of revision and reversibility and the extend of increasingly expenditure of diversity and variety in the environment would be taken into account as a criteria." (Ladeur, 1994, 312)

Die Stoppregeln, welche das Schadenspotential von offenen Experimenten begrenzen sollen, sollen nicht additiv - von Fall zu Fall oder von Substanz zu Substanz - orientiert sein, sondern Reversibilität als Kriterium beinhalten und so irreversible Schäden für Mensch und Natur verhindern. ${ }^{126}$ Offensichtlich nimmt die Stoppregel hier ethischen Gehalt auf, den sie aber weder begründet noch kognitiv expliziert. Die so zwischen vermeintlicher sozialer Akzeptanz und rechtlichen Stoppregeln hin und her lavierende Theorie kaschiert die kommunikationstheoretische Differenz zwischen epistemologischer und prognostischer Unsicherheit und Risiken. Die Stoppregeln werden nicht innerhalb des Wissenschaftssystems gefunden - beziehungsweise erscheinen nicht als möglicher Konsens eines theoretischen Diskurses zur Epistemologie -, sondern werden extern aus der Beobachterperspektive eines Systemtheoretikers des Rechts vorgelegt. Ein solches Recht bzw. die Praxis eines solchen Rechtssystems aber verdeckt Unsicherheit (vgl. Smith, 1994) und transformiert vielmehr auch das Wissenschaftssystem von einem Wissens- in ein Handlungssystem. Ladeur entwirft hier in der Konsequenz eine Selbstversuchsgesellschaft, die Experimente vom geschlossenen Labor in die offene Natur und Gesellschaft überführt.

Nach Ladeur verweist der Begriff prozeduraler Rationalität auf eine 'nichtallgemeine, heterarchische Vernunft', welche die verschiedenen teilsystemischen Rationalitäten über die prozedurale Rationalität des Rechtssystems systemtheoretisch integrieren soll. Prozeduraler Rationalität komme es demnach zu, Subsysteme bzw. deren Organisationen zu verbinden. Ladeurs Version prozeduralen Recht soll autopoietisch aus dem modernen Rechtssystem emergieren. Dabei macht der Ansatz offensichtlich Anleihen bei der libertären Theorie. Doch im Unterschied zu dieser erfolgt die Staatswerdung trotz der prominenten Rolle des Eigentums in dieser Rechtstheorie (vgl. Ladeur, 1995, 45 ff) nicht aus dem Geist ökonomischer Rationalität, sondern aus der Akteurswerdung der Subsysteme. Die ökonomische Rationalität wird fragmentarisch in eine systemische transformiert, die sich am Marktmodell orientiert und über Organisationen prozessiert werden soll. Diese Akteurswerdung bleibt indes auf das ökonomische Subsystem und die Verwaltung beschränkt und schließt zivilgesellschaftliche Akteure beinahe vollständig aus. Ladeurs Modell eines prozeduralen, rationalen Rechtssystems ist nicht hinriechend sozialwissenschaftlich informiert und deshalb unterkomplex.

\subsubsection{Theoretische Steuerungsgrenzen des Rechts ?}

126 Ladeur (vgl. 1994, 312) hält dies in der Tat für ein Argument gegen Kernenergie jedoch nicht gegen Gentechnologie. 
Ulrich K. Preuß (1989a) hat in der epistemologischen Schwäche des Rechts eine theoretische Grenze für das Gefahrenabwehrmodell gesehen, die sogar den originär umweltrechtlichen Begriff der Vorsorge unterminiere. Preuß schließt daraus, daß eine Epistemologie von Nöten sei, "die das linear-kausale Erkenntnismodell ergänzt und uns auf die Einmaligkeit der eigenen Überraschung vorbereitet." (ebd., 534) Dagegen beziehe sich der Gefahrenbegriff auf die Wiederherstellung einer gegebenen Ordnung, d.h. er beruhe auf der Annahme der Reversibilität der Zeit. Das klassische Polizeirecht sei weder von seiner normativen (Gefahr, Risikoverdacht) noch seiner kognitiven (praktische Erfahrung, Stand der Wissenschaft/ Technik) Struktur her in der Lage, die ökologische Krise zu bewältigen. Die staatliche Herrschaft kraft Wissen, die sich in der Anwendung und Ausführung generellen Rechts manifestiert, wird der ökologischen Krise nicht gerecht, obwohl Legislative, Exekutive und Judikative das generelle Recht durchaus an ökologische Sachverhalte anzupassen versucht haben (vgl. Wolf, 1988). Diese umweltrechtliche Diagnose hat R. Wolf auf die These zugespitzt, "daß die Entwicklung der Moderne das historisch produktive, weil verdichtete Spannungsverhältnis von Recht und Gerechtigkeit in ein Verhältnis zunehmender Distanz verwandelt hat, aus dem ein rechtspolitisches Projekt zu 'Modernisierung der Moderne' zwar Anstöße, aber keine instrumentellen Direktiven mehr gewinnen kann." (Wolf, 1991b, 352) Die sozialen Quellen von Gerechtigkeitsvorstellungen konnten zwar nicht rechtstheoretisch dauerhaft domestiziert werden, sie ließen sich aber reflexiv wenden, was in der Selbstreflexivität des modernen Rechtssystems manifest geworden sei. Diese Entwicklung zur Reflexivität des Rechts sei ebenfalls hinsichtlich des Umweltrechts anzustreben: Trotz anhaltender Verrechtlichungstendenzen sei das Umweltrecht gegenwärtig aber noch weit davon entfernt, so etwas wie 'ökologische Gerechtigkeit' widerzuspiegeln.

Das Rechtssystem im Ganzen beruht auf verfassungsrechtlich verankerten Rechtsgrundsätzen, die zugleich auch Prinzipien einer postkonventionellen, universalistischen Moral sind. Das moderne, positive Recht mit seinen vernunftrechtlichen Grundlagen übernimmt keinen materiellen Gehalt einer inhaltlichen definierten Moral, sondern gibt nur Regeln dafür an, in welchen Verfahren und Prozeduren sich vernünftige Selbstbestimmung realisieren soll. Es kann somit nicht das Rechtssystem selbst sein, das die Kriterien für riskante gesellschaftliche Entscheidungen vorgibt. Als Problem erscheint T. Blanke, daß "[d]ie Dynamisierung der kognitiven Programmstruktur des Rechts [...] in zunehmendem Maße in Kollision mit seiner normativen, erwartungsstabilisierenden Funktion [gerät]. Der Wandel der Konditionalprogramme läßt sich nicht beliebig beschleunigen, ohne daß das Recht seine Orientierungsfunktion einbüßt und die Adressaten den Glauben daran, daß, 'was Recht ist auch Recht bleiben muß', verlieren." (Blanke, 1989, 201; vgl. Günther, 1988, $323 \mathrm{f}$ ) Gerade das Umweltrecht ist angesichts der Dynamik der sozio-ökologischen Entwicklung mit diesem Problem konfrontiert. Es zeigt sich daneben ein gravierendes Vollzugsdefizit von Umweltrecht, daß auf eine systemische, ökologische Irrationalität des Rechts hinweisen könnte.

Die von Wolf angesprochene Reflexivität des sozialstaatlichen Rechtssystems hat B. Peters unter dem generellen Aspekten einer Veränderung der horizontalen Rechtsstruktur nach moralischen Gesichtspunkten skizziert, was er an Redistribution, Effizienz, kollektiven Gütern und 
Sozialisation/soziale Integration festmacht. Mit dem Vordringen redistributiver Sozialpolitik wurden moralische Gesichtspunkte in das liberale Rechtsmodell hinein getragen (Peters, 1991, 76), die jedoch die motivationale Basis sozialer Solidarität und wirtschaftlicher Aktivität nicht zerstören durften. Deshalb wanderten noch weitere Ziele in das Rechtssystem ein, wie etwa Stabilität und Wachstum der Wirtschaft. Diese Ziele wiesen nicht mehr nur eine moralische Komponente auf, sondern ein Klugheitsprinzip einerseits und nichtmoralische kollektive Ziele andererseits. Peters erläutert dies am Effizienzprinzip, das "in gewisser Hinsicht gleichbedeutend mit 'Ökonomie' als Handlungsprädikat" und "Klugheitsprinzip par excellence" sei (ebd., 78). Trotz des Problems, eine kollektive Präferenzbasis zu bestimmen (Problem des interpersonalen Nutzenvergleichs und der Aggregation), fungiere ein ökonomisch-rationales Effizienzprinzip als Klugheitskriterium, da moralische Normen wie Gerechtigkeit oder Gleichheit gegenüber diesem Kriterium indifferent blieben, es aber immer noch ein Gebot der Klugheit sei, individuell eine präferenzmaximierende Version des Effizienzprinzips zu wählen. Wenn man mit Peters zwischen moralischen Normen/Prinzipien und Werten unterscheidet, können plurale Werte als Handlungsalternativen verstanden werden, die auch in einer deontologischen Moralkonzeption erlaubten, von Handlungszielen zu sprechen. Diese müßten freilich spezifiziert werden. Innerhalb des politischadministrativen Systems würde die politisch Operationalisierung in die Kategorie kollektiver Güter fallen (ebd., 81 ff), wobei nach Peters moralische Standards in den Begriff einflössen. Mit Rawls (1971, 282 f) lehnt Peters eine Einstimmigkeitsregel für kollektive Güter ab und verweist statt dessen auf die demokratische Mehrheitsregel. Kollektive Güter setzen, wie Normen, "keine Übereinstimmung von Wertmaßstäben voraus - sondern nur eine Koinzidenz von Zielen auf einer konkreteren Ebene oder die Akzeptanz von Tauschprozessen." (Peters, 1991, 87) Auf Basis dieser rechtssoziologischen Definition kollektiver Güter eröffnen die von Peters aufgezeigten Rationalitätsdimensionen Zugang zur Reflexivität des Rechtssystems.

Peters zeigt im folgenden, daß die Diskurstheorie des Rechts gegenüber anderen Rechtstheorien in der Lage ist, diese Rationalitätsgesichtspunkte zu berücksichtigen, dies sowohl bezüglich der internen, als auch der externen Evaluation bzw. Kritik des Rechtssystems. Er interpretiert Verfahren zugleich als normative Schemata und reale sozialer Prozesse, wobei Diskursivität nicht ausreiche, um die Legitimität von Verfahren zu begründen. Die Gültigkeit von Ergebnissen werde nicht durch ideale, diskursive Verfahrensbedingungen sichergestellt (ebd., 246 ff). Damit ist aber noch nichts über das Verhältnis zwischen der rechtlichen Geltung prozeduraler Verfahren und ihrer materiellen Richtigkeit gesagt. Dieses bleibt auch bei Peters unklar: Zwar ist Verfahrensrationalität ein zentrales Element der Vernünftigkeit des Rechts, aber sie ist nur eine notwendige - keine hinreichende - Bedingung für rational begründete Entscheidungen (ebd., 309 ff). Die von Peters aufgefächerten Rationalitätsdimensionen des Rechts deuten nur in Ansätzen auf eine Reflexivität des Rechtssystems hin, so ev. hinsichtlich der sozialen Reproduktionsbedingungen des Rechtssystems. Wenngleich damit auch nicht der Vernunftanspruch der Moderne bekräftigt wird, ${ }^{127}$

127 Auch Peters kann den Wandel zwischen Beobachter- und Teilnehmerperspektive metatheoretisch nicht auflösen . 
so eröffnet Peters' Ansatz doch zumindest Zugang zur internen und externen Kritik des Rechtssystems.

Wie das Wirtschaftssystem muß das Rechtssystem mit der regulativen Idee von Nachhaltigkeit objektive Unsicherheit bewältigen. Da ökologische Rechtstheorien die ex-post auftretenden Umweltschäden (Unsicherheit) und den damit einher gehenden Legitimationsverlust allenfalls bedingt im Regelungsgehalt von Umweltgesetzen antizipieren können, scheint zwangsläufig die Reflexivität des modernen Rechtssystems zum Ausgangspunkt der Ökologisierung werden zu müssen. Die Ökologisierung des Rechtssystems wurde nicht nur von Ladeur (1995), sondern auch von verschiedenen anderen Rechtstheorien entworfen (vgl. Kloepfer, 1989; Wolf, 1996; Steinberg, 1998), die sich darauf konzentrierten,

- die demokratischen Prozeduren durch neue Instrumente zu ergänzen (Plebiszite, Ausweitung von Beteiligungsansprüchen, Mitbestimmungsrecht, Ökobeauftragte, Vetopositionen etc.),

- neue Grundrechte und Rechtspositionen für Tiere und Pflanzen zu begründen und sie der Treuhandschaft von Umweltschutzverbänden zuzuweisen,

- ökologische Staatsziele zu bestimmen und

- Umweltrecht zu rationalisieren.

Mit einer epistemologisch begründeten Abkehr vom Gefahrenmodell hin zu einem objektive Unsicherheit inkorporierenden Modell ist noch kein negatives Urteil über das Recht als umweltpolitisches Steuerungsmedium gesprochen. Gegen die pessimistische These einer Überforderung des Rechtssystems weist etwa G. Lübbe-Wolff darauf hingewiesen, daß bereits eine systematische, an materiellen Zielen orientierte Rechtsvereinfachung - wie etwa die Kodifikation des Umweltrechts dies angestrebt - die ökologische Effektivität des Rechtssystems verbessern kann (vgl. Lübbe-Wolff, 1998a). Selbiges gilt auch für die Modernisierung des umweltbezogenen Ordnungsrechts (vgl. Lübbe-Wolff, 1996). "Die Schwäche des Rechtsstaats dokumentiert sich zuvörderst als Schwäche des Gesetzes; ist aber keine Schwäche des Rechtssystems insgesamt." (Ritter, 1990, 79) Das bestehende Rationalitätspotential des Rechtssystems scheint hinsichtlich seines Einsatzes als Steuermedium zur Bewältigung der ökologischen Krise noch nicht ausgeschöpft. Doch diese These muß sich erst noch empirisch bewahrheiten. Prüfen wir im folgenden also zumindest ihre Ausgangslage.

\subsection{Recht als Steuerungsmedium}

In der Staatswissenschaft sind die Sozialwissenschaften wenig einflußreich (vgl. Offe, 1990a). Das politisch-administrative System tritt der Gesellschaft hier als Institution gegenüber, die durch intentionales Handeln Gesellschaft steuern soll (vgl. dazu König, Dose, 1993). Dabei treten die Strukturen öffentlicher Willensbildung zumeist in den Hintergrund (vgl. Offe, 1990b). Die staatswissenschaftliche Perspektive weist Parallelen zu steuerungsoptimistischen Ansätzen der Policyforschung auf, wie etwa dem akteurzentrierten Institutionalismus (Mayntz, Scharpf, 1995a). 
Im Rahmen dieser Blickrichtung entwickelt sogar die Systemtheorie moderate Steuerungsabsichten (Willke, 1992, vgl. auch Görlitz, 1993).

Die Beobachterperspektive auf das Recht als Steuerungsmedium ist jedoch eine soziologische. Sie wurde von der soziologischen Debatte um die Steuerungsfähigkeit moderner, ausdifferenzierter Gesellschaften ganz wesentlich mitbestimmt, indem Recht als Medium sozialer Selbststeuerung angesehen wurde (Luhmann, 1990a). Die Debatte ist geprägt von einem systemtheoretischen Steuerungspessimismus, der auch in das Recht eingezogen ist (vgl. dazu Schuppert, 1990; Ritter, 1990). Im folgenden soll die (soziologische) Kritik am regulativen Recht, die in die Ansätze des reflexiven und des prozeduralen Rechts einmündete, wiedergegeben werden. Das Konzept des reflexiven Rechts knüpft dabei an staatstheoretische Überlegungen an, und löst sich vom absoluten Steuerungspessimismus Luhmanns. Dagegen folgt zwar auch das prozedurale Recht der soziologischen Blickrichtung, es betont jedoch die Bedeutung des Prozesses sozialer Willensbildung unter Legitimitäts- und sozialen Selbststeuerungsaspekten.

\subsubsection{Regulatives Recht und Umweltpolitik}

In ihrer Entstehungsphase Ende der 60er Jahre beruhte Umweltpolitik auf regulativer Steuerung. Sie baute das klassische Polizei- und Ordnungsrecht aus und griff zur Regulierung auf Auflagen und Ge- und Verbote zurück. Es wurden Genehmigungsvorbehalte ausgesprochen, Grenzwerte gesetzt und so Umweltverschmutzungsniveaus in verschiedenen Bereichen des Umweltrechts festgeschrieben. Die Umweltpolitik hat dazu insbesondere das klassische Konditionalprogramm benutzt, welches die Verwaltung zum Eingreifen ermächtigt bzw. verpflichtet, wenn bestimmte Tatbestände erfüllt sind. Auftretende Normierungsprobleme wurden dabei durch bedeutungsoffene, unbestimmte Rechtsbegriffe zu lösen versucht. In der weiteren Herausbildung des Umweltrechts wurde deshalb auch auf finale Programmelemente zurückgegriffen. Das regulative Umweltrecht beruht auf einer Steuerungsform, die Gesellschaft hierarchisch regieren und dabei rechtlich bestimmte Verschmutzungsniveaus organisieren will.

Doch die Umweltpolitik hat in der regulativen Steuerung Grenzen erfahren. Die regulative Form zielt auf eine direkte Umweltsteuerung. Dabei zeigten sich Schwächen in der Programmimplementation, die ein soziologisch unzureichendes Modell von Gesellschaft nahelegen. Regulatives Recht zeugte aber mehr noch von unterkomplexem Verständnis der nichtmenschlichen Umwelt. Regulative Umweltpolitik fokussierte sich auf Umweltmedien. Ziel war es, Boden, Wasser und Luft vor Immissionen zu schützen und so die weitere Verteilung und Wirkung von Schadstoffen zu begrenzen. Über das Rechtsstaatsprinzip als Basis des Umweltrechts wurde das lineare Ursache-Wirkungs-Gefüge des Rechtssystems jedoch ebenso auf die offene Natur übertragen, ohne daß so ökologische Unsicherheit hinreichend berücksichtigt worden wäre. "Gleichwohl klammerte sich die juristische und administrative Entscheidungstheorie bzw. Entscheidungspraxis, die sich dem Rechtstaatsprinzip verpflichtet glaubt, an die materielle Richtigkeit der auf diese Weise entstandenen Entscheidungsgrundlagen bzw. -kriterien." (Knoepfel, 
1991, 116) Die mißachtete ökologische Unsicherheit und die Kausalitätsproblematik wurde schließlich durch materielle Normen und finale Programmelemente wieder aufzufangen versucht.

Aufgrund ökologischer Unsicherheit ist die materielle Normierung der nichtmenschlichen Umwelt notorisch schwer wenn nicht gar unmöglich. Die über regulatives Recht gleichwohl angestrebte rechtliche Normierung, die durch keinerlei soziale Normen vorstrukturiert war, sah sich zudem erheblichen Implementationsproblemen ausgesetzt. Neben zu erwartenden Widerständen in der Phase der Politikformulierung zeigte sich auch ein markantes Vollzugsdefizit. Bestehende Normen wurden nicht vollzogen (vgl. Mayntz, Hansmeyer, 1978). Regulatives Umweltrecht brachte eine Reihe rechtsinterner Probleme mit sich, die R. Voigt folgendermaßen zusammengefaßt hat: "Steuerungsprobleme ergeben sich bei diesem Instrumententyp [...] aus seiner begrenzten Eignung für die Lösung materieller Probleme, aus der zunehmenden Detaillierung regulativer Normen ('Verrechtlichung'), aus der mangelnden Steuerbarkeit der Vollzugsinstanzen sowie aus informellen Abweichungen von fixierten Normvorgaben." (Voigt, 1991, 180 f.)

Regulative Steuerung sah sich besonders von soziologischer Seite dem Vorwurf ausgesetzt, Gesellschaft unterkomplex zu reflektieren (Teubner, 1990b) bzw. ein falsches Verständnis von Komplexität zu haben (Teubner, 1990a). Dies zeigte sich etwa in den Schwächen des umweltrechtlichen Konzepts der Gefahrenabwehr. Der Rückgriff auf formales und materielles Recht kann, so der Vorwurf, die Lücken in der umweltrechtlichen Kohärenz des Rechtssystems nicht vollständig schließen. Dabei hängt die Plausibilität der Kritik von der juristischen Hintergrundtheorie ab. Regulatorisches Recht reflektierte der systemtheoretischen Rechtssoziologie zufolge nicht nur unzureichend die Gesellschaft, sondern auch sich selbst (als System). Dies wurde als gesamtgesellschaftliches Steuerungsproblem mesotheoretisch thematisiert und spiegelte nicht mehr nur ein Spannungsverhältnis zwischen Rechtsfunktion und Rechtsleistung wider (Willke, 1987a). Luhmann schlägt makrotheoretisch vor, Steuerung als Minderung von Differenz - im Sinne eines (kybernetischen) 'control' - auszuarbeiten (Luhmann, 1991).

Dagegen hat die mikrotheoretisch orientierte Implementationsforschung insbesondere die Defizite in der Implementation regulativer Politik aufgezeigt. Sie diagnostizierte zwar auch Wirkungsgrenzen regulativer Politik (Mayntz, 1979) und analysierte in der Folge insbesondere die Instrumente regulatorischer Politik näher, um daraus Aussagen über effektivere Steuerungsmittel der (Umwelt)politik abzuleiten, doch wies sie ihrerseits die systemtheoretische Kritik am Primat des politisch-administrativen Systems zurück (Scharpf, 1989). Die Schwächen regulativer Politik sind auch auf den historischen Wandel von Ordnungs- zu Gestaltungszielen zurückzuführen. In neuen Politikfeldern wie der Umweltpolitik, die auf keinen vorgängigen sozialen Konsens aufbauen könnten, befinde sich regulative Politik zwar tatsächlich in einer Krise, doch nähre dies die Hoffnung, daß Policy-Implementation und Implementationsforschung kooperativ lernen könnten (Mayntz, 1979).

Während die Evolutionsannahme der Systemtheorie keinen Rationalisierungsprozeß kennt, sondern die soziale Evolution als durch die Differenz von Gesellschaft und Interaktion angetriebene Selektion von Selektionen beobachtet, hält die Implementationsforschung zwar an der Möglichkeit 
rationaler Politik fest, doch hat sie keine normativen Maßstäbe für einen Primat der Politik benannt. Während nach der Systemtheorie die interne Ausdifferenzierung der Gesellschaft empirisch zur Transformation der Subsystemumwelt führt, hat Habermas Rationalität an die Lebenswelt angeknüpft und daraus den empirischen Rationalisierungsprozeß sozialer Evolution als eine pathologische Kolonialisierung der Lebenswelt durch Systeme diagnostiziert. Auch aus dieser Perspektive ist eine Krise regulativen Rechts zu konstatieren. Doch Habermas' normative Kritik trifft auch noch die Implementationsforschung. K. Günther hat davon gesprochen, daß die Debatte zwischen Implementationsforschung und Systemtheorie die kategoriale Verschiedenheit der beiden Maßstäbe Demokratie und Rechtsstaat empiristisch umgedeutet habe. "Legitime politische Meinungs- und Willensbildung sowie effiziente Durchsetzung werden als zwei gleichartige Bedingungen der Möglichkeit erfolgreicher gesellschaftlicher Strukturveränderung durch politische Planung modelliert." (Günther, 1990, 65) Doch wenn die formal- und materialrechtlichen Interpretationen des Reziprozitätsprinzips im regulativen Recht die rationale Weiterentwicklung des Rechtssystems nicht gewährleisten kann, stellt sich die Frage, wie sich Demokratie und ökologische Rechtsstaatlichkeit rational zusammen entwickeln können. System- und Diskurstheorie haben auch hier unterschiedliche Konzepte präsentiert.

\subsubsection{Das Konzept reflexiven Rechts}

Die Konzeption des reflexiven Rechts geht auf Teubner (1980) und Teubner/Willke (1984) zurück. Es soll sich dezidiert vom regulatorischen Recht unterscheiden, indem das Rechtssystem auf seine Steuerungsmöglichkeit reflektiert. Dabei taucht wieder die subjekttheoretische Erbmasse der Systemtheorie (Habermas) auf, die nicht erklären kann, wie Systeme reflektieren. Teubner und Willke begründen ihre Rechtstheorie mit einer Eigenkomplexität der Teilsysteme, welche die Weltkomplexität einer ausdifferenzierten modernen Gesellschaften derart steigert, daß das Recht nur noch die Kontextbedingungen der jeweiligen Subsysteme steuern könne. Interventionen in die Subsysteme müßten dagegen fehlschlagen. In dem Widerstreit zwischen zentraler Kontextsteuerung und dezentraler Teilbereichsautonomie erweise sich Reflexion als adäquates Steuerungsprinzip, dem die Rechtsform reflexiven Rechts entspreche. Die Kontextregelung erscheine nicht mehr als politische Kontrolle zugelassener Selbststeuerung, sondern die Interaktionsbeziehungen zwischen politischer Steuerung und selbststeuernden Subsystemen selbst sollten die Kontrolle der Kontrolle ausüben. Dies geschehe in Verhandlungssystemen oder neokorporatistischen Strukturen (ebd., 6). Die Kompetenz-Kompetenz über diese postmoderne politische Steuerung liege nicht mehr beim demokratisch legitimierten Staat, sondern wird von Teubner und Willke den funktional strukturierten Verhandlungssystemen selbst zugesprochen.

Gegenüber den libertären Versionen von Selbststeuerung machen Teubner und Willke geltend, daß die teilsystemische Ausdifferenzierung der Gesellschaft über eine ökonomisch-formalrechtliche 'Rationalisierung' im Sinne Webers hinausgehe. Es sei eine Emergenz lateraler Weltsysteme zu verzeichnen, was aufgrund der herkömmlichen, positivistischen Struktur des Rechtssystems dazu 
führe, daß Probleme der Gegenwart in die Zukunft verschoben würden (ähnlich auch Ladeur, 1990). Als Beispiel führen Teubner und Willke den demokratischen Wohlfahrtsstaat an, der politisches und ökonomisches Subsystem zueinander in Beziehung setze, ohne doch die jeweilige Komplexität des jeweils anderen Subsystems reduzieren zu können. Da weder Hierarchie noch Markt im Wohlfahrtsstaat die Prärogative ergreifen könnten, biete es sich an, den Wohlfahrtsstaat als Beziehung zwischen Kontext und Autonomie zu verstehen. Die Funktion gesellschaftlicher Steuerung durch Recht ließe sich dann folgendermaßen näher bestimmen: Eine durchgängige Verrechtlichung gesellschaftlicher Bereiche sei abzulehnen, da diese die Identität und Eigendynamik gesellschaftlicher Teilbereiche bedrohen könnte. Eine Entrechtlichung sei aber ebenso problematisch, da diese sich von den Funktionsbedingungen des Gesellschaftsganzen abkoppeln würde. ${ }^{128}$

Unumgänglich ist für Teubner's und Willke's Konzept reflexiven Rechts eine reflexive Orientierung der Teilsysteme, also "eine gesteigerte Form der Selbstreferenz, in welcher der Rückbezug eines Teiles sich nicht einfach auf sich selbst, sondern intentional auf seine Identität richtet." (Teubner, Willke, 1984, 14) Diese zweifache Form der Selbstreferenz soll eine Reduktion der Optionen des (Teil-)Systems unter dem Aspekt einiger zentraler Funktionsprobleme des Gesamtsystems ermöglichen. Es geht hierbei nicht um ein politisches 'Gemeinwohl', sondern um die funktionale Re-Integration von Gesellschaft. Im Falle des Rechtssystems findet sich Reflexion in drei Formen: 1. als interne Rationalität des Rechtssystems, welche die selbstreferentiellen Strukturen des Rechts erfaßt, 2. als Normrationalität, die nicht nur nach gerechtfertigten Prinzipien der Verhaltensregulierung fragt, sondern auch nach den inneren Modellen des Rechts von seiner Umwelt (mit anderen gesellschaftlichen Teilsystemen) und 3. als Systemrationalität, welche die Interaktion des Rechtssystems mit den anderen Teilsystemen systemtheoretisch beobachtet. Reflexives Recht läßt sich gegenüber dem formalen und materialen Recht in allen drei Rationalitätsdimensionen abgrenzen: Die interne Rationalität reflexiven Rechts basiert nicht auf der Alternative von Konditional- versus Zweckprogramm, sondern auf "prozeduralen Programmen, die sich auf die Meta-Ebene der Regulierung von Prozessen, von Organisationsstrukturen, auf die Verteilung und Neudefinition von Steuerungsrechten und von Entscheidungskompetenzen konzentrieren." (Teubner, Willke, 1984, 23) Die Normrationalität weist Parallelen zu neoliberalen Rechtskonzepten auf, indem es Invisible-hand-Machanismen fördern soll, die Teubner und Willke für lernfähig halten. Systemrationalität zielt auf die rechtliche Integration der Gesellschaft, - im Unterschied zur normativ-nachhaltigen funktionalen Integration durch Recht, welche sich vom politisch-rechtlichen Subsystem aus auf alle Teilsysteme erstreckt.

Die Reflexivität der gesellschaftlichen Teilsysteme sehen Teubner/Willke als Bedingung und Voraussetzung der Integration moderner, ausdifferenzierter Gesellschaften. Dazu müßten innerhalb der Teilsysteme diskursive Strukturen erzeugt werden, gegebenenfalls auch durch Demokratisierungsprozesse. Doch gesamtgesellschaftlich beobachtet erfolge Demokratisierung

${ }^{128}$ Im Kontext des Wohlfahrtsstaates sei beispielsweise die Identität der Familie als gesellschaftlicher Teilbereich zu verstehen, der nur kontextual wohlfahrtsstaatlich gesteuert werden kann. 
weniger aus Partizipationssteigerung oder Machtneutralisierung, als aus Reflexion auf gesellschaftliche Identität. Im Falle des Rechtssystems als Reflexion darauf, "das Spannungsverhältnis zwischen Rechtsfunktion und Rechtsleistung zu entschärfen, indem sie den inneren Kapazitäten des Rechtssystems Beschränkungen auferlegt." (Teubner, Willke, 1984, 28) Bevor eine Verrechtlichung anderer Subsysteme eingeleitet werde, sei also erst auf die Regulierungsfähigkeit des Rechts in diesem Teilbereich zu reflektieren. Das hinter dem Konzept reflexiven Rechts liegende Staatsverständnis weist fort von Hierarchie auf Heterarchie. Das politische Subsystem ist nur noch gleichgestelltes Subsystem unter anderen, primus inter pares, ein dezentrales Netzwerk von öffentlichen und privaten Kollektivakteuren, in welchem private Akteure zu Teilen des Staates werden (vgl. Teubner, 1999). Im umweltrechtlichen Kontext werden gemeinhin die gesetzlichen Pflichten zur Bereitstellung von Umweltbeauftragten, Pflichten zur Erstellung von Sicherheitsanalysen oder zur Erstellung von Abfallwirtschaftskonzeptionen, Betriebsorganisationspflichten und das Öko-Audit als reflexive Kontextsteuerung angesehen. Doch diese Ergebnisse der theoretischen Reflexion sind selbst für eine rein ordnungspolitisch ansetzende Umweltpolitik sehr wenig. Sie können nicht darlegen, wie sie den ökologischen Problemen angemessener entgegen treten könnten, als intervenierendes regulatives Recht.

Reflexives Recht problematisiert gegenüber regulatorischem Recht rationalitätstheoretisch, was bisher nur Mittel zum Zweck war, nämlich die interne Struktur des Rechtssystems als Form sozialer Organisation (Eder, 1987, 198). Derart konstruiertes reflexives Rechts weist aber im theoretischen Kontext das grunsätzliche Problem von Asymmetrie auf. Während alle Subsysteme der Gesellschaft reflexive Selbstbeschränkung aufweisen müssen, kann dies für das politische System nicht gelten, denn es ist zwar Umwelt aller anderen Subsysteme, es kann aber nicht Umwelt seiner selbst sein (Cohen, Arato, 1992, 484 f ). Dieses Problem wird zwar auch von Teubner und Willke erkannt (1984, 17 f), es bleibt aber mit dem Verweis auf die systemtheoretisch begründete Notwendigkeit zur Erhaltung der autonomen Subsysteme ungelöst. In gewisser Weise übernimmt die subsystemische Selbstbeschränkung die Rolle einer dezentralisierten Moral - oder eher: Sittlichkeit der Systemtheorie -, doch wie sollen die sich herausbildenden diskursiven Strukturen zwischen den Subsystemen $^{129}$ ihre organisatorischen Strukturen transzendieren können, in denen sie sich als nichthierarchische Verhandlungssysteme oder (poly)korporatistische Arrangements manifestieren? Der systemtheoretische Ansatz reflexiven Rechts läuft scheinbar unweigerlich auf einen reformulierten Korporatismus hinaus. ${ }^{130}$

129 Was 'eine pareto-optimale Minimierung' der Beschränkungen subsystemischer Potentialität sein soll, bleibt angesichts diskursiver Strukturen unverständlich, suggeriert es doch einen einzigen, nämlich zweckrationalen, subsystemischen Bewertungsmaßstab für alle Subsysteme; vgl. Teubner, Willke, 1984, 18.

130 Cohen und Arato (1992, 485 f) haben zu dem rechts- und steuerungstheoretischen Ansatz reflexiven Rechts bemerkt, daß die Lebenswelt aufgrund ihrer geringeren Komplexität gegenüber den Subsystemen diese nur indirekt und weich steuern könne. Im Gegensatz zu Willke (1987a) skizzieren sie eine 'influence theory', welche über Normen und Intentionen anstatt über subsystemischen Medien Einfluß auf Subsystem nimmt. Diskurse können Subsysteme beeinflussen, ohne deren Selbstregulierung zu zerstören, doch entspringen sie keiner zentralen, die Subsysteme regulierenden Öffentlichkeit, sondern Teilöffentlichkeiten, an denen sich die Knappheit von Zeit und Information widerspiegelt (Cohen, Arato, 1992, 486 f). Diese Teilöffentlichkeiten entstehen als Teil des sozialen Selbstregulierungsprozesses. Ohne sie sei (politische) Steuerung schlechterdings undenkbar. 
Diesen hatTeubner später (1999) als 'polykorporatistisches Modell' entworfen und in die zivilgesellschaftliche Tradition einzuordnen versucht. Organisationen fungieren darin als Vermittler zwischen verschiedenen Gesellschaftsdiskursen. Ihr politischer Gehalt wird davon bestimmt, inwieweit sie die Fähigkeit des politischen Subsystems stärken können, die vielen gesellschaftlichen Diskurse hinreichend wahrzunehmen. Verbände haben dabei jedoch nur eine relative Autonomie, denn Rechtspolitik weist ihnen ihre politische Funktion zu. Gegenstand der Rechtspolitik soll - sowohl in externer als auch in interner Hinsicht - der rechtliche Status der intermediären Organisationen sein. Gegenüber der politischen Theorie des Pluralismus beansprucht Teubner für sein Modell nicht eine einfache, sondern eine zweifache rechtliche Orientierung von Verbänden und Interessengruppen, nämlich auf Politik und auch auf Zivilgesellschaft, obwohl die Autonomie von Verbänden durch die Rechtspolitik relativiert wird. Netzwerke des Polykorporatismus hält Teubner u.a. für die Politikfelder Umweltpolitik und technische Standardisierung für erreicht. Teubner schlägt vor, den Staat insgesamt mit den nichthierarchischen Netzwerken öffentlicher und privater Kollektivakteure innerhalb des politischen Systems zu identifizieren (Teubner, 1999, 363). Sein ordnungstheoretischer Ansatz will somit insgesamt einen Beitrag zum konstitutionellen Design moderner Politik erbringen. Das sich jedoch Reflexivität vom Rechtssystem polykorporatistisch auf die Zivilgesellschaft übertragen kann, läßt sich bezweifeln.

\subsubsection{Prozedurales Recht}

Regulatives Recht dient der Sicherung von Kollektivgütern und kontrolliert Prozesse der Strukturbildung in der Gesellschaft. Prozedurales Recht dagegen koordiniert die Handlungen sozialer Akteure. Es zielt auf die Lösung sozialer Konflikte durch rechtlich verfaßte Prozesse und Verfahren, wobei es die Kommunikation im und mit dem Rechtssystem sichert. In normativer Hinsicht ist die Inklusion (oder Exklusion) von Staatsbürgern in das Rechtssystem - und damit in die politischen Institutionen des Staates - ebenso Gegenstand prozeduralen Rechts wie die Beteiligung Dritter an juristischen Verfahren. Prozedurales Recht formuliert die rechtlichen Regeln zur Normierung oder Regulierung sozialer Verhältnisse. Es ist regulativem Recht somit logisch vorausgesetzt. Die Ausweitung regulativen Rechts ohne eine parallele Ausgestaltung prozeduralen Rechts hat K. Eder als 'Pathogenese des modernen Rechts' bezeichnet (Eder, 1990, 155 f).

Im Unterschied zum Verfahrensrecht liegt ihm keine strikte Trennung von Modus und Inhalt zugrunde; die prozeduralen Vorschriften beinhalten eine materielle Stoßrichtung. Prozedurale Vorschriften setzen zwar beim Verfahren an, folgen aber einer materiellen Zielsetzung. Modus und Inhalt sind nicht strikt zu Trennen. "Der prozedurale Ansatz konzentriert sich auf die Rationalität der Prozeduren der Normerzeugung, -durchsetzung und -überprüfung. Er thematisiert damit auch die Rolle der gesellschaftlichen Akteure, die das Recht setzen, es umsetzen oder unterlaufen." (Wolf, 1996, 59) Dies unterscheidet sie sowohl vom Verfahrensrecht als auch vom materiellen

Recht. Im Gegensatz zum Verfahrensrecht, daß parlamentarisch-administrativ festgelegte Rechtspositionen verwirklichen soll, will prozedurales Recht auf die materiellen Inhalte selbst 
einwirken. Prozedurale Rechtskonzepte begleiten materiell-rechtliche Normen dort, wo das Rechtssystem an seine Grenzen stößt.

K. Eder (1986) hat versucht, prozedurales Recht ausschließlich aus der (internen) Entwicklungslogik des Rechtssystems zu begründen. Wie in der Theorie kommunikativen Handelns und der Systemtheorie wird Kommunikation zum zentralen Begriff seiner Theorie. Die Rationalisierung des Rechts sei theoretisch das entscheidende, erklärungsbedürftige Phänomen. Diskurs- und Systemtheorie ist gegen behavioristischen und ökonomischen Rechtstheorien zuzustimmen, daß sozialwissenschaftliche Theorie - genauer gesagt: die Soziologie - die Reflexivität des Rechtssystems erfassen muß, daß sozialwissenschaftliche Rechtstheorie dem Rechtssystem also nicht extern sein Rationalitätsparadigma aufzwingen darf. Für die reflexive Wendung erscheint Eder vor allem die interne Kommunikation des Rechtssystems relevant. (Er verweist in diesem Zusammenhang auf Alexys Theorie juristischer Argumentation.) Gegen Habermas' älteres, mit Faktizität und Geltung revidiertes Rechtskonzept wendet er ein, daß die Wertrationalität moralischpraktischer Diskurse den Begriff der materiellen Rationalität des Rechts dadurch verwische, daß Habermas zwischen genetischem und funktionalem Recht unterscheide (vgl. dazu Habermas, 1981, 537 f). Nach Habermas basiert nur das genetische Recht auf evolutionären Lernprozessen. ${ }^{131}$ Derartige Lernprozesse aber - einschließlich ihrer institutionellen Dimension - möchte Eder insgesamt für die Entwicklung des Rechts zum prozeduralen Recht anbringen.

Gegen die Systemtheorien des Rechts führt Eder an, daß sich Recht nicht darin erschöpfe, Entscheidungsprogramm zu sein, sondern als prozedurales Recht gerade Entscheidungsprogramme regele. "Die Rechtssetzung und die Rechtsauslegung, die sich einerseits schon immer der Form der konditionalen Programmierung entzogen haben, lassen sich nicht mehr durch Zweckprogrammierung regeln." (Eder, 1986, 27) Sie seien ohnehin schon immer Gegenstand von politischen Auseinandersetzungen um deren verfahrensmäßige Kontrolle gewesen. Diese Auseinandersetzungen würden zwar kommunikativ aber nicht im Diskurs ausgetragen. Recht und Demokratie würden sich erst in durch prozedurales Recht konstituierten Rechtsarenen reproduzieren. $^{132}$

Eder will prozedurales Rechtssystem als institutionelles Lernen entwickeln. Alle Zwecksetzungen durch System- und Wertrationalität sind deshalb zu substituieren. "Prozedurales Recht ist also ein Recht, das nicht die Regulierung von Systemproblemen (Recht als Problemlösung), sondern die Herstellung einer symbolischen Ordnung, einer 'Verfassung' der Gesellschaft oder ihrer Teilbereiche ermöglicht (Recht als Konfliktlösung)." (Eder, 1990, 172) Das

${ }^{131}$ Recht sei zwar genetisch gesehen die Verkörperung von moralisch zu begründenden Prinzipien, doch die Anwendung dieser Rechtsinstitutionen müsse sich auf systemisch geregelte Bereiche des sozialen Lebens beschränken (genetische vs. funktionale Rationalität je nachdem ob evolutionärer Lernprozeß oder Kommunikationsmedium).Die von Eder angesprochene Unterscheidung hat Habermas mit Faktizität und Geltung revidiert.

132 Eder sogar spricht davon, daß sich Recht generell nicht als ein konsistentes Regelwerk konstruieren lasse, welches entweder einer Subsumtionslogik folge oder durch Anwendungsdiskurse (Günther) oder Second-order-Rules (Hart) die Differenz zwischen Widerspruchsfreiheit und empirisch zwingenden Fehlern der Subsumtion zwar zu berücksichtigen versuche, aber die Basisannahme der Widerspruchsfreiheit aufrecht erhalte, Eder, 1990, 163 und Fn 39. 
Recht werde zu einem Medium, welches konfligierende Akteure in eine kollektive Handlungsstruktur presse, die sie zum Lernen zwinge. Den Zwang zum Lernen übten dabei mögliche Nachteile und drohende Exklusion aus. Eder grenzt diese Prozeduralisierung des Rechts von einer involutiven und devolutiven Rechtsentwicklung ab. Bei ersterer, breche Prozeduralisierung unter der 'litigation explosion' zusammen und schaffe eine Form symbolischer Macht jenseits der politischen Legitimation. Im zweiten Fall, verwandele sich das Recht zu einer nur noch symbolisch produzierten und reproduzierten 'simulierten Welt' ohne sozialen Bezug (Eder, 1990, 171).

Tatsächlich haben prozedurale Rechtsformen insbesondere in die Umweltpolitik Eingang gefunden, welche sich Anfang der 90er Jahre als das innovativste Politikfeld darstellte (vgl. Fürst, 1990, 294 f). Im Umweltrecht werden Ordnungs- und Rahmenregelungen sowie Organisations- und Verfahrensregeln eingesetzt. Es existieren materielle Richtwertvorgaben bzw. Grenzwerte, operationalisierte Restriktionen (Schutzgebietsausweisungen) und planungstechnische Abwägungsregeln (UVP). Überdies wurde und wird das Mitwirken der Adressaten durch die Ausweitung der Partizipation über Beteiligungsrechte (Verbandsklage in manchen LNatG, Beteiligung von Verbänden, etc.) angestrebt. ${ }^{133}$ Ferner existieren innerbetriebliche Arrangements unter prozeduraler Regelung wie etwa der Betriebsbeauftragten für Umweltschutz (z.B. im BImSchG § 53, im WHG § 21a und im KrW-/AbfG §54) und Öko-Audit. Prozedurales Recht besitzt in derartigen Regelungen den Vorteil, weniger eingriffsintensiv als materielles Recht zu sein.

Der Rückgriff auf prozedurale Rechtsformen gerade in der Umweltpolitik resultiert dabei nicht zuletzt aus den Mängeln materieller Normen des Umweltrechts. Als immer wiederkehrendes Problem der Umweltpolitik erweist sich die ungenügende Konditionierbarkeit administrativer Entscheidungsprozesse durch materielle Selektionskriterien. Die Unbestimmt der Umweltgesetze im Regelungsgehalt erweist sich aber auch für das Rechtssystem als Ganzes als Herausforderung, denn es läßt zum einen das Subsumtionsmodell scheitern (vgl. Steinberg, 1998, 396 ff), zum anderen kollidiert die Unbestimmtheit im Umweltrecht mit der Wesentlichkeitstheorie des Rechts (vgl. Kloepfer, 1984, 685 ff, Lübbe-Wolff, 2000b). Die Rechtssicherheit prozeduraler Regelungen ist allgemein geringer als die materiellen Rechts. Andererseits ist faktisch festzustellen, daß auftretende Regelungslücken im Umweltrecht vermehrt durch unbestimmte Rechtsbegriffe geschlossen werden, wodurch die Rechtsanwendung an Bestimmtheit verliert. Dieses interne Problem des Rechtssystems drängen die politische Frage der Steuerung durch prozedurales Recht oftmals ganz in den Hintergrund (vgl. Hagenah, 1994).

Das Medium prozeduralen Rechts verweist auf das politische System von Staat und Administration und dessen Verhältnis zur Zivilgesellschaft. Ein Charakteristikum prozeduralen Rechts - im Vergleich zu materiellem und formalem Recht - ist, daß sich mit seinem Einsatz das Verhältnis von Staat zu Adressat/en wandelt: Der Staat verhält sich kooperativ zu den Adressaten in den entsprechenden Politikfeldern. Er kooperiert mit ihnen, wozu er mit den Adressaten seiner Politik

133 In der Bundesrepublik wurde diese Entwicklung durch die Beschleunigungsgesetzgebung wesentlich zurückgedreht. 
stärker argumentativ und weniger direktiv kommuniziert. ${ }^{134}$ Beratung und soziale anstatt administrativer Kontrolle können dabei das Steuerungspotential des Staates erweitern, wenn eine politische Öffentlichkeit die Bedeutung der Kommunikation zwischen Staat und Adressaten reflektiert (Fürst, 1990, 297 f). Diese von Fürst als Metakommunikation bezeichnete öffentliche Reflexion über die Bedeutung der Kommunikation zwischen kooperierendem Staat und Adressaten sei nicht nur wichtig, um die Ziele des Senders gegenüber dem Adressaten zu vermitteln, sondern auch, um der Bevölkerung in der allgemeinen Öffentlichkeit Politik nahe zu bringen. Eine derartige Politikvermittlung wird aber auch mit symbolischen Elementen durchzogen sein, was die Gefahr der Entstehung symbolischen Umweltrechts (vgl. Kapitel 5.2.3) im Zuge einer devolutiven Entwicklung des Rechtssystems (Eder) beinhalten könnte.

Es ist in dieser Hinsicht problematisch, daß die Theorie des reflexiven Rechts dem politischrechtlichen Subsystem jede übergeordnete, oder auch nur koordinierende Rolle abspricht. Hier unterscheidet sich Ladeurs systemische Rechtstheorie einer ökologischen Wissensgesellschaft. In Ladeurs prozeduraler Theorie werden Administration und private Organisationen zu den Trägern des Staates, womit das politische System, aber auch das ökonomische, in den Mittelpunkt rücken. Dem folgt prozedurales Recht und richtet sich an den Netzwerkstrukturen aus. Umweltpolitisches Handeln konzentriert sich auf diese Netzwerke und bleibt an prozedurales Recht rückgebunden. Dies erscheint zunächst als dynamische, umweltpolitische Innovation, denn Netzwerke stellen sich für alle beteiligten Akteure als Form der Problemlösung dar. Unter dem Aspekt der Fähigkeit von Verhandlungssystemen zur kooperativen Problemlösung gruppieren sich Akteure um bestimmte Politikfelder wie etwa der Umweltpolitik. Während der Staat durch Netzwerke Zugang zu Informationen erhält und seine (umwelt)politische Akzeptanz erhöhen kann, nehmen private Akteure in der Absicht teil, den politischen Prozeß zu beeinflussen (Mayntz, 1993, 3). Generell werden nur über Verbände organisierte Interessen repräsentiert. Der Staat nimmt nur als gleichberechtigter Akteur am Verhandlungssystemen teil oder beschränkt sich sogar ganz auf die rechtliche Regelung. Unabhängig von staatlicher Beteiligung flankiert prozedurales Recht die sektorale umweltpolitische Selbstregulierung, die schließlich über 'konstitutionelle Verhandlungen' zu stabilen Netzwerke führen kann. Prozedurales Recht erscheint dann in Verhandlungssystemen als ein intermediäres Arrangement, während sie in der Umweltverträglichkeitsprüfung als ein staatliches und mit dem Umweltschutzbeauftragten als ein gesellschaftliches Arrangement auftritt (vgl. Hagenah, 1994). Eine Politik der Dematerialisierung muß ihr Augenmerk auf institutionelle Arrangements im intermediären Bereich zwischen Staat und Markt richten. ${ }^{135}$

\footnotetext{
${ }^{134}$ Vgl. zur steuerungstheoretischen Diagnose eines kooperativen Staates Mayntz, Scharpf, 1995b; Kühn, 1997, 530 und zur daraus resultierenden administrativen Praxis Bohne, 1982, 1984.

135 Die Systemtheorie favorisiert dagegen gesellschaftliche Arrangements. W. Breuning und J. Nocke haben aber keinen Unterschied zwischen regulativem und reflexivem Recht bezüglich des Umweltbeauftragten ausmachen können (Breuning, Nocke, 1994, 286). In beiden Rechtstypen träten dem Unternehmen Umweltbeauftragte systemtheoretisch beobachtet als 'externe Daten' entgegen, die keine eindeutige Unterscheidung zwischen ökologischer Umwelt und ökonomischem System gewährten. Diese Heteronomie der Ziele könne gar nicht in einer Person aufgefangen werden. Mehrere Ziele könnten sogar eine Organisation in manifeste Problem stürzen, wie die Systemtheorie gezeigt habe. Sie kritisieren, daß die Systemtheorie (des Rechts) die subsystemischen Beobachtungsstandpunkte in bezug auf die ökologische Krise zwar ständig wechsele, aber schließlich doch kein
} 
Traditionell orientieren sich Verhandlungssysteme am Gegensatz von Kapital und Arbeit. Dies färbt auch noch auf die Zusammensetzung umweltpolitisch relevanter Verhandlungssysteme ab. ${ }^{136}$ Zudem macht sich eine nur sehr geringe Konfliktfähigkeit von Umweltschutzinteressen bemerkbar: Selbst bei idealer Institutionalisierung eines Konfliktes durch die vollständige Repräsentation konfligierender Interessen resultiert daraus kein Lösungsautomatismus, da Verhandlungssysteme überwiegend nach dem Konsensprinzip arbeiten. Je vollständiger dabei die Informationen sind und je mehr sie berücksichtigt werden, desto komplexer und konflikthafter wird der Entscheidungsprozeß. Überdies sind Verhandlungssysteme wenig lernfähig; und korrigieren nur selten Entscheidungen. Hagenah konstatiert ein Dilemma zwischen notwendiger kognitiver Rationalität von Entscheidungen und der Lernfähigkeit von Verhandlungssystemen (1994, 513).

Trotzdem ist anzunehmen, daß sich durch die partizipatorische Einbindung Betroffener über prozedurales Recht die Legitimität des Staates erhöhen läßt. Prozedurales Recht würde demnach die Repräsentation der Mitglieder der Gesellschaft an den sie betreffenden Entscheidungen regeln, "indem es den Präferenzen des 'politischen Volkes' eine institutionelle Ausdrucksmöglichkeit gibt." (Eder, 1990, 162) Derartige Möglichkeiten prozeduralen Rechts können durchaus gegeben sein, ob dies jedoch die Steuerungsfähigkeit des politisch-administrativen Systems erhöhen, erscheint fraglich. Die bisher vorliegenden, rudimentären empirischen Bestandsaufnahmen sind wenig ermutigend (vgl. Böhm, 1997, Hagenah, 1994). Böhm (1997) kritisiert die stark prozeduralisierten Verfahren der amerikanischen Grenzwertfestlegung, deren Offenheit immer wieder zur Anfechtung der Ergebnisse führe und die Anpassung der Grenzwerte behindere.

Auch normative Gründe sprechen gegen eine generelle Ausbreitung von Verhandlungssysteme im Medium prozeduralen Rechts. Denn diese sind durch das faktische Fehlen noch nicht existierender, zukünftiger Betroffener eingeschränkt. Eder hat die normative Problematik zutreffend folgendermaßen zugespitzt:

Die Idee einer Kollektivgütergemeinschaft wie die Idee einer Sicherung der Lebensbedingungen zukünftiger Generationen, über deren Präferenzen nichts bekannt ist, überschreiten den Horizont individueller Interessenverfolgung und individueller moralischer Bewertung. [...] Prozeduralisierung heißt dann Vergesellschaftung von Unsicherheit, eine rechtlich auf Dauer gestellte Verteilung möglicher Kosten von Vergesellschaftung auf möglichst viele. (Eder, 1990, 159)

Prozedurales Recht kann nicht als Rechtsform intergenerationeller Gerechtigkeit interpretiert werden. Im intertemporalen Kontext existieren keine reziproken Interessen mehr. Die fehlende Reziprozität läßt sich auch nicht als fehlendes Wissen simulieren (so Ladeur, 1986, 273), da Kognition moralische Urteilsbildung im Diskurs nicht zu ersetzen vermag. Prozedurales Recht läßt sich nicht rechtssoziologisch als ein Evolutionsstadium des Rechtssystems deuten. Es muß vielmehr einen Bezug zur moralischen Dimension praktischer Vernunft aufrechterhalten. Praktische Vernunft

gesellschaftliches Subsystem ausmache, über welches die Bewältigung der ökologischen Krise gelingen könnte. Grund dafür ist wiederum, daß die nicht-menschliche Umwelt externe Umwelt aller Subsysteme ist; ebenso wie diese zueinander nur Umwelten sind.

${ }^{136}$ So arbeiteten nach Hagenah (1994) in der Konzertierten Aktion Sonderabfallentsorgung 1 Umweltschützer, 6 Gewerkschafter, 8 Arbeitgebern und die Vertreter von Bund und Länder. 
enthält advokatorische Elemente. Durch diese Einschränkung kommt Eders lerntheoretisches Konzept prozeduralen Rechts allenfalls eingeschränkt als 'der Versuch der Korrektur eines abstrakten Gerechtigkeitsbegriffs' in Betracht (vgl. Eder, 1990, 164 ff); - dies gilt auch hinsichtlich der symbolischen Dimension des Rechts. Eine moralanaloge Entwicklungslogik des Rechts auf prozedurales Recht hin läßt sich nicht in dieser Form verteidigen. Recht kann, da es nur als funktionale Ergänzung kommunikativ handelnder Gesellschaft anzusehen ist, nicht unmittelbar analog dem moraltheoretischen Entwicklungsmodell gedacht werden. Es fließen nämlich neben moralischen immer auch ethische und pragmatische Gründe und Bedürfnisinterpretationen in das Handlungssystem der Gesetzgebung ein. Letztlich wird das Intertemporalitätsproblem auch empirisch bestätigt, indem etwa Stoff- und Energieströme weiter anschwellen, das Artensterben noch immer zunimmt etc. Es käme demgegenüber darauf an, über prozedurales Recht institutionelle Arrangements der Nachhaltigkeit zu etablieren. Dies erinnert an Dryzeks 'discoursive design' (Dryzek, 1990, 43 ff).

Die Erwartungen an prozedurale Arrangements waren z.T. so groß, daß die Neutralisierung moralischer Forderungen durch rechtliche Verfahren und ihre Substituierung durch Kollektivgüter für möglich erachtet wurde (Eder, 1990, 160). So sind Verfahren nicht nur im Gefolge von Luhmanns Legitimation durch Verfahren (vgl. dazu Machura, 1993), sondern auch unter Berufung auf die Diskurstheorie als Möglichkeit der gesellschaftlichen Integration gesehen worden und in der Technikfolgenabschätzung angewandt worden (vgl. Bora, 1993). Dies verkennt jedoch den Unterschied zwischen Prozeduren als regulativer Idee und tatsächlichem Verfahren der Gesellschaft. Diskurstheoretisch sind in sozialen Verfahren erzielte Ergebnisse nur dann gültig, wenn sie moralisch gerechtfertigt und kognitiv begründet werden können, also wahr sind. Genau dieser Wahrheitsanspruch aber wird im Risikodiskurs suspendiert. ${ }^{137}$ Andererseits legt die

137 Die umweltpolitische und -soziologische Forschung hat sich im letzten Jahrzehnt stark auf Verfahren in umweltpolitischen Konflikten fokussiert (vgl. anstatt vieler Renn, 1996, 1999). Diese umweltpolitische Forschung weist insofern einen großen Praxisbezug auf, als daß die rechtlichen Zulassungsverfahren oft Gegenstand heftiger sozialer Konflikte sind. Die Diskurstheorie ist dabei als Möglichkeit gesehen worden, konfliktträchtige Verfahren zu öffnen, d.h. der Beteiligung zugänglich zu machen, um materiell gerechte Ergebnisse zu erzielen. Sofern hierbei nachgelagerte Konflikte (um Müllverbrennungsanlagen, Deponien, Infrastrukturprojekte etc.) im Vordergrund stehen, haben derartige Verfahren End-of-the-pipe-Charakter und sind kritikanfällig (Keller, Poferl, 1994).

Bezüglich der öffentlichen Planung von Politik und der Zulassung von Technologien nehmen Verfahren Ex-anteCharakter an. Es läßt sich nur von Ex-ante-Charakter sprechen, da derartigen Verfahren immer vorgängig im Rechtssystem institutionalisiert sind und damit Machtverhältnisse (finanzielle, kognitive etc.) widerspiegeln. Sie verletzen Regeln des Diskurses, obgleich sie legal sind und strahlen mit dieser Regelverletzung in die Zukunft hinein. G. Bechmann hat unter der Prämisse, daß angesichts einer fehlenden gesellschaftlichen Instanzen, "der man die zukünftigen Schäden zurechnen kann, [...] nur noch die Entscheidung unter Unsicherheitsbedingungen [bleibt]" (1996, 50), eine Prozeduralisierung vorgeschlagen, unter der er die Rationalität von Verfahren versteht, "in dem Sinne, daß die gewählten Verfahren und Prozeduren als Garanten für die Rationalität ihrer Ergebnisse stehen" (ebd., 54) Als Verfahren kollektiver Entscheidung unter Unsicherheit nennt er Mediationsverfahren, Diskursverfahren und Partizipationsverfahren. Diesen Verfahren sei zwar die Fähigkeit zur Selbsttransformation und zum Lernen zu bescheinigen, es bestehe jedoch beim Mediationsverfahren die Gefahr, daß im Konflikt der Interessen das Gemeinwohl verloren geht, daß der Diskurs keinen Abschluß finde und daß der legitime Wertepluralismus in Partizipationsverfahren einen auch nur vorrübergehenden Wertekonsens verhindere.

In einem späteren Aufsatz hat Bechmann bezüglich der hier vertretenen argumentationstheoretischen Differenzierung Schombergs seinen Einwand gegen Diskurse zugespitzt: "Aus der Sicht epistemischer Diskurse, die mit Unsicherheitsbedingungen zu kämpfen haben, und dies sind genau Risikodiskurse, zeigt sich, daß der dort eintretende Dissens nicht ausschließlich als Verletzung von Regeln des Argumentierens erklärt werden kann, sondern daß hier inkommensurable Orientierungssysteme aufeinandertreffen, deren Divergenz auf die logisch und korrekte 
empirische mikrosoziologische und sozialpsychologische Procedural-Justice-Forschung durchaus nahe, daß Verfahren und Fairneß sich entsprechen können. Dieser Zusammenhang ist hinsichtlich von sozialen Verfahren und politischen Institutionen generalisiert worden. Röhl (1993) spricht hierbei vom Procedural-Justice-Effekt; doch er hält die Lücke zwischen empirischer mikrosoziologischer Forschung (vgl. Epp, 1998; Kals et al., 2001) und normativer (makrosoziologischer) Rechtstheorie nicht für geschlossen. Ansätze, die Gerechtigkeit allein über faire Prozeduren sichern wollten, seien konstruktivistisch und bisher der empirischen Hypothesenbildung unzugänglich. Röhl zählt dazu auch die Diskurstheorie.

\subsection{Das Paradigma des Umweltstaats}

Habermas führt in Faktizität und Geltung den Begriff des Rechtsparadigmas ein. Dieser ergibt sich aus dem Wechsel von der Teilnehmer- zur Beobachterperspektive; er enthält einen objektivierenden Blick auf die historischen Entwicklungen der Gesellschaft und ihres Rechtssystems. Ein Rechtsparadigma manifestiert sich in erster Linie in exemplarischen Entscheidungen der Justiz und spiegelt so das paradigmatische Rechtverständnis einer gesellschaftlichen Epoche. Die Paradigmen haben insofern eine 'welterschließende Funktion', die 'handlungsanleitende Situationsdiagnosen' ermöglichen. Denn die Experten eines Rechtssystems interpretieren Normensätze nicht nur vor einem bestehenden Rechtssystem, sondern ebenso "aus dem Horizont eines jeweils leitenden Vorverständnisses der zeitgenössischen Gesellschaft" (Habermas, 1992, 468).

Habermas zeichnet die Entwicklung der Paradigmen und ihr Reflexivwerden in der Jurisprudenz nach. Er unterscheidet drei Paradigmen: 1. den (liberalen) Rechtsstaat, 2. den Sozialstaat, 3. den Sicherheitsstaat. Ersterer bewältigte die Willkür absolutistischer Staatsgewalt, der Sozialstaat stellte die Antwort auf die soziale Frage dar, der Sicherheitsstaat schließlich meint den auf die ökologischen und wissenschaftlich-technischen Risiken mit Präventionsstrategien reagierenden demokratischen Rechtsstaat (Habermas, 1992, 524f).

Anhand der Ablösung des Rechtsstaatsparadigmas vom Sozialstaatsparadigma, zeigt Habermas auf, daß der Paradigmenstreit bis in die Rechtsdogmatik hineingetragen wurde. (Habermas, 1992, 470) Gleichwohl lehnt Habermas die Vorstellung ab, daß ein Paradigma den wachsenden Partikularismus der Rechtsordnung mit Hilfe von rechtswissenschaftlichen oder

\footnotetext{
Befolgung verschiedener bestehender Regeln und Normsysteme zurückzuführen ist. Selbst Begriffe wie Kommunikation, Verständigung und Argumentation sind in diesem Rahmen noch kontrovers." (Bechmann, 1997, S. 155) Tatsächlich sind Argumentations-, Erkenntnistheorien, pragmatische Präsuppositionen etc. selten unangefochten. Die darüber bestehenden Dissense sind jedoch nicht Gegenstand praktischer Diskurse, sondern werden in theoretischen Diskursen thematisiert. In diesen werden in der Tat u.a. Argumentationsregeln diskutiert. Hierbei dürften das Diskurs- und das Universalisierungsprinzip Habermas' gegenwärtig die prominentesten Vorschläge sein. Bereits Habermas hat gegen Alexy eingewandt, daß man den Begriff der Diskursregel nicht im engen Sinne einer logischen Spielregel verstehen dürfe. Genau dies aber tut Bechmann, wenn er soziale Praktik und Diskurse (der Begründung) aneinander anschließt. Im Widerspruch zu Bechmann können Diskurse jedoch nicht als Verfahren - auch nicht als quasi-reine im Sinne Rawls - interpretiert werden.
} 
rechtsoziologischen Theorien überwinden könne, da diese wiederum nur reines Expertentum bleiben müßten. Nur als unthematisches Hintergrundwissen erfassen Rechtsparadigmen das Bewußtsein aller Aktoren - "das Bewußtsein der Staatsbürger und der Klienten nicht weniger als das des Gesetzgebers, der Justiz und der Verwaltung." (Habermas, 1992, 476) Der Streit um das richtige paradigmatische Verständnis eines Rechtssystems, das sich als Teil im Ganzen der Gesellschaft reflektiert, ist demnach im Kern ein politischer Streit, der nicht auf Unsicherheiten in der Rechtstheorie zurückzuführen ist (kritisch dazu: Alexy, 1995a, 170 f). Habermas führt das mit diesem Begriff verbundene Rechtsverständnis gegen jene Auffassungen in der Jurisprudenz an, die mit der Konzedierung einer Krise des Rechts (als Steuerungsmedium) auch den sozialintegrativen Aspekt von Rechtsstaatlichkeit preiszugeben bereit sind. Er kritisiert aber auch jene Positionen, die Recht als Verfassungsprojekt reanimieren wollen.

Bei dem von Habermas festgestellten Paradigmenstreit in der Rechtsdogmatik ging es im Kern um den Kampf der liberalen Privatrechtsdogmatik mit dem sich herausbildenden sozialstaatlichen Rechtsmodell, das die statische Trennung zwischen Privatrecht und Öffentlichem Recht in Frage stellte, ohne daß die Privatrechtsdogmatik darauf eine hinreichende Antwort fand. Dem liberalen Staat schien die Freiheit der Staatsbürger bereits durch das bürgerliche Formalrecht - und über die Rechtsinhaltsgleichheit immer auch die Gleichheit der Staatsbürger - in der bevorzugten Form konditionaler Rechtsprogramme gesichert. Die dahinterliegende Rationalität war eine Rationalität der effizienten Allokation von Gütern, die soziale Gerechtigkeit bzw. ethische Standards ausschloß, da diese die formale Rationalität sogar zu bedrohen schienen. Die tatsächlichen Bedingungen der Freiheit erlaubten nicht die Schaffung sozialer Gerechtigkeit.

Erst die Herausbildung des Sozialstaates schuf soziale Gerechtigkeit; es brachte eine Materialisierung des bürgerlichen Formalrechts mit sich, die sich insbesondere auf das Eigentums- und das Vertragsrecht konzentrierte und in diesen Bereichen das liberale Modell des marktfixierten Staates teilweise hinter sich ließ. Diese distributive Rationalität ersetzte jedoch nicht die allokative Rationalität des liberalen Staates, sondern ergänzte das formale Recht durch materielles. Das neue Modell des Sozialstaates setzte dabei auf die reaktive oder präventive Steuerung durch die Medien administrativer Macht und Geld, um so Kontingenzen der sozialen Entwicklung abzufedern. Materielles Recht begrenzte in diesem Kontext die Allokation von Ressourcen ebenso wie die Ausdehnung von Macht; allerdings institutionalisierte Recht nicht soziale Gerechtigkeit innerhalb einer normativ integrierten Sozialordnung, sondern beschränkte sich auf die Korrektur von Marktergebnissen, d. h. materielles Recht beließ weitestgehend die Selbstorganisationsfähigkeit des ökonomischen Subsystems. Preuß (1989b) hat darauf hingewiesen, daß distributives Recht genauso wie allokatives Recht funktioniere; ein Unterschied bestehe nur mit dem Telos sozialer Gerechtigkeit, auf den sich distributives Recht fokussierte. Die funktionale Ähnlichkeit zwischen allokativer und distributiver Rationalität des Rechts bedingt aber, daß die Gesetzgebung der permanenten Modernisierung bedarf, um sozialem Wandel folgen zu können. Da die Steuerungsmedien Macht und Geld unabhängig vom kulturellen Kontext funktionierten, seien sie normativen Anforderungen nicht zugänglich. Sie produzierten keine gesellschaftliche Solidarität. 
Auch der Sozialstaat halte am Modell des (wachsenden) Marktes fest, und indem er dies tue und dabei auf das Medium der Solidarität verzichte, müsse er sich auch Krisen als Steuerungsdefizite zuschreiben lassen. Dies berechtige jedoch nicht zu der Annahme, daß das Recht selber als Steuerungsmedium unbrauchbar sei.

In normativer Hinsicht bleibt das materielle Recht des Sozialstaates nur von formalrechtlichen Freiheitsrechten abgeleitet.

Ob es sich um den aktiven Interventions- oder den ironischen Supervisionsstaat handeln soll, was ihm an Fähigkeiten zur sozialen Steuerung zugesprochen wird, scheint den in ihre systemische Abhängigkeiten verstrickten einzelnen an privater Autonomie genommen werden zu müssen. Aus dieser Sicht besteht zwischen privaten und staatlichen Handlungssubjekten ein Nullsummenspiel: der Kompetenzzuwachs der einen bedeutet einen Kompetenzverlust der anderen. (Habermas, 1992, 490)

Habermas hält die Rückkehr zum liberalen Rechtsparadigma des Formalrechts für ebenso unmöglich wie die legitime Fortführung des Sozialstaatsmodells unter den gegebenen normativen Prämissen - nämlich der weiteren Materialisierung des Rechts, die sich nur durch die Kritik am Formalrecht begründet. Legitimes (sozialstaatliches) Recht reproduziert sich dagegen

nur in Formen eines rechtsstaatlich regulierten Machtkreislaufs, der sich aus den Kommunikationen einer nichtvermachteten, über zivilgesellschaftliche Institutionen in den privaten Kernbereich der Lebenswelt verwurzelten politischen Öffentlichkeit speist. Mit dieser Konzeption der Gesellschaft verschiebt sich die Bürde der normativen Erwartungen überhaupt von der Ebene der Eigenschaften, Kompetenzen und Handlungsspielräume von Aktoren auf die Ebene der Kommunikationsformen, in denen sich das Zusammenspiel der informellen und der nichtinstitutionalisierten Meinungs- und Willensbildung vollzieht. (Habermas, 1992, 492)

Damit ist ein prozedurales Rechtsverständnis angedeutet, daß Habermas im folgenden präzisiert.

Ein prozedurales Rechtsparadigma kann nicht mit nur einer Rechtsform identifiziert werden, wie dies bei jenen systemtheoretischen Theorien geschieht, die auf reflexives Recht abgestellt haben. "Die Wahl der jeweiligen Rechtsform muß [...] auf den ursprünglichen Sinn des Systems der Rechte bezogen bleiben - nämlich die private und öffentliche Autonomie der Bürger dadurch uno actu zu sichern, daß jeder Rechtsakt zugleich als Beitrag zur politisch-autonomen Ausgestaltung der Grundrechte, also als Element eines auf Dauer gestellten verfassungsgebenden Prozesses verstanden werden kann." (Habermas, 1992, 494)

Dazu ist zunächst einmal neben der Rechtsanwendungsgleichheit auch die extensivere Rechtsinhaltsgleichheit zu gewährleisten. Habermas bietet zwar keine Grundrechtstheorie an, verweist aber dennoch auf den relativen Charakter sozialstaatlicher Leistungen und des Schutzes vor ökologischen und wissenschaftlich-technischen Gefahren zu den Grundrechten. Die Gewährleistung von individuellen Leistungen und von ökologischer Sicherheit ist aber gleichzeitig notwendige Bedingung der politischen Willensbildung. Sozialstaatlichen Leistungsrechten und ökologischen Schutzrechten kommt damit der Zweck zu, einen autonomen Bürgerstatus zu sichern. Doch schränkt Habermas ein, daß nicht alle Grundrecht derart auf den demokratischen Prozeß hin funktionalisiert werden dürften. 
Ferner bedarf ein prozedurales Rechtsparadigma nicht nur der Gleichverteilung von Rechten, sondern zuerst einmal der gegenseitigen Anerkennung aller als freie und gleiche Mitglieder einer Rechtsgemeinschaft. Dies soll den Fehler des liberalen Rechtsparadigmas vermeiden, Rechte an Güter zu assimilieren, welche dann (gleich)verteilt werden. Individuelle staatsbürgerliche Selbstbestimmung beruht auf der Ausübung von Rechten, die sich aus legitim erzeugten Normen herleiten. Rechte bedürfen dieser faktischen, aktiven Ausübung, die im Gegensatz zum passiven Besitzen von Rechten steht. Die Gleichverteilung von Rechten bleibt an die öffentliche Autonomie im Zuge der staatsbürgerlichen Praxis gebunden. Demnach ist die Verwirklichung von Grundrechten ein Prozeß, "der die private Autonomie gleichberechtigter Bürger nur im Gleichschritt mit der Aktivierung ihrer staatsbürgerlichen Autonomie sichert" (Habermas, 1992, 515, kursiv i. O.).

\subsubsection{Das Präventionsparadigma als Umweltstaat}

Der Begriff des ökologischen Rechtsstaates oder auch des Umweltstaates wird von verschiedenen Autoren verwandt (Kloepfer, 1989; Baumeister, 1994; Wolf, 1996; Steinberg, 1998). Auch die bundesrepublikanische Debatte um die Normierung der Staatszielbestimmung Umweltschutz hat zu dieser Begriffsbildung beigetragen. Beide Begriffe werden in der Diskussion synonym benutzt, ohne daß rechtstheoretisch an Habermas' Paradigmathese angeschlossen würde. Auch das prozedurale Rechtsverständnis ist in der umweltrechtlichen Debatte präsent; der explizite, systematische Bezug zur Rechtstheorie Habermas' wurde aber bisher auch noch nicht hergestellt.

Dem prozeduralen Rechtsverständnis zufolge kann der Gesetzgeber frei auf die Rechtsform zurückgreifen, sofern er dabei nicht die Eigenfunktion des Rechts zerstört. Da dies die Konstitutionsbedingungen von Recht und politischer Macht unterminieren würde, muß die mit dem freien Rückgriff auf Rechtsformen verbundene Vorstellung medialer Steuerung immer an die Interpretation bestehender Grundrechtsinstitutionen rückgebunden bleiben. Dies gilt auch für präventive Staatstätigkeit.

Präventive Staatstätigkeit ist politisch riskant, denn sie setzt nicht bei öffentlich leicht wahrnehmbaren Problemen an, sondern dient der Vermeidung schwer erkennbarer, nicht erwünschter Entwicklungen und Ereignisse. Indem sie Folgen des Handelns zu antizipieren beabsichtigt, ist sie kognitiv voraussetzungsvoll. Sie greift auf natur- und sozialwissenschaftliche Theorien über die zu erwartenden Folgen zurück. Sie agiert im Bereich von Risiko und Unsicherheit. Präventive Staatstätigkeit ist prospektiv und flächendeckend. Treffen prognostizierte Folgen nicht ein, so leidet die Autorität der politischen und administrativen Akteure. Sie kann somit sozial risikoreich sein, wie D. Grimm festgestellt hat:

Eine solche zukunftsgerichtete und komplexe Aktivität läßt sich aber gedanklich nicht vollständig vorwegnehmen und daher auch nur begrenzt in generelle und abstrakte Normen einfangen. In der Regel müssen sich Präventionsnormen deswegen auf die Vorgabe von Zielen und die Aufreihung von Gesichtspunkten beschränken, die bei der Zielverfolgung vorrangig berücksichtigt werden sollen. Das Handlungsprogramm ist dann aber nur zum kleineren Teil 
Produkt des demokratischen Prozesses. Die handelnde Verwaltung muß es vielmehr von Situation zu Situation vervollständigen oder korrigieren. Sie programmiert sich auf diese Weise weitgehend selbst, ohne dabei spezifische normative Techniken zu verwenden. (Grimm, 1986, 39 f; ähnlich Wahl, Appel, 1995, 58 ff)

Historisch hat der Gedanke der Prävention mit der Etablierung des Sozialstaates Einzug in die Staatstheorie gehalten. Dabei konzentrierte sich der Sozialstaat in der frühen Phase auf die Abfederung der Kontingenzen der individuellen Erwerbsbiographie; später trat die Bestandssicherung des ökonomischen Systems mit auf den Plan. Die sozialstaatliche Entwicklung der Daseinsvorsorge ging einher mit einem äußerst dynamischen Expansion des industriellen Metabolismus, der die Lebenswelt technisch und ökologisch zunehmend riskant werden läßt. Diese Prozesse sind nicht abgeschlossen, sondern haben im Zuge der Globalisierung noch an Dynamik und Schärfe zugenommen. Prävention hat sich jedoch bisher überwiegend auf die klassische Realprävention im Bereich der technischen Sicherheit beschränkt (Grimm, 1986, ). Sie ist dabei auf die Risikoabwehr fixiert geblieben und erhielt erst über das Vorsorgeprinzip allmählich eine erste ressourcenbezogene Ausprägung. Nachhaltigkeit kann aber nur auf dem vorsorgenden Niveau eines präventiven Stoffstrommanagements gelingen.

Hinsichtlich von 'Prävention' ist darauf hingewiesen worden, daß Grundrechte nicht mehr nur als subjektive Abwehrrechte gegen den Staat verstanden werden können, sondern auch als Abwehrrechte gegen Eingriffe Dritter Geltung beanspruchen (ebd. 48; dagegen Steinberg, 1998, 77 ff). Danach ist der Staat nicht nur verpflichtet, selbst Grundrechte zu beachten, sondern darüber hinaus auch die grundrechtlich garantierten Freiheiten vor Beeinträchtigung durch Dritte aktiv zu schützen. ${ }^{138}$ Grimm nennt drei Bereiche der Freiheitsgefährdung und sieht parallel dazu folgende Lösungen: 1. Der wissenschaftlich-technische Bereich erfordere gesetzliche Regelungen, 2. die Privatautonomie müsse material gebunden werden und 3. der Freiheitsschutz müsse dort vorverlagert werden, wo strafrechtliche Sanktionen und zivilrechtlicher Schadensersatz keine angemessene Wiedergutmachung versprächen (Grimm, 1986, 48 f). Wegen der möglichen Freiheitsgefährdung ist aber auch festzustellen, daß die Gesetzgebung technischem Wandel wie ökologischen Schäden immer nur folgt. Beide Bereiche erfordern die häufige Novellierung der Gesetze. Dem schließt sich dann das Problem der verwaltungsgerichtlichen Kontrolle an. ${ }^{139}$ Dabei besteht für das Rechtssystem insgesamt noch die Gefahr, daß Gesetze als Mittel der Zielverwirklichung angesehen werden, die nicht mehr den Schutz durch Rechte sicherstellen, sondern sich unmittelbar auf Rechtsgüter beziehen, die (kontingent) mit bestimmten Rechten verbunden sind.

E. Denninger hat in diesem Zusammenhang von einem 'Verfall der Rechtssicherheit' gesprochen, den er sowohl im Bereich der Rechtserzeugung als auch in der Rechtsanwendung fortschreiten sieht

138 Ohne auf die damit verbundenen Fragen der Grundrechtsdogmatik eingehen zu können: Diese Auffassung ist unter Juristen umstritten; sie hat aber durch den dynamischen Grundrechtschutz in der Rechtsprechung das BVerfG Bestätigung erfahren. Vgl. zu den entsprechenden Positionen der Grundrechtsdogmatik; Steinberg, 1998, 116 ff.

139 Grundrechtlich die Verhältnismäßigkeitsprüfung zwischen dem geschützten und verkürzten Grundrecht und die Abwägung der gesetzlichen Grundlage der Prävention gegen die vermeintliche Grundrechtsbeschränkung. 
(Denninger, 1988). Dieser Prozeß werde besonders durch einen unmittelbaren Rechtsgüterschutz hervorgerufen, den u. a. die Normenkontrolle des Bundesverfassungsgerichts fördere. Dies führe tendenziell zu einem am Einzelfall orientierten kasualistischen Gerechtigkeitsdenken, das über ein generalisierendes Rechtssicherheitsdenken prävaliere. Mit der Aufgabe aber, einzelne Rechtsgüter zu schützen, werde das politisch-rechtliche System privilegiert. Dies könnte zu einer politisch vernetzten Verwaltung von kollektiven Gütern durch Legislative, Exekutive und Judikative führen (so auch Günther, 1990, 64). Nicht zuletzt einer solchen Gefahr stellt Denninger einen Maßstabskatalog des Präventionsstaats entgegen, der neben Daseinsvorsorge, Rechtssicherheit und sozialer Gerechtigkeit auch Risikovorsorge umfaßt (Denninger, 1988, 14 f). Auch D. Grimm hat verfassungsrechtliche Schwächen bei der Prävention beanstandet, "die sich aus der begrenzten gesetzlichen Steuerbarkeit präventiver Staatstätigkeiten ergeben." (Grimm, 1986, 52) Die verfassungsrechtlichen Strukturprinzipien des Rechtsstaats und der Demokratie sind auf das Medium Recht angewiesen, doch dieses kann Verwaltungshandeln nicht mit einer dynamischen Blankettverweisung zur Verwirklichung eines unbestimmten Rechtsbegriffes wie Prävention ausstatten.

Für den umweltrechtlich spezifizierten Präventionsstaat hat das Vorsorgeprinzip besondere Bedeutung erlangt. Der Begriff der Vorsorge geht nicht auf den Begriff der Daseinsvorsorge zurück, sondern ist eine Weiterführung des polizeirechtlichen Begriffs der Gefahrenvorsorge. Er hat im Umweltschutz, aber auch auf anderen Rechtsgebieten, seine spezifischen Ausprägungen erfahren. Vorsorge liegt der eigentlichen Gefährdungssituation voraus. Die Gefahrenabwehr ist, wie dargestellt, deshalb rechtlich geboten, weil sie sich auf rechtlich geschützte Güter bezieht. Demgegenüber ist Vorsorge rechtlich unbestimmt, da die Vorsorgesituation durch prognostische Ungewißheit gekennzeichnet ist: Ein konkreter Schaden ist noch nicht eingetreten, sondern nur prognostiziert. Da in der lebensweltlichen Situation die Übergänge von Risiken (zu Unsicherheiten) fließend sind, handelt es sich bei der Unterscheidung zwischen Gefahrenabwehr und Gefahrenvorsorge um eine normative Wertung des Rechtssystems (vgl. Schmidt, 1994, 753; Rehbinder, 1988, 132). Rechtskonservative Versuche, den Vorsorgeanlaß auf einen konkreten, wissenschaftlich begründeten Gefahrenverdacht $\mathrm{zu}$ beschränken und Vorsorge rigide in Proportionalität zum prognostizierten Risiko zu fixieren (vgl. Ossenbühl, 1986), ignorieren die Ergebnisse der Risikoforschung. Trotz derartiger sozialmächtiger Interpretationen des Vorsorgeprinzips besteht seit den 70er Jahren ein politischer Konsens über die prinzipielle Notwendigkeit eines vorsorgenden Umweltschutzes (Jänicke, 1988), der auch progressive Interpretationen befördert hat.

Als Prinzip des Umweltrechts tritt das Vorsorgeprinzip E. Rehbinder zufolge in zwei Formen auf: "als rechtsstaatförmiges Prinzip und als Strukturprinzip. Als rechtssatzförmiges Prinzip ist das Vorsorgeprinzip zu einem unmittelbar anwendbaren Maßstab verdichtet und hat die Funktion einer Norm (Genehmigungsvoraussetzung, Eingriffsermächtigung, Planungsleitlinie, Ermächtigung zum Erlaß von Rechtsverordnungen und Verwaltungsvorschriften). In dieser Form findet es sich, wenngleich in Recht differenzierter Art und keineswegs flächendeckend, in einer ganzen Reihe 
wichtiger Umweltgesetze" (Rehbinder, 1988, 130). Es bezeichnet dabei Maßnahmen, die im Vorfeld der Gefahrenabwehr ergriffen werden und etabliert eine gefahrenenabhängige Politik.

Im Gegensatz zu seinem rechtsstaatförmigen Prinzipiencharakter ist das Vorsorgeprinzip als Strukturprinzip "ein Leitgedanke allgemeiner Art, der bestimmten Regelungen zugrunde liegt und diese legitimiert, aber darüber hinaus nicht direkt anwendbar ist." (Rehbinder, 1988, 130) Die betreffenden Regelungen (z.B. Vorschriften, die eine Berücksichtigung des Umweltschutzes in der Planung gebieten, die Umweltverträglichkeitsprüfung; Anmelde- und Prüfverfahren für Chemikalien) dienen der Vorsorge; bei der Anwendung spielt das Vorsorgeprinzip dann aber keine direkte Rolle. ${ }^{140}$ Anders wäre dies nach Rehbinder nur, wenn das Vorsorgeprinzip noch in einer dritten Form anerkannt werden würde, nämlich als "allgemeines Rechtsprinzip, das über den aus den gesetzlichen Regelungen unmittelbar ableitbaren oder in den Regelungen festgeschriebenen Regelungs- oder Anwendungsbereich hinaus verallgemeinert werden kann und die Rechtsanwendung und Rechtsfortbildung im Umweltrecht allgemein zu steuern vermag" (ebd.).

Erste Ausprägung hat das Vorsorgeprinzip nach überwiegender Auffassung im Atomrecht von 1959 erhalten, wo es angesichts der neuen Rolle des Staates als Förderer einer Großtechnologie erstmals über die klassische Gefahrenabwehr hinauswies. ${ }^{141}$ Es findet sich heute u.a. im Bundesimmissionsschutzgesetzt wieder, wo es Risiken unterhalb der Gefahrenschwelle erfassen soll, d. h. sich allein auf eine 'Risikobesorgnis' gegenüber bisher noch unbekannten schädlichen Wirkungen bekannter Stoffe. Eingang hat das Vorsorgeprinzip ferner in das Wasserhaushaltsgesetz und das Abfallrecht sowie in das Kreislaufwirtschaftsgesetz (WHG §§ 1a Abs. 1, 6 u. 7a; KrW/AbfG §§ 4 Abs. 1 u. 22 ff) gefunden, ohne dort allerdings explizit Erwähnung zu finden.

Das Vorsorgeprinzip wird auch im Sinne einer Ressourcenvorsorge ausgelegt. Nach Kloepfer wird mit dem Vorsorgeprinzip in struktureller Hinsicht der Gedanke ausgesprochen, durch die Vermeidung von Umweltbelastungen an der Outputseite des Produktionsprozesses schrittweise die Umweltrisiken durch Stoffeinträge zu minimieren (Kloepfer, 1998, 168). Es wird nicht mehr normativ zwischen Struktur- und Niveausteuerung der Wirtschaft unterschieden, sondern kognitiv auf die Gewißheit einer konstanten Materialbilanz bezug genommen. Diese Outputorientierung ist als 'ökologisches Generationenverhältnis' zu interpretieren. Für ein solches strukturelles Verständnis des Vorsorgeprinzips finden sich aber bisher nur Ansätze im BImSchG, im WRMG und AbfG und noch bescheidener im ChemG. ${ }^{142}$ Aber erst in dieser zusammenhängenden Auslegung des Vorsorgeprinzips verweist Vorsorge angemessen auf die Zeitlichkeit und die notwendige Steuerungstiefe von Nachhaltigkeit. Anzumerken ist, daß auch in dieser extensiven Auslegung des Vorsorgeprinzips normative und kognitive Grenzen für den Präventionsstaat bestehen (Wolf, 1996, $71)$.

${ }^{140}$ Vgl. dazu auch: Winter, 1992, 1994.

141 Dagegen hat M. Kloepfer eingewandt, das sich "Vorsorge gegen Schäden", so der Wortlauf von § 7 Abs. 2 Nr. 3 AtomG, ohne weiteres als "Gefahrenabwehr" verstehen lasse; vgl. Kloepfer, 1998, 169.

142 Lediglich als dogmatisches Problem erscheint mit der Freiraum-These des BImSchG die Kollision zwischen Vorsorge und grundrechtlich verbürgtem Eigentumsschutz. 


\subsubsection{Der Umweltstaat als prozedurales Programm}

Als zentrales Problem des (präventiven) Umweltrechts erweist sich die Konditionierbarkeit administrativer Entscheidungsprozesse durch materielle Selektionskriterien. Unter der Bedingung ökologischer Unsicherheit können kaum hinreichend rechtliche Kriterien zur Verfügung gestellt werden. Als Handlungssystem erlaubt das Recht aber alles nicht explizit Verbotene. Fehlende materielle Normen (Verbote, Gebote) führen dazu, daß das Recht Entwicklungspfade freigibt, wobei die Rechtsgenese der technisch-stofflichen Entwicklung dann wieder nachläuft. Dazu erschweren fehlende materielle Normen selbst bei regelmäßig anzutreffenden und deshalb wohl institutionalisierten Interessenkonflikten die Implementation. Prozedurales Recht könnte, so die Erwartung, das Umschlagen materieller Ungewißheit in rechtliche Unbestimmtheit kompensieren und damit zur Effektivierung des umweltpolitischen Vollzugs und der richterlichen Überprüfung beitragen (vgl. Wahl, Appel, 1995, 139).

Prozeduralisierung erscheint vor diesem Hintergrund nur noch als ein 'unerfreulicher Sachverhalt', der einen Vertrauensverlust in die Richtigkeit einer zentral gesatzten Rechtsordnung und ihren materiellen Normen offensichtlich werden läßt. Die normative Kritik richtet sich jedoch nicht allein gegen das Recht, sondern ebenso gegen das politisch-adminstrative System. Denn das Recht ist seinerseits auf die umweltnormsetzende Politik angewiesen, welche ihrerseits vor der politischen Herausforderung steht, unter Unsicherheit entscheiden zu müssen. Dies bedroht den Fortschritt der Umweltpolitik fortwährend, obgleich die ökologische Herausforderung klar darin besteht, ökonomisches Wachstum und Umweltzerstörung zu entkoppeln. Prozedurales Umweltrecht muß hier ansetzen und primär die Rationalität der Prozeduren der Normerzeugung thematisiert. Dabei darf aber eine prozedurale Theorie und Systematik des Umweltrechts die Normendurchsetzung und -kontrolle nicht aus den Augen verlieren.

Ein rationales Umweltrecht kann nur in Verbindung zum ökonomischen System und unter Rückgriff auf ökonomische Instrumente entwickelt werden. In der umweltadministrativen Praxis wird jedoch die wechselseitige, dynamische Abhängigkeit der Steuerungsinstrumente häufig nicht problematisiert: die Koppelung von Rahmenvorgaben und fallspezifischen Umsetzungsinstrumenten intensiviert u.a. die Bürokratisierung und die Zentralisierung, weil die rahmensetzende Ebene ihren Steuerungszugriff nicht an die Vollzugsverwaltung mit deren wachsenden Freiräumen verlieren will und persuasive Instrumente können im kooperativen Staat zu do-ut-des-Geschäften zwischen Behörden und privaten Institutionen umkippen. Kooperatives Staatshandeln ist häufig mit staatlichen Transfers verbunden, welche die Wirkung der Rahmensteuerung zugunsten der einzelfallspezifischen Steuerung reduzieren (vgl. Fürst, Henke, 1988; Fürst, 1990). In der Umweltpolitik scheint sich hier lediglich die alte ordnungspolitische Diskussion über Widersprüche zwischen wachsender Regelungsdichte und marktwirtschaftlicher Freiheit zu wiederholen.

Für den Erfolg systemischer (politisch-administrativer und ökonomischer) Steuerung von Nachhaltigkeit erscheint allerdings nicht nur eine Effektivierung des Rechts, sondern vor allem die 
Entwicklung einer Systematik des ökologischen Rechtsstaats als prozedurales Programm zwingend. Im folgenden wird dazu das Konzept R. Wolfs näher ausgeführt (vgl. Wolf, 1996).

Umwelt ist ein problematisches Rechtsgut. Das moderne Recht beruht auf der Ausdifferenzierung in subjektive Rechte, welche die Freiheit des Bürgers garantieren und durch ihn aktiviert werden, und objektive Rechte, welche der Staat in Gemeinwohlverantwortung realisiert. Doch der Schutz der menschlichen Lebensgrundlagen wird mit dieser Grundstruktur nicht angemessen erfaßt. Im positiven Recht schützen primär objektivrechtliche Verbots- und Gebotsnormen Natur und Umwelt. Diese objektivrechtlichen Rechtssätze bestimmen so die staatlich gesetzte Rechtsordnung des Umweltschutzes. Dies erfolgt jedoch ohne die Autonomieverbürgung subjektiver Rechte, d.h. der Staat kann die Umwelt schützen oder sie der Nutzung durch Dritte oder durch seine eigenen Institutionen (umweltbenutzende Infrastruktur) freigeben. Weil die Umwelt nicht Träger subjektiver Rechte ist, kann sie keinen Individualrechtsschutz in Anspruch nehmen. ${ }^{143}$ Damit lassen sich nicht nur Tier- und Artenschutz schwer thematisieren, sondern auch Kollektivrisiken und -gefährdungen. Ein Problem kollektiver Güter besteht somit auch für das Rechtssystem. Unter dem Gesichtspunkt der Steuerung können weder die Zuschreibung von subjektiven Rechten an Naturentitäten, noch die Moralisierung des Rechts dieses Problem lösen, denn das Recht ist niemals nur Normen-, sondern immer auch Handlungssystem. Allein die Auszeichnung und Rücksichtnahme auf Kollektivgüter der Menschheit durch die jeweilige Gesellschaft konstituiert die Grenze der menschlichen Eingriffe in die Natur. Eröffnete Risiken und erkannte Gefahren von Umwelteingriffen stellen die bestehenden Gesellschaft-Natur-Verhältnisse unter Rechtfertigungsdruck. Kollektivgüterschutz ist die zentrale Herausforderung für das prozedurale Recht. Wolf rechnet natürliche Ressourcen unabhängig von ihrer eigentumsrechtlichen Zuordnung $\mathrm{zu}$ den Kollektivgütern, die einen Regelungsauftrag im Sinne nachhaltiger Nutzung implizieren (Wolf, 1996, 66). Artikel 20a GG gebe diese Zielsetzung der legislativen Agenda vor. Im Paradigma des Umweltstaates bzw. des ökologischen Rechtsstaates kommt damit implizit das Leitbild der Entkoppelung zur Geltung.

Als zentrales, handlungsleitendes Prinzip des Umweltschutzes fungiert in diesem Konzept trotz seiner Lückenhaftigkeit das Vorsorgeprinzip. Seine Lücken bleiben notwendig bestehen, da Risikovorsorge sich nur an der Kontrolle und Minimierung von Risiken versuchen kann, ohne potentielle Gefahren tatsächlich vollständig antizipieren zu können. Wolf verweist auf drei materielle Zentralinstitute des Umweltschutzes: Nutzungsordnung, Eingriffsminimierung und Eingriffsausgleich (Wolf, 1996, 77 ff).

Die Kategorisierung der Umwelt als Kollektivgut macht alle ökologisch relevanten Eingriffe begründungspflichtig. "Die ausschließliche Fassung privater Rechte als individuelle Verfügungsmacht ist für ökologisch relevante Nutzungen nicht mehr haltbar." (Wolf, 1996, 78) Eigentum wird über die Sozialpflichtigkeit hinaus auch in die ökologische Verantwortung genommen. Damit

${ }^{143}$ Wolf läßt damit rechtstheoretisch noch offen, "ob sich das Umweltrecht als Recht von Kollektivgütern im institutionellen Rahmen der Dichotomie von objektiven und subjektiven Rechten entwickeln kann oder ob es einer Entfaltung einer dritten Grundkategorie bedarf." (Wolf, 1996, 66) Bereits ohne weitere Grundkategorie könne die Dichotomie nicht mehr in ein duales Akteursmodell übersetzt werden, sondern muß kollektivgut-spezifisch erweitert werden wie durch Verbandsbeteiligung oder Verbandsklage als objektiv-rechtlicher Beanstandungsklage. 
werden Umweltnutzung, Produktion und Emissionen ordnungsrechtlichen Vermeidungsgeboten und abgabenrechtlichen Vermeidungszwängen zugänglich. Sie beruhen auf nur demokratisch zu bestimmenden Nutzungsordnungen, welche insbesondere den Konflikt zwischen Kollektivgüterschutz und individualrechtlichen Ansprüchen auf die Nutzung natürlicher Ressourcen bewältigen müssen. Es ergibt sich ebenso das vorgelagerte Problem, ob Ressourcen überhaupt genutzt oder Risiken eingegangen werden sollen. Potentiell ökologisch relevante technische Innovation würde damit eine Pflicht zur Gesetzgebung anzeigen. Gesetze müßten in der Folge so gestaltet sein, daß sie Lernprozesse sichern könnten.

Aus der Begründungslast für Umwelteingriffe folge das akzessorische Gebot der Intensitätsminimierung von Belastungsfolgen.

Soweit die Pflicht zur Minimierung der Inanspruchnahme von Umwelt unabhängig von dem Zustand der Umwelt bejaht wird, abstrahiert die systematische Variante des Vorsorgeprinzips von konkreten Risikolagen und konstituieren einen 'gefahrenunabhängigen, gleichmäßigen und generell-abstrakt gebotenen Umweltschutz'. Im Konzept der Eingriffsminimierung liegt daher auch eine implizite Absage an das Modell des Kausalnachweises und des heuristischen Prinzips von Versuch und Irrtum. (Wolf, 1996, 80)

Darüber hinaus dürfe die Generalklausel 'Stand der Technik' kein begrenzendes Kriterium für den Umweltschutz sein; sie unterliege allerdings auch dem Grundsatz der Verhältnismäßigkeit, so daß eine prozedural gefärbte Abwägung Eingang in die Vorsorge finde. Im übrigen werde das Prinzip der Minimierung von Belastungen im Konzept der Umweltabgaben weitergeführt, wobei sich deren Einfluß im wesentlichen auf Stoffströme und die zivilisatorische Nutzung der Umwelt erstreckt. Dieses Konzept könnte weiter in Richtung Vorsorge ausgeweitet werden (vgl. Köck, 1993b), wenn etwa analog zur bergrechtlichen Förderabgabe für Bodenschätze Abgaben auf die Nutzung von Naturgütern oder Material-Input-Steuern erhoben werden würden (vgl. Bonus, 1998).

Gegenüber diesen prozeßorientierten Aspekten setze der Bestandschutz relativ feste Grenzen zum Schutz des vorhandenen Umweltbestandes. Derartige bestandsschutzrechtliche Grenzen bestehen etwa mit den Grenzwerten der TA Luft, auch im Wasserrecht und besonders im Naturschutzrecht. Das Prinzip sei zwar strikt, aber auch statisch und lasse sich deshalb kaum generalisieren. Es diene eher als Notstandsmaßnahme zum Erhalt von Minimalstandards, denn der Vorsorge. Durch die Eingriffsregelung werde der Bestandsschutz zwar in gewisser Weise relativiert, doch sei die Eingriffsregelung effektiver als zivilrechtliche Kompensation durch Schadensersatz, da sie ex-ante ansetzt. Die funktionelle ökologische Kompensationspflicht der Eingriffsregulierung führe das Verursacherprinzip weiter zur Umweltpflichtigkeit des Eigentums. Diese zeige sich "nicht mehr nur in den gesetzlichen Restriktionen seiner Nutzung, sondern zusätzlich in komplementären Leistungspflichten gegenüber dem Naturhaushalt." (Wolf, 1996, 83 f)

In der jüngeren umweltpolitischen und -rechtlicher Literatur ist immer wieder auf den staatlichen Informationsmangel gegenüber den Unternehmen aufmerksam gemacht worden. Umweltpolitik, insbesondere präventive Umweltpolitik, sieht sich nicht zuletzt aufgrund dieses Informationsmangels mit ökonomischen und sozialen Steuerungsrisiken konfrontiert. Deshalb wurden die Unternehmen als Ansatzpunkt prozeduraler Regelungen ausgemacht. Die normativen 
und demokratisch-rechtsstaatlichen Erfordernisse, die unmittelbar mit der asymmetrischen Verteilung von Wissen (über toxische und umweltschädigende Effekte) einhergehen, werden oftmals ignoriert. Tausch von Wissen (so Willke, 1995) wäre rechtlich allenfalls im Bereich der Vorsorge statthaft; mit der Umweltpflichtigkeit des Eigentums wird dieser allerdings insgesamt umweltrechtlich aufgewertet (vgl. Führ, 1996). Umfassende Informationsgewinnung ist letztlich nur durch ausgewogene Beteiligung und durch Offenlegungspflichten sicherzustellen. Dies gilt insbesonders, wenn in den Gremien der (entstehenden) Verhandlungssysteme materiale Vorentscheidungen getroffen werden, welche die Öffentlichkeit des Parlaments (und der Regierung) in der Regel ohne weitere Deliberation passieren. ${ }^{144}$

Indem prozedurales Recht ein zivilgesellschaftliches Assoziationsgeflecht (associative design) konstituieren kann, erlaubt es auch eine Neubestimmung der Aufgabenerfüllung durch die öffentliche Verwaltung. In Teilbereichen, wie bereits im Naturschutzgesetz geschehen, läßt sich die Verwirklichung des Gemeinwohls aus der alleinigen Zuständigkeit der Behörden lösen und der Mitwirkung gesellschaftlicher Träger öffentlicher Belange (im Fall des BNatSchG die Naturschutzverbände) anvertrauen. Überdies kann die Verbandsklage als objektive Beanstandungsklage gegen die Verletzung von objektivrechtlichen Gewährleistungen für Umwelt und Natur als Kollektivgutäquivalent zum Individualrechtsschutz fungieren. "Sie bündelt nicht mehrere Individualrechtspositionen in einem Modus kollektiven Rechtsschutzes, sondern sichert den Schutz von Kollektivgütern durch die Überprüfung der objektiven Rechtmäßigkeit von Verwaltungsentscheidungen. Sie ist die prozeßrechtliche Verlängerung der staatsrechtlichen Funktion der Verbandsbeteiligung, in der allgemeine öffentliche Interessen subjektiviert sind." (Wolf, 1996, 89)

\subsubsection{Vorsorgender Umweltstaat und Stoffstrommanagement}

Ein nachhaltiger Umweltstaat steht vor der Aufgabe, die anthropogenen Stoffströme in ihrer 1. Quantität, 2. Qualität des Stoffverbrauchs sowie der Stofffreisetzung und Stoffresorption zu steuern (vgl. Führ, 1997, 160). Im Sinne einer regulativen Idee von Nachhaltigkeit muß er dabei 3. Unsicherheit in allen relevanten Rechtsbereichen berücksichtigen. In sachlicher und zeitlicher Hinsicht bedeutet die erwähnte Perspektivausweitung des Stoffstromansatzes eine Verschiebung von der Outputkontrolle zur Inputsteuerung. Dies führt dazu, daß rechtlich konstituierte Kausalzusammenhänge aufgrund von ökologischer Unsicherheit brüchig werden. Der nachhaltigkeitsorientierte Stoffstromansatz zielt primär auf eine Stoffmengensteuerung. Diese liegt jenseits der unmittelbaren Gefahrenabwehr und häufig auch noch jenseits der Risikovorsorge. Die Problematik wird noch dadurch verstärkt, daß Nachhaltigkeit bis in jüngster Zeit unzureichend konzeptionalisiert war.

144 Die rechtlichen Aspekte (z.B. Drittschutz) sind vom politisch-administrativen System zu wahren; die demokratietheoretischen von der rechtssoziologischen Theorie. 
Bis auf wenige Ausnahmen ließen sich bisher kaum konkrete Ansätze zur Verwirklichung der Idee eines umfassenden Stoffstromrechts in der Rechtswissenschaft finden. Grund dafür ist die mit dem Stoffstromansatz notwendige sachliche, zeitliche und räumliche Perspektivausweitung. So hat die von der Enquete-Kommission des Deutschen Bundestages in Auftrag gegebene Studie zum stoffbezogenen Umweltrecht Mängel und Lücken im Bereich 1. des Schadstoffrechts, 2. der Ressourcenschonung, 3. des Stoff- bzw. Chemikalienrechts und 4. des anlagen- bzw. medienbezogenen Umweltrechts konstatiert (BT, 1994, 646 f):

$\underline{\operatorname{ad} 1 .}$

- starke Betonung von technik- und medienbezogenen Aspekten, Vernachlässigung stoffbezogener Aspekte

- Mangel an Koordination und Integration im Stoffrecht

- Lücke im Bodenschutz

- Betonung auf Änderung der Freisetzung von Stoffen, keine Strategie im Hinblick auf geringeren Einsatz von Stoffen (außer Wasch- und Reinigungsmittelgesetz und Chemikaliengesetz)

- fehlende Strategie gegen die indirekte Freisetzung gefährlicher Stoffe über Produkte

- Mangel an genereller Stoffbeobachtung, fehlende Transparenz der Stoffströme (außer etwa beim Pflanzenschutzgesetz)

$\underline{\operatorname{ad} 2 .}$

- Ressourcenschutz besteht nur ansatzweise im Berg-, Forst- und Wasserrecht

- ansatzweise Berücksichtigung des Stoffeinsatzes bei der Produktion

- bis auf wenige Ausnahmen keine Berücksichtigung von Produktdesign und Produktverwendung

- fehlende Transparenz der Stoffströme

$\underline{\operatorname{ad} 3 .}$

- Chemikaliengesetz soll Information über potentielle Gesundheits- und Umweltgefahren neuer Chemikalien bringen, um regulative Maßnahmen zu ermöglichen. doch ein präventives Verbot von Stoffen ist trotz der herabgesenkten Eingriffsschwelle nach der Novellierung nur in Ausnahmefällen möglich

- Übergewicht der Wirkungs- gegenüber den Expositionsinformationen und der Verzicht auf die Berücksichtigung des angestrebten Nutzens schließen präventive Maßnahmen in der Regel aus

- die Ungleichbehandlung von alten und neuen Stoffen ist ökologisch und ökonomisch fragwürdig

$\underline{\operatorname{ad} 4 .}$

- die an Umweltqualitätszielen orientierte Festlegung von Immissionsgrenzwerten ist prinzipiell ein adäquater Ansatz zur Abwehr von Gesundheitsgefahren 
- die zum Schutz ökologischer Elemente und Funktionen gesetzten Immissionsgrenzwerte sind unzureichend und können daher das Steuerungsdefizit der emissionsorientierten Strategie nicht beheben

Einschlägige Vorgaben für die Behandlung von Stoffströmen finden sich in anlagenbezogenen und in stoffbezogenen Regelungen (vgl. zum folgenden Führ, 1997, 164 ff). So schreibt das Bundesimmissionsschutzgesetz die Vermeidung von Reststoffen vor, die durchbrochen wird, wenn eine technische Beseitigung nicht möglich oder unzumutbar ist. Auch werden in der Praxis Vermeidung und Verwertung als gleichrangige Pflichten angesehen. Der Immissionsschutz von Luft und Wasser ist ansonsten weitgehend auf die nachgeschaltete Begrenzungen der Emissionen gerichtet. Nach dem Urteil von Führ verfolgt das Recht zwar einen medienübergreifenden Ansatz bei der Beurteilung der Stoffverluste von Industrieanlagen. "Defizite ergeben sich jedoch zum einen daraus, daß die Produkte (und Kuppelprodukte bzw. 'Wertstoffe'), die die Anlagen verlassen, nicht berücksichtigt werden. Außerdem stößt der Vollzug der Vorschriften auf eine Vielzahl struktureller Hemmnisse." (Führ, 1997, 165)

Stoffbezogene rechtliche Regelungen finden sich primär im Chemikaliengesetz und im Kreislaufwirtschafts- und Abfallgesetz. Zweck des 1990 novellierten Chemikaliengesetzes ist es, den Menschen und die Umwelt vor schädlichen Einwirkungen gefährlicher Stoffe und Zubereitungen zu schützen, sie erkennbar zu machen, abzuwenden und ihrem Entstehen vorzubeugen (§ 1 ChemG). Gesundheitsgefährdende Stoffe ( $\S 3 \mathrm{a}$ ChemG) werden reguliert. Bezüglich stoff- und produktbezogener Grundpflichten legt das ChemG jedoch jenen, in deren Handlungsbereich die Zielverwirklichung fällt, keine rechtsverbindlichen Pflichten auf. Allenfalls in Form einer Obliegenheit könnte das ChemG trotz seines appellativen Charakters noch rechtliche Steuerungswirkung haben. Neben den Pflichten, Gefahren abzuwenden und Vorsorge zu treffen, schlägt Führ (1997, 172) zur Schließung chemikalienrechtlicher Lücken vor, über die Wirkung eines Stoffes (oder Erzeugnisses), seine Gewinnungsorte und -verfahren, Anwendungsbereiche, Anwendungsmengen und Verwertungs- und Beseitigungsmöglichkeiten die Erhebung und Mitteilung von Daten gesetzlich festzuschreiben.

Demgegenüber zielt das Kreislaufwirtschafts- und Abfallgesetz (KrW-/AbfG) auf die Verringerung von Massenstoffe. Im Mittelpunkt des 1994 verabschiedeten Gesetzes steht die Verantwortung des Herstellers für sein Produkt (§ 22 Abs. 1, S. 1). Das Gesetz reklamiert den Gedanken der Kreislaufwirtschaft, nach der lineare Stoffflüsse im Sinne der Ressourcenschonung zunächst zu vermeiden und dann zu recyceln sind. Dies findet in dem Vorrang der Verwertung vor der Beseitigung Ausdruck und gilt unabhängig davon, ob die Beseitigung nicht auch schadlos erfolgen könnte. Lediglich 'technische Unmöglichkeit' und 'Unzumutbarkeit' (aufgrund zu hoher Kosten) begründen hier wiederum Ausnahmen von der Beseitigungspflicht, die aber ihrerseits wieder durch eine größere Umweltverträglichkeit der Beseitigung (unter qualitativen und quantitativen Emissionsaspekten) durchbrochen werden kann. Das Gesetz konkretisiert Abfallverwertung durch Recyceln nicht über eine allgemeine Verpflichtung hinaus, sondern überläßt dies (umfassenden) Rechtsverordnungen. Das $\mathrm{KrW}-/ \mathrm{AbfG}$ vermengt private und 
öffentliche Steuerungsformen und versucht, über das traditionelle Ordnungsrecht hinauszugehen. Es nimmt nicht mehr Bezug auf das Modell der Gefahrenabwehr und operiert auch nicht mit Ge- oder Verboten, sondern regt durch öffentliche Zwänge die Schaffung eines privaten, selbstorganisierten Sammelsystems an. Handel und Industrie können bei Verkaufsverpackungen von ihrer individuellen Rücknahmepflicht freigestellt werden, wenn sie sich einem flächendeckenden und haushaltsnahen System zur Erfassung, Sortierung und Verwertung von gebrauchten Verkaufsverpackungen anschließen. Die Verordnung über die Vermeidung und Verwertung von Verpackungsabfällen (VerpackV) vom 12. Juni 1991 wurde im Sommer 1998 novelliert. Die Novelle schreibt Quoten für die Verwertung gebrauchter Verkaufsverpackungen, gestaffelt nach Materialarten, vor. In jährlich zu erbringenden Leistungsnachweisen, den so genannten Mengenstromnachweisen, muß das Duale System den Landesumweltministerien die ordnungsgemäße Erfassung, Sortierung und Verwertung der gebrauchten Verkaufsverpackungen belegen. ${ }^{145}$

Ladeur (1998) hat den stoffbezogenen Ansatz des KrW-/AbfG grundsätzlich kritisiert, weil er insgesamt die Ablösung eines erfahrungsbasierten Ordnungsrechts (mit unbestimmten Rechtsbegriffen und Vollzugsdefiziten) durch Verordnungen vorsehe. Er kritisiert die Festlegung auf ein Kreislaufmodell im Gesetz und moniert zu Recht die Bildung von Durchschnittspreisen für Abfälle, was die Produzenten problematischer Abfälle begünstige (ebd., 295). Gleichzeitig aber spricht sich Ladeur grundsätzlich gegen einen stofflichen Ansatz im Abfallrecht und im Umweltrecht aus (vgl. Ladeur, 1997; ders., 1998). Er befürchtet u.a., daß Ökobilanzen zeitlich entfernte Folgeverantwortung ohne Handlungsbezug etablieren würden (Ladeur, 1998, 302 f) - gemeint ist wohl eine ordnungspolitisch nicht konforme Folgeverantwortung - und daß stoffbezogene Kooperation prinzipiell mißlingen müßten, wenn Win-win-Strategien nicht durch kooperatives Verwaltungshandeln - und nur dieses beobachtet Ladeur - zu erschließen seien. ${ }^{146}$ Diese grundsätzliche Kritik an der Genese eines problembehafteten 'Stoffstromrechts' erweist sich aber ihrerseits gegenüber der ökonomischen Nachhaltigkeitsdebatte als wenig lernfähig, insofern sie mehr noch als die Probleme des Rechtssystems jene des Wirtschaftssystems herausstellt, ohne die Gefahr des Staatsversagens (Vollzugsdefizit) überhaupt zu thematisieren. 'Problematisch' ist Kooperation im Konzept eines Stoffstromrechts fast zwangsläufig, weil Eigentumsrechte (an Natur) nicht ausgeweitet, sondern durch die demokratische Willensbildung eingeschränkt werden sollen. Kooperation entlang von

145 Daneben besteht seit dem 20. Dezember 1994 die Europäische Verpackungsrichtlinie. Ihr Ziel ist es, bis zum Jahre 2001 europaweit Verpackungsabfälle zu reduzieren. Die Richtlinie schreibt für die Verwertung gebrauchter Verpackungen Zielmarken von mindestens 50 und maximal 65 Prozent vor. (Die Höchstgrenze soll das wirtschaftspolitische Ziel haben, Verwerfungen des Binnenmarktes zu verhindern.) Zur Ausgestaltung der Systeme werden sonst keine konkreten Vorgaben gemacht. Eine dem deutschen Recht vergleichbare Abfallhierarchie besteht nicht: Vermeidung wird nicht angestrebt und Verwertung kann sowohl energetisch - durch Verbrennen mit Energierückgewinnung - als auch stofflich erfolgen. Auf die stoffliche Verwertung muß lediglich ein Anteil von mindestens 25 Prozent und maximal 45 Prozent des gesamten Verpackungsmaterials entfallen.

${ }^{146}$ Er wirft dem Konzept der Dematerialisierung und den neueren Ansätzen der ökologischen Wirtschaft vor, "völlig diffus" zu bleiben und "jeden Bezug auf die Entwicklungsbedingungen der Technologie" vermissen zu lassen (Ladeur, 1998, 311, Fn 91). Er verkennt mit seiner polemischen und falschen Kritik die bestehende Verknüpfungen von Dematerialisierungsansätzen und Wachstumstheorien mit endogen Technologiepfaden; vgl. Bleischwitz, 1998, 138 ff; ders., 2002, 6 f. 
Stoffströmen ist aber als wechselseitige Bedingtheit von Mikro- und Makroprozessen zu verstehen, die auf beiden Ebenen dem ökologischen Leitbild einer Dematerialisierung folgt (vgl. Bleischwitz, 2002, 15 ff). Das derartige Makroprozesse allein durch das administrative System - wie Ladeur vorschlägt - auf einen Nachhaltigkeitspfad gelotst werden könnten, erscheint nicht nur zweifelhaft, sondern wäre unter demokratietheoretischen Aspekten auch falsch.

Das Leitbild eines kooperativen Stoffstrommanagements lag der EG-Öko-Audit-Verordnung von 1993 zugrunde, welche das betriebsinterne Monitoring von Stoffströmen (Environmental Management and Audit Scheme, kurz: EMAS) als Bestandteil der EU-Umweltpolitik einführte. Das EMAS soll auf der Mikroebene den betrieblichen Umweltschutz verbessern, den Unternehmen Kostensenkungsmöglichkeiten aufzeigen und die Rechtssicherheit des Umweltschutzes erhöhen. ${ }^{147}$ Es soll ein proaktives Verhalten von Unternehmen fördern (vgl. dazu Führ, 1994) und unterwirft das Monitoring spezifischen Anforderungen (stoffliche Kenngrößen, Öffentlichkeit etc.). Das EMAS ist ein freiwilliges Verfahren, das kurz nach seinem Entstehen durch den privatwirtschaftlichen Umweltmanagementstandard (ISO-Norm 14001) Konkurrenz bekam (vgl. dazu Bültmann, Wätzold, 1999). Die vorgesehene Revision der Öko-Audit-Verordnung durch die EU zielte demzufolge darauf, die Attraktivität des EMAS gegenüber der ISO-Norm zu erhöhen und deren Kompatibilität zu fördern (ebd., 36 f). Es ist zu erwarten, daß das Öko-Audit das innerbetriebliche Informationsniveau über (entfernte) Umweltauswirkungen des Unternehmens deutlich erhöhen wird (vgl. Führ, 1996, 244 ff). Darüber hinaus sind zur Sicherung der Eigenverantwortung der Unternehmen ein zentrales Stoffstromregister und der unmittelbare Zugang zu umweltrelevanten Daten der Unternehmen notwendig (Führ, 1997, 173 ff). Die Informationspflicht muß auch Betriebs- und Geschäftsgeheimnisse umfassen, wobei dem eine Geheimhaltungspflicht der Behörden korrespondieren muß (Wolf, 1996, 85).

Das Monitoring des Stoffstroms erfordert zusätzlich zu den proaktiven Beiträgen der Unternehmen zivilgesellschaftliche Kooperationen zur Informationsverarbeitung. Dies betrifft die Zusammenarbeit von Herstellern, Ärzten, Sozialversicherungen, Behörden, Verbraucherverbänden und Öffentlichkeit (Führ, 1997, 175). Kooperation kann nicht auf dualistisch-korporatistische Verhandlungsgremien beschränkt werden (vgl. Ladeur, 1994, 322 ff), sondern muß die faktische Pluralität der Zivilgesellschaft widerspiegeln und sich in praktischen Diskursen über die Gestaltung fairer Verfahren (faire Datenverkehrsordnung, informationelles Gleichgewicht) verständigen (vgl. BT, 1994, 652, 666 ff). Es geht hierbei um die systematische und effektive Erfassung negativer Effekte von Stoffen und Produkten. Der Stoffstromansatz macht hier die Hinwendung von der direkten, ordnungsrechtlichen zur indirekten, ökonomischen und informatorischen Verhaltenssteuerung notwendig.

147 Die Einführung des EMAS hat u.a. die Absicht, umweltrechtliche Wissenslücken in Unternehmen zu schließen und dadurch die Rechtsbefolgung zu erhöhen. Dies kann natürlich die Außenbeziehung mit den Umwelt- und Aufsichtsbehörden verbessern (vgl. Becke, 1999, 308). Von administrativer Seite würde die EMAS-Teilnahme jedoch mit zweifelhaften Erlassen honoriert, die immissions- und abfallrechtliche Betriebsprüfungen für auditierte Betriebe auf besondere Anlässe beschränkten; vgl. Lübbe-Wolff, 1998c. 
Auf der Makroebene sind Abgaben und Steuern angesiedelt, die entsprechende Mikroprozesse des betrieblichen Stoffstrommanagements in First-Mover-Vorteile verwandeln. Die mit Ökoabgaben verbundene Steuerungstiefe läßt sich nur durch Ökoeffizienzanalysen prognostizieren. Während der ordnungsrechtliche Bereich der Gefahrenabwehr durch Ressourcen- und Stoffsteuern nicht betroffen wird, erlangen derartige Steuern Dominanz über den Vorsorgebereich des Ordnungsrechts. Für das Rechtssystem ist dabei nicht apriori erkennbar, ob zukünftige Veränderungen des Rechtssystems allein das Umweltrecht betreffen oder nicht auch etwa das Wirtschafts- und Steuerrecht. Klar ist hingegen, daß der Rückgriff auf ökonomische Instrumente weiterhin einen ordnungsrechtlichen Rahmen benötigt. Aufgrund der ökonomisch-materiellen Dynamik der Stoffströme wird es kaum zu Rechtsvereinfachungen im Umweltrecht kommen, selbst wenn ein implementiertes, effektives Stoffstromrecht die Vollzugshäufigkeit senken könnte. In räumlicher Hinsicht erfordert der Stoffstromansatz die Perspektivausweitung auf europäisches und internationales Recht.

Aufgrund der unvermeidlichen Abhängigkeit vom Ordnungsrecht haben sich einige Umweltökonomen auf die Verzahnung von ökonomischen Instrumenten und regulativem Umweltordnungsrecht konzentriert. Das Programm führt mikroökonomische Analysen des Ordnungsrechts durch und analysiert dabei die Effizienz der eingesetzten Instrumente (Gawel, 1996). Ein Ergebnis ist, daß Umweltökonomen wieder begonnen haben , Abgaben- und Kompensationslösungen Ökosteuern vorzuziehen: "Ökosteuern sind weder eine Alternative zur imperativen Umweltpolitik, noch eignen sie sich systematisch zu deren Ergänzung. Da sie typischerweise Inputs und Güter belasten, lassen sich Ökosteuern weder über das Anlagenkonzept noch über das Emissions- oder Immissionsprinzip mit dem Ordnungsrecht verknüpfen." (Ewringmann, 1994, 277) Mit Gawel kommt Ewringmann deshalb zu dem Schluß, daß Ökosteuern effizienzfreien Demeritorisierungsund Finanzierungszwecken zuzuordnen seien. Dies gestattet es, "sich einzig auf den Wirkungszweck zu konzentrieren und Fiskalerwägungen zu vernachlässigen." (Köck, 1996, 154). Eine Fokussierung auf bestehendes Umweltrecht wäre jedoch insofern unzureichend, als daß dies allein allokativ ansetzt und zudem die Rolle der Ökonomik im politischen Prozeß nicht hinreichend reflektiert.

In der Ökonomik wird nämlich regelmäßig das Aufkommen doch wieder in den Mittelpunkt der Betrachtung gestellt, indem in der Tradition von der Public-Choice-Theorie die ökologische Lenkungsabsicht bezweifelt und Rent-Seeking durch Politiker und Interessengruppen unterstellt wird. Die Public Choice Theorie hat zwar selbst nie eine intertemporale Allokation jenseits von dezisionistischer Coase'scher Umweltdistribution begründet, doch sie kann so zumindest antiaufklärerisch in Ökonomik und Gesellschaft die Nachhaltigkeitsagenda zersetzen und damit Politik machen (Buchanan, 1976). Aufgrund widersprüchlicher Empfehlungen der Ökonomik an die Politik unterliegt auch die an sich erfolgversprechende mischinstrumentelle Umweltstrategie in hohem Maße der 'Gefahr des Zerredens' (Benkert, 1994). Doch jede umweltökonomische Regulierung - und dies schließt Selbstregulierung ein - bleibt auf einen rechtlichen Rahmen angewiesen, der notwendig unsicherer ist als die geschlossenen Modelle intertemporaler 
Allokation. ${ }^{148}$ Die Probleme von Unsicherheit im rechtlichen Kontext sind jedoch von der Umweltökonomie bisher fast gänzlich vernachlässigt worden (vgl. Köck, 1996, 154 f).

Im Unterschied zur Umweltökonomie ist nach der Umweltpolicyforschung die Instrumentenwahl für das Politikergebnis generell "wenig erklärungsfähig, wenn die Stärke, Konfiguration oder Kompetenz der Akteure, ihre strategische Langzeitorientierung, ihre situativen und strukturellen Handlungsbedingungen und der Charakter des Problems ausgeklammert werden." (Jänicke, 1996, 11) Von daher verbietet sich die strikte Entgegensetzung einer ordnungsrechtlicher versus einer marktkonformer Steuerung, denn das Umweltordnungsrecht ist durch immanente Effizienzprobleme charakterisiert: Die Effektivität der Rechtsanwendung bzw. des Vollzugs läßt sich nicht sinnvoll mit dem ökonomischen Maßstab effizienter Allokation beurteilen, da dieser Maßstab immer auch das unzureichende intertemporale Verständnis der ökonomischen Theorie und ihrer strategisch-instrumentellen Rationalität widerspiegelt. Von einem rationalen Umweltrecht im Sinne ökonomischer Rationalität - kann allenfalls in Verbindung zu umweltpolitischen Zielen gesprochen werden (vgl. Lübbe-Wolff, 1996). Mit Habermas gesprochen: Sinn kann weder vom ökonomischen noch vom politisch-administrativen System intern reproduziert werden. W. Köck (1996, 156 ff) hat deshalb auf die Bedeutung von Umweltzielen für den Einsatz umweltökonomischer Instrumente hingewiesen.

Führ zählt derartige Umwelthandlungsziele in Form von Umweltplänen zu den Instrumenten eines übergreifenden Stoffstromrechts (vgl. Führ, 1997, 171). ${ }^{149}$ Es ist vorgeschlagen worden, Umweltqualitätsziel und Umwelthandlungsziel unter einen (nichthierarchischen) Oberbegriff des Umweltziels zu stellen (Rehbinder, 1997, 314 f). Dabei geben Umwelthandlungsziele an, wie (in einzelnen Schritten) Umweltqualitätsziele erreicht werden können. Diese wiederum können unterschieden werden in Schutz-, Sanierungs-, Vorsorge- und Nachhaltigkeitsziele. Die sachliche Hierarchie folgt diesen rechtlichen Kategorien von Umweltqualitätszielen annähernd mit der Unterscheidung zwischen Gefahren- und Massenstoffen: Massenstoffe eigenen sich eher für eine hohe Steuerungsebene mit großer Steuerungstiefe als Gefahrenstoffe die humantoxisch wirken oder nur lokal verbreitet sind. Korrespondierende Umweltziele lassen sich quantitativ spezifizieren und gehen dann über qualitative Umweltziele hinaus (vgl. Nordbeck, 2001, 8 f). Gleichwohl wiegt Ressourcenschonung als rechtliches Schutzgut weniger schwer als das Schadstoffproblem (Rehbinder, 1995, 10).

Aus rechtlicher Sicht eröffnen Umweltqualitätsziele vier Entwicklungsperspektiven (vgl. Köck, 1997, 529 ff): 1. Sie stärken die Umweltqualitätsorientierung des Umweltrechts gegenüber technikund anlagenbezogenen Regelungen. 2. Sie lassen sich in Verbindung bringen mit Forderungen nach einer Umweltgesamtplanung. 3. Sie dienen als Basis für umweltökonomische Lösungen der Umweltproblematik. 4. Sie lassen sich als Instrument eines kooperativen Umweltstaates interpretieren, der auf öffentliche Selbstverpflichtungen zurückgreift.

148 Auch kann, wie Kirchgässner und Pommerhehne (1993) dargelegt haben, Recht - oder genauer: gerechte Rechtsanwendung - für den homo oeconomicus das Kriterium der Indifferenz erfüllen; s. S. 286.

149 (Vgl. aus sozialwissenschaftlicher Sicht auch: Carius, Sandhövel, 1998 und Nordbeck, 2000; ders., 2001. 
Der rechtliche Gehalt von Umweltzielen wird bisher in allgemeiner Form in gesetzlichen Zielbestimmungen, Grundsätzen oder Optimierungsgeboten in den maßgeblichen Umwelt- und Planungsgesetzen festgehalten (vgl. ebd., 533 ff, Rehbinder, 1997, 321 ff). Die gesetzliche Fixierung von Umwelthandlungszielen ist dagegen noch äußerst selten. Es überwiegen exekutive Programme. Im stofflichen Bereich stellt lediglich das Abfallrecht eine Ausnahme dar, welches nach der Verpackungsverordnung Mehrweg- und Verpackungsquoten festlegt, die mittelbare Außenwirkungen haben. Erst wenn die Quoten kollektiv verfehlt wurden, treten die Pfanderhebungs- bzw. Rücknahme- und Verwertungspflichten in Kraft. ${ }^{150}$ Nach Rehbinder $(1997,318)$ "könnte die Ermächtigung für Zielfestlegungen nach § $25 \mathrm{KrW}-/$ AbfG als Beleg für die Notwendigkeit und als Modell für die künftige gesetzliche Legitimierung von in ihrer Wirkung politischen Umweltzielen angesehen werden." Zu verallgemeinern sei diese Vorschrift aber nur dann, wenn Umweltziele einseitig vom Staat gesetzt werden könnten. ${ }^{151}$

In bezug auf den Rechtsschutz können Umweltziele immer im Rahmen des Inzidentrechtsschutzes überprüft werden, d.h. es kann ihre Verhältnismäßigkeit und Gleichheitswidrigkeit bei Einzelmaßnahmen überprüft werden (vgl. Rehbinder, 1997, 326). Mit Kenntnis des Verlaufs der Diskussion über Ökosteuern empfiehlt es sich, die Struktur von Umweltzielen analytisch in ihre ökonomischen, politischen, administrativen und planerischen Aspekte zu zerlegen (vgl. Nordbeck, 2001, 9 ff). Zwar sind die administrativen Aspekte bei R. Nordbeck nur institutionell und nicht rechtlich geprägt (was auch dazu geführt haben mag, daß planerische Aspekte als rein kognitive und nicht als rechtlich-institutionalisierte Verfahren ausgeführt werden), doch geben die ökonomischen und die politischen Aspekte hinreichend Aufschluß über potentielle Konflikte in deliberativen Prozeduren der Umweltzielfindung. Nach Nordbeck beschränkt sich der ökonomische Aspekt auf die optimale Allokation knapper Ressourcen, während die politischen Aspekte komplexer sind (vgl. auch Fürst, 2002, 184 ff). Die politische Funktion von Umweltzielen im Rahmen des politischen Prozesses ist demnach:

- Machterwerb oder Machterhalt für ökologisch interessierte Gruppen,

- Interessenausgleich hinsichtlich knapper Ressourcen, d.h. die Bewältigung von Verteilungskonflikten,

- Integration der Beteiligten durch Konsensbildung bei Werten, Zielen und Überzeugungen

- Selbstdarstellung nach innen und außen,

- Legitimation der Entscheidung durch Rekurs auf Ziele.

${ }^{150}$ Die Sanktionen sind in diesem Sinne die Wiederherstellung ordnungsrechtlicher Individualpflichten, die durch die kollektiv verbindlichen Quoten nur temporär suspendiert wurden. Gegenüber einzelnen Abfallverursachern entfallten sie keine Rechtswirkung, so Rehbinder, 1997, 319.

${ }^{151}$ Köck hat in diesem Zusammenhang darauf verwiesen, daß (n. h. M.) für die Exekutive nur die Verpflichtung zur Beteiligung des Parlaments an der Umweltzielplanung bestehe (was in den Enquete Kommissionen des BT auch geschieht), nicht aber zur Beteiligung gesellschaftlicher Gruppen. Allerdings habe sich der Kontext verschoben: Der Umweltstaat lege einen institutionell vorgezogenen Grundrechtschutzes in Form der Verfahrensbeteiligung mittelbar Betroffener nahe; Köck, 1997, 534 f. 
Können Umweltziele demnach sogar distributive Rationalität (vielleicht gar in intergenerationeller und internationaler Hinsicht) in das Rechtssystem einführen, welches im Bereich des Umweltrechts sonst ganz vorwiegend einer allokativen Rationalität verhaftet bleibt? Die Frage ist bisher von der Forschung noch nicht beachtet worden. 


\section{Solidarität und politische Öffentlichkeit}

\subsection{Nachhaltigkeit für eine wohlgeordnete, zivile Gesellschaft}

Gegen die Übertragung der bisher entwickelten, wissenbasierten Fundierung auf das Politische ließe sich empirisch anbringen, daß "theories of knowledge rarely (if ever) determine institutional structure. More usually, they legitimate and justify or (conversely) criticize and undermine particular practices. Nevertheless, theories of knowledge and rationality can inform political development to the extent they permeate the understanding of political actors." (Dryzek, 1990, 29) Die Diskurstheorie teilt diese halboptimistische Einschätzung J. Dryzeks; sie überträgt objektives Wissen nicht als Utopie oder Sozialtechnologie unmittelbar in die politische Theorie, sondern geht einen über die politische Philosophie normativ und über die Policyforschung empirisch begründeten Weg zum politischen Objektbereich.

Hierbei scheint es, als würde die normative politische Theorie ungleich stärker von den Verschiebungen und Brüchen des kulturellen Selbstverständnisses beeinflußt werden als die Policyforschung. Die sich in der Risikogesellschaft wiederfindende Moderne, so lautete die soziologische These in Kapitel 2.2, wird durch die ökologische Krise vor die Herausforderung eines möglichen Epochenbruchs gestellt. ${ }^{152}$

Während B. Latour das modernisierungstheoretisch geprägte Selbstbewußtsein mit der These erschüttert, daß wir gemäß der in der Moderne proklamierten Standards niemals modern gewesen seien (Latour, 1995), diagnostizieren die Theoretiker des 'integrativen Kommunitarismus' (Benhabib) einen Epochenbruch. Allerdings erweist sich Latours Theorie handlungstheoretisch kaum zugänglich und blieb bisher für die Politikwissenschaft unterkomplex. Demgegenüber weisen neoaristotelische Theorien eine große handlungstheoretische Klarheit und eine lange ideengeschichtliche Tradition auf, denen jedoch fundamentale Probleme entgegenstehen, einen nacharistotelischen Naturbegriff zu entwickeln und eine Ethik ohne Referenz auf die Natur zu begründen. ${ }^{153}$ Der Krise der Moderne stellen sie einen gemeinschaftlichen Ethos entgegen, dessen sozialintegrativer Kraft sie alles anvertrauen. Der Ethos wird mit Handlungstheorien verbunden, die sich teilweise auf den Republikanismus (H. Arendt, 1989; O'Neill, 1993) und teilweise auf moderne Handlungstheorien berufen (MacIntyre, 1984). Die Abweisung jedweder systemischer Gesellschaftsintegration erweist sich aber nicht nur im Politischen als problematisch, sondern vor

152 Latours Antithese (1995), daß wir niemals modern gewesen seien, negiert zwar einen solchen Epochenbruch, doch zerrüttet es das modernisierungsgeprägte Selbstbewußtsein der Gegenwart noch nachdrücklicher. Bezeichnenderweise verzichtet Latour dann im Gegensatz zu Beck auch ganz darauf, der Politik einen Platz zuzuweisen.

153 Der Aristotelismus hat das Problem, daß er das menschliche Telos aus der Natur ableiten will. Doch mit der Widerlegung der aristotelischen Physik und Biologie und der Unzulässigkeit von Sein-Sollens-Schlüsse entfällt Natur als normative Instanz. Das Gute läßt sich weder metaphysisch noch erkenntnistheoretisch aus der Natur herleiten. C. Taylor hat die erkenntnistheoretischen Probleme einer solchen an Aristoteles orientierten Ethik, die auf die Natur als normative Instanz verzichten muß, eingestanden (Taylor, 1986, $101 \mathrm{ff}$ ) und deshalb auf eine Güterethik verwiesen. 
allem auch im Ökonomischen: Zwar könnte die Rückkehr (von Marx) zum (aristotelischen) Haushalt (Oikos) durchaus den Nachhaltigkeitsaspekt der Suffizienz befördern (O'Neill, 1993, 168 ff), einen Weg zu einer ökoeffizienten Wirtschaft scheint dies jedoch nicht aufzuzeigen. Einsinnig politisch aber dürfte sich Nachhaltigkeit kaum verwirklichen lassen.

Dagegen sprechen nicht nur die normativen besitzindividualistischen Theorien der libertären Tradition, sondern auch die ideengeschichtliche Beobachtung, daß das private Eigentum fundamentale Legitimations- und Zielkategorie aller bürgerlichen Politikkonzepte der Neuzeit war, wenngleich sie auch intern an Gleichheit und Freiheit orientiert schienen (Bermbach, 1991, 205 f). Dies gilt besonders für die libertäre Theorie, die zwar rhetorisch Gleichheit und Freiheit bestätigt, jedoch Allokation dem Mehrheitsprinzip voranstellt. Während etwa Gauthier (1986) dem produktivistischen Fehlschluß erliegt, will Buchanan Wahrheitsgeltung aus der politischen Debatte verweisen und Politik als reines Nullsummenspiel begründen (Buchanan, 1975). ${ }^{154}$ Es ist jedoch nicht einsichtig, wieso das Politische normativ eingeschränkt werden sollte, wenn die empirische Theorie doch die von der libertären Theorie bestrittenen Kooperationsformen eindeutig nachweisen kann. Gemeinsam ist der libertären Kritik, daß sie sich gegen wissens- und wahrheitsbasierte Modelle der Politik richtet. Dies teilt sie mit der konservativen Dezisionismus. Allerdings behauptet dieser stärker noch ein neuzeitliches Geltungsproblem aufgrund fehlender wahrer, normativer Bezugssysteme (vgl. v. Beyme, 1993, 90 ff).

Aus der dezisionistischen Tradition heraus, aber auch in Abgrenzung zu ihren undemokratischen Auswüchsen, hat T. Greven (1992) einen demokratischen Dezisionismus zu rechtfertigen versucht. Greven macht seinen Begriff des demokratischen Dezisionismus am Gegensatz von Begründung vs. Willkür fest. Er moniert, daß Probleme der Gesellschaft oft nicht im Sinne demokratischer Entscheidung, sondern häufig als Routineprozesse der Subsumtion im administrativen System behandelt werden würden. Damit vollziehe sich eine Entradikalisierung der Problemwahrnehmung und -bearbeitung, die gegenüber ökologischen Fragen gefährlich erscheine. "Unter Legitimationsgesichtspunkten reißt eine immer tiefere Kluft zwischen der sich tendenziell radikalisierenden gesellschaftlichen Problemwahrnehmung und der Wahrnehmung politischer Entscheidungsroutinen auf, die in der Paradoxie mündet, daß niemand mehr der Politik zutraut, was doch allein politisch gelöst werden könnte." (T. Greven, 1992, 202) Grevens demokratischer Dezisionismus strebt die Vergrößerung von Legitimation durch Partizipation an und will sich gerade der dezisionistischen Tradition eines Gegensatzes von Entscheidung versus Nichtentscheidung verweigern.

Doch obwohl sich die Unterscheidung zwischen Begründung und Willkür, welche eine Entkoppelung von Wahrheit und Politik mit sich führt, zwar gegen die konservative dezisionistische Tradition ebenso sperrt wie die reduktionistische Widergabe von Objektivität in der libertären Tradition, beinhaltet sie aus demokratietheoretischer Sicht doch mindestens zwei fundamentale

154 Buchanans Bannspruch trifft sowohl Tatsachen- als auch Vernunftwahrheit (vgl. zu dieser Unterscheidung Arendt, 1994). Er betrifft so natürlich auch den Diskurs zur Nachhaltigkeit. 
Fehler: Zum einen unterscheidet der Dezisionismus nicht hinreichend präzise zwischen dem (unhaltbaren) Anspruch einer Determinierung von Politik durch Gründe und einem Gebrauch von Gründen in der politischen Praxis; zum anderen mißversteht er die politische Praxis, indem er diese nur aus der systemischen Beobachterperspektive und nicht aus der Perspektive von Beteiligten rekonstruiert (Schmalz-Bruns, 1995a, 146; vgl. auch Peters, 2001, 674 f).

Unter dem empirischen Aspekt der Integration von Gesellschaft unterliegt das Politische der funktionalen Anforderung, die Gesellschaft systemisch zu integrieren. "Die Politik springt in Funktionslücken ein, die sich durch die Überlastung anderer gesellschaftlicher Integrationsmechanismen öffnen." (Habermas, 1992, 386f) Während die vom ökonomischen und zivilgesellschaftlichen System aufgenommen Probleme das politische System mit einem Input versorgen, ist unter umweltpolitischen Legitimitätsgesichtspunkten das Output des politischen Systems entscheidend. Während die Offenheit und Input-Orientierung des politischen Systems im Bereich der politischen Öffentlichkeit sichergestellt wird, ergibt sich die Leistungsanforderung an das Output des politischen Systems im Policy-Bereich. Dieser ist Gegenstand der Policyforschung.

Die deutsche umweltpolitische Policyforschung hat sich in der Vergangenheit ausgiebig mit dem Problem politischer Legitimation auseinandergesetzt. Die Debatte lief über Begriffe wie 'Unregierbarkeit', 'Legitimationskrise' und 'Staatsversagen' und hatte eine deutliche wohlfahrtsstaatliche Ausrichtung. Diese wohlfahrtsstaatliche Ausrichtung der Policyforschung besteht bis heute. Doch die Politikforschung kann sich nicht auf statische Verteilungsaspekte im Feld der Umweltpolitik zurückziehen, sondern muß sich auch normativ, wie seit Jonas eingefordert, am praktischen Diskurs der Nachhaltigkeit orientieren. Die im Brundtlandbericht angemahnte Zukunftsorientierung von Politik fordert ersichtlich mehr als die bloße Fokussierung auf das Politikfeld der Umweltpolitik; sie bezieht sich auf eine umfassende Koordination von Politiken. Andererseits spiegelt Nachhaltigkeit zwar ein normatives, kollektives Interesse wider, doch konnte dies bisher in Ermangelung der entsprechenden sozialwissenschaftlichen Theorie kaum die heteronomen Partialinteressen diverser Politikfelder integrieren. Wohlfahrtsökonomisch erscheint ein nachhaltiges Gemeinwohl unbestimmbar. Außerdem werden rein normative Forderungen von der systemischen Funktionalität hartnäckig abgewiesen werden. Doch dies rechtfertigt selbst dann noch nicht die empirizistische Ablehnung von Normativität überhaupt, wenn klar ist, daß die funktionale Integration nicht durch eine moralisch-soziale ersetzt werden kann.

Es sind die systemischen Erfolgschancen einer im Allgemeininteresse begründeten Politik, an denen sich die Zuweisung von Legitimität letztlich orientieren muß. Die Prinzipien der Demokratie und des Rechtsstaates bleiben damit Thema auch einer mit Policy-, d. h. politikinhaltlichen Problemen befaßten Staats- und Regierungslehre, nur daß sie jetzt nicht mehr primär in ihrem Eigenwert, sondern in ihrer funktionalen Beziehung zum Leistungsstaat betrachtet werden. (Decker, 1994, 21; Hervorhebung i. O.)

Trotz der Referenz auf ein Input-Output-Modell ist die empirische Unzugänglichkeit der Systemtheorie für die Politikwissenschaft höchst problematisch, da der politische Prozeß überwiegend auf einem mesotheoretischen Niveau stattfindet, dessen Beschreibung nur unter Rückgriff auf mikrosoziologische Prozesse gelingen kann. Das mesotheoretische Niveau wird aber 
auch von der mikrosoziologisch orientierten ökonomischen Theorie der Politik oft nicht hinreichend beschrieben. Deren analytischer Brillanz in der Beschreibung von Handlungs- und Entscheidungssituationen steht eine unübersehbare makrosoziologische Schwäche entgegen: Von Entscheidungsparadoxien und Dilemmasituationen scheinen politische Steuerungsansprüche, die auf dem mikrotheoretischen Niveau expliziert wurden, zwangsläufig abgewiesen werden zu müssen. Zu einem politikwissenschaftlichen Begriff der Steuerung gehören neben einem Subjekt und Objekt auch Intentionen bzw. Steuerungsziele (oder die Zustandsänderung des als Steuerungsobjektes fungierenden Systems) ebenso wie der Einsatz von Maßnahmen. Um das Steuerungsziel zu verwirklichen ist - als unerläßliche Voraussetzung der Maßnahmenwahl - eine Vorstellung der Wirkungsbeziehungen zwischen Steuerungsaktivität und -ergebnissen unerläßlich (vgl. Mayntz, 1995, 186 ff). ${ }^{155}$ Das empirisch-theoretische Programm des akteurzentrierten Institutionalismus hat versucht, die Unklarheiten um den Steuerungsbegriff zu überwinden. Der Steuerungsakteur kann hier Teil des gesteuerten Systems sein und in Netzwerken gleichwohl die systemische Eigenlogik teilweise überwinden. Anzustreben wäre für eine empirische Steuerungstheorie ein Erklärungsmodell mittlerer Reichweite (Schimank, 2000, 267 ff), das die regulativen Ideen von Nachhaltigkeit sozial, sachlich, zeitlich und räumlich zum Tragen kommen läßt. Allerdings ist für prozedurale Theorien wie der Habermas'schen nicht unmittelbar Legitimitätskriterium, ob Steuerung auch erfolgreich ist (vgl. auch Kühn, 1997, 548 ff, Mayntz, 1995, 192). Im Rückgriff auf die Theorie des kommunikativen Handelns sind "Institutionen als jene Transferinstrumente zu bestimmen, die die normativen Orientierungen, die innerhalb der Lebenswelt vorhanden sind, an das System weitergeben und so dafür sorgen, daß dessen Funktionieren der Lebenswelt substantiell verpflichtet bleibt." (Bermbach, 1991, 246) Dies bleibt eher demokratietheoretischen als steuerungstheoretischen Gesichtspunktspunkten verpflichtet.

Trotz ihrer makrotheoretischen Schwächen eröffnet zweifellos die Institutionentheorie, welche in den letzten Jahrzehnten einen rasanten Aufschwung erfahren hat (Göhler, Kühn, 1999), den am weitesten verbreiteten Zugang zur empirischen Analyse prozeduraler Arrangements der Nachhaltigkeit. Der Erfolg der Institutionentheorie verdankt sich vermutlich der integrativen Kraft der Spieltheorie, der die sozialwissenschaftlichen Disziplinen von der Ökonomie über die Soziologie bis zur Politikwissenschaft methodologisch miteinander verbindet. Die dabei zugrundegelegten Rationalitätsannahmen reichen von starker bis zu schwacher Rationalität und bestimmen den Erklärungsgehalt der Analyse entscheidend (vgl. Zintl, 1990). Wenn die strikte Annahme vollständiger Information durch die schwächere optimaler Information ersetzt wird, besteht die Integrationsfähigkeit des spieltheoretischen Ansatzes auch disziplinintern in der Anwendbarkeit auf gänzlich verschiedene Kontexte. In der Politikwissenschaft greifen so u.a. Regimeanalyse, Governanceansatz, akteurzentrierter Institutionalismus und Neue Politische Ökonomie (NPÖ) auf das Modell des rationalen Individuums zurück.

155 Vgl. zur Steuerungsdebatte auch: Braun, 1993; Görlitz, 1995; König, Dose, 1993; Kühn, 1997; Martinsen, 1992; Mayntz, 1995, 186 ff, 263 ff; Offe, 1990b; Scharpf, 1989, Schuppert, 1990. 
Während Regimeanalyse (Krasner, 1991; Kohler-Koch, 1989; Rittberger, 1993) und Governanceansatz (Rosenau, Czempiel, 1992; Young, 1994) mit Hilfe der spieltheoretischen Methodologie die internationale Politik untersuchen, beziehen sich akteurzentrierter Institutionalismus (Mayntz, Scharpf, 1995a) und Neue Politische Ökonomie (Holzinger, 1987; Horbach, 1992) vornehmlich auf die nationalstaatliche Ebene. Allerdings hat der akteurzentrierte Institutionalismus seinen Erklärungsbereich schon früh auf die supra- und die internationale Ebene ausgedehnt (Scharpf, 1985, 1993, 1996). Die Regimetheorie ist einem problemorientierten Ansatz gefolgt, der die Herausbildung und die dynamische Entwicklung von Regimen zum Schutz international gefährdeter Umweltgüter analysierte und in ihrer Effektivität erforschte. In bezug auf die stofflich-wohlfahrtsstaatliche Dimension von Nachhaltigkeit sind hier die Regime zum Schutz der Ozonschicht (Montrealer Protokoll, 1987), der Erdatmosphäre (Kyoto-Protokoll, 1997) und das Regime zum Verbot des Handels mit Giftmüll (Baseler Konvention, 1989) zu nennen. Dabei meint die Rede von der stofflich-wohlfahrtsstaatlichen Dimension die mit der in Frage stehenden Stofflichkeit verbundene Regelungstiefe, die zu ganz unterschiedlichen Ausgestaltungen spieltheoretisch-formal gleicher Kontexte (Gefangendilemmasituation in einer Welt souveräner Nationalstaaten) führt, und die wohlfahrtstheoretische Regelungsfunktion, die sich über die erzielte nationalstaatliche Handlungskoordination (vgl. Stein, 1983) ergibt. Nur wenn Geltungsbereich (Regelbereich) und Struktur (Regelstruktur) einer Institution (Regime) den situativen Anforderungen entsprechen, ist wohlfahrtstheoretisch Koordination zu erzielen (v. Prittwitz, 2000, 16). Diese kann im Sinne eines wohlfahrtsstaatlichen Kapitalismus als internationale Kooperation verstanden werden, welche eine nachhaltige Entwicklung durch die Expansion von Stoff- und Energieströmen sowie die Ausblendung internationaler Verteilungsgerechtigkeit aufs Spiel setzt (vgl. aber Helm, Simonis, 2000) und welche permanent der Gefahr unterliegt, in Verletzung internationalen Rechts durch einzelne Staaten blockiert zu werden (vgl. Grundmann, 2000).

Für die sozialwissenschaftliche Forschung zur nachhaltigen Entwicklung eröffnet der Neoinstitutionalismus methodologisch einen weiten Zugang zu den komplexen Problemen nachhaltiger Entwicklung. Er zeichnet sich dadurch aus, daß er übersichtlich strukturiert ist und damit die nachhaltigkeitsrelevanten Kriterien hoher Operationalisierbarkeit und Kommunizierbarkeit gewährleistet (Öko-Institut, 2001, 21 f). Institutionen können sowohl auf die Sicherstellung von Leistungen als auch auf die Gewährleistung von Verfahren zielen. Sie finden sich auf allen Ebenen der Gesellschaft: von zivilgesellschaftlichen oder ökonomischen Organisationen bis zur supranationalen Ebene. Die Probleme der Nachhaltigkeit sind sehr häufig dadurch charakterisiert, daß sie jenseits von oder quer zu den bestehenden Ebenen staatlicher Institutionen stehen. Oft bestehen neben formellen Institutionen auch informelle. Diese Heterogenität der zu erforschenden Regelstrukturen und institutionellen Muster lassen sich unter dem Begriff 'institutioneller 
Arrangements' (v. Prittwitz, 2000) zu einem Brückenkonzept formeller und informeller Institutionalisierung bündeln. ${ }^{156}$

In der Forschung für eine nachhaltige Entwicklung sind inzwischen einige dieser institutionellen Arrangements untersucht worden. Allerdings analysiert nur ein kleiner Teil explizit die stoffliche Dimension von Nachhaltigkeit (vgl. dazu Öko-Institut, 2001). Gleichwohl finden sich natürlich Untersuchungen, welche Aspekte des Stoffstroms aus der institutionellen Perspektive untersuchen (z.B. Biermann, 2000a, 2000b; Öko-Institut, 2000, vgl. auch die Beiträge in: v. Prittwitz, 2000).

Der umweltpolitische Forschungsansatz institutioneller Arrangements transzendiert im Anschluß an die internationalen Probleme das nationalstaatliche, politisch-administrative System, ohne dabei die zumeist implizite These einer Kolonialisierung der Lebenswelt durch das ökonomische System normativ (moralisch) zu begründen. Zweifellos ist in ethisch-moralischer Hinsicht einzig die Demokratie realistischer Ausgangspunkt für die erfolgreiche Umsetzung von Nachhaltigkeit in der internationalen Staatenwelt. Die Theorie ökologischer Modernisierung und die Theorie der Dematerialisierung präzisieren diesen Gegenstand, indem sie dabei auf die industrialisierte Demokratie verweisen. Andererseits ist Habermas auf den internationalen Aspekt von (Rechts)Staatlichkeit - geschweige denn Verteilungsgerechtigkeit - bisher kaum eingegangen (vgl. aber Habermas, 1996, 128 ff, 192 ff). Nachhaltige Entwicklung beinhaltet auch in der internationalen Dimension Verteilungskonflikte (vgl. Martinez-Alier, 1995).

Rationalitätstheoretisch bewegt man sich hier im Modus zweckrationalen, strategischinstrumentellen Handelns: strategische Rationalität in der sozialen Interaktion, instrumentelle Rationalität im sozialen Metabolismus mit der Natur. Ebenso wie derartige institutionelle Arrangements immer eine Wohlfahrtsdimension haben, hat auch die aggregierte Wohlfahrt immer eine materielle Dimension. Institutionen bestehen niemals ausschließlich nur aus symbolischen Elementen, sondern immer auch aus materiellen Strukturen. Diese betreffen den Metabolismus zwischen Gesellschaft und Natur unmittelbar. Die Materialität und Trägheit von Institutionen zeigt sich insbesondere in der diachronen Dimension des Sozialen. Institutionen zeigen persistente materielle Elemente, und sie haben eine temporale Dimension. Institutionen bauen auf Artefakten, materiellen Ressourcen und menschlichen Fähigkeiten auf, deren Reproduktion immer materielle Elemente umfaßt. Diesen Aspekt von Institution zu betonen, ist aufgrund der stofflichen Dimension von Nachhaltigkeit notwendig. Es ist vorgeschlagen worden, daß "solche materiellen Elemente [...], soweit sie Resultat sozialer Aktivität sind oder durch solche Aktivitäten verändert werden könnten, in einem indirekten Sinn als mehr oder weniger rational betrachtet werden [können]. Man kann insofern von der Rationalität oder Irrationalität eines Verkehrsnetzes oder einer Siedlungsstruktur oder einer sozialen Ressourcenverteilung sprechen." (Peters, 1991, 202) Von der Rationalität materialisierter Institutionen im engeren, stofflichen Sinn ist soziologisch bisher nur in bezug auf sozio-technische Systeme gesprochen worden (vgl. Mayntz, 1988; 1997, 70 ff; Joerges, Braun,

156 Obgleich Prittwitz auf Göhlers Begrifflichkeit zurückgreift, bezieht er sich nicht auf dessen politische Institutionentheorie, so daß man Prittwitz' Brückenkonzept durchaus eine unzureichende theoretische Fundierung vorwerfen kann. 
1994). ${ }^{157}$ Im weiten Sinne können jedoch auch institutionelle Arrangements dazu gezählt werden, die Stoffflüsse, nichtintendiert oder intendiert beeinflussen bzw. steuern und damit nachhaltigkeitsrelevante Funktionen oder Aufgaben zu erfüllen. Angesichts der Dynamik der Vergesellschaftung der Natur sind Grenzen von Allokation und Distribution deskriptiv schon schwer zu erfassen und analytisch noch schwerer zu ziehen. Es scheint sich deshalb anzubieten, auf einen methodisch einfachen Ansatz zurückzugreifen, der einen möglichst direkten Zugang zur Allokations- und Verteilungsdimension von Nachhaltigkeit bietet.

Die Kapitalismuskritik des Nachhaltigkeitsdiskurses ist hierbei ambivalenter Natur. Einerseits folgt der Diskurs in seiner Kritik dem ökonomischen Funktionssystem und zeigt die ökologischen Grenzen ökonomischen Wachstums auf, andererseits kann der nachhaltige Umweltstaat - wie der Sozialstaat - die funktionelle Eigendynamik des Marktes kaum aufheben. Die Wachstumskritik mündet dann in der Forderung nach einer qualitativ verschiedenen, nachhaltigen Entwicklung oder einer ökologischen Modernisierung bzw. Dematerialisierung. ${ }^{158}$ Dabei konzentrieren sich diese Konzepte mehr oder weniger stark auf die Modernisierung der Produktion, da distributive oder redistributive Konzepte die ökonomischen und politischen Umsetzungschancen a priori zu verschlechtern scheinen. Doch die so theoretisch latent gehaltenen Verteilungskonflikte schwelen in den praktischen umweltpolitischen Policy-Verhandlungen als hidden agenda weiter. Diese These dürfte im Rahmen des Nachhaltigkeitsdiskurses insbesondere für das Strukturproblem von Massenstoffen gelten. Denn "es spricht vieles dafür, daß weniger die gut politisierbaren Probleme der 'Risikogesellschaft' (Beck) als die weniger aktuellen Probleme einer schleichenden Degeneration das eigentliche Umweltthema der reichen (und alten) Industrieländer sind." (Jänicke, 1996, 21) Fischer-Kowalski (1997) hat dies auf die These zugespitzt, daß es dem politischen System zwar mit den klassischen umweltpolitischen Institutionen durchaus gelinge, den gesellschaftlichen Metabolismus zu regulieren, daß diese Institutionen aber versagen würden, wenn ihre Aufgabe auf 'Lebensstil' und 'Konsumverhalten' ausgedehnt werden würden, sich also Problemen eines suffizienten Sozialverhaltens annehmen müßten.

Der Umstand, daß institutionelle Arrangements insbesondere an der Interferenzstellen zwischen Systemen und Lebenswelt angesiedelt sind - so sind sie etwa an systemische Funktionsweisen rückgekoppelt -, spricht sehr dafür, ihre systemischen Handlungsbedingungen eingehend zu berücksichtigen. Hinzu kommt, daß mit Berücksichtigung der systemischen Bezüge institutioneller Arrangements auch wieder die funktionale Differenzierung der Gesellschaft in das Blickfeld rückt. Eine auf sozio-ökologische Integration zielende Politik der Nachhaltigkeit wird so wieder auf die geringen intrasystemischen Spielräume insbesondere des ökonomischen Systems zurückverwiesen, die sich dort weitestgehend auf Win-win-Potentiale zu beschränken scheinen. Stoffstrom- und Substitutionsanalysen eröffnen jedoch zweifellos neue, sektorenübergreifende Perspektiven für eine

157 Die sozialwissenschaftliche Forschung zu Großen Technischen Systemen (GTS) weist leider gerade hinsichtlich der energetisch-stofflich Beschreibung von GTS Forschungsdefizite auf, so Joerges, Braun, 1994.

158 Meines Erachtens unterscheidet sich das MIPS-Konzept von produktionsorientierten Ansätzen dahingehend, daß der Bezug auf Serviceeinheiten es ermöglicht, Konsumgewohnheiten zu kritisieren, und gleichzeitig ein Suffizienzkonzept ohne Leistungseinbußen zu entwerfen. 
solche Politik. Gleichwohl bleibt die Frage, welche anderen Gesichtspunkte neben der ökonomischen Systemlogik noch die Handlungsorientierung von Akteuren beeinflussen können. H.-P. Feindt (2002) hat hier auf den akteurzentrierten Institutionalismus verwiesen.

Gegenüber der notwendigen Output- oder Steuerungsorientierung der bisher angerissenen empirischen Policyforschung darf aber die Bedeutung des (kognitiven) Inputs keinesfalls unterschätzt werden. Für die Umweltpolitikforschung ist dabei nicht nur die Klärung von Unsicherheiten im naturalen Bereich wichtig, sondern, wofür die Theorie ökologischer Modernisierung als Beispiel dienen kann, auch die Berücksichtigung von Ideen, Politikprogrammen, Ordnungsprinzipien etc. im sozialen Bereich. Dies gilt um so mehr für eine Politik der Dematerialisierung. Im politischen Handlungsraum treffen die empirisch bedeutsamen Wissensressourcen der Akteure aufeinander. "Dieses Wissen ist nicht auf ein 'angeborenes' kognitives Kategoriensystem rückführbar, sondern auf gesellschaftlich hergestellte symbolische Systeme." (Keller, 2001, 113) Das Wissen wird in empirischen Diskursen produziert und reproduziert und ist moralischer, ethischer und pragmatischer Art. Es ist der Diskursanalyse, aber auch anderen kognitiven Ansätzen der Politikwissenschaft (Ansätze der kognitiven Strukturen, Überzeugungssysteme, Ideen, Wissensgemeinschaften, Deutungsmuster, Argumentationen etc.) zugänglich. Nullmeier hat unter dem Begriff der Wissenspolitologie zahlreiche kognitive, politikwissenschaftliche Ansätze zusammengefaßt und nach Objektbereichen unterschieden (Nullmeier, 2001, 294 f):

- Mikroebene (u.a. Argumente, Begriffe, Metaphern, Schlagwörter, Narrationen, Mythen, Begriffe, einzelnes Kausalwissen, Theorien, Prinzipien)

- Mesoebene (u.a. Policy-Prinzipien, Ordnungsprinzipien, Policy-Identitäten, Policy-Diskurse, Rahmen)

- Makroebene (u.a. Sprachen, Diskurse, Weltsichten, Weltbilder)

Verbleibt man zunächst in einem engeren institutionentheoretischen Rahmen, könnten sich empirische Theorie des Wohlfahrtsstaates (akteurzentrierter Institutionalismus) und normative politische Gerechtigkeitstheorie (Rawls) ergänzen. Allerdings soll auf der Mesoebene nur der wohlfahrtsstaatliche Prozeduralismus beider Theorien näher interessieren. Die makrotheoretische Einbindung erfolgt dann über die Diskurstheorie, die mit der Unterscheidung zwischen strategischinstrumenteller Rationalität und symbolisch-expressiver Rationalität - und stärker noch argumentativer Rationalität - bislang noch weitgehend ungenutztes kritisches Potential für die empirische politikwissenschaftliche Forschung besitzt. Indem die Diskurstheorie methodisch auf die empirische Diskursanalyse zurückgreift, kann sie über diese an die Institutionentheorie anschließen und zugleich die Diskursanalyse durch ihre systemtheoretischen Einsichten bereichern. 


\subsubsection{Gerechtigkeit und Verhandlungssysteme}

Die berühmt gewordene Theorie der Gerechtigkeit (1971) von J. Rawls ist spieltheorisch begründet worden, da sich so die Gerechtigkeitsprinzipien wohlfahrtstheoretisch ausdrücken ließen. Gemäß des Gedankengangs des Urzustands (original position) stimmen die Vertragsindividuen unter einem Schleier der Unwissenheit (veil of ignorance) zwei Gerechtigkeitsgrundsätzen zu: Das erste Prinzip sichert jeder Person ein gleiches Recht auf das umfassendste System gleicher Grundfreiheiten (basic liberties) zu, das mit demselben System von Freiheiten für alle vereinbar ist. Das zweite Prinzip, welches dem ersten lexikographisch nachgeordnet ist, formuliert eine Verfahrensregel sozialer Gerechtigkeit und die Bedingung fairer Chancengleichheit (fair opportunity) (vgl. Rawls, 1971, 302). Dieses sogenannte Differenzprinzip (difference principle) besagt, daß soziale und ökonomische Ungleichheiten dann zulässig sind, wenn sie auch den am wenigsten Begünstigten einer Gesellschaft zum größten zu erwartenden Vorteil dienen, wobei eine intergenerationelle Sparrate zu berücksichtigen ist. Zudem müssen Ungleichheiten, Positionen und Ämter zurechenbar sein, die allen unter Bedingungen fairer Chancengleichheit offen stehen. Schließlich bestimmt eine Prioritätsregel, daß Chancengleichheit dem Differenzprinzip vorgeht und dieses wiederum ökonomischer Effizienz und der Maximierung des Durchschnittsnutzens.

Die spieltheoretisch begründete Kongruenz verschiedener gesellschaftlicher Teilbereiche beinhaltete einen moraltheoretischen Konsequentialismus, den Rawls zumindest bis 1974 verteidigte. Im Sinne dieser Kongruenz bestätigte Rawls, daß die Grundstruktur einer wohlgeordneten Gesellschaft produktiv und kein Nullsummenspiel sein dürfe, bei dem der Gewinn einer Gruppe zugleich einen Verlust für eine andere Gruppe darstelle (vgl. Rawls, 1974a, 635). Rawls verstand eine wohlgeordnete Gesellschaft als soziale Kooperation, die die gerechte Verteilung eines kollektiven Wirtschaftswachstums organisiert. Dieses Verständnis liegt auch der ökonomischen Interpretation des Differenzprinzips zugrunde, das neben die wohlfahrtstheoretischen Kaldor-Hicksund Pareto-Kriterien trat, wobei das Differenzprinzip selbst auch das Pareto-Kriterium erfüllt. In der ursprünglichen Begründung von 1971 schienen Moraltheorie, ökonomische und politische Theorie in den beiden Prinzipien der Gerechtigkeit zusammenzufallen.

Die Abkehr von den konsequentialistischen Hintergrundannahmen des Differenzprinzips begann 1975 und wurde in einer Reihe von Aufsätzen vollzogen, die schließlich zur Reformulierung der Gerechtigkeitstheorie als Political Liberalism führten (Rawls, 1993). Political Liberalism enthält zwei fundamental Änderungen gegenüber A Theory of Justice: Die Vertragsindividuen vertreten nun einen Pluralismus von Konzeptionen des Guten, die zu verwirklichen ihnen die Theorie der Gerechtigkeit ermöglicht. Zudem unterscheidet Rawls nunmehr zwischen dem Rationalen und dem Vernünftigen in bezug auf den Begriff der Person.

Während die erste Änderung versucht, der kommunitaristischen Kritik gerecht zu werden, antwortet die zweite auf libertäre Kritik, die vor allem von ökonomischer Seite gegen die Theorie der Gerechtigkeit gerichtet wurde. Auf der Argumentationsbasis des methodologischen 
Individualismus wurde Rawls nämlich vorgeworfen, daß die Wahl des Differenzprinzips im Urzustand lediglich der spieltheoretischen Maximin-Entscheidung bei einer Wahl unter Risiko entspräche, wofür es nicht mehr Berechtigung gäbe als für jedes andere entscheidungstheoretische Kriterium. Dagegen hat Rawls auf die Priorität des ersten Prinzips der Gerechtigkeit vor dem zweiten Differenzprinzip verwiesen, welches durch mit dem ersten Prinzip verbundene Rechte eingeschränkt bzw. verwirklicht wird.

Rawls reformulierte deshalb seine Theorie als rationale Konstruktion sozialer Gerechtigkeit weiterhin im ökonomischen Sinne - unter dem vernünftigen philosophischen Konsens von Vertragsindividuen. Damit verwarf er philosophisch seinen spieltheoretischen Konsequentialismus. (Dieser war jedoch bereits in der ursprünglichen Formulierung der Theorie der Gerechtigkeit durch die Priorität des ersten Prinzips der Gerechtigkeit über das zweite, das Differenzprinzip, eingeschränkt gewesen):

As understood in justice as fairness, reciprocity is a relation between citizens expressed by principles of justice that regulate a social world in which everyone benefits judged with respect to an appropriate benchmark of equality defined with respect to that world. This brings out the further point that reciprocity is a relation between citizens in a well-ordered society (§6) expressed by its public political conception of justice. Hence the two principles of justice with the difference principle (§1.1), with its implicit reference to equal division as a benchmark, formulate an idea of reciprocity between citizens. Finally, it is clear from these observations that the idea of reciprocity is not the idea of mutual advantage. (Rawls, 1993, 17) ${ }^{159}$

Im Sinne der theoretischen Begründung hat die Reformulierung der Theorie der Gerechtigkeit einige Schwächen, wie etwa widersprüchliche Rationalitätskonzepte (Kersting, 1996), verschiedenen Konsensmodellen (Hinsch, 1997) und Unklarheiten des zugrunde gelegten Prozeduralismus. Rawls hat diese theoretischen Widersprüche nicht eindeutig aufgelöst. Doch hat Rawls allen Änderungen zum Trotz strikt auf die Anwendung des Differenzprinzips auf die Grundstruktur (basic structure) der Gesellschaft beharrt. Es läßt sich sogar feststellen, daß Rawls mit der moralphilosophischen Abwendung von seiner konsequentialistisch formulierten Gerechtigkeitstheorie als Moralphilosophie auch Abstand von einem rein wohlfahrtstheoretischen Verständnis des Politischen genommen hat.

Das in der Theorie der Gerechtigkeit formulierte Differenzprinzip konnte Wohlfahrtstheoretiker ohnehin nicht völlig zufrieden stellen. Man versuchte, das Prinzip zu präzisieren, wobei jedoch einige Probleme auftraten. So etwa in allen Fällen, in denen mehr als zwei Gruppen betroffen sind (vgl. Koller, 1983). Zudem erfüllte das Differenzprinzip nicht die Erfordernisse des starken ParetoKriteriums (Rex, 1994). Unter den wichtigsten Präzisierungsvorschlägen des Differenzprinzips findet sich Amartya Sens Leximin-Prinzip, das die ökonomischen Verhältnisse verschiedener Gruppen lexikographisch von der am wenigsten begünstigten Gruppe zur nächst schlechtest gestellten etc. ordnet. Doch auch das Leximin-Prinzip vermag nicht alle Aporien zu beseitigen, die

159 Rawls folgt damit dem Vorschlag Barrys (1996, 211), Gerechtigkeit als Reziprozität zu interpretieren. Interessant ist dabei, daß diese Unterscheidung zwischen 'mutual advantage' und 'reciprocity' genau jener entspricht, die Apel zwischen technisch-instrumenteller und strategischer Rationalität trifft, wobei letztere Apel als Grenzfall kommunikativer Rationalität gilt, vgl. Apel, 1995. 
aus dem Gegensatz von Gleichheit - im politischen (equality) und ökonomischen (equity) Sinne und Effizienz entstehen. ${ }^{160}$ Allerdings ist die zweite Prioritätsregel hier unmißverständlich, indem sie Gleichheit über Effizienz stellt. Indirekt verweist sie darauf, daß das Differenzprinzip nicht als rein distributives Kriterium verstanden werden kann, das alleine schon mit einer wohlfahrtsökonomischen Anwendung politische Verteilungskonflikte entscheiden könnte.

In späteren Veröffentlichungen hat Rawls sich von einer reinen Verteilungsgerechtigkeit distanziert, die allein auf wohlfahrtökonomischen Instrumenten beruht. In Political Liberalism hat Rawls die Idee der Reziprozität gegenüber der Idee des gemeinsamen Vorteils favorisiert (Rawls, 1993, 17). Die theoretische Implikation ist die Abkehr von Verteilungsgerechtigkeit als bloße Surplus-Verteilung:

Suppose that we transpose people from one society in which property, in good part as a result of fortune and luck, is very unequal into a well-ordered society regulated by the two principles of justice. There is no guarantee that all will gain by the change if they judge matters by their previous attitudes. Those owning large properties may have lost greatly and historically they have resisted such changes. No reasonable conception of justice could pass the test of mutual advantage thus interpreted. (Rawls, 1993, 17)

Das Differenzprinzip schließt demnach zwar ausgleichende Gerechtigkeit nicht unmittelbar ein, doch diese kann ihrerseits Vorraussetzung für die Anwendung des Differenzprinzips auf die Grundstruktur sein. Dagegen wird in der Wohlfahrtsökonomie Rawls' Differenzprinzip als konsequentialistisches Wohlfahrtskriterium verstanden. Die Theorie der Gerechtigkeit wird präferenzindividualistisch interpretiert, was vor dem spieltheoretischen Hintergrund der Theorie zwar verständlich, aber angesichts von Rawls' Ausführungen in Political Liberalism dennoch falsch ist. Ohnehin muß festgehalten werden, daß bereits die Theorie der Gerechtigkeit institutionalistisch angelegt war, indem sich das Differenzprinzip auf die Grundstruktur bezog. ${ }^{161}$ Nur wurde dieser Aspekt der Theorie in der Diskussion seitens der Ökonomie nur wenig beachtet. Die wohlfahrtsökonomische Fehlinterpretation mag schließlich dadurch gefördert worden sein, daß es Rawls durchweg vermieden hat, das Differenzprinzip als Rechtsposition zu formulieren, denn Rechte lassen sich als Trümpfe gegen konsequentialistische Optimierung ausspielen. ${ }^{162}$

Eine konsequentialistische Vereinnahmung wird von Rawls allerdings auch dadurch leicht gemacht, daß das Differenzprinzip im Sinne reiner Verfahrensgerechtigkeit (pure procedural justice) auf die Grundstruktur der Gesellschaft anzuwenden sei (Rawls, 1971, 86 f). Rawls unterscheidet diese Form der Verfahrensgerechtigkeit von fast reiner Verfahrensgerechtigkeit (quasi

160 Koller (1983) schlägt eine Interpretation des Differenzprinzips vor, die sich im Ergebnis nur geringfügig von Sens Leximin-Prinzip unterscheidet.

161 In diesem Zusammenhang sei angemerkt, daß W. Kersting Dworkins Theorie der Verteilungsgerechtigkeit als eine 'cartesianische' bezeichnet hat, da sich ihre starke subjektivistische Begründungsbasis nicht mehr institutionell umsetzen lasse (Kersting, 1997, 224 ff). Diese Kritik kann zweifellos nicht auf Rawls' Theorie ausgedehnt werden, da diese trotz der individualistischen Begründung eindeutig institutionalistisch ausgerichtet ist.

162 In diesem Verzicht auf eine konkretere Verrechtlichung des Differenzprinzips besteht meines Erachtens die größte theoretische Differenz zwischen M. Walzers Spheres of Justice (1983) und der Theorie der Gerechtigkeit, da Rawls' erstes Prinzip erlaubt, Tausch zu verrechtlichen und damit im Sinne Walzers' blocked exchanges auch zu blockieren, doch das zweite Prinzip aufgrund seiner deontologischen Perspektivenicht auf etwa Not (bzw. Notwendigkeit) - im aristotelischen Sinn - verweisen kann. 
pure procedural justice). Beide Formen haben kein unabhängiges Kriterium (außerhalb des Verfahrens). Bei reiner Verfahrensgerechtigkeit führt die Prozedur auch ohne externes Kriterium sicher zu einem gerechten Ergebnis. Vollkommene (perfect) und unvollkommene (imperfect) Verfahrensgerechtigkeit (procedural justice) haben dagegen ein derartiges, unabhängiges Kriterium. Mit diesem kann vollkommene Verfahrensgerechtigkeit ein gerechtes Ergebnis gewährleisten. Dagegen ist unvollkommene Verfahrensgerechtigkeit trotz unabhängigem Kriterium dadurch gekennzeichnet, daß ihre Prozedur nicht die Hervorbringung eines richtigen Ergebnisses garantieren kann.

Rawls versucht, die Theorie der Gerechtigkeit als reine Verfahrensgerechtigkeit zu formulieren, was überhaupt nur vor dem Hintergrund einer gerechten Grundstruktur denkbar ist. Diese wird durch die reine Verfahrensgerechtigkeit des Differenzprinzips bestimmt. Ergebnisse, von den auch der Am-schlechtesten-Gestellte profitiert, werden insbesondere dadurch wahrscheinlich, daß auch der zweite Zusatz des Differenzprinzips (fair equality of opportunity) reine Verfahrensgerechtigkeit widerspiegelt (Rawls, 1971, 87 f). Rawls begründet die reine Verfahrensgerechtigkeit des Differenzprinzips mit den Mängeln des Utilitarismus, der unterschiedslos auf jede Situation angewandt werde und dabei dem Übermaß an Informationen erliege. Den Utilitarismus charakterisiert Rawls als eine Form unvollkommener Gerechtigkeit (ebd., 88 f; ähnlich Rawls, 1993, 285). Die Anwendung des Differenzprinzips auf die Grundstruktur blendet dagegen persönliche Umstände aus, wie sie die utilitaristische Gerechtigkeitsvorstellung beherrschen. Die Theorie der Gerechtigkeit besagt unmißverständlich, daß das Differenzprinzip auf die Grundstruktur der Gesellschaft, also auf die Verfassung, die legalen Formen des Eigentums und das Wirtschaftssystem etc., angewandt werden muß - und diese Position hat Rawls konsequent beibehalten (Rawls, 1993, $257 \mathrm{ff}$ ).

Der Prozeduralismus in der Theorie der Gerechtigkeit erscheint zunächst irritierend, da die Grundstruktur sowohl vom ersten als auch vom zweiten Prinzip der Gerechtigkeit bestimmt wird. Denn Rawls spricht in Political Liberalism davon, daß "the two principles of justice as they work in tandem incorporate an important element of pure procedural justice in the actual determination of distributive shares. They apply to the basic structure and its system for acquiring entitlements; within appropriate limits, whatever distributive shares result are just." (Rawls, 1993, 282) Die Grundstruktur scheint also sowohl in ihrer institutionellen wie in ihrer materiellen Struktur durch reine Verfahrensgerechtigkeit bestimmt zu sein. Die reine Verfahrensgerechtigkeit würde notwendig konsequentialistisch auf die Grundstruktur angewandt werden. Obwohl Rawls das Differenzprinzip nicht als allokative Gerechtigkeit verstanden wissen will - diese verteile nur einfach eine gegebene Gütermenge auf Individuen, die für deren Produktion nicht miteinander haben kooperieren müssen -, wird nicht klar wie oder ob dies eine Abgrenzung von konsequentialistischen Verfahren innerhalb der Grundstruktur beinhalten könnte. In bezug auf konkrete soziale Reformen oder Politiken verweist Rawls nämlich wiederum nur auf das Konzept 
der Grundgüter (primary goods). ${ }^{163}$ (Rawls, 1971, 90 ff; ders. 1993, 178 ff) Diese werden von den Individuen bereits im Urzustand mit eingebracht; sie gehen insofern der durch das Differenzprinzip gestalteten Grundstruktur voraus und einige der in ihnen enthaltenen Elemente beziehen sich auch auf das erste Prinzip der Gerechtigkeit. Bei konkreten sozialen Reformen erhalten sie durch die Grundstruktur ihren Hintergrund. Hier nehmen die materiellen Grundgüter, um die es dann bei sozialen Reformen in erster Linie geht, einen geradezu tautologischen Charakter an.

Rawls verweist wiederholt auf die Stufenbau seiner Theorie der Gerechtigkeit, bei der jede Stufe der Theorie die nachfolgende begrenzt. Erst dieser Stufenbau löst den Verdacht des Konsequentialismus auf: Zwar findet die reine Verfahrensgerechtigkeit auf die gesamte Grundstruktur Anwendung, doch bleibt das erste Prinzip der Gerechtigkeit dem zweiten Prinzip dabei vorgeordnet. Dies begründet dann auch die relative Unbestimmtheit der materiellen Gerechtigkeit, (weshalb Rawls aber tatsächliche Verteilungspolitiken wiederum als quasi reine Verfahrensgerechtigkeit charakterisiert):

Thus a just constitution is one that rational delegates subject to the restrictions of the second stage would adopt for their society. And similarly just laws and policies are those that would be indeterminate: it is not always clear which of several constitutions, or economic and social arrangements, would be chosen. But when this is so justice is to that extent likewise indeterminate. Institutions within a permitted range are equally just, meaning that they could be chosen; they are compatible with all the constraints of the theory. Thus on many questions of social and economic policy we must fall back upon a notion of quasi-pure procedural justice: laws and policies are just that they lie within a allowed range, and the legislature, in ways authorized by a just constitution, has in fact enacted them. (Rawls, 1971, 200 f; meine Hervorhebung)

Der Typus fast reiner Verfahrensgerechtigkeit ist wie die reine Verfahrensgerechtigkeit eine Form von kriterienunabhängiger Verfahrensgerechtigkeit, doch im Gegensatz zu dieser Form der Verfahrensgerechtigkeit ist fast reine Verfahrensgerechtigkeit mit normativer Verbindlichkeit ausstattet (Rawls, 1971, 360 ff). Diese kommt ihnen durch das Gesetzgebungsverfahren zu. Keine politischen Verfahren können vollkommen gerechte Ergebnisse garantieren. Dennoch besitzen Gesetzen (im Rahmen von Politikentwicklung) aufgrund des gerechten Gesetzgebungsverfahrens eine normative Verbindlichkeit. Die fast reine Verfahrensgerechtigkeit des politischen Prozesses kann gerechte Ergebnisse im Sinne des Differenzprinzips nur wahrscheinlich machen; sie kann aber nicht mit der Sicherheit reiner Verfahrensgerechtigkeit gerechte Ergebnisse implizieren. KollektiveWahl-Theorie (collective choice theory) und politische Tauschtheorie (bargaining theory) streben in diesem Sinne eine reine Verfahrensgerechtigkeit an, die deliberativen Elemente des politischen Prozesses vollständig vernachlässigt. Reine Verfahrensgerechtigkeit aber bleibt der Wunsch des Theoretikers.

Es sind vermutlich derartige Unklarheiten, die D. MacLean (1994) dazu veranlaßt haben, die Kosten-Nutzen-Analyse (KNA) als Umsetzung von Rawls' Konzept von Verfahrensgerechtigkeit anzusehen. Wie Rawls' rein prozedurales Verfahren verfüge die KNA über kein unabhängiges

163 Das Konzept der Grundgüter scheint Rawls auch dazu zu dienen, das Problem des Arrow Paradoxes zu umgehen. 
normatives Kriterium, das ein bestimmtes Resultat determinieren würde. Die KNA bestimmt durch Konsumentenbefragung externe Kosten und internalisiert die Kosten des Marktversagens wieder in den Markt ohne dabei auf externe Kriterien zurückzugreifen. Als typischer Fall von Marktversagen werden Umweltschäden angesehen. Die Interpretation der KNA als eine Form reiner Verfahrensgerechtigkeit ist angesichts der Unbestimmtheit des Begriffs der Grundstruktur nicht prinzipiell abwegig. Die Grundstruktur bezieht sich nämlich auf Institutionen und nicht auf politische Steuerung und politische Steuerungsinstrumente. Zwar spricht sich Rawls dagegen aus, distributive auf allokative Gerechtigkeit $\mathrm{zu}$ reduzieren, doch inwieweit die Theorie der Gerechtigkeit tatsächlich bestimmte Politikinstrumente präjudiziert oder - nach der Reformulierung in Political Liberalism - theoretisch unterschiedene Kooperationsformen vielleicht auf andere Steuerinstrumente verweisen, hat Rawls nicht ausgeführt. ${ }^{164}$

Kritik an der KNA ist nicht neu, sie erhält jedoch angesichts der ökologischen Krise neue Bedeutung, da mit der KNA Umweltgüter beurteilt und unter einem einzigen Maßstab optimiert werden, - als Wohlfahrtskriterium bspw. unter dem Differenzprinzip. Die KNA macht so produzierte Konsumgüter und nichtproduzierte Umweltgüter kommensurabel und konsumierbar. (Martinez-Alier et al., 1999). Doch die KNA hat notorische Schwächen bei der Bewertung von Umweltgütern, bei der Erfüllung distributiver Kriterien und bei der Berücksichtigung intergenerationeller Folgen (vgl. Pearce, 1976). Die KNA dient nicht der Verbesserung von Umweltqualität, sondern bewertet politische Projekte monetär unter der Annahme eines intertemporal existierenden ökonomischen Optimums. Die KNA schließt damit an die PigouLösung des Externalitätenproblems an und handelt sich die damit verbundenen Informationsprobleme ein (Baumol, Oates, 1975, 57 ff). Angesichts der unzureichenden Konzeptionalisierung der ökologischen Krise als singuläre Umweltschäden in der neoklassischen Umweltökonomie und der Notwendigkeit eines ökologischen Rahmens kann Rawls' Differenzprinzip nur nichtkonsequentialistisch verstanden werden. Rawls' Theorie folgend, wären Umweltschäden damit nach dem Preis-Standard-Ansatz zu internalisiert und nicht nach der KNA (vgl. Rawls, 1971, 268). Die ökologische Modernisierung der Grundstruktur einer Gesellschaft erscheint nur möglich, wenn sie sich in der umweltökonomischen Instrumentenwahl vom Leitbild der Optimalität verabschiedet, das ein widerlegtes, gleichgewichtigen Wachstums ohne Verteilungsdimension versinnbildlicht.

Während die Pigou-Lösung davon ausgeht, Externalitäten im Rahmen einer gleichgewichtigen intertemporalen Allokation von Ressourcen internalisieren zu können läßt der Preis-StandardAnsatz diesen Anspruch explizit fallen. Charakteristisch für den Preis-Standard-Ansatz ist, daß er nicht auf Präferenzen basiert, sondern durch politische Vorgabe definiert ist und eine (volkswirtschaftlich) kostenminimale Lösung darstellt. Es werden umweltpolitische Ziele festgesetzt, die maximale Emissionsmengen (Zertifikate) oder einen Steuersatz (Abgaben) vorschreiben. Bei vollständiger Information könnte die KNA nun wieder als Instrument der

164 Joshua Cohen beschreibt Rawls' liberale Politik als einen Prozeß, der Ergebnis und Verfahren verbinden würde. Cohen hält dabei explizit am Kriterium der Pareto-Effizienz fest, daß seiner Ansicht nach, das Interesse jedes Bürgers fördern würde (1994, 105 f). Diese Interpretation steht nicht nur Rawls' Verteidigung ausgleichender Gerechtigkeit in Political Liberalism entgegen, sondern auch wohlfahrtsökonomischen Einsichten. 
Umweltpolitik angesehen werden (so wohl Keck, 1988). ${ }^{165}$ Doch die Grenzen für den Einsatz von Kosten-Nutzen-Analysen sind (aufgrund der ökonomischen und ökologischen Informationsprobleme) relativ eng gesetzt (vgl. Endres, Schwarze, 1993). Die KNA dient hierbei nicht mehr der endogenen, umweltpolitischen Zielfindung des Wirtschaftssystems, sondern ist auf einen umweltpolitischen Rahmen verwiesen (vgl. Ewers, Rennings, 1996; Blazejczak, Krähmer, 1996). Dabei fließt ökologisches Wissen in den Rahmen ein, das überwiegend nicht endogen vom Wirtschaftssystem bereit gestellt wird. Während die angeführten Ökonomen die Konstitution eines solchen umweltpolitischen Rahmens ihrer Profession zuschreiben, hat S. O'Hara (1996) hier statt dessen wiederum die bereichsspezifische Relevanz der Diskursethik herausgearbeitet. Sie schlägt vor, partizipative Elemente in die KNA aufzunehmen und deren Prozedur damit diskursiv zu verflüssigen. Obwohl dies durchaus eine gewisse Öffnung administrativer Entscheidungen bedeutet, bleibt es doch hinter demokratischen Erwartungen an deliberative Beteiligung zurück: KostenNutzen-Analysen berühren prinzipiell die ökonomische Wachstumsrationalität kaum, da sie nur öffentliche Projekte ihrem Verfahren unterwerfen. KNAs bleiben auf einen ökologischen Rahmen angewiesen, der im Umweltstaat durch Recht demokratisch-partizipatorisch institutionalisiert werden muß. ${ }^{166}$ Empirisch besehen ist der Prozeduralismus durch Diskurse mit Verhandlungen und Argumentationen charakterisiert, die sich nicht auf politisch gewählte Akteure beschränken.

Wohlfahrtsökonomisch bedeutende Entscheidungen wie etwa die Einführung von Ökosteuern werden kaum jemals einseitig vom politischen System getroffen. In der Praxis der Demokratie sind derartige Entscheidungen regelmäßig in Verhandlungssysteme und Netzwerke eingebunden. Netzwerke und Verhandlungssysteme kennzeichnen dem akteurzentrierten Institutionalismus zufolge reale Veränderungen in den politischen Entscheidungsstrukturen, indem nämlich öffentliche und private Organisationen, also korporative Akteure, in den staatlichen Entscheidungsprozeß eingebunden werden (Mayntz, 1993, 40). Die spezifische Logik beruht auf Tausch und Verhandlungen (bargaining) im Unterschied zu Wettbewerb und Autorität bzw. Gehorsam. Zunächst einmal ist das Verhältnis zwischen Staat und gesellschaftlichen Organisationen bzw. Verbänden ein hierarchisches. ${ }^{167}$ Das Verhältnis zwischen Staat und intermediären Organisationen

165 Ein optimaler Steuersatz könnte nach Ansicht von Endres (1994, 95) durch eine versuchsweise Annäherung an das Optimum gefunden werden, was allerdings die Unsicherheit im Markt erhöhen würde (und natürlich auch den Anspruch eines intertemporalen Optimums fallen läßt, vgl. Streissler, 1993.

166 In diesem Zusammenhang ist auch bei Alexy die Vernachlässigung des kognitiven Gehalts der Theorie des kommunikativen Handelns zu beobachten. Dieser hat für seine rechtstheoretische Variante der Diskurstheorie eine "Einbeziehung von Kriterien aus dem Bereich der ökonomischen Rationalität" (Alexy, 1995, 168) konzeptionalisiert, die dem Verhältnismäßigkeitsgebot des Rechts entsprechen soll. Das bei ihm von Prinzipien ausgehende Optimierungsgebot soll der Sicherung bzw. Einschränkung von Grundrechten dienen, wenn (nach dem BVerfG) der Eingriff in ein Grundrecht geeignet, erforderlich oder proportional sei (ebd.). Diese Einschränkung könne zugunsten Dritter oder eines Kollektives - hinsichtlich der Sicherung kollektiver Güter - erfolgen (vgl. ebd., 232 ff). Individuelle Rechte behielten aber einen prima facie Vorrang gegenüber kollektiven Gütern. Alexys Konzept impliziert zwar nicht die ökonomische Vorstellung von Internalisierung, doch deutet es klar die pragmatischen Schwierigkeiten an, die sich dem Verfassungsgericht bei derartigen Abwägungen (im ökologischen Kontext) in den Weg stellen würden; vgl. zur Kritik: Maus, 1994, 314 f.; Habermas, 1992, 181 ff, 1996, 366 ff.

167 Allgemein sind Informationsasymmetrien (Keck, 1987) ein wichtiger Grund für den Wandel von Staatlichkeit von der Hierarchie über zur staatlichen Kooperation mit den Steuerungssubjekten; vgl. Scharpf, 2000, 286 ff. Willke (1995) hat von einer Transformation der Gesellschaft zu einer Wissensgesellschaft gesprochen, die durch eine qualitativ neue Rolle von Wissen, Expertise und Intelligenz definiert werde. Dem Staat komme dabei die Aufgabe zu, eine teils öffentliche, teils private, wissensbasierte Infrastruktur zu etablieren, welche die Produktion von 
enthält jedoch auch Elemente wechselseitiger Abhängigkeit, welche die hierarchische Asymmetrie abschwächen ohne sie aufzuheben (vgl. Scharpf, 1988). Zudem beruht das Verhältnis auf dauerhaften Beziehungen zwischen den beteiligten Interaktionspartnern, welche die Hierarchie weiter abflachen und konsensuales Verhandeln zur Norm werden lassen. ${ }^{168}$ Wo derartige Relationen zwischen Staat und Steuerungsobjekten zur Regel werden, spricht Scharpf von 'Verhandlungssystemen'. In ihnen wird von Hierarchie auf Verhandlungen mit beiderseits konsensenfähigen Lösungen umgeschaltet. Kooperation tritt an die Stelle von Hierarchie. Konträr zur Konstanz formaler Hierarchie impliziert Kooperation ein hohes Maß an kontingenter Handlungsmacht, die sich aus den potentiellen Optionen im Falle eines Abbruchs der Verhandlungen ergibt. Da der Staat im Prinzip immer auf autoritative Regelungen zurückgreifen könnte, ist seine Verhandlungsposition theoretisch besser, doch kann das politische System seine Kompetenzen nicht zu jedem Zeitpunkt geltend machen, so daß der kurzfristige Erfolgszwang für die Politik immer wieder zum Tausch kurzfristiger Vorteile gegen institutionelle Konzessionen führen wird (Scharpf, 1988, 71f).

Verhandlungssysteme lassen sich aufgrund der begrenzten Zahl der Beteiligten und des hohen Maßes an strategischer Interaktion spieltheoretisch darstellen, womit nicht notwendig die Maximierung von Interessen unterstellt wird. Scharpf hat angenommen, daß Kooperation grundsätzlich Ergebnisse ermöglichen kann, die für alle Parteien vorteilhafter sind, daß aber die Ergebnisse unterschiedlich attraktiv für die einzelnen Parteien sind. Damit werden Verhandlungssysteme spieltheoretisch Mixed-Motive-Spielen zugerechnet, bei denen die Parteien zwischen Konflikt und Kooperation schwanken (vgl. Anhang, S. 313 ff). Es treten soziale Dilemmata wie Prisoner's Dilemma (PD) und Chicken Game (CG) auf: Kurzfristige Eigeninteressen können kollektive Selbstschädigung zur Folge haben. Da die rechtliche Fixierung von Verhandlungsergebnissen notwendig Kooperativität im Sinne der Spieltheorie sicherstellt, grenzt sich die spieltheoretische Analyse auf das Spiel der Battle of the Sexes (BS) ein, denn bei diesem kann das Spannungsverhältnis nicht wie beim PD oder beim CG trivial aufgelöst werden. Vielmehr können in bezug auf die Ergebnisalternativen nur solche Lösungen ausgeschlossen werden, die beide Partner schlechter stellen würde. Darüber hinaus aber gibt es keine analytisch

Gefährdungen zweiter Ordnung als Folge wissensbasierter Technologien durch Gegen-Wissen kontrollieren kann. Er nimmt damit Becks Ruf nach Gegengiften auf. Präventive Umweltpolitik, die informationstheoretisch eine Antizipation von Schäden unter unvollständiger Information bedeutet, wäre demnach wesentlich als Abbau von Informationsrestriktionen zu konzeptionalisieren (d.h. Beweislastumkehr, Verbandsklage, Haftungsrecht; vgl. Keck, 1988). Hecht führt das Informationsproblem generell gegen eine prospektive Stoffpolitik ins Feld (Hecht, 1999, 15, 36), übersieht dabei jedoch, daß Tatsachenaussagen nicht nur eine pragmatische Dimension besitzen, sondern auch eine kognitive. Zwar bestreitet er nicht den Wahrheitsgehalt konstanter Materialbilanzen, er beachtet jedoch nur anthropogen produzierte Stoffinformation - das wohl am ehesten als ,emergierendes Rauschen' beobachtet werden kann - in der pragmatischen Dimension und ignoriert den pragmatischen und kognitiven Gehalt von Nachhaltigkeitsindikatoren. Steuerungspraktisch dürfte sich präventive Stoffpolitik vielmehr mit Motivations-, denn mit Informationsproblemen konfrontiert sehen. Wie P. R. Ehrlich et al. (1999) festgestellt haben, bedarf es keiner vorgängigen Wissensexplosion, um die ökologische Krise präventiv zu bewältigen. (Ihre öko-sozialen Indikatoren weisen im übrigen große Parallelitäten zu den Kategorien des MIPS-Konzeptes auf; vgl. ebd., $274 \mathrm{ff}$.)

168 Es kommt dabei zu Oligopolen und Monopolen unter den beteiligten Interaktionspartnern. In der Folge können solche Dauerbeziehungen zu oligopolitischen Funktionssystemen führen, wenn die nachgefragte Leistung nicht unter Konkurrenzbedingungen produziert wird, der Staat aber für den entsprechenden sozialen Funktionsbereich die politische Verantwortung übernommen hat. Ein noch stärkeres Abflachen der Hierarchie läßt sich schließlich beobachten, wenn der Staat unmittelbar Nachfrager der angebotenen Leistungen ist, wie etwa bei großen technischen Systemen; vgl. Mayntz, 1995, 70 ff; Wasem, Schimank, 2000. 
zwingende Lösungen für dieses Spiel, d.h. es stellt sich auch unter (getrennter) Anwendung von bestimmten Entscheidungskriterien kein spieltheoretisches Gleichgewicht ein, sondern nur wiederum eine für beide Parteien suboptimale Lösung. In Rückgriff auf sozialpsychologische Experimentalstudien hat Scharpf die verschiedenen Transformationen des Battle of the Sexes unterschieden in eine kompetitive, eine solidarische und eine kooperative Variante (vgl. dazu die formale Darstellung im Anhang S. 314).

In der kompetitiven Variante des Battle-Spiels kommt es nicht auf die absolute Größe des eigenen Abschneidens an, sondern auf die Differenz zum Ergebnis der anderen Partei. Dagegen ist in der solidarischen oder kooperativen Lösung der relative Gewinn ohne Bedeutung, und es zählt nur der Beitrag zum kollektiv höchstmöglichen Gewinn. Bezogen auf reale Verhandlungssysteme läßt sich das Schwanken zwischen Konflikt und Kooperation an der Vermeidung offener Konflikte zwischen Umweltministerium und Verbänden bei gleichzeitig divergierenden Zielen über den Inhalt von Regelungen verdeutlichen. "Kurz: Nicht nur zwischen unmittelbaren Konkurrenten im selben Funktionsbereich, sondern auch zwischen funktional komplementären Partnern sind die Verhandlungsbeziehungen fast immer ambivalent. Die Koexistenz von gemeinsamen (Produktions-) und konfligierenden (Verteilungs-)Interessen gehören $\mathrm{zu}$ den Grundbedingungen der sozialen Interaktion." (Scharpf, 1988, 73)

Praktisch hat die fehlende Gleichgewichtslösung des Battle-Spiels zur Folge, daß Verhandlungssystemen nur präskriptive Empfehlungen an die Hand gegeben werden können, da alle Auszahlungen instabil sind. Die präskriptiven Empfehlungen orientieren sich gewöhnlich an der sogenannten Nash-Verhandlungslösung, die Unterschiede in der Verhandlungsmacht zwar widerspiegelt, sie aber relativiert und variable, monetäre Kommensurabilität voraussetzt (vgl. Anhang S. 316). Angesichts häufig inkommensurabler, d.h. diskreter und qualitativ ungleicher Ergebnisse können Verhandlungen aber oft auch nicht nach der Nash-Lösung abgeschlossen werden. Eine Trennung von 'Produktion' und 'Verteilung', deren permanente Interferenz das eigentliche Problem des Battle-Spiels darstellt, könnte, wenn sich beide Parteien zuvor auf generelle Regeln ausgleichender Gerechtigkeit verständigt haben, zur Stabilisierung von Verhandlungssystemen beitragen, denn dadurch würde der Verteilungskonflikt neutralisiert und der Abschluß könnte sich am gesamtgesellschaftlich produktivsten Ergebnis orientieren. ${ }^{169}$

Mit dieser Lösung ist aber noch nicht die Frage beantwortet, ob und eventuell wie in Verhandlungssystemen positive Koordination erzielt werden kann. Versteht man mit Scharpf unter Koordination 'Formen der Abstimmung', "deren wohlfahrtstheoretisches Anspruchsniveau über das durch wechselseitige Antizipation in nichtkooperativen Spielen erreichbare Nash-Gleichgewicht

169 Schmalz-Bruns $(1995,10)$ hat positiv auf Scharpfs Auflösung des Geschlechterkampf-Spiels verwiesen, da Fragen des Verfahrens von solchen des Kompromisses oder des Verhandlungsergebnisses getrennt werden würden. Argumente für ein institutionelles Design, die auf Präferenzstrukturen von Individuen aufbauten liefen Gefahr, die institutionelle Ordnung, von der Meta-Präferenzen auch geformt werden, lediglich zu reproduzieren. Dies Problem manifestiere sich auch bei Preuß und Offe. Ein besseres Ergebnis ließe sich dann erzielen, wenn man den Repräsentationsgedanken selbst gleichsam dynamisieren und dialogisieren würde. Als Grund dafür nennt er die Kluft zwischen der Zeitstruktur der Präferenz und deren institutioneller Mediatisierung. 
hinausgeht" (Scharpf, 1993, 58), lassen sich die soeben angestellten Überlegungen fortführen. Findet Koordination nicht über Markt oder Gemeinschaft (Solidarität) sondern über Verträge statt, zeigt sich, daß Lösungen systematisch trotz Verbesserung einer aggregierten Wohlfahrt nicht zustande kommen, weil die Partner sich nicht gleichzeitig beide gegenüber dem Status Quo verbessern. Dies kann selbst beim Fall mehrerer pareto-superiorer Lösungen eintreten, wenn die Partner in der Bewertung nicht vom Pareto-Kriterium auf das Kaldor-Hicks-Kriterium wechseln, also Ausgleichszahlungen an die Schlechtergestellten zulassen. ${ }^{170}$ (Die Probleme nehmen noch ganz erheblich zu, wenn die Zahl selbständiger Partner steigt, da sich damit auch die Zahl von notwendigen Transaktionen erhöht.) ${ }^{171}$ Vorausgesetzt, die Lösungen sind eindeutig zu bewerten, könnte dieses Verhandlungsdilemma durch Hierarchie gelöst werden, indem durch den Staat eines der pareto-superioren Ergebnisse bestimmt wird (und gegebenenfalls in Anwendung des KaldorHicks-Kriteriums Ausgleichszahlungen an Schlechtergestellte vorgenommen werden).

Allerdings zeigt hierarchische Koordination unter den Bedingungen zunehmender reziproker Interdependenzen generell Limits, die Scharpf auf die modulare Organisationsstruktur der Bürokratie zurückführt. ${ }^{172}$ Und obwohl hierarchische Strukturen eine wirksame Koordination nicht leisten können, bestimmt ihr 'Schatten' Scharpf zufolge doch den Kontext, "innerhalb dessen Verhandlungen stattfinden müssen. Einerseits schafft die hierarchische Organisation Bedingungen für Zwangshandlungen, durch die einseitige Aktionen aus dem Handlungsrepertoire der Akteure eliminiert werden; andererseits schafft sie Bedingungen welche die Versuchungen beseitigen oder jedenfalls mindern, die andernfalls die Parteien in der Falle des 'Verhandlungsdilemmas' festhalten würde." (Scharpf, 1993, 70 f) Die hierarchische Einbettung von Verhandlungssystemen in das vertikale Dialogmodell mit der Bürokratie - sowohl während der Politikformulierung als auch der Politikimplementation - steigert somit die Koordinationsleistung von Verhandlungssystemen. Dies wird auch für die Umweltpolitik geltend gemacht (vgl. Jänicke, 1996).

${ }^{170}$ Das dies normative Implikate mit sich führt, verkennt Scharpf zwar nicht (2000, 159 ff), diese dürften jedoch im umweltpolitischen Kontext größer sein, als in wohlfahrtsstaatlichen Politikfelder, die auf zuverlässigere Formen der Monetarisierung zurückgreifen können.

${ }^{171}$ Während für kooperative Spiele unter multilateralen Bedingungen nur extrem komplexe mathematische Lösungen existieren, kann die kompetetive Nash-Lösung vergleichsweise einfach auf den N-Personen-Fall erweitert werden, wenn Zwangsverhandlungen zum Ausschluß von Partial-Koalitionen zugelassen werden und enge Grenzen für den weiteren Verhandlungsprozeß gesetzt werden. Jenseits dieser Grenzen sind die Anforderungen an die Informationsverarbeitungs- und Konfliktregelungskapazitäten so hoch, daß sie die Verhandlungen scheitern lassen. Kurzum: Die Zahl der Partner beschränkt die Funktionsfähigkeit von Verhandlungssystemen aufgrund prohibitiv hoher Transaktionskosten; vgl. Scharpf, 1993, $66 \mathrm{f}$.

${ }^{172}$ In der Politik werden regelmäßig separate Bewertungen von Projekten mit komplementären Kosten-NutzenBilanzen durchgeführt, und zu komplexen Verhandlungspaketen mit positiven Wohlfahrtsbilanzen geschnürt. Obwohl diese Mechanismen normativ defizitär sind, finden sich entsprechende Strategien zur Überwindung von Verhandlungsblockaden beispielsweise als 'issue-linkage' und 'log-rolling' in der Politik wieder. Innerhalb der Administration sichert Regierungstätigkeit im Modus einer negativen Koordination wohlfahrtstheoretisch besehen die Pareto-Superiorität von Politikinitiativen. Dagegen wird im Modus der positiven Koordination das KaldorOptimum angestrebt. Negative Koordination zielt auf die Vermeidung von Störungen, die aufgrund der egoistisch Zielverfolgung der einzelnen Ministerien oder Abteilungen in anderen Ministerien bzw. Abteilungen entstehen können. Negative Koordination reduziert entscheidend das Problem der großen Zahl; sie kann allerdings auch zu einer Kumulation von Veto-Positionen führen und so die angenommene Wohlfahrt unter das Niveau einer positiven Koordination drücken. Dieses läge aber noch immer über dem zu erwartenden Niveau einer unkoordinierten, fachfixierten Handlungsweise der Administration. 
Dieser 'Schatten der Hierarchie' kommt auch in pluralistischen und korporatistischen Politiknetzwerken zur Geltung. Dabei bleibt die gelungene Selbstkoordination an rechtliche Verfahrensregeln und staatliche Zustimmung gebunden. Verhandlungen zielen auf ein gemeinsames Ergebnis und daneben individuell auch auf eigene Verbesserungen. Politiknetzwerke dienen den beteiligten Akteuren der Problemlösung und dem Interessenausgleich, dem Staat dienen sie zur Beschaffung von Informationen und zur Erhöhung der Akzeptanz von Politiken. Mehr noch: Die in Netzwerkstrukturen regelmäßig zu beobachtenden Dauerbeziehungen erfordern 'Vertrauen' welches durch kooperative Beziehungen entsteht, d.h. durch Beziehungen bei denen die Partner von der Schädigung ihrer wechselseitigen Interessen absehen (vgl. Mayntz, 1997, 252). (Dagegen würde die egoistisch rationale Nutzenmaximierung bei Mixed-Motive-Spielen diese in ein kompetitives Spiel einmünden lassen. Indifferente Beziehungen, mit schwankenden teils kooperativem, teils kompetetiven Verhalten, seien für den Markt generalisierbar.)

Netzwerkstrukturen ermöglichen demnach Formen positiver und negativer Selbstkoordination, die der Koordination durch hierarchische Organisationen ähnlich ist: Die Einbettung von Verhandlungen in hierarchische Strukturen reduziert Transaktionskosten, welche die Reichweite und die Effektivität der positiven Koordination erhöhen. Negative Koordination flankiert die Struktur des Netzwerkes durch Vertrauen, für die auch die Rechtsordnung keinen Ersatz bietet, da sie einseitiges Handeln zugunsten anderer nicht vorschreiben kann. Es ist allerdings wichtig zu sehen, daß der jeweils aktualisierte, positive Koordinationsbedarf nur dann die Wohlfahrt erhöhen wird, wenn die analytische Problemstruktur mit der Netzwerkstruktur übereinstimmt. Die Ergebnisse der Koordination sind unmittelbar von der strukturellen Konfiguration des Netzwerks abhängig. Insofern externe Interessen berücksichtigt werden müssen, verschärft sich aber wiederum das Problem der großen Zahl und mit ihm erhöhen sich dann auch die Transaktionskosten. In gewissem Umfang kann negative Koordination auch hier stabilisierend wirken; dies hängt u.a. von dem Verhältnis zwischen tatsächlicher Interdependenz und der Struktur des Netzwerks ab.

Selbstkoordination durch Verhandlungen im Schatten der Hierarchie ist abhängig von der jeweils gegebenen Struktur von Autoritätsbeziehungen (oder asymmetrischen Machtbeziehungen) und von den Grenzen formaler Organisationen. Und auch wo Netzwerkstrukturen über Organisationsgrenzen hinausreichen, ist ihre Wirksamkeit doch mindestens ebenso selektiv. Sie hängt ab von der jeweils gegebenen Verteilung starker und schwacher Dauerbeziehungen zwischen formell unabhängigen individuellen und korporativen Akteuren. Auch wenn das Gesamtniveau der Koordiniertheit wesentlicher erhöht wird, gibt es also keinen Grund für die Annahme, daß alle oder auch nur die meisten Chancen zur Optimierung auch tatsächlich genutzt werden oder daß alle oder die meisten Interessen gegen die negativen Externalitäten von Entscheidungen an anderer Stelle geschützt werden. (Scharpf, 1993, 79 f)

Negative und positive Koordination funktioniert demnach nicht nur in hierarchischen Strukturen, sondern auch in Verhandlungssystemen.

Im Unterschied zu Rawls' normativer Theorie hat der empirische Forschungsansatz des akteurzentrierten Institutionalismus spieltheoretisch-strategische Rationalität und historische Dimension über die Differenzierungstheorie kritisch weitergeführt (Mayntz et al., 1988; Mayntz, 
Scharpf, 1995c). ${ }^{173}$ Die Systemtheorie wird durch die Akteur-Struktur-Dynamiken fortgeschrieben, wonach neben institutionellen Ordnungen und Akteurskonstellationen auch teilsystemische Orientierungshorizonte bestehen. Das letztere Konzept teilsystemischer Orientierungshorizonte knüpft an Luhmanns frühe Theorie an (vgl. Schimank, 1988, Braun, 1993). Danach reduzieren teilsystemische Orientierungshorizonte für die Akteure die Komplexität der Welt und "zwar in um so stärkerem Maße, je mehr sich eine selbstreferentiell geschlossene teilsystemspezifische Handlungslogik herauskristallisiert." (Schimank, 2000, 243) Wie bei Luhmann ist das Teilsystem um einen binären Code zentriert. Der für Luhmann unbedeutende Akteur erhält im Ansatz des akteurzentrierten Institutionalismus durch das Teilsystem eine volitionale Ausrichtung. Gesellschaftliche Teilsysteme sind in diesem Sinne als Akteursfiktionen zu verstehen.

Innerhalb und zwischen den jeweiligen Teilsysteme bestehen zahlreiche Akteurskonstellationen. In dieser Dimension der ausdifferenzierten Strukturen sind Akteure die Strukturkomponenten, die ihr Handeln wechselseitig prägen. Dies läßt sich als strategisch-rationales Verhalten beobachten. Akteure versuchen ihre Intentionen umzusetzen, beobachten dabei ihre jeweiligen Gegenüber und erhalten so Informationen darüber, ob und eventuell wie diese zur Unterstützung der eigenen Intentionen stehen. Daraufhin kann eine möglichst zutreffende Handlungsrichtung gewählt werden, in der sich das Können der Akteure ausdrückt. Die Sollens-Seite gesellschaftlicher Vorgaben tritt dem Akteur über die institutionelle Ordnung entgegen. Dabei existieren unterschiedliche Formen, angefangen von Sitten und Gebräuchen über formalisierte Rechtsnormen und Verfahrenregeln und Verhaltenserwartungen für Organisationen. Diese normativen Kontexte institutioneller Ordnungen stabilisieren ebenso wie Teilsysteme die wechselseitige Erwartungssicherheit von Akteuren. Institutionelle Ordnungen sind jedoch stärker spezifiziert als Teilsysteme. "Wollens- und Sollensvorgaben sowie Könnenskalküle bestimmen vereint die Handlungssituation. Die evaluative Modalität der teilsystemischen Orientierungshorizonte geht in die normative Modalität der institutionellen Ordnung und diese in die kognitive Modalität der Akteurskonstellation über; und so geht das teilsystemische geprägte Wollen in das institutionell geprägte Sollen und dieses in das konstellationsgeprägte Können der Akteure ein." (Schimank, 2000, 246; vgl. auch Mayntz, Scharpf, 1995, 49 ff) Entlang dieser Richtungsangabe sinkt auch die Generalisierbarkeit des empirischen Ansatzes. ${ }^{174}$ In differenzierungstheoretischer Perspektive sind teilsystemische und institutionelle Struktur die entscheidenden Variablen.

Im Unterschied zur Systemtheorie richtet sich das Augenmerk des akteurzentrierten Institutionalismus dabei auch auf das für die Politikwissenschaft interessante Mesoniveau sozialer Prozesse. Dies sind in erster Linie Netzwerke. Gegenüber der Systemtheorie verweist der Ansatz auch auf die Ressourcenabhängigkeit funktionaler Systeme vom Staat (und vom Wirtschaftssystem) ohne damit jedoch schon die von der Systemtheorie betonte Fähigkeit zu gesellschaftlicher

173 Allerdings ist der Rückgriff auf die differenzierungstheoretische Erklärung von Selbststeuerung gegenüber der akteurstheoretischen zunehmend in den Hintergrund getreten, Schimank, 2000, $241 \mathrm{ff}$.

174 Auch Prittwitz hat darauf hingewiesen, daß der Erklärungsgehalt, der die Entstehung und Entwicklung institutioneller Arrangements intentionalem Handeln zuschreibt, in der historischen Dimension schwindet; vgl. von Prittwitz, 2000, $24 \mathrm{ff}, 31 \mathrm{ff}$. 
Selbststeuerung zu negieren. Die zu Selbstorganisation fähigen formalen Organisationen tragen innerhalb von Netzwerken die funktionale Ausdifferenzierung, so daß Netzwerke als Indikatoren für gesellschaftliche Modernisierung gesehen werden können. ${ }^{175}$ Differenzierungstheoretisch liegen Netzwerke mit ihren lose gekoppelten formalen Organisationen zwischen Markt (ohne strukturelle Koppelung) und Hierarchie (feste Koppelung). Die von Netzwerken getroffenen Entscheidungen sind systemübergreifend (vgl. Braun, 2000, 138). In der Policyforschung wird dann nach der Steuerbarkeit gefragt, was zunächst nicht mehr kennzeichnet als eine Bezugnahme auf soziale Selbstorganisation. Wird Steuerbarkeit auf staatsnahe Sektoren bezogen, so ist der Bereich zwischen Markt und Staat gemeint (Mayntz, Scharpf, 1995b). Für den akteurzentrierten Institutionalismus impliziert Steuerbarkeit keine rationalitäts- oder systemtheoretische Stellungnahme, sondern folgt einer politikwissenschaftlichen Forschungspragmatik.

\subsubsection{Eine Theorie der Zivilgesellschaft}

In der Theorie des kommunikativen Handelns rekonstruiert Habermas eine Entwicklungslogik politischer Modernisierung, die den historischen Wandel politischer Institutionen als lernende Annäherung an die Prinzipien Egalität und Diskursivität versteht. In der späteren Rechtstheorie verbinden sich normative und systemische Aspekte politischer Institutionen, indem der systemischen Faktizität moderner Gesellschaften die normative Geltung kontrafaktischer Konsense entgegenstellt wird. Die Verbindung dieser beiden gegensätzlichen möglichen Entwicklungstendenzen erfolgt innerhalb des Rechtssystems; sie ist immer sozial situiert, da Recht lediglich als Medium und funktionale Ergänzung kommunikativen Handelns verstanden wird. Doch Recht reproduziert zugleich politisches Teilsystem und Rechtssystem und ist beständig gefährdet, zu einer irrationalen Herrschaft zu verkommen. Denn der Rückgriff auf das Medium des Rechts eröffnet auch die Gefahr asymmetrischer Macht. Einverständnisorientiertes Handeln kann diese Gefahr bannen und die Asymmetrie aufheben. Im demokratischen Rechtsstaat, der durch das Faktum des politischen Pluralismus charakterisiert ist, wird kommunikatives Handeln nur in begrenztem Maße als einverständnisorientiertes Handeln aus der Lebenswelt in die Systemwelt überführt.

Habermas hat aus der Asymmetrie zwischen Sprechern und Rechtspersonen die normative Forderung abgeleitet, daß, um staatsbürgerliche Autonomie zu ermöglichen, zivilgesellschaftliche Macht die Ungleichverteilung sozialer Machtpositionen neutralisieren müsse (Habermas, 1992,

175 Schimank benutzt ein Konzept reflexiver Interessen zur Erklärung weiterer Differenzierungsvorgänge in Verhandlungssystemen. Als reflexiv bezeichnet er solche Interessen, "die sich auf die generellen Bedingungen der Möglichkeit der Realisierung spezifischer substantieller Interessen beziehen" (Schimank, 2000, 253), und er nimmt an, daß Akteure sowohl innerhalb ihrer Interessensphäre nach Dominanz streben als auch außerhalb die Entscheidungsautonomie zu vergrößern beabsichtigen. Interessen stünden dergestalt mit dem Einflußpotential der Akteure im zirkulären Zusammenhang. So ließen sich Differenzierungsvorgänge als komplexes Zusammenwirken von Leistungsdefiziten, Akteursinteressen sowie kulturellen Legitimationen verstehen. Allerdings dürften dabei Cournot-Effekte, die sich nur historisch verstehen ließen, nicht weggeneralisiert werden; diese setzten der Verwissenschaftlichungsdynamik generelle Grenzen, die berücksichtigt werden müßten, Schimank, 2000, $254 \mathrm{f}$. 
215). Die Asymmetrie zwischen Sprecher und Rechtsperson fällt nicht in die Gesellschaft zurück, sondern in die Zivilgesellschaft. Diese ist eine durch Solidarität, politische Öffentlichkeit, freie und unfreie Assoziationen, Verbänden, Organisationen und partizipationsoffene Institutionen strukturierte Sphäre der Gesellschaft. Habermas hat zunächst Hegels Unterscheidung von Sittlichkeit und Moralität beibehalten (vgl. Habermas, 1963) und in der Theorie des kommunikativen Handelns mit der Unterscheidung zwischen Lebenswelt, Ökonomie und Staat auch dessen Konzept der Zivilgesellschaft andeutungsweise fortgeführt und zugleich an die zivilgesellschaftliche Tradition intermediärer Institutionen Montesquieus assimiliert. Schließlich ist Habermas jeodch in Faktizität und Geltung zugunsten eines Prozeßmodells deliberativer Politik vom Konzept der Zivilgesellschaft abgerückt und hat sich nicht näher auf die entsprechenden Arbeiten von Cohen und Arato bezogen.

Generell steht eine Theorie des demokratischen Rechtsstaats vor der Frage, ob und wie sie mikrostrukturelle, egalitarisierende Prozesse der Selbstorganisation fördern kann oder ob sie diese sich selbst überlassen muß. Dabei geht es um nicht weniger als die Reproduktion und Selbstorganisation von Zivilgesellschaft angesichts ihrer Kolonialisierung durch das politische und das ökonomische System. Cohens und Aratos Konzept ist kulturalistisch und vernachlässigt die institutionellen Aspekte von Zivilgesellschaft. Doch es schließt einen institutionellen Zugang auch nicht a priori aus, so daß soziopolitische Selbstorganisationsprozesse der Zivilgesellschaft vor dem Hintergrund ausdifferenzierte Teilsysteme durchaus angemessen erfaßt werden können (Cohen, 1989).

Demokratische Praxis kann ihrerseits die systemische Kolonialisierung der Lebenswelt zu bewältigen versuchen oder diese ignorieren; sie kann aus der Kontrafaktizität der Diskursethik substantielle Erkenntnis ziehen oder sich in Utopie verlieren. In dieser Perspektive erscheinen zwei grundsätzliche Zukunftsszenarien demokratischer Praxis denkbar (vgl. Eder, 1989, 118): Im ersten Szenario würde der Staat entdifferenziert werden und sich in die Öffentlichkeit verlagern. Dabei könnte die Entwicklung eine radikaldemokratische und eine populistische Richtung nehmen. Im zweiten, Szenario würde die politische Öffentlichkeit zum Publikum neutralisiert werden und das Zusammenspiel von Staat und Öffentlichkeit als Garant demokratischer Institutionen wegfallen. Neben der Systemtheorie könnte auch eine sich spieltheoretisch-mikroökonomisch beschränkende Sozialtheorie zu einem solchen Szenario führen. Wahrscheinlicher wäre für letztere indes vermutlich eine populistische Entwicklung. Gleichwohl könnten beide Differenzierungsvarianten ihre demokratische und ökologisch-soziale Integration nicht mehr sicherstellen.

Nach Cohen und Arato ist die Zivilgesellschaft eine soziale Sphäre, die sowohl vom Staat als auch vom Wirtschaftssystem zu unterscheiden ist. Sie beinhaltet vier Prinzipien: Pluralismus, Öffentlichkeit, Privatheit und Legalität (Cohen, Arato, 1992, 346). Das Wechselspiel dieser Prinzipien mit den diskursiv generierten Normen der Diskursethik erlauben die Verteidigung einer diskurstheoretischen Version von Zivilgesellschaft gegen die Einwände, daß eine solche Konzeption die notwendige Unterscheidung zwischen Gesellschaft und Staat unterminieren muß (Arendt), daß Normen in der Zivilgesellschaft die soziale Disziplinierung steigern müssen 
(Foucault) oder daß Zivilgesellschaft notwendigerweise staatszentriert (Hegel) bzw. ökonomistisch (Marx) sein muß. Cohen und Arato entfalten ihre Theorie der Zivilgesellschaft in mehreren Schritten entlang Habermas' Theorie und seiner universalpragmatischen Unterscheidung von System und Lebenswelt:

Im Gegensatz zu den dualistischen Konzeptionen von Zivilgesellschaft vs. Staat besteht das diskurstheoretische Modell aus drei Ebenen: der Lebenswelt sowie dem administrativen und dem ökonomischen System. Im Gegensatz zum systemtheoretischen und ökonomistischen Reduktionismus sind Systeme der Theorie kommunikativen Handelns zufolge nicht streng analog, sondern hierarchisch. Dies führt "to conditions of weaker symbolization in a far more heterogeneous system of codes, less fluid circulation, less stable accumulation, greater difficulties in measurement, and greater dependence on organization but also to a direct legitimation linked to tradition or agreement." (Cohen, Arato, 1989, 426) Die politische, rechtsetzende Macht sei zwar an Interessen gebunden, bleibe aber im Gegensatz zum ökonomischen System auf kommunikatives Handeln verwiesen. Sie geht also nicht auf Interessen zurück. Als administrative Macht wende sie zwar Recht an, generiere dieses jedoch nicht eigenständig, sondern sei auf zivilgesellschaftliche Infusionen aus der Lebenswelt angewiesen, die kommunikative Macht in politische transformiere. Denn eben diese Lebenswelt sei immer schon kommunikativ verfaßt und, im Gegensatz zu den systemisch integrierten Systemen Ökonomie und Administration, sozial integriert in den Formen kultureller Reproduktion, sozialer Integration und individueller Sozialisation. Die Reproduktion der Lebenswelt vollziehe sich dabei in zwei Dimensionen, nämlich über den sprachlich-kulturellen und über den institutionell-soziologischen Hintergrund. Vor diesem Hintergrund ordnen Cohen und Arato Öffentlichkeit und Privatheit der Lebenswelt zu. In bezug auf die systemische Integration besäße nur das politisch-administrative System eine Öffentlichkeitsdimension, die dieses an die Lebenswelt rückbinde. Eine solche Rückbindung könne das ökonomische System nicht vorweisen. Nach Cohen und Arato bietet dieses Konzept den Vorteil, Interventionen des Staates in die Ökonomie nicht mit Staatsinterventionen in die öffentliche Sphäre gleichsetzen zu müssen.

\begin{tabular}{|c|c|c|}
\cline { 2 - 3 } \multicolumn{1}{c|}{} & Public & Private \\
\cline { 2 - 3 } System & political subsystem /state & economic subsystem \\
\hline Lifeworld & public sphere & private sphere \\
\hline
\end{tabular}

(Cohen, Arato, 1992, 431, Schaubild 2)

Die beiden Arten der Unterscheidung zwischen öffentlich und privat liegen im einen Fall auf der Ebene der Systeme im anderen Fall auf der Ebene der Zivilgesellschaft bzw. der Lebenswelt. Diese Konzeption eines dualen Schemas von Öffentlichkeit und Privatheit wäre streng symmetrisch. Dies wird erst dadurch gebrochen, daß Cohen/Arato die institutionelle Dimension der lebensweltlichen Reproduktion ganz von der kulturellen und der individuellen unterscheiden und außerhalb der Dichotomie von Öffentlichkeit und Privatheit verorten. "Of the three institutional dimensions of the 
lifeworld, the notions of public and private as used here activate only those of the reproduction of culture and personality. The institutions of social integration, institutionalized groups, collectives, and associations are omitted from this treatment, despite their obvious political and economic relevance." (Cohen, Arato, 1992, 431) Über die ausgeklammerte institutionelle Dimension halten die beiden Autoren ihr Konzept der Zivilgesellschaft für lebensweltliche Einflüsse offen. Zugleich etablieren die Einflüsse der Lebenswelt über die Vielzahl der damit verbundenen partiellen Öffentlichkeiten einen (politischen) Pluralismus in der Zivilgesellschaft, der sich gleichsam selbst vor jeder totalitären Wendung bewahrt. "The lifeworld is dissimilar to money and power; even its associationally organized institutions cannot easily or spontaneously invade and subsume the differentiated subsystems. Even more important, its own modernization depends on the differentiation of modern economy and state; their dedifferentiation would deprive civil society of time resources for democratic deliberation and decision making." (ebd., 543 f) Die Einflüsse der Lebenswelt sind jedoch nicht nur institutioneller, sondern ebenso kultureller Art.

Für Cohen und Aratos Theorie der Zivilgesellschaft ist Habermas' Ansatz einer verstehenden Soziologie - also das hermeneutische Konzept von System und Lebenswelt - problematisch. Wie sie konstatieren, ermöglicht es diese Unterscheidung nicht, etwa Barrieren gegen die Kolonialisierung der Lebenswelt zu errichten oder auch nur Sensoren gegen die Ausweitung von Systemen (vgl. Cohen, Arato, 1992, 473). Das Medium der Lebenswelt, Solidarität, ist im Gegensatz zu den Medien Macht und Geld keine Steuerungsressource, sondern eine ubiquitäre und dennoch diffuse, nicht dirigierbare Ressource, die nur indirekt auf die geschlossenen Systeme Einfluß nehmen kann. Für soziale Bewegungen entsteht daraus das Problem, daß sie einerseits ihre lebensweltliche Bindung zu verlieren drohen, wenn sie erstarken und sich zu komplexen formalen, bürokratisch geführten Organisationen entwickeln und daß sie anderseits als soziale Institutionen immer lebensweltlich verankert bleiben. Dieses Problem besteht nicht nur aufgrund Cohen und Aratos dualistischer Sicht auf System und Lebenswelt, sondern auch in rationalitätstheoretischer Hinsicht als Widerstreit zwischen kommunikativem und strategischem Handeln.

Cohen und Arato thematisieren jedoch nur die theoriestrategische Frage, inwieweit Zivilgesellschaft überhaupt mit Lebenswelt identifiziert werden kann. Im Gegensatz zum Konzept der Lebenswelt beinhalte das der Zivilgesellschaft vertikale Verbindungen der Mediation zwischen den zwar analytisch trennbaren aber komplementären politischen und ökonomischen Institutionen der Zivilgesellschaft. Während die kommunikative Koordination von Institutionen zur Lebenswelt gehöre, zähle die Steuerung von Institutionen durch Medien demgegenüber zu den Systemen (vgl. Cohen, Arato, 1992, 480).

Die Kategorien Lebenswelt und System haben für Cohen/Arato eine heuristische Funktion. Sie geben zumindest grobe Hinweise auf Gewichtungen innerhalb des institutionellen Rahmens.

Cultural, social, and personality-reproducing institutions have their center of gravity in communicative/normative forms of actions coordination. Nevertheless, it becomes possible to locate strategic dimensions as well as forms of administration and monetarization in lifeworld institutions [...] without pathological consequences, as long as they remain subordinated to 
communicative coordination and goal definition and as long as they are not allowed to develop their own logics - the proper meaning of colonization. (Cohen, Arato, 1992, 479)

Eine Demokratisierung der Gesellschaft erscheint aber durch das Eindringen kommunikativer Rationalität in Systeme prinzipiell möglich. Cohen und Arato bezeichnen die gesellschaftliche Demokratisierung auf der Ebene der Zivilgesellschaft als ihr zentrales theoretisches Anliegen, halten indes auch nur auf dieser Ebene - und nicht auf der Systemebene - eine Demokratisierung für erfolgversprechend. Gleichwohl schließen sie innersystemische Demokratisierungen nicht aus (ebd., 417). Jede Demokratisierung finde jedoch ihre Grenze an der von den Medien erbrachten Steuerungsleistung, d. h. "the center of gravity of the coordinating mechanisms (in a modern society) is and must be on the level of steering performance through media of money and power, that is, through system rationality." (Cohen/Arato, 1992, 480) Sie muß die selbst-regulativen Steuerungsmechanismen der Systeme intakt lassen. Deshalb wird sich die Steuerungsleistung der Systeme empirisch nur sehr begrenzt durch kommunikatives Handeln im Medium der Solidarität ersetzen läßt. Die Ersetzung von binären Codes durch kommunikatives Handeln würde die zeitlichen Ressourcen der Zivilgesellschaft in einem großen Maße binden und könnte dabei das zivilgesellschaftliche Medium der Solidarität überlasten. Prinzipiell aber erscheint die Infusion kommunikativen Handelns in die gesellschaftlichen Systeme, und damit verbunden deren Demokratisierung, möglich.

Cohens und Aratos Theorie der Zivilgesellschaft eröffnet hier grundsätzlich die Möglichkeit, Institutionen zwischen Zivilgesellschaft und Ökonomie zu etablieren, die systemische und lebensweltliche Aspekte miteinander verbinden und damit eine demokratische Reproduktion der Gesellschaft ermöglichen. (Cohen und Arato konkretisieren ihre konstruktivistische Theorie auch in bezug auf das ökonomische System und nennen die Einführung von Konsumenten- und Produzentenkooperativen, Angestellten- und Gewerkschaftsrepräsentanten in Körperschaften, verschiedene Formen von Räten etc. als Aufgaben.) Allerdings wäre dabei überhaupt erst noch zu klären, was unter 'systemischen Steuerungsmechanismen' zu verstehen ist. Da Dissens über das Potential von Steuerungsmechanismen erst auf institutioneller Ebene zu erwarten ist, ist die Spezifikation empirischer Kriterien ein Grunderfordernis für politikwissenschaftliche Forschung.

Cohen und Arato haben sich an dieser Stelle auf die Diskussion über die Zukunft des Wohlfahrtsstaates bezogen und mit Habermas die reflexive Fortführung des Wohlfahrtsstaates befürwortet. Die Sicherungs- und Verteilungsfunktionen des Wohlfahrtsstaates werden durch die Verteilungsmasse und durch den Modus der Steuerung geprägt. Die Steuerung ist an das Medium Geld gebunden. Das Individuum und seine soziale Sicherung wird von einer sozialstaatlichen Infrastruktur gewährleistet. Das Sozialstaatsprinzip - oder allgemeiner: soziale Gerechtigkeit - ist organisationsabhängig. Individuelle Leistungsansprüche bestehen nicht autonom, sondern werden durch eine sozialstaatliche Infrastruktur mediatisiert. Nicht subjektive, einklagbare Rechtsansprüche, sondern das objektive Recht, verpflichten den Staat zum Aufbau und Erhalt sozialer Sicherheitssysteme. 
Die Parallele zum Umweltstaat ist offensichtlich: Nicht Grundrechte oder Eigenrechte der Natur konturieren den rechtlichen Schutz der Umwelt, sondern nichtindividualisierbare Kollektivgüter (vgl. Wolf, 1994; Alexy, 1995b). Kausalität löst sich bei einer (versuchten) Zuschreibung von der individuellen Handlung ab (vgl. Ladeur, 1997). ${ }^{176}$ Smog ist demokratisch. Wo tatsächlich Grundrechte berührt werden, haben sich Risiken längst in möglicherweise irreversible Gefahren verwandelt. Ebenso wie im Fall des Sozialstaats werden die Funktionen des Umweltstaates durch das ökonomische System mediatisiert. Der Metabolismus der modernen Gesellschaften mit der Natur - d.h. die Quantität und Qualität des Stoff- und Energiestroms - wird durch das Medium Geld gesteuert. Betriebe und Haushalte sind die primären Adressaten monetärer der Steuerung.

Mit dem Wohlfahrtsstaat teilt der Umweltstaat auch das Problem der Kolonialisierung der Lebenswelt. Mit dem Übergang von einer Klassengesellschaft zu einer Risikogesellschaft geht auch ein entsprechender Wechsel von moralischen Dilemmatasituationen in der Auseinandersetzungen zwischen Moralität und Sittlichkeit einher. An die Stelle von Positivsummenspielen in Gestalt wachsender Wohlfahrtsgewinne treten potentielle Negativsummenspiele kollektiver Selbstschädigung, bei dem alle Schäden erleiden, ohne daß irgend jemand einen Nutzen zu erzielen vermag (vgl. Beck, 1986, 50). Für demokratisch verfaßte Gesellschaften hat dies (schleichende) Folgen:

Die erforderlichen Steuerungsleistungen werden in einer solchen Konstellation vielmehr, statt Angelegenheit der staatlichen Redistributation von Rechten und Ressourcen zu sein, gleichsam subjektiviert. Sie wandern von der Bühne staatlicher Politik ab und kommen unmittelbar im 'Publikum', d. h. in der Lebenspraxis derjenigen zur Wirkung, die ihr Handeln an Regeln der kollektiv-rationalen und verantwortlichen Selbstbindung zu orientieren bereit und fähig sind, die in ihrem funktionalen Stellenwert stark aufgewertet werden und für welche die staatliche Regulierung allenfalls Orientierungspunkte angeben, aber keine Alleinzuständigkeit für Normsetzung und -durchsetzung übernehmen kann. (Offe, 1989, 743)

Unter diesen Vorzeichen erscheint Solidarität im Umweltstaat noch stärker gefährdet zu sein als im Wohlfahrtsstaat. Es ist Cohen und Arato daher zuzustimmen, daß Solidarität auch um ihrer selbst Willen gefördert werden muß (Cohen, Arato, 1992, 470). Im Unterschied zu den Steuermedien Geld und Macht kann Solidarität andere Medien nicht kontrollieren: Soziale Bewegungen und freie Assoziationen bleiben bezüglich ihrer sozialen Selbstorganisation immer der Lebenswelt verhaftet, selbst wenn sie im Zuge ihrer Entwicklung lebensweltliche Bezüge dadurch verlieren sollten, daß sie zu komplexen, formalen Organisation anwachsen, die bürokratischen Organisationsmechanismen unterliegen. Aufgrund dieser Rückbindung an die Lebenswelt ist ihr Einfluß auf das politische System immer begrenzt. Aus eben diesem Grund können soziale Bewegungen und freie Assoziationen auch nur eingeschränkt vom politisch-administrativen System funktional vereinnahmt werden (vgl. Cohen, Arato, 1992, 473). Es stellt sich daher immer wieder praktisch die normativ-theoretische Frage, wie Solidarität indirekten geschlossene Systeme beeinflussen kann, in die keine direkte Intervention möglich ist.

176 Dies bestreitet nicht etwa das Verursacherprinzip, sondern verweist auf die kollektive Verursachung von ökologischen Effekten, die sich nur um den Preis eines ökologischen Tugendterrors individualisieren ließen. 
Soziale Bewegungen zeitigen auf drei Ebenen system- und sozialintegrative Effekte: erstens tragen sie zur Modernisierung (politischer) Institutionen bei, da sie dieselbe Art von Informationen wie Bürokratien produzieren; zweitens stellen sie neue Eliten und drittens beinhalten sie auch eine kulturelle Modernisierung (sozialer Beziehungen, der Affektionen, der Gewohnheiten und der Sprache). Sie operieren dabei als Signale, die aus partikularen, sozialen Kontexten hervorgehen, welche ihrerseits durch paradoxe Bedeutungen charakterisiert sind. Soziale Bewegungen decken über ihre (Selbst-)Repräsentation die Irrationalität bestehender Codes auf. Dabei wird diese Form kollektiven Handelns lediglich von dem Selbstzweck getragen, den Telos sozialen Lebens explizit darzustellen; indem sie dies jedoch im öffentlichen Raum tun und dabei als Signal und Repräsentation für paradoxe Bedeutungen fungieren, reflektieren sie zugleich Machtbeziehungen (vgl. Melucci, 1988, 250 f).

Für soziale Bewegungen bzw. freie Assoziationen ist Öffentlichkeit von entscheidender Bedeutung. Zwar variiert der unmittelbare Bezug auf Öffentlichkeit je nach Typus der Assoziation, nach Entwicklungsphase, Zielgruppe und Eigenschaften der Gegner, doch verschwindet die Bedeutung öffentlicher Meinung niemals vollständig. Ganz im Gegenteil, ohne öffentliche Resonanz finden soziale Bewegungen nicht statt. D. Rucht hat zwei Situationen der Entwicklung sozialer Bewegungen unterschieden: Zum einen können marginale Bewegungen ein Problem auf die öffentliche Agenda bringen. Zum anderen kann ein Problembereich durch öffentliche Thematisierung zur Entstehung von sozialen Assoziationen beitragen (vgl. Rucht, 1994). Beide Fälle werden vor allem dann wahrscheinlich, wenn das politische System die entsprechenden gesellschaftlichen Probleme nicht hinreichend wahrnimmt.

Dies gilt insbesondere, wenn sich Parteien, Verbände und Staat gegenüber als drängend empfundenen Problemen indifferent zeigen, diese bloß rhetorisch aufgreifen oder mit zu wenig Nachdruck bzw. zu geringer Wirkung verfolgen: Dann ist es möglich, daß sich von 'unten' her, vorbereitet über kleinere Formen von Öffentlichkeit (z. B. Veranstaltungen und einzelne Protestaktionen), oder aber von 'oben' her, angestoßen durch die Thematisierung in den Massenmedien, Bewegungen formieren - sofern zusätzliche Entstehungsbedingungen vorliegen. (Rucht, 1994, 338)

Öffentlichkeit, insbesondere die massenmediale Öffentlichkeit, ist für soziale Bewegungen, (freie, aber auch unfreie Assoziationen) von so großer Bedeutung, da nur sie es überhaupt ermöglicht, daß, im Vergleich zu Parteien und Verbänden, geringe Einflußpotential sozialer Bewegungen zu kompensieren. Nur in der Öffentlichkeit kann es ihnen gelingen, die fehlenden Medien der Einflußnahme (Geld, Macht als Kontakt zu Eliten) auszugleichen und öffentliche Meinung zu ihren Gunsten zu mobilisieren (Gerhards, 1992, 307 f). Dergestalt können sie indirekt auf Entscheidungen des politischen Systems einwirken. Gerhards hat mehrere wichtige Strategien ausgemacht, die ein auf die Herstellung von Öffentlichkeit gerichtetes Verhalten sozialer Bewegungen beschreiben: dies sind im wesentlichen Fokussierung und Problematisierung, Kausalattribution und Zuweisung von Verantwortlichkeit, sowie Selbstlegitimation (vgl. Gerhards, 1992, 310 ff; Gerhards/Neidhard, 1990, 37 ff). Dies scheint strategisches Handeln der kollektiven Akteure zu indizieren. Tatsächlich werden solche Strategien von den Framing-Konzepten der amerikanischen Policyforschung als strategisches Handeln beschrieben (vgl. Rucht, 1994, 343 f). 
Allerdings können die handlungsleitenden Frames (Rahmen) selbst nur nichtstrategisch verstanden werden.

Ein Gegenstand, bzw. ein Sachverhalt muß zunächst einmal als ein Thema definiert werden. Es muß ein geeigneter Überbegriff zur Bezeichnung komplexer Zusammenhänge gefunden werden (z.B. Waldsterben, Ökosteuer, Atomausstieg). Solche Schlagworte bringen komplexe Themenbereiche begrifflich 'auf den Punkt', und setzen sich somit leichter im Gedächtnis der Öffentlichkeit fest. Der Bezug des Themas zur Realität muß empirisch evident sein. Weiterhin muß das Thema als ein Problem gekennzeichnet sein, als eine "...Diskrepanz zwischen Ist-Zuständen und Soll-Zuständen..." (Gerhardt/Neidhardts, 1990, 40) Ferner muß erfolgversprechende Öffentlichkeitsarbeit, einen Bezug zwischen dem diskutierten Sachverhalt und den Alltagserfahrungen der Bürger herzustellen (So wird ein wenig brisantes Thema wie die Abholzung des tropischen Regenwaldes erst dann interessant, wenn man aufzeigt, daß Klimaveränderung als partielle Folge der Abholzung alle betrifft). Neben der Konkretisierung von Problemen ist aber auch deren Einbindung in allgemeine Wertvorstellungen von Bedeutung. So kann eine Meinung schon im voraus entlang eines links/rechts, bzw. extrem/gemäßigt Schemas stigmatisieren und somit positiv oder negativ aufgeladen werden. Die Aktualität eines Problems wird verstärkt, wenn es gelingt, eine sich abzeichnende Zuspitzung zu unterstellen. Auch eine auffällige Präsentationsform ist ein Mittel, die Aufmerksamkeit des Publikums zu gewinnen. Das Aufzeigen von Ursachen (z.B. zunehmender Individualverkehr und Klimaveränderung), und besser noch Verursachern (verantwortliche Personen), sensibilisiert die Öffentlichkeit ebenfalls für Probleme. Die Aufmerksamkeit wird noch gesteigert, wenn dem Verursacher intentionales Handeln nachgewiesen werden kann. Ein breites öffentliches Interesse entsteht schließlich, wenn unterstellt werden kann, daß die für die Lösung des Problems Verantwortlichen - des politischen Systems - ihrer Verantwortung nicht gerecht werden.

Gerhard hat weiter angeführt, daß es für den Öffentlichkeitsakteur (oder die Interessengruppe) genauso zwingend erforderlich ist, sich als vertrauenswürdig zu präsentieren. Die eigene Motivation soll nicht auf eigenem Interessen beruhen, sondern auf das Gemeinwohl verweisen. Schon eine geeignete Bezeichnung mache eine Interessengruppe schwerer angreifbar. Durch die Rekrutierung prominenter und allgemein als vertrauenswürdig anerkannter Personen (z.B. Wissenschaftler, aber auch Schauspieler etc.), werde die Legitimation von Interessen noch verstärkt. In diesem empirischen Zusammenhang wäre ein vermehrter Gebrauch von Attestargumenten zu erwarten.

Als Gegenstrategien zur Moralisierung des Umweltthemas läßt sich laut K. Eder folgendes Verhalten beobachten (1997, 32): 1. die Strategie, ökologische Kommunikation auf technische Gesichtspunkte zu reduzieren, und Kausalwissen gegen moralische Argumente auszuspielen. (Diese Rationalität habe insbesondere der Risikokommunikation zugrunde gelegen.) 2. die Strategie, ökologische Kommunikation als politisches Problem rationaler Umweltpolitik zu definieren. Demnach sei Moralisierung bloße Zeitverzögerung oder gar Hemmnis rationaler Lösungen von Umweltproblemen 3. die Strategie, ökologische Kommunikation mit identifikationsfähigen Symbolen aufzuladen, welche die Moralisierung noch überbieten. Diese Strategie wird sowohl von 
Protestakteuren als auch von deren Gegenspielern verfolgt und ist ambivalent, da sie ökologische Kommunikation metaphorisiert und kognitiv reduziert.

Es ist offensichtlich, daß sich Authentizität und Vertrauenswürdigkeit von Öffentlichkeitsakteuren nur sehr begrenzt strategisch verwenden lassen, so daß nicht von einer strategischen Herstellung von Öffentlichkeit gesprochen werden kann. Dies trifft jedoch nur auf die sozialintegrative Dimension sowohl von sozialen Bewegungen als auch des politischadministrativen Systems zu. In der systemischen Dimension konkurrieren dagegen soziale Bewegungen um Mitglieder und Gelder und verschiedene Bereiche des politisch-administrativen Systems und des ökonomischen (Medien)systems weisen unterschiedliche Vermachtung und funktionale Integration auf.

In systemischer Hinsicht ist vor allem das politisch-administrative System Bedingung und Gegenstand der emanzipatorischen Herausbildung sozialintegrativer, kommunikativer Macht. Für soziale Bewegungen sind Rechte ein wichtiges Telos, auf das sich ihr soziales Handeln ausrichtet, das jedoch für die sozialen Akteure mit seiner Realisierung verschwindet, da errungene Rechte ihre teleologische Struktur für die zivilgesellschaftlichen Akteure verlieren. Mit der Realisierung erlangen sie eine vorrangig institutionelle Dimension. Insofern sich die Zivilgesellschaft insgesamt institutionalisiert, beinhaltet dies die Stabilisierung sozialer Institutionen mittels des Rechts. Die Institutionalisierung muß durch inklusorische Demokratisierung und über Rechte erfolgen. Die Rechte müssen nach ihrer Setzung durch das Handeln von Individuen oder sozialen Gruppen wiederum praktisch bestätigt werden. Sie sind nur in dem Sinne negative Rechte, als daß sie staatliches Handeln beschränken. Sie können nicht logisch auf eine Grundnorm zurückgeführt werden (vgl. Gerstenberger, 1996, 59). In dieser Perspektive sind Rechte zivilgesellschaftliche Institutionen und spiegeln eine reflexive Selbstbegrenzung des politischen Systems wider. Dem Recht wird dabei die Fähigkeit zugesprochen, seine Genese über demokratische Prozeduren an die Zivilgesellschaft zurückzubinden, und so durch demokratische Institutionen legitime Politik sicherzustellen. "Rights, however, represent a from of self-regulation of the political system whose consequence is only the strengthening of the barriers defending the lifeworld. They do not in themselves go beyond the first phase of the program of 'barriers' and 'sensors.' Nevertheless, their particular double status, as institution of civil society and as self-limitation of the state, recalls the original mediating role of a whole series of institutions in the classical theory of civil society." (Cohen, Arato, 1992, 478; ähnlich auch Schmalz-Bruns, 1995a, 133f) Die zivilgesellschaftlichen Akteure bedient sich der Sprache des Rechts, "[d]enn das Recht ist ein Medium, über das sich die einfachen Interaktionen und naturwüchsigen Solidarverhältnissen bekannten Strukturen gegenseitiger Anerkennung in abstrakter, aber bindender Form auf die komplexen und zunehmend anonymen Handlungsbereiche einer funktional differenzierten Gesellschaft übertragen lassen. Intern ist das Recht allerdings so strukturiert, daß ein rechtsstaatlich verfaßtes politisches System die naturwüchsigen Integrationsleistungen, die sich unterhalb der Artikulationsschwelle des formalen Rechts vollziehen, nur auf reflexiver Ebene fortsetzen kann." (Habermas, 1992, 386 f) Recht ist für die zivilgesellschaftlich verfaßte Gesellschaft eine funktionale Notwendigkeit. 
Arato hat unter Verweis auf Habermas' Rechtstheorie die Bedeutung prozeduralen Rechts für die Zivilgesellschaft hervorgehoben. Wie seine zusammen mit Cohen erarbeitete Theorie der Zivilgesellschaft verweise demnach auch Habermas' Theorie prozeduralen Rechts auf die unbegrenzten Kommunikationsabläufe nur schwach institutionalisierter Öffentlichkeiten der modernen, dezentrierten Gesellschaften. Demgegenüber fokussiere sich die Diskussion über Deliberation einseitig auf die starke Öffentlichkeit politischer Institutionen. Diese träfen zwar definitive Entscheidungen - was Aspekte wie Legitimität und Effektivität berühre -, doch seien sie prozedural und zeitlich begrenzt, so daß diese Form starker Öffentlichkeit normativ defizitär sei.

From the point of view of a discourse theoretical understanding of democratic legitimacy, such restriction of communication can be justified only to the extent that we can see formal political publics as particularly sensitive outposts within the structure of the state to processes of public communication in civil society. Thus the politics of civil society should be seen as a dualistic one, aiming at both the expansion of the civil public that can influence state actors and the redesign of state institutions. (Arato, 1998, 33)

Es sei das Medium prozeduralen Rechts, daß es der Zivilgesellschaft erlaube, in schwachen Öffentlichkeiten fortzubestehen, da die Rechtsform im prozeduralen Recht unbestimmt bleibe: Sie könne sowohl formale oder materielle als auch prozedurale Form annehmen. Prozedurales Recht überwinde demokratietheoretische Defizite, die sich im Medium Recht als Teil eines Sozialsystems laut Arato notwendig ergeben, denn im Gegensatz zum materialen oder formalen Recht könne prozedurales Recht seinen Status selbst thematisieren und so reflexiv werden (vgl. auch McCarthy, 1998, 139 f). Als solchermaßen reflexiv gewordenes Recht weise Habermas' prozedurale Rechtstheorie Arato zufolge drei Vorteile auf: Erstens führe sie postregulative Regulation ein, die nicht interventionistisch sei; zweitens erneuert sie formal-rechtliche Strukturen, was die Integrität des Rechtsmediums sichert; und drittens ergebe sich ein normativ wünschenswertes Verhältnis von Freiheit und Regulation. Im prozeduralen Paradigma könne so schließlich Verfassungsrecht als Reflexivität des Rechts par excellence erscheinen, indem es die Legitimität der Rechtsgenese sichere. Prozedurale Rechtsformen könnten dabei nicht nur auf Verteilungspolitiken bezogen werden, sondern sollten auf Institutionen und die Verfassung angewandt werden und könnten auch zur Begründung einer ökologische Verfassung ausgeweitet werden. (vgl. Arato, 1998, 34)

In der modernen Demokratie kommt der Zivilgesellschaft eine grundrechtlich gesicherte Sphäre zu, in der ihre diversen Akteure autonom agieren können (vgl. Habermas, 1992, 445 f). 'Autonomie' beschreibt jedoch nicht nur die Zivilgesellschaft der Demokratie, sondern ist auch in autoritären und totalitären Staaten Ziel. Historisch besehen haben sich Zivilgesellschaften immer wieder mit emanzipatorischer Absicht gegen staatliche Beschränkung durch autoritäre und totalitäre Regimen gewandt, ohne auf Grundrechte zurückgreifen zu können. Auf diesen Sachverhalt scheint sich Cohen und Aratos These zu beziehen, daß die Normen von Öffentlichkeit in Zivilgesellschaften einen konstanten Bedarf nach demokratischen Verfahren auch dann noch reflektieren würden, wenn sie verzerrt seien. Allerdings geht ihre These weiter, wenn sie feststellen, daß auch alle Demokratien Formen von Exklusion zeitigen würden, die ebenso Öffentlichkeit verzerrten (Cohen, Arato, 1992, 418 f). Denn innerhalb von Demokratien richtet sich die Zivilgesellschaft nicht mehr einfach gegen einen repressiven Staat, sondern sie muß ihre Reproduktion - und damit auch jene 
der demokratischen Gesellschaft - selbsttätig und selbstreflexiv unter allgemeine Normen stellen können, die inklusorisch und nicht beliebig strategisch verfügbar sind: Der Pluralismus muß unter ethisch-moralischen Normen stehen können. Dies impliziert keine substantielle (ökologische) Gerechtigkeit, der zivilgesellschaftliche Akteure über Handlungsnormen folgen sollten. Somit müssen sich die auf Autonomie, Voluntarismus und Selektivität gründenden Organisations- und Handlungsformen sozialer Bewegungen, weder notwendigen mit Ansprüchen einer (ökologischen) Vernunft noch mit denen des politisch-administrativen Systems decken.

Es bestehen sowohl sozial- als auch systemintegrative Grenzen für soziale Bewegungen und freie Assoziationen. Das Spannungsverhältnis zwischen Zivilgesellschaft, Demokratie, kollektiven und globalen Gütern ist auch immer eines zwischen sittlichem Partikularismus und vernunftrechtlichem Universalismus. Diese historische Spannung kann unter den gegebenen institutionellen Bedingungen nicht allein in der Zivilgesellschaft bewältigt werden, sondern muß primär von den ökologisch zu modernisierenden funktionalen Systeme des Rechts und der Wirtschaft aufgehoben werden.

Cohen und Arato betonen in hohem Maße die Bedeutung schwacher Öffentlichkeit und heben deren kritisches Potential hervor. Dies läuft Gefahr, die Relevanz starker politischer Öffentlichkeit bei der Lösung materialer, politisch-gesellschaftlicher Probleme zu verkennen und das produktive sozialintegrative Potential schwacher Öffentlichkeiten zu überschätzen und damit letztlich soziale Bewegungen zu überfordern.

\subsubsection{Solidarische Integration als reflexive Demokratie}

Schmalz-Bruns hat im Unterschied zu Cohen und Arato ein zivilgesellschaftliches Modell vorgestellt, bei dem es - im Sinne eines post-staatlichen zivilgesellschaftlichen Integrationszusammenhangs (nach Bobbio) - auf die enge Verklammerung und Vermittlung der unterschiedlichen Politikbereiche wie -stile insofern ankommt, als "daß die Vorbereitung, Planung, Gestaltung und Durchführung materialer und thematisch spezifizierter Politiken (policies) in den Horizont einer allgemeinen, offenen Willensbildung zurückgestellt werden." (Schmalz-Bruns, 1995a, 132) Schmalz-Bruns geht es um die materielle Politikformulierung in öffentlichen Diskursen und damit um die demokratietheoretische Reformulierung systemtheoretisch orientierter Steuerungsansätze, - auch solcher wie Cohens und Aratos. Gegen deren Ansatz hat Schmalz-Bruns eingewandt, daß auch er noch auf den tradierten Dualismus von Staat und bürgerlicher Zivilgesellschaft hinauslaufe, indem es von eng umgrenzten zivilgesellschaftlichen Reproduktionszusammenhängen ausgehe und durch die starke Bezugnahme auf die sozialen Bewegungen zu selbstbezogen erscheine. Cohen und Aratos Modell der Zivilgesellschaft würde derart sogar noch die dem Liberalismus zugeschriebene 'Kunst der Trennung' (vgl. Walzer, 1984) durch die theoretische Auszeichnung der selbstbezüglichen Reproduktion kollektiver Identitäten differenztheoretisch steigern. Gegen Habermas wendet Schmalz-Bruns ein, daß dessen Theorie das kognitive Potential partizipatorischer Demokratie nicht voll ausschöpfe und die vielen Mikro- 
Entscheidungen sowie dezentralen Entscheidungsstrukturen nicht ausreichend einbinde. Habermas habe sich in seiner legitimationstheoretischer Absicht zu sehr auf rationale Regelbefolgung und die Output-Seite von Politik konzentriert (vgl. Schmalz-Bruns, 1995a, 102 ff, 147). Auch berücksichtige die Fixierung auf diskursive Vernunft nicht hinreichend, in welchem Maße demokratisch-rechtsstaatliche Verfahren diese überhaupt erbringen könnten.

Die öffentliche Auseinandersetzung über Politiken soll dagegen bei Schmalz-Bruns situationsspezifisch und problembezogen durch demokratische Verfahren so mediatisiert werden, daß die Öffentlichkeit der Bürgergesellschaft zu einer Ressource hinsichtlich der Formulierung und Durchsetzung einzelner Politiken wird. Durch den Rückgriff auf den Pragmatismus - und im folgenden auf Joas' Theorie kreativen Handelns und Deweys Theorie demokratischer Öffentlichkeit - will Schmalz Bruns die von ihm konstatierten systemtheoretischen und partizipatorischen Beschränkungen der Habermas'schen Theorie hinter sich zu lassen. ${ }^{177}$ Er folgt dabei weitgehend dem Modell des Policyzyklus, ${ }^{178}$ das er jedoch durch Öffentlichkeitseinflüsse und nichtstaatliche Initiativen reflexiv bricht, um schließlich die stark vermachteten korporativen Arrangements demokratisch und material zu modernisieren. Schmalz-Bruns erweitert den demokratischen Handlungsrahmen um Netzwerke, Verhandlungssysteme und deliberative Arenen. Er nimmt insbesondere Umwelt- und Technologiepolitik in den Fokus, denn diese verweisen auf die "Gefahren und Risiken in einem Prozeß der materialen Politisierung der gesellschaftlichen Evolution, der sich mit den institutionellen Mitteln der repräsentativen Demokratie allein nicht mehr beherrschen läßt." (Schmalz-Bruns, 1995a, 233)

Kein Politikfeld fordert so regelmäßig die Interventionsbereitschaft und -fähigkeit des Staates heraus wie die Umweltpolitik (vgl. Jänicke, 1993a), dennoch trifft der Staat in institutioneller Hinsicht seine Entscheidung nach dem Mülleimermodell (garbage-can-model) nicht systematisch sondern anarchisch. ${ }^{179}$ Auch sieht sich der Staat in der Umweltpolitik einem nur schwach organisierten Bereich gegenüber. Beides trage ihm Effizienzprobleme ein, so daß sich hier nur noch das 'Interesse des Staates an seiner eigenen Entlastung' zur Geltung bringe. Genau darin sieht Schmalz-Bruns nun eine Chance für deliberative Prozesse, denn diese könnten eine metapolitische Konsensplanung herbeiführen, welche noch vor der Debatte über Sach- und Normprobleme eine reflexive Verständigung über Verständigungsaufgaben initiieren. Dies ist allenfalls sehr bedingt als Metakommunikation über Staatsaufgaben (Fürst) zu verstehen. Denn von einer Öffentlichkeit im politischen Sinne könne erst gesprochen werden, wenn die Öffentlichkeit ein Bewußtsein ihrer

177 Dabei muß er aber einerseits Grenzen der Joas'schen Theorie als Grundlage der Demokratietheorie anerkennen, andererseits wird indirekt wieder der Zusammenhang von Demokratietheorie und philosophischer Begründung in normativer und von Demokratie und sozialwissenschaftlicher Theorie in empirischer Hinsicht deutlich.

178 Das politikwissenschaftliche Modell des Policy Cycle (Politikzyklus) wurde aus D. Eastons systemtheoretischem Input-Output-Modell der Politik heraus entwickelt. Damit ließ sich die politische Leistung in zeitlichen Phasen vom gesellschaftlichen Input bis zur Implementation analysieren. In den achtziger Jahren wurden dann die ersten Modelle veröffentlicht, die sich allein auf die Steuerungstätigkeit als zeitlichen Prozeß bezogen, vgl. dazu auch Kapitel 5.3.2.

179 Das 1972 entwickelte garbage-can model nimmt an, daß Organisationen anarchisch funktionieren: Sie hätten problematische Präferenzen, unklare Techniken und wechselnde Partizipation. Organisationen suchten nach neuen Problemen und entsprechender Entscheidungskompetenz darüber. 
selbst und die Fernfolgen ihres Handelns ausgebildet habe, wie Schmalz-Bruns im Anschluß an J. Dewey feststellt (vgl. Schmalz-Bruns, 1996, 44). Die Konsensplanung müsse wiederum in partielle Verständigungsaufgaben gegliedert werden, und Kristallisationskerne für demokratische Politik bereitstellen. Eine konsensuale Energiepolitik stünde etwa unter der Frage, zu welchen energiepolitischen Themen längerfristig eine breite Mehrheit angestrebt werden soll (SchmalzBruns, 1995a, 238).

Laut Schmalz-Bruns wäre die Grenze zwischen administrativer und gesellschaftlicher Politik neu zu bestimmen, wozu Verfahren auf Teilhabe hin weiterzuentwickeln seien, so daß an ihnen demokratische Gesellschaftsformen entstehen könnten. Schmalz-Bruns' demokratische Stoßrichtung orientiert sich nicht an systemischen Differenzierungen, sondern will diese gerade demokratischpartizipativ durchbrechen. Damit entfällt in seiner Theorie zugleich die historische Dimension sozialer Differenzierung. Wenig überraschend lehnt Schmalz-Bruns dann Habermas' institutionelle Fassung der praktischen Vernunft ab. Anstand praktische Vernunft institutionell zu fassen, wie Habermas dies getan hat, sollte sie sequentiell bestimmt werden, nämlich als stufenartigen Willensbildungs- und Entscheidungsprozeß auf der Refexionsebene einzelner Entscheidungsprogramme. So brauche reflexive Demokratie nicht wie die Diskurstheorie auf eine Trennung von Staat und Gesellschaft und ein 'Übergewicht staatlicher Politik' zu bestehen. Und dies gelte auch für die Systemtheorie, welche die Konstitutionalisierung aller Funktionssysteme und korporativen Akteure voraussetze (Schmalz-Bruns, 1995a, 240 ff). Die Politikwissenschaft stehe als Demokratiewissenschaft innerhalb dieses interaktiven Prozesses der kollektiven Problemlösung. Sie liefert partizipativen Regungen innerhalb der Zivilgesellschaft weitgehend unabhängig vom massenmedialen Vermittlungsprozeß handlungsrelevantes Wissen.

Schmalz-Bruns nennt als Beispiele deliberativer Verfahren Sozial- sowie Umweltverträglichkeitsprüfung und - nach amerikanischem Vorbild - Mediationsverfahren. Paradigmatisch für Schmalz-Bruns' Modell könnte eventuell die erfolgreiche Entwicklung von Verfahren der Technikkontrolle stehen, welche von der parlamentarischen Technologiefolgenabschätzung zur gesellschaftlichen Techniksteuerung fortentwickelt wurde (Eichner, Heinze, 1991) und ansatzweise auch das privatwirtschaftliche Öko-Audit. Schmalz-Bruns geht indes nicht näher auf diese deliberativen Verfahren ein, sondern bezieht sich im Gegensatz zu Habermas positiv auf Verhandlungssysteme.

Schmalz-Bruns führt mehrere Gründe dafür an, weshalb deliberative Politik auf Verhandlungssysteme und ihre engen Arenen konzentriert werden soll. Zum einen habe die Politikwissenschaft erbracht, daß institutionelle Arrangements einen erheblichen Einfluß auf die Qualität materialer Politiken haben können, wobei solchen institutionellen Arrangements noch ein demokratisches Risiko anhafte, "das sich in der Tendenz zur Selbstsektorierung und Selbsttransformation solcher Netzwerke und ihrer problematischen Vermittlung in den übergreifenden Gesamtzusammenhang der demokratischen Willensbildung zur Geltung bringt." (Schmalz-Bruns, 1995a, 251) Die interne Kooperation derartiger Verhandlungssysteme führt immer auch zur Schließung sozialer Interaktionszusammenhänge. Ein weiterer Grund, sich auf 
Verhandlungssysteme zu fokussieren, bestehe darin, daß plural zusammengesetzte PolitikNetzwerke ausdifferenzierte demokratische Strukturen repräsentierten, die sich nicht nur verschließen könnten, sondern im demokratischen Prozeß auch ausbaufähig seien. Im Kontext des kooperativen Staates könnten Verhandlungssysteme zu einer stärkeren Vergesellschaftung von Politik führen, ohne daß Politik unter Effizienzverlusten leiden müsse. Deshalb will Schmalz-Bruns sie nicht auf einen Bargaining-Modus beschränken, sondern ihre Legitimität im Arguing-Modus reflexiv an den demokratischen Prozeß zurückbinden.

Die Verschränkung einer rationalen, argumentativen Praxis mit der Idee einer politischen Öffentlichkeit muß sich auch in Hinblick auf die institutionellen Arrangements ausdifferenzierter Verhandlungssysteme zeigen lassen. Schmalz-Bruns erblickt die notwendige politische Problemlösungskapazität in deliberativen Arenen, die er mit mittlergestützten diskursiven Verfahren verbindet. Diese Form der Konfliktregelung zeichne sich durch drei Elemente aus: 1. suchten alle von einer Entscheidung Betroffenen nach einer Problemlösung; 2. ziele diese auf einen vernünftigen Konsens, der im gleichmäßigen Interesse aller liege; 3. müsse dabei die Verfahrensdefinition ebensoviel Beachtung finden wie der Konfliktinhalt (vgl. auch Renn, 19896, 1999). Der letzte Punkt impliziert, daß die Frage des Arenazuschnitts und des Designs der Verfahren an die Praxis der demokratischen Selbstbestimmung zurückgereicht werde, "was zu einer internen Differenzierung der Problemlösung nach der Behandlung pragmatischer, ethischer und moralischer Fragen im Rahmen eines mehrstufigen Verfahrens der Relationierung aufeinander abgestimmter Willensbildungsprozesse führt." (Schmalz-Bruns, 1995a, 261) Diese selbstreflexive, rekursive Prozeßorientierung überträgt Schmalz-Bruns näherungsweise auf ein Phasenmodell der Konfliktvermittlung.

Die kognitive Anreicherung der Mediationsverfahren erfolgt durch einen Rückgriff auf Experten, die nicht der Wahrheitssuche, sondern nur der demokratischen Willensbildung dienen sollten. Die demokratische Willensbildung solcher Verfahren stehe hinsichtlich der materiellen Richtigkeit ihrer Ergebnisse über den Versuchen von Normierungen durch das politisch-administrative System, wenn dieses etwa unbestimmte Rechtbegriffe (Stand der Technik, Grenzwerte, etc.) interpretiert oder technische Anleitungen beschließt. Allerdings sei die rechtliche Absicherung derartiger Verfahren nach wie vor notwendig. Der Zusammenhang zwischen (demokratisierter) Politikformulierung in Verhandlungssystemen und dem Anschluß an die vorherrschende Verwaltungspraxis müsse gewahrt bleiben.

Die Interdependenzen von Verhandlungssystemen zur Demokratie bestehen also für die Theorie deliberativer Demokratie in der Schaffung von spezifischen Politikarenen für je verschiedene Probleme. Neben einer positiven deliberativen Bedeutung von Verhandlungssystemen nimmt Schmalz-Bruns an, daß auch mediatorische Verfahren Konflikte materiell so bewältigen könnten, daß eine gemeinwohlverträgliche Lösung erzielt werden kann. Explizit verweist er auf derartige Verfahren der Problemlösung für den ökologischen Kontext (Schmalz-Bruns, 1995a, 265; ders., 1996). Es drängt sich die Vermutung auf, daß Schmalz-Bruns nicht zuletzt aufgrund der geringen Verfügbarkeit (und damit Selektivität) entsprechender empirischer Studien, welche die ökologische 
Steuerungsleistung sozio-ökologischer Institutionen untersuchen, zu seiner optimistischen Einschätzung von Verhandlungssystemen und auch mediatorischen Verfahren gelangt. Es fällt des weiteren auf, daß Schmalz-Bruns deliberative Arenen nur für nicht-distributive Politiken ausführt, die keine Verteilungsaspekte beinhalten. Dabei nimmt er umweltpolitisch nur auf den Risikodiskurs Bezug, während er den Nachhaltigkeitsdiskurs mit seinen Verteilungsaspekten nicht berücksichtigt. Deshalb auch erscheint Schmalz-Bruns Partizipation in der Umwelt- und Technologiepolitik erfolgversprechender als in der Sozialpolitik.

Schmalz-Bruns' Demokratiebegriff ist der eines diskursiven, Rationalität erzeugenden Verfahrens, das zwar keine wahrheitstheoretischen Annahmen wie bei Habermas beinhaltet, dennoch im argumentativ erzielten Konsens die rationalere (und kreativere) Problemlösung gegenüber dem Mehrheitsprinzip erblickt. Dies läuft natürlich Gefahr, demokratische Legitimität mit politischer Steuerung kurzzuschließen. M. T. Greven (1995) hat daran vor allem das Problem eines Auseinanderdriftens von Rationalitätsanforderungen und institutionell verbürgten Rationalitätschancen gesehen. Zwar müsse die reflexive Institutionalisierung als zweidimensionale diskurstheoretische Symbiose von Beteiligungs- und Problemlösungserwartung gegenüber einer eindimensionalen liberalen Rationalitätserwartungen entworfen werden, es dürften damit aber nicht unmittelbar Erwartung an materiale Politikergebnisse verbunden werden. Die enge Verbindung von Steuerungserwartung und demokratischer Partizipation könnte im materialen Ergebnis wesentlich problematischer sein, als Schmalz-Bruns dies realisiert.

Greven hat Schmalz-Bruns in diesem Zusammenhang vorgeworfen, mit einem empirisch noch zu wenig gehaltvollen Konzept von Öffentlichkeit zu arbeiten. Die auf Verhandlungssysteme bezogene Variante von Zivilgesellschaft laufe letztlich - wie bei den von Schmalz-Bruns kritisierten Autoren Dryzek, Barnes und Ueberhorst - auf die Schaffung bloß lokaler Optima hinaus. Schmalz-Bruns' Theorie reflexiver Demokratie folgt insgeheim den zivilgesellschaftlichen Resonanzen auf die Politisierung der Agenda. Dies ist mit dem an Dewey geschulten, intersubjektivem Modell der Öffentlichkeit gut begründet. Falsch wäre es erst dann, wenn der Anspruch demokratischer Selbststeuerung auf Durchsetzbarkeit hin verengt werden würde und damit - ohne soziologische Aufklärung der Demokratietheorie - die Verselbständigung des Sozialen normativ akzeptiert werden würde. Im Unterschied zu Schmalz-Bruns wird hier mit Habermas und Cohen/Arato die Auffassung vertreten, daß institutionelle Innovationen gerade durch die Theorie der Differenzierung vielversprechend begründet werden können. Dazu wurde in Kapitel 2.3.3 die unter ökologischen Vorzeichen veränderte Reflexivität des ökonomischen und des politisch-administrativen Systems dargestellt. Hier nun ist die Öffentlichkeit demokratietheoretisch und in ihrer empirischen Fähigkeit zur Themensetzung zu betrachten. 


\subsection{Politische Öffentlichkeit}

Erst im Prozeß der Aufklärung hat der klassische Begriff der Öffentlichkeit seine spezifisch moderne Bedeutung erhalten. Öffentlichkeit erhielt einen normativen Gehalt. 'Öffentlichkeit' implizierte nicht nur kritischen Zugang zu staatlichen Institutionen und deren Bindung an das Räsonnement der Bürger, Öffentlichkeit vertraut seit der Moderne auch auf das bürgerliche Räsonnement der Meinungen. Der normative Begriff wird damit kognitiv höchst voraussetzungsvoll. Er ist zu einem politischen Grundbegriff geworden, der über die klassischhellenische Öffentlichkeitskonzeption hinausgeht. In ihrer modernen doppelseitigen Bedeutung Öffentlichkeit der Macht und Macht der Öffentlichkeit - ist Öffentlichkeit zur zentralen Legitimationsinstanz im Prozeß der Aufklärung geworden, die auch kritische Instanz der Demokratie ist.

Als einzige Legitimationsquellen der Demokratie wird in der Theorie des kommunikativen Handelns ihre historische Entstehung und ihre Bindung an Argumentation angesehen.

Die in der Theorie des kommunikativen Handelns vorgenommene sprachliche Grundlegung von Gesellschaftstheorie ist daher auch nicht nur Grundlegung einer kritischen Gesellschaftstheorie; sie ist ihrer Struktur nach isomorph der demokratischen Organisationsidee, in der unterstellt wird, daß es die 'Stärke' eines Argumentes ist, die die Teilnehmer eines Diskurses überzeugt und zur Änderung ihrer eigenen Haltung führt, damit auch den Konsens in bezug auf zu treffende Entscheidungen überhaupt erst ermöglicht. (Bermbach, 1991, 242)

Der Diskurs erscheint dann als eine Strukturparallele zum Modell der bürgerlichen Öffentlichkeit. Doch dieser Einschätzung steht die empirische Struktur der massenmedialen Öffentlichkeit fundamental entgegen. Während praktischen Diskursen symmetrische Sprecherrollen zugrunde liegen, kommunizieren Massenmedien einseitig und direkt. Sind somit strikt asymmetrisch angelegt. Diese gewaltige Spannung will Habermas über das Diskursprinzip normativ schließen.

Die Normativität des modernen Konzepts von Öffentlichkeit hat Habermas 1962 in seiner empirischen Studie Der Strukturwandel der Öffentlichkeit aufgezeigt. Habermas' Untersuchung der Entwicklung moderner Öffentlichkeit ist historisch angelegt. Als Kontrastfolie der empirischen Entwicklung der bürgerlichen Öffentlichkeit von ihren Anfängen bis zu ihrer heutigen massenmedialen Gegenwart dient ihm die normative politische Theorie Kants, J. S. Mills, Tocquevilles sowie Hegels und Marx'. Obwohl Habermas, ausgehend vom normativen Gehalt dieser politischen Theorien, durchaus Krisenerscheinungen der Öffentlichkeit konstatiert, widerspricht er sittlichen Verfallsdiagnosen, die eine Vereinnahmung der politischen Öffentlichkeit durch Intimität und Bedürfnisse diagnostizieren (Arendt, 1989; Sennett, 1985). Die Studie griff noch nicht auf die erst mit der Theorie des kommunikativen Handelns ausgearbeitete sprachpragmatische und mit Faktizität und Geltung anwendungsbezogen entwickelte normative Basis zurück. 
Im Vorwort zur Neuauflage seiner Studie von 1990 hat Habermas drei Revisionen für notwendig erachtet: Erstens seien aufgrund empirischer Ergebnisse die Demokratisierungschancen des Wirtschaftssystem skeptischer zu beurteilen als noch 1962 angenommen; zweitens sei die Vermutung einer gradlinigen Entwicklung vom politischen aktiven zum privatistischen Publikum überspitzt; drittens stelle sich die Auffassung, daß kritische Öffentlichkeit nur durch die interne Demokratisierung von Verbänden und Parteien zu erreichen sei, heute ambivalenter dar (Habermas, 1990, 27 ff). Unberührt bleibt davon jedoch der grundsätzliche normative Anspruch einer politischen Öffentlichkeit des demokratischen Rechtsstaates. Diesen normativen Gehalt bezieht Habermas heute aus der Diskurstheorie. Angesichts seiner kritischen Aneignung des aufklärerischen liberalen Erbes, ist es wenig verwunderlich, daß in der Diskussion zwischen Liberalismus (Rawls) und Diskurstheorie (Habermas) 'Öffentlichkeit' sogleich auf die Agenda der politischen Theorie zurückkehrte, verkörperte der Liberalismus doch jene Tradition, der Habermas 1962 den Spiegel vorgehalten hatte.

Rawls hat 'Öffentlichkeit' im Gegensatz zu Habermas philosophisch entworfen und den politischen Liberalismus als einen öffentlichen Vernunftgebrauch charakterisiert, der versöhnend wirke (Rawls, 1993, 372 ff). ${ }^{180}$ Zweifelsohne kann der Gebrauch der Vernunft diesen Charakter annehmen. Unmittelbar schließt sich dem aber die Frage nach dem Zusammenhang von Vernunft, Wahrheit und Rationalität an. Für den politischen Liberalismus ergeben sich daraus begründungstheoretische Probleme, wie Habermas aufgezeigt hat (Habermas, 1996, 65 ff; vgl. auch Alexy, 1997). Ferner aber, und dies ist hier bedeutsam, wird die interne Verbindung zwischen Öffentlichkeit und Demokratie(theorie) durch Rawls' Konzept nur in Ansätzen erfaßt. Zwar teilt Rawls nicht die in der liberalen Tradition weit verbreitete Furcht vor einer despotischen Masse (vgl. König, 1992) und beruft sich auf die Rousseausche Linie der politischen Theorie, doch ist Rawls' Verweis auf den Supreme Court als Beispiel öffentlichen Vernunftgebrauchs (Rawls, 1993, 231 ff) nicht nur institutionentheoretisch ein ungenügendes Beispiel, sondern verkürzt auch seine Demokratietheorie. Denn der Verweis auf die Verfassungsgerichtsbarkeit bleibt zwangsläufig dem Rechtssystem immanent und verkleinert die partizipative und sogar epistemische Basis der Demokratietheorie. Nicht nur Verfassungsgerichtsbarkeit, sondern auch politische Programme und zivilgesellschaftlicher Kritik werden öffentlich wahr genommen und beurteilt. Der öffentliche Vernunftgebrauch in der Demokratie ist somit weiter zu spannen als bei Rawls. Er darf sich nicht nur auf die starke Öffentlichkeit politischer Institutionen beschränken, sondern muß auch die kritischen oder instruktiven Potentiale schwacher Öffentlichkeit aus der Zivilgesellschaft aufnehmen und rationalen Standards unterwerfen. Rawls hat darauf aufmerksam gemacht, daß Habermas mit dem Begriff der Legitimität anstelle des Begriffs der Gerechtigkeit arbeite. Er hat ganz zu Recht festgestellt, daß dieser nicht dem Gerechtigkeitsbegriff überlegen sein müsse. "Legitimacy allows an undetermined range of injustice that justice might not permit." (Rawls, 1993, 428)

180 Die Reply von Rawls bezog sich auf Habermas' Versöhnung durch öffentlichen Vernunftgebrauch; vgl. Habermas, 1996, $65 \mathrm{ff}$. 
Die zentrale diskurstheoretische Annahme besteht darin, daß das Publikum nur durch Diskurse zu vernünftigen Einsichten gelangen kann. Aber wie verhält sich die Struktur der demokratischen Entscheidungsprozesse zur öffentlichen Meinungs- und Willensbildung? Die Frage verweist direkt auf das demokratietheoretische Problem der Selbstgesetzgebung (Habermas, 1992, 600 ff): Öffentliche Meinungs- und Willensbildung soll in eine institutionalisierte Beschlußfassung einmünden. Konträr zu diesem weitreichenden Anspruch scheint das Zivilgesellschaftskonzept Cohen und Aratos lediglich die Begrenzung der formellen staatlichen Prozesse über informelle zivilgesellschaftliche Kommunikation zu verfolgen. Cohen und Aratos Konzept zeigt nicht auf, wie Demokratie zur Herausbildung von Vernunft führen kann oder gar führen muß. Öffentlichkeit beschränkt sich auf die kritische Kontrolle politisch-administrativer Macht. Die Transformation der öffentlichen Meinung zum Gesetz erscheint als offener Prozeß, der eventuell mit Rawls als quasireine Verfahrensgerechtigkeit gedacht werden könnte. Das Konzept bricht lediglich mit der Konsenserwartung des klassischen Begriffs der opinion publique.

Zur Begründung der normativen Bedeutung von Öffentlichkeit lassen sich zwei Argumente unterscheiden: das strukturelle und das funktionale Argument. Das strukturelle Argument orientiert sich am Input politischer Institutionen und stellt vorrangig auf politische Stabilität ab. Das funktionale Argument hingegen ist am Output des politischen Systems orientiert und zielt wesentlich auf dessen Effektivität ab. Es will durch Öffentlichkeit deliberative Kooperation fördern. Das funktionale Argument verweist auf die Aufgabe der politischen Steuerung gesellschaftlicher Entwicklungen. Das strukturelle Argument verteidigt den normativen Anspruch der Demokratie. Letztlich aber können auch beide Argumente zusammen nicht die empirische Frage entscheiden, ob Demokratie oder autoritäre Herrschaft Öffentlichkeit im jeweiligen Sinn besser erfüllen kann. Allerdings beruht Demokratie als normativ auszuzeichnende Lebensform "auf dem prinzipiellen Anspruch der Veröffentlichbarkeit aller mit politischer Relevanz versehenen Meinungen und Handlungen, tendenziell sogar der Motive - das gilt im Grundsatz selbst dort, wo aus strategischen Notwendigkeiten heraus Bereiche des Geheimen institutionell gesichert werden." (Rehberg, 1995, 198) Es zeigt sich, daß politische Freiheit und Gleichheit als normative Grundlagen der Demokratie notwendig sind.

Beides ist in der Diskurstheorie Bestandteil der Diskurssituation. Alle Teilnehmer eines Diskurses sind gleichberechtigt (Gleichheit) und haben uneingeschränktes Recht zur Stellungnahme (Freiheit). Zentral wird in der Diskurstheorie dann die Frage, inwieweit eine aufgeklärte Öffentlichkeit auch als Garant für gute Gründe dienen kann. Im normativen Modell von Öffentlichkeit soll die öffentliche Meinung rational und aufgeklärt sein. Dennoch bleibt ihr epistemischer Status im theoretischen Diskurs umstritten: "Handelt es sich um eine präsumtiv 'wahre' Meinung - oder um 'Meinung' im Gegensatz zum 'Wissen', zumal auf dem Gebiet praktischer Fragen, wo sicheres Wissen gar nicht möglich oder die Begriffe der Wahrheit und des Wissens überhaupt unangemessen sind?" (Peters, 1994, 47)

Die praktische Vernunft der Diskurstheorie erfordert einen Vorrang politischer Werte gegenüber umfassenden Weltbildern, da sich in diesen Werten die Idee der Unparteilichkeit ausdrückt 
(Habermas, 1996, 116 f). Die epistemische Autorität praktischer Vernunft und ihres Anspruchs auf Wahrheit begründet den Vorrang des Gerechten vor dem Guten. Das diskursive Modell vertritt damit aber keinen absoluten Wahrheitsanspruch, der einer demokratischen Praxis widersprechen würde. Die Diskurstheorie verteidigt vielmehr den universalistischen Gehalt unserer demokratischen Praxis gegenüber jeder anderen sozialen und politischen Praxis. Sie macht also nicht einen korrespondenztheoretischen Wahrheitsanspruch zum Maßstab sozialer Praxis, sondern (demokratische) Konsensfindung. Sie richtet Wahrheit im Politischen nicht an einem einzigen umfassenden Weltbild aus, sondern sichert vielmehr Toleranz: "Von ethischen Auseinandersetzungen über die Bewertung von konkurrierenden Lebensstilen und Lebensformen dürfen wir vernünftigerweise nichts anderes als einen für die Beteiligten einsichtigen Dissens erwarten. Demgegenüber erwarten wir - im Prinzip - allgemeinverbindliche Antworten, wenn es um Fragen der politischen Gerechtigkeit und der Moral geht." (ebd., 124) Über ein Faktum des Pluralismus (Rawls) hinaus macht die Diskurstheorie einen kognitiven Gehalt geltend. Kann sie diesen aber noch im Prozeß der Öffentlichkeit zur Geltung bringen? Auf welche Formen von Öffentlichkeit(en) muß ein normativer Öffentlichkeitsbegriff also zurückgreifen, um Demokratie und Rationalität aneinander anzunähern? ${ }^{181}$

Habermas' Modell von Öffentlichkeit hat gegenüber der kritischen Studie Strukturwandel der Öffentlichkeit zunehmend eine normative, demokratietheoretische Einbettung erhalten, die in Faktizität und Geltung schließlich voll ausgearbeitet wurde. Noch immer setzt Habermas an der Input-Seite des politischen Prozesses an. Hier treten verschiedene gesellschaftliche Assoziationen aus dem zivilgesellschaftlich-lebensweltlichen Kontext heraus. Entgegen systemisch-funktional vereinnahmten Interessengruppen weisen diese Assoziationen keine Bindung an systemspezifische Spezialcodes auf, sondern bleiben über die Gesellschaftskomponente mit ihren legitim geordneten interpersonalen Beziehungen an die Lebenswelt gekoppelt. ${ }^{182}$ Die Assoziationen kommunizieren in der Umgangssprache. Einige dieser Assoziationen lösen sich aus der sozialen Integration und bilden eigene Codes aus, die aber, obwohl inzwischen systemisch verfaßt, über das Recht immer noch an die Gesellschaftskomponente der Lebenswelt gebunden bleiben. Assoziationen bilden gegenüber dem zentralen politischen System (mit dem institutionellen Komplex der Verwaltung, der Regierung, des Gerichtswesens und der demokratischen Meinungs- und Willensbildung mit parlamentarischen Körperschaften, politischen Wahlen etc.) die Peripherie, genauer gesagt die Inputseite der Peripherie. Auf der Outputseite der Peripherie stehen dagegen die korporatistischen Verhandlungssysteme, welche die Implementation politischer Programme beeinflussen. Habermas zeichnet freie Assoziationen im Gegensatz zu Interessengruppen in seinem Modell normativ aus, da erstere nicht systemisch vereinnahmt seien. Freie Assoziationen müßten vielmehr erst eigene (nichtsystemische) Identifikationsmerkmale hervorbringen und sich ihrer Identität ständig vergewissern.

181 Habermas spricht vom 'diskursiven Niveau' der Meinungsbildung, welches die Qualität des Ergebnisses bestimme; vgl. Habermas, 1992, 438.

182 Vgl. zur Frage nicht freiwillig gewählter Assoziationen (Walzer, 1999, 11 ff). Walzer vertritt darin einen sehr weiten Begriff von Assoziationen, der etwa Familie, Kultur, Staatsbürgerschaft und moralische Beziehungen einschließt. Sein Begriff ließe sich durchaus im lebensweltlichen Sinne verstehen, wenn Walzer nicht die aus nicht-gewählten Assoziationen erwachsenden Fesseln als grundsätzliche Beschränkung universaler Ansprüche interpretieren würde. 
Die Qualität der öffentlichen Meinung richtet sich nicht nach inhaltlichen, sondern nach formalen Kriterien des Zustandekommens. Öffentliche Meinung ist nicht im statischen Sinne repräsentativ, d.h. sie kann über politische Meinungsforschung nur abgefragt werden, wenn dem eine themenspezifische Meinungsbildung innerhalb einer bereits mobilisierten Öffentlichkeit vorausgegangen ist. Die Öffentlichkeit als solche reproduziert sich (wie die Lebenswelt insgesamt) über kommunikatives Handeln (Habermas, 1992, 436). Sie zeichnet sich durch Kommunikationsstrukturen aus, die sich auf den durch kommunikatives Handeln erzeugten sozialen Raum beziehen und nicht auf die Funktion oder den Inhalt alltäglicher Kommunikation. Die Ausweitung des sozialen Raums zieht eine Ausdifferenzierung von Akteursrollen in Veranstalter, Redner und Zuhörer, in Arena, Galerie und Publikum nach sich. Als politische Öffentlichkeit muß Öffentlichkeit aus den Kommunikationszusammenhängen der potentiell Betroffenen entstehen.

Das Publikum besitzt letzte Autorität - wobei es Staats- und Gesellschaftsbürger in Personalunion verkörpert -, denn es ist in das gemeinsame Unternehmen eingebunden, die bestehenden Foren nicht bloß (strategisch) zu nutzen, sondern sie zu erhalten und zu erneuern. Politische Öffentlichkeit muß sich mithin selbst stabilisieren. Daß die zivilgesellschaftliche Kommunikationspraxis selbstbezüglich ist und damit die Fähigkeit zur Selbststabilisierung aufweist, zeigt sich daran, daß sie immer wieder (latent und teilweise auch manifest) die kritische Funktion von Öffentlichkeit überhaupt reproduziert.

Die Öffentlichkeit bezeichnet Habermas als intermediäre Struktur, "die zwischen dem politischen System einerseits, den privaten Sektoren der Lebenswelt und funktional spezifizierten Handlungssystemen andererseits vermittelt." (Habermas, 1992, 451) Offensichtlich orientiert sich Habermas hier an Cohen/Arato. Dieses komplexe Netzwerk gliedert sich in diverse Arenen und Teilöffentlichkeiten, die rechtlich auf Inklusion und Gleichheit normiert sind.

Habermas' Modell von Öffentlichkeit ist als dualistisches charakterisiert worden. Es bestünde demnach eine dualistische Version zwischen einer vermachteten Öffentlichkeit einerseits und einer nichtvermachteten Öffentlichkeit andererseits (Bermbach, 1995, 28 f). Habermas' Gegenüberstellung sei jedoch falsch. Insbesondere den systemisch verfaßten Massenmedien komme positive Bedeutung für die moderne Demokratie zu. Massenmedien würden Öffentlichkeit verstetigen und quasi als Platzhalter und Interpret der politisch passiven Staatsbürger agieren. "Es gibt in den Gesellschaften des westlich-kapitalistischen Typus keine politisch relevanten Bereiche mehr, in denen der Anspruch autonom-spontaner Diskursivität ungestört von instrumenteller Anbindung an Formen bereits organisierter Öffentlichkeit sich durchsetzen und über längere Zeit bestehen könnte." (ebd., 25) Statt dessen stünden kommunikative und systemrationale Selbst- und Außensteuerung in allen institutionell verfaßten Gesellschaftsbereichen nebeneinander.

Diese Einschätzung hat einige empirische Plausibilität. Sie erlaubt es indes noch nicht, von einer dualistischen Öffentlichkeit in Habermas' Theorie zu sprechen. Zwar steht die einseitige und direkte Kommunikationsstruktur von Massenmedien im Widerspruch zu der diskurstheoretischen Annahme symmetrischer Sprechersituationen, doch dieser kann aufgelöst werden, wenn man die Begriffe autonome vs. vermachtete Öffentlichkeit analog zu den Begriffen Lebenswelt und Systemwelt 
versteht. $^{183}$ Die beiden Begriffe von Öffentlichkeit dienen dann nur der heuristischen Verlängerungen der beiden Grundbegriffe der Theorie des kommunikativen Handelns, befinden sich innerhalb des zivilgesellschaftlichen Konzepts von Cohen und Arato und leiten sich nicht unvermittelt aus der Diskurssituation ab. Dies wird etwa schon dann deutlich, wenn Habermas im Anschluß an Dryzek von 'discoursive designs' als Organisationsform spricht, um die herum sich wesentliche Züge der Art von Kommunikation herausbildeten, die Kommunikation Kontinuität und Dauer verliehen (Habermas, 1992, 443 f). Es ist aber zu vermuten, daß autonome Öffentlichkeiten eine Verstetigung der Öffentlichkeit, wie sie durch die Massenmedien erbracht wird, nicht sicherstellen können. Autonome Öffentlichkeiten könnten mit den komplexen Aufgaben einer stetigen politischen Öffentlichkeit (Agenda-Setting, etc.) überfordert sein.

Ähnlich wie Cohen zwischen starker und schwacher Öffentlichkeit hat S. Dietz zwischen informellen und formellen Verfahren der Legitimation institutionell verfaßter Macht durch Öffentlichkeit unterschieden. Sie hat die Zweifel an informellen Öffentlichkeiten präzisieren können (Dietz, 1995, 127 ff). Informelle Verfahren erfordern im Prozeß der öffentlichen Auseinandersetzung eine selbstorganisierte Fokussierung auf Themen und Positionen, die nur unter bestimmten Bedingungen erreicht werden kann. Themen müßten in der schwachen Öffentlichkeit nicht nur als grundsätzlich oder richtungsweisend erkannt werden, sondern sie müssen sich auch noch zur öffentlichen Dramatisierung eignen und adressierbar sein (s. S. $217 \mathrm{ff}$ ). Zudem dürfen sie weder zu speziell noch zu abstrakt sein. Doch dies präjudiziere noch keine bestimmte institutionelle Beschlußfassung, sondern könne allenfalls bevorstehende Entscheidungen beeinflussen. In formellen Verfahren wird dagegen die Beschlußfassung mit der öffentlichen Meinungsbildung direkt verbunden. Das institutionelle Verfahren kann dabei Anlaß für die öffentlichen Auseinandersetzungen sein, oder umgekehrt kann die öffentliche Thematisierung bestimmter Fragen den Ausgangspunkt für formelle Beschlußverfahren bilden (Wahl, Volksbegehren und Volksentscheid).

Dietz kommt angesichts der komplexen Probleme informeller Verfahren zu dem pessimistischen Schluß, daß

gerade in schwierigen Konflikten, die eine differenzierte Problemerfassung und -lösung erfordern, [...] die öffentliche Meinung auf diese Weise kaum zum entscheidenden Faktor werden [kann]. Darüber hinaus bleibt aber auch bei gelungener Zuspitzung auf ein erkennbares öffentliches Votum eine Lücke in der Verfahrensanbindung, die dem Machtkalkül der Entscheidungsträger vorbehalten bleibt. Wenn dieses Kalkül begrenzt werden soll, muß die informelle öffentliche Meinungsbildung durch formelle Verfahren der allgemeinen Beschlußfassung ergänzt werden. (Dietz, 1995, 128)

Die Entscheidungshoheit über das Gemeinwohl könne aber von den Entscheidungsträgern letztlich immer auch unabhängig von der öffentlichen Meinung bestimmt werden. Institutionell gebundene Entscheidungsgewalt bleibe ein dezisionistisches Moment inne. Allerdings würden derartige elitäre Begründungen wieder an theoretische oder philosophische Positionen

183 Die von Habermas vorgenommene Aufsplittung in zwei Partialtypen von Öffentlichkeit ist nicht zwingend; vgl. Bermbach, 1994, 25. 
zurückverwiesen und müßten sich öffentlich rechtfertigen können. Dabei würden alle Begründungen den normativen Gehalt von Öffentlichkeit - allgemeine Zugänglichkeit der Debatte, Rationalität der Argumente und Authentizität der Darstellung - wahren müssen.

Eine direkte Anbindung der institutionellen Entscheidungsfindung an die öffentliche Meinungsbildung könnte die Rolle des Staatsbürgerkonsenses nicht nur gegenüber den staatlichen Repräsentanten stärken, sondern vor allem auch gegenüber den Massenmedien. Massenmedien würden nämlich "als Gesamtheit eine besondere politische Institution mit eigenen internen Entscheidungsstrukturen" (ebd., 128) bilden. Demgegnüber würden sich unter direktdemokratischen Institutionen eine eigenständigere Form der Öffentlichkeit herausbilden.

Ich werde im folgenden auf den Versuch der Medienwissenschaften eingehen, Habermas' diskurstheoretisches Modell empirisch fruchtbar zu machen. Insbesondere ist das Modell von Gerhards und Neidhard vorzustellen. Sie verstehen unter Öffentlichkeit ein intermediäres Kommunikationssystem, das die Aufgabe hat, zwischen den Interessen und Meinungen der Bürger und dem politischen System zu vermitteln. Ähnlich argumentiert auch B. Peters. Ziel ist eine ökologiespezifische Berücksichtigung der empirischen Medienforschung.

\subsection{1 Öffentlichkeit als funktional stabiliserte Integration}

Die medienwissenschaftlichen Annäherungsversuche an diesen normativen Begriff von Öffentlichkeit waren, mit wenigen Ausnahmen, bisher eher spärlich. Defizite lassen sich allerdings nicht nur in den Medienwissenschaften, sondern auch bei der politischen Theorie beobachten:

Während im Rahmen der empirischen Medienforschung der theoretische Rahmen oft diffus und auf eine eher rhetorische Adaption systemtheoretischer Begrifflichkeiten beschränkt bleibt, leiden gesellschaftstheoretische Konzepte der Öffentlichkeit, wie beispielsweise die in den letzten Jahren grassierenden 'civil society' Ansätze, im Hinblick auf empirische Aspekte der Massenkommunikation unter systematischer Unterbelichtung. Dem 'erheblichen TheorieDefizit' der empirischen Forschung entspricht damit seitens der Politischen Theorie ein Empiriedefizit, das von einer am Öffentlichkeitsbegriff ansetzenden Demokratietheorie noch behoben werden muß. (Dietz, 1995, 129) ${ }^{184}$

In dieser Hinsicht verdient das von Gerhards und Neidhardt (1993) entwickelte Modell von Öffentlichkeit besondere Beachtung. Es nimmt sowohl auf die empirische Forschung in den Medienwissenschaften als auch auf die normative, demokratietheoretische Politikwissenschaft bezug. Ihr Modell orientiert sich stark an Habermas' normativen Begriff von Öffentlichkeit und läßt sich überdies gut an die Theorie des kommunikativen Handelns anschließen. Auf die Diskurstheorie bezieht sich explizit auch B. Peters' normatives Modell der Öffentlichkeit. Einige politiktheoretischen Probleme mit Gerhards/Neidhardts Öffentlichkeitsmodell können durch eine Synthese beider Modelle überwunden werden.

184 Ähnlich auch. Gerhards, Neidhardt, 1993, 33; Peters, 1994, 49 f. 
Eine Schwierigkeit des Modells von Gerhards/Neidhardt liegt darin, daß sie über den Entwicklungs- und Ausdifferenzierungsaspekt moderner Gesellschaften zu einem funktionalen Verständnis von Öffentlichkeit kommen, das sich rhetorisch an die Systemtheorie anlegt. Faktisch hat es jedoch nur wenig mit dem systemtheoretischen Verständnis der öffentlichen Meinung als gesellschaftliche Beobachtung zweiter Ordnung zu tun hat. Es erinnert vielmehr an die systemische Integration in der Theorie kommunikativen Handelns: Innerhalb der verschiedenen Teilsysteme kommt dem politischen System eine Sonderstellung zu, nämlich kollektiv verbindliche Entscheidungen zu treffen. Gerhards/Neidhardt bezeichnen die Politik als Problemadressat - und Problemlösungssystem. "Die Interessen der Allgemeinheit sollen von der Politik wahrgenommen, operationalisiert und durchgesetzt werden." (ebd., 34) Sämtliche Probleme der anderen Teilsysteme, die diese nicht eigenständig lösen können, fallen unter die Verantwortung des politischen Systems. Damit es seine Aufgabe als Problemadressat erfüllen kann, besitzt das politische System besondere Kompetenzen. Es hat ein Zugriffs- bzw. Steuerungsrecht auf alle anderen Teilsysteme. Diese Macht erfordert andererseits die Kontrolle durch eine politische Öffentlichkeit. Gerhards und Neidhardt vertreten also einen diskurstheoretischen Systembegriff.

Die beiden Autoren verstehen Öffentlichkeit als ein ausdifferenziertes Kommunikationssystem mit der intermediären Funktion der Aufnahme, Verarbeitung und Artikulation von Informationen, Meinungen und Interessen. Öffentlichkeit soll dasjenige Organ sein, das zwischen der Gesellschaft und dem politischen System vermittelt. Es soll sowohl Orientierung als auch Kontrolle leisten. Hier entstehen öffentliche Meinungen mit mehr oder minder allgemeinen Einstellungen zu den verschiedensten Themen (vgl. Gerhards/Neidhardt, 1990, 12 ff). Innerhalb des Systems Öffentlichkeit sind drei Prozesse von Bedeutung:

1. Input (Informationssammlung)

2. Throughput (Informationsverarbeitung)

3. Output (Informationsanwendung)

Öffentlichkeit ermöglicht es der Politik, die in der Gesellschaft diskutierten Themen und Meinungen zu erkennen und darauf zu reagieren. Andererseits vermag die Gesellschaft mit Hilfe von Öffentlichkeit, die Leistungen des politischen Systems zu kontrollieren. Insofern konstituiert das Kommunikationssystem Öffentlichkeit eine spezifisch politische Öffentlichkeit, der eine intermediäre Funktion zukommt. (In dieser Zuschreibung hat Öffentlichkeit eine ähnliche politische Funktion wie der Markt für das Wirtschaftssystem.)

Bezüglich der Informationssammlung muß Öffentlichkeit ein gewisses Maß an Sensibilität für die in der Gesellschaft diskutierten Themen und den dazu vorherrschenden Meinungen aufbringen. Diese Sensibilität darf aber nicht zu hoch sein, da ansonsten eine Überfrachtung mit Informationen das Funktionieren von Öffentlichkeit in hohem Maße erschweren würde. Bei der Frage des Inputs kommt der Selektivität des Systems (Welche Themen werden berücksichtigt, welche nicht?) eine besondere Bedeutung zu. Informationsverarbeitung meint, daß die gesammelten Themen und Meinungen geordnet werden müssen, um sinnvolle Zusammenhänge herzustellen. Gelingt diese 
Synthetisierung nur unzureichend, herrscht Überkomplexität, und es kann zu keiner vernünftigen Informationsanwendung kommen. Mit Informationsanwendung ist dabei die Umsetzung der Informationen in Entscheidungen gemeint.

Zwei Grundmerkmale des Kommunikationssystems Öffentlichkeit sind nach Gerhards/Neidhardt seine grundsätzliche Unabgeschlossenheit und seine Laienorientierung. Unabgeschlossenheit bedeutet, daß sämtliche Mitglieder der Gesellschaft die Möglichkeit zur Teilnahme haben. ${ }^{185}$ Auch wenn nicht alle Themen und Meinungen berücksichtigt werden, da auch Öffentlichkeit Grenzen ziehen muß, um funktionsfähig zu sein, und die Aufnahme von Themen an bestimmte Bedingungen geknüpft ist, muß dennoch eine 'prinzipielle Unabgeschlossenheit des Publikums' bestehen bleiben. (Diese Offenheit hatte Habermas bereits in Strukturwandel der Öffentlichkeit zugrundegelegt. Auch Peters orientiert sich an ihr.) Aus dieser Forderung ergibt sich auch das weitere Merkmal von Öffentlichkeit, seine Laienorientierung. Um möglichst allen Mitgliedern der Gesellschaft die Chance zur Teilnahme zu geben, darf die Teilnahme nicht von Stand oder Status der Person abhängig sein, noch darf das Mitwirken an Öffentlichkeit an bestimmte Expertenrollen gebunden sein. Öffentliche Kommunikation ist Laienkommunikation. Experten (z.B. Wissenschaftler) wenden in der Öffentlichkeit nicht den gleichen Code wie untereinander an.

Unterschiedliche Teilbereiche von Öffentlichkeit sind in bezug auf Informationssammlung, Informationsverarbeitung und Informationsverwendung analytisch voneinander zu unterscheiden. Die Medienwissenschaften haben die Vorstellung einer homogenen Öffentlichkeit widerlegt und gezeigt, daß vielmehr sehr komplexe und vielschichtig aufgebaute Öffentlichkeiten existieren, die sehr variabel im Zeitverlauf sind. Diese 'Teilöffentlichkeiten' sind auf unterschiedliche Weise miteinander vernetzt. Obwohl Gerhards/Neidhardt von subsystemspezifischen Codes sprechen, impliziert Laienkommunikation die eine, lebensweltliche Umgangssprache, die soziale Integration ermöglicht. Die Integration der Öffentlichkeit findet dann auch nicht über subsystemische Teilöffentlichkeiten, sondern über Laienkommunikation statt. Diese findet sich in verschiedenen Ebenen von Öffentlichkeit wieder.

Die elementarste Form von Öffentlichkeit wird durch 'Encounter' (nach Goffman) hergestellt. Encounter-Öffentlichkeiten sind Gespräche, die unmittelbar in einem lebensweltlichen Kontext situiert sind. Typisch für diese Art Öffentlichkeit ist ihre geringe Stabilität und ihr Mangel an Strukturiertheit. So wechseln häufig die Themen und auch der Meinungsstand schwankt mit dem Wechsel der Teilnehmer. Diese Merkmale (relative Strukturlosigkeit, Episodenhaftigkeit und geringe Kontinuität) können in totalitären Staatssystemen einen großen Vorteil gegenüber größeren und strukturierteren Öffentlichkeiten bilden. Denn Encounter-Öffentlichkeiten können sich aufgrund dieser Merkmale am leichtesten staatlicher Kontrolle und Manipulation entziehen. Zugleich bilden Encounter-Öffentlichkeiten auch mögliche Ausgangspunkte für die Verringerung des Einflusses von Massenöffentlichkeiten in der Demokratie. Sie sind häufig Orte, an denen gesellschaftliche Wandlungsprozesse zuerst beobachtet werden können.

${ }^{185}$ Vgl. auch B. Peters (1994) der unter den Begriffen Gleichheit, Reziprozität und Offenheit ähnliches anführt. 
Die nächst größere und komplexere Öffentlichkeitsstufe ist der Bereich der öffentlichen Veranstaltungen. ${ }^{186}$ Diese Art der Öffentlichkeit wird durch eine Organisation, d.h. Organisatoren und thematische Verbindlichkeit strukturiert (vgl. auch Gerhards, 1992). Es gibt ein Publikum, das über den Ort,das Thema und die Referenten der Veranstaltung vor der Veranstaltung informiert wird. Auch gibt es im Rahmen der Veranstaltung deutliche Hierarchien, etwa zwischen Diskussionsleiter, Diskussionsteilnehmer und Zuschauer. Diese Hierarchien erzeugen Komplementarität: Der große Teil der Individuen schweigt, hört zu, klatscht, einige verlassen die Veranstaltung etc. während der sehr viel kleinere Teil der Gruppe über eine zuerkannte Redeerlaubnis verfügt und seine Meinungen vor dem größeren Publikum darstellt.

Eine besondere Form von öffentlicher Veranstaltung ist öffentlicher Protest. Hier wurde die Stufe der Diskussion schon überwunden und die des kollektiven Handelns erreicht. Für diese Stufe muß die Organisation noch mehr leisten. Sie muß die Protestabläufe planen und die Protestierenden motivieren. Diese Art von Öffentlichkeit kann sich auf das Recht der Demonstrationsfreiheit berufen.

Die dritte Ebene von Öffentlichkeit, massenmediale Öffentlichkeit, setzt im Gegensatz zu den beiden ersten Ebenen eine gut entwickelte Infrastruktur voraus. Es werden technische Kommunikationshilfen benötigt, und es gibt professionelle Kommunikatoren (Journalisten), die diese Öffentlichkeit organisieren und strukturieren. Diese professionellen Akteure erhöhen die Wahrscheinlichkeit einer breiten und kontinuierlichen Aufbringung von Themen in einer großen Öffentlichkeit. D. h. Themensynthetisierung und Meinungsakkumulation können eher stattfinden, als auf den beiden ersten Ebenen.

Diese Art Öffentlichkeit weist eine starke Ausdifferenzierung zwischen den Leistungsrollen der Kommunikatoren und den Leistungsrollen des Publikums auf. So gibt es kein Präsenspublikum mehr, das Publikum wird abstrakter und ist sehr viel größer, als auf den beiden anderen Ebenen. Die Komplementarität ist noch ausgeprägter, als auf der zweiten Ebene. Das Publikum hat nur noch wenig Handlungsmöglichkeiten, die im wesentlichen nur im An- und Abschalten von Öffentlichkeit bestehen. Nur Themen, die auch auf diese dritte Ebene der Öffentlichkeit gelangen, wird die allgemeine Aufmerksamkeit zuteil, d.h. sie gelangen in die allgemeine Wahrnehmung. Trotzdem müssen diese Themen auch in den Präsensöffentlichkeiten Akzeptanz finden können, sonst werden sie zu speziell und können einem Massenpublikum nicht mehr gerecht werden

Unter dem Aspekt des Zugangs für möglichst viele Menschen erweist sich die massenmediale Öffentlichkeit gegenüber den beiden anderen Öffentlichkeitsebenen als relativ geschlossen und damit unsensibel gegenüber einer möglichst großen Meinungs- und Informationsbehandlung (Sammlung, Bearbeitung u. Verwendung). Eine Offenheit dieses Teils der Öffentlichkeit ist nur

186 B. Peters (1997) hat (vermutlich für diese Ebene) die Ergänzung des Drei-Ebenen-Modells um freie Assoziationen vorgeschlagen. Dieser Vorschlag lehnt sich an Habermas' Modell politischer Deliberation an, wo freie Assoziationen als Knotenpunkte eines aus der Verflechtung autonomer Öffentlichkeiten entstehenden Kommunikationsnetzes verstanden werden. Die Laienorientierung in Gerhardts'/Neidardts Modell beinhaltet aber medienwissenschaftlich eine ganz ähnliche Konsequenz, die eine Erweiterung des Modells m.E. obsolet macht. 
möglich, wenn die Pluralität der Massenmedien groß genug und das Spektrum der gesammelten Informationen möglichst breit ist und diese Informationen dann auch so vollständig wie möglich an das Publikum weitergegeben werden. Diese dritte Stufe der Öffentlichkeit kann sich auf das Gesetz der Pressefreiheit berufen.

Gerhards/Neidhardt billigen allen drei Ebenen eine prinzipielle Gleichrangigkeit zu. Jede dieser Ebenen ist für das Funktionieren einer modernen Massengesellschaft notwendig. Sie nehmen jedoch an, daß von der ersten bis zur dritten Ebene die Leistungsfähigkeit zur Informationssammlung, -verarbeitung und -verwendung zunimmt. Durch die zunehmende Professionalisierung der Informationssammler (Journalisten ) auf der dritten Ebene werden dem Publikum zwar feste, doch keine professionellen Rollen zugewiesen. Das Publikum kann nur noch indirekt in den Kommunikationsprozeß eingreifen. Außerdem ist mit zunehmender Ebene die Gefahr einer zentralen Einflußnahme von Außen eher möglich, wie z.B. durch staatliche und politische Kontrolle.

Die Ebenen sind voneinander abhängig. Die Massenöffentlichkeit kann nur existieren, wenn sie auch in tieferen Öffentlichkeitsebenen wahrgenommen wird. Andererseits brauchen diese tieferen und kleineren Öffentlichkeiten die Massenöffentlichkeit zur Informationssammlung und um ihr eigenes Wirken durchsetzen zu können, d.h., um ihren eigenen Einflußbereich zu überschreiten und um in die breitere Öffentlichkeit gelangen zu können. Diese Rückbindung auch der massenmedialen Öffentlichkeit an interpersonale Kommunikation ist einer der großen Vorzüge des Modells von Gerhards/Neidhardt. Es erlaubt eine auch demokratietheoretisch wünschenswerte Rückbindung der massenmedialen politischen Öffentlichkeit an interpersonale Kommunikation (vgl. Schmitt-Beck, 1994). Dabei ist eine Ähnlichkeit zum Lebensweltkonzept der Theorie des kommunikativen Handelns unverkennbar. Zunehmende Ausdifferenzierung löst den auf die Lebenswelt verweisenden interpersonalen Diskurs nicht ab, sondern bleibt auf diesen verwiesen. Es kann nun Ebene 3, die Ebene der Massenmedien, eingehender betrachtet werden.

Hinsichtlich der Struktur von Öffentlichkeit ergeben sich mehrere Probleme, die für die Funktion massemedialer Öffentlichkeit von Bedeutung sind: Trotz der prinzipiellen Unabgeschlossenheit von Öffentlichkeit, können nicht alle Themen und Meinungen beachtet werden. Vielmehr zeigt sich eine ausgesprochene Selektivität der Massenmedien (aber auch der vorausliegenden Öffentlichkeitsebenen). Die massenmedialen Selektionsmechanismen sind vor allem Gegenstand der Agenda-setting-Forschung (vgl. Bettschneider, 1994). Zum anderen muß der Öffentlichkeitsbereich vom Privatbereich abgegrenzt sein. Diese Grenze ist nicht durch Persönlichkeitsrechte ein für alle mal gegeben, sondern kann im Diskurs kritisiert und verändert werden. Generell aber ist eine solche Grenze für die Funktionsfähigkeit der massenmedialen Öffentlichkeit unerläßlich. Ferner können bestimmte Meinungen ganz bewußt in der öffentlichen Diskussion tabuisiert werden (Gerhards/Neidhardt, 1990, 30 f). Diese Meinungen werden dann nur noch auf der untersten Öffentlichkeitsebene, bzw. im Privatbereich diskutiert, was dazu führen kann, daß sich öffentliche Meinung und Denken größerer Teile der Bevölkerung unterscheiden. 
Im normativen Modell sind latente Thematisierungsverbote oder Kommunikationssperren durch soziale Praktiken, nicht vertretbar. Andererseits ist die normative Bestimmung von Relevanzkriterien für öffentliche Diskussionsbeiträge äußerst schwierig. B. Peters hat angenommen, daß diejenigen Themen wichtig seien, "die in einer egalitären, verständigungsorientierten Debatte unter Beteiligung des gesamten Publikums auf die oberen Plätze der öffentlichen Tagesordnung gesetzt würden." (Peters, 1994, 64) Läßt sich diese Vermutung aber bereits als Kriterium verwenden? Wie und wo ließe es sich anwenden?

Mit dem Aufkommen moderner Kommunikationstechniken, entwickelt sich besonders bei den höheren Öffentlichkeitsebenen die Tendenz zu einer Differenzierung von Sprechern, Thema und Publikum (Gerhards/Neidhardt sprechen von Arena und Galerie). Damit geht die Gefahr einher, daß Öffentlichkeit mit zunehmender Rollendifferenzierung zum bloßen Publikum verkommt, das keinen direkten Anteil mehr an der öffentlichen Diskussion hat, und es immer unwahrscheinlicher wird, "daß sich in der Öffentlichkeit Allgemeinheit auch nur annähernd repräsentativ unmittelbar zu Sprache bringen kann." (Gerhards, Neidhardt, 1990, 33 f) Einen wichtigen Faktor für die Repräsentativität von Öffentlichkeit, insbesondere auch für die unteren Ebenen 'Begegnung' und 'Veranstaltung', stellt die Öffentlichkeits- bzw. Kommunikationsbereitschaft der Bürger da. Die dazu benötigten Fähigkeiten und Motive (z.B. politisches Interesse) sind innerhalb der verschiedenen Bevölkerungsteile nicht gleichmäßig verteilt, so daß damit gerechnet werden muß, daß auch hier nicht völlige Repräsentativität gewährleistet ist. Überdies beanspruchen freie Assoziationen den Zugang zur Arena. Demokratietheoretisch geht es um die Interdependenz von Rollen (und nicht die Rücknahme der Rollendifferenzierung).

Der Machtfaktor im Öffentlichkeitsbereich spielt besonders bei der massenmedialen Kommunikation eine wichtige Rolle. Massenkommunikation ist einseitig und direkt. Dadurch wird die Selektivität nochmals relevanter. Im Gegensatz zu den unteren Öffentlichkeitsebenen kann auf der Ebene der Massenmedien durch Besitzverhältnisse, Sponsorenunterstützung, Authorität/Prominenz usw. Einfluß darauf genommen werden, wer wie lang welche Meinung zu welchem Thema sagen darf.

\subsubsection{Die Öffentlichkeit politischer Institutionen}

Gerhards'/Neidhardts Konzeption von Öffentlichkeit bleibt relativ unspezifisch auf das politische System bezogen. Encounter Öffentlichkeit, öffentliche Versammlung und massenmediale Öffentlichkeit umfassen zwar alle empirischen Formen von politisch relevanter, rechtlich institutionalisierter Öffentlichkeit, doch deren Verhältnis zum demokratischen Entscheidungsprozeß wird nicht näher ausgeführt.

Politische Institutionen stehen in vielerlei sozialen und kommunikativen Beziehungen, die selbst in autoritären und totalitären Staaten noch eine Öffentlichkeitsdimension haben. In der Theorie des kommunikativen Handelns entstehen Institutionen zweiter Ordnung bei der Differenzierung der 
systemischen Bereiche von der Lebenswelt. Gegenüber Institutionen erster Ordnung (z.B. Familie, Ehe, etc.) beinhalten Institutionen zweiter Ordnung (z.B. Parlament, Börse, etc.) ein reflexives Element und verweisen auf entsprechende Begründungs- bzw. Anwendungsdiskurse. Institutionen zweiter Ordnung erhalten neben der synchronen Dimension (aufgrund der Differenzierung von Systemen und Lebenswelt) über Habermas' kritischen Anschluß an Webers Rationalisierungstheorie auch eine diachrone Dimension (vgl. Gimmler, 1998, 178 ff), indem die Entwicklung des kollektiven moralischen Bewußtseins auf entsprechende pathologische Lebensformen reagiert (vgl. Habermas, 1991, 9 ff; 31 ff). Derartige Kolonialisierungsprozesse lassen sich nur aus der (Teilnehmer-)Perspektive der Lebenswelt wahrnehmen, während diese Prozesse aus der (Beobachter-)Perspektive der Systeme lediglich als Steuerungsprobleme (Grenzen der Verrechtlichung) erscheinen. Institutionen überbrücken die Kluft zwischen Lebenswelt und Systemen, weil diese durch empirisch vermehrt zu beobachtendes zweckrationales Handeln und nicht-intentionale Handlungsfolgen nur systemisch integriert werden und strukturell auf den sozialintegrativen Handlungstyp des kommunikativen Handelns angewiesen bleiben. Die primären Institutionen der Lebenswelt reproduzieren das moralische Bewußtsein über Sozialisation (Gesellschaft) und Identitätsbildung (Person); über die reflexive Sprache können sie wiederum kritisch hinterfragt werden. Die sekundären Institutionen systemischer Differenzierung belegen die Lebenswelt mit Anpassungsanforderungen und entlasten sie gleichzeitig durch den Rückgriff auf Medien von kommunikativen Aufgaben. Sekundäre Institutionen geben keine Orientierungsinhalte vor, sondern eröffnen auf einem neuen Lernniveau "strukturelle Möglichkeiten für die Rationalisierung des Handelns" (Habermas, 1981, II, 464). Institutionen zweiter Ordnung werden von Habermas als sedimentiertes, mit Geltungsmacht versehenes Wissen verstanden.

Während A. Gimmler primäre Institutionen strukturell ganz der Lebenswelt zurechnet, zählt sie sekundäre Institutionen eher zu den Systemen, versteht sie aber auch noch lebensweltlich. ${ }^{187}$ Gimmler schließt mit ihrer Zuordnung primärer und sekundärer Institutionen an die bereits erwähnte Auffassung an, daß Habermas die Unterscheidung zwischen Lebenswelt und Systemen metatheoretisch nicht gelöst hat und die Kolonialisierungsthese demzufolge nur empirisch zu bestimmen sei (Gimmler, 1998, 183 f). Sekundäre Institutionen liegen mit ihrer ambivalenten Natur zwischen System und Lebenswelt. ${ }^{188}$ Als formelle Institutionen funktionieren politische Institutionen nur durch das Rechtssystem. Formelle Institutionen des politisch-administrativen und des ökonomischen Systems sind immer von der Steuerbarkeit durch Recht abhängig. Recht ist in seiner motivierenden Kraft empirisch und in seinem Legitimitätsanspruch durch rationale Gründe zu bewerten. Im Fall des politisch-administrativen Systems verbindet sich Recht mit dem Machtmedium und schließt staatliche Zwangsbefugnis ein. Die Legitimität des Handlungssystems Recht ist aber durch die symbolische Bedeutung politischer Institutionen, deren Funktion nicht

187 Gimmlers Ansatz stimmt damit im wesentlichen mit Cohen/Aratos Theorie der Zivilgesellschaft überein (s. S. 213 ff), obwohl Gimmler ihre institutionelle Deutung von Habermas aus der Diskussion ganz anderer Soziologen als Cohen/Arato entwickelt.

${ }^{188}$ Habermas (1992, 90 ff) rekonstruiert dies später nur noch als Widerstreit zwischen philosophischem Gerechtigkeitsdiskurs und empirischer Rechtssoziologie und läßt die ursprüngliche Unterscheidung zwischen Recht als Institution und Recht als Medium fallen; Habermas, 1981, II, 536. 
einfachhin unter Effizienzgesichtspunkten subsumiert werden kann, immer an die kritische Instanz der Lebenswelt zurückgebunden. Seit der historischen Durchsetzung des Prinzips der Volkssouveränität besteht diese kommunikative Beziehung in demokratischen Staaten immer als Legitimationsbeziehung (Habermas, 1992, 600 ff).

Jede Selbstorganisation der Gesellschaft findet aber ihre Grenzen an der Historizität des Sozialen, sowohl in der synchronen als auch in der diachronen Dimension. Bereits in der synchronen Dimensionen finden sich unbeherrschbare Interdependenzen zwischen handelnden Zeitgenossen. In der diachronen Dimensionen sind diese noch prägnanter; aktuelles Handeln wird durch vorangegangenes Handeln bedingt. Im Bildungs- und Rentenversicherungssystem tritt dieses Phänomen als Generationenfolge auf. Nicht immer aber lassen sich temporale Strukturen der Gesellschaft derart deutlich abgrenzen, auch wenn sie über Lebenszyklen zugänglich sind. Verselbständigung erfolgt sowohl in der materiellen als auch in der symbolischen Objektivation der Gesellschaft. Auch für eine kommunikativ-handelnde Gesellschaft könnte dies zur Verselbständigung der Gesellschaft führen (vgl. Peters, 1993, 229 ff). Nicht für eine Verselbständigung des Sozialen stehen hingegen die Fehlbarkeit unseres Wissens und die Offenheit moralischer Lernprozesse, da es sich hierbei um Ungewißheit und offene Möglichkeiten und nicht um Bindung oder Zwang handelt.

G. Göhler hat im Unterschied zu Habermas die soziale Beziehung zwischen politischen Institutionen und Bürgern als Macht- und Repräsentationsbeziehung entwickelt, denn politische Institutionen könnten nicht als Sonderfall sozialer Institutionen verstanden werden. Vielmehr wiesen sie einen ideativen 'Überschuß' gegenüber sozialen Institutionen auf, den eine allgemeine, soziologische Theorie der Institution nicht erfassen könne. Politische Institutionen gehen über eine instrumentelle (strategische) Begründung hinaus; sie verweisen auf eine normative Begründung. Göhler entwickelt seine Theorie politischer Institutionen entlang von Willens- und Symbolbeziehungen, die den gesamten politischen Handlungsraum wechselseitig symmetrisch und asymmetrisch durchdringen.

Eine Diskrepanz zu Habermas rührt im wesentlichen aus der mit Schmalz-Bruns geteilten Auffassung her, daß in der Gegenwart kein Begriff substantieller Vernunft mehr zur Verfügung stehe (Göhler, Schmalz-Bruns, 1988, 313 f). Gleichwohl hat die Diskurstheorie im letzten Jahrzehnt eine Ausprägung erhalten, welche die Theorien näher aneinander herangeführt hat (Habermas, 1992; Günther, 1998, 1999). Während, nach Göhler, soziale Institutionen als relativ auf Dauer gestellte, durch Internalisierung verfestigte Verhaltensmuster und Sinngebilde mit regulierender und orientierender Funktion verstanden werden könnten, seien politische Institutionen "Regelsystem der Herstellung und Durchführung verbindlicher, gesamtgesellschaftlich relevanter Entscheidungen und Instanzen der symbolischen Darstellung von Orientierungsleistungen einer Gesellschaft. Als solche seien sie sowohl festgelegter Rahmen als auch geronnene Muster des Handlungsraums Politik." (Göhler, 1997, 26)

Verbindlichkeit und Relevanz politischer Entscheidungen grenzten diese von anderen gesellschaftlichen Entscheidungen ab (vgl. dazu auch Habermas, 1992, 465 ff). Es könnten Räume 
des Nicht-Politischen entstehen, die nicht zwangsläufig mit Cohen/Aratos Begriff von Privatheit zusammenfallen müßten. Politik als Handlungsraum erfülle zwei Funktionen, die in Konkurrenz zu nicht-politischen Handlungsräumen treten könnten: Politik erbringe Steuerungsleistungen für die Gesellschaft und dient deren Integration. Steuerung bezieht sich auf "alle Formen zweckbestimmter Regulierung von Handlungsoptionen in einer politischen Einheit." Integration auf "die Orientierung der Bürger an den Werten und Ordnungsprinzipien, die der Ordnung des Gemeinwesens zugrunde liegen, um ein Mindestmaß an Identifikation und kollektiver Identität zu erreichen." (Göhler, 1997, 19 f) Im politischen Handlungsraum regele und normiere Politik reflexiv ihre Erstellung und Durchführung. Dabei liege dem Begriff des Handlungsraums im Unterschied zu Habermas kein systemisches, sondern ein strukturelles Verständnis des politischen Prozesses zugrunde, daß unter dem Gesichtspunkt der Steuerung aber an das systemtheoretische Modell Eastons anschließe.

In der Willensdimension handeln Menschen mit bestimmten Zwecken und Absichten. In der Symboldimension kommunizieren Menschen mit Symbolen über die soziale Welt. Hier flössen normative, expressive und politische Ordnungsprinzipien verdichtet ein. Die Beziehung zwischen Bürgern und den politischen Institutionen drückten analytisch zugleich eine Willens- und eine Symbolbeziehung aus, welche sie kommunikativ miteinander verbänden. In der Willensdimension werde nicht nur Macht konstituiert, sondern, da Willensbeziehungen nie einseitig seien, immer auch ein zumindest minimales Maß an Reziprozität geschaffen; dies gelte selbst für den Fall transitiver Macht, d.h. einer (durch Gewalt oder Befehl) auf ein anderes Subjekt bezogenen Machtbeziehung. Intransitive Macht erwächse hingegen aus der (kollektiven) Affirmation eines anderen Willens (vgl. Göhler, 1997, 38 ff). ${ }^{189}$

U. Preuß hat der Diskurstheorie indirekt ein Modell transitiver Macht nahegelegt, müsse diese doch eine Pflicht zur Teilnahme an Diskursen umfassen (Preuß, 1998). K. Günther hat dagegen mit dem Konzept kommunikativer Freiheit intransitive Macht verteidigt (Günther, 1998; 1999). Intransitive Macht kann nur argumentativ in Diskursen erzeugt werden und bleibt auf sich selbst bezogen. Der diskurstheoretische Personenbegriff dient Günther zur Vergegenwärtigung des Zusammenhangs zwischen deliberativer Person, Staatsbürger und Rechtsperson und nicht zur Begründung der Diskurstheorie. ${ }^{190}$

Das Konzept kommunikativer Freiheit beruht ausschließlich auf der Möglichkeit eines Sprechers 'Nein' zu sagen (Günther, 1998, 237). Dabei bezieht sich diese Freiheit zur Negation auf die Geltungsansprüche eines Sprechaktes. Günther versteht die Möglichkeit eines Sprechers zur Negation zugleich als doppelte Verneinung eines Aktors zu einem Handlungsplan. Denn in der Verneinung eines Aktors verneint dieser auch die Möglichkeit, seine Intentionen zu verneinen: Das

189 Diese Faktizität von Macht in der Institutionentheorie Göhlers konstituiert scheinbar den größten Kontrast zum kontrafaktischen Ideal des symmetrischen Diskurses in der Diskurstheorie. Doch kommt in dieser durch den erwartungsstabilisierenden Rückgriff auf das Rechtmedium ebenfalls transitive Macht zum Tragen. Diese ist jedoch in der Diskurstheorie durch begründete Grundrechte auf die Verwirklichung intransitiver Macht qua kommunikativer Macht eingeschränkt. Zugleich wird das Recht primärer Maßstab von Legitimation und nicht das Verhältnis zwischen Bürgern und Repräsentanten.

190 Dies unterscheidet ihn u.a. vom liberalen Begriff der positiven und negativen (politischen) Freiheiten. 
Nein eines Sprechers ist die illokutionäre Verweigerung des Geltungsanspruchs (vgl. auch Habermas, 1999, 111f). Mit der Annahme eines Sprechaktangebotes erwächst daraus die (gegenseitige) illokutionäre Verpflichtung, selbst Gründe in bezug auf die Geltungsansprüche des Sprechers anzugeben. Habermas spricht von 'interaktionsfolgenrelevanten Verbindlichkeiten' (Habermas, 1984, 596). Die vom Hörer angebrachten Gründe können gegenüber den angeführten Gründen des Sprechers affirmativ oder ablehnend sein; im affirmativen Fall überbrücken die eingegangenen illokutionären Verpflichtungen den Unterschied zwischen Gründen und Motiven (Günther, 1998, 240). Im intersubjektiven Bereich gewinnen Motive so einen objektiven Charakter.

Dieser objektive Charakter erlaubt Ego, die Perspektive eines Beobachters gegenüber seinen eigenen Motiven einzunehmen. Hinsichtlich der geteilten Geltungsansprüche ist er aber Mitglied der darauf bezogenen singulären Handlungsgemeinschaft. Im Gegensatz zu Gegenmotiven können Gegenargumente, sofern sie bessere Argumente darstellen, jederzeit die Handlungsgemeinschaft auflösen. Kommunikative Freiheit schließt dabei immer noch eine Exit-Option ein, d. h. die Kommunikation kann jederzeit ohne/mit Angabe von Gründen aufgegeben werden. Insofern nun die illokutionären Kräfte von Kommunikation zur Koordinierung von Handlungsplänen dienen, müssen die Sprecher und Hörer also ihre Rollen wechseln und zu Aktoren werden. Dabei wandelt sich kommunikative Freiheit zu Handlungsfreiheit, die auf einer gegenseitigen Zuschreibung der Fähigkeit basiert, gemäß von Geltungsansprüchen zu handeln. Durch die illokutionäre Rückkoppelung von Gründen an Motive schließt Handlungsfreiheit dabei die autonome Motivation von Aktoren ein. Wie Günther mit Habermas feststellt, hat kommunikative Macht nicht nur einen kognitiven Aspekt (als Ermöglichung rationaler Meinungs- und Willensbildungsprozesse), sondern auch motivierende Kraft durch intersubjektiv geteilte Überzeugungen, wenn auch nur in Form schwach motivierender Gründe (vgl. Habermas, 1992, 183, 188). Die kommunikative Handlungsmacht folgt den Gebrauchsweisen praktischer Vernunft.

Auch Göhler zufolge ist intransitive Macht das Gegenteil eines Nullsummenspiel. Sie konstituiert nämlich eine Gemeinschaft. Sie ist demnach primär keine Willensbeziehung, sondern eine Symbolbeziehung, weil es hierbei nicht darum gehe, den eigenen Willen gegenüber anderen durchzusetzen. Es werden gemeinsame Werte und soziale Ordnungsprinzipien konstituiert und in politischen Institutionen auf Dauer gestellt und repräsentiert. "Der gemeinsame Handlungsraum der intransitiven Machtbeziehung ist zu unterscheiden von dem verschränkten Handlungsraum der transitiven Machtbeziehung." (Göhler, 1997, 44) Während der verschränkte Handlungsraum eine reine Willensbeziehung widerspiegelt, wird der gemeinsame Handlungsraum durch Symbole mediatisiert.

Die Symbolbeziehung von Bürgern zu politischen Institutionen wird nicht nur in der kognitiven sondern auch in der expressiven Dimension geschaffen. Der Assoziationszusammenhang von Symbolen ist nicht eindeutig, sondern für verschiedene Interpretationen offen. Dies ermöglicht die Integration trotz pluraler Politik im gemeinsamen politischen Handlungsraum. Während also die politische Realität wesentlich durch Symbole konstituiert wird, wird sie (vor allem) durch Institutionen strukturiert. Die symbolische Dimension politischer Institutionen ist zugleich aber 
Voraussetzung für die Wirkungsmächtigkeit politischer Institutionen. Sie tritt neben die Willensbeziehung.

Intransitive, kommunikative Handlungsmacht ist ungleich flüchtiger. Sie kann durch jeden Dissens aufgehoben werden, der legitime motivationale Gegengründe oder andere Geltungsgründe anführt. Auch extern bleibt kommunikative Handlungsmacht fragil. Einen Ausweg bietet die Institutionalisierung kommunikativer Handlungsmacht an, so daß nicht jeder Gegengrund zum Zusammenbruch des durch illokutionäre Verpflichtungen begründeten Konzerts von Aktoren führt.

Therefore, communicative power is applied to itself-the We, made up of those who factually accepted a validity claim and reidentified and reconfirmed themselves as a singular action community, can itself become a political community. The reidentification and the reconfirmation of a singular action community is interpreted as the foundation of constitutional rules, procedures, and institutions which enable its members to reproduce communicative power through and within an institutional framework. (Günther, 1998, 250)

Erst in diesem Zusammenhang stellt sich das Problem von Macht, denn der mit staatlichem Zwang verbundene Effekt, die Gegenmotive von Aktoren zu übergehen, entkoppelt die interne illokutionäre Verbindung zwischen kommunikativer Freiheit und Handlungsmotiven und kann so kommunikative Macht aushöhlen. Die Strategie der Institutionalisierung ist somit in Gefahr, den Aktor als einen virtuosen Staatsbürger mißzuverstehen, der jederzeit die Verfassung zu unterstützen hat, selbst dann, wenn sein Dissens vernünftig wäre. Im Gegensatz zu partikularen Rechtsnormen impliziert das Diskursprinzip, daß jeder Betroffene eine Handlungsnorm zwanglos akzeptieren kann. Die Relation zwischen Gründen und Motiven stellt sich jedoch im Medium des Rechts anderes dar als beim kommunikativen Handeln.

Im Gegensatz zu reziprok von Sprecher und Hörer bestätigten Handlungsnormen enthalten Rechtsnormen nämlich für die Aktoren keine Verpflichtung, Rechtsnormen zu Gründen für zukünftige Handlungen zu machen. Damit verbindet sich mit Rechtsnormen auch nicht die Erwartung, daß diese zu Motiven für Aktoren werden. Rechtsnormen unterscheiden grundsätzlich zwischen der Freiheit eines Aktors, eine Meinung zu haben und der Verpflichtung, einen Grund als seinen Handlungsgrund anzunehmen. Rechtsnormen werden relevant für eine Handlungssequenz, weil sie sich mit Zwang verbinden. Und gerade dies beraubt sie ihrer illokutionären Verpflichtungen. Letztlich bildet die Angst vor staatlichem Zwang ein vergleichbar starkes Motiv für eine Rechtsperson wie die Affirmation von Gesetzesnormen. Allerdings kommt auch über den nur schwachen Wandel von Einstellung und Motiven im Zuge einer kollektiven Willensbildung Rechtsnormen noch ein volitives Moment zu. ${ }^{191}$

Macht als Willensbeziehung wird bei Göhler durch die Symbolbeziehung als Repräsentation ergänzt. Aus dessen Willensdimension leitet Göhler den Legitimationsbegriff ab: "Es kommt vor allem darauf an, daß die Kontrolle der Repräsentierten der Komplexität anstehender Entscheidungen, insbesondere aber einer vermehrten Macht der politischen Entscheidungsträger

191 Vgl. Habermas (1992, 193): "Wegen dieses Bezuges auf das faktische Willenssubstrat einer Rechtsgemeinschaft geht ein volitives Moment in den Sinn der Gültigkeit (und nicht erst der sozialen Verbindlichkeit) von Rechtsnormen ein." 
angemessen bleibt. Darin liegt die Legitimation, welche die Repräsentation als Willensbeziehung dem politischen System verleiht." (Göhler, 1997, 48) Legitime Repräsentation beschränkt sich also nicht auf die Symbolbeziehung. In der Repräsentation durch Mandat manifestiere sich auch die Willensbeziehung. ${ }^{192}$ Legitimation kann deshalb für Göhler nicht unmittelbar politischen Institutionen zugeschrieben werden, da ausgeübte Repräsentation ebenfalls Willenssubstrate beinhalte.

Politische Institutionen können analytisch weiter im Verhältnis zu Akteuren, im Verhältnis zu Adressaten und nach institutionellen Mechanismen differenziert werden. Politische Institutionen mit Akteuren können formell (Legalität, Gesetz oder Satzung) oder informell (Gewohnheiten, Verhaltensregelmäßigkeiten) sein. Nur wenige direktdemokratische Institutionen heben den Unterschied zwischen Akteuren und Adressaten auf. Gewöhnlich wird dagegen ein Herrschaftsverhältnis geschaffen. Göhler bezeichnet den Charakter oder die Eigenschaften von Institutionen als institutionellen Mechanismus, welche, wenn sie eine bestimmte Institution mit ihren dazugehörigen Sozialbeziehungen kennzeichneten, eine institutionelle Konfiguration darstellen würden. Als institutionelles Arrangement wird der Zusammenhang bzw. das Zusammenwirken von Institutionen in ihrer jeweiligen Konfiguration bezeichnet.

Im Gegensatz dazu verfügt die Diskurstheorie über keinen gleichartigen Begriff der Repräsentation, der einen direkten Bezug der Bürgern zum politisch-administrativen System sichern würde. Ein solcher Begriff dürfte schwer zu entwickeln sein, denn zwar finden sich 'Prozeduralisierungen' nicht nur in der rechtlichen Regelung von formalen Organisationen und systemisch strukturierten Institutionen, sondern auch in rechtlichen Regelungen der Lebenswelt (vgl. Eder, 1989, 120), doch ein personales Verantwortungsverhältnis wird damit nicht notwendig konstituiert. Das Recht als Medium des politisch-administrativen Systems kann sich gegenüber der Lebenswelt ebenso verselbständigen wie die vom Recht getragenen politischen Institutionen. ${ }^{193}$ Mit Cohen/Arato ist festzuhalten, daß bisher keine empirischen Maßstäbe zur Validierung der Kolonialisierungsthese durch Recht bestehen. Dieses Problem zeigt sich deutlich im Fall der Europäischen Union, wo EURecht zunehmend nationales Recht überlagert (vgl. Scharpf, 1996). Das u.a. aus der Verselbständigung des Rechts resultierende Demokratiedefizit ist nicht notwendig durch Erhöhung der Partizipation zu beheben (vgl. Zürn, 1996). Fehlende Repräsentation ist Folge der systemischen Integration und zugleich Indikator mangelhafter sozialer Integration. Diese aber kann die Diskurstheorie wiederum explizieren.

Die Öffentlichkeit des politischen Handlungsraums wird durch eine Kultur mit diskursiven und präsentativen Bedeutungselementen eingerahmt. Während diskursive Symbole einfache, sprachliche Zeichen sind, die Bedeutung und Sinn mit sich führen und so strukturiert sind, daß sie

192 Zwar spricht Göhler davon, daß auch Argumente diese Willensbeziehung konstituierten (Göhler, 1997, 13)., doch führt er diesen interessanten Punkt nicht aus, so daß eine Ablösung des Repräsentationsprinzips etwa durch argumentativ legitimierte direktdemokratisch Institutionen nicht in Sicht geraten kann.

193 Schmalz-Bruns (1990, 1995) vertritt die Auffassung, daß Recht gerade durch seine systemtheoretische Vereinnahmung in die Krise geraten sei, d.h. er stimmt Teubners Diagnose eines regulativen Trilemmas zu und will deshalb Recht nicht als Medium einsetzen, sondern auf seine Angemessenheit prüfen. 
Inhalte semantisch und syntaktisch über Kommunikation (zeitlich) linear transportieren, sind präsentative Symbole Totalitätsdarstellungen. (Sie werden auch als Verdichtungssymbole bezeichnet.) Ihr Gegenstand erscheint unvermittelt, simultan und ohne sich zeitlich zu erstrecken. Sie transportieren häufig Ideen, da sich diese in präsentativen Symbolen zu einem (einzigen) Bild zusammenziehen lassen; sie können ebenfalls sprachlich erzeugt werden, doch nicht diskursiv, d.h. Satz für Satz. ${ }^{194}$ Präsentative Symbole funktionieren in erster Linie als Bilder, die vor allem affektiv wahrgenommen werden. Derartige präsentativen Bedeutungen können aber in der Umgangssprache argumentativ interpretiert und kritisiert werden. Präsentative Bedeutungen sind prinzipiell argumentativ zugänglich und können damit Eingang in den Diskurs finden (Peters, 1997, 5 ff). Habermas hat diesen Übergang vom symbolischer Interaktionismus zum kommunikativen und schließlich normenregulierten Handeln ausführlich dargestellt (1981, II, 15 ff). Das symbolische Universum geht über eine diskursive Vergesellschaftung hinaus; es beherbergt beispielsweise auch nicht-argumentative und nicht-intentionale Aspekte der Vergesellschaftung. Das symbolische Universum umrahmt die diskursiven Praktiken und damit auch die politische Öffentlichkeit. Dies wird durch einen faktischen Pluralismus im Politischen reflektiert, der erst mit einer Fragmentierung des symbolischen Universums durch inkommensurable Sprachspiele im Zuge funktionaler Differenzierung oder durch einen kulturellen Pluralismus gefährdet erscheint. Dagegen beansprucht kommunikatives Handeln, die Integrationsfähigkeit der Gesellschaft sichern zu können.

Peters hat die Differenz zwischen Diskursen und symbolischem Universum bekräftigt, indem er explizit auf symbolische Verständigungsschranken hinwies. Diese existieren auch für expressive Kommunikation, die aber nur ein Teil der öffentlichen Kommunikation sei. Daneben sind Verhandlungen zu nennen, die ebenfalls an Diskurse zurückgebunden sind. Ferner beschränkt symbolische Gewalt als Beleidigung oder Herabsetzung und Täuschung oder Manipulation (etwa durch die gezielte Selektion von Informationen) die Möglichkeit zur Verständigung. Schließlich stellt auch das Abschneiden von Negationsmöglichkeiten als sozial erzwungene Konsenserwartungen, die Dissens ächten, ein Hindernis für Verständigung dar.

Argumentativer Konsens bedeutet die Lösung eines vorangegangenen Dissenses, der jedoch offen bleibt für neue Kriterien und Problematisierungen: Und wo Konsens nicht denkbar ist oder als unerwünscht gilt, kann man auch von Dissens nicht reden: denn kontroverse Argumentation macht nur Sinn, wo die Möglichkeit gegenseitiger Überzeugung vorausgesetzt wird. Nicht erst der Konsens, schon der Dissens bzw. Disput (im Gegensatz zum bloßen Konflikt) sind 'unwahrscheinlich' - nämlich angewiesen auf eine eingeübte Praxis wechselseitigen Respekts. (Peters, 1994, 68)

Zuletzt ist auch die Differenzierung der Geltungsansprüche in kognitive, moralische-evaluative und expressive notwendig, wenn Kommunikation nicht beschränkt werden soll. Symbolische oder expressive Kommunikation im politischen Bereich stelle sich aber schnell als Gefahr für die diskursive Vergesellschaftung dar und drohe offene Kommunikation insgesamt zu schließen.

194 Die Bedeutungen von Verdichtungssymbolen können durch nicht-sprachliche Symbole (Bilder, Gegenstände, Flaggen, Musik etc.) und symbolische Praktiken (Signale, Rituale, etc.) repräsentiert werden. Daneben existiert auch nicht-geschriebene, figurative oder poetische Sprachverwendung (Fiktion, Poesie, Metaphern etc.). 


\subsubsection{Symbolische Politik und argumentative Kritik}

Da Symbolik in der Öffentlichkeit über die Verwendung von Zeichen hinausgeht und symbolische Handlungen umfaßt, denen nicht nur eine teleologische Struktur, sondern auch Sinn inne ist, läßt sich politische Symbolik verstehen und in ihrem Symbolwert ähnlich erfassen wie sprachliche Äußerungen. "Politische Symbolik dient der Orientierung im politischen Feld und der Selbstinterpretation der Gesellschaft, indem politische Gehalte durch Symbole so aufbereitet werden, daß grundsätzliche Differenzen und Optionen sichtbar und darstellbar werden.[...] Sie ist damit komplexitätsreduzierend und schafft Überblick." (Speth, 1997, 95) Allgemein läßt sich, wie gesehen, demokratischen, politischen Institutionen eine unproblematische, symbolische Ordnungsleistung zuschreiben, die als solche immer einen unspezifischen Öffentlichkeitsbezug aufweist. Dieser unspezifische Öffentlichkeitsbezug spiegelt allerdings noch keine Offenheit oder allgemeine Zugänglichkeit politischer Institution wider (vgl. Rehberg, 1995). Diese variiert vielmehr mit dem lebensweltlichen Bezug der politischen Institution. Es bilden sich spezifische Teilöffentlichkeiten an den Interferenzstellen von Lebenswelt und politischem System und den dazugehörigen Institutionen. Derartige Teilöffentlichkeiten sind Ergebnis von Differenzsetzungen zwischen dem Öffentlichen und dem Geheimen oder Öffentlichkeit und Privatheit, die durch die normative Bezugnahme auf eine politische Theorie gesetzt werden, welche die Exklusivität politischer Institutionen (öffentlich) expliziert. Öffentlichkeit ist nicht Antipode der Macht, sondern "eine Variable der jeweiligen Formation der Macht (lateral/instrumentell) und der jeweiligen Formen der Machtausübung und der mit ihnen verbundenen Visibilitätsoptionen (autokratisch, demokratisch, expertokratisch)." (Münkler, 1995, 216) Öffentlichkeit erscheint so nicht als eine allein der kritischen Zivilgesellschaft reservierte Ressource, sondern kann in ihrer ganzen Breite auf demokratische Selbstregierung bezogen werden.

Während politische Institutionen in der öffentlichen Dimension immer auch Macht repräsentieren, wird diese in der internen institutionellen Praxis verdrängt. Doch politische Institutionen müssen unter demokratischen Gesichtspunkten ihre interne Praxis legitimieren und Interessenhintergründe offenlegen können. Sie müssen ihre repräsentierte und ihre ausgeübte Macht nach bestimmten Kriterien rechtfertigen können. Der Legitimationsanspruch geht über die bloße Transparenz politischer Institutionen hinaus. Denn würde Legitimation allein auf die symbolische Ordnungsleistung und nicht auch auf die materielle Leistung oder Nichtleistung politischer Institutionen bezogen werden, würde Politik zum Ritual degradieren.

Der politologische Begriff der symbolischen Politik ist ambivalent, da ebenso die legitime Vermittlung von Politik über unvermeidliche Symbole gemeint sein könnte, also politische Symbolik. Doch im Gegensatz zu diesem Begriff wird symbolische Politik negativ als Entpolitisierung der Gesellschaft bestimmt (Voigt, 1989). So werden Wahlkämpfe dem Bereich symbolischer Politik zugerechnet, "weil in ihnen de facto keine politischen Sachfragen auf der Grundlage eines rationalen Diskurses, der zwischen Zielen und Mitteln abwägt, entschieden 
werden." (Kaase, 1998, 45) Sie zeigten stark Merkmale wie Entsachlichung und Personalisierung (vgl. Habermas, 1962).

Radikaler noch hat dies M. Edelmann in seiner klassischen, phänomenologischen Arbeit über politische Symbolik zugespitzt (Edelmann, 1976). In seiner Analyse politischer Sprachstile gesteht er dem politischen Prozeß zwar grundsätzlich die Fähigkeit zur Sinnstiftung zu, doch die politische Symbolik überlagere die Rationalität politischer Institutionen. "Die Analyse von Sprachstilen sollte auch gewisse irreführende Eindrücke aufklären helfen, die unser beharrliches Festhalten an Montesquieus Kategorien vermittelt." (Edelmann, 1976, 183) Sprache transformiere den institutionell-rechtlichen Kontext und degradiere den politischen Prozeß zu rein strategischen Handeln. Kommunikatives, verständigungsorientiertes Handeln ließe sich demnach nicht mehr in der Politik finden.

Auch Politikfelder wie die Umweltpolitik sind von der Politikwissenschaft in einem 'erweiterten Edelmann-Diskurs' (v. Prittwitz) als symbolische Umweltpolitik charakterisiert worden (vgl. dazu Hansjürgens, Lübbe-Wolff, 2000). Hajer (1995, 269 f) hat in bezug auf die niederländische und die britische Luftreinhaltepolitik von symbolischer Umweltpolitik gesprochen. V. v. Prittwitz hat symbolische Politik als Handeln bezeichnet, "das sich von praktischen Sinn- und Leistungserfordernissen abkoppelt." (v. Prittwitz, 2000) Er stellt den kritischen Forschungsansatz symbolischer Umweltpolitik in den Kontext der Policy-Analyse, verweist aber auch darauf, daß Symbole in allen Politikdimensionen (policy, politics, polity) ebenso integrative Funktion hätten, indem sie Legitimation herstellten und keineswegs nur Macht repräsentierten. Im Rahmen des Policyprozesses unterscheidet v. Prittwitz dann 'vorwiegend symbolgestützte Öffentlichkeit' und 'vorwiegend expertengestützte interessenpolitische Verhandlungs- und Diskursarenen' voneinander, erkennt aber auch eine Konvergenz der Symbolnutzung von Umweltbewegungen und Regierungen seit Ende der 60er Jahre. Die beiden Öffentlichkeitsformen bezögen sich im politischen Willensbildungsprozeß in komplexer Weise aufeinander. ${ }^{195}$ Dabei erlange der situative Grad an Öffentlichkeit für die Wahrnehmung und Verwendung politischer Symbole besondere praktische Bedeutung. Es gelte die These, daß mit geringer versus größerer Öffentlichkeit der Policyphasen die Akteure weniger bzw. stärker auf Symbole zurückgriffen.

Bei Konflikten in etablierten politischen Arenen ist Öffentlichkeit Voraussetzung für das Zustandekommen wirksamer materieller Regelungen. Es geht um die Überprüfung der den Policies zugrundeliegenden Annahmen und ihrer rechtlichen Absicherung. Öffentlichkeit ist hierbei strikt verfahrensorientiert und bezieht sich direkt auf das Rechtssystem. Für die Beteiligung der Öffentlichkeit an umweltrechtlichen Verfahren bestehen neben allgemeinen verfassungsrechtlichen Gründen auch spezielle europarechtliche Anforderungen aus der EU-Umweltinformationsrichtlinie (vgl. Lübbe-Wolff, 2000b). Doch trotz Öffentlichkeitsbeteiligung und verfassungsrechtlicher

195 Einerseits gewännen die öffentlichen und nichtöffentlichen Politikformen zunehmend an Eigenständigkeit; andererseits würden öffentliche und nichtöffentliche Politikprozesse immer mehr Einfluß auf- oder gegeneinander erlangen, was zu Phasenbrüchen des politischen Willensbildungsprozesses und zur Diffusität politischer Kommunikation führen würde; v. Prittwitz, 2000, 265. 
Grenzen symbolischer Politik, lassen sich Teile des Umweltrechts nur als symbolisches Umweltrecht verstehen, daß "nicht als Instrumente der Steuerung fungiert, sondern als Medium zur Vermittlung der Botschaft, daß gesteuert wurde." (Lübbe-Wolff, 2000a, 25) Symbolisches Umweltrecht werde, so G. Lübbe-Wolff, u.a. durch die systematische Mißachtung der Wesentlichkeitslehre produziert. Das tatsächliche Schutzniveau werde in den geltenden bundesdeutschen Umweltgesetzen nur generalklauselartig bestimmt. Dies trifft auf verschiedenste Bereiche des Umweltrechts zu (vgl. Lübbe-Wolff, 2000a, 42 ff; Steinberg, 2000; Schink, 1999). Hinzu kommen institutionelle Bedingungen wie durch das föderale Mehrebenesystem, das z.B. die Aufhebung von Landesrecht durch Bundesrecht ermöglicht. Im Fall des sog. Ozongesetzes von 1995 wurde das BimSchG vom Bund eingesetzt, um striktere Ländesgesetze aufzuheben (vgl. Böhm, 2000). Auch die Rechtsfortbildung durch den Europäischen Gerichtshof kann zur Entstehung symbolischen Rechts beitragen, so geschehen im Abfallrecht (vgl. Schmidt, 2003). Allerdings hat die systeminterne Entstehung von symbolischem Umweltrecht durch Rechtsfortbildung bisher relativ wenig Forschungsinteresse auf sich gezogen.

Wichtigste Erscheinungsform symbolische Umweltrechts ist nach Lübbe-Wolff (2000a) das 'programmierte Vollzugsdefizit' bei welchem effektive Instrumente und Ressourcen zur Implementation rechtlich vorenthalten würden. Davon $\mathrm{zu}$ unterscheiden sei das 'erlaubte Vollzugsdefizit'. Dabei gelte Umweltrecht zwar, doch seien Behörden nach herrschender Auffassung nur eingeschränkt zum Vollzug verpflichtet. Außerdem bestünden rechtliche Programm- und Grundsätze, die nicht oder nur eingeschränkt operationalisiert werden könnten (vgl. Kapitel 4.2.2).

Die junge Forschungsrichtung symbolischer Politik erweist sich speziell für die kritische Analyse der Umweltpolitik und des Umweltrechts potentiell als fruchtbar. Sie befindet sich R. Speth zufolge jedoch latent in Gefahr, politischen Prozeß und politische Symbolik voneinander zu trennen, so daß politische Inszenierung und politischer Prozeß sich als zwei Wirklichkeitsebenen Inszenierung versus Macht - gegenüberstünden. Trotz des medienwissenschaftlichen Bezugs würde der Ansatz dann kommunikationstheoretisch eng geführt. "Es gibt dann keine falschen Entscheidungen mehr, sondern nur noch mangelhafte Darstellungsleistungen." (Speth, 1997, 98) Dieser Einwand trifft jedoch nur solche Studien, welche die integrative Kraft des unvermeidlichen Symbolgehalts von Politik nicht berücksichtigen. Erst dadurch wird die Möglichkeit der Repräsentation bestritten und die Analyse eindimensional auf die Willensbeziehung hin angelegt.

Problematisch an Göhler erweist sich in diesem Zusammenhang, daß dieser den Legitimationsbegriff einzig aus dem Repräsentationsbegriff ableitet und sich damit den kritischen Zugang zur Institution symbolischen Rechts verstellt. Habermas hat in Abgrenzung dazu das Rechtssystem sowohl als Symbol- wie auch als Handlungssystem verstanden. Der Kritik öffnen sich die Symbolgehalte des Rechtssystems durch den (argumentativen) Nachweis, daß die reklamierte Handlungsabsicht handlungstheoretisch nicht eingeholt werden kann. Diese Differenzierung zwischen den Argumentationen in einer diskursiven Öffentlichkeit und der nichtargumentativen Reproduktion von Öffentlichkeit über Symbole ist notwendig, denn nur in 
Diskursen kann die latente Struktur der Gesellschaft öffentlich thematisiert und kritisiert werden (vgl. Sarcinelli, 1998a).

\subsection{Massenmediale Vermittlungen des politischen Systems}

In den Medienwissenschaften ist in den letzten Jahrzehnten die Relevanz eines normativen, politikwissenschaftlichen Begriffs von Öffentlichkeit zunehmend skeptischer eingeschätzt worden. Die Ausdifferenzierungen des Medienangebots hat empirisch zu einer Vielzahl von Teilöffentlichkeiten geführt, die sich ganz auf partikulrare Berichterstattung beschränken und der redaktionelle Wandel läuft zunehmend auf Infotainment hinaus, so daß die reflexive Bedeutung der massenmedialen Öffentlichkeit für die Demokratie schwindet. ${ }^{196}$

Konträr dazu hat Peters die Bedeutung von Teilöffentlichkeiten positiv eingeschätzt. Ihre Offenheit könnte Partizipation erhöhen, wenn Kommunikationsprozesse durch die porösen Grenzen in größere Öffentlichkeiten übergehen könnten. "Eine solche Struktur ermöglicht ein höheres Maß an aktiver Partizipation, verglichen mit einer undifferenzierten großen Öffentlichkeit, aber sie birgt natürlich auch die Gefahr der Fragmentierung in spezialisierte Interessengruppen." (Peters, 1994, 56) Es ist letztlich eine empirische Frage, ob die Öffentlichkeit in Teilöffentlichkeiten zerfällt oder weiter ausdifferenziert wird.

\subsubsection{Massenmediale Kommunikation als (umwelt)politische Sozialisation?}

Seit den 70er Jahren werden die Massenmedien als Faktor politischer Sozialisation untersucht (Kepplinger, Mathes, 1987, 183 ff). Dabei zeigte sich in den 80er Jahren, daß Fernsehberichten die höchste Glaubwürdigkeit zugeschrieben wurde. Im Gegensatz zum Zeitungskonsum erhöhten Fernsehkonsum das Interesse an Politik, die in dieser Darstellungsform als spannend und abwechslungsreich erfahren wurde. Es führte andererseits auch $\mathrm{zu}$ einem problematischen Verständnis von Politik (ebd., 189 ff). Es zeigt sich beispielsweise, daß Informationen zu Personen leichter rezipiert werden als Sachthemen (vgl. Wehner, 1998), so daß die subjektive Einschätzung der Kenntnisse von Politik in der Regel zu hoch ist und "ohne ergänzende Tiefeninformation von Tageszeitungen der Differenziertheit und Komplexität demokratischer Politik in zeitgenössischen

196 Vor diesem Hintergrund hat der Medienwissenschaftlicher P. Ludes (1993) Gerhards'/Neidhardts Modell der Öffentlichkeit in mehreren Punkten kritisiert. Er plädiert für einen umfassenden medienwissenschaftlichen Öffentlichkeitsbegriff, der sich nicht nur auf politische Öffentlichkeit beschränkt, sondern andere Teilbereiche der Gesellschaft mit ihren Teilöffentlichkeiten umfaßt. Damit könnte die legitimatorische Aufladung des Öffentlichkeitskonzepts von Gerhards/Neidhardt entfallen und expressive Aspekte über das kulturalistische Öffentlichkeitskonzept (Sennett) der Analyse zugänglich gemacht werden. Da er den Begriff des Diskurses mißversteht, geht Ludes fälschlicherweise davon aus, daß das Modell diskursiver Öffentlichkeit die empirische Analyse begrenze. Dies ist jedoch nicht der Fall, da Diskurse expressive Geltungsansprüche einschließen. Über repräsentative Sprechakte werden von Sprechern subjektive Geltungsansprüche der Wahrhaftigkeit erhoben. Diskurse bieten expressiven Argumenten Zugang, wenn diese universalierbare Geltungsansprüche mit sich führen und konstituieren zugleich wieder eine symbolische Realität. 
Gesellschaften nicht gerecht werden." (Kaase, 1998, 41) Die Sozialisationswirkung der Massenmedien ergibt sich dann nach Hans-Mathias Kepplinger und Rainer Mathes "quasi unbeabsichtigt und nahezu unbemerkt bei der Verfolgung anderer politischer Kommunikationsziele der Massenmedien." (Kepplinger, Mathes, 1987, 195) Es ist ein wesentliches Merkmal der Massenmedien in liberalen Demokratien, daß sie über die Primäraufgabe der Nachrichtenvermittlung auch der Sekundäraufgabe der Politikvermittlung zuarbeiten. Ist damit aber das Verhältnis zwischen Demokratie und Massenmedien von normativen Ansprüchen freigestellt und dürfen Massenmedien deshalb selbstreferentiell arbeiten?

Die massenmediale Kommunikation ist in vielfacher Hinsicht institutionalisiert. Während der Zeitungsmarkt marktwirtschaftlich organisiert ist, der Literaturmarkt an feste Buchpreise gebunden ist, hat sich für das Leitmedium Fernsehen, ebenso wie für das Radio, eine duale Struktur herausgebildet. Die Entwicklung dieser dualen Struktur stellt den bedeutensten institutionellen Wandel in den letzten zwei Jahrzehnten dar. Es ist jedoch nicht der erste Wandel massenmedialer Institutionen in der Demokratie. Dieser Wandel hat Auswirkungen auf die Wahrnehmung von Politik in der Bevölkerung: So haben empirische Studien ergeben, "daß die häufige Nutzung privater Fernsehprogramme sowohl die Sicht von Politik negativ beeinflußt als auch die Wahlbeteiligung mindert." (Kaase, 1998, 44) Als Hauptinformationsquelle politischer Tagesnachrichten für die Bevölkerung stimmt diese Tatsache bedenklich. Diesem nicht nur auf das Leitmedium Fernsehen beschränkten Institutionenwandel hat U. Saxer bescheinigt, daß er weiterhin die Informationsbedürfnisse befriedige, aber auf einem geringeren Sinnkonsens beruhe (Saxer, 1998, 60). Übertragen auf den ökologischen Sachverhalt erscheint es angesichts dieses empirischen Hintergrunds unwahrscheinlich, daß die Rationalität des Diskurses über Nachhaltigkeit durch die Resonanz der Massenmedien erhöht werden kann. Auch führt die stärkere Lösung der Medien von gesellschaftlichen Gruppen und ihrer Orientierung hin zu Publikums- und Werbemärkten zu einer geringeren bzw. selektiveren Berücksichtigung von zivilgesellschaftlichen Themen (vgl. Jarren, 1996).

Die Schwierigkeit, Medienkommunikation in diesem Wandlungsprozeß zu normieren, lassen sich auf das demokratische Prinzip der Medienfreiheit und auch auf das generelle Problem Kommunikation zu steuern zurückführen. Der Wandlungsprozeß kann sich gegen die demokratische Vergesellschaftung wenden. Eine Loslösung der Medien vom polischen System und von den intermediären Institutionen der Zivilgesellschaft bei einer zunehmenden Symbiose von Ökonomie und Medien birgt insofern erhebliche Risiken für die Demokratie selbst (Jarren, 1998, 77 ff).

In diesem zivilgesellschaftlichen Kontext, der nach der obigen These heute weniger Beachtung seitens der massenmedialen Institutionen erfährt, steht auch die Thematik der ökologischen Krise. Die Entwicklung der Umweltberichterstattung folgt den allgemeinen Entwicklungsphasen der staatlichen Umweltpolitik (vgl. dazu Wilhem, 1994; Jänicke et al., 2000, 34 ff). In der frühen Latenzphase der 60er Jahre werden Umweltthemen nur vereinzelt von den Medien aufgenommen. Die Themen haben vorwiegend lokalen Bezug und beschränken sich auf einige wenige 
Themenbereiche wie Abfall und Abwässer. In den 70er Jahren etabliert sich Umwelt vor dem Hintergrund der einsetzenden Umweltpolitik des Bundes als Dauerthema. Die Quantität der Artikel steigt um das dreifache an. Die Berichterstattung findet vor einem breiten gesellschaftlichen Konsens über Umweltpolitik statt. Dieser zerbricht in der Folge von Ölkrise und wirtschaftlicher Rezession. Die Berichterstattung über Umweltthemen nimmt aber in den 80er Jahren weiter zu. Der Einzug der Grünen in den Bundestag 1983 und zahlreiche Umweltforschungsinstitute machen umweltpolitische Themen zu einem alltäglichen Medienthema. Die Anfang der 80er Jahre zu beobachtende Polarisierung in der Umweltdiskussion ist hochgradig medienkompatibel. Ebenso haben Unfälle und Umweltschäden bisher unbekannten Ausmaßes (1984 Waldsterben, 1986 Tschernobyl, Ozonloch 1988, Robbensterben, etc.) großen Nachrichtenwert und führen zu relativ starken Schwankungen der Themenfrequenz in kurzer Zeit. Umweltschädigungen sind als bad news - wie alle schlechten Nachrichten - für das Mediensystem good news. Die Skandalisierung von Sachverhalten kann voll greifen, sofern Verursacher auszumachen sind. Dies führt nicht unbedingt zu einer hohen Informationsqualität (über die entsprechenden ökologischen und technischen Hintergründe), aber es führt doch zu einer quantitativen Zunahme an Umweltberichterstattung, wie entsprechende Inhaltsanalysen bestätigten (de Hann, 1995, 19). Der Umweltjournalismus entwickelt sich dabei immer auch parallel zu den umweltpolitischen Konjunkturen, d. h. er bleibt abhängig vom Themenangebot von Umweltministerien, umweltpolitischen Institutionen oder Umweltverbänden und folgen deren Publikationsangeboten reaktiv (vgl. Müller, 1997, 383 f). Die Berichterstattung wird damit zugleich referierender. Sie thematisiert kaum Aspekte präventiver Umweltpolitik und bleibt überwiegend eingetretenen Umweltkatastrophen verhaftet (ebd., 386). Die Darstellung der alltäglichen, gesellschaftlichen Dimension der ökologischen Krise fehlt fast gänzlich. Allerdings hat die Häufung von Umweltproblemen und die Gegenwart langfristiger, globaler ökologischer Gefahren (Klimawandel) zu einer bleibenden Präsenz umweltpolitischer Berichterstattung in den Medien geführt. Zur 2. UN-Umweltkonferenz in Rio 1992 bildet sich erstmals temporär eine globale umweltpolitische Medienöffentlichkeit heraus.

Dennoch hat die quantitative Steigerung der Umweltberichterstattung in den Medien es nicht vermocht, die strukturellen Grenzen der Massenkommunikation zu überwinden. Die Selektivität der Medien erklärt sich in bezug auf die Umweltberichterstattung schon auf der organisatorischinstitutionellen Ebene des 'Ressorts'. Als Querschnittsthema ist es keinem der klassischen Ressorts zuzuordnen, und es ist auch kein eigenes Ressort 'Umweltschutz' gegründet worden. 'Umwelt' wurde an etablierte Ressorts angegliedert. Es finden sich z.T. regelmäßige Seiten zum Thema in den überregionalen Tageszeitungen. Es gibt einige Magazine (Natur, Öko-Test, Politische Ökologie, etc.) und auch TV-Magazine (natur Trend, Natur Zeit etc.). Doch der Nachrichtenwert von Nachhaltigkeit ist gegenüber dem von Katastrophen vergleichsweise gering. Gerade in dieser Hinsicht bekräftigen Umweltgruppen mit publikumswirksamen Aktionen eher die massenmedialen Mechanismen, als daß sie die expressive Ebene hinter sich ließen. "Der Selektionsmechanismus, nach dem die Medien derzeit Umweltthemen generieren, beläßt es bei Ereignissen und Emotionalisierung. Wie der Rezipient dann mit seinem Umweltbewußtsein resonanzfähig wird innerhalb der Systeme Politik, Wirtschaft, Recht und Haushalt, das wird unter den bestehenden 
Selektionsmodi nicht thematisiert." (de Hann, 1995, 33) Die symbolische Ebene der Konfrontation kann nicht immer argumentativ überwunden werden. Dennoch ist das Symbolische als Teil des zivilgesellschaftlichen Handlungsraums zu verstehen.

Gleichwohl zeigen die Massenmedien kulturelle Resonanz. Die Berichterstattung über Umweltprobleme hat seit Mitte der 80er Jahren zu einem allgemeinen Umweltbewußtsein geführt. Dieses hat sich auch vom Bezugsrahmen der Tagesaktualität fortbewegt (Kuckartz, 1995). In der Wahrnehmung der Bevölkerung liegen Umweltprobleme an der Spitze der langfristigen politischen Aufgaben. Es wird nicht mehr nur dem politischen System zugeordnet, sondern hat auch in anderen Gesellschaftsbereichen an Bedeutung gewonnen, so etwa in der Konsumgüterwahl der privaten Haushalte (Haase, 1995). Hier etwa spielen Umweltzeichen als Symbole für ökologisch geprüfte Konsumgüter eine Rolle (D'Haese, 1995). Andererseits läßt sich kaum ein Zusammenhang zwischen der Nutzung der streuenden Massenmedien und ökologischem Handeln nachweisen (Lehmann, 1995). Und das tatsächlich vorhandene Umweltbewußtsein führt im Alltag nur selten zu entsprechenden Verhaltensänderungen (Preisendörfer, Franzen, 1996).

Diese unvollständige Beobachtung empirischer Öffentlichkeitsstrukturen legt zwei Thesen nahe: Die Thematisierung von Umweltproblemen und politischen Lösungsansätzen erfolgt weniger durch die Massenmedien, über deren Vermittlung. Die Akteursrolle der Massenmedien ist in bezug auf ökologische Probleme schwach ausgebildet. Die umweltpolitische Themensetzung erfolgt nicht auf Betreiben der Massenmedien, sondern ist im wesentlichen Akteuren des politisch-administrativen Subsystems und teilweise zivilgesellschaftlichen Akteuren zuzuschreiben. Später wird Umweltpolitik in den Arenen von Verhandlungssystemen und Netzwerken fortgeschrieben, ohne daß dies noch besondere massenmediale Resonanz finden würde (Ronge, 1997). Mit der Institutionalisierung zivilgesellschaftlicher Beteiligung an Verfahren sinkt das massenmediale Interesse in der Regel weiter.

Demgegenüber steigt die Bedeutung der Massenmedien im schwächer institutionalisierten Kontext internationaler Umweltpolitik. Allerdings sind die supranationalen Teilöffentlichkeiten institutionell an das internationale politische und ökonomische System gebunden. Sie bestehen als massenmediale Öffentlichkeit nicht dauerhaft, sondern sind stark auf die Konferenzzyklen der internationalen Politik bezogen. Allerdings besteht die Möglichkeit der Thematisierung auch für Nichtregierungsorganisationen, wobei die Thematisierungschancen vom Neuigkeitswert der ökologischen Katastrophe oder des Szenarios bestimmt zu sein scheinen. Dies bedeutet allerdings nicht, daß Umweltverbände die Agenda immer wieder neu erfinden müßten, denn neue Katastrophen und Szenarios beziehen sich häufig auf alte Problem, die bereits zu Politiken geronnen sind.

Als Aufgabe für die Medienwissenschaften bleibt die Forschungsfrage zurück,

in welchem Umfang die technisch ermöglichte Allgegenwart der Medien [...] die politischen Akteure so beeinflußt, daß daraus konstitutionelle, institutionelle und verfahrensmäßige Veränderungen im regelhaften politischen Willensbildungsprozeß entstehen. Unter dem Aspekt der symbolischen Politik geht es bei der Veränderung von Akteurskognitionen vor allem um die antizipierten bzw. gewollten Effekte der öffentlichen Darstellung von Politik, d.h. um die 
bewußte Auswahl derjenigen Präsentationskontexte (framing) und Inhalte, die den Akteuren zur Verwirklichung ihrer Ziele als besonders dienlich erscheinen. In diesen Bereich fallen insbesondere Strategien der Ereigniskonstruktion und die Instrumentalisierung der Medien über Nachrichtenwerte, also die Indienstnahme eines Kernelements der medienspezifischen Binnenlogik. (Kaase, 1998, 48 f; kursiv i.O.)

Aus diskurstheoretischer Perspektive ist präzisierend $\mathrm{zu}$ fragen, wie in der massenmedialen Öffentlichkeit ein Prozeß politischer Deliberation in Gang gebracht werden kann, der System und Lebenswelt so miteinander verbindet, daß er zu Nachhaltigkeit hinführt. Die Bedeutung der politischen Öffentlichkeit liegt darin begründet, daß Umweltpolitik unabdingbar auf die kommunikative Reproduktion von Nachhaltigkeit durch zivilgesellschaftliche Akteure angewiesen ist. Dieses Phänomen ist als capacity-building in der Umweltpolitik hinlänglich bekannt (Jänicke, 1997). Ökologische Deliberation und ihr institutionelle Kontext ist so zu gestalten, daß sich Systemimperative und Nachhaltigkeit tatsächlich für die Staatsbürger kognitiv nachvollziehen lassen und sich vernünftig miteinander versöhnen. Einen entsprechenden deliberativen Rahmen für Nachhaltigkeit hat H. Zilleßen (1998) vorgestellt.

In der Abfolge von Politikformulierung, Entscheidungsfindung und Umsetzung ist nach Erkenntnissen der Policyforschung insbesondere der Prozeß der Entscheidungsvorbereitung relevant. Zilleßen plädiert deshalb für "einen qualitativen Sprung in die Bürgerbeteiligung und letztlich in die Modernisierung der Demokratie. Es geht nicht mehr nur um Partizipation an politisch, administrativ initiierten Planungen, Entscheidungen und Maßnahmen, sondern um die selbstbewußte und mitverantwortliche Teilnahme an der Beratung über gemeinsame Angelegenheiten an der Gestaltungsaufgabe der Politik." (Zilleßen, 1998, 8) Der deliberative Prozeß sei teilweise am Parteiensystem vorbei, jedoch nicht dagegen zu entwickeln. Auch bleibt Zilleßen trotz seiner Befürwortung einer funktionalen ökologischen Elite distanziert gegenüber der funktionalen Vereinnahmung zivilgesellschaftlicher Solidarität durch einen ökologischen Korporatismus (O'Riordan, 1996). Eine Verbindung zwischen politisch-administrativen und ökonomischen System findet nur insofern statt, als daß zivilgesellschaftliche Akteure der Nachhaltigkeit direkte finanzielle Unterstützung erfahren sollen. Eine detaillierte Konzeption der systemischen Verhältnisse oder des diskursiven Designs bleibt dagegen offen.

\subsubsection{Die Thematisierung von Umweltpolitik}

Die Policyforschung hat im wesentlichen zwei dezidiert politikwissenschaftliche Ansätze zur Thematisierung in der Politik erarbeitet: die Theorie der Themenkarrieren, welche auf die Systemtheorie bezug nahm (Kepplinger, 1985, 1989) und der erstmals von A. Downs beschriebene Issue-Attention-Cycle (Downs, 1972). Im folgenden soll näher auf den zweiten Ansatz eingegangen werden.

Nach dem Issue-Attention-Cycle durchlaufen politische Themen einen Prozeß von fünf Phasen: In der Vor-Phase (pre problem stage) existiert das entsprechende politische Problem zwar bereits, doch interessiert es nur eine kleine Öffentlichkeit von Experten und Interessengruppen. Zumeist ist 
das objektive Problem in dieser Phase stärker als in späteren Phasen. Mit Verzögerung setzt dann die Alarm-Phase ein, die von weitem öffentlichen Interesse begleitet wird (alarmed discovery and euphoric enthusiasm). Das öffentliche Interesse ist vom Vertrauen in die gesellschaftliche Fähigkeit zur Lösung des Problems bestimmt. Das öffentliche Interesse wird von der Annahme getragen, daß die Problemlösung keine fundamentale Reorganisation der Gesellschaft verlangt. Mit der Realisierung der für die Lösung notwendigen Kosten, gelangt das politische Problem in die dritte Phase (realizing the cost of significant progress). In dieser Phase werden die anfallenden Kosten mit sozialen Gruppen identifiziert, die aber z.T. durch technischen Fortschritt gemindert werden können. Dies führt in der Folge zu einem nachlassenden öffentlichen Interesse (gradual decline of intense public interest). Oft wird das nicht mehr aktuelle Thema durch ein anderes abgelöst. In der Post-Problem-Phase (post-problem stage) entschwindet das Problem weitestgehend der Öffentlichkeit; es kann aber im Zirkel eine Institutionalisierung erfahren haben, die zukünftig einen leichteren Zugang zur Öffentlichkeit sichert als noch in der nichtproblematisierten Phase. Downs hat den Issue-Attention-Cycle am Beispiel der Ökologiediskussion entfaltet. Im Unterschied zu anderen Politikthemen hielt Downs das ökologische Problem bereits für ein mögliches Dauerthema - es befand sich Downs zufolge 1972 in der mittleren Phase des Zyklus -, da es sichtbarer sei als soziale Themen, potentiell jeden betreffen könne und affektiv Verursachern zugeschrieben werden könne und zudem technologische Lösungen die Öffentlichkeitsfähigkeit des ökologischen Themas ebenfalls erhöhen würden. ${ }^{197}$

Im Rahmen der Policyforschung ist der Policyzyklus genauer gefaßt worden. Demnach werden folgende Stadien unterschieden: Problemwahrnehmung (problem perception), Thematisierung (agenda setting), Politikformulierung (policy formulation), Entscheidung (decision making), Politik- und Verwaltungsvollzug (implementation), Ergebnisbewertung (evaluation) und Politikneuformulierung oder -beendigung und politisches Lernen (termination) (vgl. Heritièr, 1993, v. Prittwitz, 2000, Jänicke et al., 2000, 52 ff). Der Policyzyklus ist nicht auf Umweltpolitik oder distributive bzw. redistributive Politik begrenzt (Downs, 1972, 41 ff; Ruß-Mohl, 1993, 358). Neben Themenkarriere und Issue- und Policyzyklen hat Ruß-Mohl noch lange Wellen der politischen Konjunktur ausgemacht, "die generationsübergreifend wirken und das jeweilige politische 'Großklima' mitprägen." (Ruß-Mohl, 1993, 359) Eine solche Unterscheidung zwischen kurzfristigen Politikprozessen und langfristigen politischen Zyklen ist überaus angebracht. ${ }^{198}$ Für die Umweltpolitikforschung scheinen etwa lange, umweltpolitische Wellen vor dem Hintergrund von ökologischen Bewußtseinsbildungsprozessen, Mobilisierungszyklen der Umweltbewegung,

${ }^{197}$ Einerseits seien die ökologischen Probleme nicht sofort sozial zu verorten (wie z.B. Rassendiskrimierung) und damit leichter dem Issue-Attention-Zyklus zuzuführen andererseits wird die Lösung des Problems dadurch erschwert, daß sie die historische Demokratisierung von Privilegien in Frage stellt, was potentiell alle sozialen Gruppen betreffen würde. "The elite's environmental deterioration ist often the common man's improved standard of living." (Downs, 1972, 44) Über die Erhöhung der Produktionskosten, wobei Downs Subventionen ausschließt, sei eine Entschärfung der ökologischen Probleme möglich.

198 Ruß-Mohl bezieht langen Zyklen der Politik auf ökonomische Konjunkturzyklen. Naheliegend wäre im Anschluß daran die Einbindung ökonomischer Forschungsergebnisse zu langen ökonomische Zyklen (Kondratiev-Wellen), wenn diese z. B. den Zusammenhang zwischen Beschäftigungsstand und Umweltschutz simulieren; vgl. Ryzhenkov, 2000. 
sozialwissenschaftlich-ökonomischer Theorien, oder neuer naturwissenschaftlicher Theorien, Prognosen oder Daten zur Umweltsituation etc. denkbar. Die Einbettung umweltpolitischer Konflikte in größere politische und ökonomische Problemkonstellationen und die daraus folgende Dynamisierung dürfte den Erklärungsgehalt umweltpolitologischer Analysen erhöhen (vgl. Brand, 1995, 55 f). Dies wäre etwa im Rahmen diskursanalytischer Forschung möglich. Bisher hat sich jedoch weder Forschung zum Thema langer umweltpolitischer Wellen eingestellt noch hat die politologische Diskursanalyse derartige Zusammenhänge aufgezeigt (vgl. aber die theoretische Bezugnahme K. Eders auf Zyklentheorien, 1997, 25 ff).

Wie dargestellt haben für die Herausbildung von Umweltpolitiken nicht nur Prognosen, sondern auch ökologische und technische Katastrophen katalytische Wirkung. Es tritt dabei das Katastrophenparadox (v. Prittwitz) auf. Dieses besteht darin, daß es während der katastrophalen Zuspitzung ökologischer Problemlagen zumeist noch nicht zu einer gezielten Umweltpolitik kommt, obwohl soziale Wahrnehmungsprozesse bereits begonnen hatten. Diese konnten aber noch nicht handlungsmächtig werden. Vielmehr wird erst in Reaktion auf Katastrophen effektive Umweltpolitik initiiert, so daß es in der Post-Katastrophen-Phase zu administrativem Handeln kommt, welches den objektiven Zustand (im Regelfall) zwar verbessert, gleichwohl aber in der Öffentlichkeit aufgrund des staatlichen Handelns der gegenteilige Eindruck einer Verschärfung des Zustands signalisiert wird (v. Prittwitz, 1990). Das Katastrophenparadox erstreckt sich auf die ersten beiden Phasen des Policyzyklus. In den Folgephasen korrespondiert nach v. Prittwitz der Policyzyklus der Umweltpolitik "mit einer Art Demokratiezyklus: Ist ein Umweltthema erst einmal auf die politische Tagesordnung gesetzt und kommt es $\mathrm{zu}$ einer verbindlichen Programmentscheidung, so haben repräsentative Mechanismen überragende Bedeutung. [...] die Institution der politischen Öffentlichkeit gewinnt [dagegen] insbesondere in der Vorphase der verbindlichen Programmentscheidung durch repräsentative Organe an Gewicht." (v. Prittwitz, 1990, 178)

Im Entscheidungszentrum des politischen Systems, also im hier nach Cohen sogenannten Bereich starker Öffentlichkeit, mit Parlament und Regierung im Zentrum und Rechtssystem im institutionellen Hintergrund, zeigt sich ein schwindendes Medieninteresse. Die späteren Policyphasen bleiben so relativ vom Einfluß der Massenmedien ausgespart. Im Bereich der Policy vermögen Medien kaum die Agenda eigenständig zu setzen, sondern sind vielmehr auf die Akteure des politischen Systems angewiesen (vgl. v. Beyme, 1994, 321 ff). ${ }^{199}$ Die Abhängigkeit der Massenmedien von neuen Informationen bedingt zwar eine größere Offenheit der Medien gegenüber zivilgesellschaftlichen Akteuren als gegenüber Parteien und Verbänden, doch der Einfluß von zivilgesellschaftlichen Akteuren verbleibt im wesentlichen auf die stark symbolisch vereinnahmten Politikphasen beschränkt, d.h. auf Informationen im Kampf um Zutritt zur politischen Arena, auf die konflikthaften politischen Auseinandersetzungen in der Arena und auf die antagonistischen Verhandlungen in den Frühphasen des Policyzyklus. In den späteren Phasen

199 Diesen wird durch das Grundgesetz, wie den Parteien in Art. 21 des GG der Bundesrepublik, die Rolle des Agenda Setters auch explizit zugeschrieben. 
des Policyzyklus sinkt dagegen das massenmediale Interesse, so daß administrativer Politik nur geringe öffentliche Aufmerksamkeit zuteil wird. Demzufolge greift Öffentlichkeit nach v. Prittwitz lediglich in den medienwirksamen Vorstadien und den kulturellen Nachphasen des eigentlichen politischen Entscheidungsstadiums. Dagegen behielten die repräsentativen demokratischen Institutionen mit den verbindlichen Programmentscheidung ungebrochen ihre zentrale Bedeutung.

Schmalz-Bruns hat an v. Prittwitz' These des Katastrophenparadoxes kritisiert, daß diese "einer kontraproduktiven Gegenläufigkeit von öffentlicher und administrativer Macht Raum gibt, die zu einer Entwertung der öffentlichen Problematisierungsleistung und partizipatorischen Kontrollstrukturen tendiert, weil diese nicht wirklich auf das korporative Zusammenspiel von Verwaltung und gesellschaftlichen Interessenverbänden in der Entscheidungsfindung durchgreifen." (Schmalz-Bruns, 1995a, 235) Allerdings hat v. Prittwitz durchaus festgestellt, daß umweltpolitisches Handeln institutionelle Folgen zeitigen würde, also nicht nur durch bestehende staatliche Institutionen bestimmt werde, sondern diese auch selbst wiederum beeinflusse. Derartige Veränderungen hat v. Prittwitz entlang der umweltpolitischen Handlungstypen der Gefahrenabwehr, des Risikomanagements und der strukturellen Ökologisierung gezeigt (s. S. 35 f). Die beiden ersten Handlungstypen stünden in Spannung zu Erfordernissen einer vitalen Demokratie, da sie staatlichen Instanzen größere Verfügungsgewalt zusprächen und zivilgesellschaftliche Handlungskapazitäten zurückdrängten. Das politisch-administrative System sei aber auch in relativ öffentlichkeitsfernen Policyphasen auf überzeugende ökologische Kommunikation angewiesen. Diese ist letztlich Voraussetzung der zivilgesellschaftlichen Kooperation verschiedenster Akteure. ${ }^{200}$ Erst die strukturelle Ökologisierung würde sich nicht einseitig auf Experten und Beamte beschränken, sondern auch Individuen und soziale Bewegungen in die öffentliche Diskussionen einschließen (v. Prittwitz, 1990, 178 f). Dabei erscheint strukturelle Ökologisierung Resultat von Policies zu sein, wohingegen historisch-empirisch die kulturelle Umweltbewußtseinsbildung umweltpolitischen Maßnahmen in der -Regel vorauslag. Es ist auch keineswegs so, daß (mit dem vermeindlichen oder tatsächlichen Alarmismus sozialer Bewegungen) die politische Relevanz von Umweltverbänden enden und in eine vornehmlich kulturelle, symbolische Bedeutung übergehen würde. Deshalb ist Schmalz-Bruns in der Einschätzung Recht zu geben, daß v. Prittwitz' Modell das Zusammenspiel zwischen Verwaltung und partizipatorischen Interessen nicht hinreichend ausführt. So könnte der Alarmismus auch den Spielregeln des Mediendiskurses geschuldet sein, und Umweltverbände tatsächlich als kontinuierliche Träger von Werten und Ideen fungieren, welche überhaupt nur in bestimmten Situationen in der massenmedialen Öffentlichkeit und in bezug auf den Policyzyklus wirkungsmächtig werden können. $^{201}$

${ }^{200}$ So auch die ehemalige niedersächsische Umweltministerin Monika Griefahn, 1997.

201 So wurde die Einführung der Ökosteuer in der Bundesrepublik durch Greenpeace (1994) wieder auf die politische Agenda gebracht und der Diskurs über Nachhaltigkeit durch den BUND (1996) fortgeschrieben, ohne daß dies zu diesem Zeitpunkt einen unmittelbaren Bezug zu Politiken aufgewiesen hätte. 
Mit Habermas (1992) und Preuß (1989b) faßt Schmalz-Bruns (1995) Recht als ein Medium gesellschaftlicher Selbstorganisation auf. ${ }^{202}$ Recht sei aber durch die Inanspruchnahme als Steuerungsinstrument in ein 'regulatorisches Trilemma' geraten, das nach Teubner (1985) in der Inkompatibilität des Rechts mit der Struktur der zu regulierenden Sozialbereiche bestehe und das sich entweder in der Irrelevanz des Steuerungsversuchs, seiner desintegrativen Wirkung auf das Steuerungsmedium oder auf den zu regulierenden Handlungszusammenhang zeige. Gleichwohl hält Schmalz-Bruns am Recht fest und faßt es insofern als Medium gesellschaftlicher Selbstorganisation auf, als daß "über die Einbindung der in kommunikativen Strukturen angelegten Rationalitätspotentiale zugleich auch eine Nötigung zur gesellschaftlichen Selbstrationalisiserung und -verbesserung ausgeübt wird." (Schmal-Bruns, 1995b, 43 f, ebenso ders., 1995a, 33) Dies sei aber nur dann zu gewährleisten, wenn sich die Strukturen der Rechtserzeugung, -begründung und anwendung selber für die Thematisierung ihrer Angemessenheit öffneten, was nur über ein radikalisiertes Konzept von Öffentlichkeit erreicht werden könne. "Auf diese Weise wird Recht in seinen sozialen Reproduktionszusammenhang zurückgestellt und öffentliche Deliberation als eine im Medium von Recht vermittelte reflexive Praxis sichtbar." (Schmalz-Bruns, 1995b, 43f)

Um diese theoretische Zielsetzung institutionell einlösen zu können, schließt Schmalz-Bruns an Gerhards' und Neidhardts Modell von Öffentlichkeit an. Dies eröffne die Möglichkeiten der Rückbindung und Reintegration funktional spezialisierter Handlungssysteme in der komplementären Institutionalisierung von Experten- oder Leistungsrollen einerseits und Klientelrollen anderseits durch ein Handlungssystem, in dem sich die mit den Rollen gesetzten Verhaltensmuster durchdringen und so eine Zone der Interpenetration entstehe. ${ }^{203}$ Dadurch sollen (relevante) Informationen erzeugt werden, die für die Akteure in den komplementär ausdifferenzierten Handlungssystemen verwendbar, d.h. anschlußfähig, sind. Die Radikalisierung bezieht sich auf Öffentlichkeit als 1) Medium kultureller Produktion und Reproduktion 2) reflexive politische Praxis und 3) Form der Erschließung von kognitiven Rationalitätspotentialen zur Verbesserung der Qualität politischer Entscheidungen. Schmalz-Bruns spricht dabei im Anschluß an Nullmeier (1993) von einer 'marktanalogen Funktion' (umwelt)politischer Öffentlichkeit. Öffentlichkeit erzeuge öffentliche Meinung. Der sich so reproduzierende und dabei institutionell abzusichernde demokratische Diskurs unterteilt sich in mehrere Phasen (nach Schmalz-Bruns, 1995a, 230): 1. die Problemdefinition, 2. die Klärung moralisch relevanter Aspekte, 3. die Spezifizierung der Kosten, der möglichen Folgen wie der Wertberücksichtigungspotentiale alternativer Entwicklungspfade, 5.

${ }^{202}$ Gegen Habermas wendet Schmalz-Bruns (1995b) allerdings ein, daß dieser mit seiner Rechtstheorie zwar ein Modell für die Durchbrechung des selbstrekursiven Kreislaufs von Macht und Recht aufgezeigt habe, doch die Relevanzaspekte für Habermas' drei Formen praktischer Vernunft unklar blieben. Dadurch könne die Diskursethik keine materiellen Normen festgelegen. Dieses Problem sei demokratietheoretisch relevant, da Verfahren nicht allein die Angemessenheit der Entscheidung verbürgen könnten und substantielle Entscheidungsgründe mitunter geradezu von Verfahren abgewiesen würden. Der demokratietheoretische Zusammenhang zwischen rationalem Verfahren und rationalem Ergebnis bliebe deshalb offen.

203 Dabei geht Schmalz-Bruns (1995b) davon aus, daß das Öffentlichkeitsprojekt von Alternativbewegungen und Bürgerinitiativen, in denen das Bedürfnis nach unvermittelter, alltäglicher Kommunikation zum Ausdruck komme, gescheitert sei und sich nur noch in lokalen Öffentlichkeiten. manifestiere. Damit gehe eine selbstbezügliche Intimisierung der Öffentlichkeit einher, die das Politische beschränke. Mit diesen Bewegungen habe sich aber auch eine Partizipationsöffentlichkeit gebildet, die an der Trennung von öffentlich und privat festgehalten hatte. 
die Perspektivverschmelzung zwischen den beteiligten Akteuren im Rahmen eines kollektiven Lernprozesses, 5. Festlegung der Entscheidungsregeln 6. Entscheidung und Implementation.

M. Hajer hat aus diskursanalytischer Perspektive ähnlich wie Schmalz-Bruns die Formulierung von Politiken als Problemschließung (problem closure) verstanden, da Politik (als policy-making) die vorherrschende Regulierung sozialer Konflikte in modernen Industriegesellschaften darstelle. Auch Hajer betont die Bedeutung der Problemkonstruktion für die Formulierung von Politiken. "Hence policies are not only devised to solve problems, problems also have to be devised to be able to create policies." (Hajer, 1995, 15) Hajer schlägt deshalb institutionalisierte Verfahren insbesondere für die Projektionsphase vor. Dabei sei folgendes zu berücksichtigen (vgl. Hajer, 1997, 123):

1. Die sozio-kognitive Basis von Diskurskoalitionen sei einzubeziehen. (Die Entwicklungsländer stellten die globalen Umweltproblemen nicht in naturwissenschaftlicher, sondern in sozialer Hinsicht in Frage.)

2. Bei den reflexiven Arrangements sollten sozio-kognitive Faktoren zur Entwicklung einer Wissensbasis mitbedacht werden. Reflexive Arrangements sollten sich in der Hauptsache der Konstruktion von sozialen Problemen widmen und nicht der Umsetzung objektiver Erkenntnis.

3. Bei der Entwicklung reflexiver institutioneller Arrangements sollte große Aufmerksamkeit für das Ausfindigmachen von sozialen Autoritäten aufgewandt werden, die 1. das Problem 2. die daran Beteiligten und 3. die Art der Lösung, die überhaupt erwogen werden, definieren.

Hajer vernachlässigt jedoch in der Präskription spätere Politikphasen, da er sich von der PolicyAnalyse abgrenzen möchte. Zwar erkennt er an, daß die Auseinandersetzung der politischen Akteure innerhalb eines Politikfeldes die entscheidende Größe für das materielle Ergebnis sei, doch hält er den Policyzyklus für ungeeignet, die längerfristige Dynamik des ökologischen Diskurses analytisch angemessen zu fassen. So wendet er u.a. gegen Sabatiers advocacy-coalitions Ansatz ein, daß sich darin policy-bezogenes Lernen zu eng an der Annahme wissenschaftlich-objektiven Wissens orientiere, wohingegen sowohl Dissense als auch politisierte Standpunkte unter Experten im Policybereich zu beobachten seien (vgl. van den Daele, 1996). Hajer kann hierbei auf die reichen Ergebnisse der Wissenssoziologie verweisen. In dieser Hinsicht sei außerdem zu konstatieren, daß Sabatier belief-systems für a priori gegeben halte, obwohl sie durch soziales Lernen verändert und sogar erst konstituiert werden könnten. In beiden genannten Fällen werde Sprache von Sabatier dabei fälschlich als Mittel zum Zweck angesehen. Hajer spricht deshalb anstatt von politikorientiertem Lernen von sozialem Wandel. Dieser vollziehe sich diskursiv und damit nichtstrategisch. Als konkrete Institution zur Effektivierung der Umweltpolitik empfiehlt Hajer insbesondere Enquete-Kommissionen, die nicht der Entscheidungsfindung, sondern der Debatte dienten. ${ }^{204}$ Tatsächlich hat das politische System über verschiedene Enquete-Kommissionen des

${ }^{204}$ In The Politics of Environmental Discourse schlägt Hajer als institutionelle Innovation vor, gesellschaftliche Untersuchungen (societal inquiry) und diskursives Recht (discursive law) zu etablieren. Gesellschaftliche Unter- 
deutschen Bundestages wichtige gesellschaftliche Debatten anstoßen können, wie in umweltpolitischer Hinsicht etwa die Enquete-Kommissionen des BT zum 'Schutz der Erdatmosphäre' (Deutscher Bundestag, 1992) und zum 'Schutz des Menschen und der Umwelt' (Deutscher Bundestag, 1993). ${ }^{205}$ Ebenso stellen sich langfristige Umweltplanung und Nachhaltigkeitspläne als erfolgversprechende, innovative Möglichkeiten der Umweltpolitik dar, da sie eine mehr oder weniger breite kognitiv-soziale Basis für die Umweltpolitik schaffen. Dies ist von politikwissenschaftlicher Seite sowohl hinsichtlich von Enquete-Kommissionen (vgl. Euchner et al., 1993) als auch von Nachhaltigkeitsplänen (Nordbeck, 2000, 2001) gezeigt worden. Aus ähnlichen Gründen hat die im Auftrag der Enquete-Kommission des deutschen Bundestags angefertigte Studie "Institutionelle Reform für eine Politik der Nachhaltigkeit" (Tscheulin et al., 1998) dafür plädiert, nachhaltige Entwicklung als regulative Idee auf allen Handlungsebenen anzusehen. Wie jedoch die sozio-kognitive Basis davor bewahrt werden kann, im Policyprozeß zersetzt oder als allgemeines Umweltbewußtsein zu zerfallen, wäre im Rahmen einer Stoffstrompolitik der Nachhaltigkeit erst noch zu erforschen.

\subsubsection{Innovationsorientierte Vermittlung von Umweltpolitik}

Fürst hat im Gegensatz zu dem bisher entwickelten Ansatz dem Staat die zentrale Aufgabe der Themensetzung zugesprochen. Der Staat solle, ohne dabei ein Kommunikationsmonopol anzustreben, eine umweltpolitische Kommunikation anleiten, welche die politische Debatte auf einen Grundkonsens fokussiere. Der auf diesen Grundkonsens ausgerichteten Kommunikation komme die Rolle einer argumentativen Metakommunikation zu, während mit der Öffentlichkeit durch die gewählten umweltpolitischen Instrumente symbolisch kommuniziert werde. Diese Metakommunikation habe staatliche Politik lediglich zu begleiten, denn Fürst sieht die Gefahr, daß sich der Staat persuasiv wendet und den Eindruck von Staatsdirigismus erzeugt. Um diese Gefahr abzuwenden, empfiehlt er das Management der Kontextbedingungen staatlicher Steuerungsinstrumente (Fürst, 1990, 302). Innerhalb der durch staatliche Steuerinstrumente definierten Politikfelder solle der Staat berücksichtigen - und sich insofern nach der öffentlichen Meinung richten -, daß bestimmte Instrumente (bspw. Grenzwerte) mit ihrer Symbolik (Kontrolle der Emittenten) eher einer bestimmten öffentlichen Perzeption (Ängste der Bürger) entsprächen. Politische Metakommunikation bleibe für politische Programme dabei fortwährend relevant, da ihr Verschwinden die Wirksamkeit von Instrumenten schwächen, wenn nicht gar lähmen könne.

suchungen würden die Bedeutung ökologischer Modernisierung als gemeinsames politisches Projekt betonen. Sie könnten neue Dynamik in den Politikprozeß bringen und den Issue-attention-Zirkel durchbrechen und schließlich wäre es möglich, Macht zwischen sozialen Akteuren zu balancieren. Ihre wichtigste Aufgabe wäre, Orientierung (auch normative) für Fluchtlinien zukünftiger Modernisierung zu liefern. In gleicher Weise käme einem (von ihm nur angedeuteten) diskursiven Recht die Aufgabe zu, normativ soziale Beziehungen so zu konstituieren, daß Diskurskoalitionen in Argumentationen eingebunden werden würden. Hier übersieht Hajer offensichtlich das Theorieangebot prozeduralen Rechts.

${ }^{205}$ Mit Blick auf die Debatte über Kommissionen und diskursive Verfahren ist zu betonen, daß Enquete-Kommissionen nicht 'aus den Verfassungsinstitutionen auswandern', weil sie Expertise im Parlament entwickeln; vgl. Blumenthal, 2003. 
Gefahren bestünden beim Aussetzen der Metakommunikation vor allem hinsichtlich des Verwischens der Grenzen zwischen Öffentlichkeit und Privatheit und in der Verdeckung der faktischen Steuerungszentren und damit der politischen Verantwortlichkeit. Dies könne zu einem rein instrumentellen Rückgriff auf umweltpolitische Instrumente führen. ${ }^{206}$ Es besteht aber auch, was Fürst weniger explizit benennt, das Risiko symbolischer Umweltpolitik, welche irrationale gesellschaftliche Orientierungen aufgreift und bekräftigt, ohne dem Ziel der Nachhaltigkeit inhaltlich entgegen zu arbeiten. Schließlich ist unklar, welche politisch-administrativen Institutionen eine solche Metakommunikation anleiten könnten.

Für Fürst resultieren durchaus auch Probleme aus einer solchen strategischen Politikvermittlung: Er spricht die Exklusivität der Entscheidungsprozesse und die sozialwissenschaftlich vorgeprägte Wertsetzung für die Gesellschaft $a n,{ }^{207}$ doch begnügt er sich mit dem Hinweis, daß sich gesellschaftliche Wahrheitsfindung immer normativ an bestimmten Zielen ausrichte und nicht technisch-wissenschaftlich zu determinieren sei. Dies scheint einen schwachen politischen Dezisionismus anzudeuten. Diesen führt er jedoch nicht aus, auch nicht implizit, indem er etwa das Verhältnis zwischen Verfassung und prozeduralem Umweltrecht behandeln würde. Fürst verbleibt ausnahmslos auf der Ebene der von Instrumenten bestimmten politischen Programme.

Die Bedeutung eines umweltpolitischen Grundkonsenses hat neben Fürst auch M. Stewens (2000) betont. Sein methodologisch im Rahmen der Neuen Politischen Ökonomie stehender Ansatz unterscheidet zwischen einem Grundkonsens auf ordnungspolitischer und Einzelfallentscheidungen auf prozeßpolitischer Ebene. Auf der ordnungspolitischen Ebene sei das Fehlen einer langfristigen Orientierung der Umweltpolitik zu bemängeln, auf der prozeßpolitischen Ebene der ausbleibende Einsatz effizienter ökonomischer Steuerungsinstrumente. In der Folge Buchanans interpretiert Stewens Grundkonsensentscheidungen als konstitutionelle Entscheidungen. Die konstitutionellen Regeln würden politisch immer dann relevant, wenn neue institutionelle Arrangements (Haftungsregeln, Internalisierungsprinzipien, neue Umweltbehörden) getroffen oder Art, Richtung oder Zeithorizont ökologischer Zielsetzung (Reduktion bestimmter Emissionen oder Immissionen, ökologische Schutzziele, inputorientierte Umweltpolitik, sowie kombinierte Zielsetzungen) festgelegt würden. Im Unterschied zu späteren Einzelfallentscheidungen sei bei der Bestimmung konstitutioneller Regeln noch Unsicherheit über die Wirkung des Instrumenteneinsatzes gegeben.

${ }^{206}$ In der Praxis werde, so Fürst (1990), die wechselseitige Abhängigkeit der Steuerungsinstrumente selten bedacht, die zudem zumeist dynamisch sei: So könnten sich Anreizinstrumente zu selbständigen Verteilungsinstrumenten entwickeln, die Koppelung von Rahmenvorgaben und fallspezifischen Umsetzungsinstrumenten könne die Bürokratisierung und die Zentralisierung intensivieren, weil die rahmensetzende Ebene ihren Steuerungszugriff nicht an die Vollzugsverwaltung mit deren wachsenden Freiräumen verlieren will und persuasive Instrumente könnten im kooperativen Staat zu do-ut-des-Geschäften zwischen Behörden und privaten Institutionen umkippen. Handlungsfelder, in denen der Staat kooperativ tätig ist, sind häufig mit staatlichen Transfers verbunden, so daß die Wirkung der Rahmen-Steuerung zugunsten der einzelfallspezifischen Steuerung reduziert werde. Alles in allem fehle eine systematische Diskussion über die Vereinbarkeit von Instrumenten. In der Umweltpolitik wiederholte sich lediglich die alte ordnungspolitische Diskussion über Widersprüche zwischen wachsender Regelungsdichte und Freiheit marktlicher Parameter (Fürst, 1990). Zweifellos läßt sich inzwischen konstatieren, daß die Diskussion in den letzten Jahren intensiver geführt worden ist.

207 Diese unterscheidet Fürsts von Luhmanns Ansatz, der Umweltpolitik lediglich als funktionales Resonanz- und Akzeptanzmanagement des politischen Systems versteht; vgl. zur Kritik Luhmanns auch Reese-Schäfer, 1996,95 f. 
Diese Unsicherheit bestehe insbesondere hinsichtlich der Verteilungswirkung des Instrumenteneinsatzes, wie Stewens anhand empirischer Studien argumentiert. Die Bedeutung von Verteilungskonflikten (GD-Situation) könne in der Phase der Zieldefinition durch lange Zeithorizonte der Zielsetzung weitgehend relativiert werden, während der politische Prozeß über Einzelfallentscheidungen, deren Verteilungswirkung leichter zu bestimmen sei, langfristige Ziele nicht verfolgen könne. ${ }^{208}$ Auf prozeßpolitischer Ebene führten neben ökonomischen Interessen, Eigeninteressen der Verwaltung und Wiederwahlinteressen von Politikern zu einer suboptimalen Umweltpolitik. Stewens schlägt deshalb insbesondere vor, eine unabhängige Umweltbehörde auf der Ebene konstitutioneller Entscheidungen zu schaffen.

Die Etablierung solcher konstitutioneller Regeln wäre wohl als Verhandlung vorzustellen, die, wenn sie vollständig von der prozeßpolitischen Ebene abstrahieren würde, einen umweltpolitischen Top-down-Ansatz zum Ergebnis hätte. Die Policyforschung hat jedoch die theoretischen Zweifel der Systemtheorie an der Effektivität linearer Top-down-Steuerung empirisch bestätigt. Stewens entgeht der Gefahr eines solchen Top-down-Ansatzes, weil er sich implizit am Ziel der Stoffstromreduktion orientiert und die prozeßpolitische Diskussion über die Wahl der richtigen Instrumente ausspart. Gerade diese Diskussion zeigt aber die Grenzen der NPÖ auf, denn unter der Annahme vollständiger Information der Akteure ist die Wahl zweitbester umweltpolitischer Lösungen nur statisch erklärbar. Die unterstellten Interessen der Akteure können einzig zur Wahl zweitbester Lösungen führen. Daß die Wahl umweltpolitischer Instrumente aber auch auf Lernprozesse hinweist, wird von der umweltpolitischen Rational Choice Theorie nicht erkannt. Ideen und Überzeugungssysteme spielen für die Entwicklung der umweltpolitischen Instrumentenwahl eine mindestens ebenso wichtige Rolle. Lernprozesse finden aufgrund von negativen Erfahrungen und neuen Erkenntnissen in der Zeit statt (Wandel vom Ordnungsrecht zu Ökosteuern). Sie greifen auf soziales Wissen anderer Akteure und Institutionen zurück (Diffusion der Idee der Ökosteuer durch die Umweltpolitikforschung, politischer Institutionen wie der OECD etc.). Ebenso ist die Entstehung von umweltpolitischen Befürworterkoalitionen überaus wichtig. Erst politik-orientiertes Lernen eröffnet aus der Policy-Perspektive die Möglichkeit institutioneller Reformen (vgl. Böcher, 2001).

Dazu würde gehört, und hier ist Stewens zuzustimmen, daß sich die umweltpolitische Diskussion von ihrer (ökonomischen) Instrumentenfixierung löst und die Ergebnisse der empirischen Evaluationsforschung berücksichtigt, wie M. Jänicke (1997) angemahnt hat. Denn diese hat gezeigt, daß insbesondere unter Innovationsaspekten die gewählten Instrumente weniger Bedeutung als die öffentliche und politische Willensbekundung besitzen. Der Staat kann durch Kooperation ebenso effektiv wie durch hierarchische Steuerung Umweltpolitik betreiben. Nach Jänicke verbiete es sich von daher, die Wirkung staatlicher Instrumente losgelöst vom Politikprozeß zu betrachten. Er empfiehlt die systematische Verknüpfung von Top-down- und Bottom-up-Perspektive, insbeson-

${ }^{208}$ Hier bezieht sich Stewens u.a. auf Downs' Issue-Attention-Cycle-Hypothese sowie auf Informations- und Wahrnehmungsrestriktionen, soziologische und psychologische Annahmen (416 ff). Trotzdem befürwortet er direktdemokratische Elemente, da diese den Einfluß von organisierten Interessengruppen mildern würden und einen gewissen ökologischen Lerneffekt für die Bürger hätten. 
dere dann, wenn Innovationswirkungen erzielt werden sollten. Ein entsprechendes Regulierungsmuster müsse zumindest folgende Einflußfaktoren berücksichtigen (Jänicke, 1997, 8 ff):

- das Instrumentengefüge bezogen auf spezifische Umweltziele (dominante Instrumente im Instrumentenmix, Grad der Verhaltensdeterminierung, punktueller vs. strategischer Ansatz),

- den Politikstil staatlicher Träger von Umweltbelangen (Art der Zielbildung, Flexibilität des Instrumenteneinsatzes, Timing der Maßnahme, Konsensorientierung, Verrechtlichung/Bürokratisierung, Kalkulierbarkeit),

- den politisch-institutionellen Akteurs- und Handlungskontext (Kompetenz und Einfluß der Regulierungsinstanzen, Rolle anderer Politiken integrativ beachten, Beziehung zwischen Regulatoren und Regulierten, Rolle nichtstaatlicher Träger von Umweltbelangen).

Während die bisherige staatliche Umweltpolitik eher zur Diffusion umweltentlastender Technologien denn zu Innovationen geführt habe, könnten Regulierungsmuster Innovationsprozesse durch eine frühzeitige und klare staatliche Zielbildung mit kalkulierbaren Handlungsfolgen richtungssicher einleiten und dadurch die politischen Kosten des Instrumenteneinsatzes minimieren. Diese Innovationsstrategie stellt Jänicke in den Kontext der ökologischen Modernisierung.

Stewens (2000) hat der von ihm vorgeschlagenen, unabhängigen umweltpolitischen Institution neben der autonomen Instrumentenwahl, auch die Bestimmung von Zielkorridoren für Auflagenund Grenzwertregelungen sowie für Nachhaltigkeitspfade zugesprochen. Problematisch dürfte sich in dieser Hinsicht jedoch erweisen, und dies ist prinzipieller noch gegen Fürst einzuwenden, daß sich die Metakommunikation staatlicher Institution nicht strategisch steuern läßt, obzwar ein gesellschaftsweiter Nachhaltigkeitsdiskurs angesichts eines fehlenden autonomen (systemrationalen) Pfades für Preis-Standard-Steuern/-Zertifikate unerläßlich ist. Obwohl Stewens' konstitutionelle Regeln insofern zwar nicht das Ergebnis von sozio-politischen Lernprozessen darstellen, haben sie gleichwohl kognitiven Gehalt, da sie sich implizit auf die ökologische Metakommunikation des Nachhaltigkeitsdiskurses beziehen. Nur entsteht durch die instrumentelle Begründung einer unabhängigen Umweltbehörde ein kognitiver Bruch zwischen prozeßpolitischer und konstitutioneller Ebene, so daß Stewens sogar von der Gegensätzlichkeit einer unabhängigen Umweltbehörde zum Demokratieprinzip sprechen muß (Stewens, 2000, 429). Diesen Bruch will er funktional überbrücken, indem er vorschlägt, der Umweltbehörde die Ziele auf (direkt)demokratischem Wege hinreichend konkret vorzugeben. So erscheint ihm sogar die Behebung von Vollzugsdefiziten der prozeßpolitischen Ebene denkbar. Wie die demokratische Bestimmung ökologischer Ziele aber mit dem autonomen Handeln einer solchen Umweltbehörde harmonieren soll, bleibt bei Stewens offen. Eine über die Theorie-Rationaler-Wahl begründete direktdemokratische Bestimmung von (stofflichen und energetischen) Umweltzielen sieht sich mit Buchanans pessimistischer Hypothese konfrontiert, daß Externalitäten des Konsums zwangsläufig zu ordnungsrechtlichen und nicht zu ökonomischen Instrumenten führen werden (Buchanan, 1976). Unter dieser Prämisse ist zu bezweifeln, daß selbst die Sozialwissenschaften im Selbstverständnis einer Demokratiewissenschaft die Legitimität einer unabhängigen umweltpolitischen Institution 
dauerhaft stützen könnten. Vielmehr scheinen sich nur wieder endlose Fahrten im Karussell der Marktversagen-versus-Staatsversagen-Debatte anzukündigen.

Es wäre hingegen aussichtsreicher, die nachhaltige Funktionsweise einer solchen Institution kognitiv, d.h. hier vor allem makroökonomisch zu begründen. In dieser Perspektive ergibt sich nämlich entlang der Steigerung der Ressourceneffizienz quasi autonom ein Nachhaltigkeitspfad für Umweltzertifikate/-steuern (Bleischwitz, 1998). Die von Stewens selbst angeführten Elastizitätsanalysen zur Ressourcenproduktivität widerlegen die Vermutung, daß eine makroökonomische Dematerialisierungspolitik einem Top-down-Ansatz entspricht. Vielmehr verbinden gerade sie mikroökonomische Bottom-up-Perspektive und makroökonomische Zielsetzung. Aus diskurstheoretischer Perspektive stellt der Nachhaltigkeitsdiskurs einen Rahmen (frame) dar, innerhalb dessen die Ressourcenproduktivitätstheorie die systemischen und die lebensweltlichen Anforderungen über Elastizitätsanalysen und Steuerungsinstrumente aneinander angleicht. Die beiden systemischen Dimensionen umweltpolitischer Instrumente (rechtliche und ökonomische Anbindung) treten nur dann gegenüber der Lebenswelt in den Hintergrund, wenn die Instrumente symbolisch und materiell der Lebenswelt zugerechnet werden können. So sind etwa ökonomische Instrumente, die zweifellos effektiv Stoff- und Energieströme reduzieren können, in ihrer sozialintegrativen Rückbindung an die Lebenswelt ebenso von ihrer ökonomischen Begründung abhängig (vgl. Kapitel 3.2) wie von zumindest rudimentären ökonomischen und wirtschaftlichen Kenntnissen der Bürger. Deutlicher als in anderen Politikfeldern tritt in der Umweltpolitik die wechselseitige Bedingtheit von Instrumenten und Programmen zutage. Regulierungen müssen insofern Regulierungsmuster aufweisen, und sie kommen dann nicht umhin, auch wieder spätere Politikphasen zu betonen. Das sie gleichwohl in der Öffentlichkeit erfolgreich sein können, ist darauf zurückzuführen, daß mit ihnen Dematerialisierung als Idee verfolgt wird. Eine solche Begründung unterscheidet sich etwa grundlegend von jenen mischinstrumentellen Konzepten einer antiaufklärerischen Umweltökonomie, welche die Schwächen der ökonomischen Systemrationalität ignoriert und gleichwohl auch das Rechtssystem noch eigenen Standards unterwerfen will. 


\section{Zur umweltpolitischen Demokratiewissenschaft}

\section{1 Ökologische Kommunikation}

\subsubsection{Die Diskursanalyse von Umweltpolitik}

Umweltpolitik ist dadurch charakterisiert, daß ihre zwischen Gesellschaft und Natur liegenden Probleme aufgrund ihrer Referenz auf die Umwelt komplexer sind als jene anderer Politikfelder. Die Probleme sind hier fast nur naturwissenschaftlich zugänglich, obwohl sie unmittelbar in der Lebenswelt situiert sind. Dies führt dazu, daß öffentliche Konflikte sich auf naturwissenschaftliche Theorien und Prognosen beziehen. Trotz dieser wissenschaftlichen Vorstrukturierung des kognitiven Feldes werden Umweltkonflikte selten allein von wissenschaftlicher Seite angestoßen. Vielmehr treten verschiedene Akteursgruppen bei der Setzung des Themas auf. Zu nennen sind vor allem: politische Akteure, Umweltgruppen oder -organisationen und Wirtschaftsakteure (Brand, 1994, 49 f). Diese erzeugen vor einem kulturellen Hintergrund und der jeweiligen Polity- und auch Policy-Situation des Nationalstaates öffentliche, massenmediale Resonanz. Derartige kulturelle Resonanzstrukturen entgehen der Kommunikationswissenschaft gemeinhin. Diese untersucht primär die Massenmedien als Akteure. Massenmedien sind aber zugleich immer auch Bühne sozialer oder politischer Akteure. Die Policy-Forschung betrachtet die massenmediale Öffentlichkeit primär aus der Perspektive politischer und sozialer Akteure und somit als Arena. In beiden Rollen wird die massenmediale Öffentlichkeit erst durch die empirische Diskursanalyse zugänglich gemacht. Diese tritt gewöhnlich ohne normativen Geltungsanspruch auf, weshalb mitunter eine gewisse theoretische Opposition zur normativen Diskurstheorie beansprucht wird. Gegenüber den medien- und den politikwissenschaftlichen Ansätzen erschließt erst die Diskursanalyse die kulturelle, ökologische Resonanz der Massenmedien und des politischen Systems. Der Ansatz führt von der Medien- und Politikanalyse hin zur Analyse ökologischer Diskurse.

Als empirische Untersuchung ökologischer Kommunikation beansprucht die Diskursanalyse, ihren Gegenstand als öffentliche Thematisierung und Kommunikation von Umweltproblemen zu rekonstruieren. Dabei wird die Interaktion zwischen verschiedenen Arenen mit unterschiedlichen Öffentlichkeitsgraden analysiert und der soziale Wissens-, Deutungs- und Wertevorrat als Kontext der Bedeutungszuschreibung verstanden. Die Diskursanalyse fragt danach, "wie sich ein öffentlicher Diskurs in einem sozio-historischen Kontext reproduziert." (Brand et al., 1997, 26) 209 Sie will dabei die veränderbaren Reproduktionsbedingungen von Diskursen analysieren, d.h. sie will die historischen Prozesse ökologischer Kommunikation sozialer Akteure, die Prozesse der Formulierung und symbolischen Organisation des Umweltthemas untersuchen. Wieso setzen sich

209 Allgemein zur sozialwissenschaftlichen Diskursanalyse: Keller et al., 2001. 
beispielsweise bestimmte ökologische Problemwahrnehmungen gegenüber anderen, konkurrierenden Perzeptionen durch und wieso können diese dann autoritativ gelten?

Die Diskursanalyse geht auf unterschiedliche, sprach- und textkritische sozialwissenschaftliche Ansätze zurück. Viele Untersuchungen, die in der Tradition von Foucaults diskursanalytischen Studien stehen, schließen Sinnebene und Praktiken zusammen und setzen sich deshalb sehr grundlegenden Einwänden aus (vgl. Habermas, 1985, 279 ff). ${ }^{210}$ M. Hajer hat als Ziel seiner Analyse des Umweltdiskurses zur Luftreinhaltung (in Großbritannien und den Niederlanden) genannt, "to make sense of the regularities and variations in what is being said (or written) and try to understand the social backgrounds and the social effects of specific modes of talking. First by analysing in which context a statement is made or to whom statements are directed. Discourse is then seen as internally related to the social content of what is said. A discourse is then seen as an ensemble of ideas, concepts, and categorisations." (Hajer, 1995, 44) Eine Kohärenz des Diskurses sei analytisch nicht notwendig; je nach Kontext stelle sich diese mehr oder weniger stark ein. Der soziologischen Diskursanalyse geht es somit darum, "Prozesse der sozialen Konstruktion, Objektivierung, Kommunikation und Legitimation von Sinnstrukturen auf der Ebene von Institutionen, Organisationen beziehungsweise kollektiven Akteuren zu rekonstruieren und die gesellschaftlichen Wirkungen dieser Prozesse zu analysieren." (Keller, 1998, 34)

Hajer flechtet die zumindest philosophisch losen Fäden zum Konzept des 'roten Fadens' (story line). Darunter versteht er "a generative sort of narrative that allows actors to draw upon various discursive categories to give meaning to specific physical or social phenomena. The key function of story-lines is that they suggest unity to the bewildering variety of separate discursive components part of a problem like acid rain." (Hajer, 1995, 56) Der rote Faden wird von Diskurskoalitionen gesponnen, die sich im argumentativen Ringen um die Diskurshegemonie befinden. Dabei können ihnen soziale Fertigkeiten wie Glaubwürdigkeit, Akzeptanz und Vertrauen entgegen kommen. Der politische Einfluß ihres Textes (oder Arguments) ergibt sich nicht aus dessen Konsistenz, sondern aus dessen interpretatorischer Vielfältigkeit (multi-interpretability). Der von der Diskurskoalition gesponnene rote Faden läßt sich über Metaphern wie 'der saure Regen' stets als Ganzes erneut wachrufen. Der rote Faden webt so über Metaphern (s. S. 46) einerseits komplexe ökologische Probleme in sich ein, anderseits stellt er durch seinen rituellen Charakter die Permanenz des Umweltthemas sicher und erlaubt anderen Aktoren bzw. Diskurskoalitionen ganz allgemein daran anzuschließen (Hajer, 1995, 62 ff). Dem gesamten Prozeß der Diskursformation liegen laut Hajer Institutionen wie Wissenschaft, Politikprozeß und demokratische Verfahren voraus bzw. die Diskursformation findet innerhalb dieser Institutionen statt. Dabei zeige allerdings das Beispiel des

${ }^{210}$ A. Honneth hat in beeindruckender Klarheit die Konsequenzen Foucaults für die Sozialphilosophie benannt, die ansonsten durchaus einen Ansatz für den Suffizienzaspekt im Nachhaltigkeitsdiskurs bieten könnte: Seit Foucault steht die Sozialphilosophie unter dem generellen Verdacht, "daß in allen kontexttranszendierenden Normen, erst recht in einem Verweis auf eine Natur des Menschen bloß eine machtgebundene Konstruktion zu erblicken sei." (Honneth, 1994, 58.) Damit hängt ihr Fortbestand völlig von der Begründbarkeit einer formalen Ethik ab. Nun kann die Diskursethik eine derartige Begründung liefern, doch gereicht der erhöhte Begründungsanspruch der ethischen Tradition der Sozialphilosophie sicher nicht zum besten. Zur Kritik Foucaults vgl. auch Cohen, Arato, 1992,255 ff; Habermas, 1985, 279 ff und indirekt auch Apel, 1988b. 
Vorsorgeprinzips, ein Policy-Prinzip, daß rote Fäden nicht institutionell strukturiert seien müßten, und sie von anderen Akteuren übernommen werden könnten: So hätten sich nicht politische Akteure, sondern Naturwissenschaftler in ihrer Berichterstattung entgegen den bis dato geltenden statistischen Standards auf das Vorsorgeprinzip berufen.

Hajer hofft, die Regeln des (Umwelt)diskurses selbst aufzeigen zu können, denn diese konstituierten Institutionen und legitime Autorität. Tatsächlich aber sind es nicht Diskursregeln, die dann in der Arbeit relevant werden, sondern das Konzept ökologischer Modernisierung (s. Kapitel 2.2.2). Der Erfolg der britischen und der niederländischen Luftreinhaltepolitik fußt Hajers Analyse zufolge auf der praktischen Anwendung des Konzeptes ökologischer Modernisierung. Doch welches sind die Diskursregeln?

Hajer thematisiert den Zusammenhang zwischen Politiken und Diskursen als ökologische Modernisierung. Das Verhältnis wird empirisch bestimmt, zuvor aber reflexiv gewendet. "Policymaking is in fact to be analysed as the creation of problems, that is to say, policy making can be analysed as a set of practices that are meant to create the sort of problems that institutions can handle and for which solutions can be found." (ebd., 15) Die Formulierung von Politiken stellt sich im Umweltdiskurs als Problemschließung (problem closure) dar, weil Politik (als policy-making) die vorherrschende Regulierung sozialer Konflikte in modernen Industriegesellschaften sei. Der Umweltdiskurs verändere dabei, so Hajer, das Umfeld von Politiken diskursiv. Und dies sei kategorisch von manipulativer Veränderung verschieden (Hajer, 1995, 22 f). Hajers Untersuchung arbeitet einige wichtige Charakteristika des umweltpolitischen Prozesses heraus, so Elemente symbolischer Politik in der britischen Luftreinhaltung und die soziale Konstruktion von Nichtwissen (ignorance) im holländischen Fall.

Hajer konstatiert aber über die Policy-Dimension hinaus, daß die im Umweltdiskurs von der ökologischen Bewegung vorgebrachte Kritik grundsätzlicher gewesen sei als der später umgesetzte ökologische Modernisierungsansatz. Die Kritik richtete sich sogar weiter gegen die historischen Modernisierungs- und Rationalisierungsprozesse - offensichtlich im intuitiven Einklang mit Habermas' Kolonialisierungsthese. Hajers Definition der Glaubhaftigkeit eines Akteurs, die auf der Verwendung des Begriffs der ökologischen Modernisierung beruhe (Hajer, 1995, 60 f), läßt zivilgesellschaftlichen Akteuren zwar zunächst noch ein reflexives kulturelles Moment (ebd., 102), doch mit dem Übergang in die Policy-Dimension resultieren durchgesetzte Geltungsansprüche einzig aus dem Konzept ökologischer Modernisierung. Allerdings macht Hajer gegenüber Becks Theorie noch ein leicht modifiziertes Konzept geltend, in welchem Reflexivität als relationale Idee (relational notion) der diskursiven Praktiken von Akteuren angesehen wird. "Such practices are reflexive if they allow for the monitoring and assessment of the effect of certain social and cognitive systems of classification and categorisation of our perception of reality. Reflexivity can thus be a quality of a metaphor or story-line that in a given context changes the perception of future perspectives." (Hajer, 1995, 40) Reflexivität schließe Werte und Normen in den Umweltdiskurs ein. Eine Habermasche Perspektive kann dies nur bestätigen. Hajer assimiliert jedoch unter der Hand die Glaubwürdigkeit von Akteuren an makrosoziologische Erklärungen (Theorie der ökologischen 
Modernisierung), etwa wenn er konstatiert, daß allein die Referenz auf ökologische Modernisierung den Akteuren in der politischen Arena Glaubwürdigkeit zukommen lasse. Die expressive Rationalität von Akteuren geht jedoch zweifellos über die Handlungsdimension des politischadministrativen Systems hinaus und findet eventuell in den solidarischen Ressourcen der Zivilgesellschaft Widerhall. Mit Glaubhaftigkeit verbinden sich aber zunächst einmal nur (kontrafaktische) Geltungsansprüche.

Die eigentliche Herausforderung sieht Hajer in der Gestaltung institutioneller Reflexivität. Dabei verweist er darauf, daß Demokratisierung keinesfalls notwendig in bessere umweltpolitische Ergebnisse einmünden müsse und daß Mediation daran kranke, daß sie keine Phase der öffentlichen Problemdefinition beinhaltet. Reflexive Modernisierung sollte deshalb generell erst einmal der sozialen, kognitiven Basis von Diskurskoalitionen gerecht werden, sodann Institutionen auf die Konstruktion sozialer Problem ausrichten und schließlich den Kreis der an diesem Prozeß der Problemdefinition beteiligten bestimmen (ebd., 286 ff).

\subsubsection{Die Analyse des Mülldiskurses}

In einer diskursanalytischen Untersuchung der öffentlichen Auseinandersetzung um das Abfallproblem seit Anfang der 70er Jahre in Deutschland und Frankreich, hat Rainer Keller (1998) in der deutschen Diskussion zwei Diskurstypen konstatiert: ${ }^{211}$ Einen strukturkonservativen Abfalldiskurs, der die materiale Abfallpolitik dominiert und die industriegesellschaftliche Produktions- und Konsumkultur fortschreiben will und einen kulturkritischen Abfalldiskurs, der beides kritisiert und die bestehende industriekapitalistische Struktur politisch reformieren will, um so das materiale Resultat, nämlich Müll, zu reduzieren. Dagegen setzt der strukturkonservative Diskurs auf die technische Handhabung des Müllproblems. Die beiden Diskurse weisen eine polarisierende Konkurrenz auf, die Abfall als beständiges Politikum in der Öffentlichkeit etablieren konnte. Dennoch gibt es auch inhaltliche Übereinstimmungen etwa in der Anerkennung von Handlungsbedarf, dem Grundsatz der Inlandsentsorgung, der Notwendigkeit von Umweltschutz und der Ressourcenschonung. Auch wird auf das gleiche Vokabular (Nachhaltigkeit, Vermeidung, Verwertung, Produktverantwortung) zurückgegriffen, dessen Bedeutung jedoch unmittelbar zum Gegenstand der Auseinandersetzung wird.

Demgegenüber hat Viehöver (1999) im Mülldiskurs drei konkurrierende Diskurskoalitionen unterschieden, denen er deskriptiv eigene Narrationen zuordnet. Er spricht von 1. der Akteurskonstellation der Regulierungsgegner oder Marktregulierer, 2. der Konstellation der sanften Regulierer und 3. der Diskurskoalition der radikalen Regulierer. Dabei werden die zentralen Akteure, welche in bestimmten Akteurskoalitionen stehen, und ihre Problemnarrationen unterschieden. Akteure werden gemäß der Theorie des akteurzentrierten Institutionalismus als

211 Hingegen besteht in Frankreich nur ein 'administrativer Abfalldiskurs', der eine hegemoniale öffentliche Präsenz hat vgl. Keller, 1998, $201 \mathrm{ff}$. 
korporative Akteure (z.B.: Verbände, Regierung, Bundesrat, Umweltministerium) oder als kollektive Akteure ohne klare formale Organisation (z. b. die Müllbewegung) beschrieben (ebd. 39). Die in den massenmedialen Diskurs der Öffentlichkeit eingebrachten Narrationen dieser Akteure entwickeln gegenüber den Akteurskonstellationen eine kontingente Eigendynamik. Während bei Keller Diskurse nebeneinander in einem Politikfeld (Abfallpolitik) stehen, gehen bei Viehöver über die Narrationen Diskurskoalitionen aus Akteurskonstellationen und Policies hervor, ohne doch deren Ergebnis zu sein. Ihr Entstehen ist vielmehr in weiten Teilen kontingent, und es kann überhaupt nur durch das Bestehen der Öffentlichkeit verstanden werden. Solche kulturellen Sachverhalte hat Keller dagegen direkt im Konzept des roten Fadens zusammengezogen. Den roten Faden des strukturkonservativen Diskurses beschreibt er folgendermaßen:

Das Abfallproblem entsteht aus der Diskrepanz zwischen verfügbaren Anlagen der Abfallbehandlungen und dem Abfallaufkommen: Abfallentstehung ist unabänderliche Begleiterscheinung von Wohlstand, Massenkonsum und Fortschritt. Die vernünftige Problemlösung besteht im Ausbau der fehlenden technischen Infrastruktur. Das Fehlen der Anlagen ist ein Versäumnis der Politik und eine Konsequenz von lokalen Widerständen nach dem St. Florians-Prinzip. Um den drohenden Entsorgungsnotstand $\mathrm{zu}$ vermeiden, ist ein schneller Ausbau insbesondere von Müllverbrennungsanlagen (thermische Verwertung) notwendig.[...] Abfallvermeidung setzt bei den entstehenden Abfällen an und besteht im wesentlichen aus der (vor allem thermischen, aber auch stofflichen) Weiterverwertung der Abfälle, sofern dies ökonomisch und ökologisch tragbar ist. Schließlich verbleibende Abfälle können sicher entsorgt werden. Staatliches Handeln soll sich auf ein Minimum an Rahmenbedingungen konzentrieren, den (auch unter Umweltaspekten) richtigen Umgang mit den Abfällen garantiert dann das freie Spiel des Marktes. [...] Fragen des Umweltschutzes, der Knappheit von Natur als Ressource und Schadstoffsenke sind grundsätzlich anzuerkennen, aber der Ökonomie untergeordnet." (Keller, 1998, 208)

Die story line des kulturkritischen Abfalldiskurses ist dagegen die folgende:

Das Abfallproblem hat zwei Seiten: Zum einen die prinzipielle Risikohaltigkeit der Abfallbeseitigung (Gesundheits- und Umweltrisiken), zum anderen das ökologisch und ethischmoralisch unhaltbare Ausmaß der Material-, d.h. Naturvernutzung und -vergeudung.[...] Verantwortlich für diesen Ressourcenverbrauch sind die Produktions- und Absatzstrategien der Wirtschaft, die mit den Mitteln beständiger Bedürfniserzeugung, Produktionssetzung, der Umstellung auf Einweg-Produkte u.a.m. die gesellschaftliche Wegwerf-Kultur erzeugt. Verantwortlich ist auch die Politik, da sie der Wirtschaft nicht die entsprechenden Rahmenbedingungen für eine stark reduzierte und global tragfähige Stoffnutzung setzt.[...] Von den existierenden Abfallbehandlungsanlagen gehen Gefährdungen für menschliche Gesundheit und die Umweltmedien (Luft, Wasser, Böden) aus, die in ihren Folgen kaum kalkulierbar und akzeptabel sind. Dieses grundsätzliche Unsicherheitsproblem führt zur Forderung nach einer notwendigen Minimierung der Zahl von Anlagen zur technischen Abfallbehandlung (insbesondere Deponien und Verbrennungsanlagen). Fortschritte der Abfallbeseitigungstechnik und des (ökologisch, teilweise bedenklichen) Recyclings blockieren weitergehende 'Vermeidungstrategien'. Technische Problemlösungen (auch in Form von Recyclingtechnologien) sind nur Hilfsmittel einer grundsätzlich nötigen politischen Umsteuerung der Produktionsund Konsumverhältnisse. (Keller, 1998, 219)

In den roten Fäden beider Diskurse finden sich sowohl Kausalbeschreibungen, Verantwortungszuweisung, Problemlösungen als auch Wertbezüge und kulturelle Hintergrundannahmen. Letztere verweisen auf den Rahmen des jeweiligen Diskurstypen, der von verschiedenen, unabhängigen Elementen konstituiert wird. Im Zeitablauf werden diese Elemente unterschiedlich aktualisiert. Zwar werden sie, bzw. die Diskurstypen, immer wieder aktualisiert, doch erlangen sie 
keine Diskurshoheit im Sinne eines Konsenses (aufgrund argumentativer Stichhaltigkeit), der zur Grundlage materialer Politiken geworden wäre bzw. die institutionellen Effekte der Abfalldiskussion kontrolliert hätte. Die Diskussion zwischen beiden Diskurstypen findet im öffentlichen Raum statt, wobei die Massenmedien, Keller zufolge, "eine Doppelrolle als Akteur (e) und Bühne zugleich" einnehmen (ebd. 261). Der so strukturierte öffentliche Raum der Abfalldiskussion ist wiederum allgemeine Voraussetzung von Partizipation. Die massenmediale Öffentlichkeit fungiert als kultureller Selektionsmechanismus für beide Diskurse.

Zentral für den Rahmen des strukturkonservativen Abfalldiskurses ist die Autonomie der Wirtschaft. Demnach stellen marktwirtschaftliche Allokationsprinzipien die sozial-optimale Art und Weise da, Interessen von gegenwärtigen und zukünftiger Gesellschaft sowie Gesellschaft und Umwelt (Natur) zu vermitteln (vgl. ebd., 214). Daran knüpft die Quasi-Naturalisierung gesellschaftlicher Stoffströme an, die wie Gefährdungen 1. Ordnung behandelt werden und auch wieder nur technisch kontrolliert werden können. Dies drückt auch die Kontinuität des Fortschritts aus, die sich in der Innovationsbedürftigkeit von Produktions-, Entsorgungstechnologie bei gleichzeitiger Beibehaltung des erreichten Ausdifferenzierungsniveaus von Wirtschaft und Politik zeigt. Die Natur wird als Rohstofflieferant und Senke des ökonomischen Systems verstanden. Sie erscheint unbegrenzt.

Dagegen wird der Rahmen des kulturkritischen Diskurses zentral von der Annahme einer knappen Natur konstituiert. Im Anschluß daran werden Vergesellschaftungsmodi befürwortet, die von der ökonomischen Naturaneignung wegweisen. Die Politisierung des Wirtschaftens soll Konsum und Produktion in die Zivilgesellschaft zurückstellen, ohne daß dabei auf kommunistische oder sozialistischen Ideen Bezug genommen würde. Vielmehr werden post-materielle Werte eines gewandelten Entwicklungsmodells bemüht. Der Risikorahmen verweist auf die Unsicherheit der industriegesellschaftlichen Kultur, woraus eine präventive Orientierung im politischen Kontext abgeleitet wird.

Beiden Rahmen gehört Verantwortungsethik an. Während der strukturkonservative Abfalldiskurs Verantwortungs- und Gesinnungsethik einander gegenüberstellt, werden vom kulturkritischen Diskurs Profitinteressen der eigenen, verantwortungsethischen Position gegenübergestellt. Beide Diskurse beanspruchen also für sich je die verantwortungsethische Position, während dem anderen Diskurs die negative besetzte antagonistische Position zugeschrieben wird. Gleichzeitig aber konvergieren strukturkonservativer und kulturkritischer Diskurs auf unterschiedlicher argumentativer Basis in einem Prozeß der Individualisierung und Subpolitisierung der Abfallverantwortung als individuell-moralischer Pflicht zur Erhaltung der Natur durch Abfallverwertung und Abfallvermeidung. Im kulturkritischen Diskurs wird die Abfallentstehung im Konsumalltag moralisiert. Im strukturkonservativen Diskurs der Konsum dagegen als Bedürfnisinteresse interpretiert, das der Produktion zwingende Vorgaben macht. Die Entlastungsstrategie des strukturkonservativen Diskurses und die Politisierungsstrategie des kulturkritischen Diskurses konvergieren dann zur Übertragung von Verantwortung auf die Konsumenten. Als kognitive Ressourcen werden Ökobilanzen und Produktlinienanalysen zur 
Auseinandersetzung um die Verantwortung des Konsumentenherangezogen. "Ethik und Moral sind als Ressource der Transformation zugelassen, solange sie nicht zur Grundlage der Politik werden. Ökonomische und wissenschaftlich-technische Rationalität sind für viele Handlungsbereich die legitimen funktionalen Äquivalente für Politik." (Keller, 1998, 252)

Wichtig ist für Keller die Statik und Dynamik des jeweiligen Abfalldiskurses. Der kulturkritische Abfalldiskurs hat seit der Revision des in den 70er Jahren auch von ihm gestützten technischen Paradigmas im wesentlichen unverändert an den Grundpositionen seines Rahmens festgehalten. Dagegen hat der strukturkonservative Abfalldiskurs kontextabhängig auf wechselnde Prinzipien des Rahmens zurückgegriffen. Insbesondere alternieren technisch-administrative Kontrolle und Autonomie der Ökonomie je nach gesetzgeberischem Kontext. Anhaltend hat sich der Verhältnis von Naturalisierung, Autonomie der Ökonomie und unerschöpfliche Natur gewandelt. Die Relevanz von Fragen des Umweltschutzes und des Ressourcenverbrauchs wurde im Angesicht technologischer Substitutionspotentiale generell anerkannt. Die Autonomie der Ökonomie blieb dabei aus der Sicht des strukturkonservativen Diskurses unangetastet, da sich Ökonomie und Ökologie in der umweltökonomisch orientierten Umweltpolitik nicht mehr unversöhnlich entgegenstanden. Technische Lösungen der Abfallfrage werden so zur Lösung der Umweltprobleme, denndie Knappheit von Natur (als Ressource und als Senke) scheint nur noch relativ, weil sie wissenschaftlich-technisch verändert werden kann.

Ebenso wie Keller verweist auch Viehöver auf die Relevanz kultureller Faktoren im Mülldiskurs. Bei ihm gewinnen Narrationen zentrale Bedeutung. Diese seien eine fundamentale Gebrauchsweise von Kultur und erlaubten die Kommunikation von komplexen Situationsdeutungen in strukturierter Form.

Narrationen umfassen unterschiedliche Elemente wie Problemdiagnose (z.B. drohender Entsor-
gungsnotstand, Müllawine), Ursachenzuschreibungen, Lösungswege, erwartete Nebenfolgen
und Leitbilder. Sie können Wirklichkeitsvorstellungen verändern, Handlungen und Präferenzen
strukturieren (insbesondere durch die Integration von Leitbildern, Feindbildern, Normen und
Prinzipien) und zur Konstitution der Identität der (kollektiven) Akteure beitragen. Sie begrenzen
nicht nur die Rationalität der Akteure (bounded rationality), sie können sie durchaus auch
konstituieren. Öffentliche Narrationen werden damit zum Strukturelement öffentlicher Diskurse
und zum Kriterium der Einheit der Akteurskoalitionen, sowie zum Moment der Abgrenzung
von anderen, möglicherweise konkurrierenden Diskurskoalitionen. (Viehöver, 1999, 34)

Auf der Akteursebene im Politikfeld der Abfallpolitik konstatiert Viehöver deshalb neben konservativen und kulturkritischen Diskurskoalition (bzw. der Akteurskonstellation der Regulierungsgegner und der Konstellation der radikalen Regulierer) noch eine Diskurskoalition der sanften Regulierer. Zwischen Diskurskoalitionen und dem eigentlichen Politikfeld findet über die massenmediale Öffentlichkeit eine symbolische Vermittlung statt. Deutlich wird so bereits, daß Kellers Diskursbegriff einen interpretativen Vorgriff auf Kultur beinhaltet, der für die Politikwissenschaft Viehövers Begriff der Diskurskoalition unterlegen scheint. ${ }^{212}$

${ }^{212}$ Viehöver bezieht seinen Begriff der'Diskurskoalitionen' auf Majones Tendenzkoalitionen (advocacy coalitons) und bemerkt dazu, daß gerade bei Verhandlungen, "in denen es auf die ökonomische, technische, politische Machbarkeit (feasibility) und die soziale Wünschbarkeit/Angemessenheit der verhandelten Lösungen ankommt, kulturelle 


\subsubsection{Das abfallpolitische Verhandlungssystem in Deutschland}

In der Bundesrepublik fällt die Entsorgung des Mülls seit dem ersten Gesetz zur Abfallbeseitigung von 1972 den nach Landesrecht zuständigen Körperschaften des öffentlichen Rechts zu. Dies sind für gewöhnlich die Kreise und kreisfreien Städte. Hier wurden die Probleme des wachsenden Stoffstroms zuerst augenfällig: Sichere Deponiekapazitäten waren knapp; Müllverbrennung erhöhte das Sondermüllaufkommen und stand im Verdacht, giftige Schadstoffe (Dioxine, Furane) freizusetzen . Die Errichtung neuer Deponien stieß auf politischen Widerstand seitens betroffener Bürger, um Gewerbeflächen konkurrierender Unternehmen und anderer mittelbar Betroffener (vgl. Viehöver, 1999, 97 f).

Die Planungshoheit über die Abfallentsorgung obliegt den Ländern. Die Planung stößt jedoch im Stadium der Planfeststellungs- und Genehmigungsverfahren nicht nur auf den Widerstand Privater, sondern auch auf jenen der dezentralen Gebietskörperschaften, deren Mitwirkungsmöglichkeiten in diesen Verfahren landesgesetzlich festgeschrieben sind. Planung ist so nur schwer realisierbar, die Beteiligungsrechte an diesen Verfahren sind darüber hinaus oft ungenügend. Auch steht die Dezentralisierung der Entsorgung mitunter im Widerspruch zum Erfordernis, die bestgeeignetsten Standorte zu wählen. Zwar läßt sich feststellen, daß kleinräumige Abfallsysteme, in denen Nutznießer und Kostenträger des Müllsystems weitgehend übereinstimmen, weniger Akzeptanzprobleme aufweisen als großräumige, doch kann dies nicht den Legitimitätsmangel der fehlenden Gesamtkonzeption einer Müllreduktion wettmachen.

Kooperatives Staatshandeln richtet sich dem akteurstheoretischen Institutionalismus zufolge am wohlfahrtstheoretischen Modus des Verhandelns (bargaining) und des Problemlösens aus. Auf dem Bargaining-Modus beruht eine Absprache zwischen Bundesinnenministerium und den korporativen Akteuren der involvierten Wirtschaftszweige aus dem Jahre 1977. Diese sah eine Stabilisierung des Mehrweganteils bei Getränken, den Verzicht auf großvolumige Kunststofflaschen und die Steigerung der Altglas- und Weißblechverwertung vor. Nach R. Spies fiel in dieser Phase 'der Schatten der Hierarchie' (Scharpf) durch die Androhung staatlicher Intervention auf die wirtschaftenden Akteure und führte zu einer negativen Koordination - im Sinne Scharpfs - der Akteure des Müllnetzwerkes. ${ }^{213}$ Doch im folgenden Jahrzehnt wurde die negative Koordinationsfähigkeit des Staates stark in Frage gestellt, da die verbandliche Selbstbeschränkung in wesentlichen Teilen mißlang: Der Mehrweganteil konnte nicht stabilisiert werden, die Verwertungsrate sank und 1987 wurde von Coca Cola und Aldi das Branchenabkommen aufgekündigt, und es sollten großvolumige Kunststofflaschen auf dem deutschen Markt eingeführt

(kognitive, moralische und symbolische) Faktoren eine entscheidende Rolle spielen. Dies rückt die diskursive Dimension in den Vordergrund des Aushandlungsprozesses. Politik ist in diesem Sinne im wesentlichen symbolische Politik. Dies hat uns dazu bewegt, advocacy-Koalitionen im Sinne von Diskurskoalitionen (Hajer 1995) zu verstehen."(Viehöver, 1999, 33) Viehöver spricht auch davon, daß Diskurskoalitionen als spezifische Akteursnetzwerke mit durch Narrationen bestätigte, gemeinsame Orientierungen zu verstehen seien.

213 Viehöver (1999, 22) stellt in Übereinstimmung mit Spies fest: "Vieles spricht dafür, daß der Gesetzgeber im Hinblick auf die Verpackungsabfallpolitik Mitte der siebziger Jahre und auch noch 1986, bei der 4. Novellierung des Abfallbeseitigungsgesetzes, die Strategie der negativen Koordination gewählt hat." 
werden. Zwar litt die staatliche Interventionsglaubwürdigkeit unter den unklaren Eingriffsvoraussetzungen für Verordnungen nach § 14 AbfG - ein Manko, das erst mit der Novellierung des AbfG 1986 behoben wurde - doch hielt die damalige Regierung unvermindert am Kooperationsprinzip fest. Dieses wurde bei der Novellierung von 1986 in der Rechtsfigur der 'Zielfestlegung' eigens institutionalisiert. Sie sieht vor, daß von umweltpolitischer Seite unter Unterlassung rechtlicher Verordnungen klare Handlungsvorgaben formuliert werden, deren Umsetzung den Verbänden und wirtschaftenden Akteuren überlassen bleibt. Am Kooperationsprinzip wurde seitens der Regierung auch dann noch festgehalten, als weiter reihenweise abfallpolitische Ziele verfehlt wurden. ${ }^{214}$ Erst mit der 'Verordnung über die Rücknahme von Getränkeverpackungen aus Kunststoff' von 1988 (PET-Verordnung) reagierte der Staat auf die durch die Coca Cola und Aldi GmbH gebrochene verbandliche Selbstverpflichtung und belegte PET-Flaschen mit einem Pfand.

1991 folgte dann die Verpackungsverordnung (VerpackV) auf Grundlage von § 14 AbfG. Ziel der Verordnung war die Vermeidung von Verpackungsabfällen durch wiederverwertbare Verpackungen und die stoffliche Verwertung von Verpackungen, die nicht wiederverwertbar sind. Es wird zwischen Transport-, Um- und Verkaufsverpackungen unterschieden, wobei die verschiedenen Verpackungsarten unterschiedliche Rücknahme- und Verwertungspflichten nach sich ziehen: Transportverpackungen sind vom Hersteller und Vertreiber zurückzunehmen, erneut zu verwenden oder privat zu entsorgen. Umverpackungen müssen nur vom Vertreiber zurückgenommen werden. Der Wegfall der Rücknahme-, Wiederverwertungs- oder der stofflichen Verwertungspflicht von Verkaufsverpackungen wird für die Hersteller und Vertreiber suspendiert, wenn sie am Sammelund Verwertungssystem des später gegründeten Dualen Systems Deutschland AG (DSD) teilnehmen, wobei die Suspensionsklausel an weitere Bedingungen wie der Stabilisierung des Mehrweganteils und bestimmten Erfassungs- und Verwertungsquoten geknüpft ist.

Dem akteurzentrierten Institutionalismus zufolge begünstigt die "Herausbildung einer mehrstufigen Binnenstruktur und damit von handlungsfähigen Akteuren höherer Ordnung (Organisationen, Verbänden, Dachverbänden, Organisationsverbünden)" die Selbststeuerung in gesellschaftlichen Teilbereichen (Mayntz, 1997, 103). Sind derartige institutionelle Strukturen nicht oder nur in Ansätzen vorhanden, kann der Staat den Aufbau von Politik-Netzwerken aus öffentlichen und privaten Organisationen gezielt fördern, um so Politikblockaden zu überwinden (ebd., 105). Dabei stellt sich die Frage, inwieweit Verantwortung übertragen werden kann. Wenn interne Sozial- und externe Systemintegration innerhalb des Verbandes kollidieren, wird die innerverbandliche Integration gefährden (vgl. Streek, 1987). Dem akteurzentrierten Institutionalismus zufolge dürfte sich die Vetomacht von Verbänden gegen die Errichtung eines Netzwerkes durch den Staat in Grenzen halten, wenn sie dazu öffentlich nicht-gemeinwohlorientiert handeln müßten.

214 So konnte der Mehrweganteil nicht stabilisiert werden; die Kennzeichnung von Getränkeverpackungen scheiterte ebenso wie die Verwertung von Verpackungen sowie die Beschränkung der verwendeten Kunststoffe und der Aufbau von Recyclingstrukturen für Kunststoffverpackungen; vgl. Spies, 1994, 279 f. 
Die Verpackungsverordnung etablierte erstmals eine Form prozeduraler Selbststeuerung im gesellschaftlichen Teilbereich der Abfallbeseitigung und bestätigte so scheinbar diese spezifische Erwartung des akteurzentrierten Institutionalismus (vgl. Spies, 1994, 288).

Im Fall des Abfallsystems sind derartige Akteure nur rudimentär entwickelt gewesen. Es existierten bereichsspezifische Industrieverbände, jedoch kein privatwirtschaftlicher Akteur, der den ganzen oder überwiegenden Teil des Abfallproblems repräsentierte. Das Abfallproblem fiel in den Kommunen an und wurde innerhalb des föderalen politischen Systems von den Ländern vertreten. Seine Dynamik erlaubte die Überwindung der Politikverflechtungsfalle (Scharpf, 1985) und eine relativ geschlossene Interventionsdrohung des politischen Systems, nachdem zahlreiche Versuche zur kooperativen Stabilisierung des Abfallaufkommens gescheitert waren.

Spies zufolge hat die institutionelle Struktur mit ihren drei föderalen Ebenen die Definition des politischen Problems der Abfallbeseitigung entscheidend geprägt. Der dezentral anfallende Problemdruck, der von der unteren Ebene nicht verantwortet wurde, habe die gesellschaftlichen Interessen und die 'institutionellen Eigeninteressen' (Autonomieinteressen, Abwehr von Störungen der eignen Aufgabenerfüllung) der 'korporativen Akteure' (Kommunen, Länder) zur Deckung gebracht. "Der Handlungsdruck innerhalb des vertikal verflochtenen Entscheidungssystems [...wurde] dadurch verstärkt, daß aufgrund fehlender Handlungskompetenzen der dezentralen Institutionen diesen auch nicht etwaige Kosten (Abwanderungsdrohungen, Arbeitsplatzverluste, Steuerausfälle u.s.w.) von Eingriffen des Bundes beispielsweise in den Verpackungsmarkt angelastet werden können." (Spies, 1994, 271) Die anstehenden Entsorgungsprobleme etablierten eine neue umweltpolitische Problembearbeitungskapazität - im Sinne v. Prittwitz' und Jänickes -, die durch Helferinteressen von Seiten der Verpackungsindustrie und Recyclingunternehmen partiell verstärkt wurde. Einzelne Sektoren der Verpackungsindustrie zeigten sich empfänglich für verschiedene Varianten einer Müllreduktion, obwohl eine Verpflichtung zum gleichzeitigen Angebot von Ein- und Mehrwegsystemen bereits im Gesetzgebungsverfahren am Widerstand des Handels scheiterte. ${ }^{215}$

Die Wirtschaftsverbände hatten wiederholt das Kooperationsprinzip mißachtet und staatlichkorporative Absprachen gebrochen, bzw. konnten die entsprechenden Absprachen nicht gegenüber

${ }^{215}$ Insofern die eingebrachten Problemlösungen auf die generelle Vermeidung von Abfall zielten und sich für Mehrwegsysteme aussprachen, implizierte dies eine Ausweitung von mehrwegfähigen Glasverpackungen. Dies hätte nicht nur für alle anderen Verpackungsindustrien außer der Glasindustrie Umsatzrückgänge bedeutet, sondern auch für diese selbst, da die Glasindustrie nur ca. 1/3 ihres Umsatzes mit Mehrwegsystemen erzielt. Für den Handel hätte die Ausweitung von Mehrwegsystemen Kosten nach sich gezogen, die nicht erwünscht waren, weshalb man auch ein Mehrwegsystem politisch abgelehnte. Für eine generelle Vermeidung von Abfällen fanden sich in der Wirtschaft folglich keine Helferinteressen, so daß zur Reduktion des Abfallaufkommens lediglich die Erhöhung der Recyclingquoten angestrebt wurde. Glas-, Papier-, Weißblech- und Aluminiumindustrie basierten bereits in unterschiedlichem Maße auf Recycling bzw. sind prinzipiell zu Recycling fähig. Dagegen ist die stoffliche Wiederaufbereitung von Kunststoff- und Verbundverpackungen technisch schwierig und erst in Ansätzen möglich. Die Beziehungen zum Recyclingsektor sind folglich unterschiedlich ausgeprägt; sie werden entscheidend von den technischen Eigenschaften der Stoffe bestimmt. Glas- und Papierindustrie greifen seit langem auf Sekundärrohstoffe zurück, und die Weißblechindustrie etwa hat dem Schrotthandel eine generell Abnahmegarantie für Weißblechschrott gegeben. Dagegen existierte kein Markt für Sekundärkunststoffe. Die Bewertung der verschiedenen politischen Lösungen des Müllproblems durch die Wirtschaftsakteure richtete sich sehr konkret an der Ausgestaltung der Eingriffe bzw. der mit ihnen verbundenen Kosten aus. 
ihren Mitgliedern durchsetzen. Allgemein kennzeichnete Konflikt die heterogenen Interessen von Verpackungsindustrie, Konsumgüterproduzenten und Handel untereinander, - aber auch gegenüber drohender politisch-rechtlicher Intervention. Der Antagonismus der verschiedenen Branchen wurde schließlich durch die Spitzenverbände von Handel und Industrie (BDI, DIHT) unter Verweis auf das makroökonomische 'Gesamtinteresse' in dem Augenblick überwunden, als erkennbar wurde, daß sich Umweltschutzmaßnahmen nicht länger per se blockieren ließen und eine umweltpolitische Regulierung unausweichlich würde. Entsprechend riet man den jeweiligen Industrien des nun entstehenden Abfallsystems zu Selbstregulierungsinitiativen (vgl. Spies, 1994, 286 ff).

Zentrale Organisation des Abfallsystems wurde das Duale System Deutschland AG (DSD), der Grüne Punkt. Seine Gründung geht direkt auf die Verpackungsverordnung zurück, welche mit der Suspensionsklausel ein derartiges privatwirtschaftliches Sortierungs- und Sammelsystem zum Ziel hatte. Die Bildung des DSD wurde dadurch erleichtert, daß die Handelsverbände in einer Selbstverpflichtung den Grünen Punkt als Abnahmekriterium bestimmten. Die Gründung des DSD ließe sich spieltheoretisch als eine Abfolge von Spielen mit wandelnden Auszahlungen darstellen (Wiesenthal, 1987, 441). Die Integrationsleistung, die das DSD erbringt, indem es sich als den einzigen, quasi-hoheitlichen Steuerungsakteur etablieren konnte, löst nicht die nach wie vor konfligierenden Interessen auf. Diese können aber in der Entgeldstruktur des Grünen Punkts latent gehalten werden. Der DSD übernimmt die logistische Aufgabe des Sammelns und Sortierens der Abfälle. Die sortierten Stoffe werden dann an private Unternehmen weitergegeben, welche die eigentliche Verwertung und Entsorgung übernehmen. Die Konsumgüterproduzenten können das Logistiksystem des DSD gegen ein Entgeld in Anspruch nehmen, wenn für die verwendeten Verpackungsmaterialien eine Verwertungsgarantie der jeweiligen Industriezweige vorliegt.

Für das politisch-administrative System ist mit dem DSD eine intermediäre Institution mit Akteurseigenschaften geschaffen worden, welche die Rolle eines Verhandlungspartners gegenüber den wirtschaftlichen Interessen einnehmen kann. Aufgrund seiner Monopolstellung ist der DSD einflußreich genug, um den strukturellen Kontext des Verpackungsmarktes insgesamt zu beeinflussen. Doch löst das Monopol des DSD die gegensätzlichen Interessen auf dem Verpackungsmarkt nicht auf. Sie kollidieren insbesondere mit den gesellschaftlichen Umwelt- und Verbraucherinteressen und den sie repräsentierenden Verbänden, die der DSD nach anfänglicher Ablehnung doch noch über ein Kuratorium integrieren wollte. Allerdings verweigerten sich die entsprechenden zivilgesellschaftlichen Umweltgruppen/Repräsentanten von vorn herein (BUND) oder aber stiegen nach kurzer Zeit aus (E. U. von Weizsäcker). Laut Spies blieb einzig das politisch-administrative System zur Ökologisierung der abfallwirtschaftlichen Selbstregulierung. Dies war seinerseits durch heterogene Interessen charakterisiert. ${ }^{216}$

216 Dies bezog sich zunächst einmal auf die Aushandlung des Rahmens zwischen Länder und Kommunen und dem DSD. "In der Praxis haben sich die dem Bund von den dezentralen Politikakteuren abgerungenen Kompetenzen in äußerst konfliktträchtige Verhandlungsbeziehungen mit dem DSD gewandelt." (Spies, 1994, 291) Die kommunalen Verbände, welche die typischen verhandlungsschwächenden Koordinationsschwierigkeiten der großen Zahl aufwiesen, sind teilweise gegeneinander ausgespielt worden, sie haben aber auch in ihrem Interesse liegende umweltpolitische Forderungen (Ausweitung des Mehrwegsystems, Ausschluß bestimmter Verpackungsarten) 
Das Dilemma des DSD, zwischen Bestandserhaltung und individuellen Interessenpositionen agieren zu müssen, dürfte solange organisationsintern bearbeitbar bleiben und extern mit umweltpolitischen Gemeinwohlforderungen seitens der Politik, der Gegenverbände und der Öffentlichkeit verknüpfbar sein, wie intern bestandserhaltende Teilkoalitionen zu Lasten von Verlierern gebildet werden können. Daß Verlierer die Entscheidungsfähigkeit des Selbstregulierungssystems durch exit oder voice nicht ohne weiteres gefährden können, liegt an der hierarchischen Absicherung des DSD durch die VerpackV. Der Handel wurde aus strategischen Gründen zur Rücknahme verpflichtet und wird daher versuchen, die Funktionsfähigkeit des Dualen Systems so lange wie mögliche aufrechtzuerhalten. Denn vor dem Hintergrund der Verordnung stellt das DSD für den Handel eine First-Best-Lösung dar. (Spies, 1994, 295)

Gegenüber Spies' Erklärung des DSD hat W. Viehöver auf die Bedeutung der Öffentlichkeit verwiesen. Er versteht Öffentlichkeit in Anlehnung an Habermas als Resonanzboden von Diskurskoalitionen in der Peripherie des politisch-administrativen Systems (Viehöver, 1999, 71 f, 74). Seine These ist, "daß sich die Kommunikationsbedingungen realer Verhandlungssituationen ständig durch die öffentliche Resonanz der von den Akteuren jeweilig verwendeten rhetorischen Strategien und öffentlichen Narrationen verändern." (ebd., 36 f) Dazu analysiert er die formale und inhaltliche Dimension der Interaktionen der beteiligten Akteure. Wie der akteurzentrierte Institutionalismus sieht er die Praktiken der am Mülldiskurs beteiligten Akteure (Diskurskoalitionen) durch die institutionellen Konstellationen und die Interaktionsorientierung der Diskurskoalitionen bestimmt. Viehöver teilt damit auf institutioneller Ebene Scharpfs (und Spies') spieltheoretische Auffassung über positive Koordination in Verhandlungssystem (mixed-motive game). Allerdings macht er geltend, daß die normativen und kognitiven Orientierungen der Diskurskoalitionen über diesen institutionellen Kontext hinausweisen, daß also der Kontext der Akteure nicht mehr nur hinsichtlich von Institutionen bestehe. ${ }^{217}$ Die Öffentlichkeit des Diskurses (zum Müllsystem) beeinflußt vielmehr maßgeblich die Interaktionsbeziehungen (kooperativ, kompetitiv, indifferent, feindselig) zwischen Akteursnetzwerken und so die Policy-Lösung der zugrundeliegenden mixedmotive Konstellation. Die Narrationen der jeweiligen Diskurskoalitionen würden in der Öffentlichkeit aufgenommen und deliberativ vollzogen, ohne daß das Ergebnis vorab für die Diskurskoalition strategisch zu bestimmen wäre. Die Niederlage, welche die Diskurskoalition der Regulierungsgegner mit der Etablierung des DSD erlitt, obwohl dessen Konzeption paradoxerweise

\footnotetext{
gegenüber dem DSD durchzusetzen versucht. Die Länder hatten ähnlich Koordinierungsschwierigkeiten, unter denen ihr Drohpotential gegenüber dem DSD litt, die Freistellung (partiell) zu verweigern. Es ist noch ungeklärt, ob sich der Entzug der Freistellung von Stoffen überhaupt als landespolitisches Eingriffsinstrument praktisch eignet. Aufgrund der langfristigen Abnahmeverträge zwischen DSD und Kommunen verschlechterte sich die Verhandlungsposition der Länder weiter, da nun ein (politisches) Interesse der Kommunen bestand, die geschaffenen Kapazitäten auch auszunutzen. Einfluß konnten Ländern und Kommunen nur in Teilbereichen nehmen: so dürfen Verkaufsverpackungen nicht kommunal entsorgt werden, die Verwertungsleistungen nicht unterschritten werden und die Sortierungstiefe wurde beibehalten. Auch mußte der DSD nach der Weigerung der Länder und Kommunen, mittelbare Verwertungsgarantien durch Dritte zu akzeptieren, neben Sammlung und Sortierung nun auch die Verwertung selbst übernehmen, was in der Folge eine Veränderung der Kostenstruktur für Kunststoffverpackungen bewirkte.

${ }^{217}$ In ganz ähnlicher Weise hat Feindt (2002) die Bedeutung von Akteureskonstellationen im Verhältnis zur funktionalen Differenzierung der Gesellschaft herausgestellt.
} 
auf sie zurückging, sei nur vor dem Hintergrund des öffentlichen Bedeutungsverlustes ihrer Position im Anschluß an eine Reihe von öffentlich bewerteten Ereignissen zu verstehen. ${ }^{218}$

Der Mediendiskurs erscheint als "ein institutioneller Kontext, der die Beziehungsstrukturen und Anlässe für Interaktionen strukturiert und somit bestimmte Handlungsergebnisse erklären kann." (Viehöver, 1999, 88) Der Mediendiskurs kann ressourcenschwachen Akteure Einflußchancen eröffnen und den politischen Verhandlungsprozeß von außen beeinflussen oder sogar eine Einbindung dieser Akteure in bestehende Politiknetzwerke bewirken. Öffentliche Diskurse können derart soziale Lernprozesse anregen. Zwar hat sich im Mülldiskurs die kulturkritische Diskurskoalition nicht durchgesetzt, wohl aber hat sie die positive Koordination (Scharpf) durch den Staat überhaupt erst möglich gemacht. Viehöver geht somit deutlich über Spies' Erklärung hinaus. Er hat zudem die These abgeleitet, daß Kooperation zwischen etablierten Netzwerkakteuren unter bestimmten Bedingungen negative Konsequenzen für das zu schützende Gemeingut Umwelt haben kann. So können vorübergehende Nichtkooperation von nicht-etablierten Umweltgruppen u.U. die Problemlösungsfähigkeit von Netzwerken insgesamt verbessern, indem sie partikulare Interessen abschwächt und eine gemeinwohlorientierte Orientierung auf nachhaltige Entwicklung erzwingt. Viehöver zufolge können Diskurskoalitionen somit sowohl in der materiellen (Koordinationsveränderungen in Netzwerken) als auch in der symbolischen Dimension (Narrationen in der Öffentlichkeit) substantiell wirken, wobei allerdings Argumenten im gesamten Prozeß der diskursiven Deliberation keine große Bedeutung zukomme. "Die Legitimität, die eine Problemdefinition im öffentlichen Diskurs erfährt, hängt aber nicht nur von der Qualität der Argumente ab, sondern von der symbolischen Form, in der diese Argumente in öffentlichen Diskursen verpackt werden." (ebd., 100)

\subsection{Die politikwissenschaftliche Herausforderung der Dematerialisierung}

\subsubsection{Netzwerke und politische Wohlfahrtsoptimierung}

Erfolg oder Mißerfolg politischer Steuerung hängen stark von den eingesetzten Steuerungsinstrumenten und der Intensität ihres Einsatzes ab. Massiv und flächendeckend eingesetzte Instrumente wirken zumeist zuverlässig, können jedoch bei starren Verhandlungssystemen an Grenzen stoßen. Ihr Einsatz kann mit hohen, sowohl finanziellen als auch politischen Kosten

218 1.) Kam es am 26. April 1986 zur Reaktorkatastrophe in Tschernobyl. Sie stellt den Höhepunkt im Prozeß der Institutionalisierung des Umweltdiskurses in der deutschen Medienarena und im politisch-administrativen System dar (Schaffung des Bundesumweltministeriums). 2.) Verstärkten sich Proteste gegen die Müllverbrennung. 3.) Müllflut und die Proteste gegen den Entsorgung werden in das Standardrepertoire der Medienberichterstatter aufgenommen, und es kommt zur symbolischen Verbindung der Müllverbrennung mit der Dioxin-Katastrophe in Seveso. 4.) Kunststoffabfälle erhalten aufgrund dessen im öffentlichen Diskurs ein Negativimage wobei im Mediendiskurs Themen mit einander verflochten werden (z.B. Verbrennung, Mülltourismus, Dioxine und Kunststoffverpackungen). 5.) Aufkündigung des Branchenabkommens von 1977 zwischen Industrie, Handel und Politik; vgl. Viehöver, 1999, 98. 
verbunden sein, so daß besser auf selektive Instrumente zurückgegriffen wird. Auch können rechtliche Grenzen für flächendeckende Instrumente bestehen. Der bereits mit der Verpackungsverordnung von 1991 erfolgte Verzicht auf ökonomische Instrumente zur Reduktion von Stoffströmen erfolgte zugunsten einer prozeduralen Outputsteuerung. Dieser Ansatz wurde 1996 durch das KrW-/AbfG gesetzlich bestätigt. Dabei wurde weiterhin am Umweltziel sektoraler Mehrwegquoten festgehalten und die Preisfindung dem monopolisierten Quasi-Markt überlassen. Das Duale System ist damit faktisch als privatisierte Regulierungsagentur zu charakterisieren, die sich allein auf die Müllzusammensetzung bezieht. Dabei ist Wettbewerb als Steuerungsmechanismus fast vollständig ausgeschaltet. Dem DSD kommt ein Monopol im Bereich des Verpackungsabfalls zu. Weil die Regulierung so funktionell-rechtlich an eine Gesellschaft des Privatrechts (DSD AG) überantwortet wurde, ist sie zugleich der demokratischen Kontrolle des Parlaments entzogen.

Die Bildung des abfallpolitischen Netzwerkes hat kaum eine Senkung der politischen Transaktionskosten für das politisch-administrative System bewirkt, wie die schwierige Durchsetzung des Dosenpfandes zeigt. Der rechtliche Bestand der vom Gesetzgeber gewählten Verordnungsform wurde bis in die letzte Instanz von der Wirtschaft angefochten. Zwar kann bei Interessenkonvergenz von Verbands- und staatlichen Steuerungszielen Steuerung wesentlich begünstigt werden, bei Divergenz allerdings auch erheblich erschwert werden. Schimank/Wasem (1995) haben dies mit der wechselseitigen Beobachtung der Steuerungsadressaten in Netzwerken erklärt. Dies gelte für privatwirtschaftliche Akteure ebenso wie für die Interaktion zwischen politischen Beratungsgremien (Sachverständigenrat für Umweltfragen) und politischen Akteuren und Steuerungsadressaten. Die Diskurskoalition der Regulierungsgegner erwies sich nach wie vor in hohem Maße als konfliktbereit, auch wenn die Erwartung des akteurzentrierten Institutionalismus zutreffend scheint, daß sich gemeinwohlunverträgliche Partialinteressen nicht dezisonistisch durchsetzen lassen (s. S. 271). Doch auch wenn ihre öffentliche, rechtliche Niederlage das Müllsystem in seiner gegenwärtigen Form bestätigt hat, sind weiter externe, politische Vorgaben (Verordnungen) notwendig, um die Entkoppelung von Wachstum und Ressourcenverbrauch zu sichern. Dabei wird die Legitimität der Vorgaben um so eher juristisch angefochten werden, je weniger die Unterstützung im massenmedialen Diskurs sicher ist. Insbesondere die Diskussion um Instrumente zeigt aber - wie im 'Dosenstreit' - die Schwierigkeiten bei der Vermittlung von Policies.

In ökologischer Hinsicht kann dem DSD durchaus eine positive Ökobilanz bescheinigt werden (Duales System Deutschland, 2000 a und 2000 b). Er trägt zu einer nachhaltigen Entwicklung bei. Der Grüne Punkt ist anderen Entsorgungsalternativen von Leichtverpackungen ökologischenergetisch überlegen, insbesondere verschiedenen Formen der Müllverbrennung. Die vom ÖkoInstitut Freiburg durchgeführte Studie für den DSD empfiehlt eine Ausweitung des Grünen Punktes hin zur Gesamtmüllsortierung, die ökologisch die meisten Vorteile besäße. Allerdings sei dies zugleich die teuerste Form der Abfallbeseitigung (mit Mehrkosten von 61,4 \%). Es zeigt sich , daß das Duale System ökologisch richtungssicher funktioniert, die Abfallmenge seit 1990 sank, 
während das Recycling zunahm, und der Ressourcenverbrauch im gleichen Zeitraum sogar abnahm. Die Ausschöpfung ökologischer Dematerialisierungspotentiale werde jedoch durch die Quasipreisstruktur des Müllnetzwerkes allein langfristig nicht gewährleistet werden können. Auch bezieht sich dies nur auf den vom DSD behandelten Verpackungsmüll und nicht auf das gesamte Hausmüllaufkommen. Zweifellos ist die im KrW-/AbfG erfolgte Zuweisung von Verantwortung für eine Reduktion der Stoffströme an die Abfallwirtschaft sehr hochgesteckt (vgl. auch Spangenberg, Verheyen, 1996, 6 f), doch läßt sich angesichts dieser Rechtsnorm feststellen, daß der Ressourcenverbrauch der Bundesrepublik im selben Zeitraum konstant geblieben ist (Bleischwitz, 2002, 20), daß noch keine makroökonomische Dematerialisierung durch das Abfallnetzwerk stattgefunden hat.

Im Kontext einer Stoffstromsteuerung sind nicht nur interdependente Handlungssituationen von Interesse, in denen, wie im Fall des institutionalisierten Müllsystems, die Kooperation zwischen einzelnen Akteuren ein gemeinsames Output hervorbringen soll (vgl. Lütz, 1995), sondern auch Verhandlungssysteme, die in erster Linie der Produktion individueller Güter dienen (z.B. globale Verbreitung von ISO-Normen des Umweltaudits). Im Unterschied zu Verhandlungssystemen in interdependenten Handlungssituationen ist hier die Rolle der Öffentlichkeit bisher kaum analysiert worden. Es liegt die Vermutung nahe, daß dies mit dem selbstorganisatorischen Charakter solcher Verhandlungssysteme im Zusammenhang steht.

Kodifizierte technische Normen sind nicht als emergente Phänomene zu verstehen, sondern als revidierbares Ergebnis eines Entscheidungsprozesses (vgl. Mayntz, 1990). Sowohl Absender als auch Adressaten solcher technischen Standards sind individuelle oder kollektive Akteure. Es ließe sich analytisch weiter zwischen Setzung, Implementation und Durchsetzung von technischen Normen differenzieren. Werle (1995) unterscheidet (nur) zwischen zwei Zwecken von Standards, nämlich ermöglichenden Standards, die technische Funktionsfähigkeit sichern sollen und dazu Akteure koordinieren müssen, und verhindernden Standards, welche die negativen Externalitäten von Technik verhindern oder einschränken sollen und dazu Akteure regulieren. Während koordinierende Standards das Funktionieren des technischen Systems gewährleisten, setzen regulative Standards an den Funktionsdefiziten des Systems an und legen über Höchstwerte und Grenzwerte externe Restriktionen des technischen Systems fest, die systemintern in der Regel frei umgesetzt werden können. Diese Unterscheidung entspricht der zwischen freisetzendem und einschränkendem Technikrecht (vgl. Kapitel 4.2.1). Im Umweltrecht fällt die regulative Normierung im allgemeinen unter den Rechtsbegriff 'Stand der Technik'.

Die Erfolge koordinierender, nationaler Standardisierung gehen auf das Interesse der Produzenten und Nutzer von Technik an niedrigen Transaktionskosten zurück. Kompatibilität erhöht unmittelbar den allgemeinen Nutzen der Technik. Koordinative Standards greifen zwar stärker als regulative Standards in die Technikgenese ein, doch muß zur Setzung von regulativen Standards zunächst ein Gefangenendilemma überwunden werden, das aus dem schwachen Organisationsgrad zivilgesellschaftlicher Akteure resultiert. Und während sich der Staat bei koordinativen Standards regelmäßig in Zurückhaltung üben kann und Standardi- 
sierungsverhandlungen in Erwartung gesamtwirtschaftlich positiver Effekte nur positiv zu koordinieren braucht, treten bei regulativen Standards während der Setzung oft kognitive und evaluative Unsicherheiten auf (Mayntz, 1990). Die Implementation von regulativen Standards kann für Verursacher schließlich ein Negativsummenspiel darstellen, so daß gesellschaftliche Selbstregelung beinahe ausgeschlossen ist. Die Verhinderung negativer Externalitäten erscheint dann nur durch eine positive Koordinationsleistung des Staates möglich. Auf die generellen Probleme der Durchsetzung und der Ineffizienz regulativer Standards im Bereich der Umweltpolitik wurde bereits in Kapitel 4.3.1 hingewiesen.

Folgerichtig hat Werle dann auch festgestellt:

Den klassischen, steuernden Staat, der dort eingreift, wo eine Unterproduktion öffentlicher Güter droht, gibt es so nicht einmal mehr in der nationalen regulativen Standardisierung, obwohl die Verhinderung negativer Externalitäten der Technik ein gewisses Maß staatlicher Intervention erforderlich macht. Viele Standardisierungsaufgaben hat der Staat an intermediäre Standardisierungsorganisationen delegiert. Er koordiniert und finanziert die regulative Standardisierung institutionell, steuert indirekt, gibt gelegentlich Standardisierungsaufträge und nutzt die Ergebnisse, indem er sie in sein regulatives Programm übernimmt. Er garantiert die Durchsetzung von Standards, wobei er jedoch auch die Überwachungsaufgaben zu einem großen Teil delegiert hat. (Werle, 1995, 290)

Eine strategisch ansetzende Umweltpolitik könnte darauf zielen, die internationalen Normensysteme (Ökobilanzen, Auditing- und Monitoringsysteme) mit dem Ziel einander anzugleichen, Mikro- und Makroebene des Wirtschaftssystems miteinander zu verbinden. Eine derartige supranationale staatliche Koordinationstätigkeit würde den nachgeschalteten regulativen Aufwand vermutlich senken und die Internationalisierung des ökonomischen Systems (Globalisierung) im Sinne von Nachhaltigkeit beeinflussen können (Governance). Dazu wäre prozedurales Umweltrecht auf die europa- und völkerrechtliche Ebene auszudehnen. Da sich die koordinierende Standardisierung material sehr beschränkt, sind kaum rechtliche Konflikte zu anderen internationalen Abkommen zu erwarten. Derartige Ansätze zu einer internationalen Standardisierung von stoffstrombasierten Nachhaltigkeitsindikatoren (material flow accounting) bestehen bereits im Rahmen der statistischen Systeme der EU und der UNO.

\subsubsection{Ideen und sozio-politische Netzwerke}

Das Verhältnis zwischen Öffentlichkeit und politischen Institutionen, also solidarischer Zivilgesellschaft und politisch-administrativem System, weist vor allem in den Teilarenen Einschränkungen auf. Nur sporadisch können nicht-etablierte, zivilgesellschaftliche Akteure wie in der Abfallpolitik die Routine von Netzwerken durchbrechen, die ansonsten noch weitgehend Restriktionen des rechtlich-administrativen und des ökonomischen Systems unterworfen sind. Dauerhaften Einfluß - im Sinne positiver Regulierungen - kann zivilgesellschaftliche Solidarität kaum ausüben. Zudem scheint eine Exklusion zivilgesellschaftlicher Solidarität intermediären Verhandlungssystemen bereits durch die vorherrschende Fixierung auf die Produktion eingeschrieben zu sein, d.h. bezogen auf den Markt repräsentieren sie die Interessen von 
Konsumenten nur unzureichend. Diese Rolle muß in der Regel vom Staat eingenommen werden, wobei die paternalistische Rollenübernahme als Indiz dafür anzusehen ist, wie schlecht sich wenig konfliktfähige Interessen überhaupt repräsentieren lassen. ${ }^{219}$

Im Hinblick auf den Suffizienzaspekt von Nachhaltigkeit gibt die mangelnde Inklusion von Konsumenteninteressen von daher Anlaß zur Besorgnis: Denn selbst wenn die Reduktion von Stoffströmen im Produktionsbereich erfolgreich sein sollte, könnte Nachhaltigkeit durch einen absolut steigenden Endkonsum von Stoffen noch immer verfehlt werden. Das Suffizienzproblem wirft deshalb die Frage auf, ob nicht durch die policyspezifische Herausbildung von umweltpolitischen Verhandlungssystemen die gesamtgesellschaftliche Deliberation zur Nachhaltigkeit in Teilarenen zu zerfasern droht. In den einzelnen Arenen würden dann jeweils Teilaspekte von Umweltpolitik unverknüpft nebeneinander mehr oder weniger erfolgreich bearbeitet. Dies könnte verhindern, so die These im Anschluß an Downs, daß sich die öffentliche Aufmerksamkeit (attention) für Nachhaltigkeit erfolgreich reproduziert. Ein Verlust zivilgesellschaftlicher Solidarität bzw. ökologischen Bewußtseins wäre die Folge. Aus funktionaler Sicht mögen Verhandlungssysteme dann zwar sogar ökologisch effektive Ergebnisse erzielen, doch würde Nachhaltigkeit anstatt in einen lernenden, deliberativen Prozeß doch wieder in ein technokratisches Verfahren einmünden, das langfristig seine zivilgesellschaftliche Basis nicht sichern kann. So wurde im abfallpolitischen Fallbeispiel mit der VerpackungV der öffentliche Mülldiskurs augenblicklich beendet und durch einen Expertendiskurs abgelöst. Die Exklusion der Öffentlichkeit erfuhr erst mit Einführung des Pfands auf Einweggetränkebehälter wieder eine gewisse Umkehr, ohne daß sich hier jedoch Diskurskoalitionen in das nunmehr geschlossene Verhandlungsverfahren hätten einbringen können. Denn öffentliche Resonanz und Partizipationsmöglichkeit sind im abfallpolitischen Verhandlungssystem gegenläufig. Obgleich laut Meinungsumfrage eine Mehrheit der Bundesbürger die Einführung des Dosenpfandes unterstützte, hat dies, ebenso wie die eindeutige Rechtslage, nicht zu einer Senkung der politischen Transaktionskosten geführt. ${ }^{220}$ In steuerungstheoretischer Hinsicht zeigt die Quotenregelung überdies, daß Netzwerke auch nicht zu einer Verringerung oder Vereinfachung ordnungsrechtlicher Regulierung führen müssen. 'Schatten' wird in Verhandlungssystemen letztlich durch Recht geworfen. Zwar wurde im Fall der bundesdeutschen Abfallpolitik die netzwerktheoretische Erwartung bestätigt, daß sich einzelne Akteure einem etablierten Netzwerk nicht mehr verweigern können, doch insgesamt wurde der Regulierungserfolg für das politisch-administrative System mit dem bitteren Beigeschmack politischer Inkompetenz versehen. Während die Netzwerktheorie die Integrationskraft von Netzwerken mit der Macht von Öffentlichkeit richtig erklärt, erfaßt sie nicht den externen Bedeutungswandel von Politiken in der Öffentlichkeit. Dieser kann jedoch höchst relevant sein.

${ }^{219}$ Wird die Beteiligung derartiger Interessen gesetzlich festgeschrieben, kann dies wiederum die ökonomisch-funktionale Selbstregulation stören - wie im Fall des Kuratoriums des DSD, das zivilgesellschaftliche Interessen nicht in das Preisbildungsverfahren des DSD integrieren konnte.

${ }^{220}$ Der juristische Widerstand wurde im Bundestagswahlkampf 2002 von FDP und CDU/CSU politisch aufgegriffen; vgl. Geyer, Smoltczyk, 2003. 
In vielen Ansätzen der Rational-choice-Theorie wird implizit unterstellt, daß der Kommunikationsmodus des 'bargaining' eine große Affinität zu Verteilungsfragen aufweise. ${ }^{221}$ Diese These wird sowohl hinsichtlich der Distribution materieller Ressourcen als auch hinsichtlich der Zuteilung von Kompetenzen vertreten. ${ }^{222}$ Die so eingeführten normativen Implikate sind für eine Reihe von Ansätzen der Rational-choice-Theorie charakteristisch. Während die Spieltheorie Verhandlungsprobleme so primär als Verteilungsprobleme versteht, wird von der Theorie der Netzwerke geltend gemacht, daß bereits negative Koordination den Interessenausgleich sichert und überhaupt nur zur Lösung von Problemen eine positive Koordination notwendig ist. Ob damit allerdings bereits das Gemeinwohl erfüllt wird oder doch nur partielle, subsystemische Interessen, kann nicht auf der Mesoebene beantwortet werden, sondern verweist auf die Makroebene zurück. Normativ könnte dies durch Bezugnahme auf die Wohlfahrtstheorie des Differenzprinzips geschehen (Rawls, 1971, Barry, 1989, 1996), wobei hier jedoch neben der offenen ökologischen Frage wesentliche Fragen der Implementation unbeantwortet bleiben. Braun hat stattdessen auf die Theorie gesellschaftlicher Ausdifferenzierung verwiesen (Braun, 2000). Diese bietet Vorteile gegenüber einer normativen Makrotheorie, läuft aber gleichzeitig Gefahr, in den Politikfluß (policy-stream) hineingezogen zu werden, ohne die materiellen Kriterien (öko-soziale Indikatoren) benennen zu können, welche die wohlfahrtsstaatliche Entwicklung tatsächlich in eine nachhaltige Entwicklung transformieren könnten. Es erscheint, wie schon Greven zu Schmalz-Bruns' zivilgesellschaftlicher Version von Verhandlungsdemokratie angemerkt hatte, nicht undenkbar, daß Netzwerke lediglich lokale Optima entstehen lassen, die weder auf der nationalen geschweige denn der internationalen Ebene tatsächlich eine nachhaltige Entwicklung beschreiten. So zeigt das Fallbeispiel der Abfallpolitik, daß selbst Netzwerke, die erfolgreich die Ressourcenproduktivität ihres Politikfeldes steigern konnten, keinen nachweisbaren Auswirkungen auf nationale Stoffströme haben müssen. Für den Nachhaltigkeitsdiskurs bedeutet dies, daß die Konzentration auf einzelne Felder der Umweltpolitik nicht zur Verwirklichung der materiellen Zielen von Nachhaltigkeit genügen muß, sondern sich eventuell nur mit diesen Zielen deckt.

Vor dem methodischen Hintergrund eines durch den Schatten der Hierarchie quasi finalisierten Handlungsrahmens sind die normativen Implikate in der assoziativen Demokratie relativ schwach. ${ }^{223}$ Es könnte deshalb politikwissenschaftlich gerechtfertigt erscheinen, vom Prozeß der

${ }^{221}$ T. Saretzkis hat zu Recht betont, daß Verhandeln nicht per se zu gemeinwohlabträglichen Ergebnissen führen muß; genausowenig, wie Argumentieren automatisch das Gemeinwohl bestimmen kann (Saretzki, 1996, 24 ff). Die beiden Kommunikationsmodi können somit nicht einfach mit Equity- vs. Equality-Gesichtspunkten identifiziert werden. Argumentation entspricht nicht Gleichheit oder Repräsentation im politischen System, sondern begründet diese durch bessere Argumente (Gründe).

222 Die Unterscheidung zwischen integrativem und distributivem Verhandeln (integrative and distributive bargaining; Young, 1994, 43 f, 100 f, 127 f) kann dieses Problem nur partiell überwinden. Sie ermöglicht nicht, Verhandeln als Gegenbegriff zum Argumentieren zu begründen.

${ }^{223} \mathrm{Im}$ internationalen System ist der Kontext für Verhandlungssysteme natürlich ein anderer. Ohne die globale Monopolisierung von Macht ist das internationale System beinahe gänzlich auf Verhandlungssysteme verwiesen. Governance findet nur selten im Schatten von Hierarchie (Hegemon) statt. Sie ist unter dem Sicherheitsdilemma (GD) - wie im Fall des Klima- und des Ozonschutzregimes oder des Regimes zur Verhütung von Giftmüllexporten - auf Formen horizontaler Koordination angewiesen. Dabei können sich internationale Institutionen (Regime und Organisationen) nicht nur zur Bereitstellung von kollektiven Gütern etablieren, wenn es also um die Sicherung von 
Willensbildung abzusehen und sich auf Interessen zu beschränken. Fragen des Wollens und des Sollens werden dann nicht mehr separat gestellt. Doch "[d]ies schränkt sozusagen die Perspektive schon unzulässig ein angesichts der Herausforderungen durch die fortschreitende Vergesellschaftung der Natur und den wichtiger werdenden Problemen kultureller Identität." (Saretzki, 1992, 303) Es ist darauf zu beharren, daß vom politischen Prozeß her besehen beide Modi - sowohl Argumentieren als auch Verhandeln - der Phase der Meinungs- und Willensbildung zuzuordnen sind. Sie dienen der Vorbereitung von Verfahren und sind selbst keine Entscheidungsverfahren. $^{224}$ Allein öffentliche Diskurse können die Angemessenheit von Verhandlungssystemen (wie z.B. Tarifverhandlungen) festlegen und den Modus des Verhandelns rechtfertigen (Saretzki, 1996, 32 ff). Hierbei wird Verhandlungssystemen Legitimation extern zugesprochen. Die mit der Kompetenzübertragung erteilte Legitimität ist an den demokratischen Prozeß und den praktischen Diskurs zurückgebunden. ${ }^{25}$ Beide sind relativ bzw. vollständig beteiligungsoffen.

Die Bedeutung von freien argumentativen Willensbildungsprozessen wird insbesondere bei Verfahren deutlich, die Entscheidungen unter epistemischer Unsicherheit erzwingen. Deshalb hat Schmalz-Bruns für diese gefordert, vorab einen Verfahrensmodus festzulegen, der die Lücken eines argumentativ nicht zu bestimmenden Konsens schließt und ein verbindliches Ergebnis (unter dem Aspekt der internen Verfahrensgerechtigkeit) erreichen kann (Schmalz-Bruns, 1995a, 269). Dies verwischt jedoch den Legitimitätsgesichtspunkt.

Policyarenen, die unmittelbar an das wissenschaftliche Symbolsystem anschließen und Handlungsräume eröffnen, so die These in Anschluß an Kapitel 2.3.2, sind argumentationstheoretisch zugänglich und direkt an sie anschließende Verfahren mit Legitimationsdefiziten

'Kollaboration' (vgl. zur Terminologie Stein, 1983, 127 ff) geht, sondern auch, wenn 'Koordination', wie etwa bei internationaler Standardisierung, angestrebt wird; Werle, 1995, 283.

${ }^{224}$ In den internationalen Beziehungen sind Argumentieren und Verhandeln T. Gehring zufolge zunächst gleichwertige Interaktionsmodi, die im institutionellen Rahmen des internationalen Verhandlungssystems eingebunden seien. Im von ihm vorgeschlagenen Phasenmodell internationaler Verhandlungen ist Argumentation ein dem Verhandeln vorgeschalteter Modus zur Klärung kognitiv relevanter Sachfragen. Argumentieren erscheint als geeignetes Verfahren "zur Erzielung von Verständigung, mit dem Unsicherheit gemeinsam beseitigt werden kann." (Gehring, 1996, 219) Allerdings reduziert Gehring die argumentativ zu klärende kognitive Unsicherheit im Fall des Ozonschutzregimes auf soziale, ökonomische Risiken (Nachfrageentwicklung, Substitute etc.), während die Klärung naturwissenschaftlicher Tatsachen (etwa epistemische und prognostische Unsicherheit) dem argumentativen Prozeß vollständig vorausliegen soll. Nur kognitive Unsicherheiten über ökonomische Risiken erlangten demnach im Verhandlungsprozeß Bedeutung, da sie die zugrunde gelegten wohlfahrtstheoretischen Vorstellungen bedrohen. Daß Gehring damit auch differenzierungstheoretische Annahmen ins internationale System überträgt, entgeht ihm. Bereits im Fall des Klimaschutzregimes zeigte sich, daß es der Schaffung einer unabhängigen supranationalen Organisation (des International Panel on Climate Change, IPCC) bedurfte, um die gesellschaftliche Ausdifferenzierung der Moderne, d.h. die Freiheit der Wissenschaft, überhaupt fortführen zu können. Dennoch nahmen wirtschaftliche und politische Interessen noch immer erheblichen Einfluß auf die naturwissenschaftliche und die ökonomische Problemdefinition des globalen Klimawandels (vgl. Godard, 1997). Es zeigt sich, daß der Institutionenbegriff in den internationalen Beziehungen zumeist sehr eng ist und bisher Argumentation und Ideen nicht hinreichend berücksichtigt; vgl. zur intensiv geführte Debatte über kommunikatives versus strategisches Handeln in den internationalen Beziehungen zusammenfassend Holzinger, 2001.

225 Schmalz-Bruns (1995b) hat in diesem Zusammenhang die Vermutung geäußert, daß Habermas die politische Willensbildung deshalb in pragmatische, ethisch-politische und moralisch-praktische Fragen aufteile, weil er das Anwendungsproblem nicht gelöst habe. M.E. ist hier jedoch weniger die Anwendungsfrage problematisch, als vielmehr die Rationalitätstheorie (s. S. 48 ff). Die Tatsache, daß generell die Güte der Gründe in der Politik nicht für die Güte der Resultate bürgen muß, erklärt sich aus der systemischen Einhegung der Öffentlichkeit. 
behaftet, wenn sie unter epistemischer Unsicherheit Entscheidungen erzwingen (vgl. Saretzki, 1996b, Schiller, Tänzler, 2003). Entsprechenden Verfahren fehlt Legitimität. Wissenschaftliche Forschung degeneriert dann insofern zu instrumentellem Handeln ohne verantwortungsethischen Bezug, als daß das folgenentlastete wissenschaftliche Symbolsystem in ein Handlungssystem transformiert wird. Verfahren reklamieren zwar gegenüber den Naturwissenschaften auch dann einen rationalitätstheoretischen Anspruch, wenn der demokratische Rechtsstaat von einer Wahrheitsgeltung entbunden ist, doch verkommt wissenschaftliche Argumentation zu Rhetorik, wenn epistemische Unsicherheit in Verfahren ignoriert wird. Die Ausweitung von Partizipation sichert nicht die Richtigkeit der Ergebnisse. Mit Entscheidungen unter epistemischer Unsicherheit wird vielmehr das Abstimmungskriterium (Mehrheitsprinzip) der repräsentativen Demokratie strategisch vereinnahmt. Wissenschaft instrumentalisiert dann Öffentlichkeit. Die soziale Verantwortung für die Folgen wird dem politisch-administrativen System überantwortet, ohne daß dieses potentielle Folgen revidieren könnte. Macht wird so zu einem offen eingesetzten Medium. Es zeigt sich somit, daß das diskursive Reflexivitätskonzept durch die Argumentationstheorie in der Lage ist, systemtheoretische Restriktionen hinter sich zu lassen. Es geht dabei teilweise auch über das Konzept reflexiver Demokratie hinaus, da es neben Reflexivität im sozialen Prozeß auch Reflexivität im Forschungsprozeß aufzeigen kann und angesichts der immanenten Unsicherheit ethisch-kommunikatives Handeln anmahnt. Damit ist zugleich einer ordinären Demokratisierung der Wissenschaften vorgebeugt.

Habermas hat vor allem das Rechtssystem als Symbol- und Handlungssystem verstanden. Die argumentativen Diskursanalyse (Hajer, 2003) kann diese symbolische Dimension des Rechtssystems kritisch erschließen und so unwirksames Recht offenlegen. Indem sie den argumentativen Nachweis führt, daß reklamierte Handlungsintentionen handlungstheoretisch nicht eingeholt und implementiert werden können, öffnet sie die Rechtsentwicklung der Kritik. So ist das Abfallrecht der Bundesrepublik als solchermaßen symbolisches Recht kritisiert worden. A. Schink (1999) hat darauf verwiesen, daß das in der VerpackV statuierte Verursacherprinzip (§§ 5. 2, II. 1 KrW-/AbfG) sogleich wieder auf den DSD übertragen werden konnte (nach § 16. 2 KrW-/AbfG und §§ 17, 18 $\mathrm{KrW}$-/AbfG) und deshalb keine Reflexivität im ökonomischen System ausgelöst habe. So konnten Einwegverpackungen weiterhin über den DSD entsorgt und die Kosten an die Kunden weitergegeben werden. Da die internen Vorgaben für den DSD niederig waren, ging dies zunehmend zu Lasten der externe vorgegebenen Mehrwegquote und führte zum 'Dosenstreit'. Doch nicht nur das Verursacherprinzip ist in dieser Hinsicht weitgehend programmatisch: Nach dem KrW-/AbfG sind Interventionen in den Abfallpartialmarkt nur durch zukünftige Verordnungen möglich, die das Prinzip der Vermeidung materiell konkretisieren müssen (§ 5. $1 \mathrm{KrW}-/ \mathrm{AbfG}$ ). Diese Verordnungen sind inzwischen durch EU-Richtlinien für Altautos, Elektrogeräte und Batterien Teil des deutschen Abfallrechts geworden, wobei die Kompetenz des Parlaments auf die supranationale Ebene ausgelagert wurde und dort nur über eine rudimentäre Öffentlichkeitsbindung verfügt. Problematisch ist zudem der Einfluß des Bundesimmissionsschutzgesetzes auf das KrW/AbfG über § $9 \mathrm{KrW}$-/AbfG. Dieser Paragraph gestattet die Mitverbrennung von Müll in Industrieanlagen als Verwertungsmaßnahme, womit die Abfallhierarchie (Vermeidung vor 
Verwertung) de facto außer Kraft gesetzt wird. Die Mitverbrennung hatte dabei zudem wesentlich geringere Umweltstandards zu erfüllen als die öffentliche Müllverbrennung. ${ }^{226}$ So ergibt sich für das bundesdeutsche Abfallnetzwerk das Bild eines inzwischen wieder exklusiv geführten Expertendiskurses, der von Akteuren bestimmt wird, die überwiegend rechtlichen und ökonomischen Eigenlogiken folgen. Dabei drängt sich die These auf, daß das so entstandene Müllnetzwerk mit seinen detailreichen Regulierungen unnötig hohe Kosten verursacht. ${ }^{227}$

Aus diesen Gründen wäre ein zu stark rechtsbezogenenes Lernkonzept für die Politikwissenschaft von bescheidenem Ertrag. Zwar korrespondiert der auf die Rechtsgenese gerichtet Blick weitgehend mit der Schließung des öffentlichen Diskurses und dem Übergang zum Expertendiskurs im Policyzyklus, doch öffnet dies für sich noch keine Forschungspersepktive auf eine materiale Umweltpolicyforschung, die sich etwa mit der Wirkung umweltpolitischer Instrumente beschäftigen muß. An der bundesdeutschen Abfallpolitik verdeutlich: Zwar statuierte die VerpackV eine Produktverantwortung für Händler (und Unternehmen) und gab mit den Mehrwegquoten auch gleich noch langfristige, rechtlich verbindliche Ziele vor (s.o. S. 189), doch wurden diese Ziele von den Akteuren des ökonomischen Systems verfehlt, da die staatliche Zielvorgabe nicht mit ökonomischen Anreizen versehen waren. Damit konnte das Netzwerk nicht einmal jene Mehrwegquoten wahren, die nur den Status Quo festschrieben. Wie zu Zeiten der negativen Koordination in den 80iger Jahren konnte das GD nicht durch die verbandliche Selbstregulierung überwunden werden. In diesem Sinne versagte die Regulierung durch die Medien Recht und Sprache erneut.

Ökonomisch-politische Macht manifestiert sich rein faktisch zunehmend in Netzwerken und Verhandlungssystemen. G. Majone (1993) hat zwischen allokativen und distributiven Politiken unterschieden - eine Unterscheidung, die auch bezüglich der deutschen Abfallpolitik gemacht wurde (Gawel, 1999). Majone hat in seinem Ansatz die These vertreten, daß Wissen (Ideen) nur hinsichtlich von Allokationsproblemen politische Macht erzeugen könne, bei Verteilungspolitiken aufgrund deren Charakters als Nullsummenspiele hingegen kaum relevant sei. Majones kategorische Grundannahme ist dabei, daß objektive, wohlfahrtsökonomische Problemlösungen gefunden werden können. Er stellt jedoch im partiellen Widerspruch dazu fest, daß die Arenen der Umwelt- und Risikoregulierungen keine angemessenen Standards aufwiesen, was er auf die Komplexität der Probleme im ökologischen Bereich und deren Transnationalität zurückführt (ebd., 113). (Coase und z.T. auch Scharpf fassen das ökologische Problem sogar noch restriktiver, indem

${ }^{226}$ Dieser Konflikt um die Materialisierung der Abfallhierarchie wurde durch zwei höchstrichterliche Entscheidungen des Europäischen Gerichtshofes zum Abfallrecht noch verschärft (vgl. Schmidt, 2003, 938 ff) Er konnte jedoch inzwischen durch die neue Bundesimessionsschutzverordnung korrigiert werden. Gleichwohl bestätigt dies eindruckvoll Habermas' These systemischer Verselbständigung.

227 So läßt sich mit Verweis auf die britische Abfallpolitik zeigen, daß mittels Zertifikatlösung und dem Rückgriff auf das Kommunikationsmedium Geld die Steuerungsziele zu geringeren Transaktionskosten hätten erreicht werden können (vgl. Ewers et al., 2002, 19 f). Dies scheint sowohl unter finanziellen Aspekten als auch unter dem Gesichtspunkt politischer Kosten zu gelten. Während in Deutschland die Regelung bei einzelnen Verpackungsarten ansetzt, bezieht sich die britische Regelung auf Verpackungsmaterialien. Dies gestattet zwar unerwünschte Querverschiebungen zwischen Abfallströmen, doch schränken Quoten diese Möglichkeit wieder ein. 
sie die Verteilungsdimension von Politiken zum eigentlichen Policyproblem erklären. ${ }^{228}$ ) Bereits der Ansatz der Tendenzkoalitionen (advocacy coalitions) von P. Sabatier (1993) hatte jedoch bestritten, daß wohlfahrtstheoretische Annahmen unumstrittene Konzepte seien, und verwies dazu auf solche ideelle Konflikte, die sich gerade nicht in Kosten-Nutzen-Kalkulationen fassen ließen, aber dennoch 'fair' zu lösen seien. ${ }^{229}$ Nach Sabatier sei zwar oft ein gemeinsames Interesse an Kooperation (der Produktion eines Gutes) vorhanden, es komme jedoch zu normativen Konflikten bei der Erzeugung des Kollektivguts. Der Konflikt um die ideellen Güter könne dabei den materiellen Verteilungskonflikt überlagern.

Tendenzkoalitionen, die Sabatier gegen die Phasenheuristik abgrenzt, sind plural, und die sie konstituierenden Überzeugungssysteme (belief systems) werden wie bei Diskurskoalitionen durch rote Fäden (story lines) oder Geschichten (narratives) zusammengehalten. Sie sind mehrdimensional: Es gibt grundlegende Werte (deep core), einen Policy-Kern (policy core) und kausale Überzeugungen (causual beliefs). Nur wenn ein die Koalitionen übergreifender Lernprozeß einsetzt, besteht die Möglichkeit einer positiven Koordination bzw. fairen Lösung (Sabatier, 1993, 119 ff). Dies ist um so einfacher, je 'äußerlicher' die Konflikte verlaufen, d.h. wenn die Überzeugungssysteme über kausale Überzeugungen, Argumente und Überredung lernen würden. Der Lernprozeß erfasse nur dann die grundlegenden Werte, wenn der Policybereich durch exogene Ereignisse erschüttert werde (ebd., 125f). Tendenzkoalitionen können so bei Konflikten in der äußerlichen Dimension ihrer Überzeugungssysteme wohlfahrtstheoretische Lösungen erlernen. ${ }^{230}$ Hinsichtlich einer nachhaltigen Entwicklung wäre nach entsprechenden Ereignissen zu fragen, welche die grundlegenden Werte des Umweltpolicybereichs erschüttern könnten. Während Katastrophen - im Anschluß an v. Prittwitz - derartigen Ereignischarakter besitzen dürften, scheint dieser bei (alarmierenden) Prognosen und Szenarios dagegen nicht gegeben zu sein. Diese müßten einer politikwissenschaftlichen Analyse im Rahmen des Advocacy-coalitions-Ansatzes unzugänglich bleiben. Es läßt sich aber bereits an der bundesdeutschen Abfallpolitik beobachten, daß Diskurskoalitionen, die zwar in vielem Tendenzkoalitionen ähnlich, jedoch insgesamt inklusiver sind, einen internen Wandel des Politikfeldes herbeigeführt konnten. Die aus normativen Gründen erforderliche und empirisch tatsächlich $\mathrm{zu}$ konstatierende Einbindung von naturwissenschaftlichem Wissen in die politische Diskussion muß demnach anders vonstatten

${ }^{228}$ Während die Allokation im Markt der Wohlfahrtstheorie zufolge vom Preis gesteuert wird und lediglich im Falle öffentlicher Güter meritorische Staatsinterventionen erfordert, modelliert die Neue Politische Ökonomie (NPÖ) politische Steuerung als Abstimmung zwischen konkurrierenden Vorhaben und knappen Mitteln mit Hilfe öffentlicher Planung. Die Aufteilung der Allokationsaufgabe zwischen Markt und Staat funktioniert aus der Sicht der NPÖ als Nullsummenspiel. Es bestehen Opportunitätskosten der Ressourcenverlagerung, d.h. das Wachsen eines der beiden Subsysteme bedingt zugleich eine Verschiebung zu seinen Gunsten im gesamtwirtschaftlichen System. Wille (1990) weist gegen die Diskussion im methodologischen Karussell der NPÖ darauf hin, daß in vielen Fällen nicht Marktmechanismus und öffentliche Planung miteinander konkurrierten, "sondern vielmehr bestimmte Kombinationen von privater und öffentlicher Tätigkeit. Es geht dann nicht um Mehr oder Weniger an Markt- bzw. Staatswirtschaft, sondern um alternative Formen ihrer Synthese." (Wille, 1990, 273) Zweifellos verfolgt Scharpf ein solches Programm.

229 Dem Ideenstreit zwischen den Tendenzkoalitionen liegt somit ein Mixed-motive-Spiel und kein Nullsummenspiel wie bei Majone zugrunde.

${ }^{230}$ Hajer hat Sabatier's Tendenzkoalitionen als zu restriktiv kritisiert und sich folglich davon abgegrenzt (Hajer, 1995, $68 \mathrm{ff})$. 
gehen. Darüber hinaus besteht ein weiteres Problem des Tendenzkoalitionenansatzes darin, daß das Zusammenspiel zwischen vorgängigen kognitiven Grundlagen und nachfolgender institutioneller Entwicklung nicht hinreichend präzise dargestellt wird. Politische Eigendynamiken wie etwa die Politikverflechtungsfalle und ähnliche Multi-level-Governancestrukturen werden nicht angemessen beschrieben.

D. Braun (1999) konstatiert in diesem Zusammenhang die Zunahme von Ein-Themen-Gruppen (single issue groups), die dann als Tendenzkoalitionen (advocacy coalitions) in Policy-Subsystemen und nicht mehr im Markt, im Forum oder im Diskurs wieder aufeinanderträfen. Dies könne die Gemeinwohlorientierung gefährden, da Befürworterkoalitionen trotz oft funktional gleicher Interessen heterogen seien und keine gemeinsame Definition allgemeiner Wohlfahrt etablieren könnten. Als Lösung eines solchen Konfliktes zwischen Befürworterkoalitionen bietet sich nicht systemische Selbstbindung (Willke, 1993, 138 ff, vgl. dazu auch Hesse, 1998), sondern PolicyLernen an (Sabatier, 1993), das durch reflexive Rahmendiskurse befördert werden könne (Braun, 2000, 148).

Gegen den von Scharpf analysierten latenten wohlfahrtstheoretischen Verteilungskonflikt bei Policyverhandlungen hat Braun die Bedeutung von Ideen und Überzeugungssystemen geltend gemacht. ${ }^{231}$ Diese seien bereits für die auch von Hajer betonte Problemdefinition relevant. Braun schließt nicht an Sabatiers Ansatz an, sondern kritisiert diesen dahingehend, daß er die Blockade von ganzen Policynetzwerken möglich mache, da Sabatier nicht hinreichend zwischen normativen und distributiven Aspekten von Konflikten differenziere. Sabatier habe zwar Lernprozesse als (wohlfahrtstheoretisch äquivalente) Möglichkeit angesehen, um die Vereinnahmung von Politiknetzwerken durch partikulare Tendenzkoalitionen zu verhindern, doch bedrohe natürlich deren Macht als die Möglichkeit, nicht lernen zu müssen, fortwährend politikfeldinterne Lösungen. Erst der Rekurs auf das Forum eröffne dann wieder die Möglichkeit, andere Gesichtspunkte und Akteure in den Diskurs einzubringen und Politiken zu ändern.

Braun hat deshalb sorgfältig zwischen Ideen im Kontext von Verhandlungssystemen und Ideen im öffentlichen Diskurs unterschieden. Während Ideen in Policyarenen an Probleme kollektiven Handelns und an materielle Interessen gebunden blieben, seien Ideen im Forum eher mit roten Fäden zu vergleichen, die in einer historischen Situation plausibel seinen bzw. überzeugten. Wenn derartige Narrationen im öffentlichen Diskurs die Oberhand gewännen, würden sie von allen Akteuren als Maßstab auch für die eigene Narration herangezogen werden (vgl. Braun, 1999, 26). Eine hegemoniale Idee wie der Keynesianismus in den 60iger Jahren hätte beispielsweise den gesamten öffentlichen Diskurs beeinflußt.

${ }^{231}$ Unter Ideen in der Policyforschung versteht Braun Ideen (ideas), Paradigmen (paradigms), Überzeugungssysteme (belief systems), Episteme, Metaphern etc. als ein methodologisches oder theoretisches Set von Aussagen über Ursache- und Wirkungszusammenhänge, die Policies beeinflussen können. Ideen seien rein kognitiv. Erst durch Überzeugungssysteme träten normative Elemente hinzu und schüfen Handlungsmotive. 
Braun hat in diesem Zusammenhang Indifferenz als Möglichkeit angeführt, Blockaden von Politikfeldern zu verhindern (Braun, 1998, 812 ff; Braun, Busch, 1999, 197 ff). ${ }^{232}$ Zwar nimmt Braun wie Sabatier an, daß Indifferenz aus fehlender monetärer Vergleichbarkeit herrühren kann, doch bedeutet dies für Braun nicht, daß Indifferenz auf fehlenden Informationen oder fehlendem Wissen (über mögliche finanzielle Kosten) beruhen muß. Insofern ist Brauns Ansatz offen dafür, Indifferenz auch aus finanzieller Nichtbetroffenheit bei der Schaffung eines Kollektivgutes herzuleiten (Low-cost-Situation). Nach G. Kirchgässner und W. Pommerhehne (1992) kann Indifferenz absolut oder relativ sein. Während bei absoluter Indifferenz der individuelle Beitrag sowohl für einen Einzelnen als auch für alle anderen unbedeutend sei - obwohl die kollektive Entscheidung sehr wohl für alle wichtig sei und deren Interessen berühre - sei bei relativer Indifferenz die individuelle Entscheidung für den Einzelnen zwar unbedeutend für alle anderen jedoch wichtig.

Für eine Politik der Dematerialisierung heißt dies, daß im Forum zwar immer - auch unter prognostischer Unsicherheit - Wissen über die stoffliche Dimension von Wirtschafts- und Umweltpolitik existiert, daß dies jedoch nicht generell Indifferenz im Sinne finanzieller Nichtaffektion beinhalten muß. Erst durch die Konkretisierung von Stoffflüssen kann Indifferenz näher bestimmt werden.

Braun hat bezüglich der Relevanz von Ideen explizit einen Vergleich zum Medianwähler der Public-Choice-Theorie gezogen. Parallel zur inhaltlichen Konvergenz politischer Parteien nach dem Modell des Medianwählers würden Akteure in ihrer Handlungsorientierung durch Ideen beeinflußt. Akteure begännen sich eher als Advokaten denn als Händler zu betätigen. Die Etablierung von Ideen erfolge dabei - wie im Fall der bundesdeutschen Müllpolitik - parallel zu bestehenden Policyarenen. Dabei sei der Politikwandel wesentlich auf den einsetzenden Diskurs im Forum zurückzuführen, der sich u.U. von materiellen Beschränkungen löse. "In the focus of the forum idealistic actors may indeed be more important than materialistic actors." (Braun, Busch, 1999, 194). Gleichwohl dürfe die analytische Unterscheidung nicht als dichotomische mißverstanden werden. Im allgemeinen hätten Konflikte in Policy-Netzwerken keinen Einfluß auf tiefer liegende Aspekte von Policy-Prinzipien respektive Ideen. Wandel träte vielmehr nur auf, "when policy problems generate general questions about the world-view and about the basic principles of policy

${ }^{232}$ Ideen erweisen sich auch bei der Lösung von Blockaden im internationalen Verhandlungssystem als wichtig (Grundmann, 2000). Blockaden entstehen dabei aus Situationen heraus, in denen Akteure ihre Präferenzen und Strategien unabhängig voneinander, aber in Kenntnis der Schritte der anderen formulieren und trotz angebotener Kooperationsmöglichkeiten stur verfolgen. Konträr zur Lösung eines Gefangenendilemmas durch den Versicherungsmechanismus (s. zum assurance game Anhang S. 314) kann eine Blockade nur durch die Hegemonie eines Akteurs (bzw. einer Akteursgruppe) durchbrochen werden (vgl. Grundmann, 2000, 154 ff). Unter der Bedingung von Unsicherheit, die sich auf die zukünftige Wohlfahrt bezieht, erhöhen Ideen gegenüber Interessen die Möglichkeit von Kooperation im (internationalen) Verhandlungssystem. So können Ideen Konflikte über kognitive Orientierungen innerhalb von Institutionen abschwächen (Goldstein, Keohane, 1993, Jachtenfuchs, 1995). Dies eröffnet die Chance zu umfassenden Problemlösungen (mit Ausnahmen und flexiblen Instrumenten) gegenüber technischen Problemlösungen (Anpassungsklauseln) bzw. Verhandlungen (Ausgleichszahlungen). Auf diese Weise können umfassende Problemlösungen, wie im Fall des Ozonschutzregimes, Blockadestrukturen auflösen; Grundmann, 2000, 164 ff. 
actions." (Braun Busch, 194) Braun hat speziell die Untersuchung von solchen Policy-Konflikten angeregt, die sich in ideelle Güterkonflikte transformieren lassen (Braun, 1999, 815).

Es spricht einiges dafür, die Theorie wachsender Ressourcenproduktivität als Idee im Sinne Brauns zu verstehen. Die Theorie ist zwar noch nicht vollständig entwickelt, doch sind bereits hinreichend theoretische Bausteine vorhanden, um sie als Idee zu interpretieren. Wie in Kapitel 3.3.1 dargestellt, kulminiert die ökonomische Storyline des Nachhaltigkeitsdiskurs in dem Streit zwischen den Konzepten starker und schwacher Nachhaltigkeit (Stoffströme vs. Naturkapital). Beide ließen sich dem durch die Annahme einer konstanten Material- und Energiebilanz charakterisierten Paradigma der ökologischen Ökonomie zuordnen. Während das Paradigma der ökologischen Ökonomie die systemische Reflexion der Ökonomik auf moralische Normen widerspiegelt, kann Dematerialisierung als Idee verstanden werden, welche den Rahmen von Ökonomen, Juristen und Bürgern informiert oder nicht informiert, - was eine empirische Frage ist. Die Idee der Dematerialisierung zeichnet sich ferner dadurch aus, daß sie von der Theorie ökologischer Modernisierung den Ansatz der Ökoeffizienz übernommen und weitergeführt hat. Die Ressourcenproduktivitätstheorie bietet die Möglichkeit, ökologisch-stoffliche Indikatoren zu integrieren und gleichzeitig an die ökonomische Wachstumsdebatte anzuschließen. Entgegen dem interdisziplinären Ansatz ökologischer Modernisierung ist die Idee der Ressourcenproduktivität noch stärker auf den Input orientiert, so daß Substitutionspotentiale nicht nur statisch (in bezug auf einen bestehenden Kapitalstock), sondern auch dynamisch erschlossen werden könnten.

Letzteres verweist auf den makroökonomischen Ansatz von Dematerialisierung. In mikroökonomischer Hinsicht nähert sich die Dematerialisierungsidee dagegen wieder stark der Theorie ökologischer Modernisierung an. Der Kampf von Ideen zeigt sich im Abfalldiskurs etwa bei inputorientierten Ansätzen vs. output-orientierten Ansätzen. ${ }^{233}$ Dabei können Positionen fließend sein und sogar das Paradigma bestreiten. (Dies läßt sich in diesem Fall mit dem Verweis auf den präparadigmatischen Zustand der Sozialwissenschaften nicht mehr erklären, da in das Paradigma der ökologischen Ökonomie naturwissenschaftliche Fakten einfließen.) Allerdings schwindet mit Blick auf anstehende Instrumente die Bedeutung des Ideenkampfes wieder.

\subsection{3 Ökologische Kommunikation und Nachhaltigkeitsdiskurs}

Ökologische Kommunikation wirkt nicht nur integrativ, sondern erzeugt auch Differenzen. Eder hat darauf hingewiesen, daß dieser doppelte Prozeß von Integration und Differenzerzeugung durch ökologische Kommunikation bislang kaum analysiert worden ist, "obwohl er zentral für das Verstehen und Erklären der Dynamik ökologischen Handelns in modernen Gesellschaften ist." (Eder, 1997, 55) Mit diesem Problem sieht sich unter anderem die Diskursanalyse konfrontiert.

${ }^{233}$ So hat H. Zimmermann (1993) die theoretische Bezugnahme auf Entropie in der umweltökonomischen Debatte zur Abfallwirtschaft scharf zurückgewiesen. 
In interpretativen Ansätzen der Policyanalyse tritt das Problem von Integration und Differenz etwa beim Konzept der Rahmen/Deutungsmuster (frames) auf. Deutungsmuster bündeln die soziale Empirie und lassen die einfache Tatsache-Wert-Dichotomie der Policy-Analyse hinter sich, indem sie auch Werte integrieren. Folglich begnügt sich das Konzept nicht mit einer empiristischen Epistemologie. $^{234}$ Rahmen beanspruchen, hermeneutisch die Perspektive der Bürger sowie von Wissenschaft und Politik zu erfassen. Rahmung ist "a way of selecting, organizing, interpreting, and making sense of a complex reality to provide guideposts for knowing, analyzing, persuading, and acting. A frame is a perspective from which an amorphous, ill-defined, problematic situation can be made sense of and acted on." (Rein, Schön, 1993, 146) Die Rahmen sind selbstreferentiell, aber interpretierten sich nicht eigenständig. Rahmen könnten unter Umständen relativistische Konsequenzen haben (vgl. Rein, Schön, 1993, 149; Donati, 2001, 169 ff). Hatte Keller (die gemeinsame) Umweltkultur als Resultat von Praxis ausweisen können, sprechen Rein/Schön dagegen von Metanormen für verschiedene Kontexte, die Einigung in Policy-Konflikten erleichtern könnten. Derartige Metanormen sind jedoch, da sie Normen an Werte assimilieren, normativ und damit begründungspflichtig. ${ }^{235}$ Der Nutzen solcher Analysen ist für die Policy-Forschung vielfach dadurch beschränkt, daß '"frames' auf ganzheitliche Erfassungen und Deutungen von Situationen zielen, dagegen einzelnes Tatsachenwissen, Informationen und Daten aus ihren Definitionsbereich herausfallen." (Nullmeier, 1993, 181) In die Diskurstheorie lassen sich Rahmenanalysen jedoch integrieren, wenn sie meta- und mesotheoretisch eingebettet werden können. Die Rahmen von Ökonomen, Juristen und Bürgern wären dann nicht nur interpretativ zugänglich, sondern können auch kritisch hinsichtlich der sie konstituierenden Ideen befragt werden.

Eine dem Problem von Metanormen vergleichbare Schwierigkeit wird bei Hajer deutlich: Der integrative Charakter ökologischer Kommunikation wird durch Verweis auf sozialwissenschaftliche Makrotheorie aufzuzeigen versucht. Trotz ihres analytischen Fundus kann die mesotheoretische Diskursanalyse dabei in Widerspruch zur Makrotheorie (hier: reflexiver Modernisierung) geraten. Dies wird etwa deutlich, wenn Hajer feststellt: "The problem is rather the lack of debate on what an ecological modernisation should mean. [...] The challenge does not concern the goal but the process. The challenge seems to be to think of an organisation of ecological modernisation as a process that allows for social change to take place democratically and in a way that stimulates the creation of an—at least partially_shared vision of the future." (Hajer, 1995, 280) Das Ziel ökologischer Modernisierung kann in einem schwach institutionalisierten Prozeß durchaus verloren gehen. Indem Reflexivität in der sozialen Praxis als Reflexion auf die Bedeutung ökologischer Modernisierung dominierend wird und sich kulturell manifestiert (ebd., 284), kann Hajer zwar in den beiden von ihm gewählten Fällen den modernisierungstheoretischen Gehalt von Becks Theorie in der Praxis der Akteure selbst aufzeigen, doch liefe eine Generalisierung seiner Fälle vermutlich Gefahr, mesotheoretisch erfaßte Praxis mit makrotheoretischem Sinn kurzzuschließen. Hajers

\footnotetext{
${ }^{234}$ Davon etwa kann sich W. N. Dunns (1993) post-positivistische Policy-Analyse noch nicht lösen.

235 Für den politischen Kontext geben Rein/Schön den Glaube an den demokratischen Kapitalismus (sic!) als Metanorm an, was die ökologische Problematik vollkommen ignoriert.
} 
Forderung, den Prozeß ökologischer Modernisierung demokratisch und mit einem geteilten Zukunftsbezug zu gestalten, verweist auf die Notwendigkeit einer weitergehenden institutionellen Strukturierung der Gesellschaft. Hier erscheint das Habermas'sche Theorieangebot Ansätzen überlegen, welche die Differenz zwischen Struktur und Handlung direkt durch kulturelle Erklärungen überbrücken wollen (vgl. Donati, 2001, 146). Allerdings ist in diesem Bereich bisher noch kaum von Habermas' Theorieangebot Gebrauch gemacht worden.

Diskurskoalitionen handeln in der Öffentlichkeit im Schatten der Institutionen des politischadministrativen Systems, wo Dissens und Meinungsstreits an der Tagesordnung sind. ${ }^{236}$ Gleichwohl streben öffentliche Diskurse insofern Konsens an, als sie durch Kritik und Problematisierung Dissens aufzulösen helfen. Dabei wird Konsens nicht Entscheidungskriterium der Politik, sondern bleibt Prinzip der (philosophischen oder makrosoziologischen) Begründung, d.h. des argumentativen, praktischen Diskurses über Gründe. Es läßt sich in diesem Sinne nicht (mit Hajer) davon sprechen, daß Institutionen der Diskursformation vollständig vorauslägen. Das Verhältnis zwischen Lebensform und kommunikativem Handeln ist vielmehr ein reflexives, d.h. es verläuft nicht unidirektional. Demokratische Institutionen spiegeln Lebensformen wider, wie sie praktischen Diskursen entgegenkommen müssen. Der normative Gehalt eines praktischen Diskurses aber ist von der Politikwissenschaft zu berücksichtigen und von der empirischen Wirkung von Debatten und Diskursen und politisch-administrativen Institutionen zu unterscheiden. Die empirische Forschung legt sogar nahe, daß politische Debatten Legitimität nicht ohne weiteres steigern können, insbesondere wenn sie nur formell in den administrativen Prozeß eingebunden sind. Die Ergebnisse der Diskursanalyse fallen, sofern sie längere Zeiträume (und politisch-deliberative Prozesse) analysiert, ungleich positiver aus: Im Abfalldiskurs zeigte sich eine progressive Verschiebung des Meinungsspektrums, und bis zu einem gewissen Grad kann man sogar davon sprechen, daß kulturelle Symbole zusammenfielen. Hajer konnte in seiner diskursanalytischen Untersuchung der Luftreinhaltepolitik der Niederlande und Großbritanniens die Konvergenz der länderspezifischen Politiken um das Konzept ökologischer Modernisierung aufzeigen. Dies kann durchaus als empirischer Hinweis auf den Einfluß von regulativen Prinzipien (Nachhaltigkeit), sozialwissenschaftlichen Theorien (ökologische Modernisierung) oder Ideen (Ressourcenproduktivität) auf politische Debatten verstanden werden.

Bei Brand/Eder/Poferl, Keller und Hajer wird die reflexive Modernisierung in unterschiedlichem Maße zur Fluchtlinie einer widersprüchlichen Moderne. Im Konzept ökologischer Kommunikation wird dazu auf den Risikodiskurs und systematischer auf die institutionelle Dimension verwiesen. Sowohl Hajer als auch Keller beziehen sich auf Becks Theorie reflexiver Modernisierung. Kellers Referenz auf die Becksche Modernisierungstheorie unterscheidet sich von Hajers jedoch dahingehend, daß Modernisierung erst durch das Zusammenspiel der beiden Abfalldiskurse reflexiv wird. Reflexive Modernisierung kann demnach nur für Deutschland und nicht für den singulären 'administrativen Abfalldiskurs' in Frankreich konstatiert werden. Reflexivität resultiert erst aus der

${ }^{236}$ In der Differenzierung von Teilnehmer- und Kommunikationsrollen nennt Peters folgende Teilnehmerrollen als die wichtigsten: Journalisten, Experten, Advokaten, Repräsentanten, Intellektuelle, Prominenz. 
Diskussion zwischen beiden Abfalldiskursen. Anderseits aber schreibt Keller sie "in erster Linie" der öffentlichen Resonanz auf den kulturkritischen Diskurs zu (Keller, 1998, 241 f). Von reflexiver Modernisierung könne gesprochen werden, weil Prozesse der Modernisierung (diskursiv) öffentlich verhandelbar würden und weil ökologische Nebenfolgen von Akteuren als relevant angesehen und in Diskursen zu sozialen Hauptfolgen umdefiniert würden und sich daran dann die Forderungen nach Handeln orientierten (vgl. ebd., 241). Im materialen Ergebnis jedoch seien die Unterschiede zwischen deutscher und französischer Abfallpolitik eher graduell als strukturell, wie Keller konstatiert. Er führt dies auf die Strukturparallele zwischen strukturkonservativem (dt.) und administrativem (frz.) Abfalldiskurs zurück. Beide prägen das materiale Resultat der Abfallpolitik bis zur nur noch graduell verschiedenen Gleichheit. Keller zufolge kann die deutsche Abfallpolitik jedoch als Beitrag zum Prozeß reflexiver Modernisierung verstanden werden, "weil in ihr eine Reflexion auf gesellschaftliche Modernisierungsprozesse erfolgt." (ebd., 288) Als ganzes sei die bundesdeutsche Abfalldiskussion als 'politisierte Kultur ökologischer Kommunikation' zu bezeichnen, was auf eine anstehende 'soziologische Theorie der Institutionalisierung von Umweltkulturen' verweise.

Stellt sich reflexive Modernisierung in der Abfallpolitik damit als Ergebnis einer umweltpolitischen Kultur dar und ist deshalb als Ethos zu verstehen, oder ist der Wandel in beiden Abfalldiskursen - und mehr noch der des strukturkonservativen Diskurses - als (kulturelles) Lernen zu verstehen? Der in dieser Frage liegende entwicklungstheoretische und normative Gehalt klingt auch bei Keller an verschiedenen Stellen an. Er ist aber mit dem Verweis auf Kultur nur schwer normativ und kaum zureichend politologisch einzuholen. So weist der Begriff der Streitarena oder des Präsentationsfelds keinen unmittelbaren Policybezug auf, und die Identifizierung verschiedener, mehr oder weniger statischer Diskurstypen assimiliert beispielsweise auch Policies, die nur symbolische Politik betreiben - anstatt substantiell zu steuern, an den jeweiligen Diskurstyp, ohne eine normative Bewertung vorzunehmen oder den Anspruch in der Policy-Formulierung mit den implementierten materiellen Ergebnissen zu verifizieren. Kellers Analyse bleibt auf der PolicyEbene des Abfalldiskurses vergleichsweise unbestimmt. Eingeschränkt gilt dieses auch noch für Hajers Analyse. Als institutioneller Konstruktivismus, so Hajer (1997), könne die Diskursanalyse zwischen traditionellem Institutionalismus und politologischem 'Verstehen' changieren. In der Tat unternimmt sein Konzept mit den Wechseln zwischen Arena und Bühne eine spannende Wendung hin zu einer induktiven Forschungsmethode, doch bedingt dies eine (narrative) Beobachterperspektive, welche verschiedene Teilnehmerperspektiven einnimmt, ohne eine als angemessenere auszeichnen zu können (normatives Problem) oder die Fähigkeit zu begrenzten Prognosen zu erlangen (epistemisches Problem). Nur die Ex-post-Perspektive ermöglicht ein vermeintlich nichtnormatives Fazit.

Auf kultureller Ebene sind Umweltdiskurse allen drei Studien zufolge effektiv (und könnten so auch als indirekte Bestätigung von Habermas' These einer Rationalisierung der kulturellen Struktur der Lebenswelt interpretiert werden). Doch wie kann die Effektivität von Politiken politikwissenschaftlich beurteilt werden, wenn die policy-relevanten Informationen (monetäre oder 
stofflich-energetische Indikatoren) der politischen Öffentlichkeit gegenüber der Betrachtung einer schwachen, kulturellen Öffentlichkeit in den Hintergrund treten? Die Diskursanalyse hätte hier als Erklärung dann kaum mehr zu bieten als v. Prittwitz' Katastrophenparadox: eine strukturelle Ökologisierung als Resultat von Politiken, die ihrerseits diskursiv - und stärker als bei v. Prittwitz den Prozeß der Institutionalisierung von Politiken beeinflussen soll. Kurzum: Für die Diskursanalyse besteht beim Changieren zwischen verschiedenen Perspektiven auch die Gefahr, nicht zur Institutionalisierung von Politiken beizutragen oder gar in eine Kluft zwischen (symbolischer) Kultur/ Makrotheorie und (materialer) Politik zu konstruieren.

Im Vergleich zu mikrotheoretischen Steuerungstheorien erscheinen mesotheoretische Theorien oft einen schwachen Erklärungsgehalt zu besitzen. Allerdings können die mikrotheoretischen Theorien ihrerseits dafür kritisiert werden, daß sie kaum plausible meso- und makrotheoretische Erklärungen liefern. Für die mikrotheoretisch ansetzenden Sozialwissenschaften scheint darin etwa die Gefahr zu liegen, soziale Phänomene wie Solidarität allein mikrotheoretisch erklären zu wollen, und sie gar nicht - in Verbindung mit mesotheoretischen Erklärungen - als nicht-kooperatives Verhalten verstehen zu können. In der Folge kann dies zu affirmativen Auffassungen von tatsächlich nicht zukunftsfähigen Politikprozessen führen. Dagegen erlaubt die diskursanalytische Methode, gerade auch nicht-kooperatives Verhalten als für eine nachhaltige Entwicklung sinnhaftes und effektives zu verstehen. Viehöver hat gezeigt, wie die Erklärungskraft einer empirisch gut fundierten Mesotheorie wie des akteurzentrierten Institutionalismus durch die Diskursanalyse noch gesteigert werden kann. Mittels kulturgesättigter Narrationen ringen Diskurskoalitionen um Einfluß in der massenmedialen Öffentlichkeit und um die politische Durchsetzung ihrer Werte und Ideen. ${ }^{237}$ Der öffentliche Diskurs bildet dabei den Kontext von Verhandlungen und wirkt auf Diskurskoalitionen und deren Konstellationen zurück. Zivilgesellschaftliche Akteure handeln nicht innerhalb einer einzigen Politikarena (oder eines Politikfeldes), sondern auch im Forum. Deshalb sind Problemdefinition und Lösungsideen für effektive Politiken nicht trivial. Denn Ideen sind bereits für die - auch von Hajer betonte - Problemdefinition relevant. Sie entscheiden etwa darüber, welches Politikfeld für die Lösung eines integrativen Problems wie Nachhaltigkeit überhaupt in Anspruch genommen wird. Sie könnten dabei nahelegen, daß das umfassende Ziel nachhaltiger Entwicklung durch die bestehenden Politikfeldern institutionell unterkomplex repräsentiert wird.

Die beschriebenen, qualitativen Erkenntnisse aus Mikro- und Mesophänomenen erlauben es zweifellos, der Gesellschaft hier zunächst ganz allgemein ökologische Reflexivität zu bescheinigen. Allerdings ist das Verhältnis zwischen Handlungstheorie und Strukturen der Lebenswelt bisher noch unklar. Die wechselseitige Reklamation von Verantwortungsethik für die eigenen und die Zuschreibung von Gesinnungsethik für die fremden Zwecke zeigt beim Abfalldiskurs lediglich die

${ }^{237}$ Viehöver hebt in seiner Studie des Mülldiskurses stark die kulturell-symbolische Dimension der Narrationen von Diskurskoalitionen hervor, wogegen die argumentativ-kognitive Dimension hintansteht. Dies mag dem empirischen Objekt geschuldet sein. Doch zeigt Hajer (2003) der Diskursanalyse den Weg, indem er seine Methode allgemein als argumentative Diskursanalyse bezeichnet. Zweifellos ist bezüglich des Stellenwerts von Argumentationen in der Diskursanalyse noch erheblicher Forschungsbedarf vorhanden. Den bisher einzigen argumentationstheoretischen Ansatz in der Policyforschung hat Dunn (1993) vorgestellt. 
ökologischen Widersprüche des Kapitalismus. Sie erlaubt indes nicht, diese Widersprüche auch handlungstheoretisch einzuholen. In dieser Hinsicht könnte die Brücke zwischen den verschiedenen Erklärungsniveaus in wissenssoziologischen/ -politologischen Ansätzen zu suchen sein, die auf ein mesotheoretische Erklärungsniveau zielen und offen gegenüber mikrotheoretischen Erklärungsansätzen der Politikwissenschaft sind. F. Nullmeier hat hier in integrativer, methodischer Absicht auf die große Bedeutung von Wissensansätzen verwiesen und dazu bemerkt, daß der Wissensbegriff zwar wie der Diskursbegriff problematisch jedoch als Sammelbegriff für verschiedene Policyansätze forschungspraktisch hilfreich sei. Nullmeier spricht sich für ein wissenszentriertes Konzept aus, in welchem "politische Koalitionen als Wissensvergemeinschaftungen begriffen werden." (Nullmeier, 2001, 290)

Wie gesehen konnte Keller die Entstehung von Reflexivität bei der Modernisierung der Abfallpolitik als eine Art kulturelles Lernen deuten. Meines Erachtens weist jedoch auch hier eher Viehövers Ansatz einer policy-orientierten Diskursanalyse die Richtung, denn auf der Policyebene kann Lernen institutionell, d.h. im Wandel der Konstellationen von Diskurskoalitionen im Diskurs, aufgezeigt werden. Gleichwohl bleiben hinsichtlich der Konzeptionalisierung von Lernen noch theoretische Problem für die Diskursanalyse bestehen. Die wechselseitige Begriffsübernahme zwischen Teilöffentlichkeiten und Diskursarenen - was Hajer als 'discursive contamination' bezeichnet hat (Hajer, 1995, 67) - sind nur schwer für politikorientierte Lernkonzepte operationalisierbar (vgl. Nullmeier, 2001, 300 ff). Eine mögliche Lösung der Probleme hat C. Scherrrer (2001) aufgezeigt. Er hat angenommen, daß im Widerstreit zwischen pfadabhängigem Lernen (NIÖ) und Mechanismen institutioneller Auslese (NPÖ) allein die Diskursanalyse eine empirisch gesättigte Theorie liefern kann, welche die internationale Ausbreitung von Institutionen erklärt. So verfolge die NIÖ mit der Annahme pfadabhängiger institutioneller Entwicklung eine These, die hinsichtlich des Beginns einer institutionellen Entwicklung auf Operationalisierungsprobleme stoße, denn dieser könne beliebig gesetzt werden und sich beliebig wiederholen (ebd., 6 f). Dagegen negiere die NPÖ mit ihrer These einer einzig möglichen Entwicklung (one-best-way) staatlicher Institutionen den historischen Entwicklungskontext (ebd., 3 f). Bereits die Annahme internationalen Wettbewerbs müsse keine hinreichende Spezifikation eines Kontextes darstellen. Für einen diskursanalytischen Zugang zu Institutionentransfers ${ }^{238}$ bedeutet dies "das Aufspüren von (a) - temporär - verfestigten Institutionen einschließlich ihrer strukturellen Momente, die einen solchen Transfer ermöglichen bzw. einschränken, und (b) - begrenzt - offenen Situationen, in denen Akteure um erneute Schließung ringen und dabei zugleich in Interpretationsauseinandersetzungen geraten." (ebd., 9) Die systemtheoretischen Annahmen Habermas' entfallen bei Scherrer leider, ${ }^{239}$ denn er orientiert sich an der Diskursanalyse Laclaus und

${ }^{238}$ Neben umweltpolitischen Institutionen könnte sich die Diskursanalyse so auch analytischen Zugang zu Steuerungsinstrumenten verschaffen, so daß in der Folge die Diffusion von (umweltpolitischen) Instrumenten in ihren Blickpunkt rücken könnte.

239 Sehr zutreffend hat dagegen H. Voelzkow (2000, 277 f) die Schieflage im Prozeß der internationalisierten Modernisierung als Systemfolge dargestellt: "In einer systemtheoretischen Perspektive könnte auch von einem räumlichen Auseinanderlaufen gesellschaftlicher Subsysteme gesprochen werden: Einige Subsysteme (wie 
Mouffes. Deshalb schlägt er vor: "Hinsichtlich der Strukturen wäre somit zum einen zu fragen, welche Institutionen eine Konkurrenzsituation schaffen, die auch als solche wahrgenommen wird, die eine 'natürliche Auslese' bewirkt. Zum anderen wäre zu analysieren, von welchen Institutionen Verharrungsmomente ausgehen, die wiederum auch diskursiv wahrgenommen werden." (ebd.) Aus der Habermas'schen Perspektive sind die in Frage stehenden Institutionen als sekundäre Institutionen systemischer Differenzierung (Gimmler) nicht mit eigenständigen Orientierungsinhalten versehen, sondern eröffnen lediglich 'strukturelle Möglichkeiten für die Rationalisierung des Handelns' auf einem neuen Lernniveau (vgl. Habermas, 1981, II, 464). Inwieweit praktische Diskurse von dieser Möglichkeiten tatsächlich Gebrauch machen, ist eine empirische Frage.

Weil Nullmeier kein operationalisierbares Lernkonzept für die Diskursanalyse erkennt, schlägt er der Politikwissenschaft eine empirisch gerichtete Diskursanalyse vor, deren Aufgabe darin bestehen soll, über die Konfrontation von idealem Diskursmodell und empirischen Untersuchungen realer politischer Debatten zu Modellen unvollkommener Diskurse zu gelangen. Nullmeier hat diesen Ansatz später noch zugespitzt und ein Modell skizziert, daß von einer marktanalogen Funktion der Öffentlichkeit ausgeht. So wie ein funktionaler Gleichgewichtsmechanismus nichtentendierte Handlungen zu einem Markt koordiniert, sollen Anbieter und Nachfrager von Informationen zu einer politischen Öffentlichkeit koordiniert sein. Öffentlichkeit wäre demnach kompetetiv und funktional zu beschreiben. Auch wenn derartige Konkurrenzmechanismen empirisch aufgezeigt werden könnten, scheint doch keine funktionale Notwendigkeit zu bestehen, daß verletzte Interessen tatsächlich in Diskursen berücksichtigt oder auf die politische Agenda gesetzt werden. In einer funktional stabilisierten Öffentlichkeit können Akteure allerdings Probleme wahrnehmen und problemlösende Ideen in Diskurse einbringen. Während sich das Agenda-Setting überwiegend an den Folgen und Leistungen der Systeme anschließt, ist die Genese von Problemlösungen und Ideen hingegen kontingent. Die Diskursanalyse eröffnet methodisch den interpretativen Zugang zu diesem Ideativen im kulturellen Resonanzraum.

Damit wird auch die diskursanalytische Annahme einer rein kontingenten Öffentlichkeit verworfen, denn Demokratien weisen der Öffentlichkeit eine politische Funktion zu und versuchen damit auch, sie rechtlich zu institutionalisieren. Aus Sicht der Diskurstheorie legt nicht zuletzt Habermas' Interpretation von Solidarität als zivilgesellschaftliches Äquivalent systemischer Medien eine solchermaßen funktional stabilisierte Öffentlichkeit nahe, dem der Forschungsansatz von Neidhard/Gerhards sehr nahe kommt. Zugleich sind aber einer systemischen Vereinnahmung der Öffentlichkeit seitens der Policy-Analyse Grenzen gesetzt: Die diskursanalytischen Studien weisen alle darauf hin, daß Diskurse bzw. Diskurskoalitionen nicht in der Lage sind, die politische Öffentlichkeit in Gänze strategisch zu vereinnahmen. Zugleich ermöglicht es die diskursanalytische Methode, Akteure der sozialen Funktionssysteme und der Zivilgesellschaft interpretativ 
miteinander zu verbinden und damit dichotomische Vorstellungen hinter sich zu lassen und neue Akteure und Akteurskonstellationen sowie Ideen aufzuspüren.

Nun hat Nullmeier (2001) nicht nur gegen die Diskursanalyse, sondern auch gegen das Ideenkonzept Vorbehalte geltend gemacht. ${ }^{240}$ Gegen die gegenwärtig bestehenden Ideenkonzepte wendet er ein, daß sie den Dualismus zwischen Wirklichkeit und Ideativem wiederholten: Interessen würden als real angesehen und Ideen als fiktiv. Sie erschienen so als weniger reale Phänomene. Diesen Einwand macht er nicht zuletzt gegen die Policyansätze von G. Majone und D. Braun geltend (ebd., 287 ff). Nullmeier schlägt deshalb vor, auf den Begriff der Idee als Grundbegriff einer Wissenspolitologie zu verzichten. Zudem seien, so Nullmeier, Diskurse lediglich Spezifizierungen von 'Wissen', weshalb er Diskursansätze als Teilgruppe der Wissensansätze ansehen möchte.

Während für einen epistemischen Grundbegriff 'Idee' tatsächlich nur wenig spricht, kann auf das analytische, mesotheoretische Potential des Ideenkonzepts jedoch nicht verzichtet werden. Ideen (Ressourcenproduktivität, Differenzprinzip etc.) besitzen $\mathrm{zu}$ reiche normative Geltung und kognitiven Gehalt, als daß sie allein dem Ideativen zugeschrieben werden könnten. Sie finden sich nicht nur in den Überzeugungssystemen von Akteuren und in politischen Verlautbarungen, sondern beeinflussen Politiken direkt, und sei es - wie im Fall des Mülldiskurses - zunächst nur symbolisch. Im Fall des Diskurses zur Nachhaltigkeit könnte die Theorie der Ressourcenproduktivität (Ökoeffizienz) die Möglichkeit beinhalten, Politikfelder und damit bestehende Policybereiche zusammenzufassen. Sie kann dies durch die Referenz auf ein ökonomisches System und den Nachweis eines endogenen Umweltsteuerpfades. Das Ideenkonzept bleiben dabei zwar von Begründungen auf der Makroebene (normative Theorien, Diskurse etc.) abhängig, es geht damit jedoch erkennbar über bestehende Ansätze der Policyforschung, einschließlich des Wissensansatzes, hinaus. So ist die Idee der Dematerialisierung zunächst einmal reflexiv in der Diskurstheorie verankert (vgl. Kapitel 2.2.3). Die Theorie des kommunikativen Handelns greift systemimmanente Kritik auf, wendet sie normativ und zeichnet die entstehenden Paradigmen als kritische Theorie aus. Die Paradigmen der ökologischen Ökonomie und des Umweltstaates können so als systemimmanente Resonanz auf Moral verstanden werden. Während das Paradigma Umweltstaat in der Anwendungsdimension des politisch-administrativen Systems als Kritik an symbolischer Politik bzw. symbolischem Recht weitergeführt wird, ist unter dem Paradigma der ökologischen Ökonomie die Idee der Dematerialisierung entwickelt worden. Für die Diskursanalyse ist diese Idee über den Rahmen von Ökonomen, Juristen und Bürgern interpretativ zugänglich, so daß die Annahme systemischer Resonanz empirisch überprüft werden kann.

Daneben ist die Kritik der Policyforschung an Diskursanalyse und Ideenkonzept auch direkt erwidert worden. Hajer (2003) hat gegen die Policy-Analyse eingewandt, daß sie etwa die institutionelle Leere (institutional void) übergehe, die sich im Verhältnis von policy zu politics

\footnotetext{
${ }^{240}$ Probleme sieht Nullmeier ebenfalls hinsichtlich des Wissensgemeinschaften- und des Tendenzkoalitionen-ansatzes und Konzepten der Rahmung, die er alle dahingehend kritisiert, daß sie einen nicht-realistischen, postpositivistischen Sozialkonstruktivismus der Politikwissenschaften blockierten.
} 
auftue (vgl. auch Benz, 1997). Mit dem Bedeutungszuwachs der internationalen Zivilgesellschaft, infolge der internationalisierten Modernisierung von Gesellschaften, seien Politiken keine unabhängige Variable mehr, sondern würden diskursiv. Dies bedeute, daß Verfahrensregeln für Politiken gesellschaftlich ebenso unklar würden wie die materiellen Inhalte der Politiken. Plötzlich entstehende Politiken fänden oft keine mit den definierten Problemen korrespondierenden politischen Institutionen (politics) mehr vor. Insofern sei von einer institutionellen Leere zu sprechen. Und auch "theories of steering have to be reconsidered in light of new macro-sociological parameters." (Hajer, 2003, 187) Zwar sei im Grundsatz die Aussage 'policies determine politics' (Lowi) nicht zu bestreiten, doch spreche die Policy-Analyse vielleicht nicht mehr 'truth to power'. Es läßt sich allerdings auch im Rahmen der konventionellen Policy-Analyse feststellen, daß Fragen der Verteilungsgerechtigkeit normalerweise außerhalb von etablierten Politiknetzwerken thematisiert werden (vgl. Benz, 1997, 318), und daß deren Institutionalisierung angesichts der vielfältigen potentiellen Verteilungsaspekte von Nachhaltigkeit Not tut. Es geht darum, die stoffliche Seite nachhaltiger Entwicklung in einen Konflikt zu transformieren, der die Unfairneß intergenerationeller Distribution abschwächt. Zur Veranschaulichung ist A. Hirschmanns (1994) Unterscheidung zwischen teilbaren und unteilbaren Konflikten hilfreich. Teilbare Konflikte entzündeten sich an der Verteilung knapper Ressourcen, wohingegen bei unteilbaren Konflikte die Kontrahenten um Anerkennung und Identität kämpfen. Bei teilbaren Konflikten korrespondieren den Anlässen für Konflikte Möglichkeiten der Konfliktschlichtung etwa durch die Zahlung von Geld, Verteilung von räumlichen oder zeitlichen Ressourcen. In diesem Sinne ist nach Institutionen Ausschau zu halten, die einen unteilbaren intergenerationellen Konflikt in einen teilbaren intragenerationellen Konflikt transformieren.

\subsection{Zur Institutionalisierung diskursiv vermittelter Ideen}

\subsubsection{Verteilungsarenen und Agenturen}

Obgleich der Fall des Müllnetzwerkes Anlaß zu steuerungstheoretischer Hoffnung gibt, bleibt die Konzentration prozeduralen Rechts auf Netzwerke zugleich noch der statischen Eigenlogik von Systemen, insbesondere der allokativen Rationalität des ökonomischen Systems verhaftet. Dies muß nicht notwendig in eine nachhaltige politische Steuerung einmünden. Im Sinne des akteurzentrierten Institutionalismus ist zwar die endogene Herausbildung von Verhandlungssystemen aus den Interessen der Akteure erklärbar, doch müssen die mittels prozeduralen Rechts abgesicherten Policyergebnisse nicht notwendig materieller Umweltpolitik überlegen sein. Damit stünde die Gemeinwohlverträglichkeit in Frage. Die Förderung von gesellschaftlichen und intermediären Verhandlungssystemen durch prozedurales Recht könnte im schlimmsten Fall zu einer Form symbolischer Umweltpolitik degenerieren, wenn ganz auf materielle Normen verzichtet werden würde (oder diese formal vom Rechtssystem zurückgewiesen würden) und sich Stoffströme 
und Umweltrisiken nicht im Sinne von Nachhaltigkeit selbstregulativ reduzieren würden. Bisher stellt prozedurales Recht nur unzureichend öffentlichen Zugang zur umweltpolitischen Normsetzung bereit. Zwar müssen durch prozedurales Recht konstituierte Verhandlungssysteme als politische Institutionen des Umweltrechts nicht notwendig permanent auf regulatives Recht und materielle Normen verzichten, doch zeigen Institutionen wie Verhandlungssysteme faktisch eine Pfadabhängigkeit, die nun ihrerseits wieder die Chancen von regulativen Politiken beeinflußt und die sich exogen an Verhandlungssysteme richten muß.

Akteurzentrierter Institutionalismus und institutionelle Ökonomie haben beide darauf verwiesen, daß institutionelle Arrangements, im Gegensatz zu Organisationen, nur höchst eingeschränkt strategisch durchsetzbar seien. Der geeignete Zugang zur Veränderung von Institutionen sei das 'institutional gardening', nicht das 'institutional engineering' (vgl. Scharpf, 1990, 1991). Dies sei zurückzuführen auf die '"path-dependency' der Entwicklung nationaler und sektoraler institutioneller Ordnungen ${ }^{241}$ : jeder einmal eingeschlagene Weg degradiert jeden anderen, der anfangs einmal ebenso in Frage gekommen wäre, zum Abweg, weil - je länger, desto mehr - die Kosten des Übergangs durch ungebahntes Gelände führen und daher erschreckend hoch sind." (Offe, 1989, 770f; vgl. auch Schimank, Werle, 1995b)

Wie bereits der akteurszentrierte Institutionalismus gesehen hat, kann bereits die zeitliche Divergenz von Interessen in nicht-kooperative Handlungsorientierungen übergehen. Dies muß indes nicht notwendig negative Folgen für Policies haben, wenn diese Interessen in Diskurskoalitionen integriert sind und in öffentlichen Diskursen angepaßt werden müssen. Das nicht-kooperative Handeln findet im politisch-öffentlichen Kontext statt und fällt insofern nicht vollständig institutionell ins Leere. Der ökologische Widerspruch des stofflich-ökonomischen Wachstums wird durch Diskurskoalitionen im öffentlichen, politisch konstituierten Raum (Forum) thematisiert und überschreitet dabei die partielle Öffentlichkeit der abfallpolitischen Arena. Dabei sieht sich ein kooperationstheoretischer Ansatz mit dem Problem konfrontiert, daß nicht-kooperatives Handeln politische Transaktionskosten über das Politikfeld hinaus in die Höhe treiben und doch zur Schaffung kollektiver Güter unverzichtbar sein kann. Diese Handlungstendenzen sind teilweise gegenläufig und widersprüchlich, so daß sich die Frage stellt, wie sie institutionell überwunden werden können. Weder scheint hierfür eine einzige institutionelle Lösung (one-best-way) zwingend, noch kann über kooperatives Handeln eine Pfadabhängigkeit (path-dependency) rekonstruiert werden.

Wie dargelegt, hat Braun auf die Bedeutung von Ideen gegenüber Interessen auch in Abgrenzung zur Netzwerktheorie hingewiesen. Auf Indifferenz aufbauende Ideen sind in ihrer institutionellen Ausprägung von Braun (1999) an zwei Institutionen aufgezeigt worden: Zum einen stellt er eine Auslagerung von Arenen aus bestehenden Verteilungsarenen fest, und zum anderen verweist er auf die Möglichkeit zur Ausweitung von Expertenberatung. In den industrialisierten Demokratien sei die wohlfahrtsstaatliche, (distributive und redistributive) Politik nach dem 2. Weltkrieg lange Zeit

241 Zur Pfadabhängigkeit von Umweltpolitik vgl..Häder, Niebaum, 1997. 
durch positive Koordination gesteuert worden. Mit der neoliberalen Wende seien Staatsaufgaben dann teilweise an quasi-autonome, dezentrale Institutionen delegiert worden, die - wie im Fall der Environmental Protection Agency (EPA) in den USA oder der unabhängigen Zentralbanken etc. in einer nichthierarchischen Beziehung zu den staatlichen Institutionen stehen und über ein eigenes Budget verfügen würden. ${ }^{242}$ Im Gegensatz zu redistributiver Politik oder makroökonomischem Management basiere die hinter diesem institutionellen Wandel stehende Ordnungspolitik auf dezentralen Institutionen, die aufgrund ihres Wissens zielgerichtet auf Marktdefizite reagieren könnten.

Braun zufolge brächen solche ordnungspolitischen Institutionen mit dem Zeitzyklus der Regierung und erhöhten die gesellschaftliche Reflexivität durch Rückgriff auf Expertise, weil sie qua Indifferenz außerhalb der bestehenden Werte- und Verteilungsstreits stünden (Braun, 2000, 139 ff). Braun hält deshalb derartige funktionale Agenturen für mögliche Mittler zwischen Partialinteressen und Gemeinwohl. Sie fänden in ihrer normativen Dimension im öffentlichen Forum statt, da in ihnen aufgrund der Irrelevanz des Einzelbeitrags expressives Handeln dominiere und (re)distributive Aspekte keine Rolle spielten.

Wahrend demokratische Legitimität auf politischer Verantwortlichkeit und der Möglichkeit beruht, Ämter durch Wahl neu zu besetzen, ist die Glaubwürdigkeit von Politiken oft von langfristiger Zielverfolgung abhängig. Dies kann, wie sich an der deutschen Müllpolitik zeigt, bereits für die Arenen von Verhandlungssystemen gelten. Majone (1996) hat dies auch für unabhängige Agenturen reklamiert. Deren Glaubwürdigkeit (credibility) würde vor allem darauf basieren, daß sie über weniger diskretionären Spielraum verfügten als Regierungen und deshalb ökonomische Akteure die eigentlichen Regulierungsabsichten nicht unterlaufen könnten (ebd. 3 ff). Majone verwirft einen Funktionsmonismus für Agenturen und verweist darauf, daß bereits der höhere Öffentlichkeitsgrad, die Bindung an Fernziele und die höhere Zahl von Transaktionen gegenüber Firmen die Unabhängigkeit der Agentur sichere. Politische Verantwortlichkeit sei ferner durch Kontrolle sicherzustellen. ${ }^{243}$ Dies bedeute jedoch, "that regulatory instruments should not be used to achieve redistributional or other social policy goals." (Majone, 1994, S. 4) Dieser Ansatz ist insbesondere von der Umweltökonomie aufgegriffen worden und hat zu einer Diskussion über selbstregulative, intermediäre umweltökonomische Institutionen geführt (Endres, 1993), die mit Abgaben/Zertifikaten teilweise ein eigenes Budget generieren und außerhalb der staatlichen Budgethoheit agieren würden.

Derartige parafiskalische Sonderabgaben verstoßen nach langläufiger Meinung jedoch gegen die finanzwissenschaftlichen Haushaltsgrundsätze der Zweckbindung und der Bindung an den Gebietskörperschaftshaushalt, welche auf den Prinzipien der Einheit, Vollständigkeit und Non-

${ }^{242}$ Dies gilt jedoch nicht für die EPA, deren Budget vom Kongreß verweigert wurde, so daß die amerikanische Umweltagentur 1996 für mehrere Monate geschlossen wurden mußte.

${ }^{243}$ Monitoring könne durch eng definierte Ziele, bindende Verfahren, Transparenz, öffentliche Beteiligung, richterliche Überprüfung, Professionalität und peer review erfolgen; Majone, 1996, 18, ähnlich auch Blöchliger, Staehelin-Witt, 1992, 22 ff. 
Affektion des Budgets beruhen. ${ }^{244}$ Zwar kann, da regionale und funktionale Differenzierungen der Staatstätigkeit existieren (vgl. Tiepelmann, 1975), von einer Einheit der Finanzwirtschaft nicht die Rede sein, doch beruht zumindest die parlamentarische Kontrollfunktion auf eben der Einheit und Vollständigkeit des staatlichen Budgets. ${ }^{245}$ Demokratietheoretische Bedenken gegen eine dezentralisierende Fondswirtschaft entfallen nur, wenn die Betroffenen selbst über die von ihnen aufgebrachten Mittel mitbestimmen und diese kontrollieren können, d.h. das Prinzip der fiskalischen Äquivalenz zum Tragen kommt (Schuppert, 1993, 247 f). Obwohl Sonderabgaben in zwei zentralen Bereichen der Selbstverwaltung als Finanzierungsmethode dienen, nämlich der interessensvertretenden körperschaftlichen Selbstverwaltung und der verbandsgesteuerten sozialen Selbstverwaltung der Sozialversicherung, ist die Übertragung auf den Umweltbereich problematisch.

Wie nämlich die ökonomische Debatte zu Nachhaltigkeit zeigt, besteht gerade kein allgemein akzeptiertes Wohlfahrtsmodell mehr, obgleich die umweltökonomischen Ansätze zum Paradigma der ökologischen Ökonomischen konvergieren. Diese kann jedoch die Kosten des Umweltschutzes entweder nur in finanzieller Relation zum gegenwärtigen Kapitalbestand benennen (schwache Nachhaltigkeit) oder sie muß einen nachhaltigen Umfang des ökonomischen Systems pragmatisch anstreben, ohne bei der Umsetzung jedoch entstehende, finanzielle Kosten mißachten zu können (starke Nachhaltigkeit). Praktisch heißt dies, daß sie stofflich-energetische Substitutionspotentiale und Positivsummenlösungen aufzeigen muß. Unter prognostischer Unsicherheit verlieren jedoch Effizienzprinzipien an Bestimmtheit und Ideen gewinnen über das Forum an Bedeutung. ${ }^{246}$ Dies verweist zurück auf Brauns Ansatz und die zwei Bedeutungen von Ideen: Während sich eine unabhängige Umweltagentur auf mikroökonomische Entscheidungen beschränken würde, die

${ }^{244}$ In der Finanzwissenschaft finden sich drei Forschungsrichtungen zum Teilbereich der intermediären Institutionen der Parafiski: die finanzjuristische, etatistische Sicht der Parafiski versteht Parafiski als Ausgliederungen staatlicher Aktivitäten aus dem gebietskörperschaftlichen Budget, das auf das Recht zur Erhebung von Steuern zurückgeht. Das politische System tritt dabei Rechte an eine sich finanziell selbstverwaltende Organisation ab. Die finanzsoziologische, assoziatistische Sicht der Parafiski schreibt die Entstehung von Parafiski kollektiven Interessen zu, die autonom entstehen. Demnach zeichne Selbstverwaltung und Finanzautonomie Parafiski gegenüber dem staatlichen Steuermonopol aus. Politische Relevanz und funktionale Totalrepräsentation unterscheiden sie dagegen von der privaten Sphäre. Der dritte, finanztheoretische Ansatz stellt auf die Kollektivguteigenschaften der parafiskalischen Leistungserstellung ab und bewegt sich in einem teils normativen, teils positiven Forschungsrahmen, der die Existenz und Persistenz von Parafiski vom Öffentlichkeitsgrad des Kollektivguts bestimmt sieht und somit der NPÖ folgt; vgl. Tiepelmann, van der Beek, 1992, 4.

245 Schuppert hat die Binnendifferenzierung von Verwaltung und Staatswirtschaft und ihre mögliche Entsprechung zu nichtsteuerlichen Abgaben näher untersucht und dazu die Arten von Sonderabgaben, die damit finanzierten Aufgaben und die erhebenden, verwaltenden und ausgebenden Organisationen einander gegenübergestellt (Schuppert, 1993). In bezug auf parafiskalische Sonderabgaben folgt er einer Unterscheidung zwischen Hilfsfisken und Gruppenfisken. Bei Hilfsfisken liege ein verwaltungstechnisch bedingter Dekonzentrationsprozeß innerhalb des staatlichen Aufgaben- und Entscheidungsbereichs vor, weshalb deren ausgegliederte Haushalte hilfs-fiskalischen Charakter hätten. Im Fall von Gruppenfiski entstehen dagegen autonome Entscheidungszentren mit einem eigenständigen Aufgaben- und Entscheidungsbereich. Ihre Organisation sei Ausdruck "einer Dezentralisierung der Willensbildung in der Gesellschaft." (Schuppert, 1993, 240) Während Hilfsfiski Veränderungen staatlicher Steuerungsstrukturen nur folgten, könnten Gruppenfiski derartige Veränderungen selbst auslösen.

${ }^{246}$ Es ist jedoch erstaunlich und erschreckend zu sehen, wie sehr z.B. die Debatte über Klimapolitik in den USA durch Resentiments gegen Entwicklungsländer geprägt und von konservativer Seite sogleich als kostenreiches Nullsummenspiel interpretiert und später mit breiter Kongreßmehrheit legislativ erlassen wurde. Als Folge dieser Problemdefinition sehen sich die Naturwissenschaften in den USA z.T. erheblicher politischer und ökonomischideologischer Einflußnahme ausgesetzt; vgl. Tänzler, 2002. 
weitestgehend der Indifferenz von Konsumenten folgt, zielt die Idee der Dematerialisierung auch makroökonomisch auf Nachhaltigkeit, ja behaupt sogar, daß Nachhaltigkeit ohne makroökonomische Umweltpolitik nicht zu erreichen ist (Daly, 1991). ${ }^{247}$ Doch während Braun als Beispiel einer erfolgreichen makroökonomischen Idee noch die keynesianische Politik der siebziger Jahren anführen kann, ist diese Idee im Nachhaltigkeitsdiskurs zerbrochen. Den Gegensatz zwischen Wachstum und Nachhaltigkeit kann der Keynesianismus nicht auflösen. Zwar gibt es explizit post-keynesianische Ansätze in der ökologischen Wirtschaftspolitik (vgl. dazu Gowdy, 1991; Mathieu, 1993), doch sind zumindest die Konzepte makroökonomischer Globalsteuerung nicht gesellschaftlicher Konsens. Eine über den normalen Politikfluß hinausgehende ökologische Ordnungspolitik (vgl. Kapitel 3.6) berührt schnell fundamentale Weltanschauungen. Zwar ist eine solche Ordnungspolitik im Paradigma der ökologischen Ökonomie verankert, doch können die Argumente für eine solche Politik immer aus ideologischen Motiven heraus ignoriert werden können. Dies schränkt das Potential einer makroökonomischen Idee der Dematerialisierung ein. Deshalb vermeiden delegierte Ordnungsfragen in der Regel auch den Zielkonflikten zwischen Wachstum und Nachhaltigkeit. Nach Beck (1993) sind jedoch sie Ursache für die normativmoralischen Probleme der Gegenwart, weshalb Delegation zunehmend schwieriger werde.

Parallel, doch bisher ohne Bezug zu Agenturen und intermediären Institutionen ist der Vorschlag einer Umweltzentralbank (UZB) in die Diskussion gebracht worden. Diese soll umweltpolitische Ziele wiederum in größtmöglicher Unabhängigkeit vom politisch-administrativen System verfolgen. Der Vorschlag einer UZB geht auf H. Blöchliger und E. Staehelin-Witt zurück und wurde im akteurstheoretischen Rahmen der NPÖ begründet. ${ }^{248}$

Demnach soll die Umweltzentralbank weitgehend unabhängig vom direkten Einfluß der Regierung agieren. Dazu müßte ein Umweltzentralbankengesetz den Tätigkeitsbereich und den Handlungsrahmen der Umweltzentralbank regeln und so ihre rechtliche Unabhängigkeit sicherstellen. $^{249}$ Das Gesetz würde darüber hinaus die Struktur, die Trägerschaft und das Instrumentarium der Institution bestimmen. Eine Umweltzentralbank stünde außerhalb der Verwaltungshierarchie und könnte dezentral bzw. föderal aufgebaut sein. Würde das Instrumentarium ökonomische Instrumente umfassen, hätte die Umweltzentralbank einen

${ }^{247}$ Agenturen, die das ökonomische System auch makroökonomisch regulieren, sind natürlich vor allem dann interessant, wenn sich Ressourcenproduktivität auch zentral steigern ließe. Eine erfolgreiche Implementation bleibt jedoch immer insofern von dezentral handelnden, ökonomischen Akteure abhängig, als daß nur aufgrund ihrer wirtschaftlichen Freiheit ökoeffektive Innovationen und damit ein autonomer Steuerpfades entlang von Ressourcenproduktivitätsgewinnen erwartet werden kann.

248 Blöchliger/Staehelin-Witt unterscheiden zwischen politischem Grundkonsens (Umweltziele) und prozeßpolitischer Ebene (Umweltschutzmaßnahmen). Zwar folgen sie wie M. Stewens der NPÖ (s. S. $261 \mathrm{ff}$ ), doch im Unterschied zu ihm setzen sie den Grundkonsens auf der Verfassungsebene an. Die institutionellen Arrangements, die Stewens zur Grundkonsensebene rechnet, liegen bei ihnen auf der prozeßpolitischen Ebene. Die Probleme der Umweltpolitik ließen sich zurückführen auf die GD-Situation bei dem öffentlichen Gut Umwelt und die ausgeprägte Asymmetrie der Interessen (Olson) bei der Zerstörung von Umwelt. Deshalb sei die Umweltpolitik von der Prozeß- in die Ordnungspolitik zu überführen, wozu sie eine Umweltzentralbank für die Ebene des Grundkonsenses vorschlagen. Diese soll als zentrale Institution der ökologischen Ordnungspolitik dienen und die umweltpolitische Implementation vor Rent-seeking-Einflüssen schützen.

249 Je nach Grad der Autonomie einer solchen Umweltzentralbank könnten natürlich auch Verfassungsänderungen erforderlich werden. 
parafiskalischen Charakter. Die Regierung hätte nur formale Kontrollbefugnisse (Wahl, Statuten, etc.), die im Gesetz festzulegen wären (vgl. Blöchliger/Staehelin-Witt, 1992, 22 ff). Die Autoren gehen davon aus, daß eine Umweltzentralbank sich automatisch - d.h. eigennützig - wohlfahrtsmaximierend verhalten würde, sofern die Anreize und Restriktionen richtig gesetzt seien (Blöchliger/Staehelin-Witt, 1992, 42).

Auch Tiepelmann/Frick empfehlen einen zentralen Ökoparafiskus. Zwar scheinen sie prinzipiell eine breite Anwendung - sowohl bezüglich des umweltpolitischen Einsatzfeldes als auch hinsichtlich der Instrumente (Tiepelmann, Frick, 1996, 334, ff) - für möglich zu halten, sie sprechen sich jedoch nur im ökologisch zentralen energetischen Problembereich für einen zentralen Umweltparafiskus aus. In diesem Bereich halten sie ihn konkurrierenden etatistischen Energieabgabevorschlägen jedoch für überlegen. Ähnlich diskutieren Blöchliger/ Staehelin-Witt zwar auch die Anwendung von ordnungsrechtlichen Instrumenten durch eine Umweltzentralbank, bevorzugen aber eine mengenorientierte Globalsteuerung durch Preis-Standard-Steuern/-Zertifikate, die ihnen zufolge Analogien zur Geldpolitik einer Notenbank aufweise (Blöchliger/ Staehelin-Witt, 1992, 27 ff; vgl. auch Baumol/ Oates, 1971, 50; Tiepelmann, Frick, 1996, 334 ff; Minsch, 1994; Ewers, Rennings, 1996, 430).

Auch Tiepelmann und Frick verweisen auf eine solche ökologische Globalsteuerung (des energetischen Bereichs), die sie im Sinne einer 'Ecological Functional Finance' begründen. Wie die 'Functional Finance', welche den fiskalischen Zweck der Besteuerung ignoriert, und allein die Kaufkraft der Steuerzahler regulieren will, würde die Ecological Functional Finance die Kaufkraft der Steuerzahler durch die mikroökonomische Veränderung der relativen Preise in Richtung Energieeffizienz steuern. Der Funktionsmonismus (Abgaben/Zertifikate), die Zurückweisung jeder Finanzierungsfunktion und die umweltpolitische Zielexplikation durch die Umweltzentralbank könnten eine solche Globalsteuerung prinzipiell erfolgreich realisieren.

Stewens (1998) hat in diesem Zusammenhang auf das Tinberg-Theorem verwiesen, wonach zur Vermeidung wirtschaftspolitischer Zielkonflikte die Zahl der einzusetzenden Mittel der Zahl der zu erreichenden Ziele entsprechen soll, wobei die wechselseitige Unabhängigkeit der Instrumente sichergestellt werden muß. Diese Forderung läßt sich auch auf Institutionen übertragen. Daly hat das Theorem erstmals auf die Umweltpolitik angewandt und Allokation und Distribution vom Umfang unterschieden (vgl. Kapitel 3.3.2). Stewens erwartet nur durch eine unabhängige Institution der Umweltpolitik die flächendeckende Implementation effizienter, ökonomischer Instrumente. Allerdings räumt er ein, daß die bisher fehlende Operationalisierbarkeit der heterogenen Umweltziele ein Hindernis für eine Umweltzentralbank darstelle und zu ihrer Politisierung führen könne, was aber auch auf das Analogon der Europäischen Zentralbank zuträfe.

Tiepelmann/Frick übergehen in ihrem Ansatz einer Ecological Functional Finance teilweise, daß jede interne Zielsetzung der Umweltzentralbank diese in hohem Maße politisieren würde, wenn diese Zielsetzung entweder kognitiv relativ unbestimmt bliebe und nicht ins Forum getragen oder 
mit anderen wirtschaftlichen Zielen konfligieren würde. ${ }^{250}$ Die Analogie zwischen Umweltzentralbank und Notenbank würde spätestens in Konflikten zwischen Nachhaltigkeit und Wachstum ihre Grenze finden. Für einen von Versuch und Irrtum bestimmten Abgabenpfad, wie er aufgrund des Informationsproblems bei Umweltstandards zu erwarten wäre, scheint auch eine Blockade möglich. Diese könnte zwar durch entsprechende interne Abstimmungsregeln vermieden werden, doch dürfte sich der Konflikt dann in die externe, symbolische Dimension der Umweltzentralbank verlagern und dort ihre öffentliche Legitimation untergraben, wenn progressive Abgabenziele nicht durch Diskurskoalitionen im Forum getragen würden. Die einfache Analogie zwischen Umweltzentralbank und Notenbank übersieht den andauernden Zielkonflikt zwischen Wachstum und Nachhaltigkeit und dessen sozioökonomische Tragweite.

\subsubsection{Diskursive Entzerrung der Agenda einer UZB}

Für die Deliberation zu Umweltabgaben einer UZB scheinen die vorangegangenen Überlegungen nahezulegen, Zielsetzung und Implementation entweder zeitlich voneinander zu distanzieren, oder aber die Zielsetzung doch Experten zu überantworten - beispielsweise durch Initiativrecht. In letzterem Sinne könnte die Politisierung einer Umweltzentralbank etwa durch deren Orientierung an Bleischwitz' Ressourcenproduktivitätstheorie mit entscheidungsbegleitenden empirischen Elastizitätsanalysen verhindert werden. Der über die Ressourcenproduktivitätstheorie endogen zu realisierende, durch Elastizitätsanalysen zu konkretisierende Abgabenpfad wäre in diesem Sinne nicht Meritorisierungsansatz, der auf die Bereitstellung eines öffentlichen Gutes (Natur) zielt, sondern Selbststeuerungsversuch eines wachsenden Wirtschaftssystems. Die Umweltzentralbank wäre dann als ökonomische Institution anzusehen und dem ökonomischen System endogen. Sie bliebe jedoch von ihrer Einbindung in das Rechtssystem eingewiesen und wäre nur bedingt politisch verantwortlich. Auch die durch sie konstruierten öffentlichen Güter und Instrumente blieben auf Recht angewiesen. Doch im Unterschied zu der angesprochen Policyfixierung der ordnungsrechtlichen Umweltökonomie (s. S. 187) würde eine Umweltzentralbank im prozeduralen Umweltstaat einen qualitativen Sprung hin zu Politics bzw. zur Polity bedeuten. Im Sinne des Habermas'schen Prozeduralismus könnte so den diskursiv nicht-idealen Bedingungen der Systeme eher Rechnung getragen werden.

250 Tiepelmann (1994, 84 ff) ist aber an anderer Stelle näher auf die damit verbundenen Probleme eingegangen. Basierend auf den Annahmen der NPÖ (über Regierungen, Parteien, Bürokratie, Verbände und Wähler) identifiziert er drei Bereiche drohenden Parafiskusversagens durch ein falsches Maß diskretionären Spielraums. Um interne Verhandlungsprozesse mit Einigungen auf ineffizienten Umweltstandards und die potentielle Blockade des Ökoparafiskus zu vermeiden, sollten die Umweltqualitätsziele extern (und gesetzlich gesichert) vorgegeben (und durch ein Vorschlagsrecht des Umweltbundesamtes ergänzt) werden. Weiter sollte die Finanzierung des Ökoparafiskus aus dem staatlichen Budget bestritten werden, um die Gefahr einer administrativen Verselbständigung des Ökoparafiskus zu verhindern. Schließlich ist der Modus der Rückerstattung der erzielten Einnahmen für die Funktionsfähigkeit des Ökoparafiskus besonders wichtig, da er Rent-seeking-Verhalten hervorrufen könnte. Hier kann die Regel, daß das gesamte Aufkommen rückzuerstatten ist, finanzielle Begehrlichkeiten (Subventionen, Investitionen, etc.) ausschließen. 
Wie bereits angesprochen, stellt die zeitliche Entzerrung von Zielsetzung und Implementation eine Möglichkeit der Überwindung von Blockaden dar. In diesem Sinne ließe sich die Setzung von Umweltzielen für eine UZB etwa in die Umweltplanung aufnehmen (vgl. S. 188). Umweltpläne würde Ziele für die UZB festlegen, die diese durch entsprechende Abgaben zu verwirklichen hätte. Umweltqualitätszielsetzung und Steuer-/Zertifikatimplementation wären im Anschluß an Scharpfs Hypothese zur Auflösung des battle of the sexes institutionell zu trennen (s. S. $205 \mathrm{ff}$ bzw. Anhang 314) und der deliberative Prozeß für Diskurskoalitionen zu öffnen, so daß Handlungsfähigkeit gegenüber dem funktional verselbständigten ökonomischen Systemen zurückgewonnen werden könnte. Dabei müßte jedoch der Instrumentenmonismus aufgegeben werden, da sich Umweltzustände nicht durch den generalisierten Einsatz von Umweltabgaben sicherstellen lassen. Außerdem sind (in Abhängigkeit zur Steuerungstiefe) noch immer politische Widerstände gegen Umweltplanung zu erwarten, die sich innerhalb des politisch-administrativen Systems nur noch rechtlich äußern könnten und dabei zwangsläufig ohne expressive öffentliche Resonanz (Aufmerksamkeit und Solidarität) blieben.

Insofern ist die von Schmalz-Bruns u.a. unter Berufung auf die Umweltpolitikforschung anempfohlene zeitliche Distanzierung von Agenda-Setting und Entscheidung für parallel institutionalisierte Institutionen beschränkt. Dabei geht Schmalz-Bruns' Ansatz sogar noch über Scharpfs Empfehlung hinaus, Produktion und Distribution voneinander zu trennen, und verwies auf das ideative Moment in der Politik. Der Ansatz erlaubt deshalb bereits, epistemische Unsicherheit zu berücksichtigen, wohingegen im Politikfluß die Anerkennung epistemischer und ökologischer Unsicherheit permanent durch die Reinterpretation von Unsicherheit in Distribution (z.B. durch die Monetarisierung von Natur, falsche Politik und Politikberatung und naturwissenschaftlich falsche Überzeugungssysteme, etc.) gefährdet ist. Insofern kann die temporale Entzerrung von Thematisierung und Entscheidung umweltpolitische Entscheidungen mit distributiven Folgen erleichtern; der Erfolg hängt dabei jedoch entscheidend von der zu erwartenden Steuerungstiefe ab. Hinsichtlich einer Globalsteuerung von Stoffströmen sind Wirkungsprognosen/ Modellierungen noch vielfältigen Informationsproblemen ausgesetzt, die sich angesichts der Emergenz des Stoffstroms reproduzieren und potenzieren. Die Überweisung einer stofflichen Globalsteuerung an parallel arbeitende umweltpolitische Ökoparafiski kann vor dem Hintergrund prognostischer Unsicherheit nicht zwingend überlegeneren Sachverstand geltend machen. Wenn jedoch schon wissenschaftliche Reflexivität die institutionelle Reflexivität des politisch-administrativen Systems nicht wesentlich erhöhen kann, ist dann soziale Reflexivität überhaupt noch denkbar, zumal diese konsumtive Aspekte in die nachhaltigen Entwicklung einschließen muß?

Die Diskursanalysen von Keller und Viehöver haben gezeigt, wie lebensweltliche Strukturen (Kultur) reflexiv werden und sich in der Folge Institutionen wandeln können. Auf systemischer Ebene zeigt insofern bereits institutioneller Wandel Reflexivität auf. Doch dieser kann, selbst wenn er rechtlich institutionalisiert ist, noch symbolisch bleiben, d.h. material-rechtlich leer oder ineffektiv sein. Einer solchen Gefahr ist eine zentrale Umweltzentralbank vor allem dann 
ausgesetzt, wenn sie nicht die entsprechende zivilgesellschaftliche Solidarität erfährt. Insofern ist Habermas' Konzept der antiradialen Deliberation hier nochmals heranzuziehen.

Schmalz-Bruns hat gegen dieses Modell insbesondere eingewandt, daß das systemtheoretische Verständnis von Recht Habermas den direkten Zugang zu politischen Institutionen verstelle. Aus diesem Grund befürworte Habermas serielle politische Institutionen und folge dem Repräsentativmodell. Zumindest der generalisierte Einwand, daß das mediale Verständnis von Recht die Entwicklung der Diskurstheorie beschränke, ist, wie gezeigt wurde (s. S. 256 f), unzutreffend. Es ist einer der entscheidenden Vorteile der Diskurstheorie, daß Habermas' Rechtstheorie moralische Normen, Klugheitsregeln und nichtmoralische, kollektive Güter unterscheidet. Ausgehend von einer Öffentlichkeit, die Probleme zunächst einmal wahrnehmen muß, um sie überhaupt politisch zu thematisieren, müssen politische Programme rechtlich formuliert werden. Diese versuchen, die soziale Integration der Gesellschaft wiederherzustellen, indem sie den Einfluß der Systeme zurückdrängen. Bezüglich der rechtlichen Politikformulierung ist die Aufgabenstellung somit eine doppelte: Einerseits muß die Anwendbarkeit der Gesetze sichergestellt werden, während gleichzeitig die Abkoppelung der Rechtsanwendung von der Lebenswelt unterbunden werden soll.

Eine kritische Diskursanalyse schließt deshalb an die unstete, schwache Öffentlichkeit an und verweist über das Medium 'Recht' auf das politisch-administrative System und die starke Öffentlichkeit. Da die Folgen des industriellen Metabolismus erst in der Zukunft auftreten werden, ist die öffentliche Wahrnehmung der Umweltzerstörung nur kommunikativ möglich. Solchermaßen sprachlich-argumentativ vermittelt, lassen sich reflexive Paradigmen in den Systemen der Gesellschaft konstatieren. Insofern spiegelt die Unterscheidung zwischen moralischen Normen und kollektiven Gütern, deren Etablierung im Gegensatz zu Normen auf vorgängigen Systemleistungen beruht, die Möglichkeit sozialer Reflexivität überhaupt wider (s.o. S. 158). Bereits einfache Mehrheiten sind ausreichend, um kollektive Güter (im Sinne nachhaltiger Entwicklung) zu etablieren. Diese Annahme wird dadurch bekräftigt, daß wohlfahrtsstaatliche Effizienzkriterien (als bloße Klugheitsregeln) nicht direkt modernisierungsfähig erscheinen (vgl. dazu Peters, 1991, 93 ff). Sie bleiben vielmehr der Eigenlogik des ökonomischen Systems verhaftet. Kollektive Güter werden nicht durch Konsensprinzip (so Buchanan, 1975, 35 ff), sondern durch Mehrheitsregel in das Rechtssystem aufgenommen. Daß diese begründungstheoretische Figur politisch aktualisiert wird, ist eine empirische Herausforderung. Zweifellos hängt das Gelingen von einer ökologischreflexiven Kultur und entsprechenden Sozialisations- und Individualisierungsleistungen ab.

Diese theoretischen Annahmen werden von empirischen Beobachtungen gestützt, die nahelegen, daß Deliberation (starke Öffentlichkeit) kaum sinnvoll zur Genese moralischer Normen beitragen kann (vgl. Gerhards, 1997). Deshalb hat Nullmeier (1993, 1995) denn auch vorgeschlagen, Deliberation ganz von dieser Aufgabe zu entlasten. Diesem Vorschlag wurde hier gefolgt, indem ethisch-moralische Reflexivität als Genese von Paradigmen im ökonomischen und im politischadministrativen System verstanden wurde. Nur vor dem Hintergrund dieser systemischen Resonanz auf Moral erscheint individuelle Verantwortung überhaupt zumutbar. Eigenverantwortung bleibt 
von kollektiven Verwirklichungschancen abhängig. In diesem Sinne sind deliberative Verfahren nicht auf moralische, sondern auf kollektive Güter auszurichten. Die Bedingungen von Öffentlichkeit, d.h. demokratische Rechtstaatlichkeit und Partizipationschancen, liegen kollektiven Gütern voraus. Nur so kann Nachhaltigkeit ohne produktivistischen Fehlschluß im öffentlichen Diskurs entworfen und im Rechtssystem konstituiert werden.

Schmalz-Bruns' Modell reflexiver Demokratie reagiert auf den schwindenden politischen Gehalt der Öffentlichkeit mit der Forderung radikalisierter Partizipation in politischen Arenen. Diese Ausweitung von Partizipationsmöglichkeiten soll dabei auch die Entwicklung des Umweltstaates fördern. Partizipation ist jedoch immer auch zwingend selektiv: Policyarenen sind begrenzt. Peters (2001) hat daraus den Schluß gezogen, Partizipationsansprüche wieder abzuschwächen. Lediglich Nutzerrollen sollten strikt dem Gleichheitsgebot folgen. Peters macht für diese Forderung u.a. Probleme sozialer Begleitforschung geltend: Empirisch sei die Stratifikation von Arenen kaum zu fassen; sie könne allenfalls - wie bei Nullmeier - kompetitiv beschrieben werden. Damit stößt allerdings auch Peters auf den Einwand, daß Partizipation zwar funktional enger an das politischadministrative System und das Rechtsmedium als an die plurale Öffentlichkeit gebunden ist, daß jedoch in der Demokratie Partizipation nicht von der allgemein zugänglichen, schwachen Öffentlichkeit abgeschottet werden kann. Deshalb setzen neben den Arenen im Forum immer wieder kontingent Diskurse ein, die von Partizipationsbegehren begleitet werden. Bezogen auf öffentliche Umweltgüter einer Umweltzentralbank könnte Peters Vorschlag, Nutzerrollen egalitär zu verteilen und entsprechende Zugangschancen institutionell zu eröffnen, mit der Ausweitung von Partizipation bei der Schaffung öffentlicher Güter zusammenfallen. Nämlich dann, wenn die Ziele einer UZB demokratisch bestimmt würden. So erlassene Umweltziele würden dann materiell öffentlichen Gütern entsprechen. Ob der Umweltstaat allgemein besseres materiales Umweltrecht durch Partizipation zu produzieren vermag, bleibt eine hiervon zu unterscheidende, offene empirische Frage.

Frey und Kirchgässner haben vorgeschlagen, deliberative Prozesse über kollektive Güter in Volksabstimmungen einmünden zu lassen. Gegen die falschen Konsenserwartung der NPÖ wenden sie etwas krude ein, daß bei Entscheidungen über distributive Programme gar kein Konsens zu erwarten sei. ${ }^{251}$ Die Begründung deliberativer Verfahren durch die NPÖ muß versagen, wenn "Umweltpolitik als Ordnungspolitik versucht, durch entsprechende institutionelle Arrangements den Öffentlichkeitsgrad des Gutes Umwelt zu reduzieren" (Meyerhoff, Petschow, 1996, 216). Denn dies würde bedingen, daß Umweltpolitik ihre eigenen Grundlagen untergräbt, indem sie neben der Nutzung auch die Visibilität von Umweltgütern reduziert. Umweltpolitik und kollektive Umweltgüter sind jedoch zwingend auf öffentliches Bewußtsein angewiesen. In diesem

251 Die beiden Authoren kritisieren Habermas' Konsenserwartung und weisen darauf hin, daß Habermas selbst dort, wo er auf das Prinzip der Volkssouveränität eingehe, Volksabstimmungen nicht beachte und sich ganz auf den Parlamentarismus beschränke (Frey, Kirchgässner, 1993, 133). Zwar beziehen Frey und Kirchgässner die Diskurstheorie sogar in ihr Programm ein, indem sie auf die Bedeutung politischer Diskurse im Vorfeld von Volksabstimmungen verweisen; dennoch scheint eine Verbindung beider Ansätze angesichts der Ahistorizität der NPÖ kaum möglich (vgl. Offe, 1990a). Ihre Kritik an Habermas ist gleichwohl berechtigt. 
Zusammenhang ist an Deweys Modell der Öffentlichkeit zu erinnern, auf das sich Schmalz-Bruns so nachdrücklich bezogen hat. Eine nachhaltige Stoffpolitik in Form von Steuern/Zertifikaten ist kollektiv-kognitiv vorraussetzungsvoll, auch wenn sie mit dem MIPS-Konzept einfach darstellbar ist. Der Öffentlichkeitsgrad eines Umweltgutes wird nicht objektiv determiniert, sondern insofern sozial konstruiert, als distributive und ideell-kollektive Dimension des Umweltgutes institutionell voneinander getrennt werden. Dabei ist handlungstheoretisch an Diskurskoalitionen in öffentlichen Diskursen die Erwartung gebunden, Fenster der Gelegenheiten zur politischen Fortführung der Stoffstromökonomik zu öffnen. Ökoparafiski könnten dazu beitragen, diese politischen Anstöße zur Schaffung kollektiver Umweltschutzgüter institutionell zu kanalisieren und sie damit von der Bürde der systemischen Logik zu befreien.

\subsubsection{Direktdemokratisch bestimmter Steuerpfad}

Innerhalb der systemischen Logik der Ökonomie könnte die Funktionstüchtigkeit eines Ökoparafiskus jedoch noch dadurch unterstützt werden, daß dieser durch einen Funktionsmonismus (einzig Stoffstromabgaben/ -zertifikate) für expressives Handeln geöffnet werden würde, und das stoffpolitische Agenda-Setting unabhängig vom demokratischen Wahlzyklus stattfinden würde. Die Unabhängigkeit eines umweltökonomischen Parafiskus vom Wahlzyklus der Demokratie würde eine große Visibilität bedingen. Ein Funktionsmonismus würde dabei die Zerstreuung distributiver Einwände erleichtern. Aufgrund von Indifferenz gegenüber einer Vielzahl von geringfügigen Stoffflüssen könnten Abgaben auf diese Stoffströme ein hohes Maß an Zustimmung erfahren. Distributive Erwägungen dürften dabei solange hinter allokativen zurückbleiben, wie etwa nach dem Differenzprinzip (und Kaldor-Hicks-Kriterium) pareto-verbessernende Politiken durchgeführt werden können. Eine Blockade des Agenda-Settings durch distributive Aspekte wäre so kaum zu befürchten. Die Unabhängigkeit einer UZB in Verbindung mit dem Funktionsmonismus wäre Garant für die reflexive Reproduktion einer stoffpolitischen Agenda in der breiten Öffentlichkeit: Nicht das Politikum von Umweltabgaben auf Massenströme, sondern die Indifferenz gegenüber Umweltabgaben auf Stoffflüsse würde die Fortentwicklung der Stoffstromagenda bestimmen. Die Agenda bliebe kognitiv auf die Idee der Dematerialisierung bezogen und würde die Ökoabgabendebatte den exklusiven ökonomischen und juristischen Expertenzirkeln entreißen und weitgehend unabhängig von politischen Wahlkämpfen, Konflikten innerhalb des Kabinetts (vgl. Fürst, 2002, 181 ff), Lobbying und bestehenden Vetopositionen (Scharpf, 2000, 225 ff) stattfinden und so für die Solidarität zivilgesellschaftlicher Akteure öffnen.

Zwar ließe sich der kognitive Kern der Ressourcenproduktivitätstheorie auch so an Volksinitiativen binden, daß die Regression des Steuerpfades (fall-back) verhindert werden würden - womit der Steuerpfad irreversibel wäre - doch stünde dies im Widerspruch zum Informationsdilemma: Technisch und logistisch induzierte Steigerung der Ressourcenproduktivität lassen sich ex-ante nicht sicher prognostizieren, während soziale Steigerungen der Ressourcenproduktivität erst im Zusammenspiel von Parlament und Volksinitiativen entwickelt würden. Zwar würde ethisch nur 
ein steigernder Steuerpfad der Endlichkeit von Ressourcen Rechnung zollen, doch sind die funktionalen Restriktionen von Recht und Ökonomie - etwa hinsichtlich der Elastizität und der Substitution von Stoffen oder zukünftiger Rechtssprechung - nicht vollständig zu antizipieren und die praktizierte Solidarität mit nachfolgenden Generationen kaum vorab abzuschätzen. Dies spricht gegen Fall-back-Beschränkungen der Volksinitiative.

Gleichzeitig würde ein auf die Idee der Dematerialisierung bezogener Funktionsmonismus auch die Möglichkeit symbolischer Politik aufgrund der ökologischen und ökonomischen Wirkungsweise von input-orientierten Stoffstromabgaben stark reduzieren. Abgaben sind vergleichsweise zielsicher und effektiv. Allerdings bestünde in Abhängigkeit von der Art der Zielfindung auch die mehr oder weniger ausgeprägte Gefahr der ökologischen Ineffektivität eben aufgrund des systematischen Ausweichens auf Low-Cost-Entscheidungen. Wenn erwartet werden kann, daß vornehmlich Minimalströme steuerlich verteuert werden, während Massenströme unbelastet bleiben, sind Befürchtungen hinsichtlich der Steuerungstiefe berechtigt. In diesem Zusammenhang könnte sich bei der Thematisierung von Abgaben auch wieder eine Fokussierung und in der Folge Beschränkung auf riskante Stoffströme einstellen.

Die individualistisch ansetzende Umweltsoziologie hat zu zeigen versucht, daß hohe Kosten ökologisches Bewußtsein insofern trüben können, als daß hohe Belastungen (finanzielle, zeitliche und soziale) ökologisches Verhalten systematisch in Bereiche drängen würden, die durch niedrige Kosten charakterisiert seien (vgl. Preisendörfer, Franzen, 1996, Diekmann, Preisendörfer, 1998a). ${ }^{252}$ A. Diekmann und P. Preisendörfer haben (1998b) ihre Hypothese anhand umfangreicher Daten zum ökologischen Bewußtsein in Deutschland zu belegen versucht. Für ihre These spricht die bereits erwähnte Beobachtung, daß sich die bundesdeutsche Ökosteuerdebatte von Beginn an auf Makroneutralität festlegte - und sich selbst die zivilgesellschaftlichen Politikvorschläge darauf beschränkten (vgl. Richter, 1995).

Die Gefahr eines solchermaßen ökologisch ineffektiven Steuerpfades könnte durch die Art der Aufkommensverteilung gemindert werden. Im Unterschied zu Functional Finance kann nämlich die Ecological Functional Finance den Zielkonflikt zwischen notwendigem fiskalischem Aufkommen und nichtfiskalischer Zielsetzung vermeiden, indem das Aufkommen direkt wieder ausgeschüttet wird (vgl. Mathieu, 1993). Bereits Blöchliger/Staehelin-Witt haben sich hinsichtlich des Aufkommens der Umweltzentralbank für eine Pro-Kopf-Rückerstattung des Abgabenaufkommens (Ökobonus-Konzept) ausgesprochen. Denn Umweltsteuern und Sonderabgaben können ohne Kompensation regressive Verteilungswirkungen haben, welche die politische Durchsetzbarkeit von Ökosteuern erschweren (vgl. dazu auch Welsch, 1999). Da aber nur die ökologische Lenkungswirkung von umweltpolitischem Interesse ist, sind Einkommenseffekte kontraproduktiv. Blöchliger/ Staehelin-Witt können mit dem Ökobonus zu Recht pro Ökoparafiskus anführen, daß dieser unerwünschte Verteilungswirkungen mildern kann. Auch Tiepelmann/ Frick nehmen an, daß

252 Allerdings ist die Generalisierung der mikro-theoretischen Hypothese methodisch nicht unwidersprochen geblieben (vgl. Kühnel, Bamberg, 1998) und besteht m. E. noch immer fort. 
nur Ökosteuer, Ökobonus und Ökoparafiskus dem Anforderungskriterium, regressive Verteilungswirkungen zu vermeiden, entsprechen (1996, 346 f).

Die Trennung von Lenkungs- und Fiskalziel macht parafiskalische Umweltsteuern, die nach dem Konzept des Ökobonus rückerstattet werden, in hohem Maße zustimmungsfähig. Tiepelmann und Frick halten aufgrund des höheren distributiven Kompensationsvolumens des Ökobonus höhere Steuersätze bei gleicher 'Merklichkeit' der Steuer für möglich (Tiepelmann, Frick, 1996, 346 f). Eine über den Ökobonus wieder ausgeschüttete Umweltabgabe würde so gegenüber Umweltsteuern größere Effektivität besitzen, ohne die privaten Haushalte stärker zu belasten, was ein wesentlicher Aspekt für die Bewertung der Kosten und Nutzen von Staatsleistungen durch die Staatsbürger ist (vgl. Schmidt, 1990, 226 f). Angesichts der Tatsache, daß stoffliche Emissionen zunehmend vom Konsum (insbesondere Transport) ausgehen, könnte nicht nur die direkte Substitutionswirkung der Ökosteuer, sondern darüber hinaus die positive, lernende Perzeption ökoparafiskalischer Ökobonusse ein wichtiger Aspekt einer an Suffizienz orientierten Nachhaltigkeitspolitik sein.

Frey und Kirchgässner haben die Auffassung vertreten, daß die politischen Entscheidungen hinsichtlich des Angebots an öffentlichen Gütern den Präferenzen der Stimmbürger umso mehr entsprechen, je besser Institutionen der Volksabstimmung ausgestaltet seien. Dazu verweisen sie auf ökonometrische Untersuchungen in der Schweiz (Frey, Kirchgässner, 1993). Bereits A. Downs (1968, 197, 291) hatte angenommen, daß demokratische Regierungen stärkere redistributive Tendenzen entwickeln würden als andere Regierungsformen. Hinsichtlich von Umweltgütern scheint eine höhere Nachfrage gegenüber dem Status quo partiell bestätigt zu werden (UBA, 2000). Für eine Politik der Dematerialisierung wäre mit direktdemokratischen Abstimmungen die Hoffnung verbunden, daß die widerstreitenden Interessen in der politik-ökonomischen Interferenzzone umgangen werden könnten und die Verringerung des Umfangs (scale) des ökonomischen Systems direkt den Bürgern zugänglich gemacht werden würde. Direktdemokratische Abstimmungen müßten sich nicht auf eine allokative Umweltpolitik beschränken (Stoffstrommanagement), sondern könnten auf die distributive Dimension nachhaltiger Entwicklung (Dematerialisierung) ausgedehnt werden (vgl. 114 ff). So würden direktdemokratische Abstimmungen über Stoffabgaben Trade-offs minimieren und die Unabhängigkeit der umweltökonomischen Instrumente erhöhen. Sie würden auch Suffizienzaspekte - im Sinne einer teilweise altruistischen Bereitstellung von öffentlichen Gütern bzw. des Schutzes von Umweltgütern - besser zur Geltung bringen können.

Tatsächlich ist die vergleichende Politikforschung jedoch sehr viel skeptischer hinsichtlich einer positiven Einschätzung direktdemokratischer Beteiligung auf politischen Wandel. Der Einwand lautet, daß direktdemokratische Beteiligungsrechte auch als Vetorechte wahrgenommen werden würden, die politischen Wandel entsprechend blockierten (vgl. Schmidt, 2000). Direktdemokratische Institutionen etablieren demnach sogar ausgesprochene Vetopositionen, die von der zentralstaatlichen Parlamentsmehrheit nun noch zusätzlich zu den Interessenkonstellationen der politik-ökonomischen Interferenzzone berücksichtigt werden müssen. Je zahlreicher oder 
weitreichender solche Vetopositionen seien, desto schwieriger oder langsamer werde politischer Wandel (Tsebelis, 2000).

Unterschieden wird in der Diskussion zwischen Referenden und Volksinitiativen. Während (obligatorische oder fakultative) Referenden sich allein auf Parlamentsvorlagen erstrecken und diese befürworten oder zurückweisen können, laufen Volksinitiativen parallel zum Parlamentarismus und führen neue, bisher vom Parlament nicht berücksichtigte oder verabschiedete gesetzliche Regelungen in das politische System ein. Der Volksinitiative werden zwei Arten von Einfluß auf den Steuerstaat und dessen Ausmaß zugesprochen: Direkt sollen Volksinitiativen redistributive Politiken erleichtern. Indirekt soll sie den Steuerstaat auf neue Politiken verpflichten. An diese Diskussion anknüpfend haben Freitag et al. (2003) die Auswirkungen von Finanzreferenden und Volksinitiativen auf den Steuerstaat in einer vergleichenden empirischen Untersuchung betrachtet. Ihre Ausgangsthese dabei lautete: "Während direktdemokratische Mitbestimmungsrechte in Form des Referendums die Ausdehnung des Steuerstaates bremsen, läßt die Nutzung der Volksinitiative einen gegenläufigen, d.h. expansiven Effekt erwarten." (Freitag et al., 2003, 556) Anhand der Untersuchung der schweizerischen Kantone kommen sie zu dem Ergebnis, daß Referenden in der Tat bremsend wirken, doch Volksinitiativen keine expansiven Effekte auslösen. Aufgrund dieser Ergebnisse können keine hohen Erwartungen an die Ausweitung direktdemokratischer Beteiligung an der Zielfindung einer UZB geknüpft werden. Gleichwohl könnte eine direktdemokratische Beteiligung schon deshalb sinnvoll sein, weil sie eine kontinuierliche Reproduktion der Stoffstromagenda im Forum mit sich bringt. 


\section{Schluß}

Der Diskurs über Nachhaltigkeit hat etwa zeitgleich in Ökonomie und Recht die Bedeutung von Unsicherheit für die Entwicklung der Gesellschaft entdeckt. Im Fall des ökonomischen Systems hat die ökonomische Selbstreferenz durch die Berücksichtigung thermodynamischer Gesetze einen paradigmatischen Wandel erfahren, da diese notwendig auf die Umwelt des Systems verweisen. Der im Zuge der ökonomischen Entwicklung initiierte Metabolismus ist zugleich mit Unsicherheiten belegt und deshalb auch kontingent. Unsicherheit ist auch für das rechtliche Paradigma eines Umweltstaates von zentraler Bedeutung. Sie entspringt im Rechtssystem ganz wesentlich der Schwierigkeit, Natur oder Naturzustände zu normieren, was durch unbestimmte Rechtsbegriffe auszugleichen versucht wird, aber so eben auch Unsicherheiten in das politisch-administrative System und in die Gesellschaft hineinträgt. Es kann zu Wirkungsbrüchen und symbolischem Umweltrecht kommen.

Unsicherheit wird auch in der Wissenssoziologie zunehmend Gegenstand empirischer Forschung. Die Wissenssoziologie reagiert auf die Selbstgefährdung und die ökologischen Unsicherheiten der modernen Gesellschaft mit einem Wandel des Objektbereichs hin zur Erforschung von Nicht-Wissen. Über die Soziologie wird dieses Wissen über Nicht-Wissen allmählich auch in der Politikwissenschaft rezipiert, vor allem von Ansätzen der Wissenspolitologie und der Diskursanalyse. Dabei kommt der Wissenssoziologie implizit die Rolle einer Reflexionstheorie zu, die oft weniger Sozial- und Naturwissenschaften in ein theoretisches Verhältnis setzt als vielmehr auf die Persistenz sozialer Praktiken verweisen muß. Die Diskurstheorie bietet sich in der argumentationstheoretisch ausgearbeiteten Form als Metatheorie an, da sie auf die sozialwissenschaftliche Methodik reflektiert und mit der Theorie des kommunikativen Handelns den Sozialwissenschaften ein Theorieangebot gemacht hat, das es erlaubt, die systemische Verselbständigung der modernen Gesellschaft kritisch einzuholen. Die kritische Theorie des Diskurses kann dabei die systemimmanente Kritik aus den Teilsystemen der Gesellschaft (Konzept starker Nachhaltigkeit/ Dematerialisierung, symbolisches Recht) aufgreifen. Im metatheoretischen Rahmen der Diskurstheorie lassen sich dann die partiellen Kritiken sinnvoll verbinden, so daß die Beziehung zwischen politisch-administrativem und ökonomischem System nicht als Nullsummenspiel wie bei der NPÖ erscheint, sondern normativ als vernünftige Prozedur, deren Erfolg erst noch empirisch sicherzustellen ist.

In der Politikwissenschaft haben sich Theorien bewährt, die ihren Objektbereich in der Interferenzzone zwischen ökonomischem und politisch-administrativem System ausmachen. Habermas hat hier, im Unterschied zum akteurzentrierten Institutionalismus, keinen direkten (rationalitätstheoretischen) Zugang zum politikwissenschaftlichen Objektbereich gewählt, sondern den systemischen Selbstreproduktionsmechanismen die Solidarität der Zivilgesellschaft entgegengestellt. Diese ist zwar gegenüber Geld und Macht ein vergleichsweise schwaches Medium, sie kann jedoch die stabilen Akteurskonstellationen der Verhandlungssystemen zwischen den gesellschaftlichen Systemen über eine massenmediale Öffentlichkeit aufweichen. 
Wie sich am Beispiel der bundesdeutschen Abfallpolitik zeigte, bestätigt das Müllnetzwerk weitgehend die theoretischen Erwartungen des akteurzentrierten Institutionalismus. Nicht nur konnte durch das Netzwerk die bestehende Akteurskonstellation reformiert, sondern es setzte sogar materiell eine nachhaltige Entwicklung ein. Doch dem ökonomischen System ist kein endogener Entwicklungspfad eingeschrieben, der die Steigerung der Ressourcenproduktivität dauerhaft und ohne politische Leitplanken gewährleisten würde. Noch das bestehende Netzwerk in der rechtlichen Fassung des KrW-/AbfGs wird diesem Ziel nun unzureichend gerecht. So wurde bisher das reklamierte Ziel des KrW-/AbfGs verfehlt, durch das Müllsystem auf den gesamtgesellschaftlichen Metabolismus einzuwirken. Zweifellos ist dieses Ziel sehr ambitioniert, und es geht über das etablierte Netzwerk hinaus. Es ist jedoch fraglich, ob eine Ausweitung des Netzwerkes unter Verzicht ökonomischer Instrumente generell anzustreben wäre. Zwar mag die Schaffung neuer Akteure die soziale Reflexivität erhöhen, doch zeigte sich bereits am Müllnetzwerkes, daß die Beschränkung von Eigentumsrechten auch dann auf erheblichen Widerstand wirtschaftender Akteure trifft, wenn diese Beschränkungen sich an vorhandenen Substitutionspotentialen orientieren. Erstaunlicherweise spielte bei der Entscheidung der ökonomischen Akteuren für ein Netzwerk mit der privatrechtlichen Institution des DSD auf Kosten ökonomischer Instrumente kosteneffizient keine Rolle.

Hier hat der ökonomische Ansatz (in der Ökonomie und Politik) grundlegende Schwierigkeiten, ökonomische und politische Motivation empirisch zutreffend zu beobachten. So sind Nutzung und Bewußtsein von öffentlichen Gütern in der NPÖ etwa kategorisch voneinander getrennt. Ein ähnliches Problem, akteurskonstellationsverändernde Motivation zu erfassen, konnte auch noch beim akteurzentrierten Institutionalismus festgestellt werden, der nur in dem Maße die Entstehung von reflexiven Netzwerken erklären kann, wie er kognitiv gehaltenvollere Konzeption von Öffentlichkeit in sein Programm einbezieht. Es konnte gezeigt werden, daß die Diskursanalyse über den akteurzentrierten Institutionalismus hinausgehen kann. Die Analyse des Abfalldiskurses zeigte die Bedeutung des öffentlichen Diskurses beim Übergang von einer negativen zu einer positiven Koordination der Akteure durch den Staat auf.

Gleichwohl bleiben Motivationsprobleme zentral: Eine Dematerialisierung der industrialisierten Demokratien, welche für das universale Ziel einer globalen nachhaltigen Entwicklung unerläßlich ist, sieht sich aufgrund der Persistenz sozialer Strukturen großen Motivationsproblemen ausgesetzt. Der diskurstheoretische Ansatz beschränkt sich nicht auf ökonomische Motivation, die sich für den überwiegenden Teil der Bevölkerung gegenwärtig vornehmlich auf Konsum zu reduzieren scheint, sondern setzt explizit auf Helferinteressen (v. Prittwitz) einer solidarischen Zivilgesellschaft. Die Diskurstheorie wahrt dabei die Reproduktionsfähigkeit der lebensweltlichen Strukturen über das öffentliche Bewußtsein und reflexive Institutionen. Zivilgesellschaftliche Solidarität allein wäre mit der Lösung der Probleme anthropogener Stoff- und Energieströme vermutlich überfordert. Sie ist insofern darauf verwiesen, in den institutionellen Arrangements an der Interferenzzone von Lebenswelt und Systemen ökonomische Motivation und normativ-kognitiven Vorschuß auszutarieren. Dies gilt auch für das Konzept der Dematerialisierung, das als mikroökonomische 
Idee ganz wesentlich auf Postivsummensituationen ausgerichtet ist zugleich aber auch als makroökonomische Idee in die Policyarenen hineinwirkt und Potentiale zur Steigerung der Ressourcenproduktivität aufzeigen. Als Forschungsdesiderat bleibt für die Politikwissenschaft zurück, speziell reflexive institutionelle Arrangements der Stoffstromsteuerung weiter zu erforschen und zu verbessern. Insbesondere die Einsatzmöglichkeit ökonomischer Instrumente entlang des Stoffstroms ist in bezug auf mögliche Ansatzpunkte, Steuerungstiefe und politisch-administrative Restriktionen zu klären.

Obgleich kontingent, ist der öffentliche, zivilgesellschaftliche Input in den Policyprozeß für die Forschung von entscheidender Bedeutung, denn nur dadurch erhält sie Zugang zu den diffusen normativen und kognitiven Erwartungen der Bürger an ihre Zukunft. Für die zivilgesellschaftliche Beteiligung an den Agenda-setting-Prozessen der Nachhaltigkeit - im Sinne eines kognitiv weitreichenden Policy-Inputs - bieten Nachhaltigkeitspläne bisher den einzigen erprobten institutionellen Ansatz. Diesen institutionellen Pfad kann die empirische Policyforschung weiter beschreiten und entwickeln. Die Politikwissenschaft kann aber auch die Zukunftserwartungen der Bürger institutionell zuspitzen und zur Abstimmung bringen. In diesem Sinne wäre von der Politikwissenschaft eine Umweltzentralbank zur Praxisreife zu entwickeln. Die funktionale Rationalität einer direktdemokratisch geleiteten UZB bewahrt dabei eine gewisse Distanz zu handlungstheoretischer Übermotivation. Denn die funktionale Orientierung am Einkommen versucht, Output und normatives Input des demokratischen Rechtsstaates institutionellen auszutarieren. Damit wird die demokratische Selbstqualifikation der Staatsbürger in institutionellen Bahnen gelenkt, die einer regulativen Idee der Selbstregierung besser entsprechen als einzig reflexive Policyarenen. So könnte eine direktdemokratisch angeleitete UZB die Ausdehnung von Partizipation und prozeduralen Rechts auf Arenen effektiv ergänzen und lokale Optima zu einem gesamtwirtschaftlich nachhaltigen Stoffdurchsatz integrieren. Sie erhält dabei die normativ wünschenswerte Perspektive einer gerechten intertemporaler Distribution zu Gunsten nachfolgender Generationen. Die Diskurstheorie bietet für dieses normativ und kognitiv anspruchsvolle Programm den geeigneten metatheoretischen Rahmen, indem sie der empirischen Politikwissenschaft ermöglicht, auf Elemente des theoretischen Rahmens zu referieren und diese kritisch zu interpretieren. 


\section{Anhang}

\subsection{Typen des Sprachgebrauchs nach Habermas (1999)}

$\begin{array}{cc}\text { Äußerungen } & \text { Verwendungsweise } \\ \begin{array}{c}\text { Aussage- und Absichtssätze in mente } \\ \text { (reine Darstellung und monologische } \\ \text { Handlungsplanung) }\end{array} & \text { nicht-kommunikativ } \\ \text { normativ nicht-eingebettete Willens- } \\ \text { äußerungen (einfache Imperative, An- } \\ \text { kündigungen) } \\ \begin{array}{c}\text { vollständige, illokutionäre Akte (nor- } \\ \text { mativ, konstativ, expressiv) }\end{array} \\ \text { Perlokutionen } \\ \end{array}$

\subsection{Handlungstypen nach Habermas (1999)}

Sprachgebrauch

nicht-

kommunikativ

verständigungs-

orientiert

einverständnis-

orientiert

folgenorientiert

\section{Aktoreinstellung}

objektivierend

zielgerichtete

Intervention

schwach-

kommunikatives Handeln

stark kommunikatives

Handeln

strategische Interaktion
Interaktionsform

nicht-soziales

Handeln

soziale

Interaktion

soziale

Interaktion

soziale

Interaktion

(Habermas, 1999, 130) 


\subsection{Spieltheorie}

Denn folgenden Spielen der Spieltheorie sei vorangestellt, daß sie lediglich der Darstellung von Akteurskonstellationen - im Sinne des akteurszentrierten Institutionalismus - dienen sollen, die vornehmlich auf der mesotheoretischen Ebene liegen. Analytische, mikrotheoretische Aussagen wie etwa zum Verhältnis von Argumentation und Verhandeln - sollen hier nicht getroffen werden. Es sei aber darauf hingewiesen, daß viele praktische Handlungssituationen - wie etwa die formal als Gefangenendilemma dargestellte Tragödie der Allmende, wo die individuelle Nutzung des Gemeinlandes zu seiner kollektiven Überweidung führt - bei näherer Analyse oft komplexer sind und z.B. rechtlich oder sozial reglementiert sein können (vgl. Ostrom, 1990), worauf der akteurszentrierten Institutionalismus eingehend hinweist.

\subsubsection{Mixed-motive games}

Den mixed-motive Spielen werden Versicherungsspiel (assurance game), Gefangenendilemma (priseners dilemma), chicken game und der Kampf der Geschlechter (battle of the sexes) zugerechnet. Mixed-motive games sind dadurch charakterisiert, daß die Präferenzen der Individuen sowohl Konkurrenz als auch Kooperation ermöglichen können. Sie unterscheiden sich damit von Nullsummenspielen (reiner Konflikt) und reinen Koordinationsspielen.

\section{A. Gefangenendilemma}

Beim Gefangenendilemma führen die dominaten Handlungsstrategien der einzelnen Individuen (A1B1) zu kollektiv Pareto-defizitären Ergebnissen. Das Pareto-optimale Ergebnis ist für das einzelne Individuum in der gegebenen Handlungssituation weder zugänglich noch ist es stabil, denn dazu müßten alle Akteure gleichzeitig ihre dominate Strategie aufgeben. (In der folgenden Matrix sind Kooperation und Nichtkooperation durch K bzw. N gekennzeichnet und die Optionswerte für Alter rechts und für Ego links eingetragen.)

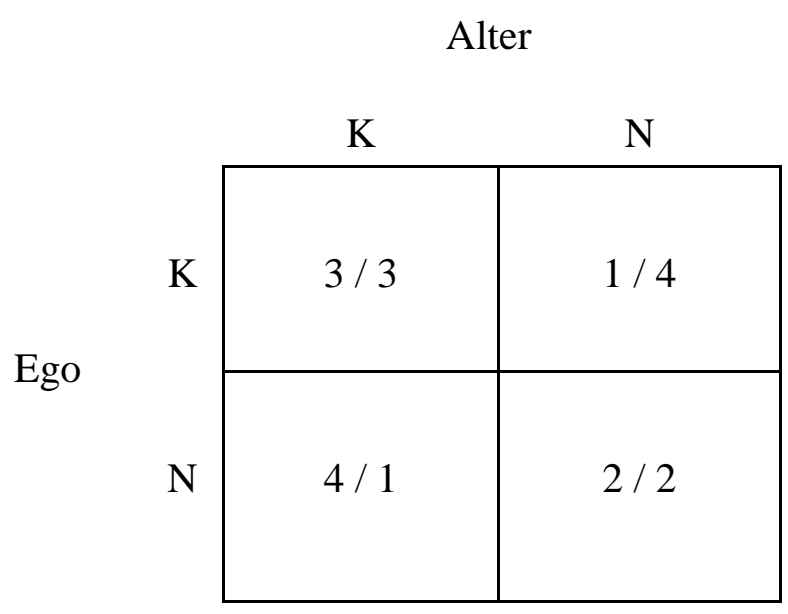




\section{B. Chicken Game}

Beim Chicken-Spiel ist die Eingung auf die kooperative Lösung $(3,3)$ plausibel, jedoch wie beim Gefangenendilemma durch einseitige Nichtkooperation (2, 4 oder 4, 2) bedroht. Gemeinsame Nichtkooperation führt im Unterschied zum GD zur schlechtesten (1,1) und nicht zur zweitschlechtesten Option. Dies hat zur Konsequenz, so Scharpf $(2000,138)$, daß rationale Akteure der Gefahr von präventiven Zügen aggressiver Gegner ausgesetzt sind, während ihre eigene Vergeltungsdrohung nicht glaubhaft ist.

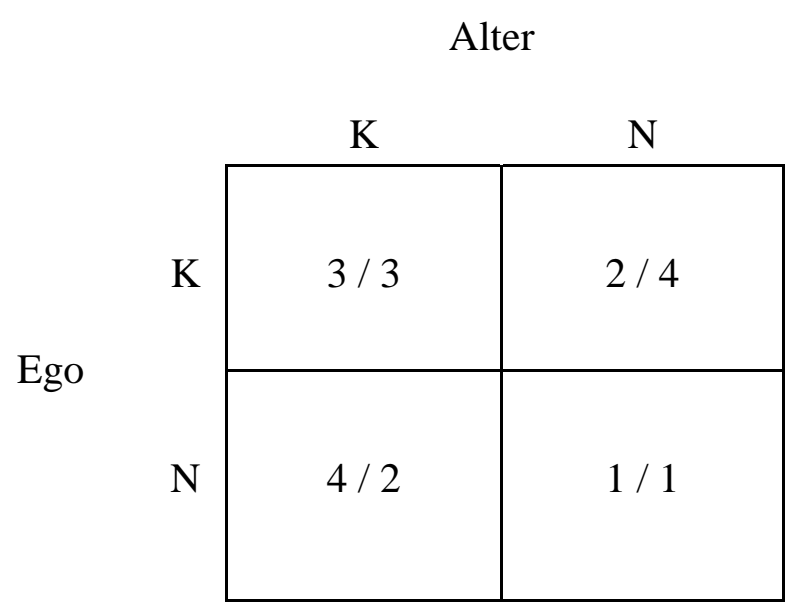

\section{Versicherungsspiel (assurance game)}

Beim Versicherungsspiel ist die Pareto-optimale Lösung durch eine beidseitige Kooperation relativ leicht zu erzielen. Diese wird jedoch bei nicht-kooperativem Verhalten verfehlt (Zellen oben rechts und unten links).

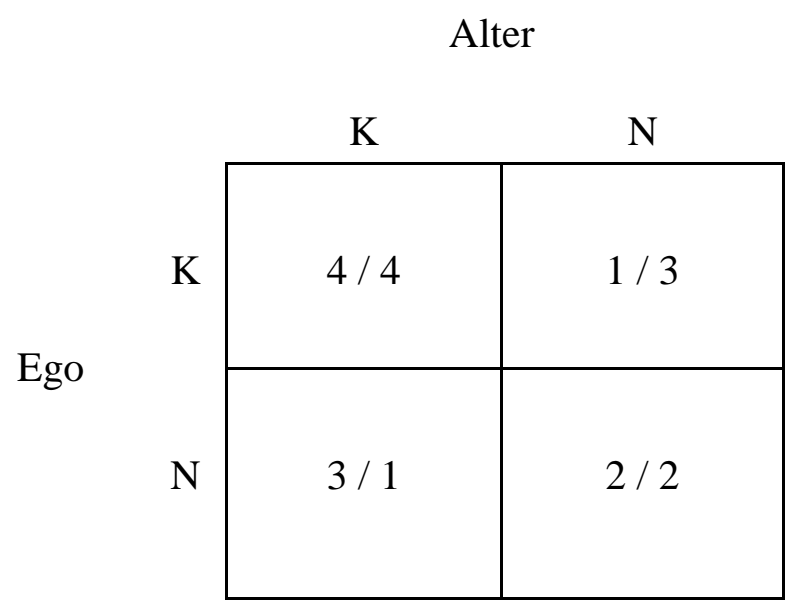




\section{Battle of the Sexes}

Der Geschlechterkampf ist ein Koordinationsspiel mit Verteilungskonflikt. Die Koordinierung von Strategien zwischen zwei Akteuren könnte die Wohlfahrt steigern (3,4 bzw. 4,3), doch Alter präferiert die erste Variante, während Ego die zweite bevorzugt.

Alter

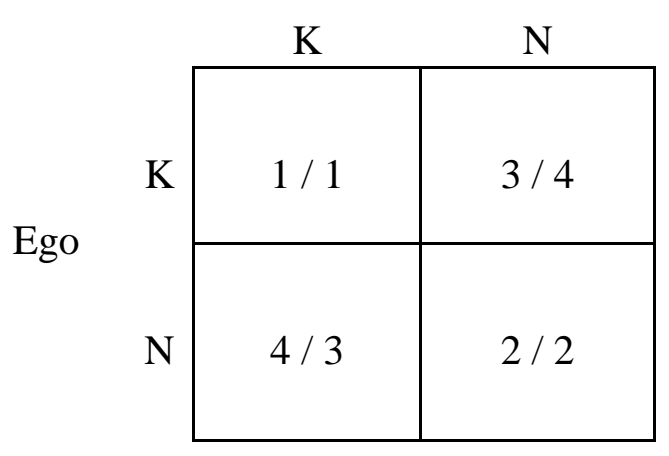

Scharpf hat das Battle of the Sexes zu den Koordinationsspielen mit Verteilungskonflikten gezählt und seine Relevanz für die Analyse von Policies noch dadurch zu erhöhen versucht, daß er bei der Lösung die Interaktionsorientierung der Akteure berücksichtigt. U.a. unterscheidet er von der bereits angeführten (individualistischen) Lösung noch eine kompetitive und eine solidarische Lösung des Geschlechterkampfs. Hierbei ändern sich die Matrizen wie folgt:

kompetitive Variante

Alter

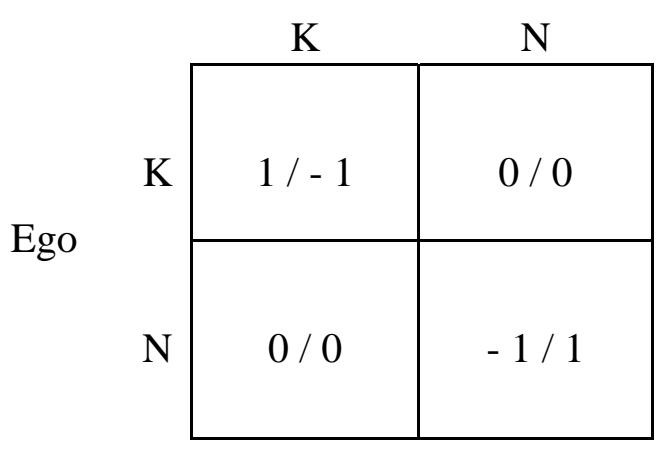

solidarische Variante

Alter

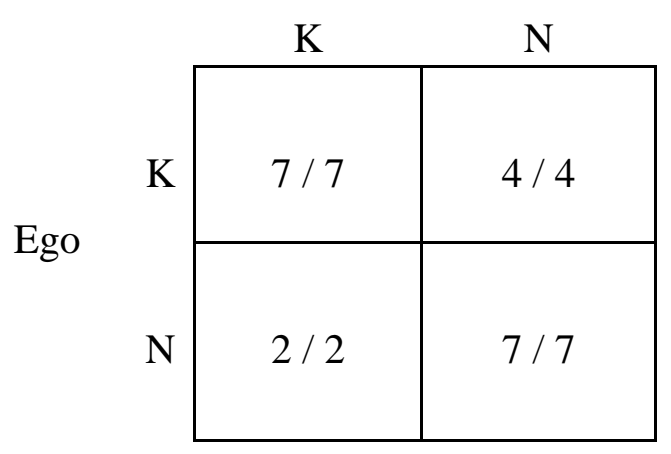




\subsection{Nash-Verhandlungslösung}

Die wohlfahrtstheoretische Lösungen von Verhandlungen besteht in der Verteilung des durch Kooperation zu produzierenden Mehrwertes (surplus) nach dem Pareto-Kriterium. D.h. rationale Akteure würden keinem Kooperationsvertrag zustimmen, der sie gegenüber der Ausgangssituation schlechter stellt. Optimal ist ein Zustand, wenn keine Besserstellung eines Individuums erzielt werden kann, ohne daß nicht jemand anderes schlechter gestellt wird. Das Kriterium ist präskriptiv und normativ und kann z.B. eine ungerechte Ausgangsituation vor der Verhandlung in das Ergebnis festschreiben.

Die Nash-Lösung kann, nach B. Barry, (1989, 14), als Versuch interpretiert werden, das Problem von Verhandlungsmacht formal zu lösen, indem Verhandlungen als Lotterie interpretiert werden, bei der kein Teilnehmer vorab die Auszahlungen kennt. Die Lösung besteht darin, daß die Verhandlungsparteien eine gemeinsame Lösung erzielen können, wenn sie für sie nicht akzeptable Ergebnisse kennzeichnen (non agreement point) und sich am Produkt ihres gemeinsamen Nutzens orientieren. Dazu müssen sie sich vom non-agreement Ergebnis (kein Nutzen) wegorientieren, individuelle Nutzenintervalle benennen und das Produkt der gemeinsamen Ergebnisse bewerten, die zwar alle auf einer Pareto-Grenze liegen, welche jedoch keiner Effizienzmaximierung entspricht. Über die so relativierte Verhandlungsmacht wird von den Ergebnissen der Pareto-Grenze jenes mit dem höchsten Nutzen (Produkt der relativierten individuellen Nutzen) ausgewählt. Einzig benötigte Informationen sind somit kardinale, individuelle Nutzenkategorien.

Scharpf (2000, 171 ff) hat darauf verwiesen, daß die Nash-Lösung als Entscheidungskriterium in Policy-Situationen fast nicht zu bewältigende kognitive Anforderungen an die beteiligten Akteure stellen würde, selbst wenn es sich dabei um Makroakteure handelte. Die Policyanalyse zeigt aber ebenso auf, daß Akteurskonstellationen mit Nash-Lösungen sehr hohe Stabilität besitzen. Sie seien gleichbedeutend mit anreizkompatiblen Lösungen. 


\section{Register}

Abduktion: Von Peirce entdeckte Form des Schlusses, der von einer Art von Fakten auf eine andere Art von Fakten mit Wahrscheinlichkeit (hypothetisch) schloß und dem Peirce die wissenschaftstheoretische Funktion zuwies, neue Hypothesen zu entdecken und aufzustellen, d.h. erkenntniserweiternd zu wirken. Das Verfahren der Abduktion sichert dabei nicht die Richtigkeit der erzielten Ergebnisse, sondern bietet nur eine potentielle neue Erklärungsmöglichkeit hinsichtlich der Ausgangsfragestellung. Gültig ist die durch die Abduktion gelieferte Hypothese, wenn sie tatsächlich zusammen mit den Ausgangsbedingungen eine mögliche Erklärung darstellen kann, daß heißt im Prozeß der Forschung (als Annäherung einer unendlichen Forschergemeinschaft an die Wahrheit) bestätigt wird.

Allokation: Die relative Aufteilung von Gütern zwischen Produzenten und Konsumenten basierend auf individuellen Präferenzen oder Zahlungsbereitschaft der Konsumenten. Eine effiziente Allokation ist pareto-optimal ( $\rightarrow$ Pareto-Kriterium).

Autopoiesis: Die Eigenschaft offener $\rightarrow$ Systemen, durch ihren Stoff- und Energiestrom neue, $\rightarrow$ dissipative Strukturen autopoietisch und irreversibel ( $\rightarrow$ Irreversibilität) zu entwickeln (Evolution). Luhmann vertritt die These, daß es sich auch bei sozialen Systemen aufgrund deren operativer Geschlossenheit bei gleichzeitig kognitiver Offenheit gegenüber der Umwelt um autopoietische Systeme handelt. Luhmann zufolge erschafft sich ein soziales System durch die operative Verknüpfung elementarer Systemelemente selbst. Autopoiesis beruht dann auf der zirkulären Selbstreferenz der Elemente, woraus neue Strukturen entstehen.

Bayes-Kriterium: $\rightarrow$ Risiko

Bifukuration: In der Thermodynamik bezeichnet man Gabelungen eines zeitlich gerichteten Dissipationsprozesses ( $\rightarrow$ dissipative Strukturen) als Bifukurationen. In der Systemtheorie (Luhmann) meint Bifukurationen den evolutionären Vorgang der Bezeichnung von anschlußfähigen Unterscheidungen, welche Beobachtungen voraussetzen und zugleich selbst Beobachtungen sind.

Diskursprinzip: Sprachregel, welche das grundlegende Prinzip eines praktischen Diskurses zum Ausdruck bringt.

Dissipative Strukturen: Als dissipative Strukturen werden spontan entstehende Strukturen fern eines thermodynamischen Gleichgewichts ( $\rightarrow$ Thermodynamik) bezeichnet, die durch ein stofflichenergetisches Fließgleichgewicht $(\rightarrow$ steady state) aufrecht erhalten werden. Diese sind irreversibel $(\rightarrow$ Irreversibilität).

Eigenwert: In der Systemtheorie bezeichnet Eigenwert die nicht-zufällige Eigenschaft von Systemen, welche Systeme strukturell bindet bzw. beschränkt.

Effektivität: Im Unterschied zum Effizienzbegriff der Ökonomik bezieht sich (ökologische) Effektivität auf eine nicht-monetäre Bewertung von Policymaßnahmen. Im Ökologischen Kontext der Nachhaltigkeit bieten sich dafür energetische Indikatoren oder das MIPS-Konzept an. 
Emergenz: Systemtheoretischer Begriff (Luhmanns), der die selbstreferentielle Erzeugung und Erhaltung von systemeigenen Elementen durch deren $\rightarrow$ Relationierung beinhaltet. Es wird nicht mehr wie in der kybernetischen Systemtheorie die Vermehrung von gegebenen Elemente durch einfache Verknüpfung angenommen, sondern die Entstehung von neuen Systemeigenschaften. Luhmann behauptet für soziale Systeme, deren Elemente psychische Systeme und Kommunikation sind, die $\rightarrow$ Emergenz von sozialen Subsystemen.

Erwartungssicherheit: T. Parsons hat die Soziologie mit der Annahme konfrontiert, daß die Interaktion von zwei Aktoren durch eine doppelte Kontingenz charakterisiert sei, die sich auf das objektivierte fremde und das subjektive eigene Verhalten beziehe. Doppelte Kontingenz sei in diesem Sinne ein pragmatisches Problem, daß Handlungen hervorrufe. Erwartungssicherheit dient der Bewältigung dieser Kontingenz in der sozialen Interaktion.

Epistemische Unsicherheit: Unsicherheit über die Gültigkeit von Theorien in der wissenschaftlichen Forschung.

Geschlossenes System: $\rightarrow$ Systeme

Grandfathering: Verfahren zur Internalisierung von Externalitäten in das Wirtschaftssystem. Die Zuteilung von Emissionslizenzen erfolgt dabei direkt an die betroffenen Betriebe, was den Status Quo der Verschmutzung zunächst beibehält und erst durch eine zuvor festgelegte zeitliche Abwertung von Zertifikaten eine Reduktion der Emissionen bewirkt. Gegenstück ist die Versteigerung einer Emissionen begrenzenden Menge von Zertifikaten.

Irreversibilität: Über die gleichgewichtsferne Thermodynamik ist der thermodynamische Begriff der Irreversibilität auf offene Systeme ausgedehnt worden. Irreversibilität erhielt über die Theorie der dissipativen Strukturen auch für die Biologie grundlegende Bedeutung. Irreversibilität beschreibt ökologische Prozesse der Biosphäre. Leben existiert notwendig unter der Bedingung von Irreversibilität und wird zugleich selbst als irreversible, dissipative Struktur beobachtet. Im Rahmen der Biologie verweist Irreversibilität auf die Entstehung geordneter komplexer Strukturen $(\rightarrow$ dissipativer Strukturen) in einer chaotischen Umwelt verbunden mit der von Genen übertragenen Selbstreproduktionsfähigkeit von Organismen. Organismen leben, indem sie Energie von einer äußeren, sie einschließenden Umwelt aufnehmen, und mit ihr innere Zustände geringerer Entropie und damit höherer Ordnung schaffen. Leben existiert fern des thermodynamischen Gleichgewichts, indem es seine organische Struktur mit Hilfe eines größeren globalen Entropiehaushalts aufrecht erhält.

Kaldor-Hicks-Kriterium: Das Kriterium orientiert sich am Pareto-Kriterium. Es erlaut aber im Gegensatz zum Pareto-Kriterium die Schlechterstellung von Personen, wenn diese durch die Wohlfahrtsverbesserungen kompensiert werden könnten.

Konsistenz: Eine Lebensweise, in der das Verhältnis von Gesellschaft und Natur nachhaltig ist.

Komplementarität: Eine Komplementarität ökologischer Funktionen ist dann gegeben, wenn bestimmte Ökosystemfunktionen durch andere Funktionen desselben Ökosystems übernommen 
werden können. Die ökologische Ökonomie grenzt sich mit diesem Ansatz vom Konzept der Monetarisierung von Naturgütern ab, das die Annahme ökonomischer Substitution auf Natur überträgt, ohne funktionale Eigenschaften von Ökosystemen zu berücksichtigen.

Koppelung: In der Terminologie der Systemtheorie durch einen Beobachter konstatierte SystemUmwelt Verbindung, die fest oder lose sein kann. Bei der losen K. entsteht die Bindung zwischen System und Umwelt medial durch ein $\rightarrow$ Medium bei fester K. kausal, d.h. durch die Gleichzeitigkeit eines Umweltereignisses für zwei Systeme.

Kuznets-Kurve: Hypothese, daß die $\rightarrow$ Ressourcenproduktivität von volkswirtschaftlichen Systemen im Laufe ihrer Entwicklung endogen zunimmt.

MAIA (Materialintensitätsanalyse): Analysemethode, die das Materialinput pro spezifischer Menge oder pro Stück eines Produktes, Zwischenproduktes oder einer Infrastruktur untersucht.

Medium: Als M. wird das symbolisch generalisierte Kommunikationsmedium eines sozialen Systems bezeichnet (z.B. Geld, Macht).

Metabolismus: Der Austausch von Stoffen und Energie zwischen Gesellschaft und Umwelt. Ein metaboles Verhältnis ( $\rightarrow$ Systeme) ist physikalisch notwendig, in seiner spezifischen Ausprägung jedoch kontingent. Insofern der Metabolismus qualitativ verändert oder quantitativ gesteigert wird, ist der daraus resultierende Stoff- und Energiestrom emergent ( $\rightarrow$ Emergenz).

MIPS (Materialintensität pro Serviceeinheit): Die Umweltbelastung durch Prozesse oder Güter im Hinblick auf ihren spezifischen Ressourcenverbrauch während ihres Lebenszyklus. Dazu wird das gesamte energetische und stoffliche Materialinput in Gewichtseinheiten erfaßt und auf Güter und Dienstleistungen angerechnet. Aus der Inverse des MIPS ergibt sich das Maß der $\rightarrow$ Ressourcenproduktivität.

Mixed-Motive-Spiele: Spieltheoretisches Modell, wonach Parteien zwischen Konflikt und Kooperation schwanken, so daß keine eindeutigen Ergebnisse erzielt werden. Es treten soziale Dilemmata wie prisoner's dilemma (Gefangenendilemma) und chicken game auf.

Operation: In der Terminologie der Theorie autopoietischer Systeme der Vollzug einer einmaligen Entscheidungshandlung, an die mit weiteren Operationen angeschlossen werden kann.

Pareto-Kriterium: Ein nach V. Pareto benanntes Kriterium, wonach innerhalb einer Gruppe niemand besser gestellt werden kann, ohne daß nicht jemand anders schlechter gestellt wird. In der Wohlfahrtsökonomie wird das Kriterium konservativ auf $\rightarrow$ Allokation bezogen und schließt distributive Aspekte aus.

Pareto-Superiorität: Potentielle, allokative Pareto-Verbesserung ( $\rightarrow$ Pareto-Kriterium), die häufig nur durch gleichzeitige Ausgleichszahlungen an schlechter gestellte Gruppen $(\rightarrow$ Kaldor-HicksKriterium) realisiert werden kann.

Proaktives Verhalten: Eine Verhaltensweise (von Unternehmen), die umweltpolitische Zielsetzung antizipiert und unterstützt. 
Produktivistischer Fehlschluß: Ein logischer Fehlschluß, der sowohl von der Produktivität als auch der Assimilationskapazität der Natur absieht und allein die anthropogene Produktion (Ökonomie) zum Maßstab der Bewertung nimmt. Er verkennt die physikalische Notwendigkeit einer stofflich-energetischen System-Umwelt-Beziehung ( $\rightarrow$ Metabolismus). Dadurch werden durch instrumentelle Rationalität gekennzeichnete Sachverhalte $\mathrm{zu}$ Aussagen strategischer Rationalität gemacht. Der p. F. ist insofern eine materialistische Ausprägung des Anthropozentrismus.

Prognostische Unsicherheit: Unsicherheit über zukünftige Zustände eines offenen Systems.

Relationierung: In der Systemtheorie (Luhmann) wird die Verknüpfung von Elementen als Relationierung bezeichnet, wobei Elemente die konstitutiven Einheiten von Systemen sind.

Ressourcenproduktivität: Die Inverse des MIPS kann auf Güter, Dienstleistungen und statistische, makroökonomische Kenngrößen bezogen werden, so daß sich Aussagen über die Ökoeffizienz von Regionen, Volkswirtschaften etc. treffen lassen.

Risiko: In der Entscheidungstheorie wird Risiko als das Produkt von Wahrscheinlichkeit und Schadenshöhe definiert ( $\rightarrow$ Bayes-Kriterium). In der Soziologie wurde als Gegenbegriff zu Risiko lange Sicherheit angesehen. Allerdings hat Luhmann anstelle des Begriffs der Sicherheit den der Gefahr angeregt, da dieser für die Soziologie erkenntnisfördernder sei als der Begriff der Sicherheit.

\section{Serviceeinheiten: $\rightarrow$ MIPS}

Skalierung: $\rightarrow$ Umfang

Steady State (Fließgleichgewichtszustand): Von der Kybernetik wurde zunächst die Auffassung eines homoeostatischen Gleichgewichts vertreten. Später wurde dies durch die Theorie multipler Stabilitätszustände bestritten (Holling). Mit der Theorie $\rightarrow$ dissipativer Strukturen $(\rightarrow$ Thermodynamik) werden nunmehr besonders dynamische Instabilitäten, $\rightarrow$ Bifurkationen und Entwicklungsaspekte betont. Dem homoeostatischen Gleichgewicht wird ein steady state (Fließgleichgewichtszustand) gegenübergestellt, der auf der Geschichtlichkeit des Systems beruht und nicht auf der Annahme starker Kausalität wie das homoeostatische Gleichgewicht eines geschlossenen $\rightarrow$ Systems.

Suffizienz: Eine Lebensweise, die 'genügsam' im Sinne ökologischer Konsistenz ist bzw. nachhaltige Konsummuster, die als Serviceeinheiten ( $\rightarrow$ MIPS) funktional ersetzt werden können.

Systeme: Man unterscheidet offene und geschlossene Systeme. In allen geschlossenen Systemen ist der Endzustand vollständig vom Ausgangszustand und den spezifischen Prozessen determiniert (Äquifinalitätsprinzip). Die Kybernetik hat nach dem 2. Weltkrieg die deterministischen Mechanismen geschlossener Systeme untersucht. Sie abstrahiert von den physikalischen Umständen der Welt und beschreibt mechanische Systeme. Die Kybernetik konstruiert geschlossene Ereignisräume, die Prognosen grundsätzlich zugänglich sind. Dieses Prinzip der Äquifinalität gilt nicht für offene Systeme wie der Natur. Offene Systeme umfassen räumlichenergetische Strukturen und sind durch die gleichgewichtsferne Thermodynamik physikalisch 
begründet. Räumlich-energetisch weisen geschlossene System Grenzen auf, die für Materie undurchlässig, für Energie aber durchlässig sind. Sowohl für Energie und Materie geschlossene Systeme werden als isoliertes System bezeichnet. Offene Systeme sind dagegen für Materie und Energie durchlässig. Offene Systeme, die Energie mit ihrer Umgebung austauschen, bilden chaotische, ganzheitliche, $\rightarrow$ dissipative Strukturen aus. Sie sind komplex in ihrer Dynamik, nicht aber notwendig in ihren Merkmalen, die sie als chaotische Systeme konstituieren. Es gibt keine geschlossene mathematische Beschreibungen solcher Systeme, die es, ausgehend von einem Anfangszustand, erlauben würden, ihre Zukunft zu berechnen. In der Ökosystemtheorie werden die entstehenden Eigenschaften von offenen Systemen deshalb als nicht-addierbare Ergebnisse funktionaler Interaktion beobachtet, und nicht als einfach-lineare Effekte bestehender Strukturen.

Thermodynamik: Die Thermodynamik ist auf zwei Hauptsätzen fundiert, die als universalgültige physikalische Naturgesetze anerkannt sind. Der erste Hauptsatz postuliert den Erhalt von Energie und Masse in geschlossenen Systemen; der zweite Hauptsatz die einseitige Ausrichtung makroskopischer Naturprozesse in der Abfolge der Zeit. Der erste Hauptsatz wird aus diesem Grund auch als Energieerhaltungssatz bezeichnet, der zweite verweist auf Entropie als Maß molekularer Ordnung. Die Thermodynamik ist auf die gleichgewichtsferne Thermodynamik $(\rightarrow$ dissipative Strukturen) und offene $\rightarrow$ Systeme ausgedehnt worden (I. Prigogine). Mit Hilfe dieser Theorie wurde der Zeitpfeil in der Physik etabliert und erstmals das Phänomen des Lebens für die Physik zugänglich (Schrödinger).

Umfang (scale): Der Größe (auch: Skalierung) des ökonomischen Systems innerhalb der Umwelt (Natur). Sie kann über den $\rightarrow$ Metabolismus bestimmt werden.

Universalisierungsprinzip: Universales Sprachspiel, welches das grundlegende Prinzip eines praktischen, moralischen Diskurses zum Ausdruck bringt. 


\section{Literaturverzeichnis}

Adriaanse, Albert et al., Stoffströme: Die materielle Basis von Industriegesellschaften, Berlin et al., 1998 Alexy, Robert, Theorie der juristischen Argumentation, Ffm, [1978], 1996 ${ }^{3}$

- Recht, Vernunft Diskurs: Studien zur Rechtsphilosophie, Ffm, 1995a

- Individuelle Rechte und kollektive Güter, in: ders., 1995a, S. 232 ff

- Theorie der Grundfreiheiten, in: Hinsch et al., 1997, S. 263 ff

Apel, Karl-Otto, Transformation der Philosophie, Bd. 2., [1973], Franfurt, $1976^{2}$

- Die Erklären: Verstehen-Kontroverse in transzendentalpragmatischer Sicht, Frankfurt, 1979

- Diskurs und Verantwortung, Frankfurt, 1988a

- Die Herausforderung der totalen Vernunftkritik und das Programm einer philosophischen Theorie der Rationalitätstypen, in: Philosophie und Poesie. Otto Pöggeler zum 60. Geburtstag, hg. von A. GethmannSiefert, Stuttgart-Bad Cannstatt 1988b, S. 17 ff

- Das Leibapriori der Erkenntnis. Eine erkenntnisanthropologische Betrachtung im Anschluß an Leibnizens Monadenlehre, in: H.-G. Gadamer, P. Vogler (Hrsg.)Neue Anthropologie, Bd. 7, Stuttgart, 1975, S. 264 ff

- Normative Begründung der Kritischen Theorie durch Rekurs auf lebensweltliche Sittlichkeit? Ein transzendentalpragmatisch orientierter Versuch, mit Habermas gegen Habermas zu denken, in: A. Honneth et al., 1989, S. $15 \mathrm{ff}$

- Diskursethik vor der Problematik von Recht und Politik, in: ders./Matthias Kettner (Hg.), Zur Anwendung der Diskursethik in Politik, Recht und Wissenschaft, Ffm, 1992, S. 29 ff

- Die ökologische Krise als Herausforderung für die Diskursethik, in: Böhler, 1994, S. 369 ff

- Rationalitätskriterien und Rationalitätstypen. Versuch einer transzendentalpragmatischen Rekonstruktion des Unterschiedes zwischen Verstand und Vernunft, in: A. Wüstehube (Hg.), Pragmatische Rationalitätstheorien. Studies in Pragmatism, Idealism, and Philosophy of Mind, Würzburg, 1995, S. 29 ff

- Die Vernunftfunktion der kommunikativen Rationalität, in: ders., Die eine Vernunft und die vielen Rationalitäten, Ffm, 1996, S. 17 ff

Arato, Andrew, Procedural Law and Civil Society, in: Rosenfeld, Arato, 1998, S. 26 ff

Arato, Andrew, Cohen, Jean L., Politics and the Reconstruction of the Concept of Civil Society, in: Axel Honneth, Zwischenbetrachtungen: Im Prozeß der Aufklärung, Frankfurt, 1989²

- Civil Society and Democratic Theory, Cambridge, Mass., 1992

Arendt, Hannah, The Human Condition, University of Chicago Press, [1958], 1989

- Wahrheit und Politik, in: dies., Zwischen Vergangenheit und Zukunft, München, 1994, S. 327 ff

Arrow, K. J., Fisher, A. C., Environmental Preservation, Uncertainty, and Irreversibility, Quaterly Journal of Economics, 88, 2, 1974, S. $312 \mathrm{ff}$

Ayres, R. U., Kneese, A. V., Production, Consumption and Externalities, American Economic Review, 59, 1969, S. $282 \mathrm{ff}$

Ayres, R. U., Martinás, K., Waste Potential Entropy: The Ultimate Ecotoxic? in: Économie Appliquée, 1995, 2, S. $95 \mathrm{ff}$

Bargatzky, Thomas, Kulturelle Rekonstruktion von Natur: Mythos, Wissenschaft und der Weg der Physis, in: B. Glaeser, P. Teherani-Krönner (Hrsg.), Human- und Kulturökologie, Opladen, 1992, S. 71 ff

Baringhorst, Sigrid, Zur Mediatisierung des politischen Protests. Von den Institutionen zur 'GreenpeaceDemokratie'? in: Sarcinelli, 1998, S. 326 ff

Barry, Brian, Theories of Justice, A Treatise on Social Justice, Vol. 1, University of California Press, Berkley, Los Angles, 1989

- Justice as impartiality, A Treatise on social Justice, Vol. 2, Oxford u. a., Clarendon Press, 1996 
- Intergenerational Justice, in: ders., 1996, [1977], S. 242 ff

- The Ethics of Resource Depletion [org.: Intergenerational Justice in Energy Policy], in: ders., 1996 [1983], S. $259 \mathrm{ff}$

Bartelmus, P., The Value of Nature - Valuation and Evaluation in Environmental Accounting, in: ders., K. Uno, Environmental Accounting in Theory and Practice, Dordrecht et al., 1998, S. $263 \mathrm{ff}$

Bartelmus, P., Vesper, A., Green Accounting and Material Flow Analysis, Wuppertaler Paper Nr. 106, Wuppertal, 2000

Bartels, A. Grundprobleme der modernen Naturphilosophie, Paderborn et al., 1996

Bartmann, H., Substitutierbarkeit von Naturkapital, in: Held, Nutzinger, 2001, S. 50 ff

Baumol, William J., Oates, Wallace E., The Theory of Environmental Policy, Cambridge University Press, New York, Melbourne, 1975, $1995^{2}$

Baumeister, H., (Hrsg.), Wege zum ökologischen Rechtsstaat, Taunusstein, 1994

Bayertz, Kurt, Verantwortung, Prinzip oder Problem, Darmstadt, 1995

Bechmann, Gotthard, Risiko und Gesellschaft, Opladen, 1993

- Risiko als Schlüsselkategorie der Gesellschaftstheorie, in: ders., 1993, S. 237 ff

- Risiko und der gesellschaftliche Umgang mit Unsicherheit, in V. Preuss (Hg.) Risikoanalysen, Bd. 1, Heidelberg, 1996, $41 \mathrm{ff}$

- Diskursivität und Technikgestaltung, in: S. Köberle, F. Gloede, L. Hennen, (Hrsg.), Diskursive Verständigung? Mediation und Partizipation in Technikkontroversen, Baden-Baden, 1997, S. 151 ff

Bechmann, G., Coenen, R., Gloede, F., Umweltpolitische Prioritätensetzung, Verständigungsprozesse zwischen Wissenschaft, Politik und Gesellschaft, Stuttgart, 1994

Bechmann, G., Grunwald, A. Experimentelle Politik und die Rolle der Wissenschaften in der Umsetzung von Nachhaltigkeit, in: Brand, 2002, S. 113 ff

Beck, Ulrich, Risikogesellschaft, Ffm, 1986

- Gegengifte : die organisierte Unverantwortlichkeit, Ffm, 1988

- Politik in der Risikogesellschaft, Ffm, 1991

- Die Erfindung des Politischen, Ffm, 1993

- Wissen oder Nicht-Wissen? Zwei Perspektiven reflexiver Modernisierung, in: Beck, Giddens, Lash, 1996, S. $289 \mathrm{ff}$

Beck, U., Giddens, A., Lash, S., (Hrsg.), Reflexive Modernisierung, Ffm, 1996.

Beck, U., Holzer, U., Kieserling, A., Nebenfolgen als Problem soziologischer Theoriebildung, in: Beck, Bonß, 2001, S. $63 \mathrm{ff}$

Beckenbach, Frank, Die Wirtschaft der Systemtheorie, in: Das Argument, 1989, 31, 6, S. 887 ff

- Die ökologische Herausforderung für die ökonomische Theorie, Marburg, 1991a

- Zwischen Frosch- und Vogelperspektive: Das Ökologieproblem als Verknüpfung von ökonomischer Entscheidungs- und Reproduktionstheorie, in: ders., 1991b, S. $63 \mathrm{ff}$

- Umweltpolitik aus der Sicht der evolutorischen Ökonomik, in: K. Eicker-Wolf et al. (Hg.), Wirtschaftspolitik im theoretischen Vakuum? Marburg, 1996, S. 323 ff

Beckenbach, Frank, Diefenbacher, Hans, Zwischen Entropie und Selbstorganisation. Perspektiven einer ökologischen Ökonomie, Marburg, 1994

Becker Soest, D. Wink, R., Wer zu spät kommt ... Beschränkungen des Verständnisses marktwirtschaftskonformer Umweltpolitik als versäumte Gelegenheit, in: Zeitschrift für angewandte Umweltforschung, 1996, 4, S. $551 \mathrm{ff}$

Benhabib, Seylia (Hg.), Democracy and Difference: Contesting the boundaries of the political, Princeton University Press, 1996 
Benkert, W., Warum sind Umweltabgaben ebenso populär wie selten? in: Mackscheidt et al., 1994, S. 47 ff

Benz, Arthur, Policies als erklärende Variable in der politischen Theorie, in: A. Benz, W. Seibel, Theorieentwicklung in der Politikwissenschaft - eine Zwischenbilanz, Baden Baden, 1997, S. $303 \mathrm{ff}$

Berkes, F., Folke, C., A Systems Perspective on the Interrelations between natural, human-made and cultural capital, in: Ecological Economics, 5, 1992, S. $1 \mathrm{ff}$

Bergh, J. C. J. M. van den, Materials, Capital, direct/indirect Substitution and Mass Balance Production Funktions, in: Land Economics, 75, 1999, 4, S. 547 ff

Bermbach, U., Überlegungen zur kommunikationstheoretischen Fundierung von Demokratie, in: M. T. Greven, Macht in der Demokratie, Baden-Baden, 1991, S. 239 ff

- Plädoyer für eine ungeteilte Öffentlichkeit, Anmerkungen zum 'normativen Begriff der Öffentlichkeit von Jürgen Habermas, in: Göhler, 1995, 25 ff

Bettschneider, Frank Agenda Setting. Forschungsstand und politische Konsequenzen, in: Jäckel, WinthoffSpurk, Politik und Medien, 1994, $211 \mathrm{ff}$

Beuning, Leonie, Nocke, Joachim, Environmental Officers: A Viable Concept for Ecological Management?, in: Teubner, Farmer, Murphy, 1994, S. $267 \mathrm{ff}$

Beuß, Wolfgang, Vom Risiko: Unsicherheit und Ungewißheit in der Moderne, Hamburg, 1995

Biermann, Frank, Stand und Fortentwicklung der internationalen Klimapolitik, WZB-Paper, Berlin, 2000a

- Die POP-Konvention: das neue Chemikalien-Regime der Vereinten Nationen, in: Zeitschrift für angewandte Umweltforschung, 13, 2000b, 1/2, S.138 ff

Biesecker, Adelheid, Habermas und die ökonomische Wissenschaft - Überlegungen zur lebensweltlichen Orientierung der Wirtschaftstheorie, Diskussionsbeiträge Nr. 1 (April 1992) des Instituts für Ökonomie und soziales Handeln, Bremen, 1992

Biesecker, A., Hofmeister, S., Vom nachhaltigen Naturkapital zur Einheit von Produktivität und Reproduktivität - Reproduktion als grundlegende Kategorie des Wirtschaftens, in: Held, Nutzinger, 2001, S. $154 \mathrm{ff}$

Bievert, B., Held, M., Veränderungen im Naturverständnis der Ökonomik, in: dies. (Hg.), Das Naturverständnis der Ökonomik, Frankfurt, New York, 1994, S. 7 ff

Binder, Manfred, Die Operationalisierung umweltpolitischen Erfolgs: Probleme und Lösungsansätze, in: Jänicke, 1996, S. $133 \mathrm{ff}$

Binswanger, Mathias, From Microscopic to Macroscopic Theories: Entropic Aspects of Ecological and Economic Processes, Ecological Economics, 8, 1993, S. 209 ff [erweiterte dt. Fassung als: Das Entropiegesetz als Grundlage einer ökologischen Ökonomie, in: Beckenbach, Diefenbacher, 1994, S. 155 ff]

Birnbacher, Dieter, Rawls' Theorie der Gerechtigkeit und das Problem der Gerechtigkeit zwischen Generationen, in: Zeitschrift für philosophische Forschung, 31, 1977, S. 385 ff

- Ökologie und Ethik, Stuttgart, 1980

- Verantwortung für zukünftige Generationen, Stuttgart, 1988

Bizer, Handelbare Flächenausweisungsrechte zur Lenkung der gemeindlichen Ausweisung von Siedlungsund Verkehrsflächen, in: Köhn, Welfens, 1996, S. 367 ff

Blanke, Thomas, Lernprozesse im Recht: Von der Ökologie der Moral zur Moral der Ökologie, in: Donner et al., 1989, S. $183 \mathrm{ff}$

- Sanfte Nötigung, in: Kritische Justiz, 27, 1994, S. 439 ff

Blazejczak, J., Krähmer, D., Mit Markt zu Nachhaltigkeit? Möglichkeiten und Grenzen einer Bestimmung von Nachhaltigkeitszielen durch marktwirtschaftliche Mechanismen, in: Mez, Weidner, 1996, S. $223 \mathrm{ff}$

Bleischwitz, Raimund, Ressourcenproduktivität, Berlin, et al., 1998 
- Cognitive and Institutional Perspectives of Eco-Efficiency, Wuppertaler Paper Nr. 123, Wuppertal, 2002

Blöchliger, Hansjörg, Staehelin-Witt, Elke, Die Umweltzentralbank: Ein ordnungspolitischer Vorschlag, Institut für Politische Bildung Forschung und Politikberatung der Friederich Naumann Stiftung, Königswinter, 1992

Blumenthal, Julia von, Auswanderung aus den Verfassungsinstitutionen, in Aus Politik und Zeitgeschichte, B 43, 2003, S. 9 ff

Bobbio, Noberto., Gramsci and the concept of Civil Society, in: John Keane (ed.), Civil Society and the State, London, New York, 1988, S. 73 ff

Böcher, M., Umweltpolitisch reformunfähige Demokratie? in: A. Gourd, T. Noetzel, Zukunft der Demokratie in Deutschland, Opladen, 2001, S. 399 ff

Bode, Otto F., Ökofiskus 'Umweltzentralbank' als Instrument der Ökologisierung des Wirtschaftssystems, Venlo, 1999

Böhler, Dieter, Ethik für die Zukunft, München, 1994

- In dubio contra projectum. Mensch und Natur im Spannungsfeld von Verstehen, Konstruieren, Verantworten, in: ders., 1994, S. 244 ff

Böhm, M., Möglichkeiten und Grenzen einer Prozeduralisierung des Umweltrechts, in: Roßnagel, Neußer, 1996, S. $193 \mathrm{ff}$

- Institutionelle Rahmenbedingungen symbolischer Umweltpolitik, in Hansjürgens, Lübbe-Wolff, 2000, S. $239 \mathrm{ff}$

Bohne, Eberhard, Absprachen zwischen Industrie und Regierung in der Umweltpolitik, in: Jahrbuch für Rechtssoziologie und Rechtstheorie, Bd. 8, 1982, S. 266 ff

- Informales Verwaltungs- und Regierungshandeln als Instrument des Umweltschutzes, in: Verwaltungsarchiv, 75, 1984, S. $343 \mathrm{ff}$

Bonß, Wolfgang, Die Rückkehr der Unsicherheit: Zur gesellschaftstheoretischen Bedeutung des Risikobegriffs, in G. Banse (Hrsg.) Risikoforschung zwischen Disziplinarität und Interdisziplinarität. Von der Illusion der Sicherheit zum Umgang mit Unsicherheit, Berlin. 1996, S. 165 ff

- Die gesellschaftliche Konstruktion von Sicherheit, in: E. Lippert, A. Prüfert, G. Wachtler, Sicherheit in der unsicheren Gesellschaft, Opladen, 1997, S. $21 \mathrm{ff}$

Bonß, W., Beck, U., (Hrsg.), Die Modernisierung der Moderne, Ffm, 2001

Bonß, W., Hohl., J., Jakob, A., Die Konstruktion von Sicherheit in der reflexiven Moderne, in: Bonß, Beck, 2001, $147 \mathrm{ff}$

Bonß, W., Hohlfeld, R. Kollek, R., Vorüberlegungen zu einem kontextualistischen Modell der Wissenschaftsentwicklung, in: Deutsche Zeitschrift für Philosophie, 42, 1994, 3, S. 439 ff

Bonus, H., Umweltzertifikate, Zeitschrift für angewandte Umweltforschung - Sonderheft 9, 1998

Bonus, H., Häder, M., Zertifikate und Neue Institutionenökonomik, in: Bonus, 1998, S. 32 ff

Bora, A., Gesellschaftliche Integration durch Verfahren - Zur Funktion von Verfahrensgerechtigkeit in der Technikfolgenabschätzung und -bewertung, in: Zeitschrift für Rechtssoziologie, 14, 1993, 1, S. 55 ff

- Inklusion und Differenzierung: Bedingungen und Folgen der 'Öffentlichkeitsbeteiligung' im Recht, in: van den Daele, Neidhardt, 1996, S. $371 \mathrm{ff}$

Böschen, Stefan, Risikogenese, in: Soziale Welt 2002, 1, S. 67 ff

Boulding, K.E., The Economics of the Coming Spaceship Earth, in: H. Daly (ed.), Toward a Steady-State Economy, San Francisco, 1973 [1966], S. 121 ff

Bouman, M., et al., Material flows and economic models: an analytical comparison of SFA, LCA and partial equilibrium models, in: Ecological Economics, 2000, $195 \mathrm{ff}$ 
Branahl, Udo Der Schutz des Privaten im öffentlichen Diskurs, in K. Imhof, P. Schulz (Hrsg.), Die Veröffentlichung des Privaten - Die Privatisierung des Öffentlichen, Opladen, 1998, $180 \mathrm{ff}$

Brand, Karl-Werner, Der ökologische Diskurs. Wer bestimmt Themen, Formen und Entwicklung der öffentlichen Umweltdebatte? in: Gerhard de Hann, 1995, S. 47 ff

- (Hrsg.), Nachhaltige Entwicklung. Eine Herausforderung an die Soziologie, Opladen, 1997

- (Hrsg.), Politik der Nachhaltigkeit: Voraussetzungen, Probleme Chancen - eine kritische Diskussion, Berlin, 2002

Brand, Karl-Werner, Eder, Klaus, Poferl, Angelika, Ökologische Kommunikation in Deutschland, Opladen, 1997

Brandt, S., Systemzeit und Zeit sozialer Systeme. Zeitverständnis des Common Sense als evidenzsichernde Größe?, in: Krawietz, Welcker, 1992, S. 162 ff

Braun, Dietmar, Zur Steuerbarkeit funktionaler Teilsysteme: Akteurstheoretische Sichtweisen funktionaler Differenzierung moderner Gesellschaften, in: Heritièr, 1993, S. 199 ff

- Der Einfluß von Ideen und Überzeugungssystemen auf die politische Problemlösung, in: Politische Vierteljahresschrift, 39, 1998, 4, S.797 ff

- Gemeinwohlorientierung im modernen Staat, in: Schimank, Werle, 2000, S. 125 ff

Braun, Dietmar, Busch, Andreas (eds.), Public Policy and Political Ideas, Edward Elgar, Cheltenham, Northhampton, 1999

Breuning, L., Nocke, J., Environmental Officers, in: Teubner et al., 1994, 267 ff

Bringezu, Stefan, Umweltpolitik, München, 1997

Bringezu, S., Schütz, H., Analyse des Stoffverbrauchs der deutschen Wirtschaft. Status quo, Trends und mögliche Prioritäten für Maßnahmen zur Erhöhung der Ressourcenproduktivität, in: Köhn, Welfens, 1996, S. $227 \mathrm{ff}$

Brumlik, Micha, Über die Ansprüche Ungeborener und Unmündiger, in: Kuhlmann, 1986, S. 265 ff

Bruyn, S. de, The need to change attractors, in: Ökologisches Wirtschaften, 1999, 3, S. 15 ff

Bruyn, S. de, Bergh, J. van den, Opschoor, H., Structural Change, Growth, and Dematerialization: An Empirical Analysis, in: van Bergh, van der Straaten, 1997, S. $201 \mathrm{ff}$

- Economic growth and emissions: reconsidering the empirical basis of environmental Kuznets curves, in: Ecological Economics, 25, 1998, S. $161 \mathrm{ff}$

Brunkhorst, Hauke, Niesen, Peter, (Hrsg.), Das Recht der Republik, Ffm, 1999

Bruvoll, Annegrete, Taxing Virgin Materials: an Approach to Waste Problems, in: Resources, Conservation \& Recycling, vol. 22, 1998, 1-2, S. $15 \mathrm{ff}$

Bruvoll, Annegrete, Ibenholt, Karin, Green Throughput Taxation, in: Environmental and Resource Economics, 12, 1998, S. $387 \mathrm{ff}$

Buchanan, J.M., The Limits of Liberty, Chicago u. a., Univ. of Chicago Press, 1975

Buchanan, James M., Tullock, G., Polluters Profits and Political Response: Direct control versus Taxes, in: American Economic Review 66, 1976, S. 983 ff

Buchanan, James M., Tullock, G., The Calculus of Consent. Logical Foundations of Constitutional Democracy, Ann Arbor, 1965

BUND, Misereror, Zukunftsfähiges Deutschland. Ein Beitrag zu einer nachhaltigen Entwicklung, Basel, Boston, Berlin, 1996

Bültmann, A., Wätzold, F., Die EG-Öko-Audit-Verordnung im verflixten siebten Jahr, in: APuZ, 1999, B 48, S. $30 \mathrm{ff}$

Burkhardt, Johannes, Das Haus, der Staat und die Ökonomie. Das Verhältnis von Ökonomie und Politik in der neuzeitlichen Institutionengeschichte, in: Göhler et al., 1990, S.155 ff 
Canzler, Weert, Dierkes, Meinolf, Informationelle Techniksteuerung: öffentliche Diskurse und Leitbildentwicklung, in: Simonis et al., 2000, S. $457 \mathrm{ff}$

Christensen, P. P., Historical Roots for Ecological Economics - Biophysical versus Allocative Approaches, in: Ecological Economics, 1, 1989, S. $17 \mathrm{ff}$

Cleveland, Cutler J., Natural Resource Scarcity and Economic Growth Revisited: Economic and Biophysical Perspectives, in: Constanza, 1991, S. $289 \mathrm{ff}$

Cleveland, C. J., Ruth, M. When, where and by how much do biophysical limits constrain the economic process? in: Ecological Economics, 22, 1997, S. $203 \mathrm{ff}$

Coase, Ronald, the Problem of Social cost, in: Journal of Law and Economics, 1960, S. $1 \mathrm{ff}$

Cohen, Jean L., Discourse Ethics and Civil Society, in: Honneth et al., 1989, S. 315 ff

Cohen, Joshua, Deliberation and Democratic Legitimacy, in: Goodin, Pettit, 1997, [1989], S. 143 ff

- Procedure and Substance in Deliberative Democracy, in: Benhabib, 1996, S. $95 \mathrm{ff}$

Cohen, Maurie J., Risk Society and Ecological Modernisation, in: Futures, Vol. 29, 1997, 2, S. 105 ff

Common, Mick, Perrings, Charles, Towards an Ecological Economics of Sustainablity, in: Ecological Economics, 6, 1992, S. 7 ff

Conrad, Jobst, Forschungsstrategische Schlußfolgerungen aus den Erkenntnissen der Umweltpolitologie, in: Mez, Weidner, 1997[a], S. $355 \mathrm{ff}$

- Nachhaltige Entwicklung - ein ökologisch modernisiertes Modell der Moderne? in: Brand, 1997[b], S. 51 ff

- Unternehmensexterne Determinanten betrieblichen Umweltmanagements, in: L. Mez, M. Jänicke, Sektorale Umweltpolitik: Analysen im Industrieländervergleich, Berlin, 1997c, S. $83 \mathrm{ff}$

Costanza, Robert, Embodied Energy and Economic Valuation, Science, 210, 1980, S. $1219 \mathrm{ff}$

- (ed.), Ecological Economics, Columbia University Press, New York, 1991

Constanza, R., Segura, O., Martinez-Alier, J., Getting Down To Earth: Practical Applications of Ecological Economics, Washington, Island Press, 1996

Costanza R., et al. Einführung in die Ökologische Ökonomik, Stuttgart, 2001

Czada, Roland, Legitimation durch Risiko - Gefahrenvorsorge und Katastrophenschutz als Staatsaufgaben, in: Simonis et al., 2000, S. $319 \mathrm{ff}$

Czada, R., Schimank, U., Institutionendynamik und politische Institutionengestaltung - Die zwei Gesichter sozialer Ordnungsbildung, in: Werle, Schimank, 2000, S. $23 \mathrm{ff}$

Czempiel, Ernst-Otto, Rosenau, James N., Governance without government : order and change in world politics, Cambridge u. a., Cambridge Univ. Press, 1992

Dahl, Robert A., Procedural Democracy, in: Goodin, Pettit, [1979], 1997, S. 109 ff

Daly, Herman E., Steady-State Economics, Washington, (1977), $1991^{2}$

- Towards an Environmental Macroeconomics, in: Land Economics, 67, 2, 1991, S. 255 ff

- Allocation, distribution, and scale: towards an economics that is efficient, just, and sustainable, in: Ecological Economics, 6, 1992, S. $185 \mathrm{ff}$

- The Economic Growth Debate: What some Economics Have Learned but Many Have Not, in: R. Krishnan, J. M. Harris (eds.), A Survey of Ecological Economics, Island Press, Washington D.C., 1995, S. $125 \mathrm{ff}$

Dasgupta, P., Heal, G., The Optimal Depletion of Exhaustible Resources, in: Review of Economic Studies, Vol. XLI, 1974, S. $3 \mathrm{ff}$

de Bruyn, Sander, The need to change attractors, in: Ökologisches Wirtschaften, 1999, 3, S. 15 ff

de Bruyn, Sander, van den Bergh, Joreon, Opschoor, Hans, Structural Change, Growth, and Dematerialization: An Empirical Analysis, in: van den Bergh, van der Straaten, 1997, S. $201 \mathrm{ff}$ 
- Economic growth and emissions: reconsidering the empirical basis of environmental Kuznets curves, in: Ecological Economics, 25, 1998, S. $161 \mathrm{ff}$

Decker, Frank, Umweltschutz und Staatsversagen, Opladen, 1994

de Hann, Gerhard, Umweltbewußtsein und Massenmedien, Perspektiven ökologischer Kommunikation, Berlin, 1995

- Ökologische Kommunikation. Der Stand der Debatte, in: ders., 1995, S. 17 ff

Denninger, Erhard, Der Präventions-Staat, in: Kritische Justiz, 1988, 1, S. 1 ff

- Wissenschaftlich-technischer Sachverstand und staatliche Technologiesteuerung durch Recht, in: A. Honneth et al. (Hrsg.), 1989, S. 627 ff

Deutscher Bundestag (Hrsg.), Klimaänderung gefährdet globale Entwicklung, Economica Verlag, Bonn, 1992

- Wege zum nachhaltigen Umgang mit Stoff- und Materialströmen, Economica Verlag, Bonn, 1993

- Die Industriegesellschaft gestalten, Economica Verlag, Bonn, 1994

D'Haese, Mariget, Die Bedeutung von Umweltzeichen, in: Gerhard de Hann, 1995, S. 157 ff

Dienel, Peter C., Zur Funktionalität technologie- und umweltpolitischer Konflikte für die Modernisierung der Demokratie, in: Zilleßen, Dienel, Strubelt, 1993, S. 59 ff

Dietz, F., Straaten, J. van der, Umweltökonomie auf dem Prüfstand: das fehlende Glied zwischen ökonomischer Theorie und Umweltpolitik, in: Beckenbach, 1991, S. 239 ff

Dietz, Simone, Lebenswelt und System, Würzburg, 1993

- Die Legitimationsmacht der Öffentlichkeit: Die öffentliche Meinung der Mediendemokratie, Göhler, 1995, S. $115 \mathrm{ff}$

Diekmann, Andreas, Carlo C. Jaeger, Umweltsoziologie, Kölner Zeitschrift für Soziologie und Sozialpsychologie, Sonderheft 36, 1996

Diekmann, Andreas, Sozialkapital und das Kooperationsproblem in sozialen Dilemmata, Analyse \& Kritik, 1, 15, 1993, S. $22 \mathrm{ff}$

Diekmann, Andreas, Preisendörfer, Peter, Zur scheinbaren Widerlegung der Low-cost Hypothese. Kommentar zu Steffen Kühnels und Sebastian Bambergs Untersuchung umweltgerechten Verkehrsverhaltens , Zeitschrift für Soziologie, 27, 1998a, 4, S. $273 \mathrm{f}$

- Umweltbewußtsein und Umweltverhalten in Low- und High-Cost-Situationen, Eine empirische Überprüfung der Low-cost-Hypothese, Zeitschrift für Soziologie, 27, 1998b, 6, S. $438 \mathrm{ff}$

Dolata, Ulrich, Risse im Netz - Macht, Konkurrenz und Kooperation in der Technikentwicklung und regulierung, in: Simonis et al., 2000, S. $37 \mathrm{ff}$

Donati, Paolo R., Die Rahmenanalyse politischer Diskurse, in: Keller et al., 2001, S. 145 ff

Donner, H., Magoulas, G., Simonis, J., Wolf, R. (Hrsg.), Umweltschutz zwischen Staat und Markt, BadenBaden, 1989

Dorschel, Andreas, Kettner, Matthias, Systemrationalität? in: K.-O. Apel, M. Kettner, Die eine Vernunft und die vielen Rationalitäten, Ffm, 1996, S. 349 ff

Downs, Anthony, An Economic Theory of Democracy, New York, [1957] 1968

- Up and Down with Ecology - The Issue-Attention Cycle, The Public Interest, 28, Summer 1972, S.38 ff

Dryzek, John S., Discursive Democracy, Cambridge, 1990

- The Politics of the Earth, Environmental Discourses, Oxford University Press, 1997

Duales System Deutschland (Hrsg.), Der Grüne Punkt und sein Nutzen für die Umwelt, Studie des ÖkoInstituts e.V. im Auftrag der DSD AG, Köln, 2002 a

- Nachhaltigkeitsbewertung und Perspektiven des Duales Systems in Deutschland, Studie der Prognos AG im Auftrag der DSD AG, Köln, 2002 b 
Dubourg, R., Pearce, David, Paradigms for Environmental Choice - Sustainability versus Optimality, in: Faucheux et al., 1996, S. $21 \mathrm{ff}$

Duchin, F., Ecological Economics: The Second Stage, in: Costanza et al., 1996, S. $285 \mathrm{ff}$

Dunn, William N., Policy Reforms as Arguments, in: Fischer, Forester, 1993, S. 254 ff

Ebeling, W., Modelle der Selbstorganisation, in: Beckenbach, 1991, S. 341 ff

- Selbstorganisation und Entropie in ökologischen und ökonomischen Prozessen, in: Beckenbach, Diefenbacher, 1994, S. $29 \mathrm{ff}$

Edelmann, Murray, Politik als Ritual, Die symbolische Funktion staatlicher Institutionen und politischen Handelns, Ffm, New York, 1976

Eder, Klaus, Prozedurale Rationalität, Moderne Rechtsentwicklung jenseits von formaler Rationalisierung, in:. Zeitschrift für Rechtssoziologie, 7, 1986, 1, S. 1 ff

- Die Autorität des Rechts, Eine soziale Kritik prozeduraler Rationalität, in: Zeitschrift für Rechtssoziologie 8, 1987, 2, S. $193 \mathrm{ff}$

- Institutionenwandel und Demokratie, in: H.-H. Hartwich (Hrsg.), Macht und Ohnmacht politischer Institutionen, Opladen, 1989, S. $110 \mathrm{ff}$

- Prozedurales Recht und Prozeduralisierung des Rechts: Einige begriffliche Klärungen, in: Grimm, 1990, S. $155 \mathrm{ff}$

- Einleitung zu: Brandt et al., 1997, S. $23 \mathrm{ff}$

Eichner, Volker, Heinze, Rolf G., Voelzkow, Helmut, Von staatlicher Technikfolgenabschätzung zu gesellschaftlicher Techniksteuerung, in: Aus Politik und Zeitgeschichte, B 43/91, S. 3 ff

Ellwein, Thomas, Joachim J. Hesse, (Hrsg.); Staatswissenschaften: Vergessene Disziplin oder neue Herausforderung?, Baden-Baden, 1990

El Serafy, S., The Environment as Capital, in: Constanza, 1991, S. $168 \mathrm{ff}$

Endres, Alfred, A Sketch on Sustainabilty, in: Zeitschrift für Umweltpolitik und Umweltrecht, 2/1993, S.177 ff

- Umweltökonomie, Darmstadt, 1994

Endres, A., Rehbinder, E., Schwarze, R., Umweltzertifikate und Kompensationslösung aus ökonomischer und juristischer Sicht, Berlin u.a., 1992a

- Haftung und Versicherung für Umweltschäden aus ökonomischer und juristischer Sicht, Berlin u.a., 1992b

Endres, A., Marburger, P., Umweltschutz durch gesellschaftliche Selbststeuerung: gesellschaftliche Umweltnormierung und Umweltgenossenschaften, Bonn, 1993

Endres, A., R. Schwarze, Umweltnormen als gesellschaftliche Zielwerte: Über Möglichkeiten und Grenzen der Nutzen-Kosten-Analyse in der Umweltpolitik, in: Endres, Marburger, 1993, S. 49 ff

Endres, Alfred, Immo Querner, Die Ökonomie natürlicher Ressourcen, Darmstadt, 1993

Epp, A., Divergierende Konzepte von Verfahrensgerechtigkeit. Eine Kritik der Procedural Justice Forschung, WZB-Paper FS II 98-302, Berlin, 1998

Ehrlich, Paul R. et al., Knowledge and the Environment, in: Ecological Economics, 30, 1999, S. $267 \mathrm{ff}$

Euchner, Walter, Hampel, Frank, Seidl, Thomas, Länder-Enquete-Kommissionen als Instrumente der Politikberatung, Baden-Baden, 1993

Evers, Adelbert., Umgang mit Unsicherheit. Zur Sozialwissenschaftlichen Problematisierung einer sozialen Herausforderung, in: G. Bechmann, Risiko und Gesellschaft, Opladen, 1993, S. 339 ff

Ewers, Hans-Jürgen, Rennings, Klaus, Quantitative Ansätze einer rationalen umweltpolitischen Zielbestimmung, in: Zeitschrift für Umweltpolitik und Umweltrecht, 4/1996, S.413 ff 
Ewers, Hans Jürgen, Tegner, Henning, Schatz, Matthias, (u. Mitarbeit von Katharina Kluth), ausländische Modelle der Verpackungsverwertung: Das Beispiel Großbritannien, Paper der TU Berlin/Wirtschaftsund Infrastrukturpolitik, 2002, [http://wip.tu-berlin.de]

Faber, Malte, Niemes, Horst, Stephan, Gunter, Entropie, Umweltschutz und Rohstoffverbrauch, Heidelberg, etc., 1983

Faber, Malte, Stephan, G., Michealis, P., Umdenken in der Abfallwirtschaft, Heidelberg, etc., $1989^{2}$

Faber, Malte, Proops, John L.R., Evolution, Time, Production and the Environment, Heidelberg, 1990

Faucheux, Sylvie, Energy Analysis and Sustainable Development, in: R. Pethig (ed.), Valuing the Environment: Methodological and Measurement Issues, Dordrecht, 1994, S. $325 \mathrm{ff}$

Faucheux, S., Pillet, G., Energy Metrics: On various Valuation Properties of Energy, in: R. Pethig (ed.), Valuing the Environment: Methodological and Measurement Issues, Dordrecht, 1994, S. $273 \mathrm{ff}$

Faucheux, S., Froger, G., Noël, J.-F., Quelle hypothèse de rationalité pour le développement soutenable, in: Economie Appliquée 1993, 4, S. 59 ff

Faucheux, S., G. Froger, Decision-making under environmental uncertainty, in: Ecological Economics, 1995, S. $29 \mathrm{ff}$

Faucheux, S., Pearce, D., Proops, J., Models of Sustainable Development, Cheltenham, UK, 1996

Faucheux, S., Froger, G., Munda, G., Toward an Integration of Uncertainty, Irreversibility, and Complexity in Environmental Decision Making, in: van den Bergh, Joreon, van der Straaten, 1997, S. 50 ff

Faucheux, S., et al. Neoclassical Natural Capital Theory and 'Weak' Indicators for Sustainability, in: Land Economics, 1997, 4, S. 528 ff

Feess-Dörr, E., Steger, U., Weihrauch, P., Sustainable Development - Nachhaltige und dauerhafte Entwicklung: Ein ökologisch relevantes und wirksames Leitbild ökonomischer Entscheidungen? in: U. Steger, M. Timmermann (Hrsg.), Mehr Ökologie durch Ökonomie?, Berlin et al., 1993, S. 93 ff

Feinberg, Joel, Die Rechte der Tiere und zukünftige Generationen, in: D. Birnbacher (Hg.), Ökologie und Ethik, Stuttgart, 1980, S. $140 \mathrm{ff}$

Feindt, Peter-Henning, Politik der Nachhaltigkeit und funktionale Differenzierung, in: Brand, 2002, S. $161 \mathrm{ff}$

Feser, Hans-Dieter Hauff, Michael von (Hrsg.), Neuere Entwicklungen in der Umweltökonomie und -politik, Regensburg: Transfer-Verl., 1997

Fischer, Frank, Bürger, Experten und Politik nach dem "Nimby"-Prinzip: ein Plädoyer für die partizipatorische Policy Analyse, in: Héritier, 1993, S. 451 ff

Fischer, Frank, Forester, John, The Argumentative Turn in Policy Analysis and Planning, Durham, 1993

Fischer-Kowalski, Marina, On the political capacity to regulate society's metabolism, in: Mez, Weidner, 1997, S. $263 \mathrm{ff}$

Fischer-Kowalski, Marina, et al., Gesellschaftlicher Stoffwechsel und Kolonialisierung von Natur, Amsterdam, 1997

Fischer-Kowalski, M., Weisz, H., Gesellschaft als Verzahnung materieller und symbolischer Welten, in: K.W. Brand (Hrsg.) Soziologie und Natur. Theoretische Perspektiven, Opladen, 1998, S. $145 \mathrm{ff}$

Fjelland, Regnar, Natur und instrumentelle Vernunft. Bemerkungen zu Marcuse, Habermas und Apel, in: G. Skirbekk, D. Böhler, T. Nordenstam (Hrsg.), Die pragmatische Wende, Ffm, 1986, S. 239 ff

Foijanty-Jost, G., Industriepolitik in Japan - Ansätze für einen strukturpolitischen Umweltschutz?, in: Internationales Asienforum, 1991, 3-4, S. 279 ff

Forbath, William E., Short Circuit, in: Rosenfeld, Arato, 1998, S. 272 ff

Forsthoff, E., Der Staat der Industriegesellschaft, München, 1971 
Foy, G., Daly, H., Allocation, distribution and scale as determinants of environmental degradation: case studies of Haiti, El Salvador and Costa Rica, in: A. Markandya, J. Richardson (ed.), Environmental Economics, London, 1992, S. $294 \mathrm{ff}$

Freitag, Markus, Vatter, Adrian, Müller, Christoph, Bremse oder Gaspedal? Eine empirische Untersuchung zur Wirkung der direkten Demokratie auf den Steuerstaat, in: Politische Vierteljahresschrift, 44, 2003, 3, S. $384 \mathrm{ff}$

Frey, B. S., Schneider, F., Warum wird die Umweltökonomik kaum angewendet? in: Zeitschrift für Umweltpolitik 2, 1997, S. $153 \mathrm{ff}$

Frey, Bruno S., Kirchgässner, Gebhard, Diskursethik, Politische Ökonomie und Volksabstimmung, in: Analyse \& Kritik, 5, 1993, 2, S. 29 ff

Frick, Siegfried, Bessere Steuerung durch 'Intermediäre Institutionen'? in: Köhn, Welfens, 1996, S. 285 ff

Fröhlich, M., et al. Wieviel wiegt Nachhaltigkeit? Entwurf für ein Paper des Wuppertaler Instituts, SERIServer, 1999-2000, [http://www.seri.at/deutschpublikationen.htm]

Führ, M., Proaktives unternehmerisches Handeln - unverzichtbarer Beitrag zum präventiven Stoffstrommanagement, in: Zeitschrift für Umweltpolitik, 1994, S. $445 \mathrm{ff}$

- Eigen-Verantwortung oder Öko-Staat? Sicherung der Selbstverantwortung in Unternehmen, in: Roßnagel, Neuser, 1996, S. $211 \mathrm{ff}$

- Ökologische Stoffwirtschaft, Vom Gefahrstoffrecht zum Stoffstrommanagement, in:: Kritische Justiz, 1997, $159 \mathrm{ff}$

Funtowicz, S. O., Ravetz, J. R., Three Types of Risk Assessment and the Emergence of Post-Normal Science, in: S. Krimsky, D. Golding (eds.): Social Theories of Risk, Westport (Connecticut), London, 1992, S. $251 \mathrm{ff}$

- Science for the post-normal-age. in: Futures. 1993, 7, S. $739 \mathrm{ff}$

- The worth of a songbird: Ecological Economics as a post-normal science, in: Ecological Economis 1994a, 10, S. $197 \mathrm{ff}$

- Emergent complex systems, in: Futures, 1994b, 6, S. 568 ff

Funtowicz, S., O'Connor, M., J. Ravetz, Emergent Complexity and Ecological Economics, in: Bergh et al., 1997, S. $75 \mathrm{ff}$

Fürst, D., Diversifikation staatlicher Steuerungsinstrumente, in: Ellwein, Hesse, 1990, S. $291 \mathrm{ff}$

- Abgabelösung - Schritte zu einem neuen Konzept staatlicher Steuerung? in: Mackscheidt et al., 1994, S. $33 \mathrm{ff}$

- Schwierigkeiten der fachübergreifenden Koordination, in: Brand, 2002, S. 179 ff

Fürst, D., Henke, K.-D., Zwischen Wunsch und Realität: Ökologische Erneuerung des Industriestaates, in: Jahrbuch für Staats- und Verwaltungswissenschaften, Band 2, 1988, S. 305 ff

Gauthier, David, Morals by Agreement, Oxford, Clarendon Press, 1986

Gawel, Erik, Ökonomie der Umwelt - ein Überblick über neuere Entwicklungen, Zeitschrift für angewandte Umweltforschung, 7, 1994, 1, S. 37 ff

- Neoklassische Umweltökonomie in der Krise? Kritik und Gegenkritik, in: Köhn, Welfens, 1996, S. 45 ff

- Theoretische Annäherungen: Zur Neuen Politischen Ökonomie der Umweltabgabe, Ökologisierung des Steuer- und Abgabensystems. Übergangsproblem und umweltpolitische Implikationen, in: Benkert et al., 1995, S. $47 \mathrm{ff}$

- Internalisierung durch das Ordnungsrecht - eine ökonomische Betrachtung, in: Zeitschrift für Umweltpolitik, 1996, 4, S. $521 \mathrm{ff}$

- Das Elend der Stoffstromökonomie. Eine Kritik, in: Konjunkturpolitik, Jg. 44, 1998, S. 173 ff 
- Konzeptionen und Instrumente zur Realisierung von Produktverantwortung im Abfallrecht - eine ökonomische Analyse, Reprints aus der Max-Planck-Projektgruppe Recht der Gemeinschaftsgüter, Bonn, 1999/4

Gehring, Thomas, Regieren im internationalen System. Verhandlungen, Normen und Internationale Regime, in: Politische Vierteljahresschrift, 36, 1995, S. 197 ff

- Arguing und Bargaining in internationalen Verhandlungen. Überlegungen am Beispiel des Ozonschutzregimes, in: v. Prittwitz, 1996, S. $207 \mathrm{ff}$

Georgescu-Roegen, N., The Entropy Law and the Economic Problem, in: Daly, Townsend, Valuing the Earth, MIT Press, 1994, S. 75 ff

Gerhards, Jürgen, Diskursdimensionen und Diskursstrategien mobilisierter Protestakteure, in: Journal für Sozialforschung, 32, 1992, S. $307 \mathrm{ff}$

- Politische Veranstaltungen in der Bundesrepublik. Nachfrager und wahrgenommenes Angebot einer 'kleinen' Form von Öffentlichkeit. in: Kölner Zeitschrift für Soziologie und Sozialpsychologie 44, 1992, S. $766 \mathrm{ff}$

- Diskursive versus liberale Öffentlichkeit. Eine empirische Auseinandersetzung mit Jürgen Habermas, in: Kölner Zeitschrift für Soziologie und Sozialpsychologie, Bd. 49 (1997), 1, S. 1 ff

Gerhards, J., Neidhardt, F., Strukturen und Funktionen moderner Öffentlichkeit, WZB-Paper, Berlin, 1993

Gerken, L. (Hrsg.), Ordnungspolitische Grundfragen einer Politik der Nachhaltigkeit, Baden-Baden, 1996

Gerstenberger, Oliver, Bürgerrechte und deliberative Demokratie. Elemente einer pluralistischen Verfassungstheorie, Ffm, 1997

Gesetz über die Umweltverträglichkeitsprüfung (UVPG), vom 5. September 2001 (BGBl. I Nr. 48 vom 19.9. 2001 S. 2350, S. 3762; 25.3.2002 S. $\underline{1193}$; 18.6.2002 S. 1914)

Gesetz über die Umweltverträglichkeit von Wasch- und Reinigungsmitteln (WRMG - Wasch- und Reinigungsmittelgesetz), vom 5. März 1987 (BGBl. I S. 875; ...; 1994 S. 1440; 2000 S. 632, 2001 S. 2331, 29.10.2001 S 2785 Art. 155)

Gesetz über Naturschutz und Landschaftspflege (BNatSchG - Bundesnaturschutzgesetz), vom 25. März 2002 (BGBl. I Nr. 22 vom 3.4.2002 S. 1193)

Gesetz zum Schutz vor gefährlichen Stoffen (ChemG - Chemikaliengesetz), vom 20. Juni 2002 (BGBl. Teil I Nr. 40 vom 27.06.2002 S. 2090; 6.8.2002 S. 3082) (Hinweise auf Änderungen vom 20.6. 2002, BGBl I Nr. 40, 27.6. 2002 S. $2076 \underline{02})$

Gesetz zum Schutz vor schädlichen Umwelteinwirkungen durch Luftverunreinigungen, Geräusche, Erschütterungen und ähnliche Vorgänge (BImSchG - BundesImmissionsschutzgesetz), vom 26. September 2002 (BGBl. I Nr. 71 vom 04.10.2002, S. 3830) (vorherige Änderungen BGBl. I 21.8.2002 S. 3322 02; 11.9.2002 S. 362202a)

Gesetz zur Förderung der Kreislaufwirtschaft und Sicherung der umweltverträglichen Beseitigung von Abfällen (KrW-/AbfG - Kreislaufwirtschafts- und Abfallgesetz), vom 27. September 1994, (BGBl. I

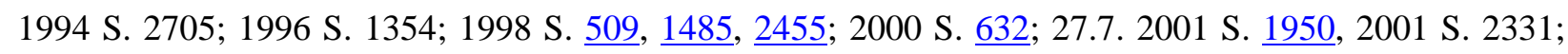
29.10.2001. S. 2785 Art. 57; 21.8.2002 S. 3322 02)

Gesetz zur Ordnung des Wasserhaushalts (WHG - Wasserhaushaltsgesetz), vom 19. August 2002 (BGBl. I Nr. 59 vom 23.8.2002 S. 3245)

Gethmann, C. F., Kloepfer, M., Handeln unter Risiko im Umweltstaat, Berlin et al., 1993

Geyer, Matthias, Smoltczyk, Alexander, Die Dosenrepublik, in: Der Spiegel, Nr. 32, 4. 8. 2003, S. 38 ff

Gill, B., Reflexive Modernisierung und technisch-industriell erzeugte Umweltprobleme, in: Zeitschrift für Soziologie, 1999, S. $182 \mathrm{ff}$ 
Godard, Oliver, Autonomie socio-économique et externalisation de l'environnement: la théorie néo-classique mise en perspective, in: Economie appliquée, 1984, 2, S. 315 ff

- Social Decision-Making under Conditions of Scientific Controversy, Expertise and the Precautionary Principle, in: C. Joerges, K.-H. Ladeur, E. Vos (eds.), Integration Scientific Expertise into Regulatory Decision-Making, Baden-Baden, 1997, S. 39 ff

Godard, O., Salles, J.-M., Entre nature et société, in: Robert Boyer, Bernard Chavance, Oliver Godard, Les figures de l'irréversibilité en économie, Paris, 1991, S. 233 ff

Göhler, Gerhard, (Hg.), Grundfragen der Theorie politischer Institutionen, Opladen, 1987

- Macht der Öffentlichkeit - Öffentlichkeit der Macht, Baden-Baden, 1995

- Der Zusammenhang von Institution, Macht und Repräsentation, in: ders. et al., 1997, S. 11 ff

Göhler, Gerhard, Schmalz-Bruns, Rainer, Perspektiven der Theorie politischer Institutionen, in: Politische Vierteljahresschrift, 1988, 2, $309 \mathrm{ff}$

Göhler, G., Lenk, K., Schmalz-Bruns, R. (Hg.), Die Rationalität politischer Institutionen, Baden-Baden, 1990

Göhler, G. et al., Institutionen - Macht - Repräsentation, Baden-Baden, 1997

Göhler, G, Kühn, R., Institutionenökonomie, Neo-Institutionalismus und die Theorie politischer Institutionen, in: Edeling et al. (Hrsg.), Institutionenökonomie und Neuer Institutionalismus, Opladen, 1999, S. $17 \mathrm{ff}$

Goldstein, Judith, Koehane, Robert O. (Hrsg.), Ideas and Foreign Policy. Beliefs, Institutions and Political Change, Ithaca, Cornell University Press, 1993

Goodin, Robert E., Pettit, Philip, Contemporary Political Philosophy, An Anthology, Oxford u.a., Blackwell Publ., 1997

Görg, C., Gesellschaftliche Naturverhältnisse, Münster, 1999

Görlitz, Axel, (unter Mitarb. von H.-P. Burth und U. Druwe) Politische Steuerung: ein Studienbuch, Opladen, 1995

Gosepath, S., Praktische Rationalität. Eine Problemübersicht, in: ders. (Hrsg.), Motive, Gründe, Zwecke, Ffm, 1999, S. 7 ff

Gottschalk-Mazouz, N., Diskursethische Varianten, in: Deutsche Zeitschrift für Philosophie 50, 2002, 1, S. $87 \mathrm{ff}$

Gowdy, John M., Bioeconomics and post Keynesian economics: a search for common ground, Ecological Economics, 3, 1991, S. $77 \mathrm{ff}$

- Hierarchies in Human Affairs: Microfoundations and Environmental Sustainability, in: J. Köhn et al., Sustainability in Question, Cheltenham, Northampton, 1999, S. $67 \mathrm{ff}$

Gowdy, J. M., Carbonell, A. F., Towards consilience between biology and economics: the contribution of Ecological Economics, in: Ecological Economics, 29, 1999, S. $337 \mathrm{ff}$

Gramlich, Edward M., A Guide to Benefit-Cost-Analysis, Englewood Cliffs, $1990^{2}$

Greenpeace e. V. (Hrsg.), Ökosteuer - Sackgasse oder Königsweg? Gutachten des Deutschen Instituts für Wirtschaftsforschung im Auftrag von Greenpeace, Berlin, 1994

Greven, Michael T., Macht in der Demokratie, Baden-Baden, 1991

- Über demokratischen Dezisionismus, in: D. Emig, C. Hüttig, L. Raphael (Hrsg.), Sprache und politische Kultur in der Demokratie, Ffm, 1992, S. $193 \mathrm{ff}$

- Macht in der Öffentlichkeit der Demokratie. Kritischer Kommentar zu R. Schmalz-Bruns, in: Göhler, 1995, $75 \mathrm{ff}$

Greven, M. T., et al. (Hrsg.), Bürgersinn und Kritik, Baden-Baden, 1998 
Griefahn, Monika, Kommunikation und Kooperation als Erfolgsbedingung von Umweltpolitik, in: Mez, Weidner, 1997, S. $394 \mathrm{ff}$

Grimm, Dieter Verfassungsrechtliche Anmerkung zum Thema Prävention, in: Kritische Vierteljahreszeitschrift für Gesetzgebung und Rechtswissenschaften, 1986, 1, S. $38 \mathrm{ff}$

- (Hg.), Wachsende Staatsaufgaben - sinkende Steuerungsfähigkeit des Rechts, Baden-Baden, 1990

- Staatsaufgaben, Baden-Baden, 1994

Grimmer, Klaus, Häusler, Jürgen, Kuhlmann, Stefan, Simonis, Georg (Hrsg.), Politische Techniksteuerung, Opladen, 1992

Gronemann, S., Hampicke, U., Die Monetarisierung der Natur - Möglichkeiten, Grenzen und Methoden, in: Ökonomie und Gesellschaft, Jahrbuch 14, 1997, S. 164 ff

Grundmann, Rainer, Wo steht die Risikosoziologie? in: Zeitschrift für Soziologie, 29, 1999, S. $44 \mathrm{ff}$

- Technische Problemlösung, Verhandeln und umfassende Problemlösung, in: Schimank, Werle, 2000, S. $154 \mathrm{ff}$

Günther, Klaus, Der Sinn für Angemessenheit, Ffm, 1988

- Der Wandel der Staatsaufgaben und die Krise des regulativen Rechts, in: Grimm, 1990, S. 51 ff

- Diskurstheorie des Rechts oder liberales Naturrecht in diskursethischem Gewande? in: Kritische Justiz, 27, 1994, S. $470 \mathrm{ff}$

- Communicative Freedom, Communicative Power, and Jurisgenesis, in: Rosenfeld, Arato, 1998, S. 234 ff

- Welchen Personenbegriff braucht die Diskurstheorie des Rechts? in: Brunkhorst, Niesen, 1999, S. 83 ff

Guinée J. B., et al., Evaluation of risks of metal flows and accumulation in economy and environment, in: Ecological Economics, 1999, S. $47 \mathrm{ff}$

Gusy, Christoph, Techniksteuerung durch Recht - Aufgaben und Grenzen, in: Donner et al., 1989, S. $241 \mathrm{ff}$

Haake, J. et al., Firms and Dematerialisation, in: Köhn, 1999, S. 193 ff

Haase, Henning, Zur Glaubwürdigkeit ökologischer Argumente: Das Beispiel Waschmittel, in: Gerhard de Hann, Berlin, 1995, S. $133 \mathrm{ff}$

Habermas, Jürgen, Erkenntnis und Interesse, Ffm, [1986], $1988^{8}$

- Strukturwandel der Öffentlichkeit, Frankfurt, [1962], 1990³

- Die klassische Lehre von der Politik in ihrem Verhältnis zur Sozialphilosophie, in: ders., Theorie und Praxis, Neuwied, 1963, S. $13 \mathrm{ff}$

- Technik und Wissenschaft als 'Ideologie', Ffm, 1968

- Legitimationsproblem im Spätkapitalismus Ffm, 1973

- Wahrheitstheorien, in: ders., [1973] 1984, S. $127 \mathrm{ff}$

- Theorie des kommunikativen Handelns, 2 Bde., Ffm, 1981

- Moralbewußtsein und kommunikatives Handeln, Ffm, 1983

- Entgegnung, in: A. Honneth, H. Joas, Kommunikatives Handeln. Beiträge zu Jürgen Habermas' Theorie des kommunikativen Handelns, Ffm, S. 327 ff

- Vorstudien und Ergänzungen zur Theorie des kommunikativen Handelns, Ffm, 1984

- Nachmetaphysisches Denken, Ffm, [1988], 1997²

- Erläuterung zur Diskursethik, Ffm, 1991

- Faktizität und Geltung, Ffm, 1992

- Replik auf Beiträge zu einem Symposium der Cardozo Law School, in: ders., 1996, S. 309 ff; [engl.: Reply to Symposium Participants, in: Rosenfeld, Arato 1998, S. 381 ff]

- Die Einbeziehung des Anderen, Ffm, 1996

- Wahrheit und Rechtfertigung, Ffm, 1999 
Hackl, Franz, Der Wahnsinn der Ökonomie oder der Unsinn der Ökologie - eine epistemologische Analyse, in: Zeitschrift für Umweltpolitik, 23, 2000, 2, S. 165 ff

Häder, M., Niebaum, H., Pfadabhängigkeit von Umweltpolitik, in Mez, Weidner, 1997, S. 463 ff

Hagenah, Evelyn, Neue Instrumente für eine Staatsaufgabe: Zur Leistungsfähigkeit prozeduralen Rechts im Umweltschutz, in: Grimm, 1994, S. 487 ff

Hajer, Maarten A. The Politics of Environmental Discourse, Oxford, 1995

- Ökologische Modernisierung als Sprachspiel, in: Soziale Welt, 1997, 2, S. 107 ff

- Argumentative Diskursanalyse. Auf der Suche nach Koalitionen, Praktiken und Bedeutung, in: Keller et al. (Hrsg.), 2003, S. $271 \mathrm{ff}$

- Policy without polity? Policy analysis and the institutional void, in: Policy Science 36, 2003, S. $175 \mathrm{ff}$

Halfmann, Jost, Japp, Klaus Peter (Hrsg.), Riskante Entscheidungen und Katastrophenpotentiale, Opladen, 1990

Hampicke, Ulrich, Neoklassik und Zeitpräferenz: der Diskontierungsnebel, in: Beckbach, Frank, Die ökologische Herausforderung für die ökonomische Theorie, Marburg, 1991, S.127 ff

Hans Böckler Stiftung (Hrsg.), Wege in eine nachhaltige Zukunft, Düsseldorf, 2000

Hansjürgens, Bernd, Lübbe-Wolff, Gertrude, Symbolische Umweltpolitik, Ffm, 2000

Hapke, U., Umwelthaftung, Versicherung und Prävention. Möglichkeiten und Grenzen haftungsinduzierter Prävention unter den Bedingungen von Wissen und Nichtwissen, in: Zeitschrift für Rechtssoziologie, 1999, 1, S. $55 \mathrm{ff}$

Healy, S., Extended peer communities and the ascendance of post-normal politics, in: Futures, 1999, $655 \mathrm{ff}$

Hecht, Dieter, Stoffpolitik als Ordnungspolitik, Marburg, 1998

Hegemann, H. Die Konsequenz des wissenschaftlich-technischen Fortschritts für die normative Demokratietheorie, in: Mayntz, 2000, S. 19 ff

Heidegger, Martin, Die Technik und die Kehre, Pfullingen, 1962

Heinemann, Volker, Zur Überführbarkeit des Entropiekonzepts in die Ökonomie, in: Beckenbach, Diefenbacher, 1994, S. $201 \mathrm{ff}$

Held, M., Nutzinger, H. G., (Hg.), Nachhaltiges Naturkapital, Ffm, 2001

Héritier, Adrienne (Hrsg.), Policy Analyse. Kritik und Neuorientierung, Politische Vierteljahresschrift, Sonderheft 24, 1993

Hessler, Heinz D., Anknüpfungspunkte für Ökosteuern und Umweltabgaben im gesamtwirtschaftlichen Kreislauf, in: Mackenscheidt et al., 1994, S. 135 ff

Hesse, Joachim J., Selbst-Beherrschung als politische Idee, in: M. Kloepfer, Selbst-Beherrschung im technischen und ökologischen Bereich, Berlin, 1998, S. 49 ff

Hesse, J. J., Zöpel, C. (Hg.), Zukunft und staatliche Verantwortung, Forum Zukunft Bd. 1, Baden-Baden, 1987

Hesse, Mary Science and Objectivity, in: John B. Thompson, David Held, Habermas, Critical Debates, London, Basingstoke, 1982, S. $98 \mathrm{ff}$

Hijkata, T., Nessehi, A. (Hg.), Riskante Strategien, Opladen, 1997

Hiller, Petra, Krücken, Georg, Risiko und Regulation, Ffm, 1997

Hinsch, Wilfried, Philosophische Gesellschaft Bad Homburg (Hrsg,), Zur Idee des politischen Liberalismus: John Rawls in der Diskussion, Frankfurt a. M., 1997

Hinterberger, Friederich, (Ko-)Evolution von Natur, Kultur und Wirtschaft. Einige modelltheoretische Überlegungen, in: Beckenbach, Diefenbacher, 1994, S. 317 ff

- Hayek, Selbstorganisation und Evolution, in: B. P. Priddat, G. Wegner, Zwischen Evolution und Institution, Marburger, 1996, S. 245 ff 
Hinterberger, Friederich, Luks, Fred, Schmidt-Bleek, Friederich, Material flows vs. 'natural capital', in: Ecological Economics, 23, 1997a, S. $1 \mathrm{ff}$

Hinterberger, F., Wegner, G., Limited Knowledge and the Precautionary Principle: On the Feasibility of Environmental Policies, in: van den Bergh, van der Straaten, 1997b, S. 344 ff

Hinterberger, F., Welfens, M., Warum inputorientierte Umweltpolitik?, in: Köhn, Welfens, 1996, S. 21 ff

Hinterberger, F., Luks, F., Dematerialization, employment and competitiveness in a globalized economy, Paper prepared for the fifth Biennial Conference of the ISEE, Santiago de Chile, 1998

Hinterberger, F., Luks, F., Stewens, M., Ökologische Wirtschaftspolitik - Zwischen Ökodiktatur und Umweltkatastrophe, Berlin et al., 1996a

- Ökonomie der Stoffströme: Ein neues Forschungsprogramm, Zeitschrift für angewandte Umweltforschung, 3, 1996b, S. $344 \mathrm{ff}$

- Wie ökonomisch ist die Stoffstromökonomik?, in: Konjunkturpolitik, 1999, 4, S. 358 ff

Hofmann, H., Die Aufgaben des modernen Staates und der Umweltschutz, in: Kloepfer, 1989, S. 1 ff

Hoffmann, V. H., Radke, V., Indikatoren einer nachhaltigen Entwicklung: Eine kritische Würdigung des Ansatzes der 'Londoner Schule', in: Zeitschrift für Umweltpolitik, 23, 2000, 2, S. $145 \mathrm{ff}$

Holzinger, K., Umweltpolitische Instrumente aus der Sicht der Bürokratie. Versuch einer Anwendung der 'Ökonomischen Theorie der Bürokratie', Ifo-Studien zur Umweltökonomie 6, München, 1987

- Kommunikationsmodi und Handlungstypen in den Internationalen Beziehungen, in: Zeitschrift für Internationale Beziehungen, 8, 2001, 2, S. $243 \mathrm{ff}$

Honneth, Axel, Hans Joas (Hg.), Kommunikatives Handeln, Frankfurt, 1986

Honneth Axel, McCarthy, T., Offe, C. Wellmer, A. (Hrsg.), Zwischenbetrachtungen: Im Prozeß der Aufklärung. Jürgen Habermas zum 60. Geburtstag, Ffm, 1989

Honneth, Axel, Pathologien des Sozialen. Tradition und Aktualität der Sozialphilosophie, in: ders. (Hrsg.), Pathologien des Sozialen, Ffm, 1994, S. 9 ff

Horbach, Jens, Neue Politische Ökonomie und Umweltpolitik, Ffm, New York, 1992

Howarth, R. B., Norgaard, R. B., Environmental Valuation under Sustainable Development, American Economic Review, 1992, S. $473 \mathrm{ff}$

Hubbert, M K., Exponential Growth as a Transient Phenomenon in Human History, in: Daly, Townsend, Valuing the Earth, MIT Press, 1994, S. $113 \mathrm{ff}$

Huber, Joseph, Ökologische Modernisierung: Zwischen bürokratischem und zivilgesellschaftlichem Handeln, in: v. Prittwitz, 1993, S. 51 ff

- Nachhaltige Entwicklung durch Suffizienz, Effizienz und Konsistenz, in: P. Fritz, J. Huber, H.W. Leve (Hrsg.), Nachhaltigkeit in naturwissenschaftlicher und sozialwissenschaftlicher Perspektive, Stuttgart, 1995, S. $31 \mathrm{ff}$

Hucke, J., Umweltpolitik: Die Entwicklung eines Politikfeldes, in: K. v. Beyme, M. G. Schmidt (Hrsg.), Politik in der Bundesrepublik Deutschland, Opladen, 1990, S. 382 ff

Huppert, Helmut P., Mackenscheidt, Klaus, Der korporatistische Zugang zu den Parafiski, in: Tiepelmann, van der Beek, 1992, S. $67 \mathrm{ff}$

Jachtenfuchs, Markus, Ideen und internationale Beziehungen, in: Zeitschrift für Internationale Beziehungen, 2, 1995, 2, $417 \mathrm{ff}$

Jänicke, Martin, Ökologische Modernisierung. Optionen und Restriktionen präventiver Umweltpolitik, in: Simonis, 1988, S. $13 \mathrm{ff}$

- Ökologische und politische Modernisierung in entwickelten Industriegesellschaften, in: v. Prittwitz, 1993 a, S. $15 \mathrm{ff}$

- Vom Staatsversagen zur politischen Modernisierung? in: Böhret, Wewer, 1993 b, S. 63 ff 
- (Hrsg.), Umweltpolitik der Industrieländer, Berlin, 1996 a

- Erfolgsbedingungen von Umweltpolitik, in: ders., 1996 b, S. 9 ff

- The Political System's Capacity for Environmental Policy, in: ders., H. Weidner (Hrsg.), National Environmental Policies. Berlin, 1997, S. $1 \mathrm{ff}$

- Umweltinnovationen aus der Sicht der Policy-Analyse: vom instrumentellen zum strategischen Ansatz der Umweltpolitik, FFU-Report 3, 1997, [http://www.fu-berlin.de/ffu/download/rep97_3.pdf]

- Dematerialisierung als Prognose und Programm - die Hypothese vom Ende der "era of materials", FFUReport 4, 1998, [http://www.fu-berlin.de/ffu/download/FFURep98 4.PDF]

Jänicke, M., Mönch, H., Binder, M., Getting Rich - Getting Clean? - Umweltindikatorenprofile im Industrieländervergleich, in: Jänicke, 1996, S. 113 ff

Jänicke, M. et al., Umweltpolitik, Bonn, 2000

Jansen, Dorothea, Gesellschaftliche Selbstorganisation durch Technikdiskurse? in: Werle, Schimank, 2000, S. $183 \mathrm{ff}$

Japp, Klaus P., Komplexität und Koppelung. Zum Verhältnis von ökologischer Forschung und Risikosoziologie, in: Halfmann, Japp, 1990, S. $176 \mathrm{ff}$

- Soziale Systeme und ihre ökologischen Selbstbeschreibungen, in: Zeitschrift für Soziologie, Bd. 25 (1996), 3, S. $207 \mathrm{ff}$

- Soziologische Risikotheorie : funktionale Differenzierung, Politisierung und Reflexion, Weinheim, 1996

- Die Idee ökologischer Prävention als moderner Mythos: Das Beispiel der Umweltgefährdungshaftung, in: Kritische Vierteljahreszeitschrift für Gesetzgebung und Rechtswissenschaften, 1997a, 1, S. 80 ff

- Die Ausdifferenzierung regulativer Risikopolitik, in: Hiller, Krücken, 1997b, S. 222 ff

- Die Beobachtung von Nichtwissen. In Zeitschrift für soziologische Theorie, 3, 1997c, 2, 289 ff

Jarren, Otfried, Auf dem Weg in die 'Mediengesellschaft'? Medien als Akteure und institutionaliserter Handlungskontext: Theoretische Anmerkungen zum Wandel des intermediären Systems, in: K. Imhof, P. Schulz (Hrsg.) Politisches Raisonnement in der Informationsgesellschaft, Zürich, 1996, S 79 ff

- Medien, Mediensystem und politische Öffentlichkeit im Wandel, in: Sarcinelli, 1998, 74 ff

Joerges, C., Trubek, M. (Hrsg.), Critical Legal Thought: An American-German Debate, Baden-Baden, 1989

Joerges, Bernward, Braun, Ingo, Große technische Systeme - erzählt, gedeutet, modelliert, in: dies., Technik ohne Grenzen, Ffm, 1994, S. 7 ff

Jörgens, Helge, Die Institutionalisierung von Umweltpolitik im internationalen Vergleich, in: Jänicke, 1996, S. $59 \mathrm{ff}$

Jonas, Hans, Das Prinzip Verantwortung, Frankfurt, [1979], 1984

Junkerheinrich, M., Handelbare Emissionsrechte im verkehrspolitischen Instrumentenmix, in: H. Bonus, 1998, S. $209 \mathrm{ff}$

Kaase, Max Demokratisches System und die Mediatisierung von Politik, in: Sarcinelli 1998, 24 ff

Kals, Elisabeth, Ittner, Heidi, Montada, Leo, Wahrgenommene Gerechtigkeit restriktiver Umweltpolitiken, in: Umweltbundesamt (Hrsg.), Perspektiven für die Verankerung des Nachhaltigkeitsbildes in der Umweltkommunikation, Berlin, 2001

Karl, H., Die räumliche Dimension einer Umweltpolitik mit Hilfe von Zertifikaten, in: H. Bonus, 1998, S. 82 ff

Keane, J. (Hg.), Civil Society and the State, London, 1988

Keck, Otto, The Information Dilemma, in: Journal of Conflict Resolution, 31, 1987, 1, S 139 ff

- Präventive Umweltpolitik als Abbau von Informationsrestriktionen, in: Simonis, 1988, S. 105 ff

Keil, Thomas, Zur Interpretation des Begriffs Sustainable Development, in: M. v. Hauff, H. D. Feser (Hrsg.), Neuere Entwicklungen in der Umweltökonomie und -politik, Regensburg, 1997, S. 17 ff 
Keller, Rainer, Müll - Die gesellschaftliche Konstruktion des Wertvollen, Opladen, Wiesbaden, 1998

- Wissenssoziologische Diskursanalyse, in: ders. et al., 2001, S. $113 \mathrm{ff}$

Keller, R., Poferl, A., Habermas und der Müll, in: Wechselwirkungen, 68, 1994, S. 34 ff

Keller, R., Hajer, M., Modernisierung im Gespräch: Die ökologische Krise als demokratische Herausforderung, in: Wechselwirkungen, 70, 1996, S. 56 ff

Keller, R., et al. (Hrsg.), Handbuch sozialwissenschaftliche Diskursanalyse, Bd. 1, Opladen, 2001

- Handbuch sozialwissenschaftliche Diskursanalyse, Bd. 2, Opladen, 2003

Kepplinger, H. M., Systemtheoretische Aspekte politischer Kommunikation, in: Publizistik 30, 1985, S. 247 ff

- Theorien der Nachrichtenauswahl als Theorien der Realität, in: Aus Politik und Zeitgeschichte, 1989, B 15, S. $3 \mathrm{ff}$

Kepplinger, Hans-Mathias Mathes, Rainer Massenmedien und politische Sozialisation, in: Politische Vierteljahresschrift, Sonderheft 18, 1987, $183 \mathrm{ff}$

Kern, Kristine, Bartzel, Stefan, Umweltpolitischer Erfolg im internationalen Vergleich: Zum Stand der Forschung, in: Jänicke, 1996, S. 29 ff

Kersting, Wolfgang, Spannungsvolle Rationalitätsbegriffe in der politischen Philosophie von John Rawls, in: K.- O. Apel, M. Kettner, Die eine Vernunft und die vielen Rationalitäten, Frankfurt, 1996, S. 227 ff

Kerwer, D. Mehr Sicherheit durch Risiko? Wildavsky und die Risikoregulierung, in: Hiller, Krücken, 1997, S. $253 \mathrm{ff}$

Kettner, Matthias, Scientific Knowledge, Discourse Ethics, and Consensus Formation on Public Policy Issues, in: von Schomberg, 1993, S. $161 \mathrm{ff}$

- Habermas über die Einheit der praktischen Vernunft. Eine Kritik, in: A. Wüstehube (Hg.), Pragmatische Rationalitätstheorien. Studies in Pragmatism, Idealism, and Philosophy of Mind, Würzburg, 1995, S. 85 ff

Kieserling, André, Zwischen Soziologie und Philosophie: Über Jürgen Habermas, in: S. Müller-Doohm (Hrsg.), Das Interesse der Vernunft, Ffm, 2000, S. $21 \mathrm{ff}$

Kirchgässner, Gebhard, Umweltschutz als Staatsaufgabe, in: Grimm, 1994, S. 453 ff

Kirchgässner, Gebhard, Pommerhehne, Werner W., Low-cost Decisions as a Challenge to Public Choice, in: Public Choice, 77, 1993, S. 107 ff

Klaassen, Ger A. J., Opschoor, Johannes B., Economics of Sustainability or the Sustainability of Economics: Different Paradigms, in: Ecological Economics, 4, 1993, S. 93 ff

Klemmer, P., Ordnungspolitische Aspekte des Nachhaltigkeitsanliegens, in: Zeitschrift für angewandte Umweltforschung, 1996, 1, S. $14 \mathrm{ff}$

Klemmer, P., et al., Mehr Nachhaltigkeit durch Marktwirtschaft: Ein ordnungspolitischer Ansatz, in: Gerken, 1996, S. $289 \mathrm{ff}$

Klepper, G., Anwendungspotential für Umweltzertifikate, in: H. Bonus, 1998, S. 137 ff

Kloepfer, M., Gethmann, C. F., Nutzinger H. G., Langzeitverantwortung im Umweltstaat, Bonn, 1993

Kloepfer, Michael (Hrsg.), Umweltstaat, Berlin et al., 1989

- Zur Rechtbildung durch Umweltschutz, Heidelberg, 1990

- Handeln unter Unsicherheit im Umweltstaat, Springer, in: Gethmann, Kloepfer, 1993, S. 55 ff

- Grundrechtsfragen der Umweltabgaben, in: Mackscheidt et al., 1994 a, S. 161 ff

- Droht der autoritäre ökologische Staat?, in: Baumeister, 1994 b, S. 42 ff

- (Hrsg.), Umweltstaat als Zukunft, Bonn, 1994 c

- Recht als Technikkontrolle und Technikermöglichung, in: Gaia 7, 1998 b, 2, S. 127 ff

Kneer, Georg, Bestandserhaltung und Reflexion, in: Krawietz, Welcker, 1992, S. 86 ff 
Knoepfel, Peter, Ökologische Vernetzung versus rechtsstaatliche Handlungsmaximen - Möglichkeiten zur Überwindung eines gespannten Grundverhältnisses, in: Regulative Umweltpolitik, Jahresschrift für Rechtspolitologie, 5, Pfaffenweiler, 1991, S. $107 \mathrm{ff}$

Köck, Wolfgang, Die rechtliche Bewältigung technischer Risiken, in: Kritische Justiz, 26, 1993, S. 124 ff

- Umweltökonomie, Umweltpolitik und Umweltrecht, in: Roßnagel, Neuser, 1996, S. $141 \mathrm{ff}$

- Rechtsfragen der Umweltzielplanung - Ein Beitrag zur Diskussion um die Erstellung eines Nationalen Umweltpolitikplanes, in: Natur und Recht, 1997, S. 528 ff

Kohler-Koch, Beate, Regime in den internationalen Beziehungen, Baden-Baden, 1989

Köhn, J., Welfens, Maria J. Neue Ansätze in der Umweltökonomie, Marburg, 1996

Köhn, Jörg, Autos und Zertifikate - Neue Ansätze für die Autopolitik aus der ökologischen und ökonomischen Perspektive, in: ders., Welfens, 1996, S. 385 ff

Köhn, J., et al., Sustainability in Question, Cheltenham, Northampton, 1999

Kollek, Regine, Controversies about Risks and their Relation to Different Paradigms in Biological Research, in: von Schomberg, 1993, S. $27 \mathrm{ff}$

Koller, Peter, Rawls' Differenzprinzip und seine Deutung, Erkenntnis, 20, 1983, S. $1 \mathrm{ff}$

König, Helmut, Zivilisation und Leidenschaft, Hamburg, 1992

König, K., N. Dose, Instrumente staatlichen Handelns, 1993

Kopperschmidt, Josef, Argumentationstheorie zur Einführung, Hamburg, 2000

Krasner, Stephen D., International regimes, Ithaca u. a., Cornell Univ. Press, 1991

Krause, Dieter, Luhmann-Lexikon, Stuttgart, 2001

Krawietz, W., Welker, M. (Hrsg.), Kritik der Theorie sozialer Systeme, Ffm, 1992

Krebs, Angelika, Ökologische Ethik I: Grundlagen und Grundbegriffe, in: Nida-Rümelin, 1996, S. 346 ff

Krohn, Wolfgang, Die Innovationschancen partizipatorischer Technikgestaltung und diskursiver Konfliktregulierung, in: S. Köberle, F. Gloede, L. Hennen (Hrsg., Diskursive Verständigung?, BadenBaden, 1997, S. $222 \mathrm{ff}$

Krohn, W., Weyer, J., Gesellschaft als Labor. Die Erzeugung sozialer Risiken durch experimentelle Forschung, in: Soziale Welt 40, 1989, S. 349 ff (wiederabgedruckt in: Halfmann, Japp, 1990, S. 89 ff)

Krohn, W., Krücken, G., (Hrsg.), Riskante Technologien: Reflexion und Regulation, Ffm, 1993

- Risiko als Konstruktion und Wirklichkeit. Eine Einführung in die sozialwissenschaftliche Risikoforschung, in: dies. 1993, S. 9 ff

Krüger, Hans-Peter, Kritik der kommunikativen Vernunft, Berlin, 1990

Kuckartz, Udo, Umweltwissen, Umweltbewußtsein, Umweltverhalten. Der Stand der Umweltbewußtseinsforschung, in: de Hann, 1995, S. $71 \mathrm{ff}$

Kuhlmann, W. (Hg.), Moralität und Sittlichkeit. Das Problem Hegels und die Diskursethik, Ffm, 1986

- Prinzip Verantwortung versus Diskursethik, in: Böhler, 1994, S. 277 ff

Kühn, R. Steuerung als Ordnungsleistung?, in: Göhler et al., 1997, S. 515 ff

Kühnel, Steffen, Bamberg, Joachim, Ist die Low-Cost Hypothese noch zu retten? Erwiderung auf Diekmann und Preisendörfer, in: Zeitschrift für Soziologie, 27, 1998, 4, S. 273 ff

Kupka, Thomas, Jürgen Habermas' diskurstheoretische Reformulierung des klassischen Vernunftrechts, in: Kritische Justiz, 27, 1994, S. 461 ff

Kurz, Rudi, Unternehmen und nachhaltige Entwicklung, in: Ökonomie und Gesellschaft, Jahrbuch 14, 1997, S. $78 \mathrm{ff}$

Kurz, R., et al., Nachhaltigkeitspolitik: Ordnungspolitische Konsequenzen und Durchsetzbarkeit, in: L. Gerken (Hg.), 1996, S. 115 ff 
Ladeur, Karl Heinz, Prozedurale Rationalität - Steigerung der Legitimationsfähigkeit oder Leistungsfähigkeit des Rechtssystems?, in: Zeitschrift für Rechtssoziologie, 7, 1986, 2, 265 ff

- Selbstorganisation sozialer Systeme und Prozeduralisierung des Rechts, in: Grimm, 1990, S. 187 ff

- Coping with Uncertainty, in: G. Teubner et al., 1994, S. 299 ff

- Das Umweltrecht der Wissensgesellschaft. Von der Gefahrenabwehr zum Risikomanagement (= Schriften zur Rechtstheorie, H. 167), Berlin, 1995

- Von der Gefahrenabwehr zum Risikomanagement im stoffbezogenen Umweltrecht, in: T. Hijkata, A. Nessehi (Hg.), Riskante Strategien, Opladen, 1997, S. $201 \mathrm{ff}$

- Das Kreislaufwirtschafts- und Abfallgesetz als Schritt auf dem Weg zu einem 'ökologischen Stoffflußrecht'?, in: Zeitschrift für Umweltpolitik, 1998, 3, S. 279 ff

Lang, Sabine, Öffentlichkeit in der Systemtheorie und in Rational Choice - Ansätzen, Überlegungen zur theoretischen Privatisierung des Politischen, in: B. Kerchner, G. Wilde (Hrsg.) Staat und Privatheit, Opladen, 1997, S. $107 \mathrm{ff}$

Latour, Bruno, Science in Action, Harvard University Press, 1987

- Wir sind niemals modern gewesen, Berlin, [frz. 1991], 1995.

Lau, Christoph, Risikodiskurse, in: Soziale Welt, 1989, 3, S. 349 ff

Lau, C., Böschen, S., Möglichkeiten und Grenzen der Wissenschaftsfolgenabschätzung, in: Beck, Bonß, 2001, S. $122 \mathrm{ff}$

Lau, C., Keller, R., Zur Politisierung gesellschaftlicher Naturabgrenzung, in: Beck, Bonß, 2001, S. 82 ff

Lehmann, Jürgen, Massenmedien und ökologisches Handeln, in: de Hann, 1995, S. 115 ff

Lehner, Franz, Ökonomische Theorie politischer Institutionen: Ein systematischer Überblick, in: Göhler et al., 1990, S. $207 \mathrm{ff}$

Leipert, C., Ökologische und soziale Folgekosten des Wirtschaftens - Zeichen der sich verschlechternden Wohlfahrtsbilanz der Industriegesellschaft, in: Donner et al., 1989, S. 103 ff

Leist, Anton, Intergenerationelle Gerechtigkeit, in: Kurt Bayertz (Hrsg.), Praktische Philosophie, Grundorientierungen angewandter Ethik, Rowohlt, 1991, S. $321 \mathrm{ff}$

- Ökologische Ethik II: Gerechtigkeit, Ökonomie, Politik, in: Nida-Rümelin, 1996, S. 386 ff

Lübbe-Wolff, Gertrude. Das Kooperationsprinzip im Umweltrecht - Rechtsgrundsatz oder Deckmantel des Vollzugsdefizits?, in: Natur und Recht, 1989, S. 299 ff

- Vollzugsproblem der Umweltverwaltung, in: Natur und Recht, 1993, S. 217 ff

- Modernisierung des Umweltordnungsrechts, in: Roßnagel, Neuser, 1996, S. 97 ff

- Anforderungen an das Umweltgesetzbuch, in: T. Meyer, J. Minzenbach, Umweltschutz zwischen Globalisierung Deregulierung, Bonn, 1998a, S. 72 ff

- Zielorientierte Umweltpolitik - Probleme der rechtlichen Steuerung, in: Renner, Hinterberger, 1998b, S. $397 \mathrm{ff}$

- Öko-Audit - der neue Fluchtweg aus Umweltrecht und behördlicher Kontrolle, in: S. Leitretter, W. Schneider (Hrsg.), Was bringt's dem Umweltschutz? Reihe Manuskripte der Hans-Böckler Stiftung Bd. 248, Düsseldorf, 1998 c, S. 45 ff

- Ist das Umweltrecht zu technikorientiert? Bielfeld, 2000 [http://www.jura.uni-bielefeld.de/luebbewolffweb/technik.htm]

- Erscheinungsformen symbolischen Umweltrechts, in: Hansjürgens, Lübbe-Wolff, 2000[a], S. 25 ff

- Verfassungsrechtliche Grenzen symbolischer Umweltpolitik, in: Hansjürgens, Lübbe-Wolff, 2000[b], S. $217 \mathrm{ff}$

Luckmann, T., Schütz, A., Strukturen der Lebenswelt, Neuwied u.a., 1975 
Ludes, Peter, Scheinöffentlichkeiten. Medienwissenschafliche Aufklärungsversuche, in: W. Faulstich, Konzepte von Öffentlichkeit, Bardowick, 1993, S. 58 ff

Luhmann, Niklas, Politische Steuerung: Ein Diskussionsbeitrag, in: Politische Vierteljahresschrift, 1, 1989, S. $4 \mathrm{ff}$

- Ökologische Kommunikation, Opladen, 1986

- Die Wirtschaft der Gesellschaft, Ffm, 1988

- Steuerung durch Recht? Einige klarstellende Bemerkungen, in: Zeitschrift für Rechtssoziologie, 1990a, 1, S. $137 \mathrm{ff}$

- Risiko oder Gefahr, in: ders., Soziologische Aufklärung 5, 1990b, S. $131 \mathrm{ff}$

- Soziologie des Risikos, Berlin, New York, 1991

- Beobachtungen der Moderne, Opladen, 1992

- Die Soziologie des Wissens: Probleme ihrer theoretischen Konstruktion, in: ders., Gesellschaftsstruktur und Semantik, Bd. 4, Ffm, 1995, S. $151 \mathrm{ff}$

- Grenzwerte der ökologischen Politik, in: Hiller, Krücken, 1997, S. 195 ff

Luks, F., Post-Normal-Science, Dematerialisierung und die Ökonomie. Über den (wirtschafts)wissenschaftlichen Umgang mit Umweltproblemen, in: Köhn, Welfens, 1996, S. 89 ff

- Throughput, Scale, Material Input, in: J. Köhn et al., 1999, S. 119 ff

Luks, F., Stewen, M., Why biophysical assessments will bring distributional issues to the top of the agenda, in: Ecological Economics, 1999, S. $33 \mathrm{ff}$

Lütz, S., Politische Steuerung und die Selbstregulierung korporativer Akteure, in Mayntz, Scharpf, 1995, S. $169 \mathrm{ff}$

Machura, S., Niklas Luhmanns 'Legitimation durch Verfahren' im Spiegel der Kritik, in: Zeitschrift für Rechtssoziologie, 14, 1993, 1, $97 \mathrm{ff}$

MacIntyre, Alasdair, After Virtue, University of Notre Dame Press, Notre Dame, Indiana, (1981), $1984^{2}$

Mackenscheidt, K., Ewringmann, D., Gawel, E. (Hrsg.), Umweltpolitik mit hoheitlichen Zwangsabgaben?, Berlin, 1994

MacLean, Douglas, Cost-Benefit Analysis and Procedural Values, in: Analyse \& Kritik, 16, 1994, S. 166 ff

Maier-Rigaud, Gerhard, Background to the Conflict between Economic and Ecological Ends, in: Ecological Economics, 4, 1991, S. $83 \mathrm{ff}$

Majone, Giandomenico, Wann ist Policy-Deliberation wichtig?, in: Héritier, 1993, S. 97 ff

- Independence vs. Accountability? Non-Majoritarian Institutions and Democratic Government in Europe, EUI Working Paper SPS No. 94/3, Florenz, 1994

- Temporal Consistency and Policy Credibility: Why Democracies need Non-Majoritarian Institutions, EUI Working Paper RSC No. 96/57, Florenz, 1996

Marcinkowski, Frank, Öffentliche Kommunikation als präventive Risikoerzeugung - Politikwissenschaftlich relevante Ansätze der Risikokommunikationsforschung und neue empirische Befunde, in: G. Simonis et al. (Hrsg.), Politik und Technik, Politische Vierteljahresschrift Sonderheft 31, 2000, $147 \mathrm{ff}$

Marburger, P., Gebhard, T., Gesellschaftliche Umweltnormierung, in: A. Endres, Umweltschutz durch gesellschaftliche Selbststeuerung: gesellschaftliche Umweltnormierung und Umweltgenossenschaften, Bonn, 1993, S. 1 ff

Rex, Martin, Economic justice: contractarianism and Rawls's difference principle, in: David Boucher, Paul Kelly, The Social Contract from Hobbes to Rawls, New York, London, 1994, S. $245 \mathrm{ff}$

Martinez-Alier, Juan, Schlüpmann, K. Ecological Economics, Oxford, New York, 1987

Martinez-Alier, Juan, Ökologische Ökonomie und Verteilungskonflikte aus historischem Blickwinkel, in: F. Beckbach, 1991, S.45 ff 
- The Environment as a Luxury Good or too Poor to be Green?, in: Ecological Economics, 13, 1995, S. $1 \mathrm{ff}$

Martinez-Allier, J., Munda, G., O'Neill, J., Commensurability and Compensability in Ecological Economics, in: M. O'Connor, C. Spash, Valuation and the Environment, Theory, Method and Practice. Cheltenham et al., 1999, $37 \mathrm{ff}$

Martinsen, Renate, Theorien politischer Steuerung - Auf der Suche nach dem Dritten Weg, in: Grimmer, Häusler, Kuhlmann, Simonis, 1992, S. $51 \mathrm{ff}$

- Ethikpolitik als mentale Steuerung der Technik - Zur Kultivierung des Gewissens im Diskurs, in: Simonis et al., 2000, S. $49 \mathrm{ff}$

Mathieu, Karl-Heinz, Bioeconomics and post Keynesian economics, Ecological Economics, 8, 1993, S. $11 \mathrm{ff}$

Matthes, J., Lebenswelt und soziale Probleme, Ffm, New York, 1981

Maus, I., Verrechtlichung, Entrechtlichung und der Funktionswandel von Institutionen, in: Göhler, 1987, S. $132 \mathrm{ff}$

- Die Trennung von Recht und Moral als Begrenzung des Rechts, Rechtstheorie 20, 1989, S. 191 ff; jetzt: 1992, S. $308 \mathrm{ff}$

- Zur Aufklärung der Demokratietheorie, Ffm, 1992

Mayntz, Renate (Hg.), Regulative Politik in der Krise? in: J. Matthes (Hrsg.), Sozialer Wandel in Westeuropa, Verhandlungen des 19. Deutschen Soziologentages, Ffm, 1979, S. 55 ff

- Zur Entwicklung technischer Infrastruktursysteme, in: dies. et al., 1988, S. 233 ff

- Entscheidungsprozesse bei der Entwicklung von Umweltstandards, Die Verwaltung, 23, 1990, S. 137 ff

- Policy Netzwerke und die Logik von Verhandlungssystemen, in: Héritier, 1993, S. 39 ff

- Soziale Dynamik und politische Steuerung: theoretische und methodologische Überlegungen, Ffm, 1997

- Wissenschaft, Politik und die politischen Folgen kognitiver Ungewißheit, in: J. Gerhards, R. Hitzler (Hrsg.), Eigenwilligkeit und Rationalität sozialer Prozesse, Opladen, 1999, S. 30 ff

- Triebkräfte der Technikentwicklung und die Rolle des Staates, in: Simonis et al., 2000, S. 3 ff

Mayntz, Renate, Hansmeyer, Karl-Heinrich, Vollzugsprobleme der Umweltpolitik, Stuttgart u.a., 1978

Mayntz, R., Rosewitz, B., Schimank, U., Stichweh, R., (Hrsg.), Differenzierung und Verselbständigung. Zur Entwicklung gesellschaftlicher Teilsysteme, Ffm, New York, 1988

Mayntz, Renate, Scharf, Fritz, Gesellschaftliche Selbstregulierung und politische Steuerung, Ffm et. al., 1995a

- Selbststeuerung und Selbstorganisation in staatsnahen Sektoren, in: dies, 1995b, $9 \mathrm{ff}$

- Der Ansatz des akteurzentrierten Institutionalismus, in: dies., 1995c, 39 ff

McCarthy, Thomas, Kritik der Verständigungsverhältnisse, Ffm, 1980

- Komplexität und Demokratie - die Versuchung der Systemtheorie, in: Honneth, Joas, 1986, S. 177 ff

- Legitimacy and Diversity, Dialectical Reflections on Analytical Distinctions, S. Rosenfeld, Arato, 1998, S. $115 \mathrm{ff}$

Melucci, Albert, Social Movements and the Democratization of Everyday Life, in: Keane, 1988, S. $245 \mathrm{ff}$

Metzner, A., Problem sozio-ökologischer Systemtheorie: Natur und Gesellschaft in der Soziologie Luhmanns, Opladen, 1993

Meyerhoff, J., Petschow, U., Nachhaltige Entwicklung als langfristiger Wandlungsprozeß: Konsequenzen für die Wirtschafts- und Umweltpolitik, in: L. Gerken, 1996a, S. $173 \mathrm{ff}$

- Nachhaltigkeitspolitik erfordert mehr als Ordnungspolitik! in: Zeitschrift für angewandte Umweltforschung, 1996b, 1, S. 27 ff

Mez, Lutz, Weidner, Helmut, (Hrsg.), Umweltpolitik und Staatsversagen: Perspektiven und Grenzen der Umweltpolitikanalyse. Festschrift für Martin Jänicke, Berlin, 1997 
Michealis, Peter, Ökonomische Instrumente in der Umweltpolitik: Eine empirische Bestandsaufnahme, in: Die Weltwirtschaft, 1995, S. 72 ff

Minsch, J., Ökologische Grobsteuerung. Konzeptionelle Grundlagen und Konkretisierungsschritte, IWÖDiskussionsbeitrag 17, St. Gallen, 1994

Mishan, E.J., The Postwar Literature on Externalities: An Interpretative Essay, in: The Journal of Economic Literature, 9, 1971, S.1 ff

Mittelstrass, Jürgen, Leben mit der Natur, in: O. Schwemmer (Hrsg.), Über Natur: philosophische Beiträge zum Naturverständnis, Ffm, 1987, 37 ff

Müller, Edda Umweltpolitik und Medien, in: Mez, Weidner, 1997, S. 382 ff

Müller, F., Nielsen, S. N., Thermodynamische Systemauffassungen in der Ökologie, in: K. Mathes, B. Breckling, K. Ekschmitt (Hrsg.), Systemtheorie in der Ökologie, Landsberg, 1996, S. 45 ff

Münkler, Herfried, Die Visibilität der Macht und die Strategien der Machtvisualisierung, in: Göhler, 1995, $213 \mathrm{ff}$

- Die Selbstauslegung der Gesellschaft und der soziopolitische Wandel. Vorstellungen über die Handlungsmächtigkeit politischer Theorie, in: H. Kaelble, J. Schriewer, Diskurse und Entwicklungspfade: der Gesellschaftsvergleich in den Geschichts- und Sozialwissenschaften, Ffm, New York, 1999, S. 291 ff

Nahamowitz, Peter, Reflexives Recht. Das unmögliche Ideal eines postinterventionistischen Steuerungskonzepts, in: Zeitschrift für Rechtssoziologie, 6, 1985, 1, S. 29 ff

Nassehi, Armin Wie wirklich sind Systeme? Zum ontologischen und epistemischen Status von Luhmanns Theorie selbstreferentieller Systeme, in: Krawietz, Welker, 1992, S. $43 \mathrm{ff}$

- Risiko - Zeit - Gesellschaft, Gefahren und Risiken der anderen Moderne, in: Hijikata, Nassehi, 1997, S. $37 \mathrm{ff}$

Nida-Rümelin, Julian (Hrsg.), Angewandte Ethik. Die Bereichsethiken und ihre theoretische Fundierung, Stuttgart, 1996

Neidhardt, Friedrich, Öffentlichkeit, öffentliche Meinung, soziale Bewegungen, in: Kölner Zeitschrift für Soziologie und Sozialpsychologie (1994), 34, S.7 ff

Nocke, Joachim, Autopoiesis - Rechtssoziologie in seltsamen Schleifen, in: Kritische Justiz, 19, 1986, S. $363 \mathrm{ff}$

- Rechtsproduktion der Juristen im Umweltrecht - eine Profession stößt an ihre Grenzen, in: B. O. Bryde und W. Hoffmann-Riem (Hrsg.), Rechtsproduktion und Rechtsbewußtsein, Baden-Baden, 1988, S. 81 ff

Nordbeck, Ralf, Nachhaltigkeitsstrategien als politische Langfriststrategien: Innovationswirkungen und Restriktionen, FFU-Report 01-02, Berlin, 2001

- Umweltplanung als institutionelles Arrangement - ein vergleichender Überblick. in: v. Prittwitz, 2000, S. $181 \mathrm{ff}$

Norgaard, R. B., Thermodynamic and Economic Concepts as related to Resource-Use Policies: Synthesis, Land Economics, 1986, 62, S. $325 \mathrm{ff}$

- Environmental Economics: An Evolutionary Critique and a Plea for Pluralism. Journal of Environmental Economics and Management, 12, 1985, S. $382 \mathrm{ff}$

Norgaard, R. B., Howarth, Richard B., Sustainability and Discounting the Future, in: Constanza, 1991, S. 88 ff

Norton, B., Costanza, R., Bishop, R. C., The evolution of preferences, Why 'sovereign' preferences may not lead to sustainable policies and what to do about it, in: Ecological Economics, 24, 1998, S. $193 \mathrm{ff}$

Nowotny, Helga, Umwelt, Zeit, Komplexität: Auf dem Weg zur Endsoziologie, in: A. Diekmann, C. C. Jaeger, Umweltsoziologie, Opladen, 1996, S. 148 ff 
Nullmeier, Frank, Wissen und Policy-Forschung.Wissenspolitologie und rhetorisch-dialektisches Handlungsmodell, in: Héritier, 1993, S. 175 ff

- Diskursive Öffentlichkeit. Möglichkeiten der Radikalisierung und der Kritik, in: Göhler, 1995, S. 85

- Politikwissenschaft auf dem Weg zur Diskursanalyse? in: Keller et al., 2001, S. $285 \mathrm{ff}$

Nutzinger, H. G., Nachhaltige Wirtschaftsweise und Energieversorgung, Marburg, 1995

Nutzinger, H. G., Radke, V., Das Konzept der nachhaltigen Wirtschaftsweise, in: Nutzinger, 1995 a, S. 13 ff

- Wege zur Nachhaltigkeit, in: Nutzinger, 1995 b, S. 225 ff

O'Connor, M., Complexity and coevolution: methodology for a positive treatment of indeterminacy, in: Futures, 1994, S. $610 \mathrm{ff}$

O'Connor, M., Martinez-Alier, J., Ecological Distribution and Distributed Sustainability, in: S. Faucheux et al., 1998, S. $33 \mathrm{ff}$

Oberthür, Sebastian, Gehring, Thomas, Internationale Umweltregime : Umweltschutz durch Verhandlungen und Verträge, Opladen, 1997

Offe, Claus, Die Utopie der Null-Option, in: J. Berger, Die Moderne - Kontinuitäten und Zäsuren, Göttingen, 1986, S. $97 \mathrm{ff}$

- Sozialwissenschaftliche Aspekte der Diskussion, in: J. J. Hesse, C. Zöpel, (Hrsg.), Der Staat der Zukunft, Baden-Baden, 1990a, S. $107 \mathrm{ff}$

- Öffentliches Handeln und Strukturen der kollektiven Willensbildung - Aspekte einer sozialwissenschaftlichen Staatstheorie, in: Ellwein, Hesse, 1990b, S. $173 \mathrm{ff}$

- Selbstbeschränkung als Methode und als Resultat, in: Beck, 1991, S. 225 ff

Offe, Claus/Preuß, Ulrich K., Democratic Institutions and Moral Resources. In: Held, D. (Hg.): Political Theory Today. Cambridge: Polity Press, 1991, S. 115 ff

O'Hara, Sabine, Discursive Ethics in Ecosystems Valuation and Environmental Policy, in: Ecological Economics. 19, 1996, 2, S. $95 \mathrm{ff}$

Öko-Institut (Hrsg.), Institutionelle Innovationen im Bereich Energie- und Stoffströme, Abschlußbericht der Sondierungsstudie für das BMBF, Darmstadt, 2001 [http://www.gsf.de/ptukf/bmbf/laufSchwp/ soef/material/endber_voss.pdf]

O'Riordan, T., Democracy and sustainability transition, in: W. M. Lafferty, J. Meadowcroft (Hrsg.), Democracy and the Environment, Cheltenham-Lyme, 1996, $140 \mathrm{ff}$

O'Neill, John, Ecology Policy and Politics, Human Well-Being and the Natural World, London, New York, 1993

Opschoor, J. B., Institutional Change and Development Towards Sustainability, Constanza et al., 1996, S. $327 \mathrm{ff}$

Ossenbühl, F., Vorsorge als Rechtsprinzip im Gesundheits-, Arbeits- und Umweltschutz, in: Neue Zeitschrift für Verwaltungsrecht, 1986, S. $161 \mathrm{ff}$

Ostrom, Elinor, Governing the Commons, Cambridge University Press, New York, Melbourne, 1990

Otway, H., Wynne, B., Risk Communication. Paradigm and Paradox, in: Risk Analysis, 9, 2, 1989, S. $141 \mathrm{ff}$

Palzer-Rollinger, Birgit, Zur Legitimität von Mehrheitsentscheidungen, Baden-Baden, 1995

Pasche, Markus, Ansätze einer evolutorischen Umweltökonomik, in: Beckenbach, Diefenbacher, 1994, S. 75 ff

Pastwoski, A., Möglichkeiten und Grenzen entropietheoretisch begründeter Folgerungen für die Wirtschafts, Umwelt- und Energiepolitik, in: Beckenbach, Diefenbacher, 1994, S. 217 ff

Patzig, Günther, Ökologische Ethik - innerhalb der Grenzen bloßer Vernunft, Göttingen, 1983 
Pearce, The Limits of Cost-Benefit Analysis as a Guide to Environmental Policy, in: ders., Economics and Environment: essays on ecological economics and sustainable development, Cheltenham, Northampton, 1998 [1976], S. 55 ff

Pearce, D. W., Atkinson, G., Capital Theory and the Measurement of Sustainable Development: An Indicator of 'Weak' Sustainability, Ecological Economics, 8, 1993, S. 103 ff

Pearce, D. W., Atkinson, G., Hamilton, K., Measuring sustainable development: progress on indicators, in: Environment and Development Economics, 1996, S. $18 \mathrm{ff}$

Peters, Bernhard, Rationalität, Recht und Gesellschaft, Ffm, 1991

- Die Integration moderner Gesellschaften, Ffm, 1993

- Der Sinn von Öffentlichkeit, in: Neidhardt (Hrsg.), 1994, S. 42 ff

- On Public Deliberation and Public Culture, Reflection on the Public Sphere, IIS-Arbeitspapier Nr. 7/97, Bremen, 1997

- Deliberative Öffentlichkeit, in: L. Wingert, K. Günther, Die Öffentlichkeit der Vernunft und die Vernunft der Öffentlichkeit, Ffm, 2001, S. 655 ff

Preisendörfer, Peter, Franzen, Axel, Der schöne Schein des Umweltbewußtseins, in: A. Diekmann, C. C. Jaeger (Hrsg.), Umweltsoziologie, Opladen, 1996, 219 ff

Preuß, Ulrich K., Sicherheit durch Recht - Rationalitätsgrenzen eines Konzepts, in: Kritische Vierteljahreszeitschrift für Gesetzgebung und Rechtswissenschaften, 1989 a, 4, S. 3 ff

- Rationality Potentials of Law: Allocative, Distributive and Communicative Rationality, in: Joerges, Trubek, 1989b, S. 525 ff

- Risikovorsorge als Staatsaufgabe, in: Grimm, 1994, S. 523 ff

- Communicative Power and the Concept of Law, in: Rosenfeld, Arato, 1998, S. $323 \mathrm{ff}$

Priddat, Birger, Der Staat, die Ökonomie und die Gesellschaft. Entwicklungen des ökonomischen Institutionenbegriffs im 19. und 20. Jahrhundert, in: Göhler et al., 1990, S. 189 ff

- Para- und Nonfiski - Zur ökonomischen Theorie 'intermediärer Institutionen, in: Tiepelmann, van der Beek, 1992, S. 163 ff

- 'Sustainability', Zur Rhetorik des Begriffs: metapolitische Erörterung, in: Greven et al., 1998, S. $281 \mathrm{ff}$

Priscoli, Jerry Delli, Öffentliche Beteiligung bei technologie- und umweltpolitischen Entscheidungsprozessen in hochentwickelten Industriestaaten - Ein Überblick, in: Zilleßen, Dienel, Strubelt, 1993, S. $40 \mathrm{ff}$

Proops, John L.R., Ecological Economics: Rationale and Problem Areas, in: Ecological Economics, 1, 1989, S. $59 \mathrm{ff}$

Proops, J.L.R., Atkinson, G., A Practical Sustainability Criterion when there is international trade, in: S. Faucheux et al., 1998, S. $169 \mathrm{ff}$

Psarros, Nikos, Der Begriff der Lebenswelt, in: D. Hartmann, P. Janich, Die kulturalistische Wende, Ffm, 1998, S. $333 \mathrm{ff}$

Radke, Volker, Wege in die Umweltkatastrophe, in: H. G. Nutzinger, Nachhaltige Wirtschaftsweise und Energieversorgung, Marburg, 1995, S. $201 \mathrm{ff}$

- Indikatoren der Nachhaltigkeit - Bedingungen der empirischen Messung des Konzepts, in: M. Held, H. G. Nutzinger (Hg.), Nachhaltiges Naturkapital, Ffm, 2001, S. 69 ff

Ramos-Martín, Jesús, Empiricism in Ecological Economics: A Visison From Complex Systems Theory, o.O., 2003 [http://www.geocities.com/jesusramosmartin]

Ravetz, J. R., What is Post-Normal- Science? in: Futures, 1999, S. 647 ff

Rawls, John, A Theory of Justice, Harvard University Press, 1971

- Reply to Alexander and Musgrave, in: Quarterly Journal of Economics, 88, 1974a, S. 633 ff 
- Some Reasons for the Maximin Criterion, in: American Economic Review, 64, 1974b, S. $141 \mathrm{ff}$

- Die Idee des politischen Liberalismus, Frankfurt a. M., 1992

- Political Liberalism, New York, 1993

Rehberg, Karl-Siegbert, Die 'Öffentlichkeit' der Institutionen, in: Göhler, 1995, S. 181 ff

Rehbinder, Eckhard, Vorsorgeprinzip im Umweltrecht und präventive Umweltpolitik, in: Simonis, 1988, S. $129 \mathrm{ff}$

- Konzeption eines in sich geschlossenen Stoffrechts, Bonn, Deutscher Bundestag, 1995

- Festlegung von Umweltzielen, in: Natur und Recht, 19, 1997, 7, S. $313 \mathrm{ff}$

Rehg, William, Against Subordination: Morality, Discourse, and Decision in the Legel Theory of Jürgen Habermas, in: Rosenfeld, Arato, 1998, S. 257 ff

Reijnders, L., Difficult Path to Factor x, in: Ökologisches Wirtschaften, 1999, 3, S. 18 f

Rein, Martin, Schön, Donald, Reframing Policy Discourse, in: Fischer, Forester, 1993, S. 145 ff

Reese-Schäfer, Walter, Sind Hoffnungen auf kommunikative Rationalität berechtigt?, in: W. Zierhofer, D. Steiner (Hrsg.), Vernunft angesichts der Umweltzerstörung, Opladen, 1994

- Luhmann zur Einführung, Hamburg, 1996²

- Jürgen Habermas, Ffm, New York, 2001

Reeve, Andrew, Property, London, Macmillian, 1986

Renn, Ortwin, Möglichkeiten und Grenzen diskursiver Verfahren bei umweltrelevanten Planungen, in: A. Biesecker, K. Grenzendörfer (Hg.), Kooperation, Netzwerk, Selbstorganisation. Elemente demokratischen Wirtschaftens, Pfaffenweiler, 1996, S. $161 \mathrm{ff}$

- Ethische Anforderungen an den Diskurs, in: A. Grunwald, S. Saupe (Hrsg.) Ethik in der Technikgestaltung, Berlin u.a., 1999, S. 63 ff

Renner, A., Hinterberger, F., (Hrsg.), Zukunftsfähigkeit und Neoliberalismus, Baden-Baden, 1998

Richter, Wolfgang, Wandel im Leitbild von Ökosteuern: Vom Standard-Preis-Ansatz zur Makroneutralität, in: Zeitschrift für angewandte Umweltforschung, 8, 2, 1995, S. 207 ff

Rittberger, Volker, Regime theory and international relations, Oxford, 1993

Ritter, Ernst-Hasso, Das Recht als Steuerungsmedium im kooperativen Staat, in: Grimm, 1990, S. 69 ff

Röhl, K. F., Verfahrensgerechtigkeit (Procedural Justice). Einführung in den Themenbereich und Überblick, in: Zeitschrift für Rechtssoziologie, 14, 1993, 1, S. $1 \mathrm{ff}$

Ronge, Volker Der Staat als PR-Veranstaltung, in: Mez, Weidner, 1997, S. 176 ff

Rosenfeld, Michel, Arato, Andrew, (ed.), Habermas on Law and Democracy, Critical Exchanges, University of California Press, Berkley et al., 1998

Roßnagel, A., Neuser, U. (Hrsg.), Reformperspektiven im Umweltrecht, Baden-Baden, 1996

Rucht, Dieter, Öffentlichkeit als Mobilisierungsfaktor für soziale Bewegungen, in: F. Neidhardt (Hrsg.), Öffentlichkeit, öffentliche Meinung, soziale Bewegung, Opladen, 1994, S. 337 ff

Ruß-Mohl, Stephan, Konjunkturen und Zyklizität in der Politik: Themenkarrieren, MedienaufmerksamkeitsZyklen und 'lange Wellen', in: Héritier, 1993, S. 356 ff

Sabatier, Paul A., Advocacy-Koalition, Policy-Wandel und Policy-Lernen: Eine Alternative zur Phasenheuristik, in: Héritier, 1993, S. 116 ff

Sarcinelli, Ulrich, (Hrsg.), Politikvermittlung und Demokratie in der Mediengesellschaft, Bonn, 1998

- Repräsentation oder Diskurs? Zu Legitimität und Legitimitätswandel durch politische Kommunikation, in: Zeitschrift für Politikwissenschaft, 2, 1998a, S. 549 ff

Saretzki, Thomas, "Arguing" oder "Bargaining": Selbstbindung der Politik durch öffentliche Diskurse: in: Göhler, 1995, S. 277 ff 
- Wie unterscheiden sich Argumentieren und Verhandeln? Definitionsprobleme, funktionale Bezüge und strukturelle Differenzen von zwei verschiedenen Kommunikationsmodi, in: v. Prittwitz, 1996a, S. 19 ff

- Verhandelte Diskurse? Probleme und Vermittlung von Argumententation und Partizipation am Beispiel des TA-Verfahrens zum Anbau gentechnisch erzeugter Herbizidresisten am Wissenschaftzentrum Berlin, in: v. Prittwitz, 1996b, S. 135 ff

- Post-positivistische Policy-Analyse und deliberative Demokratie, in: Greven et al., 1998, S. $297 \mathrm{ff}$

Saxer, U., Mediengesellschaft: Verständnisse und Mißverständnisse, in: Sarcinelli, 1998, 60

Siebenhüner, B., Das Ökologische in der ökologischen Ökonomik, in: Zeitschrift für angewandte Umweltforschung, 1996, 2, S. $210 \mathrm{ff}$

Scharpf, Fritz, W. Die Politikverflechtungsfalle, in: Politische Vierteljahresschrift, 26, 1985, 4, S. 323 ff

- Verhandlungssysteme, Verteilungskonflikte und Pathologien der politischen Steuerung, in: Politische Vierteljahresschrift, Sonderheft 19, 1988, S. $61 \mathrm{ff}$

- Politische Steuerung und politische Institution, in: Politische Vierteljahresschrift, 30, 1989, S. $10 \mathrm{ff}$

- Die Grenzen institutioneller Reform, in: Ellwein, Hesse, 1990, S. $111 \mathrm{ff}$

- Die Handlungsfähigkeit des Staates am Ende des 21. Jahrhunderts, in: Politische Vierteljahresschrift, 1991, 4, S. $661 \mathrm{ff}$

- Positive und negative Koordination in Verhandlungssystemen, in: Héritier, 1993, 57 ff

- Politische Optionen im vollendeten Binnenmarkt, in: M. Jachtenfuchs, B. Kohler-Koch, Europäische Integration, Opladen, 1996, S. $109 \mathrm{ff}$

- Interaktionsformen, Akteurzentrierter Institutionalismus in der Politikforschung, Opladen, 2000

Scherrer, C., Jenseits von Pfadabhängigkeit und 'natürlicher Auslese': Institutionentransfer aus diskursanalytischer Perspektive, WZB-Paper, FS II 01-205, Berlin, 2001

Schiller, Frank, Tänzler, Dennis, Dissent about Scientific Uncertainties: Implications in Policy Arenas, Berlin, 2002, [http://www.fu-berlin.de/ffu/akumwelt/bc2002/proceedings/bc_2002_schiller_taenzler.pdf]

Schimank, Uwe, Der mangelnde Akteursbezug systemischer Erklärungen gesellschaftlicher Differenzierung - Ein Diskussionsvorschlag, in: Zeitschrift für Soziologie 14, 1985, S. $421 \mathrm{ff}$

- Gesellschaftliche Teilsysteme als Akteursfiktionen, in: Kölner Zeitschrift für Soziologie und Sozialpsychologie, 1988, 40, S. $619 \mathrm{ff}$

- Dynamik wissenschaftlich-technischer Innovation und Risikoproduktion, in: Halfmann, Japp, 1990, S. 61 ff

- Theorien gesellschaftlicher Differenzierung, Opladen, 2000

Schimank, Uwe, Rosewitz, Bernd, Verselbständigung und politische Steuerbarkeit gesellschaftlicher Teilsysteme, in: R. Mayntz et al., (Hrsg.), Differenzierung und Verselbständigung. Zur Entwicklung gesellschaftlicher Teilsysteme, Ffm, New York, 1988, S. 295 ff

Schimank, Uwe, Wasem, Jürgen, Die staatliche Steuerbarkeit unkoordinierten kollektiven Handelns, in: Mayntz, Scharpf, 1995, S. $197 \mathrm{ff}$

Schimank, Uwe, Werle, Raymund, Gesellschaftliche Komplexität und kollektive Handlungsfähigkeit, Ffm, New York, 2000a

- Gesellschaftliche Komplexität und kollektive Handlungsfähigkeit, in: dies., 2000b, S. 23 ff

Schink, Alexander, Elemente symbolischer Umweltpolitik im Abfallrecht, in: Kritische Justiz, 32, 1999, S. $205 \mathrm{ff}$

Schlegelmilch, Kai, Energy Taxation in the EU and some Member States: Looking for Opportunities Ahead, Paper for the Heinrich-Böll-Foundation Brussels Office, 1998

Schmalz-Bruns, Rainer, Die Rationalität politischer Institutionen. Ansätze einer rechtssoziologischen Analyse, in: Göhler at al., 1990a, S. $381 \mathrm{ff}$ 
- Reflexive Demokratie: Die demokratische Transformation moderner Politik, Baden-Baden, 1995a

- Selbstorganisation, Selbstregierung, Selbstverwirklichung: Die Idee der Öffentlichkeit im Spiegel moderner Demokratietheorie, in: Göhler, 1995b, S. 39 ff

- Demokratietheoretische Aspekte einer ökologischen Modernisierung der Politik, in: P. H. Feindt, Konfliktregelung in der offenen Bürgergesellschaft, Dettelbach, 1996, 37 ff

Schmidt-Bleek, Friederich, Das MIPS-Konzept, München, 1998

Schmidt-Bleek, F., et al., MAIA, Einführung in die Material-Intensitäts-Analyse nach dem MIPS-Konzept, Berlin et al., 1998

Schmidt, K., Zur Substitution der Lehre von den öffentlichen Gütern, in: Ellwein, Hesse, 1990, S. 219 ff

Schmidt, Manfred G., Demokratietheorien, Opladen, 2000

Schmidt, Reiner, Der Staat der Umweltvorsorge, Die öffentliche Verwaltung, 47, 1994, S. 749 ff

- Neue höchstrichtlicher Rechtsprechung zum Umweltrecht, in: Juristenzeitung, 58, 2003, 19, S. 933 ff

Schmitt-Beck, Rüdiger, Politikvermittlung durch Massenkommunikation und interpersonale Kommunikation. Anmerkung zur Theorieentwicklung und ein empirischer Vergleich, in: M. Jäckel, P. Winthoff-Spurk (Hrsg.), Politik und Medien, Berlin, 1994, S. 159 ff

Schnädelbach, Herbert, Über den Realismus, in: Zeitschrift für allgemeine Wissenschaftstheorie, Band III, Heft 1, 1972, S. 88 ff

- Transformation der kritischen Theorie, in: Honneth, Joas, 1986, S. 15 ff

- Über Rationalität und Begründung, in: Forum für Philosophie Bad Homburg (Hrsg.), Philosophie und Begründung, Ffm, 1987, S. 67 ff

Schneider, Volker, Informelle Austauschbeziehungen in der Politikformulierung: Das Beispiel des Chemikaliengesetzes, in: A. Benz, W. Seibel (Hrsg.), Zwischen Kooperation und Korruption, BadenBaden, 1992, S. $111 \mathrm{ff}$

Schulz, W., Ansätze und Grenzen der Monetarisierung von Umweltschäden, in: Zeitschrift für Umweltpolitik und Umweltrecht, 10, 1987, 3, S. 231

Schulze-Fielitz, H. Staatsaufgabenentwicklung und Verfassung. Zur normativen Kraft der Verfassung für das Wachstum und die Begrenzung der Staatsaufgaben, in: Grimm, 1990, S. $11 \mathrm{ff}$

Schuppert, Gunnar Folke, Recht als Steuerungsinstrument: Grenzen und Alternativen rechtlicher Steuerung, in: Ellwein, Hesse 1990, S. 73 ff

- Nichtsteuerliche Abgaben, intermediäre Finanzgewalten und Verwaltungsorganisation, in: B. Becker, H. P. Bull, O. Seewald, Festschrift für Werner Thieme, Köln u.a., 1993, S. 227 ff

Schwinn, Thomas, Gibt es eine 'Zweite Moderne'?, in: Soziale Welt, 50, 1999, S. $423 \mathrm{ff}$

Seidel, I., Vielfalt und Homogenisierung in Ökonomik und Ökologie, in: Held, Nutzinger, 2001, S. 179 ff

Selznick, Philip, Self-Regulation and the Theory of Institutions, in: Teubner, Farmer, Murphy, 1994, S. 395 ff

Sennett, Richard, Verfall und Ende des öffentlichen Lebens: die Tyrannei der Intimität, Ffm, 1985

Siebenhüner, Bernd, Das Ökologisch in der ökologischen Ökonomik - einige Gedanken zu den methodologischen Grundlagen, in: Zeitschrift für angewandte Umweltforschung, 2, 9, 1996, S. $210 \mathrm{ff}$

Siebert, H. Ökonomische Theorie natürlicher Ressourcen - Ein Überblick, in: Zeitschrift für Wirtschaftsund Sozialwissenschaften, 3, 1981, S. 267 ff,

Sieferle, Rolf Peter, Kulturelle Evolution des Gesellschaft-Natur-Verhältnisses, in: Fischer-Kowalski et al., 1997, $37 \mathrm{ff}$

Simonis, Georg, Martinsen, Renate, Saretzki, Thomas, Politik und Technik, Politische Vierteljahresschrift Sonderheft 31, 2000.

Simonis, Udo Ernst, Präventive Umweltpolitik, Franfurt, 1988 
- Ecological Modernization of industrial society, WZB Paper, FS II 88 - 401, Berlin, 1988

Singer, Otto, Policy Communities und Diskurs-Koalitionen: Experten und Expertisen in der Wirtschaftspolitik, in: Héritier, 1993, S. 149

Skirbekk, Gunnar, Pragmatischer Naturbegriff?, in: ders., D. Böhler, T. Nordenstam (Hrsg.), Die pragmatische Wende, Ffm, 1986, S. $221 \mathrm{ff}$

Söderbaum, P., Actors, ideology, markets. Neoclassical and institutional perspectives on environmental policy, in: Ecological Economics, 1994, 10, S. 47 ff

Söllner, F., Continuous Emissions and Accidents: A Unifying Approach, in: Zeitschrift für Umweltpolitik, 1997, 4, S. $513 \mathrm{ff}$

Smith, S. C., How Law Hides Risk, in: G. Teubner et al., 1994, S. 117 ff

Spangenberg, Joachim H., Roda Verheyen, Von der Abfallwirtschaft zum Stoffstrommanagement, Friederich Ebert Stiftung, Bonn, 1996, [http://www.fes.de]

Spangenberg, J. H., Bonniot, O., Sustainability Indicators - A compass on the Road Towards Sustainability, Wuppertaler Paper 81, 1998

Speth, Rudolf, Symbol und Fiktion, in: Göhler et al., 1997a, S. 65 ff

- 'Steuerung' als Ordnungsleistung, in: Göhler et al., 1997b, S. 515 ff

Spies, Rainer, Von der Kooperation in der Abfallpolitik zur staatlich flankierten Selbstorganisation: Das Duale System, in: Staatswissenschaften und Staatspraxis, 1994, 5, 2, $255 \mathrm{ff}$

Stavins, Robert N., N. Keohane, R. Revesz, The Positive Political Economy of Instrument Choice in Environmental Policy, Resources for the Future Discussion Paper 25, 1997, [http://www.rff.org/Documents/RFF-DP-97-25.pdf]

Stengers, Isabelle, Die Erfindung der modernen Wissenschaft, Frankfurt, 1997

Streek, Wolfgang, Vielfalt und Interdependenz - Überlegungen zur Rolle von intermediären Organisationen in sich ändernden Umwelten, in: Kölner Zeitschrift für Soziologie und Sozialpsychologie, 1987, 39, S. $471 \mathrm{ff}$

Stein, Arthur A., Coordination and collaboration: regimes in an anarchic world, in: Krasner, 1983, S. 115 ff

Steinberg, Rudolf, Der ökologische Verfassungsstaat, Ffm, 1998

- Symbolische Umweltpolitik unter besonderer Bercksichtigung der Belscheunigungsgesetzgebung, in: Hansjürgens, Lübbe-Wolff, 2000, S. 63 ff

Stephan, Gunter, in: Entropie, Umweltschutz und Rohstoffverbrauch: ein thermodynamischer Ansatz in der Umweltökonomik, in: M. von Hauff, U. Schmid (Hrsg.), Ökonomie und Ökologie, Stuttgart, 1992, S. 275 $\mathrm{ff}$

Steubing, L., Immissionsökologie, in: ders., et al., Natur- und Umweltschutz, Jena, Stuttgart, 1995, S 328 ff

Steurer, R., Paradigmen der Nachhaltigkeit, in: Zeitschrift für Umweltpolitik, 2001, 4, S. 537 ff

Stewens, Markus, Eine Materialinputsteuer zur Reduktion anthropogener Stoffströme? - Erste Überlegungen, in: Köhn, Welfens, 1996, S. 173 ff

- Inputorientierte Umweltpolitik - Von der Idee zur Umsetzung, SERI-Server, 1999-2000, [http://www.seri.at/Data/themes/policy/ download/stewen160300.pdf]

- Eine unabhängige Institution für die Umweltpolitik, in: Renner, Hinterberger, 1998a, S. 443 ff

- The interdependence of allocation, distribution, scale and stability-A comment on Herman E. Daly's vision of an economics that is efficient, just and sustainable, in: Ecological Economics, 27, 1998(b), S. $119 \mathrm{ff}$

- Grundkonsens- und Einzelfallentscheidung in der Umweltpolitik, in: Zeitschrift für Umweltpolitik, 2000, 3, S. $409 \mathrm{ff}$ 
Streissler, Erich, Das Problem der Internalisierung, in: Heinz König (Hrsg.), Umweltverträgliches Wirtschaften als Problem von Wissenschaft und Politik, Schriften des Vereins für Socialpolitik, Bd. 224, 1993, S. $87 \mathrm{ff}$

Ströbele, Wolfgang, Abdiskontierung als kontextabhängiges Problem, in: Beckbach, Frank, Die ökologische Herausforderung für die ökonomische Theorie, Marburg, 1991, S. 151 ff

- Externe Effekte als Begründung von Umweltökonomik und -politik, in: Beckenbach, 1991, S. $111 \mathrm{ff}$

- Handelbare Zertifikate für natürliche Ressourcen? in: H. Bonus, 1998, S. 182 ff

Taylor, Charles, Die Motive einer Verfahrensethik, in: W. Kuhlmann (Hrsg.), 1986

Teubner, Günther, Reflexives Recht, Archiv für Rechts- und Sozialphilosophie 68, 1982, S. 13 ff

- Verrechtlichung - Begriffe, Merkmale, Grenzen, Auswege, in: F. Kübler, et al. (Hrsg.), Verrechtlichung in Wirtschaft, Arbeit und sozialer Solidarität, Vergleichende Analysen, Ffm, 1985, S. 289 ff

- Regulatorisches Recht: Chronik eines angekündigten Todes; Archiv für Rechts- und Sozialphilosophie, Beiheft 54, 1990a, S. $140 \mathrm{ff}$

- Die Episteme des Rechts. Zu erkenntnistheoretischen Grundlagen des reflexiven Rechts, in: Grimm, 1990b, S. $115 \mathrm{ff}$

- Die unsichtbare "Cupola": Kausalitätskrise und kollektive Zurechnung, in: Turo Hijkata, A. Nessehi (Hg.), Riskante Strategien, Opladen, 1997, S. 157 ff

- Polykorporatismus: Der Staat als 'Netzwerk' öffentlicher und privater Kollektivakteure, in: H. Brunkhorst, P. Niesen, Das Recht der Republik, Ffm, 1999, S. 346 ff

Teubner, G., Willke, H., Kontext und Autonomie: Gesellschaftliche Selbststeuerung durch reflexives Recht, in: Zeitschrift für Rechtsoziologie, 4, 1984

Teubner, Günther, Farmer, Lindsay, Murphy, Declan, Environmental Law and Ecological Responsibility, The Concept and Practice of Ecological Self-Organization, Chichester, 1994

Tiepelmann, Klaus, Umweltabgaben - Renaissance der Fondswirtschaft? in Mackenscheidt et al., 1994, S. $75 \mathrm{ff}$

Tiepelmann, Klaus, van den Beek, Georg, Theorie der Parafiski, Berlin, New York, 1992

Tiepelmann, Klaus, Frick, Siegfried, Der Ökoparafiskus-Vorschlag, in: Köhn, Welfens, 1996, S. 327 ff

Tscheulin, J., Feindt, P. H. Meister, H.-P., Minsch, J., Schneidewind, U., Institutionelle Reformen für Suchprozesse in Richtung Nachhaltigkeit, in: Renner, Hinterberger, 1998, S. $381 \mathrm{ff}$

Tsebelis, George, Veto Players and Institutional Analysis, in: Governance, 13, 2000, S. $441 \mathrm{ff}$

Tugendhart, Ernst, Habermas on Communicative Action, in: G. Seebaß, R. Tuomela (eds.), Social Action, Dordrecht: Reidel Verlag, 1985, S. 179 ff

Turner, Brian S., Scarcity of Means and Solidarity of Values, The Theory of Social Action in Talcott Parsons' General Sociology, in: H. Staubmann, H. Wenzel (Hrsg.), Talcott Parsons, Zur Aktualität eines Theorieprogramms, Sonderband 6 der Österreichischen Zeitschrift für Soziologie, 2002, S. 239 ff

Turner, Kerry, Perrings, Charles, Folke, Carl, Ecological Economics: Paradigm or Perspective, in: van den Bergh, Joreon, van der Straaten, 1997, S. 25 ff

Ulrich, Peter, Transformation der ökonomischen Vernunft, Bern, Stuttgart, 1987

Umweltbundesamt (Hrsg.), Umweltbewußtsein in Deutschland, Berlin, 2000 [http://staff-www.unimarburg.de/\%7Ecmperzwi/hauptframe.htm]

van den Daele, Wolfgang, Objektives Wissen als politische Ressource: Experten und Gegenexperten im Diskurs, in: van den Daele, Neidhardt, 1996, S. $297 \mathrm{ff}$

van den Daele, Wolfgang, Neidhardt, Friedhelm, (Hg.), Kommunikation und Entscheidung: politische Funktion öffentlicher Meinungsbildung und diskursiver Verfahren, WZB-Jahrbuch 1996, Berlin

- 'Regierung durch Diskussion' - Über Versuche, mit Argumenten Politik zu machen, in: dies., 1996, S. 9 ff 
van den Bergh, Joreon C. J. M., van der Straaten, Jan, (eds.), Economy and Ecosystems in Change, Cheltenham, UK, 1997

van den Bergh, Joreon C. J. M, Ecological Economics between Theory and Policy, in: van den Bergh, Joreon, van der Straaten, 1997, S. $1 \mathrm{ff}$

van der Straaten, Jan, et al. (Hg.), Economy and Ecosystems in Change: Analytical and Historical Approaches, Edward Elgar, Cheltenham, UK, 1997

Vercelli, A., From Soft Uncertainty to hard Environmental Uncertainty, in: Économie Appliquée, 1995, 2, S. $251 \mathrm{ff}$

- Sustainable Development, Rationality and Time, in: Faucheux et al. 1998, S. 259 ff

Verordnung über die Vermeidung und Verwertung von Verpackungsabfällen (VerpackV Verpackungsverordnung), vom 27. August 1998 (BGBl. I 1998 S. 2379; 1999 S. 2059; 2000 S. $\underline{1344}$, 2001 S. 2331; 25.4.2002 S. 1488; 15.5.2002 S. 1572)

Victor, P.A., Indicators of Sustainable Development: Some Lessons from Capital Theory, in: Ecological Economics, 4, 1991, S. $191 \mathrm{ff}$

Viehöver, Willy, Verschlungene Wege unterm Müllmassiv. Kooperationstheoretische Hüttenwanderung von der Verpackungsmülldebatte über die PET-Verordnung zum Abfallregime Duales System Deutschland (DSD), Draft, 1. Juni 1998, [http://www.fu-berlin.de/ffu/akumwelt/download/Viehoever Final.PDF]

Voelzkow, H., Von der funktionalen Differenzierung zur Globalisierung, in: Werle, Schimank, 2000, S. 270 ff

Voelzkow, Helmut, Eichener, Volker, Techniksteuerung durch Verbände. Institutionelles Arrangement und Interessenberücksichtigungsmuster bei der Harmonisierung technischer Normen in Europa, in: K. Grimmer et al., 1992, S. $267 \mathrm{ff}$

Voelzkow, H., Hilbert, J., Heinze, R. G., Regierung durch Verbände - am Beispiel der umweltschutzbezogenen Techniksteuerung, in: Politische Vierteljahresschrift, 1987, 1 S. 80 ff

Voet, Ester van der, Kleijn, René, Huppes, Gjalt, Economic Characteristics of Chemicals as a Basis for Pollution Policy, in: Ecological Economics, 13, 1995, S. $11 \mathrm{ff}$

Voigt, Rüdiger (Hrsg.), Politik der Symbole, Symbole der Politik, Opladen, 1989

Voigt, R., Zu den Grenzen regulativer Umweltpolitik. Von der direkten zur indirekten Umweltsteuerung, in: Regulative Umweltpolitik, Jahresschrift für Rechtspolitologie, 5, Pfaffenweiler, 1991, S. $173 \mathrm{ff}$

von Beyme, Klaus, Theorie der Politik im 20. Jahrhundert, Frankfurt a.M., 1993

- Die Massenmedien und die politische Agenda des parlamentarischen Systems, in: Neidhardt (Hrsg.), 1994, S. $320 \mathrm{ff}$

von der Pfordten, Dietmar, Ökologische Ethik, Frankfurt, 1996

von Prittwitz, Volker, Gefahrenabwehr - Vorsorge - Ökologisierung, in: Simonis, 1988, S. 49 ff

- Das Katastrophen-Paradox, Opladen, 1990

- (Hrsg.), Umweltpolitik als Modernisierungsprozeß, Opladen, 1993

- Katastrophenparadox und Handlungskapazität: Theoretische Orientierungen der Politikanalyse, in: Héritier, 1993, S. 328 ff

- Reflexive Modernisierung und öffentliches Handeln, in: ders., 1993, S. 31 ff

- (Hrsg.), Verhandeln und Argumentieren, Dialog, Interessen und Macht in der Umweltpolitik, Opladen, 1996

- (Hrsg.), Institutionelle Arrangements in der Umweltpolitik: Zukunftsfähigkeit durch innovative Verfahrenskombinatorik?, Opladen, 2000

von Schomberg, René, Argumentation im Kontext wissenschaftlicher Kontroversen, in: Apel, Kettner, 1992, S. $260 \mathrm{ff}$ 
- Die rationale argumentative Praxis der Wissenschaft, in: A. Wüstehube (Hrsg.), Pragmatische Rationalitätstheorien, Würzburg, 1995a, S. 165 ff

- Der rationale Umgang mit Unsicherheit, Frankfurt u. a., 1995b

von Weizsäcker, Ernst Ulrich, Erdpolitik, Darmstadt, $1992^{3}$

von Weizsäcker, Ernst Ulrich et al., Faktor Vier, Doppelter Wohlstand halbierter Naturverbrauch. Der neue Bericht an den Club of Rome, München, 1995

Vornholz, G., Zum Spannungsverhältnis von Ökonomie und Sustainable Development, in: Feser, Hauff, 1997, S. $39 \mathrm{ff}$

Walzer, Michael, Spheres of Justice, Basic Books, 1983

- Liberalism and the Art of Separation, in: Political Theory, Vol. 12, No. 3, 1984, S. $315 \mathrm{ff}$

- Vernunft, Politik und Leidenschaft, Ffm, 1999

Wahl, R., Staatsaufgaben im Verfassungsrecht, in: Ellwein, Hesse, 1990, S. 29 ff

- (Hrsg.), Prävention und Vorsorge, Bonn, 1995

Wätzold, F., Umweltökonomische Konzeptionen bei ökologischer Unsicherheit, Berlin, 1998

- Efficiency and applicability of economic concepts dealing with environmental risk and ignorance, in: Ecological Economics, 33, 2000, S. 299 ff

Wätzold, F., Simonis, U.E., Ökologische Unsicherheit: Über Möglichkeiten und Grenzen von Umweltpolitik, in: Aus Politik und Zeitgeschichte, B 27, 1997, S. 3 ff

Wehling, Peter, Sustainable Development - eine Provokation für die Soziologie? in: Brand, 1997, 35 ff

- Jenseits des Wissens? Wissenschaftliches Nichtwissen aus soziologischer Perspektive, in: Zeitschrift für Soziologie, 30, 2001, 6, S. $465 \mathrm{ff}$

Wehner, Josef, Öffentliche Meinung und Person - Zur Darstellung der Politik in den Medien, in: K. Imhof, P. Schulz (Hrsg.), Die Veröffentlichung des Privaten - Die Privatisierung des Öffentlichen, Opaden, 1998, $318 \mathrm{ff}$

Weimann, J., Wettbewerbspolitische Aspekte von Zertifikaten, in: H. Bonus, 1998, S. $61 \mathrm{ff}$

Weingarten, Michael, Die Krise der gesellschaftlichen Naturverhältnisse, in: D. Hartmann, P. Janich, Die kulturalistische Wende, Ffm, 1998, S. 371 ff

Weiß, J., Nachhaltigkeit als Leitbild einer Umweltpolitik?, in: K. Eicker-Wolf et al. (Hg.), Wirtschaftspolitik im theoretischen Vakuum? Marburg, 1996, S. $301 \mathrm{ff}$

Welsch, Heinz, $\mathrm{CO}_{2}$-Steuer, Beschäftigung und funktionale Einkommensverteilung, in: Zeitschrift für angewandte Umweltforschung, 12, 1999, 1, S. $30 \mathrm{ff}$

Welz, Frank, Das Recht in der Theorie des kommunikativen Handelns, in: G. Dux, F. Welz (Hrsg.), Moral und Recht im Diskurs der Moderne, Opladen, 2001, S. $331 \mathrm{ff}$

Werle, Raymund, Staat und Standards, in: Mayntz, Scharpf, 1995, S. 266 ff

- Technik als Akteur? in: Schimank, Werle, 2000, $74 \mathrm{ff}$

Werle, R., Rammert, W., Technik aus soziologischer Perspektive. Forschungsstand - Theorieansätze Fallbeispiele. Ein Überblick, in: Kölner Zeitschrift für Soziologie und Sozialpsychologie, Bd. 46 (1994), 4, S.750

Werner, M., Who counts?, in: M. Niquet (Hrsg.), Diskursethik: Grundlegung und Anwendung, Würzburg, 2001, S. $365 \mathrm{ff}$

Wiesenthal, Helmut, Rational Choice. Ein Überblick über Grundlinien, Theoriefelder und neuere Themenakquisition eines sozialwissenschaftlichen Paradigmas. Zeitschrift für Soziologie 16, 1987, 6, S. $434 \mathrm{ff}$

- Lernchancen in der Risikogesellschaft. Über gesellschaftliche Innovationspotentiale und die Grenzen der Risikosoziologie, in: Leviathan, 22, 1994, 1, S. 135 ff 
- Markt, Organisation und Gemeinschaft als 'zweitbeste' Verfahren sozialer Koordination, in: Werle, Schimank, 2000, S. $44 \mathrm{ff}$

Wilhelm, Sighard, Umweltpolitik, Opladen, 1994

Wilke, J. Analytische Dimensionen der Personalisierung des Politischen, in: K. Imhof, P. Schulz (Hrsg.), Die Veröffentlichung des Privaten - Die Privatisierung des Öffentlichen, Opaden, 1998,

Wille, E., Marktversagen versus Staatsversagen - ein ideologisches Karussell? in: Ellwein, Hesse, 1990, S. $251 \mathrm{ff}$

Willke, Helmut, Kontextsteuerung durch Recht? Zur Steuerungsfunktion des Rechts in polyzentrischer Gesellschaft, in: M. Glagow, H. Willke (Hrsg.), Dezentrale Kontextsteuerung, Pfaffenweiler, 1987a, 3 ff

- Kontextsteuerung und Re-Integration der Ökonomie. Zum Einbau gesellschaftlicher Kriterien in ökonomische Rationalität, in: M. Glagow, H. Willke, Dezentrale Gesellschaftssteuerung, Pfaffenweiler, 1987b, S. $155 \mathrm{ff}$

- Ironie des Staates, Ffm, 1992

- Politische Steuerung der Wissensgesellschaft? in: Zeitschrift für Rechtssoziologie, Bd. 16 (1995), 1, S. 94 ff

- Die Krisis des Wissens, in: Österreichische Zeitschrift für Soziologie, Bd. 26 (2001), 01, S. 3 ff

Winter, Gerd, Brauchen wir das? Von der Risikominimierung zur Bedarfsprüfung, in: Kritische Justiz, 1992, S. $389 \mathrm{ff}$

- Von der ökologischen Vorsorge zur ökonomischen Selbstbegrenzung, in: Baumeister, 1994, S. 105 ff

- Das Recht der Risikogesellschaft, in: Kritische Justiz, 1998, S. 518 ff

Wynne, B., Uncertainty and Environmental Learning, in: Global Environmental Change, 1992, 2, S. $111 \mathrm{ff}$

Wolf, Rainer, Das Recht im Schatten der Technik, in: Kritische Justiz 19, 1986, S. $241 \mathrm{ff}$

- 'Herrschaft kraft Wissen' in der Risikogesellschaft in: Soziale Welt, 39, 1988, 2, S. $164 \mathrm{ff}$

- Zur Antiquiertheit des Rechts in der Risikogesellschaft, in: Ulrich Beck, Politik in der Risikogesellschaft, Ffm, 1991a, S. $378 \mathrm{ff}$

- Im Fiaker der Moderne. Von den Schwierigkeiten ökologischer Gerechtigkeit, in: Kritische Justiz, 1991b, S. $351 \mathrm{ff}$

- Techniksteuerung durch Recht - Vorüberlegungen zu einem forschungspolitischen Desiderat, in: Grimmer et al., 1992, S. 75 ff

- Gerechtigkeit und Umweltschutz. Von subjektiv-rechtlichen Begründungsparadoxien zu kollektiv-rechtlichen Lösungsansätzen, in: ARSP 1994, Beiheft, 54, S. 163 ff

- Der ökologische Rechtsstaat als prozedurales Programm, in: Roßnagel, Nenser, 1996, S. 57 ff

Zapf, W., Die soziologische Theorie der Modernisierung, in: Soziale Welt, 26, 1975, 212 ff

- Die Modernisierungstheorie und unterschiedliche Pfade der gesellschaftlichen Entwicklung, in: Leviathan, 24, 1996, 1, S. 63 ff

Zierhofer, Wolfgang, Ist die kommunikative Vernunft der ökologischen Krise gewachsen?, in: ders., Dieter Steiner (Hrsg.), Vernunft angesichts der Umweltzerstörung, Opladen, 1994, S. 161 ff

Zilleßen, Horst, Die Modernisierung der Demokratie im Zeichen der Umweltpolitik, in: ders. et al., 1993, S. $17 \mathrm{ff}$

- Von der Umweltpolitik zur Politik der Nachhaltigkeit. Das Konzept der nachhaltigen Entwicklung als Modernisierungsansatz, in: Aus Politik und Zeitgeschichte, 1998, B 50, S. 3 ff

Zilleßen, Horst, Dienel, Peter C., Strubelt, Wendelin, (Hrsg.), Die Modernisierung der Demokratie: internationale Ansätze, Opladen, 1993 
Zimmermann, Horst, Abfallwirtschaftliche 'Philosophien' mit und ohne Rückgriff auf die Entropie, in: Horst Zimmermann (ed.), Umweltabgaben: Grundsatzfragen und abfallwirtschaftliche Anwendung, Bonn, 1993, S. $72 \mathrm{ff}$

Zimmermann, H., Hansjürgens, B., Zertifikate im Instrumentenvergleich aus ordnungspolitischer Sicht, in: H. Bonus, 1998, S. $47 \mathrm{ff}$

Zintl, Reinhard, Probleme des individualistischen Ansatzes in der neuen politischen Ökonomie, in: Göhler et al., 1990, S. $267 \mathrm{ff}$

Zundel, S., et al., Stoffstrommanagement, in: Zeitschrift für Umweltpolitik, 3, 1998, S. 317 ff

Zürn, Michael, Über den Staat und die Demokratie im europäischen Mehrebenensystem, in: Politische Vierteljahresschrift, 37,1996, 1, $27 \mathrm{ff}$

- Regieren jenseits des Nationalstaates, Ffm, 1998 
Für meine Eltern und jene Politiker der sozial-liberalen Koalition, die das BaföG auf den Weg gebracht haben. 